\title{
MICHEL DE L'HOSPITAL CHANCELIER-POÈTE
}

sous la direction de Perrine Galand-Willemen et Loris Petris

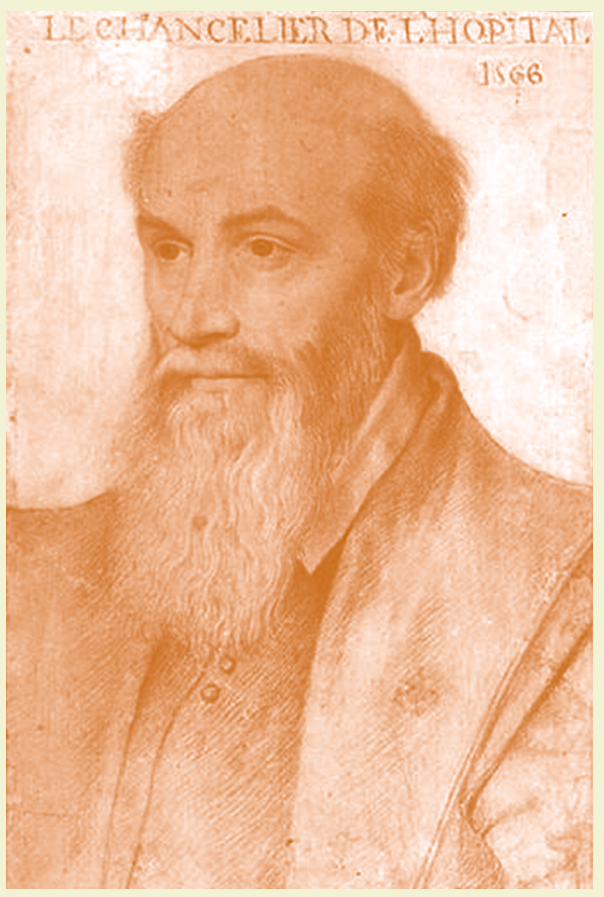




\section{LIBRAIRIE DROZ}

Tous droits réservés par la Librairie Droz SA en vertu des règles de propriété intellectuelle applicables. Sans autorisation écrite de l'éditeur ou d'un organisme de gestion des droits d'auteur dûment habilité et sauf dans les cas prévus par la loi, l'œuvre ne peut être, en entier ou en partie, reproduite sous quelque forme que ce soit, ni adaptée, représentée, transférée ou cédée à des tiers.

Ce travail est sous licence Creative Commons Attribution - pas d'utilisation commerciale - pas de modification 2.5 Suisse License. Pour obtenir une copie de la licence visitez http://creativecommons.org/licenses/ by-nc-nd/2.5/ch/ ou envoyez une lettre à Creative Commons, PO Box 1866, Mountain View, CA 94042, USA.

Pour toutes informations supplémentaires, merci de contacter l'éditeur : droits@droz.org
All rights reserved by Librairie Droz SA as proscribed by applicable intellectual property laws. Works may not, fully or in part, be reproduced in any form, nor adapted, represented, transferred or ceded to third parties without the written authorization of the publisher or a duly empowered organization of authors' rights management and except in instances provided for by law.

This work is licensed under the Creative Commons Attribution - No commercial use - No modification 2.5 Suisse License. To view a copy of this license, visit http://creativecommons.org/ licenses/by-nc-nd/2.5/ch/ or send a letter to Creative Commons, PO Box 1866, Mountain View, CA 94042, USA.

For any additional information, please contact the publisher : rights@droz.org

11, rue Firmin Massot |1206 Genève-GE|0041 (0)22 3466666 (t)|0041(0)22 34723 91(f)| droz@droz.org - www.droz.org 


\section{Cahiers d'Humanisme et Renaissance}

$$
\text { No } 168
$$


过

ํํำ

.

큼

국

(2)

(1)

甲

(8) 


\title{
MICHEL DE L'HOSPITAL CHANCELIER-POÈTE
}

\author{
sous la direction de \\ Perrine Galand-Willemen et Loris Petris
}

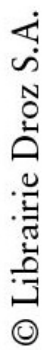

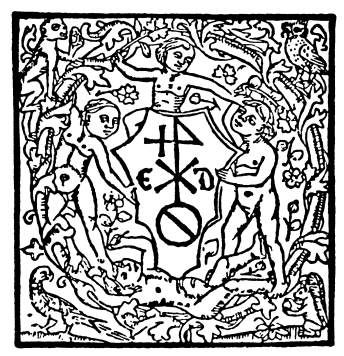


L'étape de la prépresse de cette publication a été soutenue par le Fonds national suisse de la recherche scientifique

\section{FNSWF}

FONDS NATIONAL SUISSE

DE LA RECHERCHE SCIENTIFIQUE

www.droz.org

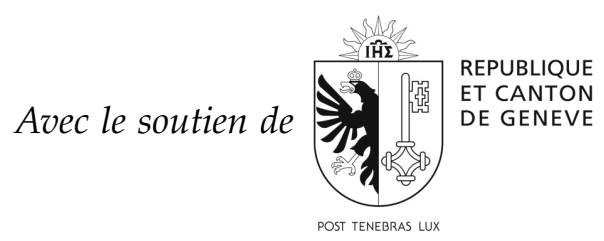

ISBN : 978-2-600-06047-9

ISBN PDF : 978-2-600-16047-6

DOI : $10.47421 /$ droz60479

ISBN EPUB : 978-2-600-36047-0

ISSN : 1422-5581

(C) 2020 by Librairie Droz S.A., 11, rue Firmin-Massot, Genève.

All rights reserved. No part of this book may be reproduced, translated, stored or transmitted in any form or by any means, electronic, mechanical, photo copying or otherwise without written permission from the publisher. 


\section{INTRODUCTION}

Les noces du droit et de la littérature, de la politique et de la poésie ne sont plus guère pensables aujourd'hui. Notre temps sépare ces champs du savoir et de l'action qui étaient réunis sous l'Ancien Régime, de Budé, Garnier et Montaigne à Montesquieu en passant par Corneille, Perrault et tous ces poètes et dramaturges dont la formation et la forma mentis furent d'abord juridiques ${ }^{1}$. Certains écrivains et poètes ont incarné au plus haut point cette union, à l'image de Michel de L'Hospital (v. 1505-1573), chancelierpoète qui, entre 1543 et 1573, quatre règnes durant, commenta poétiquement et philosophiquement les aléas de son existence et de son temps, tout en luttant, à la tribune, pour une politique de conciliation religieuse et de consensus stoïcien adapté aux temps. Bien plus, ce protecteur des poètes de la Pléiade réfléchit à son écriture, à ses conditions et à ses difficultés : il se met en scène en train d'écrire en Italie ou dans l'intimité de son domaine, entouré de son épouse, sa fille, son gendre et ses petits-enfants ${ }^{2}$; il explique parfois comment, faute de temps, il ne parvient plus à composer et doit se contenter de lire; il défend ses choix stylistiques et justifie son droit à écrire des poèmes alors même qu'il est accaparé par ses fonctions professionnelles; il médite sur les conditions d'une poésie chrétienne évangélique et christocentrique; il s'insurge enfin contre l'invida lingua qui l'accable comme elle a mordu Ronsard en 1550, manifestant ainsi cette nouvelle conscience de soi qui caractérise la Renaissance. La lecture des Anciens, et notamment d'Horace, innerve ces épîtres où se mêlent gravité et plaisanterie, éloge et réprimande, engagement dans les negotia et retrait

1 Voir Écrivains juristes et juristes écrivains du Moyen Âge au siècle des Lumières, dir. B. Méniel, Paris, Garnier, 2015.

2 VII, 2, 39-40. L'Hospital évoque Marie Morin, sa cara coniux, en I, 13, 258 ; II, 20, 15-16; III, 15, 15; VI, 2, 183; VI, 11, 28; VII, 5, 92 et IX, 39, 6. 
dans un otium où les Lettres permettent à l'âme de se refaire ses forces, de mieux se connaître et de réfléchir au monde, dans un triple programme inspiré de Pline le Jeune: aliquid vel cogito mecum, / Scribo, legove (V, 2, 15-16). Regno (VII, 1, 41) peut écrire le chancelier retiré fin 1568. Car, derrière leur apparente insignifiance, c'est bien l'utilité existentielle des Lettres et d'une émulation avec les grands esprits de la culture antique qui fonde cette écriture: comme ce protecteur de Ronsard l'écrit dans l'épître II, 16, marquée par le souvenir du Pro Archia de Cicéron et de la rivalité entre Ajax et Ulysse à propos des armes d'Achille contée au livre XIII des Métamorphoses d'Ovide ${ }^{3}$, la culture parachève les qualités naturelles tout comme les Lettres, école de prudence et d'humanité, secondent le courage des nobles d'épée. "Fault essayer à vivre doulcement $»^{4}$ exige dans son premier discours ce chancelier pour qui la douceur est marque suprême d'intelligence et d'humanitas.

Dès 1543 au moins, date de la parution de l'épître IX, 21 dans le traité du droit lignager d'André Tiraqueau, Michel de L'Hospital orchestre la diffusion de ces epistolae, qui sont autant des commentaires circonstanciels et philosophiques sur son temps que des poèmes dédicacés contribuant à son ascension sociale. En 1546 paraissent les épîtres III, 8 et 10, qui encadrent les Poemata du cardinal Jean Du Bellay, et l'épître III, 17, au seuil de la quatrième édition des lois matrimoniales de Tiraqueau. Jusqu'à l'édition posthume de $1585(B)$, rassemblée à la hâte par Jacques-Auguste de Thou, Scévole de Sainte-Marthe, Guy Du Faur de Pibrac et Michel Hurault, les epistolae de ce magistrat circuleront à des rythmes variés, dans des plaquettes (notamment en 1558-1560), des traductions (notamment l'épître IV, 2 traduite par JeanAntoine de Baïf en 1558 et l'épître V, 8 par Joachim Du Bellay en 1560), des recueils collectifs (celui de Léger Du Chesne en 1560 et celui de Buchanan en 1568) et à travers une transmission manuscrite savamment orchestrée ${ }^{5}$. L'Hospital eut de toute

3 Sur ce débat sur la légitimation de la poésie, voir Théories poétiques néo-latines, éd. V. Leroux et E. Séris, Genève, Droz, 2018, p. 3-147.

4 Petris, La Plume et la tribune, p. 392; voir la liste des abréviations p. 17-18.

5 Sur cette diffusion, voir L'Hospital, Carmina, t. I, p. 22-30. 
évidence le souci du texte, cette intense production poétique se doublant d'ailleurs d'une activité législative évidente ${ }^{6}$.

Cette diffusion concertée a permis à L'Hospital de créer et puis d'affermir un réseau de relations d'amitié et de clientèle qui ont favorisé son ascension et ses nominations successives comme conseiller au Parlement (1537), chancelier de la duchesse de Berry (1550), maître des requêtes extraordinaire (1553), premier président de la Chambre des Comptes (1555), conseiller au Conseil privé (1559) et enfin chancelier de France (1560). À propos de cette dernière nomination, l'on sait désormais qu'il prêta serment devant François II le 6 mai 1560 à Chinon ${ }^{7}$ et qu'il se retira le 27 septembre $1568^{\circ}$. Cette dissémination contrôlée de ses œuvres a aussi contribué à la construction de son èthos de robin voué par nature, comme Boccace le revendiquait pour lui-même et pour Pétrarque, à la poésie, mais détourné d'elle par ses obligations $\mathrm{d}^{\prime}$ État; L'Hospital affiche ses distances avec les poètes professionnels humanistes autant qu'avec les poètes courtisans; il se pose en dilettante - neglegentia diligens de magistrat oblige - mais définit la

6 Voir O. Poncet, «Le miroir d'un déclin? Les registres de la Grande Chancellerie à l'âge moderne (XVI $\mathrm{e}^{\mathrm{XVVIII}}{ }^{\mathrm{e}}$ siècle) ", dans L'art médiéval du registre. Chancelleries royales et princières, éd. O. Guyotjeannin, Paris, École des Chartes, 2018, p. 253-283.

7 «Jeudy dernier arriva Monseigneur le Chancellier en ceste ville [Chinon] et le lendemain ensuivant feit le serment au Roy, et hier apres disner comença à sceller où il demoura bien quatre grosses heures. Il se trouva le vendredy et samedy assez mal et ne bougea quasi de la chambre, mais je croy que ce fust plus pour le travail du chemin que pour aultre chose. Maintenant il se porte bien Dieu mercy, et s'en va ce matin à Loches attendre le Roy, qui partit hier de ceste ville pour aller à Champigny [Champigny-sur-Veude] » (BNF, lat. 8589, fol. $45 \mathrm{r}^{\circ}$, Joachim Dallier, fils d'Antoinette de Loynes, à son beau-père Jean de Morel). L'Hospital était parti de Nice le 11 avril (BNF, Dupuy 31, fol. 62ro ; Petris, La Plume et la tribune, p. 472 ; voir aussi Joachim Dallier à Jean de Morel, 28 avril 1560, BNF, fr. 4673, fol. $\left.62 \mathrm{r}^{\mathrm{o}}-\mathrm{v}^{\mathrm{o}}\right)$.

8 «Il cancelliero sono doi giorni che nel Consiglio pregò sua Maestà a liberarlo di quel carico, adducendo esser già vecchio, indisposto et non più atto alla fatica. Sarà, dicono, compiacciuto et si crede che con suo honore habbia voluto rinunciar quello che con vergogna antivedeva devergli esser levato » (Venise, Arch. di Stato, Senato, Dispacci degli ambasciatori, Francia 6, fol. 534vo, Giovanni Correr au doge, 29 septembre 1568). Le 4 octobre, Correr relève que «il cancelliero si è ritirato per qualche giorno a casa sua et ha portato il sigillo seco: ma si crede che sarà mandato a pigliare et terrassi così finche si risolvano a chi s'haverà a consignare» (id., fol. $\left.540 \mathrm{v}^{\circ}\right)$. 
poésie comme un outil indispensable pour comprendre le monde et soi-même, dans diverses circonstances intimes ou politiques; plus encore, il voit en elle un outil d'introspection qui, tout autant que la lecture des grands, crée les conditions d'une tranquillité de l'âme que toutes les philosophies ont ambitionnée et que son époque troublée lui refusait obstinément. La poésie participe d'une sagesse philosophique qui sait tirer une fleur du bourbier. "Facite ut fructus feratis ex adversis rebus », "faites en sorte de tirer du fruit du malheur » recommande L'Hospital dans ses notes autographes du discours du 17 août 1563 à Rouen ${ }^{9}$. Comme le remarquait Pline le Jeune (Ep., VIII, 19), auteur de prédilection d'un L'Hospital qui se compare à Laërte ${ }^{10}$, l'écriture permet de mieux comprendre le malheur et, peut-être, de mieux l'endurer. D'autres chanceliers disgrâciés en firent aussi l'expérience, de More à Gattinara, mais ils produisirent rarement une œuvre poétique aussi magistrale.

À la croisée de la poésie latine et néolatine, de la littérature française, des travaux contemporains juridico-politiques et des courants philosophiques, cette œuvre poétique vaste et complexe fut élaborée en prise directe avec l'actualité, en résonance avec l'Antiquité et en contact constant avec des milieux juridico-poétiques polyglottes ${ }^{11}$. Sa compréhension nécessite des compétences multiples et des regards croisés, car elle relève autant de la philologie et de la poétique néo-latines que de l'histoire des domaines socio-politique et religieux. Un colloque international, organisé sous l'égide de l'École pratique des Hautes Études et de l'Université de Neuchâtel, a ainsi tenté, les 13 et 14 octobre 2016, d'éclairer ces textes, que nous nous efforçons par ailleurs de rendre accessibles dans une édition critique commentée et accompagnée d'une traduction moderne (aux éditions Droz), et complétée d'une publication en ligne du texte latin dans le Corpus Corporum de l'Université de Zürich, ainsi que sur le site www.unine.ch/micheldelhospital. Les

9 L'Hospital, Discours et correspondance, p. 61.

$10 I d .$, p. 275 et 282 (testament), ainsi que VII, 5, 47: «Vivo tamen solo vitam Laertis in agro».

11 Voir P. Ford, The Judgment of Palaemon. The Contest between Neo-Latin and Vernacular Poetry in Renaissance France, Leyde, Brill, 2013. 
contributions rassemblées ici touchent donc autant à l'esthétique et la poétique des littératures francophones et néolatines qu'à la sociologie littéraire, l'histoire éditoriale ou encore l'esthétique de la traduction.

Présentée et étudiée par Richard Cooper, la correspondance de l'ambassadeur piémontais Girolamo Della Rovere, proche des Du Bellay autant que de la Pléiade, apporte de nouveaux éclairages sur l'entrée en fonction de Michel de L'Hospital comme chancelier de France. Pupille de Jean de Morel, le Vineus évoqué dans les Regrets commente, comme les autres ambassadeurs étrangers, les circonstances troublées du moment, depuis les États généraux jusqu'au début de la première guerre de confession. Perçu tour à tour comme un «molto homo da bene» ou un cryptoprotestant «nemico del papa e della chiesa romana», menacé personnellement au début de 1562, au point que le roi lui envoie des gardes, L'Hospital doit opter pour la prudence et la temporisation. Il accorde une attention certaine à Della Rovere, qui fait écho à différentes prises de parole du chancelier ainsi qu'à ses altercations avec le connétable puis, dès 1564, avec le cardinal de Lorraine.

$\mathrm{Au}$ long d'une analyse minutieuse de la bibliographie matérielle, Michel Magnien pose et résout les questions éditoriales essentielles liées aux plaquettes que L'Hospital publia entre 1558 et 1560 chez Fédéric Morel. Il montre qu'en choisissant un imprimeur nouvellement installé, qui fournit un travail typographique de qualité sur du matériel neuf, L'Hospital favorise ce nouveau venu, déjà connu assurément pour être le gendre du célèbre imprimeur Vascosan, mais en quête d'ouvrages de circonstances susceptibles d'être rapidement composés et vendus. Faisant alterner la diffusion restreinte ou même confidentielle de ses manuscrits et leur publication dans des plaquettes où son identité, aisée à deviner, n'est dévoilée que progressivement, le Robin en pleine ascension met en place une véritable stratégie éditoriale de courte durée, autour d'une nouvelle officine de propagande au service des Guises.

Les Carmina de L'Hospital, considérés dans leur ensemble, peuvent être lus comme une exhortation à une progression et une transformation morales, qui trouvent leur accomplissement dans la foi chrétienne. David Amherdt approfondit cette dimen- 
sion en montrant comment L'Hospital, partant souvent d'une réflexion éthique sur une circonstance particulière, compose finalement un véritable «sermon » chrétien, muant sa parole personnelle, inspirée d'abord par le sermo, la causerie satirique horatienne, en sermo evangelicus. Le discours poétique acquiert dès lors le ton et la visée de l'homélie et L'Hospital adopte un double èthos, tantôt vates sacerdos qui montre la voie au lecteur, tantôt humble chrétien qui s'efforce de mettre en pratique les préceptes qu'il énonce pour devenir, selon la formule d'Érasme, un vir pius dicendi peritus.

Nathalie Dauvois étudie les sodalitates toulousaines autour de Jacques Du Faur, son neveu Guy Du Faur et Arnaud Du Ferrier, à travers les poésies latines de Jean de Boyssoné, conservées à la Bibliothèque municipale de Toulouse (ms. 835). Boyssoné n'écrit pas directement à L'Hospital mais l'identité de leurs destinataires atteste une appartenance à des milieux communs. Dans une épître à Martin de La Haye, Boyssoné célèbre ainsi l'épître I, 4, que L'Hospital dédie à Adrien Du Drac, comme un modèle d'écriture épistolaire en vers, à la fois docte et plaisante, dont le style parvient à susciter l'enargeia et dont la prudence unit le droit et les Lettres. Lors de la révision de son procès contre Tabouet, Boyssoné renouvelle cet éloge dans une lettre à L'Hospital, à nouveau vanté pour la pureté de son style docte, digne de Cicéron comme d'Horace: le chancelier privilégie une écriture de la gravitas qui reflète un engagement éthique, politique et chrétien; partant de l'événement particulier, il sait s'élever à la considération générale et au propos gnomique.

C'est une poétique bien différente de celle de Ronsard que l'on trouve à l'œuvre chez Michel de L'Hospital et Joachim Du Bellay, tous deux imitateurs de la veine humble d'Horace et de Tibulle, comme le montre George Hugo Tucker, qui scrute les enjeux esthétiques et politico-culturels de leurs œuvres. L'Hospital doit en effet aux deux poètes latins, dont Quintilien opposait l'esthétique "simple, fort fine et élégante » à celle plus ostentatoire et savante de Properce, son idéal d'une philosophie morale portée par des vers sérieux et élégants, tournés vers la simplicité plus que vers la sophistication; précepteur des filles de Jean de Morel, Charles Utenhove retrouvera une opposition du même ordre entre Du Bellay, promptior ingenio et amabilis, et Ronsard doctior et admirandus. Les adresses de Du Bellay à L'Hospital traduisent ainsi 
un intérêt commun pour cet èthos plus humble des muses horatienne et tibullienne. Le début de l'épître I, 5 à Pontrone (mais intitulée Ad Ioachimum dans le manuscrit) contient même une comparaison entre Du Bellay et Tibulle, car le poète latin avait offert à Joachim, lors de son séjour à Rome, un modèle intéressant de poète exilé.

L'épître I, 7 De poesi christiana iudicium et exemplum, que L'Hospital dédie à Claude d'Espence, définit, dans sa première partie, une esthétique évangélique de simplicité stylistique et de sincérité éthique, proche de celle que prescrivait Battista Spagnuoli dans son Contra poetas impudice loquentes (1489). Véronique Ferrer propose une relecture de cette pièce à la lumière de la réforme littéraire menée par les protestants. Sur fond du débat autour de la foi chrétienne et de la compatibilité des ornements païens, L'Hospital se rattache à Érasme et au livre IV du De doctrina christiana d'Augustin, qui montrait que la majesté du sujet rend inutile toute ornementation du langage. Malgré certaines convergences avec l'écriture des réformés, V. Ferrer relève chez le poète-magistrat l'absence du modèle psalmique, du militantisme, d'un désir de vulgarisation et d'intérêt pour le pouvoir de la musique, qui sont autant de marques de la nouvelle poétique protestante.

Laure Chappuis Sandoz examine la mise en scène narrative de l'épître V, 9, Iter Nicaeum, récit du voyage vers Nice où Marguerite de Savoie, en deuil de son frère Henri II, doit rejoindre son futur époux Emmanuel-Philibert de Savoie. L'importance du modèle horatien, et notamment de la satire I, 5, Iter Brundisinum, y est évidente dans le contenu comme dans la forme: la satire horatienne fournit à L'Hospital un modèle structurel fait de saynettes dialoguées et axé sur le pittoresque et l'anecdotique ; elle lui permet aussi de définir sa propre persona, humoristique ou franchement critique, adepte d'une mediocritas poétique et éthique qui autorise le poète à enseigner la prudentia ou à prodiguer la consolation. Par ailleurs, la longue évocation, dans l'épître, des fortifications militaires côtières, s'ajoutant à la mention régulière des ruines du passé, sert autant à l'éloge de leur constructeur, l'époux de Marguerite, qu'à une mise en garde contre l'hybris et les ravages du temps. C'est ainsi que L'Hospital, mêlant subtilement humilité et grandeur, plaisant et sérieux, s'essaie à mériter, comme Macrin avant lui pour ses odes, le titre d'Horace français. 
La traduction de l'épître VI, 2, Ad amicos de L'Hospital, que le Poitevin Nicolas Rapin publie anonymement en 1601, soulève d'importantes questions sur le contexte précis dans lequel ce proche des premiers éditeurs des Carmina a entrepris sa version en décasyllabes. Ruth Stawarz-Luginbühl la compare au Discours $d u$ sacre $(\mathrm{V}, 8)$ et cerne les grands enjeux thématiques de la pièce composée par le chancelier dans les mois qui suivirent la fin de la première guerre de religion (1563): défense de son èthos et de sa ligne politiques, règlement de comptes avec les catholiques intransigeants et, surtout, questionnement inquiet sur la vulnérabilité d'un roi mineur. Les ajouts et les modifications du texte par Rapin permettent de rattacher sa traduction au contexte de la Journée des Barricades (12 mai 1588) et des événements qui la suivent jusqu'au début de l'année 1589, faisant de ce Discours à ses amis un témoignage de premier ordre de la réception de la pensée du chancelier dans les milieux politiques de la fin du règne d'Henri III.

Les relations entre L'Hospital et sa protectrice Marguerite de France, duchesse de Savoie, dans leur commerce épistolaire et poétique, sont étudiées par Rosanna Gorris Camos, qui les découvre fondées sur une connivence intellectuelle, humaine et religieuse. Les Carmina apparaissent comme des commentaires de la vie privée de la princesse, qui vont influer sur ses lectures et sur les ouvrages de son entourage. La poésie y devient une incitation éthique et politique autant qu'un dialogue intime et amical. L'importance des réseaux franco-italiens, et notamment des milieux hétérodoxes italiens autour de Bocchi, Flaminio, Giulia Gonzaga et Carnesecchi, apparaît à travers une nouvelle sensibilité religieuse érasmienne et christocentrique qui postule une coopération entre grâce et vertu et une douceur qui devient une force. Figure féminine importante dans les Carmina, à la fois sœur, mère, complice et amie, Marguerite de France fut une protectrice et une amie proche de L'Hospital.

Auteur d'un poème célébrant le mariage de la fille unique de L'Hospital (fin 1556-début 1557) et premier traducteur en français du futur chancelier en 1558, Jean-Antoine de Baiff ne le nomme pourtant jamais dans son œuvre et fait même disparaître son nom lorsqu'il republie ses pièces en 1573. Jean Vignes s'interroge sur les raisons de ce silence en analysant d'abord l'épithalame des noces de Robert Hurault et Madeleine de L'Hospital où, pour la première 
fois, Baïf réalise l'union de la poésie et de la musique pour célébrer, sans la moindre allusion religieuse, le mariage de deux protestants, puis l'élégante traduction par Baïf en 1558 de la pièce de L'Hospital sur la prise de Calais et Guînes (IV, 2). Baîf choisit pour cette dernière pièce le titre de Remonstrance afin de mettre en évidence la portée critique et éthique plutôt qu'encomiastique du texte de L'Hospital. Là où d'autres poètes se font les thuriféraires des Lorrains, L'Hospital, plus qu'il ne loue, admoneste le vainqueur et l'encourage à la vertu.

Jean Balsamo s'attache aux rapports ambigus qui existèrent entre Montaigne et L'Hospital. Montaigne dédia une partie des Poemata de La Boétie à L'Hospital dans une lettre du 30 avril 1570, qui frappe par son ton de réprobation (L'Hospital n'aurait pas su exploiter les qualités de La Boétie) et son silence sur la production poétique néo-latine de L'Hospital. Ailleurs, les deux passages des Essais où Montaigne loue L'Hospital sont pareillement ambigus et leur interprétation doit être nuancée, Montaigne notant que son jugement n'est fondé que sur les "apparences externes", tout comme sa dédicace des pièces de La Boétie précise que les yeux «ne peuvent entrer jusques au fond des cœurs ». Diverses allusions voilées aux textes, aux propos et à l'action du chancelier dans les Essais montrent que, si ces deux juristes-écrivains partagent une même conception de la justice, ils divergent en matière de religion, de politique et d'écriture: Montaigne est hostile aux "remuements et nouvelletés », il doute de la politique de conciliation du chancelier et sa prose personnelle des Essais rompt avec le projet des Carmina de L'Hospital.

Des lettres inédites conservées à Paris, Londres et Saint-Pétersbourg, une table des différentes éditions des Carmina et des illustrations complètent enfin le volume.

Les diverses études publiées dans cet ouvrage révèlent ainsi avec plus netteté - mais aussi d'ambiguïé - les engagements, les espoirs et les échecs de l'un des chanceliers qui ont façonné l'humanisme dans l'Europe de la Renaissance ${ }^{12}$. L'on y découvre surtout le

12 Voir L'Humanisme au pouvoir? Figures de chanceliers dans l'Europe de la Renaissance, éd. D. Crouzet, É. Crouzet-Pavan, L. Petris et C. Revest, Paris, Garnier, 2020. 
rôle décisif et fondateur que joua, chez L'Hospital, l'écriture poétique comme laboratoire de la méditation intime et de l'action politique, et comme moyen de diffusion, prudent et stratégique, de ses convictions au sein des divers cercles sociaux. En attendant l'achèvement de l'édition des Carmina prévue pour 2022 aux éditions Droz, notre volume dessine une image plus nuancée du chancelier-poète, que Charles de Sainte-Marthe, ancien maître des requêtes de Marguerite de Navarre, qualifiait $\mathrm{d}^{\prime}$ «optimus ac constantissimus Literarum Moecen[as] $\gg^{13}$.

Perrine GALAND-WILLEMEN et Loris PETRIS

13 Münich, Bayerische Staatsbibliothek, Clm 10383, fol. 130ro et 171ro, Charles de Sainte-Marthe à Jean de Morel, 20 décembre 1550. 


\section{ABRÉVIATIONS}

\section{TEXTES}

A = Michaelis Hospitalii, Galliarum Cancellarii, Carmina. Editio a prioribus diversa et auctior, Amstelaedami, apud Balthasarem Lakeman, 1732

$B=$ Michaelis Hospitalii Galliarum Cancellarii Epistolarum seu Sermonum libri sex, Lutetiae, apud Mamertum Patissonium Typographum Regium, in officina Roberti Stephani, 1585

L'Hospital, Carmina = L'Hospital, Michel de, Carmina, t. I, éd. P. Galand et L. Petris, avec la participation de David Amherdt, Genève, Droz, 2014; t. II, sous la dir. de Perrine Galand et Loris Petris, éd. D. Amherdt, L. Chappuis Sandoz, P. Galand et L. Petris, avec la collab. de C. Guerra et R. StawarzLuginbühl, Genève, Droz, 2017 ; t. III, Genève, Droz, 2018 ; t. IV, Genève, Droz, 2019; trois tomes encore à paraître (texte latin sur: www.unine.ch/micheldelhospital)

L'Hospital, Discours et correspondance = L'Hospital, Michel de, Discours et correspondance. La plume et la tribune II, éd. Loris Petris, avec la collab. de D. Amherdt, Genève, Droz, 2013

L'Hospital, Poésies complètes = L'Hospital, Michel de, Poésies complètes, éd. Louis Bandy de Nalèche, Paris, Hachette, 1857

Ronsard, Lm = Ronsard, Pierre de, CEuvres complètes, éd. Paul Laumonier, Paris, Didier, STFM, 1914-1975, 18 vol.; éd. Jean Céard revue, Paris, STFM, 2015, 7 vol.

Ronsard, OC = Ronsard, Pierre de, CEuvres complètes, éd. Jean Céard, Daniel Ménager et Michel Simonin, Paris, Gallimard, «La Pléiade», 1993, 2 vol. 


\section{ÉTUDES}

Crouzet, La Sagesse et le malheur = Crouzet, Denis, La Sagesse et le malheur. Michel de L'Hospital, chancelier de France, Seyssel, Champ Vallon, 1998

$\mathrm{DL}=$ Dupré-Lasale, Emile, Michel de L'Hospital avant son élévation au poste de chancelier de France, première partie (1505-1558), Paris, E. Thorin, 1875 (t. I); Michel de L'Hospital avant son élévation au poste de chancelier de France, deuxième partie (1555-1560), Paris, A. Fontemoing, 1899 (t. II)

Galand-Hallyn, «Michel de L'Hospital à l'école de Salmon Macrin» = Galand-Hallyn, Perrine, "Michel de L'Hospital à l'école de Jean Salmon Macrin dans les Carmina», BHR, 65 (2003), p. 7-50

Petris, La Plume et la tribune = Petris, Loris, La Plume et la tribune. Michel de L'Hospital et ses discours (1559-1562). Suivi de l'édition $d u$ De sacra Francisci II. Galliarum regis initiatione, regnique ipsius administrandi providentia, Mich. Hosp. Sermo (1559) et des discours de Michel de L'Hospital (1560-1562), Genève, Droz, 2002 


\section{LE NOUVEAU CHANCELIER JUGÉ PAR LES AMBASSADEURS À LA COUR DE FRANCE : LES DÉPÊCHES DE GIROLAMO DELLA ROVERE (1560-1562)}

Parmi la foule d'ambassadeurs qui fréquentait la cour de France pendant les années cruciales entre la mort d'Henri II et l'ouverture des hostilités, il en est un qui se détache des autres par ses relations étroites avec ce milieu. Né près de Turin et parent à la fois des papes Sixte IV et Jules II et du duc d'Urbin, Guidobaldo II, Girolamo Della Rovere (1528-1592) vivait en France depuis 1540, lorsque Guillaume Du Bellay confia cet enfant prodige de dix ans, poète et orateur en herbe, à son ami, Jean de Morel, et le fit étudier à Paris au Collège royal ${ }^{1}$. Il s'y lia avec des humanistes de la capitale comme Guillaume Toussaint et Nicolas Bourbon, avec le cercle du cardinal Jean Du Bellay, qui l'emmena à Rome, et avec la jeune Brigade, dont Du Bellay ${ }^{2}$ et Ronsard, qui adressèrent des poèmes à «Vineuf $»^{3}$, ou à « tresdocte Rouvere, amiable Rouvere $»^{4}$. Destiné à une carrière ecclésiastique, il fut chargé par Henri II et Catherine de Médicis de missions diplomatiques auprès du pape et pourvu de bénéfices en France, dont le 24 juin 1559 l'évêché de Toulon, vacant par la mort du cardinal Trivulzio.

Le traité du Cateau-Cambrésis du 3 avril 1559 impliquait un changement radical dans les rapports entre la France et la Savoie,

1 R. Cooper, Litteræ in tempore belli. Études sur les relations littéraires italo-françaises pendant les guerres d'Italie, Genève, Droz, 1997, p. 117-145.

2 Guillaume Aubert le nomma, avec Morel et Lancelot de Carles, parmi les amis et admirateurs de Du Bellay: voir son Elegie sur le trespas de feu Joach. Du Bellay Ang., Paris, F. Morel, 1560, fol. Aiiii.

3 Joachim Du Bellay, Les Regrets, no 42, 43, 46 et 124.

4 La Vertu amoureuse, à tresillustre prelat Hieronyme de la Rovere, Evesque de Toullon, dans le Bocage royal: voir Ronsard, Lm, t. III, p. 335-343; cf. t. VII, p. 385. 
dont les troupes françaises occupaient une large partie depuis 1536. Michel de L'Hospital accompagna Marguerite de Valois au Cateau-Cambrésis pour signer le contrat de mariage (qu'il avait rédigé $)^{5}$ avec le duc, Emanuele Filiberto ${ }^{6}$, neveu de Charles Quint et ancien commandant de l'armée impériale à Saint-Quentin. La France s'engagea à restituer au duc la plupart de son territoire occupé, à l'exception des places fortes de Turin, Pignerol, Savillan, Chivas, Chieri et le marquisat de Saluces, ainsi qu'à payer une dot à Marguerite de 300'000 écus en trois versements, avec une pension à son époux. L'accident de la rue Saint-Antoine faillit faire avorter cet accord mais le roi agonisant fit célébrer les noces la veille de sa mort. L'estime comme orateur dont jouissait Della Rovere auprès de la reine-mère lui valut d'être choisi pour prononcer les deux sermons funèbres pour le roi défunt ${ }^{7}$, dont le texte imprimé est accompagné de deux poèmes de Joachim Du Bellay. Deux ans plus tard, Catherine allait lui garder sa confiance, en lui demandant, dans un délai très court, de prononcer le sermon pour l'anniversaire de la mort de François II $^{8}$. Après que L'Hospital eut accompagné Marguerite à Nice pendant l'hiver de 1559-1560, les relations diplomatiques furent rétablies entre les deux pays. Della Rovere se vit nommer ambassadeur en France et prit son service le 26 avril 1560. Sa

5 Antonio Trivulzio - Carlo Carafa, Paris, 21 mars 1559, dans Correspondance des nonces en France: Lenzi et Gualterio, légation du cardinal Trivultio (1557-1561), éd. J. Lestocquoy, Rome, Université pontificale grégorienne, 1977, p. 190, no 124.

6 Giovanni Michiel - Doge, 16 mars 1559, dans Calendar of State Papers, Venice [ci-après CSP Venice], éd. R. Brown et G. Cavendish Bentinck, Londres, HMSO, 1890, t. VII, p. 49 et 181; S.-H. Kim, Michel de L'Hôpital: the Vision of a reformist chancellor during the French religious wars, Kirksville, Sixteenth Century Journal Publishers, 1997, p. 47.

7 Les deux Sermons Funebres es obseques \& enterrement du feu Roy Treschrestien Henri deuxieme de ce nom, faicts E prononcez par Messire Jerome de la Rouere, esleu Evesque de Tholon: l'un à Nostre Dame de Paris, l'aultre à Sainct Denis en France, Paris, Robert II Estienne, 1559.

8 Turin, Archivio di Stato, Lettere Ministri, Francia, mazzo 1, no 176, Della Rovere - Duc de Savoie, Paris, 7 déc. 1561: «et ancora che la brevità del tempo mi scusasse assai, nondimeno sua $\mathrm{M}^{\text {ta }}$ mi troncò la via di liberarmene: et cosi in doi giorni feci l'oratione, o piutosto aborto, et avanthieri la recitai in Santo Dionisio ».

9 Ercole Strozzi - Duc de Mantoue, Tours, 19 et 26 avril 1560, Mantoue, Archivio di Stato, Gonzaga 652. 
correspondance pour les années 1560-1562 a été peu exploitée, même si elle couvre la période qui va de la nomination de L'Hospital comme chancelier, des États d'Orléans, du colloque de Poissy, de l'Édit de Janvier, du massacre de Wassy jusqu'à la première guerre de religion ${ }^{10}$.

Ses collègues étaient très chatouilleux sur les questions de préséance entre ambassadeurs: celui de Venise rapporte la dispute sur la préséance entre les représentants d'Angleterre et de Portugal lors de la réunion du Chapitre de l'Ordre de SaintMichel en $1561^{11}$; et Della Rovere lui-même était peu disposé à assister au Chapitre de 1560 sans avoir clarifié sa propre position dans la hiérarchie diplomatique, mais il finit par y assister lorsque le cardinal de Lorraine lui promit de «dar[gli] luoco sopra tutti gli altri Ambasciatori ${ }^{12}$, peut-être en raison de ses années de service pour Henri II.

La réaction des diplomates à la nomination de L'Hospital en mai 1560 fut plutôt positive. L'ambassadeur de Mantoue rapportait que «qua è tenuto molto homo da bene $»^{13}$. L'ambassadeur vénitien Michele Suriano signalait le fait qu'il avait été au service de Marguerite de Valois ${ }^{14}$, qu'il avait la pleine confiance de la reinemère mais qu'il avait été une créature des Guises:

[Catherine] crede assai al gran cancelliero, che è uomo di spirito, e suo servitor vecchio, e forse quello che l'ha fatta ressolvere di mettersi in mano del re di Navarra, col suo essempio; che, come amico di fortuna, sebene fu creatura della casa di Guisa, però l'ha abbandonata per accostarsi a quel $\mathrm{re}^{15}$.

10 Sauf par L. Romier, Catholiques et Huguenots à la cour de Charles IX: les étatsgénéraux d'Orléans, le colloque de Poissy, le 'concordat' avec les protestants, le massacre de Vassy (1560-1562), Paris, Perrin, 1924.

11 Michele Suriano - Doge, Saint-Germain-en-Laye, 2 oct. 1561, dans CSP Venice, VII, no 282.

12 Della Rovere, $\mathrm{n}^{\circ} 154$, Paris, 10 oct. 1560.

13 Ercole Strozzi, 29 mars 1560, Gonzaga 652 ; voir Petris, La Plume et la tribune, p. 19-20.

14 Michele Suriano, Amboise, 31 mars 1560, dans CSP Venice, VII, no 145.

15 Relations des ambassadeurs vénitiens sur les affaires de France, éd. N. Tommaseo, Paris, Imprimerie Royale, 1838, t. I, p. 550. 
Ce jugement s'accorde avec celui d'un autre envoyé de Venise, Giovanni Michiel:

il cancelliere, qual è persona di spirito e molto accorto et intendente e destro nell'officio suo, convien per necessità, come uomo da novo, far quanto vuol la regina, e conseguentemente il re di Navarra ${ }^{16}$.

Nous voyons donc le chancelier, homo novus, prendre ses distances de ses anciens protecteurs, les Guises, pour se rapprocher de la reine-mère et d'Antoine de Bourbon.

Dès son entrée en service à la cour, Della Rovere dut faire face aux retards dans l'exécution des clauses du traité de paix. Une de ses premières dépêches ( 3 mai 1560) concerne le non-paiement de la dot et de la pension, pour lequel il dut consulter le tout nouveau chancelier, qui affirmait ne pas avoir reçu tous les papiers signés par le duc de Savoie ${ }^{17}$. En juillet 1560, l'ambassadeur attendait toujours les paiements ${ }^{18}$ et finit par comprendre que la couronne, avec des dettes de «molti millioni di franchi », n'avait les moyens de payer les dots d'aucune des trois filles de France - Marguerite, duchesse de Savoie, Claude, duchesse de Lorraine, et Elisabeth, reine d'Espagne ${ }^{19}$. Della Rovere se vit contraint de continuer à solliciter tout le long de $1561^{20}$.

Un second problème urgent pour la Savoie, dont la trésorerie avait été essorée pendant la longue occupation française, était l'approvisionnement en sel ${ }^{21}$, pour lequel l'ambassadeur devait à nouveau s'adresser au chancelier, "essendo massime rimesse a lui molte ispeditioni simili $»^{22}$. François II aurait promis d'en procurer des salines de Peccais en Provence, en passant par le Dauphiné: l'ambassadeur continua d'insister auprès de L'Hospital sur

\footnotetext{
16 Ibid., t. I, p. 436.

17 Della Rovere, no 146, [Chenonceau ?], 3 mai 1560.

18 Della Rovere, $\mathrm{n}^{\circ} 149,31$ juillet 1560.

19 Della Rovere, $\mathrm{n}^{\circ} 151$, Fontainebleau, 21 août 1560.

20 Della Rovere, $n^{\circ}$ 165, 23 mars 1561; no 172, Saint-Germain-en-Laye, 21 juill. 1561.

21 M. Vester, "The Political Autonomy of a Tax Farm: The Nice-Piedmont Gabelle of the Dukes of Savoy, 1535-1580 », The Journal of Modern History, 76 (déc. 2004), p. 745-792.

22 Della Rovere, no 146, [Chenonceau?], 3 mai 1560.
} 
$l^{\prime}$ « urgente necessità » de cette denrée de première importance, sur laquelle le duc comptait mettre un impôt, mais tout aussi en vain. Malgré les discussions au Conseil privé du roi et les instances répétées au cours de deux années auprès du chancelier ${ }^{23}$, dont on regrettait les absences de la cour, on ne réussit pas à trouver un accord avec les fermiers de la gabelle. Della Rovere avait l'impression non seulement que les affaires étaient au point mort lorsque L'Hospital n'était pas présent ${ }^{24}$, mais qu'on le payait de fausses promesses.

Le troisième défi était celui de la restitution de territoires prescrite dans le traité de paix, et l'ambassadeur devait à nouveau passer par le chancelier. Celui-ci rechignait à s'y conformer tant qu'on n'aurait pas résolu les prétentions de la France sur le comté de Nice, sur la Bresse, Asti, Saluzzo et le Montferrat ${ }^{25}$. Après deux années de débats infructeux, la couronne comprit que, pour bénéficier du secours des troupes du duc de Savoie contre les huguenots, il fallait faire des concessions et, par le traité de Fossano (2 novembre 1562), accepta de restituer d'autres villes, dont Turin, où le duc comptait transférer sa capitale ${ }^{26}$. L'ambassadeur se rendit chez le chancelier, qu'il trouva un peu procédurier (comme pour la dot et le sel) mais qui promit d'expédier l'affaire:

In somma Mons. il Cancelliere conclude che si haveranno quante lettere et ispeditioni faranno di mestieri; et del resto che V.A. non ha da cercar' altro, che entrare in quelle piazze ${ }^{27}$.

Le nonce pontifical Prospero di Santa Croce rapporta que le gouverneur français du Piémont, Imbert de La Plâtière, seigneur

23 Della Rovere, no 147, Blois, 7 juin 1560 ; no 149, 31 juill. 1560 ; no 153, Orléans, 29 oct. 1560 ; $n^{\circ} 165$, Fontainebleau, 23 mars 1561; n 167 , Paris, 5 juin 1561; no 170,10 juill. 1561 ; no 172 , Saint-Germain, 21 juill. 1561 ; no 199,14 sept. $1562 ; n^{\circ} 203$, Gaillon, 2 oct. 1562.

24 Même son de cloche chez l'ambassadeur impérial Thomas Perrenot de Chantonnay dans deux dépêches à Philippe II: voir Negociaciones con Francia, Madrid, Real Academia de la Historia, 1950-55, t. I, p. 371, n 142, Paris, 8 sept. 1560 ; ibid., t. I, p. 382, Paris, 18 sept. 1560.

25 Della Rovere, no 181, Saint-Germain-en-Laye, 19 févr. 1562; no 182, Paris, 5 mars 1562; Chantonnay, 2 mai 1562, dans Negociaciones con Francia, éd. cit., t. III, p. 534, n 476 .

26 Della Rovere, no 201, Paris, 6 août 1562.

27 Della Rovere, no 199, Gien, 14 sept. 1562. 
de Bourdillon, refusait de rendre les villes et certains observateurs estimaient qu'il agissait de concert avec Catherine de Médicis. Della Rovere demanda une copie de l'ordre envoyé à Bourdillon, que le roi refusa de lui montrer ${ }^{28}$. Nouveaux obstacles en décembre, dont le chancelier n'avait pas encore pu venir à bout ${ }^{29}$, et ce ne fut qu'en février 1563 que le duc fit son entrée dans sa nouvelle capitale, accompagné de Marguerite.

Le nouvel ambassadeur n'oublia pas ses relations avec les milieux littéraires parisiens, notamment avec son ancien précepteur, Jean de Morel, à qui il envoya une lettre depuis Poissy, où il participait au Colloque ${ }^{30}$. Morel transmettait au duc les dernières publications à Paris, non seulement les pamphlets ${ }^{31}$ mais aussi des livres érudits. En 1560, il lui fit parvenir un ouvrage que l'auteur, Guillaume Aubert, serviteur fidèle d'Emanuele Filiberto et de Marguerite, offrait au duc, L'Histoire des Guerres faictes par les Chrestiens contre les Turcs $^{32}$; lors des obsèques de François II, il rapporta au duc la nomination comme Grand Aumônier d'Amyot, «quell gran literato » qui avait traduit Plutarque ${ }^{33}$. En 1561, il lui envoya

un libro di Prospettiva, che ho fatto fare per la sua libraria con sopportatione dell'eccellente $s^{\text {or }}$ Pacciotto, et di più li libri del singularissimo poeta Ronsardo, il quale supplica $V^{\text {ra }}$ Altezza et quella di Madama di una raccomandazione calda alla Reina ${ }^{34}$.

Il s'agit sans doute des CEuvres de 1560 publiées chez Gabriel Buon ; l'architecte militaire Francesco Paciotto préparait quant à lui des

28 Le nonce Prospero di Santa Croce, Paris, 28 sept. 1562, dans Archives curieuses de l'Histoire de France, éd. L. Cimber, Paris, Beauvais, 1835, $1^{\text {re }}$ série, t. VII, p. 110.

29 Della Rovere, $\mathrm{n}^{\circ} 210$, Paris, 14 déc. 1562.

30 BNF, lat. 8589, fol. 37 ; voir ibid., fol. 35, une lettre précédente écrite à Rivoli en 1561 avant d'entrer en fonction.

31 Par exemple, Della Rovere, no 152, Saint-Germain-en-Laye, 18 sept. 1560 : «De par le Roy de Navarre, Prince du Sang, Aux Estats de France, contre la tyrannie du Cardinal de Lorraine et des cadets de la maison de Lorraine»; ou encore, $\mathrm{n}^{\mathrm{o}}$ 184, Paris, 13 mars 1562: « un' libretto stampato di fresco dove si discorrono le forze et pensieri dell'una parte et dell'altra. [...] non è stato pubblicato senza gran consideratione dei partigiani ancora che paia dimostra la parte catolica assai più potente ».

32 S.l.n.d., 1559. Della Rovere, $\mathrm{n}^{\mathrm{o}}$ 154, Paris, 10 oct. 1560.

33 Della Rovere, no 156, Orléans, 15 déc. 1560.

34 Della Rovere, $n^{\circ}$ 165, Fontainebleau, 23 mars 1561. 
dessins pour les forteresses du Piémont ${ }^{35}$. L'année suivante, illui écrivit au sujet du lecteur royal en mathématiques, Pierre Forcadel : «Se Vostra Altezza sarà servita ch'io stringa la prattica del Forcadello Mathematico, si degnarà farne dar' l'ordine ${ }^{36}$. On serait curieux de savoir de quel projet il s'agissait. Et il ajoutait une phrase qui révélait qu'il était chargé d'enrichir la bibliothèque ducale: «Et mentre ch'io starò qui, se mi sarà possibile attenderò ancora al particolare dei libbri : et spero che sara buona commodità di haverne alcuni scritti a penna ».

Pendant les trois années de son ambassade, Della Rovere put suivre de près le tourbillon des affaires dans un pays qui glissait inéluctablement vers la guerre civile. Le chancelier était au cœur des tentatives de pacification et la correspondance du Savoyard témoigne de l'accès facile dont il jouissait auprès de L'Hospital. Par exemple, en septembre 1560, lorsque la situation politique s'aggravait, il se rendit chez la reine, qui lui expliqua que le jeune roi était désormais « tanto intricato in facende» qu'il ne pouvait s'occuper de la question des restitutions ou des bénéfices au Piémont. L'ambassadeur s'adressa donc au chancelier, « con cui mi conservo la sicurtà di parlargli liberamente di più cose, et non gli è parso fuori di proposito ${ }^{37}$. À nouveau, en 1562, alors que les choses n'avançaient pas et que la reine était très occupée, il jugea opportun de «pigliar' la via di conferirne con Mons. il Cancelliere in camera sua, et uno o doi del Conseglio $»^{38}$. On connaît un seul exemple où il se vit éconduit, ayant attendu devant la porte du Conseil privé, pour voir, à sa consternation, le chancelier en sortir et lui annoncer «non pas pour aujourdhuy $»^{39}$.

Pendant l'été de 1560, le Conseil du roi chercha à remédier à l'endettement de la couronne. Le parlement de Paris ayant refusé de donner 800'000 francs, l'on résolut en juin d'envoyer L'Hospital pour essayer de le convaincre ${ }^{40}$. Devant le refus du Parlement, on décida de convoquer les États Généraux, pour la première fois depuis 1484, précédés d'une assemblée des notables à Fontaine-

35 Voir A. Coppa, Francesco Paciotto architetto militare, Milan, Unicopoli, 2002.

40 Michiel, 16 juin 1560, CSP Venice, VII, no 171; Petris, La Plume et la tribune, p. 20-21 et 359-367. 
bleau (21-26 août 1560) ${ }^{41}$. Della Rovere expliqua que le but de l'Assemblée était de "levare le invidie et scontentezze che si sono scoperte contro questi signori che maneggiano », mais qu'on n'avait pas cru nécessaire $d^{\prime} y$ inviter le Tiers Etat, "perche insomma si trattava piutosto di sgravare il popolo che di imporgli niuna gravezza nuova, non è stato giudicato necessario di chiamare il stato popolare $»^{42}$. L'envoyé toscan Niccolò Tornabuoni témoigne du discours prononcé par le chancelier devant l'Assemblée:

Il gran cancelliere parlò sopra la religion, e si distese molto a provare che tutti i disordini sono nati nel regno, dipendono da' preti e principalmente da' vescovi : i quali, con le buone entrate che hanno, non si curano delle anime, stanno alla corte, o dove meglio loro piace, in continui passatempi ${ }^{43}$.

Les États furent convoqués pour le mois de décembre à Orléans mais les tensions religieuses s'aggravèrent au cours de l'automne: Della Rovere parle de «discordie intestine ${ }^{44}$ et de «questi tumulti del regno $»^{45}$ et affirme, en rapportant le passage à la cour de Navarre de Théodore de Bèze, que «non manca quasi in ogni terra questo humore della Religione ${ }^{46}$. L'arrestation du prince de Condé en novembre provoqua une crise: le prince refusa de répondre aux questions du chancelier, affirmant que ce dernier était le suppôt de ses ennemis, qui voulaient sa mort, et qu'il n'acceptait pas d'être jugé sinon par ses pairs ${ }^{47}$. Craignant le pire, le chancelier réussit à retarder la sentence de mort prononcée contre Condé. La maladie et la mort de François II portèrent un rude coup, mais le Conseil privé resta en place et décida de pour-

41 Petris, La Plume et la tribune, p. 21-25.

42 Della Rovere, no 151, Fontainbleau, 21 août 1560.

43 Niccolò Tornabuoni - Cosimo I, Melun, 25 août 1560, dans Négociations diplomatiques de la France avec la Toscane, éd. A. Desjardins, 6 tomes, Paris, Imprimerie impériale, 1859-1886, t. III, p. 424.

44 Della Rovere, $n^{\circ}$ 152, Saint-Germain-en-Laye, 18 sept 1560.

45 Della Rovere, $\mathrm{n}^{\circ} 154$, Paris, 10 oct. 1560.

46 Della Rovere, no 153, Orléans, 29 oct. 1560.

47 Suriano, 22 nov. 1560, dans Despatches of Michele Suriano and Marco Antonio Barbaro 1560-63, éd. H. Layard, Lymington, Huguenot Society of London, 1891, p. vi ; Ercole Strozzi, Orléans, 28 nov. 1560, Gonzaga 652 ; S.-H. Kim, Michel de L'Hospital, op. cit., p. 59. 
suivre la réunion des États, qui s'ouvrirent à Orléans le 13 décembre 1560 avec un discours du chancelier ${ }^{48}$.

En tant qu'évêque de Toulon, Della Rovere participa avec le clergé aux États d'Orléans, dont il donne un témoignage oculaire. Dans sa première dépêche, il fait allusion à la «bellissima propositione » du chancelier, dont il promet d'envoyer au duc «li capi principali, con l'ordine del sedere, et quelli che è seguito doppoi $»^{49}$, ce qu'il fait dans sa dépêche suivante inédite ${ }^{50}$, qui mérite attention. La première partie donne une description détaillée de la disposition de la salle, description qui précède de quelques semaines celle qui allait être publiée à Paris vers la fin de janvier 1561 (privilège du 19 janvier) ${ }^{51}$, enjolivée de deux planches dépliantes. La première planche $(425 \times 285 \mathrm{~mm})$ est une gravure sur bois qui donne le plan de la disposition des sièges, Pourtraict du plant de la salle des Estatz et de l'ordre et seance tenu en iceulx.

La deuxième $(214 \times 298 \mathrm{~mm})$, Pourtraict de l'assemblée des estatz, tenuz en la ville d'Orleans, au mois de Janvier, mil cinq cens soixante, donne une vue d'ensemble des personnages assemblés dans la salle. Il en existe deux états: une gravure sur bois (par Jean II de Gourmont?), où l'on voit le représentant de la Noblesse, Jacques de Silly, qui prononce sa harangue.

Il existe également un burin, où l'on voit les trois représentants des États debout au premier plan ${ }^{52}$. Ces gravures seront reprises après 1564 par Jean II de Gourmont ${ }^{53}$ et en 1570 dans le célèbre recueil de Jean Perrissin et Jacques Tortore ${ }^{54}$. Or, si le petit volume publié à Paris contient une description en prose pour accompagner les gravures, la dépêche de Della Rovere est antérieure et fournit

48 Petris, La Plume et la tribune, p. 22-25 et 384-405.

49 Della Rovere, $\mathrm{n}^{\circ}$ 156, Orléans, 15 déc. 1560.

50 Della Rovere, $n^{\circ} 157$, [Orléans], s.d.

51 La Description du plant du theatre faict à Orleans, pour l'assemblée des trois Estatz, Paris, Vincent Sertenas, Gilles Corrozet et Guillaume Nyverd, 1561.

52 BNF, Estampes, Rés. FOL-QB-201 (5), Hennin no 468.

53 Le vray Pourtraict et Discours de l'Assemblée des trois Estatz, BNF, fr. 10193, fol. 17bis; BNF, Estampes, Ea 17, Rés.

54 L'Assemblée des trois estats tenus à Orléans au mois de janvier 1561, BNF, Estampes, Ed 9, Rés; dans P. Benedict, Graphic History: The Wars, Massacres and Troubles of Tortorel and Perrissin, Genève, Droz, 2007, p. 251-254; trad. fr. A. Alvarez, Le regard saisit l'histoire: les Guerres, massacres et troubles de Tortorel et Perrissin, Genève, Droz, 2012, p. 147-149. 


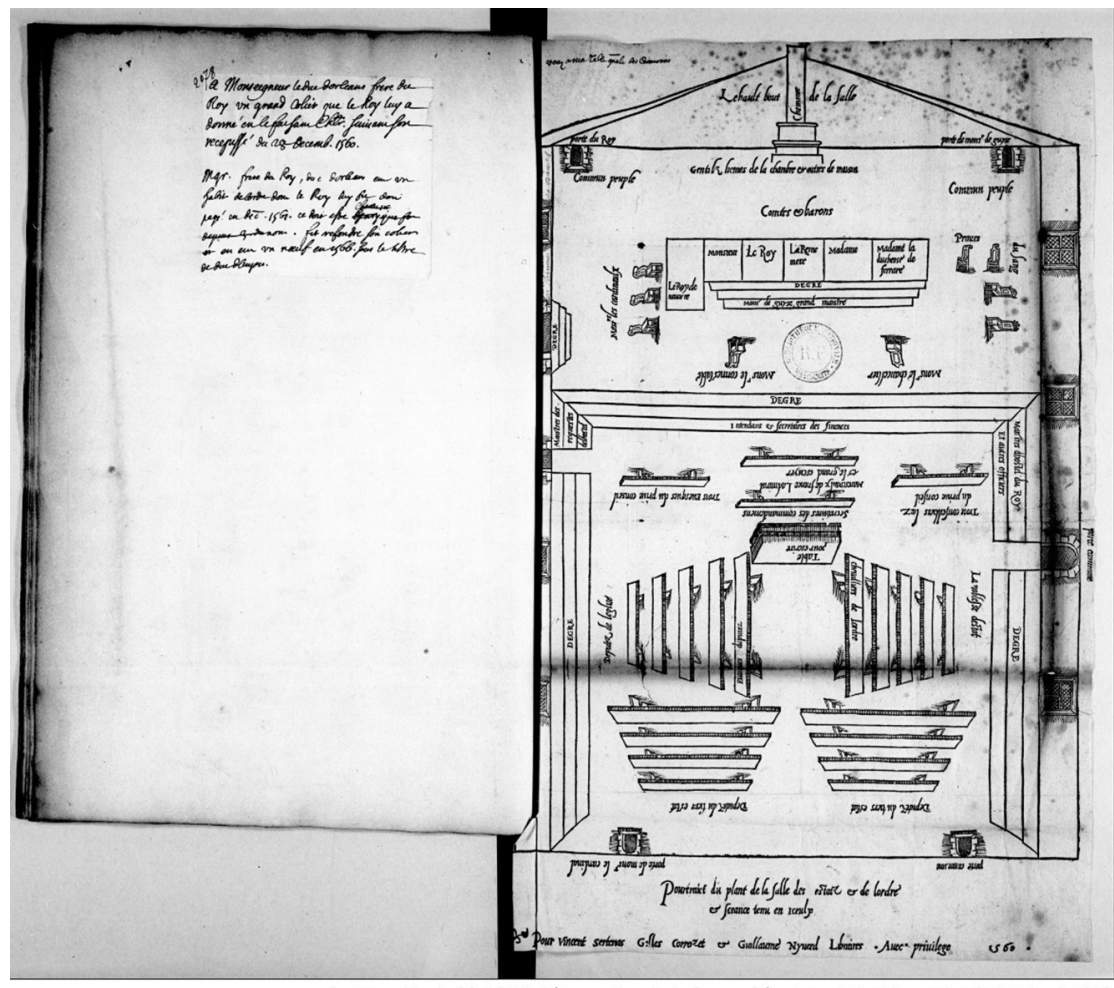

Ill. 1 : Pourtraict du plant de la salle des Estatz et de l'ordre et seance tenu en iceulx, BNF, 8 LE12 9 (2) et 8 LE12 9 (A) (2); BNF, Clairambault 1243, no 2079.

un témoignage personnel de la mise en scène, depuis sa place à gauche sur le banc des évêques:

Il Re seguitando la convocatione delli Stati del suo regno inditta dal fù Re per li X di questo mese, havendo differito sino alli XIII per l'impedimento della morte, et aspettando fusse fornita una gran sala fatta subbitamente di asse et legnami, capace per tanta gente, et quella messa all'ordine; furono venerdi mattina chiamati tutti li deputati delli Tre Stati, secondo l'ordine, che sogliono tenere in simili casi; incominciando da quegli di Parigi, et del loro Territorio, poi venendo a quelli di Borgogna, come della prima Perria di Francia, poi Normandia, et Guienna: doppoi li quali havendo a venire quelli delle altre Perrie che sono Conti: essendo li sudetti Duchi: fù chiamata 


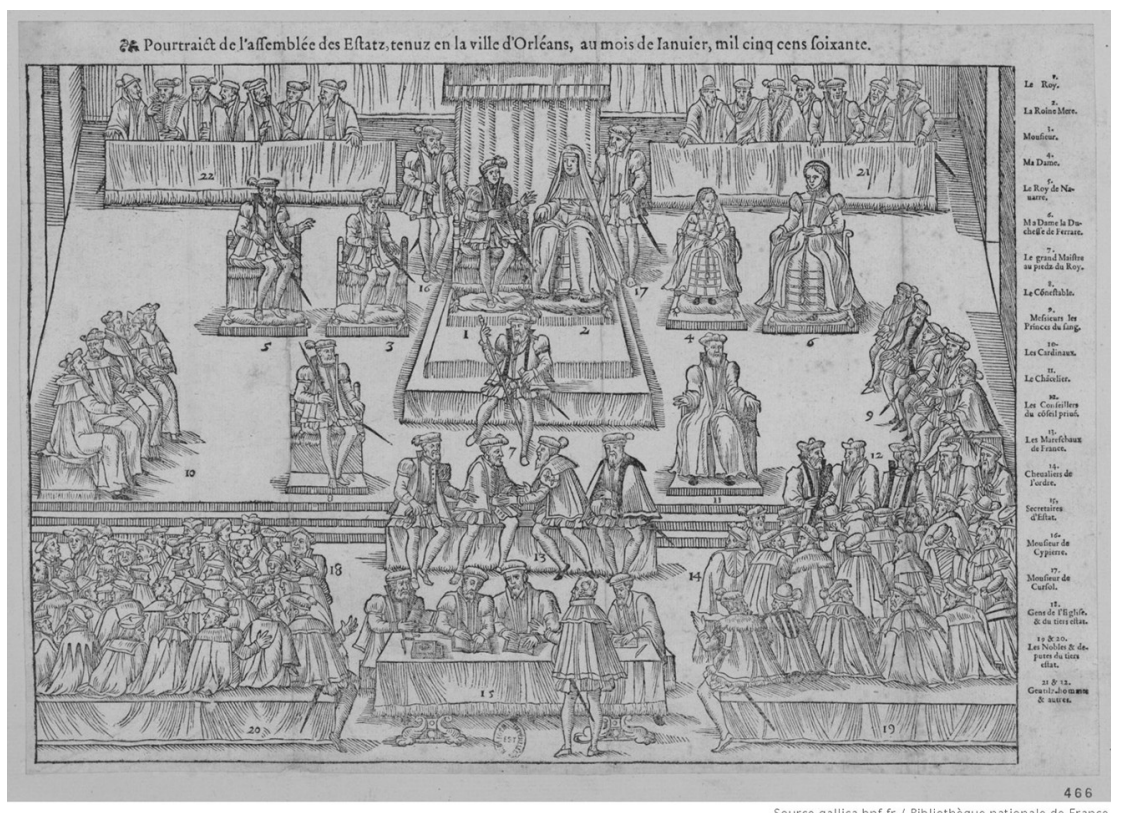

Ill. 2 : Pourtraict de l'assemblée des estatz, tenuz en la ville d'Orleans, au mois de Janvier, mil cinq cens soixante, BNF, fr. 3159, fol. 7 ; BNF, Estampes, Rés FOL-QB-201 (5), collection Hennin $n^{\circ} 466$ et 467.

Brettagna, per esser' nuovamente unita alla corona, et non mai trovatasi in alcuni stati : et di mano in mano, le dette Perrie de Conti, et poi gli altri paesi furono collocati in doe banche longhe a faccia l'una dell'altra, li Prelati a banda dritta, et li cavaglieri dell'ordine alla sinistra : et dietro a quelli, tutti li Deputati per la chiesa : dietro a questi, per la Nobiltà : Gl'ultimi quelli del Terzo Stato, cioè popolare. Fra le banche delli Vescovi et Cavaglieri, vi era un andito, che era chiusa di uno tavolino, anchora che si potesse passare da tutte due le parti, al quale sedevano li IIII secretarii dei commandamenti, con la faccia volta al $\operatorname{Re}\left[\mathrm{v}^{\mathrm{o}}\right]$, et più oltra ch'essi, erano a sedere sopra una banca maggiore et più elevata li doi Marechiali di Brissac et Santo Andrea, in mezzo, et l'Armiraglio et Gran Scudiero dalle due Bande: come li quattro principali officiali. Et a canto a questa banca, ma un poco più indietro, vi erano dalla banda diritta li Vescovi, che sono del consiglio privato del Re, et dall'altra gli signori di robba lunga laici, che sono del detto consiglio, con le faccie 
volte, come li detti IIII Uffitiali al Re: il quale sedette sopra un faldistoro rilevato, con la Reina sua Madre a canto, a banda sinistra, sotto un' gran Baldachino di drappo pavonazzo, una robba longa da duolo con una berretta quadra con una briglia di velo : e'l gran collare dell'ordine. A banda diritta di S. M ${ }^{\text {tà }}$ più basso sedevano il Duca di Orleans, et il Re di Navarra, vestiti tutti doi di longo di negro; dalla banda della Reina Madre, et più basso ancora vi era Madama sua Figlia, et Madama di Ferrara: la Reina Madre vestita, come V.A. l'ha veduta, et Madama similmente Madama di Ferrara, col duolo alla Francese. Dietro al Re stavano li Gentilhuomeni della sua Camara, serventi della casa, scudieri, et anche qualche arciere. [fol. $2 \mathrm{r}^{\circ}$ ] A basso avanti sua $\mathrm{M}^{\text {tà }}$ stava Mons di Guisa come Gran Ciamberlano, col baston' grande però di Gran Mastro, et a lati di lungo, dall'una parte, li Rmi di Tornone, Lorena, Borbone, Citattiglione, et Guisa: et a dirimpetto, cioè dalla banda stanca vi erano li principi, figliuolo di Mons di Monpensieri vestito di curto, il Principe della Roccasuryona col duolo longo : il Marchese di Beaupreau suo figliuolo: il Duca d'Aumala e'l Marchese del Ben : et nel vacuo tra queste due banche de Cardinali et Principi, et avanti alli gradi del throno Regale, sedeva sopra un scabello Mons ${ }^{r}$ il Conestabile con la spada nuda in mano : et dall'altro canto Mons ${ }^{r}$ il Cancelliere.

L'ambassadeur poursuit sa dépêche en donnant son propre résumé des points forts du long discours de L'Hospital, qui avait duré plus d'une heure et que plusieurs délégués avaient trouvé inaudible, mais qui allait être imprimé après les États ${ }^{55}$ :

il quale, come il Re si fu posto a sedere, andò da sua $\mathrm{M}^{\text {tà }}$ et dalla Reina Madre; et fatta levare la turba che si era inginocchiata all'arrivo del Re, venne come per seder al suo luoco : poi ritornò dal Re, et fatto dire per uno Uscieri di camara, che ogniuno sedesse, et si coprisse, che'1 Re lo voleva, mossosi di nuovo esso Cancelliere à sedere, mezzo volto verso il Re, et mezzo verso la compagnia, incomminciò a parlare stando sempre scoperto, et disse molte buone et belle cose, le quali si vedrano al creder' mio, ridutte in scritto da lui : per satisfar' a molti, che appena poterono sentirlo. Il suo parlare durò più d'una hora grossa et

55 Harangue, contenant La Remonstrance faicte devant la magesté du Roy treschrestien Charles neufiesme, tenant ses grans Estatz en sa ville d'Orleans: par monseigneur le Chancelier de France, Lyon, Benoist Rigaud, 1561. 
in ristretto contenne che'l Re havea voluto continuare li Stati indetti dal Re suo fratello: il quale si era risoluto di congregarli per benefitio loro: come che gia molti anni fussero disusati: allegando le cause per lequali erano frequentati dai Re passati : et qualmente in luogo di essi li Parlamenti ordinarii rendevano raggione delle querele et liti fra Privati : et gl'affari et conseglio del Re rimediavano alle cose pubbliche. Hora sendosi scoperte delle seditioni in questo Regno, il Re haveva desiderato di troncarne l'occasione, et intesa la causa rimediarvi. Et qui discorrendo sopra le cause delle seditioni, concludeva non esserne lasciata niuna in questo Regno, senon l'otio, et la povertà, et l'ambitione d'alcuni, li quali nei tumulti pubblichi speravano di crescere et di facultà, et di gradi. [ $\mathrm{f}^{\mathrm{o}} 2^{\mathrm{vo}}$ ] Rimonstrando che ai Buoni in ogniuno delli Tre Stati vi era aperta la via di salire ai maggiori honori per le buone vie : et parlando particolarmente del debbito di detti stati verso il Re, gli essortò a volerci avvertire, et star' tutti attenti che per il disordine d'alcuni non si turbasse la quiete pubblica. Allargandosi assai nel fatto della Religione, et dicendo però di intendere di parlarne grossamente, et come huomo politico, et mostrando quanto vergognosa cosa fusse, mettere avanti la Religione per pretesto di Dissensione, et di Confusione : che hormai non saria più Discordia di opinioni : ma contrarietà d'animi, et di volontà, però che per conto delle opinioni si satisfaria con questo Concilio Generale: et che nel resto tutti s'unissero d'animi, et di volontà al servitio del $\mathrm{Re}$ : che sua $\mathrm{M}^{\text {tà }}$ intendeva di alleviargli di quanto gli sarebbe possibile: tutto che si trovasse occupato di grandissimi affari. Et ch'essi facessero intender' a sua $\mathrm{M}^{\text {tà }}$ le loro doglienze et domande: che tutto il Clero di tutte le Provincie ne presentasse un scritto, tutta la Nobiltà un'altro, et il terzo stato il suo, acciochè sua detta Mtà [fo 3], insieme col suo consiglio vi possa rimediare opportunamente: et fu tutto ' 1 suo raggionamento pieno di molti belli essempii et authorità : et non senza honorata mentione della Reina Madre, et del Re di Navarra, per la cui bontà et prudenza le cose passavano quietamente, et nel modo che si saria potuto desiderare. Finito il suo parlare, montò sopra un banco un' Haraldo, et disse da parte del Re, che tutti li stati si congregassero alle otto hore il giorno seguente in San Francesco: poi si ritirasse tutto il clero pur a San Francesco, la Nobiltà a San Dominico, et il Popolo a' Carmini. Il che hanno fatto: et per quanto s'intende, non restano molto d'accordio fra loro: et il clero et popolo si contenta di venir' a presentare le loro dimande: ma la 
Nobiltà vorria una Dilatione di III settimane, per havere nuove Instruttioni dalle loro Provincie, poiche è sopragionta la morte del Re.

Et il conclut sa lettre en réfléchissant au problème de la gouvernance $\mathrm{du}$ royaume pendant la minorité du roi. Il estime que la noblesse cherche à prendre le contrôle, comme le Conseil de régence composé de douze personnes pendant la minorité de Charles VIII, et ne veut pas que Catherine soit régente, « allegando che è donna et forestiera », selon l'ambassadeur de Mantoue ${ }^{56}$. Della Rovere estime qu'on trouvera un compromis en nommant le roi de Navarre lieutenant-général, laissant à la reine-mère la garde de son fils.

Les quarante millions de dettes de la couronne furent le plus grand souci du chancelier, qui refusa pourtant de prendre la charge des finances lorsqu'on la lui proposa et menaça même de démissionner ${ }^{57}$. La réunion des États fut reportée pendant qu'on cherchait à restreindre les dépenses de la Maison du roi ${ }^{58}$, puis reprit avec la présentation des doléances des trois États ${ }^{59}$. Della Rovere raconte la séance du 16 janvier, où le roi de Navarre et le chancelier exposèrent «la necessità grande del Re, et li gravi debbiti che tiene, per i quali domandorno al clero et al popolo $\mathrm{V}$ millioni di franchi per quest'anno ${ }^{60}$. Le représentant du clergé protesta que la dette n'était pas la faute de l'Église mais de la Couronne, à quoi le chancelier répliqua que «debbiti che si erano create erano stati in sua assentia: et se trovassero che fussero per conto di qualche dono, ch'egli havesse havuto, che voleva esser' obligato di restituirlo $»^{61}$. Le chancelier se montra

56 Ercole Strozzi, Orléans, 27 déc. 1560, Gonzaga 652.

57 Tornabuoni, 16 déc. 1560, dans Négociations, éd. cit., t. III, p. 432 : «Le finanze, poi che il gran cancelliere l'ha rifiutate, rifiutando ancora il cancellierato se volevano che a queste attendesse, si sono date a tre cavalieri dell'ordine» [Lansac, Vieilleville, Cursol].

58 Della Rovere, $\mathrm{n}^{\circ}$ 159, 20 déc. 1560.

59 Della Rovere, no 160, 3 janv. 1561 ; Tornabuoni, 8 janv. 1561 dans Négociations, éd. cit., t. III, p. 443-444; Petris, La Plume et la tribune, p. 25-30.

60 Della Rovere, $\mathrm{n}^{\mathrm{o}}$ 162, Orléans, 17 janv. 1561.

61 La Harangue faite par Monsieur de Lospital grand Chancelier de France, en la presence du Roy, Blois, Julien L'Angelier, 1561. 
optimiste sur les problèmes religieux, qu'on avait renvoyés au futur colloque de Poissy: "et si tiene che le cose della relligione paseranno bene, essendo rimesse al concilio ». À la demande des catholiques de conserver la religion traditionnelle, et celle des huguenots de vivre «al modo loro », L'Hospital répondit

che $S \mathrm{M}^{\text {ta }}$ gli rengratiava delle bone volentà loro, et che gli preghava et comandava loro di voler' vivere nel timor' de Dio et che non facessero delle assemble come haveano fatto per il passato per non scandelizare il prossimo et che vivessero secondo le consitientie loro ${ }^{62}$.

Mais les édits publiés après Orléans ne firent que masquer les mésententes et le parlement de Paris refusa de les enregistrer. Della Rovere s'opposait à ces mesures de tolérance: «et certamente non ci saria piu bella via di seminare delle seditioni, et guerre civili, fra questi popoli, che di concedere loro l'Interim $»^{63}$. Et le chancelier dut se présenter en juin devant les membres du Parlement pour essayer de les convaincre:

ed a questo fine il cancelliere andò da per se solo in parlamento, pregando quelli signori, che, poiché non era parso loro bono l'editto fatto a Fontainebleau, volessino trovare qualche modo da quietare questi popoli, mostrando tacitamente dar licenza che ciascuno dicesse liberamente l'opinione sua. Non fu trovato molto buono questo procedure nel parlamento, perchè, trovandosi in dissenso col consiglio privato del Re, parve che andasse più per scalzarli, che per trovar ordine a quieter questa causa, tanto più che non ha questo cancelliere troppo buon nome in questa causa, ma di intriso, ancorchè mostri tutto il contrario ${ }^{64}$.

L'un d'entre eux aurait accusé L'Hospital d'être responsable personnellement de tous les désordres depuis la mort de

62 Ercole Strozzi, Moret, 17 févr. 1561, Gonzaga 652; voir Petris, La Plume et la tribune, p. 407.

63 Della Rovere, $\mathrm{n}^{\mathrm{o}}$ 168, Paris, 15 juin 1561.

64 Tornabuoni, Paris, 23 juin 1561, dans Négociations, éd. cit., t. III, p. 455; cf. Sebastiano Gualterio - Carlo Borromeo, 17-19 juin 1561, dans Archives curieuses, éd. cit., t. VII, p. 348, no 312 ; Chantonnay, Paris, 8 et 13 juin 1561, dans Negociaciones con Francia, éd. cit., t. II, p. 242, no 306 et p. 260, no 312 ; Petris, La Plume et la tribune, p. 409-415. 
François II et d'avoir «agevolata questa piaga, quale già era divenuta putrida ${ }^{65}$. Mais lorsque le Parlement finit par enregistrer l'édit de Fontainebleau, l'ambassadeur de Venise exprima son admiration pour la finesse du chancelier, "homo accortissimo», dont l'orthodoxie était suspecte mais qui avait rédigé un texte suffisamment ambigu pour convaincre les magistrats ${ }^{66}$.

Della Rovere fut également témoin de l'assemblée du clergé à Poissy ( 31 juillet - 19 août) et du Colloque ( 9 septembre - 14 octobre $1561)^{67}$. L'Assemblée s'ouvrit le jour même de l'enregistrement de l'édit, et le chancelier y prononça un discours qui choqua le cardinal de Tournon ${ }^{68}$, parce qu'un colloque national sur la religion risquait de compromettre le concile de Trente, qui allait reprendre ses travaux en novembre. Tournon en exigea une copie (pour l'envoyer au pape) mais L'Hospital refusa:

Quanto alla proposta fatta da Mons. il Cancelliero havendola fatta, come egli ha detto, all'improvista, et che piu facil' cosa gli saria di farne un'altra, che'l dar copia di quella, [...] ha replicato la principale intentione del Re essere che li Prelati cerchino via di acquietare questi tumulti, et ne diano il [loro] consiglio et parere al $\operatorname{Re}^{69}$.

En même temps, les États Généraux s'étaient réunis à nouveau en août à Pontoise $^{70}$ où, après un bref discours de L'Hospital, les délégués présentèrent leurs réponses plutôt intransigeantes aux propositions du chancelier à Orléans, et la rupture s'accentua

65 Tornabuoni, 5 juill. 1561, dans Négociations, éd. cit., t. III, p. 457.

66 Suriano, Paris, 27 juill. 1561, dans Despatches, p. xxxvi; S.-H. Kim, Michel de L'Hospital, op. cit., p. 71.

67 Petris, La Plume et la tribune, p. 30-40.

68 Pour une autre querelle avec Tournon, voir Chantonnay, Moret, 24 février 1561, dans Negociaciones con Francia, éd. cit., t. II, p. 76, no 235.

69 Della Rovere, $n^{\circ} 173$, Poissy, 5 août 1561 (manuscrit endommagé) ; cf. Suriano, 5 août 1561, dans Despatches, p. xxxix: "pare che vi fussero certe parole alquanto diverse da quello che tiene la Chiesa Catholica et si scandelizarono molto, et li fu dimandato che desse la proposition in scrittura, lui disse che daria quando si ricorderia, ma che non potria dar così a punto quello che haveva detto, perchè non lo havea scritto salvo per summarii »; Chantonnay, Paris, 5 août 1561, dans Negociaciones con Francia, éd. cit., t. II, p. 324-325.

70 N. Valois, «Les États de Pontoise (août 1561)», Revue d'histoire de l'Église de France, 116 (1943), p. 237-256; Petris, La Plume et la tribune, p. 419-426. 
entre les partis. Si les États acceptèrent de faire un don au Roi de quarante-trois millions de francs ${ }^{71}$, les attitudes se durcissaient sur la question de la religion. L'Hospital fit placer en résidence surveillée le premier Président du parlement de Paris ${ }^{72}$; une querelle éclata entre le chancelier, le connétable et le cardinal de Lorraine $^{73}$; et les cardinaux de Lorraine, de Guise et de Tournon prétextèrent un problème de préséance pour bouder la réunion des États, " perchè non ci havevano luoco, come alli stati di Orleans " $^{74}$. Della Rovere participa à la réunion des évêques, qui déploraient l'invitation au colloque de Poissy de Bèze et de sept ou huit autres huguenots, dont peut-être Calvin lui-même. Il fut l'un des cinq à voter contre ${ }^{75}$ mais les prélats durent s'incliner devant la volonté $\mathrm{du}$ roi, «atteso massime che Mons. il Cancelliere ci haveava detto che verrebbono da noi, come loro giudici, et come figliuoli a padri $»^{76}$.

Après le Colloque, Della Rovere put faire des progrès avec le chancelier concernant les problèmes particuliers de la Savoie ${ }^{77}$ mais, avec le Nouvel-An, l'assemblée de Saint-Germain vint interrompre les pourparlers ${ }^{78}$ et L'Hospital n'eut plus le loisir de discuter de la gabelle ${ }^{79}$. L'ambassadeur impérial ironisa sur le discours prononcé par L'Hospital, qui « presume ser humanista y gran retórico », mais qui aurait scandalisé « todos los católicos ${ }^{80}$. Il

71 Tornabuoni, Paris, 4 sept. 1561, dans Négociations, éd. cit., t. III, p. 461.

72 Tornabuoni, Paris, 23 août 1561, dans Négociations, éd. cit., t. III, p. 459-460: "Quello che ha dato il tracollo al primo presidente è stato il cancelliere, per averselo trovato contro nelle cose proposte da lui, e massime della religion ».

73 Della Rovere, no 175, Poissy, 28 août 1561: «intendo che ne seguirno non so che parole tra Mons. il Con[nestabile] et Cancelliere, similmente tra Mons. il Cancelliere et Cardinal di Lorena ».

74 Della Rovere, no 175, Poissy, 28 août 1561.

75 Chantonnay, Saint Cloud, 10 sept. 1561, dans Negociaciones con Francia, éd. cit., t. II, p. 404, no 356.

76 Della Rovere, $\mathrm{n}^{\circ} 175$, Poissy, 28 août 1561.

77 Della Rovere, no 176, Paris, 7 déc. 1561.

78 Petris, La Plume et la tribune, p. 40-53 et 433-439.

79 Della Rovere, no 177, Poissy, 12 janv. 1562: «Sono tanto occupati a questa assemblea che non attendano ad altro ».

80 Chantonnay, Poissy, 5 janv. 1562, dans Negociaciones con Francia, éd. cit., t. III, p. 236-237, no 418: «El intento desta proposición fué tirar a la conclusión de un interin, y como el chanciller presume ser humanista y gran retórico, 
se serait même querellé avec le connétable, qui estimait que L'Hospital faisait trop de concessions aux huguenots sur la liberté du culte et qui, fort de son service auprès de quatre rois de France, prétendait mieux savoir ce dont le royaume avait besoin. La riposte du chancelier fut cinglante:

A che il cancelliere soggiunse che non era più tempo a governare per 'Garde! Garde!', parole usate dal Conestabile, ma per la ragione: di che il Conestabile si alterò molto ${ }^{81}$.

Les discussions entre les théologiens catholiques et les ministres huguenots s'étant enlisées sur le chapitre des images, la reine-mère décida avec L'Hospital de clore le débat:

la Reina fece loro dire hieri da Mons ${ }^{\text {or }}$ il Cancelliere in sua presenza che dovessero ritirarsi gli uni et gli altri: et mettere per scritto quello che sarà di loro openione nelle altre materie della Religione: et mandarle alla Maestà sua ${ }^{82}$.

L'ambassadeur commençait à perdre espoir pour l'avenir de la France, déplorant «questi tempi che sono così sciaguratissimi » ${ }^{83}$, mais il trouva une lueur de réconfort dans la mise en œuvre de l'Édit de Janvier, même si le parlement de Paris refusa de l'enregistrer jusqu'au 6 mars $^{84}$. Il rapporta l'ordre donné par la reine-mère de vivre «catholiquement», d'aller à la messe, ou de quitter la cour $^{85}$, et il se réjouit du fait que le roi, la reine-mère et le chancelier avaient participé à la procession de la Chandeleur et qu'ils avaient

dispuso su habla de tal manera, que no solamente declaró lo en que inclinaba, mas aun mostró por sus razones querer persuadirlo a los otros para que diesen aquel mismo parescer de que todos los católicos han quedado muy escandalizados y con menos esperanza y mayor temor de la resolución que antes ».

81 Tornabuoni, Paris, 3 janv. 1562, dans Négociations, éd. cit., t. III, p. 470-471.

82 Della Rovere, no 180, Saint-Germain-en-Laye, 12 févr. 1562.

83 Della Rovere, no 177, Poissy, 12 janv. 1562.

84 Della Rovere, no 180, Saint-Germain-en-Laye, 12 févr. 1562 ; no 181, 19 févr. 1562.

85 Della Rovere, $\mathrm{n}^{\mathrm{o}}$ 180, Saint-Germain-en-Laye, 12 févr. 1562 : «Le cose della Religione vanno piu tosto meglio, che altramente. Et oltra il commandamento che la Reina ha fatto alle sue Donne, io intendo, che saranno anche chiamati gl'Ufficiali di casa del Re, et sarà loro commandato di vivere catholicamente, overo andarsene». 
communié ${ }^{86}$. Le prince de Condé et le cardinal de Châtillon étant partis de la cour, l'ambassadeur de Florence estimait alors que l'équilibre des forces au Conseil privé avait basculé en faveur des catholiques, "talché non c'è che il cancelliere che tenga la pugna ${ }^{87}$, c'est-à-dire pour la cause des huguenots.

Mais le chancelier n'était plus à la cour pendant les mois de février et mars 1562, prétextant une maladie ${ }^{88}$. Lorsqu'il chercha à revenir en mars, on lui dit d'attendre d'être mandé 89 . L'ambassadeur de Mantoue rapporta que le roi de Navarre ne voulait pas que L'Hospital assistât au Conseil privé, "per essere obligato con la parte adversa ${ }^{90}$; et le chancelier profita de son séjour à Paris, selon le nonce Santa Croce, pour tenir chez lui des réunions fréquentées par Condé, Châtillon, Jeanne d'Albret, Monluc, Éléanore de Roye, princesse de Condé, et Louise de Clermont, dame de Crussol, «y otros desta harina $»^{91}$. Il s'agissait précisément des personnes dont le duc de Savoie conseillait au roi de se méfier: comme le roi d'Espagne, il se disait prêt à envoyer des troupes pour aider la cause royale, à condition que le roi ne favorisât pas les huguenots et qu'il ne prêtât plus l'oreille aux mauvais conseils du chancelier et de sa bande ${ }^{92}$.

Après le massacre de Wassy, la guerre devint inévitable et le chancelier resta loin de la cour, à Paris ou à Vignay. Mais il ne s'y sentait pas en sécurité et le roi dut envoyer des gardes suisses pour le protéger contre les catholiques parisiens ${ }^{93}$.

86 Ercole Strozzi, 8 févr. 1562, Gonzaga 653.

87 Tornabuoni, 26 mars 1562, dans Négociations, éd. cit., t. III, p. 475.

88 Chantonnay, Poissy, 23 févr. 1562, Negociaciones con Francia, éd. cit., t. III, p. 366, no 442: «El Chanciller nunca quiso ir [au Parlement]; fingersi doliente ».

89 Santa Croce, 15 mars 1562, dans Archives curieuses, éd. cit., t. VI, p. 51-52.

90 Ercole Strozzi, Paris, 31 mars 152, Gonzaga 653.

91 Chantonnay, Poissy, 16 mars 1562, dans Negociaciones con Francia, éd. cit., t. III, p. 400, no 447; Sante Croce, Paris, 15 mars 1562, dans Archives curieuses, éd. cit., t. VI, p. 51-52 et 54 .

92 Sante Croce, Paris, 26 mars 1562, dans Archives curieuses, éd. cit., t. VI, p. 67.

93 Nicolas Throckmorton - Elizabeth I, Paris, 23 juill. 1562, dans Calendar of State Papers Foreign [CSP], Elizabeth, éd. J. Stevenson, Londres, HMSO, 1867, t. V, p. 176 no 351 ; Chantonnay, Paris, 30 juin 1562, dans Negociaciones con Francia, éd. cit., t. IV, p. 160. 
At this present, the Chancellor of France, being the most sincere man of this Prince's council, is in as great fear of his life as Throckmorton, being lodged hard by the Bois de Vincennes, where he has one of the King's guards to guard him, and whom the Parisians have threatened to go and kill in his lodging ${ }^{94}$.

On estimait que, s'il allait régulièrement à la messe, ce n'était que de la poudre aux yeux pour masquer ses vraies croyances $^{95}$ : «Il cancelliero, a chi ella [Catherine] crede molto, è nemico del papa e della chiesa romana! ${ }^{96}$. On rapporta même qu'il refusa de déclarer sa foi devant le parlement de Paris ${ }^{97}$. Le nonce et l'ambassadeur d'Espagne faisaient pression pour le faire remplacer par quelqu'un de plus sûr, comme le cardinal d'Armagnac ${ }^{98}$ et, même lorsque la reine-mère le défendit comme «el mejor hombre del mundo ${ }^{99}$, ils n'attendaient que l'occasion de revenir à la charge $^{100}$. L'Hospital écrivit au pape en août 1562 pour affirmer sa foi catholique et son désir d'une bonne réforme ${ }^{101}$ mais Pie IV avait déjà offert au roi de l'argent, à condition de renvoyer son chancelier ${ }^{102}$.

Un des facteurs-clés dans les tentatives de réforme et de réconciliation était le rapport entre L'Hospital et son ancien mécène, le cardinal de Lorraine. Une dépêche de Della Rovere

94 Throckmorton, Paris, 5 août 1562, dans CSP Foreign, Elizabeth, t. V, p. 212, $n^{\circ} 428$.

95 Throckmorton, Paris, 29 déc. 1563, dans CSP Foreign, Elizabeth, éd. J. Stevenson, Londres, HMSO, 1869, t. VI, p. 645-646; S.-H. Kim, Michel de L'Hospital, op. cit., p. 91.

96 Suriano dans Relations des ambassadeurs vénitiens, éd. N. Tommaseo, Paris, Imprimerie royale, 1838, 2 vol., t. I, p. 550 ; cf. Chantonnay, Orléans, 28 déc. 1560, dans Negociaciones con Francia, éd. cit., t. I, p. 517 n 191 : «El Canciller no es tenido por católico ».

97 Chantonnay, Paris, 26 juill. 1562, dans Negociaciones con Francia, éd. cit., t. IV, p. 203, no 536.

98 Sante Croce, Paris, 19 et 31 mars 1562, dans Archives curieuses, éd. cit., t. VI, p. 58 et 72 .

99 Chantonnay, Poissy, 20 mars 1562, dans Negociaciones con Francia, éd. cit., t. III, p. $418-19, \mathrm{n}^{\circ} 450$.

100 Santa Croce, 29 avril 1562, dans Archives curieuses, éd. cit., t. VI, p. 94.

101 Petris, La Plume et la tribune, p. 472-474.

102 Chantonnay, Paris, 30 juin 1562, dans Negociaciones con Francia, éd. cit., t. IV, p. 159, no $^{\circ} 24$. 
du printemps de 1562 signala le retour à la cour du cardinal, qui exprima le désir

di fare qualche apertura di riconciliatione; et cosi mi disse Mons. il Cancelliere che non haveva più speranza alcuna della reconciliatione, se non nella persona di detto signore. Il tutto sta che quegli vogliano lasciare le armi, senza che questi di qua si partino della Corte ${ }^{103}$.

Le prêche du cardinal à Notre-Dame laissait encore quelque espoir d'un accommodement ${ }^{104}$ mais la situation militaire s'était déjà trop aggravée, avec la prise d'Orléans (2 avril 1562) et la razzia du baron Des Adrets (30 avril 1562). Della Rovere rendit compte au duc de cette série noire: le massacre des huguenots à Toulouse et la ruine des églises à Vendôme ${ }^{105}$ et à Meaux ${ }^{106}$, puis en septembre le sac de Poitiers ${ }^{107}$. Après Meaux, il était question de faire venir la reine-mère à la cour pour chercher la paix, mais Della Rovere ajouta en chiffre:

Qui ogniuno desidera che venghi la Reina per ogni degno rispetto [chiffre] ma il cancelliere vi è tanto male veduto che sconsigliarà che non si venga ${ }^{108}$.

Dans un autre post-scriptum en chiffre, l'ambassadeur donna libre cours à son désespoir :

io veddo le cose della Religione andar di mal in peggio. In summa si sta in periculo di confusione delo stato o dela Religione o forse di tutti due ${ }^{109}$.

Il estimait que le parti de la guerre avait pris le dessus au Conseil privé, où le chancelier était souvent absent ${ }^{110}$.

\footnotetext{
103 Della Rovere, no 186, Paris, 27 avril 1562.

104 Della Rovere, no 189, Paris, 19 mai 1562.

105 Della Rovere, no 204, Paris, 4 juin 1562.

106 Della Rovere, no 192, Paris, 5 juill. 1562.

107 Della Rovere, no 199, Gien, 14 sept. 1562.

108 Della Rovere, $n^{\circ} 192$, Paris, 5 juill. 1562.

109 Della Rovere, $n^{\circ}$ 205, Paris, 16 juin 1562.

110 Par exemple, Della Rovere, no 204, Paris, 4 juin 1562.
} 
À l'automne, Della Rovere signala le retour à la cour du chancelier ${ }^{111}$ qui, selon l'ambassadeur espagnol, était tellement pessimiste $\mathrm{qu}^{\prime} \mathrm{il}$ était impatient de prendre sa retraite ${ }^{112}$. En septembre, Lorraine était parti pour le concile de Trente ${ }^{113}$, avec les autres prélats français qui avaient été nommés par le roi, dont Della Rovere lui-même, qui avait pu invoquer un excès de travail comme ambassadeur pour se faire excuser ${ }^{114}$. Lorraine et L'Hospital avaient été tous les deux plutôt hostiles au Concile, qui risquait de compromettre les libertés de l'Église gallicane ${ }^{115}$. Selon le chancelier, le Concile n'aboutirait à rien sans la présence des protestants et il était inutile de chercher une solution au loin lorsque c'était aux abus au sein de l'Église de France qu'il fallait porter remède ${ }^{116}$. Après le départ du cardinal pour Trente, les observateurs notèrent que Catherine avait souvent recours aux conseils de L'Hospital ${ }^{117}$ et ils étaient tous les deux soulagés de l'absence du cardinal ${ }^{118}$. Mais son retour de Trente et sa conversion à l'ultramontanisme allaient provoquer une série de brouilles avec L'Hospital ${ }^{119}$.

Les dernières dépêches de Della Rovere dans ce recueil datent de la fin de décembre 1562. Étant parvenu à faire restituer une bonne partie de ses États à son maître, il allait pouvoir rentrer au Piémont, pour être nommé archevêque de Turin (1564) puis cardinal (1586). Promoteur de la Contre-Réforme au Piémont ${ }^{120}$,

111 Della Rovere, no 201, Paris, 6 août 1562 ; no 199, Gien, 14 sept. 1562.

112 Chantonnay, Saint Cloud, 14 oct. 1562, dans Negociaciones con Francia, éd. cit., t. II, p. $489, \mathrm{n}^{\mathrm{o}} 375$.

113 Della Rovere, no 199, Gien, 14 sept. 1562.

114 Chantonnay, Saint Cloud, 7 nov. 1561, dans Negociaciones con Francia, éd. cit., t. III, p. $64, n^{\circ} 383$; cf. p. $66, n^{\circ} 384$.

115 S.-H. Kim, Michel de L'Hôpital, op. cit., p. 104.

116 Voir les dépêches de Gualterio dans Correspondance des nonces, éd. J. Lestoquoy, du 15 avril 1561, p. 336, no 298, et du 8 sept. 1561, p. 377, no 328 ; Santa Croce, Blois, 28 mars 1563, dans Archives curieuses, éd. cit., t. VI, p. 138-39; Chantonnay, Moret, 11 avril 1561, dans Negociaciones con Francia, éd. cit., t. II, p. $166, \mathrm{n}^{\mathrm{o}} 272$.

117 Suriano, 30 avril 1563, dans Despatches, éd. cit., p. 91.

118 Santa Croce, Paris, 27 juin 1563, dans Archives curieuses, éd. cit., t. VI, p. 145146.

119 Santa Croce, Melun, 25 févr. 1564, dans Archives curieuses, éd. cit., t. VI, p. 156.

120 M. Grosso et M.F. Mellano, La Controriforma nella arcidiocesi di Torino (15581610), 3 vol., Città del Vaticano, Tip. Poliglotta vaticana, 1957, vol. I, Il cardinale Girolamo Della Rovere e il suo tempo. 
c'est lui qui allait profiter de la mort de la duchesse Marguerite pour démolir le tombeau de Marot à Turin. Mais, malgré sa fidélité à la ligne catholique de son maître Emanuele Filiberto et malgré sa propre répugnance au dialogue avec les huguenots, il avait rendu, dans sa correspondance, un témoignage fort de la ténacité du chancelier dans sa recherche du compromis et de la concorde nationale, depuis son élévation à la chancellerie jusqu'à son exclusion du Conseil privé après l'ouverture des hostilités: "Silent enim leges inter arma».

Richard COOPER University of Oxford 
过

ํํำ

.

큼

국

(2)

(1)

甲

(8) 


\section{LE PLOMB ET LES SCEAUX: LES PUBLICATIONS POÉTIQUES DE MICHEL DE L'HOSPITAL CHEZ FÉDÉRIC MOREL (1558-1560)}

Ce titre, qui pastiche bien entendu celui donné par Loris Petris à ses deux sommes lhospitaliennes ${ }^{1}$, entend souligner un lien, que j'ai perçu tout au long de la période où j'ai travaillé à cette question, mais que je suis encore incapable de préciser ou d'expliquer, entre le phénomène intrigant et un peu mystérieux que constitue, dans la vie et la carrière de Michel de L'Hospital, le changement, aussi brusque que provisoire, opéré, à la fin de 1557 ou au tout début de l'année 1558, dans le mode de diffusion de sa poésie latine, et son obtention des sceaux deux ans et demi plus tard. Si l'on peut supposer, ou percevoir, ce lien, c'est qu'une fois parvenu à l'acmè de son cursus honorum, après 1560 donc, jamais plus le chancelier n'aura recours aux presses de Morel pour faire lire ses vers latins. Ces presses humanistes auraient-elles donc été pour le chancelier de Marguerite un ultime moyen de parvenir aux plus hautes marches du pouvoir? Est-ce plausible? Est-ce envisageable?

Jusqu'à ce moment avancé de son existence (il est tout de même âgé de plus de cinquante ans), il avait, en effet, comme d'autres poètes de conséquence de l'époque - et l'on peut penser ici, bien entendu, tout particulièrement à Mellin de Saint-Gelais, mais songeons aussi, pour le domaine plus proprement néo-latin, à Buchanan - très massivement opté pour, et privilégié, une diffusion manuscrite de son importante production poétique ${ }^{2}$.

\footnotetext{
1 Petris, La Plume et la tribune; L'Hospital, Discours et correspondance.

2 À ce sujet, voir la mise au point récente et très informée de P. Galand et L. Petris en tête des Carmina, t. I, p. 22-23.
} 
Or à la fin de 1557 et au début de 1558, tout à coup, de manière aussi appuyée que spectaculaire - puisque, comme le montrera l'inventaire donné en Annexe, c'est plus d'une dizaine de plaquettes qu'il lance alors auprès du public lettré par ce biais, de manière anonyme ou sous son nom propre -, il choisit de passer à la diffusion imprimée de ses textes politiques d'actualité. Pour ce faire, il s'adresse de surcroît, autre étrangeté, de manière aussi constante que systématique, à un imprimeur débutant, Fédéric Morel.

Les quelques pages qui viennent seront donc consacrées à essayer à la fois de mettre un peu d'ordre dans le véritable maquis éditorial que constituent les éditions et rééditions des plaquettes poétiques de L'Hospital débitées sous la marque au mûrier entre 1558 et 1560, et à tenter de saisir, si possible, les raisons de cette attirance soudaine pour l'imprimé: correspondelle à une nouvelle stratégie politique et/ou sociale du futur chancelier de France? Serait-elle due à la personnalité de l'imprimeur? Faut-il en chercher ailleurs les raisons?

Pour essayer de clarifier un peu les choses nous devrons procéder en plusieurs temps. Il nous faudra tout d'abord nous interroger sur la place et le rôle de L'Hospital à ce moment précis de sa carrière, au tournant des années 1557-1558. Il faudra bien entendu ensuite situer le typographe qui a retenu son attention, pour essayer de comprendre ce choix qui ne souffrira pas d'exception, pour la publication de sa poésie du moins ${ }^{3}$. Dans un troisième moment, nous présenterons un inventaire, sans doute incomplet, malheureusement, tant la bibliographie matérielle de ces plaquettes est difficile à établir et demande l'examen du plus grand nombre d'exemplaires possible, des différentes éditions/ émissions de ces grandes épîtres civiques que L'Hospital publie chez Morel de 1558 à 1560. Cet examen attentif des différents états de ces textes décisifs, car engagés au service des Guises, conduira peut-être à des perspectives renouvelées, pour peu que l'on soit par

3 Au moins un discours en prose latine sort cette année-là d'autres presses, celles de Wechel: Ex cujusdam commentariis historiarum nostri temporis excerpta oratio, quam ipsa sponsalium die regina Scotiae ad Henricum regem habuit, Paris, André Wechel, 1558, in $-4^{\circ}$ de 8 p. (ex. à la BNF et à la BN de Rome). 
exemple attentif à la production d'ensemble de Morel en ces années ou que l'on s'interroge sur l'anonymat relatif, et apparemment très contrôlé, sous lequel paraissent ces pièces.

\section{SITUATION DE L'HOSPITAL EN 1557/58}

Ce n'est nullement ici le lieu de retracer la longue et complexe carrière du futur chancelier: des plumes bien plus autorisées que la mienne, l'ont fait et fort bien fait ${ }^{4}$. Je voudrais juste me concentrer en ouverture sur ce tournant de l'année 1557/1558 où visiblement quelque chose s'est produit, sous l'effet d'une cause interne, propre à L'Hospital, ou d'une cause externe, qu'il nous faudra déterminer, événement qui l'a incité à modifier de façon brusque et radicale le mode de diffusion sinon de toute sa poésie, au moins d'une partie importante de ses vers latins.

Pour nous en tenir à la seule décennie qui va nous concerner ici, les années 50, on sait que grâce à l'entremise de Jean de Morel, L'Hospital fut aux environs de 1547 introduit auprès de Marguerite de France, et que ses talents poétiques eurent sans doute leur rôle à jouer dans le fait qu'il entra assez rapidement dans les bonnes grâces de la princesse, au point qu'elle le nomma, peu après son retour d'Italie, chancelier du duché de Berry lorsqu'elle en reçut l'apanage des mains du nouveau roi, son frère, en 1550. Cette nomination le mit davantage encore en lumière et il fut ainsi quatre années de suite, de 1550 à 1553 désigné par ses collègues du parlement de Paris pour présenter leurs remontrances au roi. Dès octobre $1553^{5}$, toutefois, il résignait son office de parlementaire, assuré qu'il était de pouvoir échapper à la monotonie des procédures et à l'agressivité des plaideurs dont il se plaint dans certaines de ses épîtres en vers (voir par ex. I, 2, 106-124), pour endosser un rôle plus politique auquel il aspire. Il faut dire qu'il avait obtenu en octobre 1553 une charge de maitre extraordinaire des requêtes qui venait concrétiser ses espoirs de changement. Bientôt, en février 1555, il sera nommé premier Président de la

4 Voir DL, et surtout le premier chapitre de Petris, La Plume et la tribune, p. 3-70.

5 Voir DL, t. I, p. 225. 
Chambre des comptes, afin de seconder le cardinal de Lorraine dans la levée des fonds nécessaires à la poursuite des campagnes militaires.

La chose est bien connue: en effet, la relation qui a sans aucun doute le plus joué pour assurer son ascension dans l'appareil d'État est celle qu'il a su développer avec différents membres de la famille des Guises, le cardinal tout particulièrement. Dès 1550, il déplore en latin la disparition de Claude de Lorraine $^{6}$ et salue dans une longue épître, mais aussi dans une belle ode, la naissance de l'aîné de son ancienne pupille Anne d'Este (IX, 12 et 13); en 1552, il célèbre les efforts du cardinal de Lorraine qui ont permis, au prix de sa santé, la campagne victorieuse du roi en Lorraine (II, 1). Il accompagne en fait la montée en puissance des différents membres de la famille à travers de grands poèmes encomiastiques comme le De Meti urbe capta (II, 13) qui salue l'action décisive de François de Guise durant le siège auquel Charles Quint en personne et les Impériaux ont en vain soumis la ville de Metz, devenue ainsi définitivement française (oct. 1552-janv. 1553).

De 1555 à 1560, L'Hospital composera en fait plus d'une vingtaine d'épîtres adressées directement au duc, au cardinal de Lorraine ou à leurs proches et affidés. Comme l'a noté L. Petris ${ }^{7}$, le seul voyage à Rome du cardinal de Lorraine en octobre 1555, qui aboutit à une alliance avec le pape pour bouter les Espagnols hors d'Italie, ne fait pas l'objet de moins de quatre épîtres (Carmina, II, 4 ; III, 5 ; III, 12 ; IV, 6). Bientôt se précipiteront les actions militaires, le retour de François de Guise pour sauver le royaume après le désastre de Saint-Quentin (automne 1557), la prise inespérée de Calais et de Guînes (4-8 janvier 1558), faits d'armes qui l'inviteront à pousser le cardinal à hâter les négociations de paix lors de l'entrevue de Marcoing en mai $(\mathrm{V}, 4)$; viendra ensuite la prise de Thionville (25 juin 1558): autant d'actions d'éclat du duc que L'Hospital célèbrera dans de grandes épîtres patriotiques, tout comme il chante à deux reprises son entrée triomphale à Paris le 16 février 1558 (IV, 2 et VII, 8). Quelques semaines plus tard (le 24 avril $1558: \mathrm{V}, 1)$, il fera très logiquement partie du chœur des

\footnotetext{
6 Voir Epitaphium Claudii Lotaringi Suessionum Ducis (IX, 4), dans A, p. 391 (ou BNF, Dupuy 901, fol. 3ro ).

7 Voir Petris, La Plume et la tribune, p. 15.
} 
poètes célébrant le mariage de la nièce des deux frères Guises, Marie Stuart (1542-1586), avec le dauphin François. Notons encore, pour souligner les liens étroits qui existent pour lors entre les Guises et leur chantre si fidèle, que lorsque sa fille Madeleine se marie à Robert Hurault, c'est le cardinal lui-même qui la dote. Ce dernier sera en outre le parrain du premier enfant issu de cette union, prénommé Charles, comme il se doit (mai 1558).

Or contrairement à ce qui avait prévalu jusque-là, nombre de ces pièces d'actualité se voient confiées dès leur achèvement aux presses de Fédéric Morel. L'année suivante en revanche, L'Hospital, ne publie aucune nouvelle plaquette. Son silence éditorial pourrait même passer pour étourdissant, puisqu'à la différence du chœur d'une cinquantaine de thuriféraires qui unissent leurs voix pour chanter les bienfaits de la paix, la signature du traité du Cateau-Cambrésis ${ }^{8}$, comme des deux mariages princiers qui en sont la conséquence, le laisse sans voix. Cette année semble être celle du retrait poétique. Il est vrai qu'il a d'autres sources de préoccupations: il entre au Conseil privé en juillet 1559; il doit ensuite accompagner sa protectrice, Marguerite de France, devenue de Savoie, jusqu'à Nice, et est rappelé fin 1559 à la cour pour reprendre en mains la gestion des finances. On sait la suite : la disparition, au début du printemps 1560, du chancelier Olivier, qui avait beaucoup fait pour l'élévation de L'Hospital, couplée au refus de Morvillier, lui vaut la promotion suprême: sur recommandation des Guises, le 30 juin 1560, L'Hospital se voit conférer les sceaux. C'est avant ce moment-là sans doute qu'il faut situer la dernière salve de publications sur les presses de Morel $^{9}$ (voir en Annexe, items 11 à 13): ensuite, et jusqu'à son décès, ne sera plus jamais imprimée par L'Hospital la moindre des nouvelles poésies qu'il continue de composer $^{10}$.

8 Voir D.J. Hartley, «La célébration poétique du traité du Cateau-Cambrésis (1558): un document bibliographique», BHR, 43 (1981), p. 303-318 et H. Fernandez, «Une paix suspecte. La célébration de la paix du CateauCambrésis », NRSS 15/2 (1997), p. 326-329.

9 La Commendatrix epistula en faveur de Ronsard, qui accompagnait l'offrande manuscrite au cardinal de l' «Hymne de Charles de Lorraine», publiée anonymement en 1560 chez Buon au sein du volume des Hymnes a un statut particulier.

10 Léger Du Chesne dans sa Farrago de 1560, les éditeurs des Poésies de Turnèbe (1564) ou Guarinus dans son édition groupée des pièces de Buchanan et de 
On le constate, cette activité politique importante - et sans doute harassante, puisque son action a permis durant toutes ces années la levée continue de fonds nécessaires aux expéditions et campagnes militaires -, n'empêche pas L'Hospital de trouver du temps pour se livrer à des compositions poétiques de conséquence. Durant cette période, il rédige en effet nombre d'épîtres en vers, non seulement adressées aux Guises mais en direction de maints protecteurs putatifs, comme celle qu'il adresse en 1551 à François Olivier à propos du procès instruit à la suite des massacres de Mérindol et de Cabrières (II, 7), ou celle qu'il envoie en 1555 à Jean Du Bellay (I, 1) qui semble ne plus vouloir s'arracher aux délices romaines. Or, ces pièces ne se contentent pas de parvenir à leur destinataire et d'être lues par eux. Elles ont une circulation qui outrepasse le simple échange amical ou courtisan. On possède en effet plusieurs témoignages de cette circulation manuscrite, apparemment intense, des pièces de L'Hospital dans les milieux humanistes et parlementaires, mais aussi dans les plus hautes sphères du royaume. Ainsi l'épitre horatienne I, 4 du voyage de Bologne, adressée à Adrien Du Drac en novembre 1547, est sous les yeux de Boyssoné, alors à la cour en raison des déboires qu'il connaît au parlement de Chambéry, dès le début de 1548. Notons en outre que ce n'est pas son destinataire qui la lui a transmise, mais un tiers, Martin de La Haye, qui en a sans aucun doute pris copie ${ }^{11}$. De manière similaire, en août 1558, François Olivier écrit à Jean de Morel pour le remercier de lui avoir communiqué une épître de L'Hospital qui ne lui était pas non plus adressée:

Monsieur, j'ay receu par les mains de Mons $^{r}$ le Prévost d'Étampes celle que Mons ${ }^{r}$ le président de l'Hospital a naguères escripte à monsieur le Rév. Card ${ }^{\text {al }} \mathrm{d}^{\prime}$ Armaignac. De qua nihil aliud dicam quam quod, uel sine titulo, auctorem suum referat: et bis mille aliis intermixta, non me fallere queat. Perlectam seposui, per ocium subinde relecturus, cùm Musis simul ac Philosophiae indulgêre iuuabit ${ }^{12}$.

Turnèbe (1568) donnent bien des pièces de L'Hospital, mais il s'agit de textes déjà imprimés par Morel.

11 Voir Carmina, t. I, p. 136 et Annexe 2, p. 368-376.

12 Lettres de J. Du Bellay publiées pour la première fois d'après les originaux, éd. P. de Nolhac, Paris, Charavay, 1883, p. 65-66. L'original de la lettre d'Olivier à Jean 
L'incipit en français permet d'identifier le texte transmis par Morel : il s'agit de l'épître I, 6 au cardinal d'Armagnac, composée par L'Hospital douze années auparavant, à l'été $1546^{13}$. On voit donc que la circulation des épîtres de L'Hospital peut être immédiate $^{14}$, mais qu'elle peut aussi être largement différée dans le temps, avec néanmoins toujours le même succès - ce qui explique sans doute qu'en 1560 L'Hospital fasse imprimer des pièces qui remontent à plusieurs années, comme celle sur le siège de Metz (II, 13: voir item 11).

On comprend donc dans ces conditions que le futur chancelier ait opté pour le mode de diffusion manuscrit, mode discret et relativement contrôlé, mais qui lui assure une renommée dans les cercles qu'il fréquente ou dans lesquels il aspire à pénétrer et à assurer sa réputation. Nul besoin de recourir à l'imprimé jusqu'à ce moment, puisque le bouche à oreille et la copie manuscrite suffisent à asseoir sa renommée de poète raffiné et d'homme d'esprit. De fait, jusqu'à la fin de 1557, le nombre de pièces que livre à l'impression L'Hospital se compte sur les doigts d'une main, ou presque, puisqu'on n'en connaît en tout et pour tout que six. Elles ont été recensées par Perrine Galand et Loris Petris au seuil de leur précieuse édition du tome I des Carmina ${ }^{15}$. Elles sont insérées dans quatre ouvrages, deux traités du grand juriste André Tiraqueau (1543 et 1546) et deux des recueils poétiques de Jean Salmon Macrin (1546 et 1549). Impressions très limitées donc, et qui doivent être interprétées bien davantage comme signes de complicité, ou d'amitié, à l'égard des deux auteurs qui accueillent ces compositions au sein de leurs propres productions, que comme marque d'une volonté de changer de régime de diffusion pour ses vers.

de Morel se lit dans BNF, lat. 8589, fol. 34. Comme elle contient ensuite un éloge des talents poétiques de Joachim Du Bellay, elle sera imprimée par Morel fin 1558 en tête de l'édition originale des Poemata (fol. 2ror).

13 Voir Carmina, t. I, p. 168, qui cite aussi cette lettre.

14 Voir aussi les deux lettres de François Olivier et de Jean de Morel, conservées à Munich et datant des années 1558/59, qui accompagnent chacune une épître en vers de L'Hospital, analysées par P. Ford, The Judgment of Palaemon. The Contest between Neo-Latin and Vernacular Poetry in Renaissance France, Leyde, Brill, 2012, p. 213-215.

15 Voir Petris, La Plume et la tribune, p. XXIV et Carmina, t. I, p. 22-23. 
Comme l'ont déjà souligné M. Simonin ${ }^{16}$ et L. Petris, l'année 1558 marque sans nul doute une rupture dans la manière dont L'Hospital entend diffuser sa production poétique. Or, pour passer à l'imprimé ${ }^{17}$, il se choisit un allié assez inattendu, il faut le souligner ici tant leurs deux noms semblent désormais associés, en la personne d'un imprimeur débutant, qui n’a pas encore une année d'exercice : Fédéric Morel.

\section{UN IMPRIMEUR ÉRUDIT À SES TOUT DÉBUTS : FÉDÉRIC MOREL (1523-1583)}

On ne sait pas grand-chose des origines de Fédéric Morel, ni de sa formation en ses jeunes années. Il était né en 1523, en Champagne, peut-être dans la ville de Chalons ${ }^{18}$. On ignore aussi à quelle date il avait quitté sa ville natale pour la capitale, mais il semble établi qu'il y devint assez tôt (vers 1540 ?) l'élève du grand helléniste et lecteur au Collège royal Jacques Thouzat. C'est sur la recommandation de ce dernier que Morel trouva à s'employer comme précepteur dans une grande famille de la robe parisienne, la famille de L'Estoile, et devint précepteur de l'un des fils du magistrat Louis de L'Estoile (sans doute un frère du célèbre auteur du journal).

L'existence du jeune humaniste bascule lorsque, autour de 1550, il pousse la porte de l'imprimerie du Soleil d'or, dirigée alors par Charlotte Guillard, la veuve Chevallon, qui l'engage à l'occasion comme correcteur. Il faut dire que les grandes entreprises d'édition

16 Dans sa notice consacrée à L'Hospital dans Centuriae Latinae II, éd. C. Nativel, Genève, Droz, 2006, p. 440-442.

17 Comme on le verra, ce passage à l'imprimé est provisoire: la grande majorité de la production poétique de L'Hospital demeurera jusqu'à son décès à l'état de manuscrit. Un seul exemple, frappant: sur la douzaine d'épîtres qu'il a composées à l'adresse du cardinal de Lorraine (II, 1, 4, 9 et 19; III, 5, 6 et 12 ; IV, 5 et $6 ; \mathrm{V}, 2,4$ et 7 ), une seule et unique sera imprimée en 1558. Le constat est strictement identique pour les épîtres à Marguerite de France (une éditée sur onze composées).

18 Hypothèse avancée avec prudence par J. Dumoulin dans sa thèse de l'École des Chartes, Vie et cuvres de Fédéric Morel, imprimeur à Paris depuis 1557 jusqu'à 1583, Paris, J. Dumoulin et A. Picard et fils, 1901 [Genève, Slatkine, 1969], p. 11. 
de textes patristiques qui sont la spécialité de la maison nécessitent un personnel particulièrement compétent et qualifié. Morel aurait ainsi peut-être participé à l'édition d'importants volumes, à plusieurs éditions successives de la Bible $(1549,1552)$ ou de certains opuscules de Jean Chrysostome (1554) ${ }^{19}$. Mais il est toutefois avéré qu'il a investi toute son énergie pour donner une édition amendée et parfaite du grand œuvre de son maître décédé en 1547, le Lexicon Graeco-latinum de J. Thouzat (1552) ${ }^{20}$.

Le deuxième événement capital dans la biographie de Morel est sans aucun doute son mariage, en 1551 ou 1552 (mais avant novembre 1552$)^{21}$, avec la descendante d'une prestigieuse lignée d'imprimeurs humanistes, puisqu'il épouse alors Jeanne de Vascosan, fille de Michel de Vascosan, petite-fille de Josse Bade, nièce de Robert Estienne... On pouvait difficilement trouver meilleur parti pour un homme espérant s'insérer dans le monde de l'édition parisienne. Ce que ne tarda pas à faire Morel qui, à une date là encore incertaine, quitta le Soleil d'or pour la maison À la Fontaine, afin de rejoindre et épauler son beau-père dans son atelier de la rue Saint-Jacques.

Après avoir formé F. Morel et travaillé avec lui pendant cinq ans, Vascosan décide en 1557 de l'établir et de l'installer un tout petit peu plus à l'est de son atelier de la rue Saint-Jacques, au clos Bruneau. Durant l'année 1557, cette collaboration qu'on imagine très étroite trouvera sa matérialisation tangible à travers la publication de cinq éditions partagées, parmi lesquelles on trouve le gros volume des Exotericae exercitationes de Scaliger, premier volume sur lequel ils aient travaillé de conserve durant l'été, puis la traduction latine des tragédies de Sophocle par Johannes Lala-

19 Selon J. Dumoulin, ibid., p. 13-18. R. Jimenes, dans sa thèse inédite ( Ch. Guillard au Soleil d'or: une carrière typographique», Tours, CESR, 22 nov. 2014 ; dir. M.-L. Demonet et C. Bénévent, p. 168-173), restreint de beaucoup le rôle et l'implication que Dumoulin avait attribués à son héros au sein de cet atelier.

20 Voir M. Mund-Dopchie, «Le Lexicon graecolatinum de J. Toussain (1552) : choix $\mathrm{du}$ vocabulaire et méthodes de traduction », dans Les origines $d u$ Collège de France (1500-1560), éd. M. Fumaroli, Paris, Klincksieck, 1998, p. 405-420 ; voir aussi la notice $n^{\circ} 17$ de R. Jimenes au sein du Catalogue de l'exposition de la BSG (30 mars-30 juin 2009), dans Passeurs de textes. Imprimeurs et libraires à l'âge de l'humanisme, éd. R. Adam, Y. Sordet et A. Vanautgaerden, Turnhout, Brepols, 2009, p. 140-143.

21 Voir J. Dumoulin, Vie et æuvres de Fédéric Morel, op. cit., p. 159. 
mantius et la Géométrie de Bovelles ${ }^{22}$. Mais durant ces premiers mois d'exercice, uniquement deux ouvrages, semble-t-il, parurent sous le nom seul de Morel: les vingt feuillets d'une plaquette donnant à lire l'Elegiaca paraphrasis, ad quartum librum Æneidos Virgilii, composée par Nicolas Chesneau ${ }^{23}$, et ses propres traductions de traités de saint Jean Chrysostome et de saint Cyprien, mentionnées et longuement citées par Du Verdier (éd. RJ III, 570-573), mais aujourd'hui disparues. On le voit, il faut attendre la fin de 1557 ou le début de 1558 pour voir paraître en nombre des publications autonomes, qui soient propres à Morel, et commencent à porter seules la marque au franc Mûrier.

Fait que personne n'a observé ou souligné pour l'instant, à ma connaissance, tant les quatre «recueils romains» de Du Bellay imprimés durant l'année 1558 par Morel ont fait sa réputation auprès de la critique, et semblent le montrer pour lors comme déjà bien installé dans le paysage typographique parisien, il faut clairement comprendre que les quelque dix plaquettes de L'Hospital imprimées par lui en 1558 figurent parmi les premières impressions que la maison au Mûrier sort en exclusivité sous sa marque. Il s'agit des premiers témoins du magnifique travail typographique produit par cette nouvelle officine sans la participation et le soutien actif de Vascosan... C'est donc bien en un sens Michel de L'Hospital qui a aidé Fédéric Morel à voler de ses propres ailes. Vascosan, ayant fait sa fortune ${ }^{24}$, avait en effet marié sa fille à ce jeune humaniste distingué, choisi comme une sorte de bâton de

22 Il s'agit dans l'ordre des $n^{\circ} 4,1$ et 5 de la bibliographie dressée par J. Dumoulin (Vie et auvres de Fédéric Morel, op. cit., p. 161-2). Dumoulin n'avait pu voir aucun ex. de la trad. de Sophocle. En fait, la BNF en possède deux exemplaires, l'un portant l'adresse de Vascosan (Yb 1788; autres ex. à la Mazarine et à Vienne, Hofbibl.), l'autre celle de Morel (Yb 1787; un autre ex. à Munich). Il s'agit d'une impression in-8 $8^{\circ}$ de 6-324 fol. Sur l'ouvrage de Scaliger, voir la notice $\mathrm{n}^{\mathrm{o}} 2 \mathrm{du}$ catalogue cité, Passeurs de textes. Imprimeurs et libraires à l'âge de l'humanisme, éd. R. Adam, Y. Sordet et A. Vanautgaerden, Turnhout, Brepols, 2009, p. 54-57.

23 L'unique exemplaire connu, signalé par l'USTC (n¹52264), est conservé par la Houghton Library au sein d'un recueil factice réunissant plusieurs plaquettes de N. Chesneau (Harvard University, Cambridge, MA-USA ; cote FC5.C4256. B559v).

24 Il ne lèguera pas moins de quatre maisons à sa fille et à son gendre, alors qu'il n'avait acquis la maison-mère de la Fontaine qu'en 1548 pour $1200 £$ (voir J. Dumoulin, Vie et æuvres de Fédéric Morel, op. cit., p. 154-7). 
vieillesse. Et plus les années passeront plus il se reposera sur l'atelier de son gendre. La mise en train de l'atelier à l'enseigne du Mûrier marque en fait ce que j'ai pu caractériser ailleurs ${ }^{25}$ comme la troisième et dernière période de l'activité de Vascosan, laquelle, à partir de 1557 jusqu'à sa disparition, vingt années plus tard, marque un net ralentissement. Les deux hommes travaillent, on l'a vu, tout d'abord en collaboration, le beau-père laisse néanmoins de plus en plus son gendre produire et s'illustrer. Alors que Vascosan a été l'éditeur des plus grands poètes néo-latins de la génération antérieure ${ }^{26}$ et a accompagné les tout débuts de la Pléiade en 1549-1550, F. Morel s'affiche ainsi, outre de M. de L'Hospital, comme l'éditeur attitré de Du Bellay, même en contrant par voie de justice les prétentions des L'Angelier; en 1570, Montaigne lui confiera ainsi l'édition des CEuvres françaises et latines de La Boétie...27

Or, dès 1558, Vascosan abandonne visiblement à son gendre l'impression des recueils de poésie profane ${ }^{28}$ - dont les quatre recueils romains de Du Bellay de 1558, qui sont élaborés strictement au même moment et en parallèle avec les plaquettes de L'Hospital -, mais aussi les éditions de textes grecs: après 1557, et l'impression d'une édition bilingue établie par Frédéric Jamot de

25 Dans ma communication «Des presses humanistes au service du vernaculaire? Le cas Vascosan (c. 1500-1577)», dans Passeurs de textes : imprimeurs et libraires à l'Age de l'Humanisme, éd. C. Bénévent, A. Charron, I. Diu et M. Vène, Paris, Publ. de l'École des Chartes, 2012, p. 145-149.

26 Vascosan a ainsi édité Buchanan (Hecuba \& Iphigenia, 1544 ; Jephtes, 1557), Bourbon (Nugae 1533; In Francisci regis obitum, 1547; Conjugum illustriss. Antoni a Borbonio ... epithalamion, 1549), Scaliger (Noua Epigrammata, 1533; Lacrymae, 1534 ; Nemesis, 1535), Salmon Macrin (Naeniae, 1550) ou encore Lotichius (Elegiae, 1551).

27 La Mesnagerie de Xenophon... (Dumoulin no 191 et 201) et les Vers françois de feu E. de la Boetie (Dumoulin no 206).

28 La salve de trois recueils poétiques de G. Du Mayne, donnée en 1556, qu'on pourrait rapprocher de la publication des trois plaquettes néo-latines de Scaliger en 1533-35, et surtout des publications ronsardiennes de 1549, correspond aux derniers textes poétiques profanes en vernaculaire jamais publiés par Vascosan: voir le tableau des plaquettes poétiques en vernaculaire publiées par Vascosan, dans notre communication "Vascosan éditeur de Guillaume Du Mayne (1556)», dans Les poètes français de la Renaissance et leurs «libraires». Actes du colloque d'Orléans (5-7 juin 2013), éd. D. Bjai et F. Rouget, Genève, Droz, 2015, p. 482-483. 
La Prise d'Ilion de Tryphiodore [BNF, Rés. Yb 702], il est notable que plus aucun texte composé en grec ne sorte des presses vascosaniennes. Au sein de ce partage, Vascosan semble toutefois se réserver les morceaux de choix, comme en 1559 l'Henrici II elogium [BNF, Lb ${ }^{31}$ 103], ou comme les grandes traductions du grec de Claude de Seyssel et de Louis Le Roy, ou bien sûr celles d'Amyot, qui ont pour bonne part assuré la survie de son nom.

Pour conclure sur ce point, le choix par L'Hospital d'un imprimeur aussi peu expérimenté et réputé est étonnant, au moment même où, on l'a vu, il se trouve en pleine ascension sociale et politique, grâce aux liens de plus en plus étroits qu'en une dizaine d'années il a su tisser avec la famille de Guise, à partir du moment où il avait accompagné Anne d'Este depuis le Piémont jusqu'à la cour. Car à tout prendre, si L'Hospital, qui a visiblement élu, pour reprendre les justes analyses de J. Balsamo ${ }^{29}$, un mode d'édition savant pour faire imprimer ses épitres, recherchait des presses humanistes en vue de diffuser ses vers latins, tout l'incitait à ce moment-là, plutôt que vers ce tout nouvel éditeur qui n'avait pas encore vraiment fait ses armes ni ses preuves, à se tourner vers André Wechel, qui secondait activement depuis plusieurs années déjà la propagande des Guises et était depuis 1554 au moins l'éditeur attitré des clients de la famille de Lorraine (tout particulièrement de Ronsard et de Ramus ${ }^{30}$.

Pour expliquer ce choix étonnant, sinon risqué, on peut estimer que le chancelier de Berry cherchait alors un imprimeur compétent, certes, mais souple aussi, et capable de se plier à ses attentes, voire ses exigences. D'où sans doute le choix d'un typographe qui avait encore à faire ses preuves, même si son assise familiale et la réputation de son beau-père constituaient assurément la garantie d'un travail soigné et de grande qualité. Il faut d'ailleurs souligner, comme le fait J. Dumoulin ${ }^{31}$, que Morel a démarré sa production au prix d'investissements très importants: il utilise dès ses premiers tirages un papier troyen d'excellente qualité, très blanc

29 «Les libraires du Palais et les poètes (1530-1610)», dans Les poètes français de la Renaissance, op. cit., p. 86-87.

30 Voir à ce sujet G. Guilleminot, «André Wechel et La Pléiade», Australian Journal of French Studies, 17 (1980), p. 65-72.

31 Vie et œuvres de Fédéric Morel, op. cit., p. 28. 
et lisse et, pour se lancer, ne récupère pas, à la différence de ce qu'avait fait Vascosan en 1532 avec les fontes de Bade, les polices de caractère de son beau-père. Au moment de ses premières impressions, il dispose en effet de fontes neuves, et magnifiques, gravées par $\mathrm{Cl}$. Garamont (en particulier cet élégant italique de corps 14 dans lequel sont composés tous les textes de L'Hospital).

\section{LES PLAQUETTES DE L'HOSPITAL IMPRIMÉES PAR MOREL (1558-1560): INVENTAIRE}

De cette brève collaboration entre un homme politique alors en pleine ascension et d'un imprimeur débutant de talent a résulté une série de publications fort élégantes et soignées, j'y insiste, qu'il faut maintenant tenter d'ordonner quelque peu. Le classement que j'ai placé à la fin de cette contribution (voir infra, p. 70-78) correspond grossièrement à l'étagement des événements historiques dont rendent compte ces plaquettes, événements qui s'étalent sur quelques mois, de l'automne 1557 à la fin juin 1558 avec la prise de Thionville.

Premier constat: les extraits de privilège, lorsqu'ils sont transcrits (ce qui est rarement le cas), ne sont que d'un faible secours pour dater les différentes impressions car il s'agit de privilèges collectifs. D'une publication à une autre Morel reprend soit son privilège personnel du moment, tel celui du 17 janvier 1558, qui protège aussi bien les textes de L'Hospital que certains recueils de Du Bellay ${ }^{32}$, soit le privilège général obtenu par ses auteurs, celui

32 On découvre ainsi le privilège personnel de Morel (du 17 janvier 1558), en tête de la réédition de l'Epistola de L'Hospital, 1558, fol. Avo (item 2) : «EXTRAICT DV PRIVILEGE DV ROY. // Il est permis à Federic Morel Imprimeur \& Libraire en l'Vniversité de Paris, d'imprimer \& vendre ceste presente Epistre d'un excellent personnage de ce Royaume, \& ensemble avec icelle une Elegie latine, \& quelques Epigrammes du seigneur IOACH. DV BELLAY : Et defendu tresexpressement de par le Roy à tous autres Imprimeurs \& Libraires, d'imprimer, n'exposer en vente d'autre impression (ny mesme de la sienne sans consentement) devant deux ans, à compter du iourdhuy, ladicte Epistre, \& ce qui s'ensuit : à peine de confiscation des exemplaires qui se trouveroyent, $\&$ aussi d'amende arbitraire. Ainsi que plus amplement il appert par le priuilege octroyé audict Morel, Donné à Paris le XVII. iour de Ianuier, Mil cinq cens cinquante sept: // Signé DVTHIER. ». Mais on le lit aussi en 1558, au vo de la 
obtenu par exemple par Du Bellay, en date du 3 mars 1558, ou celui qu'obtiendra L'Hospital le 11 mars 1560. Privilèges généraux, qu'il adapte au titre qu'il est en train de composer ${ }^{33}$. Les dates auxquelles sont obtenus ces privilèges ne sauraient donc fournir

page de titre de l'Hymne au Roy sur la prise de Calais de Du Bellay: «EXTRAICT DV PRIVILEGE DV ROY. // Il est permis à Federic Morel Imprimeur \& Libraire en l'université de Paris, d'imprimer \& vendre ce present Hymne \& autres compositions de IOACH. DV BELLAY: Et defendu tresexpressement de par le Roy à tous autres Imprimeurs \& Libraires, d'imprimer, n'exposer en vente, iusques à deux ans prochainement uenans, à compter du iourduy, lesdictz Hymnes \& compositions, sous peine de confiscation \& d'amende arbitraire. Comme plus amplement appert par le priuilege accordé \& octroyé audict DV BELLAY, Donné à Paris le XVII. de Ianuier, Mil cinq cens cinquante sept: // Signé DVTHIER.». On le lit encore, avec modifications, en 1559, au $\mathrm{v}^{\mathrm{o}}$ de la page de titre de la réédition du même Hymne au Roy: «EXTRAICT DV PRIVILEGE DV ROY. // Il est permis à Federic Morel Imprimeur \& Libraire en l'Vniversité de Paris, d'imprimer \& vendre ce present HYMNE AV ROY \& aultres œuvres poetiques de IOACHIM DV BELLAY: Et defendu tresexpressement de par le Roy à tous autres Imprimeurs \& Libraires, d'imprimer, n'exposer en vente d'autre impression (ny mesme de la sienne sans consentement) ledict hymne, \& autres œuvres poetiques dudict autheur imprimées par ledit Morel : Et ce sur peine de confiscation des livres, \& d'amende arbitraire envers le Roy, l'autheur \& ledit imprimeur. Ainsi que plus amplement il appert par le priuilege octroyé audict DV BELLAY, Donné à Paris le XVII. iour de Ianuier, Mil cinq cens cinquante sept : Signé DVTHIER». Il est à signaler qu'en 1559 encore l'Entreprise du Roy-Daulphin et l'Epithalame sur le mariage de tresillustre Prince Philibert Emanuel de Du Bellay sont protégés par un même privilège en date du 3 mars 1558.

33 On découvre ainsi des adaptations du privilège général obtenu par L'Hospital (le 11 mars 1560) au bout de l'édition du De Meti Urbe capta (1560), fol. C4vo (item 11): "Privilegii sententia. Cautum est auctoritate Francisci II. Francorum Regis, ne quis alius, praeter Federicum Morellum, Ampliss. Viri Michaëlis Hospitalii Poëmata ante sexennium excudat, neue uendat. Qui secus fecerit, libris, E poena in sanctione aestimata mulctabitur. Priuilegium Parisiis irrogatum ac consignatum, die marte undecimo, Anno M. D. LIX. Subscriptum de consiliis sententia, Lalemant. »; mais on en lit aussi une version française au bout du Discours sur le sacre dans la traduction de Du Bellay, dans l'édition originale de 1560 (fol. C4ro), et encore dans celle de 1566: «Par lettres du Roy données à Paris l'unzieme iour de Mars 1559. Il est permis à Federic Morel imprimeur \& libraire en l'université, d'imprimer \& vendre les Opuscules de M. Michel de l'Hospital Conseiller du Roy en son priué conseil, \& premier President de ses comptes: pour le temps \& espace de six ans : \& defendu tresexpressement à tous autres de ne les imprimer ne exposer en vente durant ledict temps, sur peine de confiscation, amende arbitraire, dommages \& interests dudict Morel, ainsi qu'il est plus amplement contenu \& declairé esdictes lettres signées par le conseil, \& seellées du seel dudict Seigneur. LALEMANT». 
la moindre indication précise sur le moment de la parution. Ainsi les Poemata de Du Bellay qui sont assurément sortis en novembre ou décembre 1558 (puisqu'ils contiennent une épitaphe de Saint Gelais, mort le 14 octobre: Tum. 39) portent encore au verso de leur page de titre le privilège du 3 mars, qui protège d'autres recueils publiés bien plus tôt dans l'année comme les Antiquitez...

Toutefois, si l'on considère attentivement les pages de titre de ces différentes plaquettes, on pourra y relever comme un dévoilement progressif ${ }^{34}$ de l'identité du poète: voilà qui fournit une piste permettant peut-être de classer chronologiquement les parutions.

Mais réglons tout d'abord le problème de l'item $\mathrm{n}^{\mathrm{o}} 0$ (voir Annexe infra, p. 70), le De postrema Gallorum expeditione carmen: l'examen bibliologique attentif des deux exemplaires de la BNF m'a convaincu qu'il s'agit d'une impression tardive, sur mauvais papier, que je daterais volontiers de la fin du $\mathrm{XVI}^{\mathrm{e}}$ siècle ${ }^{35}$, sans doute sur du matériel allemand ou suisse - enquête à poursuivre. L'indication même du moment de sa composition sur la page de titre est à mes yeux l'indice fort d'une publication tardive: si la pièce avait été un occasionnel, si elle avait été publiée juste au lendemain de la chevauchée italienne, cette indication n'aurait servi à rien. Ce petit cahier in-octavo n'a rien à voir de surcroît avec les extrêmes raffinement et qualité des plaquettes in-quarto de Morel en 1558: il faut donc l'exclure de notre propos.

Prenons maintenant en considération les pages de titre des items 1 à 10. Les items 1-3 et 4-5 sont classés chronologiquement par leur titre même. La longue périphrase qui livre le nom de

34 Notons que cet anonymat - qui, à l'instar des majuscules à l'antique dont était signée la Deffence, ne devait tromper personne: voir la lettre de François Olivier à Jean de Morel citée plus haut, p. 48 -, est levé dès la réédition de la deuxième plaquette par la pièce post-liminaire d'E. André (voir infra, la description de l'item 5).

35 Le possesseur d'un superbe exemplaire, grand de marges, réglé et tiré sur grand papier, relié en veau blond, des Epistolarum seu sermonum libri sex ( $B$, ex. Arsenal, Fol B 715), a jugé utile de faire recopier très soigneusement par un secrétaire l'intégralité de cette pièce, précédée d'un titre légèrement différent («De postrema Gallorum in Italia duce Guisio profectione») pour la faire relier au bout de son exemplaire, avec d'autres pièces encore inédites de L'Hospital (dont sa lettre à Pie IV du 30 juillet 1562: voir Petris, La Plume et la tribune, p. 472-474). Voilà un indice qui semble laisser supposer qu'à cette date encore ce texte ne circulait que sous forme manuscrite. 
l'auteur du Carmen de expugnatione (item 4: «cuius auctor is ipse est, qui $\mathcal{E}$ illius eruditissimae Epistolae ad Franciscum Guisiorum principem proxime a nobis editae») nous informe que l'Epistola à François de Guise (item 1) a précédé de peu (proxime) cette louange célébrant la prise inespérée de Calais. Si la première a paru en décembre 1557 ou janvier 1558, cette plaquette-ci sort de l'atelier de Morel assurément avant la mi-février 1558, moment où, comme vient de le relever L. Petris, Giovanni Dalmatio l'envoie depuis Paris au cardinal Farnèse ${ }^{36}$.

Si l'on tire ce fil du dévoilement progressif de l'identité de l'auteur, il faudrait ensuite passer à l'item 6, l'épithalame composé pour chanter l'union de François, fils aîné de Henri II, et de la nièce des Guises, Marie Stuart, encore publié sous le voile de l'anonyme: Viri cuiusdam amplissimi carmen; la formulation demeure dans le même esprit que celle adoptée quelques semaines plus tôt pour l'Epistola et pour le De ... expugnatione carmen. Ce type de pièce, on le sait, se compose et se prépare en amont de la cérémonie et d'autres épithalames du temps nous invitent à en placer la publication au plus tard au moment de la célébration ${ }^{37}$, fin avril 1558, donc.

Si cette idée est juste, viendrait ensuite le premier texte à lever partiellement le voile (on passe de la périphrase au nom en abrégé): ce serait l'item 7, l'épître incitant le cardinal de Lorraine

36 Voir la note 14 de sa notice sur l'Hymne au Roy sur la prinse de Callais de Du Bellay, à paraître au sein du tome IV,1 des O. c. de Du Bellay chez Garnier. L. Petris y renvoie à l'éd. partielle des missives de Dalmatio donnée par L. Romier (Bibl. de l'École des Chartes, LXXI (1910), p. 316): «Je vous envoye le vray pourtraict de Callais [Le pourtraict de la ville de Calais, faict au naturel, Paris, 1558 : voir ex. Maz. Rés. $5921 \mathrm{~F}$ (6)] et certayne poesie faicte par mons ${ }^{\mathrm{r}}$ de L'Hospital, n'ayant pour le present rien de meilleur» (lettre du 18 février 1558).

37 À l'exception notable d'une autre impression donnée par Morel l'année suivante, L'Entreprise du roy-Daulphin (O. poét., éd. Chamard, t. VI, p. 37-71) composée par Du Bellay au même moment que son Epithalame sur le mariage de tresillustre prince Philibert Emanuel duc de Savoie... (O. poét., éd. Chamard, t. V, p. 199-229). Cet épithalame est bien paru, lui, avant la date prévue pour la célébration du mariage (fin juin 1559). En revanche, seule «la plus grand'part» de l'Entreprise «estoit imprimée devant le malheur \& desastre » du tournoi des Tournelles, comme le précise un avis de «L'imprimeur au lecteur» (O. poét., éd. Chamard, t. VI, p. 71) inséré in fine pour justifier la publication quelque peu intempestive d'un livret de fête en plein milieu du deuil national. 
à hâter les négociations de paix lors de l'entrevue de Marcoing - qui se tint du 15 au 17 mai -, et publiée avant la fin du mois puisque Dalmatio en envoie un exemplaire au cardinal Farnèse le $27 \mathrm{mai}^{38}$. La rupture de la trêve ne tarde guère à survenir, elle se solde par la prise de Thionville, fin juin, chantée dans les items 8 et 9 , cette nouvelle épinicie étant parue sans doute en juillet.

Reste l'épître à Marguerite (item 10) dont le contenu - une réflexion morale sur le rude métier de serviteur des grands - ne permet guère de la dater avec précision puisqu'on n'y relève aucune allusion directe à l'actualité ${ }^{39}$. Puisque le nom de L'Hospital $\mathrm{y}$ apparaît en toutes lettres, mon hypothèse aurait l'avantage de pouvoir la situer au même moment, voire un peu après : elle aurait été publiée durant l'été 1558. On remarquera qu'après l'abstinence éditoriale de 1559, les pages de titre de l'année 1560 livrent en un sens la solution de la prétendue énigme posée deux années plus tôt, comme le montrent bien les items 11 et 13 qui donnent désormais à lire les initiales de $l^{\prime}$ «ampliss. viri $M . H$.».

L'autre difficulté posée par cette efflorescence de plaquettes réside dans le fait de distinguer les éditions, ou émissions, successives. Si la différence entre les items 1 et 2 est aisée à repérer, cinq pièces issues des Poemata de Du Bellay, ici données en prépublication, étant ajoutées à la réédition, seule une collation attentive des items 2 et 3 (à laquelle ne se sont pas livrés tous les bibliographes) permet de distinguer deux éditions bien distinctes, l'une en 10 feuillets, l'autre, à la composition resserrée, n'en présentant plus que huit. De même, seule la consultation effective des exemplaires (car à la différence de la réédition précédente la page de titre de cette seconde édition ne dit rien de ces ajouts) permet de distinguer les items 4 et 5, puisque deux épigrammes, l'une de $\mathrm{Du}$ Bellay, l'autre d'un ancien compagnon de Morel chez Charlotte Guillard, Elie André, ont été ajoutées à cette deuxième édition. Les différences sont parfois encore moins manifestes d'une

38 «Je vous envoye les vers de mons ${ }^{\mathrm{r}}$ de L'Hospital exhortatoyres à la paix, n'ayant rien de meilleurs à présent. De Paris ce xxvii ${ }^{\mathrm{e}}$ may 1558 » (transcrit par L. Romier, art. cit., p. 327).

39 Lors du colloque, L. Petris a placé sa composition au début de l'année 1550, puisqu'elle lui semble même être concomitante avec la disgrâce du chancelier Olivier. 
édition à l'autre et requièrent toute l'attention du bibliographe: il en va ainsi des items 8 et 9 dont seule la composition du millésime, l'une en chiffres romains, l'autre en arabes, permet de les distinguer; ou encore des items 13 a et $13 b$ qui, comme l'a déjà noté L. Petris ${ }^{40}$, présentent des différences de composition (présence de réclame ou non) et de ponctuation (voire de guillemetage des passages sentencieux) dont il est difficile d'établir si elles résultent de corrections sous presse ou correspondent à deux compositions étagées dans l'année, et partant à deux éditions distinctes - la différence des filigranes relevés sur les pages de titre inviterait toutefois à adopter la seconde hypothèse. On peut faire des remarques strictement identiques sur la réédition de l'Epistola à Marguerite en 1560, dont un exemplaire au moins présente un titre dépourvu des initiales M. H. (item 13a'). Enfin, l'existence de corrections, portées à la plume sur certains exemplaires mais typographiquement intégrées dans d'autres ${ }^{41}$, sont également l'indice soit d'interventions sur forme en cours de tirage (et donc d'une surveillance étroite du processus de fabrication au sein de l'atelier Morel), soit de réimpressions en plus grand nombre encore que n'en recense l'inventaire final.

Pour compliquer encore un peu les choses, signalons l'exemplaire aberrant de Roanne ${ }^{42}$ qui donne le premier texte, celui de l'Epistola à François de Guise: même s'il présente une page de titre de la première édition, sans la mention du nom de Du Bellay, il donne bien à lire aux feuillets Biij $\mathrm{r}^{\mathrm{O}}-\mathrm{B}[5] \mathrm{r}^{\mathrm{O}}$ ses cinq épigrammes complémentaires. Devant ce mélange manifeste de feuilles issues de plusieurs éditions, l'on songe immanquablement à la confusion qui, au sein du même atelier Morel, entourera trois ans plus tard la publication de la Harangue du cardinal de Lorraine, prononcée à Poissy, dont G. Guilleminot n'a pas relevé moins de 6 éditions in-

40 Petris, La Plume et la tribune, p. 335.

41 Voir infra note 64. Certains exemplaires portent en effet des corrections manuscrites qui semblent avoir été portées dès l'atelier. Ainsi une coquille au v. 9 de l'épigramme de Du Bellay insérée au bout de l'item 5 («At non paua tulit [sic pour parua] Virtutis praemia») a été corrigée exactement de la même façon, par l'introduction à la plume d'un $\mathrm{R}$ interlinéaire sur l'ex. de la BNF (Rés. p. Yc 1464) et sur celui de Caen (Rés. B 739 [3]).

42 BM Roanne, cote R $473 / \mathrm{B}$, ex. que nous avons en conséquence placé à la fois dans les items 1 et 2 . 
octavo pour la seule année 1561. Son hypothèse est que Morel a réédité très vite, et plusieurs fois de suite, ce texte très demandé; du coup, d'une réédition à l'autre, les feuilles se sont peu à peu mélangées au sein de l'atelier et les exemplaires sont ainsi devenus composites, réunissant des cahiers résultant de plusieurs campagnes successives de composition et d'impression ${ }^{43}$.

Il faut enfin s'attarder un instant sur les items 11 et 13, parus en 1560 , et qui présentent un mode de réédition particulier des titres déjà imprimés, parfois à plusieurs reprises, en 1558. Ces réimpressions, dépourvues de page de titre, sont désormais débitées sous forme de petit cahier autonome (items 11a-c et 13a-b), pratique directement dérivée à mes yeux du mode de diffusion manuscrit tel que l'avait si longtemps pratiqué L'Hospital. Il est probable que Morel, lassé de réimprimer à la demande ces plaquettes, et de devoir pour ce faire les réactualiser, aura imaginé d'en constituer un stock dépourvu de page de titre, de manière à pouvoir les débiter sur le long terme. Reproduisant en fait strictement le recto du deuxième feuillet des plaquettes antérieurement imprimées avec page de titre, elles débutent par le bandeau au masque, placé en haut du miroir de page, puis donnent le titre en capitale, et enfin les vers en italiques. Et de fait on trouve dans de nombreux recueils factices du temps ces cahiers devenus autonomes, totalement détachés du De Meti urbe ou de l'Epithalame du dauphin dans leur version de 1560, avec lesquels ils ont sans aucun doute été composés, puis tirés. Si cette analyse est juste, il faudrait alors autonomiser ces cahiers, dont la juxtaposition crée d'ailleurs des doublons de privilège (voir NB de l'item 11, p. 76) ou de signatures de feuillets (voir item 13a-b), ce qui plaiderait pour une vente et une diffusion sous forme de cahiers séparés. Et il faudrait les considérer comme autant d'éditions singulières et singularisées. À ce moment-là ce ne seraient plus treize, mais près de vingt éditions et rééditions des pièces de L'Hospital que Morel aurait fait passer sur ses presses en moins de deux années.

Quels enseignements tirer de ce foisonnement manifeste? Il faut assurément considérer ces plaquettes comme des pièces d'actualité.

43 Voir G. Guilleminot, Religion et politique à la veille des guerres civiles : recherches sur les impressions françaises de l'année 1561, thèse dactyl. de l'École des Chartes, 1977. 
Mais cette qualité leur confère-t-elle pour autant le statut d'occasionnels, que les imprimeurs et libraires débitaient, on le sait, pour lors en grand nombre? La langue dans laquelle sont composés ces grands éloges courtisans à la gloire de l'action militaire et politique des Guises, le latin, ne les prive-t-elle pas immédiatement de ce statut? Le nombre important d'éditions ou d'émissions (restons prudents) est-il le signe qu'un grand nombre de lecteurs achète massivement les textes poétiques de L'Hospital, et est-il l'indice de ventes importantes, puisque c'est ainsi que les historiens du livre interprètent le plus souvent ces retirages ${ }^{44}$

Ou faudrait-il imaginer que L'Hospital ait choisi tout à coup l'imprimé afin de s' «éviter la peine d'en faire des copies à la main ${ }^{45}$, et qu'il continuerait à diffuser ses compositions poétiques en petit nombre, auprès de lecteurs choisis, mais désormais sous forme de plaquettes imprimées à tirage limité? Il faudrait alors supposer que la demande, plus importante qu'il ne l'imaginait, l'aurait poussé à augmenter cette diffusion, d'où cette série de retirages ou de réimpressions - en nombre restreint ? $^{46}$ demandés à Morel, que cet inventaire, sans doute incomplet, met en lumière.

Mais si c'était vraiment une diffusion limitée et contrôlée de ses pièces sur support imprimé que visait L'Hospital, se serait-il mis en mal d'obtenir un privilège pour sa production poétique ? ${ }^{47}$ Et puis quel besoin alors de se faire le publiciste de l'action des Guises? L'impression de ce type de pièces encomiastiques implique a priori une diffusion large... Force est alors d'admettre que ces plaquettes ont été débitées en grand nombre, et la quantité importante

44 Voir déjà les affirmations, qui me semblent sans fondement, de J. Dumoulin (Vie et cuvres de Fédéric Morel, op. cit., p. 35) : il assoit la bonne santé financière de l'atelier de Morel sur les succès remportés par les poésies de L'Hospital et de Du Bellay.

45 Voir à ce sujet l'article cité de J. Balsamo, p. 86-87: il donne dans cet ordre d'idée l'exemple de $\mathrm{Cl}$. de Bénévent qui offre à son oncle, P. de L'Estoile, un des exemplaires, tirés à petit nombre sur les presses de Fédéric II Morel, de ses traductions de pièces de N. Bourbon.

46 Notons que le grand nombre d'exemplaires actuellement conservés dans de fort nombreuses bibliothèques mine beaucoup cette hypothèse.

47 Voir supra note 33 l'extrait du privilège du 11 mars 1560 (n. s.) protégeant le De Meti Urbe capta carmen. On le retrouve à l'identique au bout de la réédition de 1560 du De Theavilla capta carmen, fol. C4v (item 11c). 
d'exemplaires qui en ont survécu dans plusieurs pays d'Europe ${ }^{48}$, en est peut-être aussi l'indice.

Dernière observation enfin, mais pas la moindre: il faut bien replacer aussi ce foisonnement dans son cadre, celui d'une concurrence, apparemment féroce, des libraires et imprimeurs entre eux quand il s'agit de produire des occasionnels. Le précieux inventaire qu'a su dresser D.J. Hartley des plaquettes poétiques suscitées par un des événements chantés par L'Hospital, la prise de Calais, le montre: il n'a pas relevé moins de vingt plaquettes poétiques célébrant cet exploit militaire ${ }^{49}$. Or plus d'un tiers, sept très exactement, sont issues de l'atelier de Morel. De même un tiers des publications poétiques suscitées en 1559 par la mort de Henri II recensées par le même D.J. Hartley ${ }^{50}$ - quatre sur douze - sort des presses au franc Mûrier ${ }^{51}$.

Pour expliquer cette prolifération de plaquettes donnant à lire les beaux hexamètres de L'Hospital, il faut sans doute alors deviner une sorte de convergence entre les aspirations courtisanes de l'un

48 Et jusque dans d'aussi modestes bibliothèques que la BM de Leonessa (Rieti) où est conservé (sous la cote $\mathrm{R}$ ant. 60 1-4) un recueil factice réunissant quatre réimpressions de 1560: le De Meti urbe capta ... carmen seul, sans les pièces complémentaires (voir item 11), et l'item 13 au complet. Je remercie Rosanna Gorris de son enquête sur place et pour m'en avoir procuré reproduction.

49 D.J. Hartley («Les poètes français et la prise de Calais (janvier 1558) », BHR, 56 (1994), p. 721-725) propose un inventaire comptant 23 items; les $n^{\circ} 1,2,8,9$, 12 , 15 et 18 sont imprimés par Morel. Mais certains de ces poèmes comme ceux de Dorat ( $\left.n^{\circ} 7\right)$ ou Du Bellay ( $n^{\circ}$ ) sont des pièces figurant au sein de recueils poétiques bien plus importants et ne peuvent être considérés comme des occasionnels.

50 Il s'agit, dans la nomenclature de Hartley (« La Mort du roi Henri II (1559) et sa commémoration poétique: document bibliographique», BHR, 47 (1985), p. 380-382), des $n^{\circ} 5,8$ et 12 , auxquels il faut sans doute joindre le $n^{\circ} 1$, un placard dû à Elie André, fort lié avec Morel depuis leur commun travail chez Ch. Guillard (et dont Morel, on l'a vu, intègre des épigrammes au sein des plaquettes de L'Hospital).

51 Morel se placera moins bien dans le marché suscité par la signature du traité du Cateau-Cambrésis: seules 5 des 32 plaquettes recensées par D.J. Hartley («La célébration poétique du traité du Cateau-Cambrésis (1559): document bibliographique», BHR, 43 (1981), p. 306-309) seront alors imprimées par Morel, talonné par Wechel (qui en publie 4, dont deux de Ronsard). Mais l'on sait que L'Hospital a désapprouvé ce traité, il est donc normal qu'il ait freiné les ardeurs au sein de son think tank ou de son writing workshop: à chacun de choisir l'anachronisme qui lui conviendra... 
et l'agressivité commerciale de l'autre. Visiblement, Fédéric Morel dès ses débuts a voulu asseoir une partie de ses revenus sur les occasionnels, ouvrages vite composés et vite vendus, qui assurent un bon fonds de roulement, et il a eu la chance que L'Hospital, qu'il a magnifiquement servi, soulignons-le encore, s'adresse à lui. Oui, il s'agit bien d'une heureuse convergence d'intérêts, puisque l'imprimeur a pu ainsi inscrire à son catalogue le nom d'un poète fort en vue, car des mieux en cour, et que L'Hospital de son côté a vu ses vers diffusés par ce canal, nouveau pour lui, de la typographie, mais d'une typographie d'une rare qualité.

\section{QUELLE POLITIQUE DE DIFFUSION POUR LES COMPOSITIONS POÉTIQUES?}

Même si ces impressions et réimpressions se font en nombre, il faut toutefois souligner, comme avait pu le faire déjà Michel Simonin $^{52}$, que, somme toute, ces plaquettes ne diffusent largement qu'une bien faible partie de l'œuvre poétique, un quinzième environ de l'ensemble des pièces composées par L'Hospital toute sa vie durant: une dizaine sur plus de cent cinquante. Même durant ces années si importantes pour lui, il compose assurément beaucoup plus de textes qu'il n'en livre aux presses. En dépit de ce recours si frappant et si intrigant à l'atelier de Morel en 1558 puis en 1560, il continue au même moment de réserver à certaines de ses compositions poétiques une diffusion restreinte et confidentielle.

Il faudrait donc à ce stade s'interroger sur la politique de diffusion qu'a conçue L'Hospital pour son œuvre poétique. Pour peu qu'on parvienne à dater l'entier de sa production, ce qui se révèle souvent difficile, il faudrait distinguer dans cet imposant ensemble de plus de cent cinquante poèmes, parfois fort longs, ceux qu'il compose entre 1557 et 1560, afin de dissimiler ceux qu'il fait imprimer et ceux auxquels il réserve encore une diffusion à l'état de manuscrit. En procédant ainsi peut-être pourrait-on affiner une analyse par trop impressionniste pour l'instant, laquelle invite à considérer que L'Hospital a mis sous la presse ses grands poèmes à

52 Dans sa notice citée des Centuriae latinae, p. 441-442. 
sujet d'actualité (mais l'édition du De Meti urbe capta, sept ans après la levée du siège qu'il célèbre, pose alors problème) ${ }^{53}$ et qu'il a décidé de continuer à diffuser par le biais de copies manuscrites, auprès de ses patrons, ou dans le cercle humaniste de ses proches, les pièces trop vives ou compromettantes comme notre item 0 (De postrema Gallorum expeditione) ou les poèmes de tonalité moins héroïque ou politique, ceux qui dérivaient davantage de la veine "comique et privée » et se rattachaient au sermo horatien, telle la Commendatrix epistula (II, 19) en faveur de Ronsard qui accompagna début 1559 l'offrande manuscrite de l'Hymne de Charles, cardinal de Lorraine ${ }^{54}$.

L'autre problème que pose ce passage à l'imprimé est celui de l'anonymat des premières publications qui se voit progressivement levé. De fait, même un certain nombre de pièces manuscrites, les remarques de lecteurs extérieurs comme Jean de Morel, Boyssoné ou Olivier en font foi ${ }^{55}$, semble avoir circulé dans les cercles humanistes sans le nom de leur auteur. L. Petris analyse ce fait comme une volonté de prudence chez L'Hospital, cet anonymat lui laissant latitude de pouvoir éventuellement, en cas de critique ou d'ennuis plus sérieux, désavouer la pièce et prétendre, comme avait pu en son temps le faire Érasme, qu'il n'est pas l'auteur des vers incriminés ${ }^{56}$. Toutefois, les premières impressions chez Morel de cet

53 Elle peut toutefois aussi être l'indice fort d'un changement d'attitude entre 1553 et 1560 : voilà une grande pièce politique d'actualité comparable à l'Epistola de 1558 qui a d'abord connu la diffusion habituelle, manuscrite, à travers les cercles guisards, et qui soudain, sept années plus tard, connaît enfin l'encre de l'imprimeur parce qu'elle est a posteriori manifestement assimilée au groupe de pièces d'actualité publiées en 1558. On pourrait conduire le même type d'analyse à propos du Discours de la trefoe de Du Bellay, publié aussi avec un fort retard par rapport à l'événement (fév. 1556) sur les presses de Morel, en 1558 également.

54 Voir Petris, La Plume et la tribune, p. 152-159 (analyse) et 207-211 (texte latin et traduction).

55 Grâce au témoignage de Boyssoné (publié par P. Galand et L. Petris dans leur édition citée des Carmina, t. I, p. 368-376), on sait que l'épître I, 4 qui raconte le voyage d'Italie et surtout l'assassinat de Farnèse, sujet fort sensible, a été diffusée de manière manuscrite sous le voile de l'anonyme.

56 Voir L. Petris, «Le piédestal et la fange. La construction du "grand homme" Michel de L'Hospital», Travaux de littérature publiés par l'ADIREL. L'Écrivain et le grand homme, XVIII (2005), p. 47-48, ainsi que la lettre à B. Faye transcrite et traduite par le même Petris, La Plume et la tribune, p. 484-485. 
amplissimus vir ont-elles laissé quiconque dans le doute? Remarquons d'ailleurs que, jouant le même rôle de dévoilement que la pièce grecque de Dorat imprimée au verso de la page de titre de l'édition originale de la Deffence, l'épigramme d'Elie André, adressée "Ad clarissimum virum $M$. Hospitalem», qui clôt la deuxième édition du Carmen de Caleti $\mathcal{E}$ Guinae expugnatione (item 5, fol. Bijvo ${ }^{\circ}$ souligne l'anonymat de la publication, mais pour mieux marquer que pareilles vertus poétiques ne peuvent appartenir qu'à «Philoxenus »... ${ }^{57}$

En 1560 apparaîtront même, comme sur les pages de titre des publications de Du Bellay d'avant son séjour à Rome, les «lettres à l'antique» (M. H.) dont s'était moqué Aneau en son temps parce qu'elles ne dissimulaient rien, alors même que certaines pages de titre de 1558 déjà donnaient le nom de L'Hospital en abrégé (item 7 ), voire en toutes lettres (items 8, 9 et 10). Comment interpréter ce dévoilement progressif d'une identité qui n'a jamais sans doute échappé à quiconque était un peu informé à la fois de la marche des affaires et de l'actualité littéraire au sein du royaume de France?

Faut-il y voir, comme dans le cas de Du Bellay, une pose de modestie? Ou bien une sorte de désaveu plus ou moins explicite de l'homme public à l'égard des fruits de son otium que ses hautes responsabilités lui interdisent d'assumer, comme autant de bagatelles indignes d'un personnage si accaparé par les affaires du royaume ${ }^{58}$ Pourquoi est-ce seulement apparemment dans la seconde moitié de l'année 1558 qu'il peut pleinement assumer sous le regard de tous ce loisir lettré? On ne sait que penser. La révélation graduelle de l'identité de cet amplissimus vir a donc toutes les allures d'une sorte de coming out orchestré: plus les mois passent et plus les presses de Morel en livrent sur son identité.

57 Ce type de réflexion, qu'on a lu aussi plus haut, p. 48, sous la plume de François Olivier, reproduit le discours dominant autour de la réception des épîtres de L'Hospital et de leur impossible anonymat: au sein du volume évoqué supra note 35, la copie ms. de l'épître IX, 19 («Tertius hic tandem...»), incomplète, s'achève elle aussi sur cette mention: "Caetera desunt. Autorem et carmen et carminis argumentum satis indicat».

58 On peut à ce sujet songer à la clausule de l'épître adressée à François Olivier au moment du sacre de François II à Reims $(\mathrm{V}, 6)$ : «Quod si me nostri rationem poscitis otî, / Nil praeter nugas, $\mathcal{E}$ carmina vana feretis ». 
Faudrait-il alors considérer la première publication, celle de l'Epistola au duc de Lorraine comme un ballon d'essai, et penser que le succès public manifeste de cette première plaquette (trois éditions successives en quelques mois) a incité le poète à poursuivre, mais partiellement masqué (item 4) ? Puis, le succès ne se démentant point, à se dévoiler partiellement pour son épître au cardinal de Lorraine (item 7), et enfin totalement pour celle à Marguerite (item 10)?

Dernier point mais capital: il est passionnant de prendre en considération l'ensemble du catalogue de la jeune maison Morel entre 1558 et 1560. Outre celles de L'Hospital et de Du Bellay, les plumes de presque tous les poètes humanistes qui comptent pour lors dans la capitale (Turnèbe, Le Roy, Galland, Baï) ou de moins prestigieuses (Antoine Mizaud, Jean de Amelin, Elie André, Scévole de Sainte-Marthe, Guillaume Aubert) concourent alors à préconiser l'action et la politique des Guises. Je ne crois pas qu'il soit excessif d'envisager les débuts de la maison au franc Mûrier comme la mise en place d'une officine de propagande placée, sous la haute surveillance de L'Hospital, au service des ambitions guisardes - une organisation comparable, mutatis mutandis, à celle qu'avait créée dans les années 1530 Guillaume Du Bellay ${ }^{59}$ autour des presses de Wechel et de R. Estienne, en vue de servir alors la politique étrangère de François $\mathrm{I}^{\mathrm{er}}$. De cela, on possède un indice fort: la lettre que Du Bellay adresse, sans doute à l'été 1559, à Jean de Morel. Il y dit clairement ses craintes d'indisposer le cardinal de Lorraine en ne lui faisant point établir un exemplaire d'offrande de sa traduction en français du discours du sacre de François II (item 12bis) composé en latin par L'Hospital ${ }^{60}$ (item 12a-b).

59 Voir à ce sujet les analyses convaincantes de V.L. Bourrilly, Guillaume Du Bellay, seigneur de Langey, 1491-1543, Paris, G. Bellais, 1905, p. 206-226.

60 «Monsieur, depuys le partement d'Horace, je me suis advisé qu'il seroit bon et presque necessaire d'envoyer une coppie de la translation de l'epistre de Mons $^{\mathrm{r}}$ de $\mathrm{l}^{\prime}$ Hospital à Monseigr ${ }^{\mathrm{r}}$ le Card ${ }^{\mathrm{al}}$ de Lorraine, ne videatur sibi neglectus fuisse. Et n'est besoing d'y mectre l'epistre liminaire à la Royne mère, car l'épigramme de Mons ${ }^{r}$ de l'Hospital suffira pour luy, puys que le latin luy est dedyé. Et pour ce que nous n'en avons point de prest que celuy que vous avez faict relyer pour Madame de Savoye, il me semble qu'il seroit bon de le luy envoyer (je dy à mondict seigr le Card ${ }^{\mathrm{al}}$ ) par mesme voye. » (Lettres de J. Du Bellay publiées pour la première fois d'après les originaux, éd. P. de Nolhac, Paris, Charavay, 1883, p. 30-31). 
Mais si tel est bien le cas, que dire du plus grand et du plus en vue de tous? Pourquoi reste-t-il chez Wechel en 1558-1559, puis quitte cette dernière officine pour celles de Le Mangnier en vue de donner son Deuxième livre des Mélanges, puis de G. Buon (pour les CEuvres de 1560)? Ronsard de toute manière ne participe pas à cette vaste opération de louange des Guises: il boude depuis qu'il a été éconduit par Lorraine en $1556^{61}$.

Voilà sept ans D. Bjaï et F. Rouget nous avaient réunis autour des poètes français de la Renaissance et de leurs libraires ${ }^{62}$. Assurément, on le constate, il eût été bon que le couple L'Hospital / Morel figurât en bonne place à ce colloque et fît l'objet d'une communication. Sans doute faut-il considérer ce travail-ci comme une sorte de codicille à celui que j'y avais proposé à propos du beau-père de Morel, Michel de Vascosan.

La chose est claire à mes yeux d'ailleurs : la bibliographie matérielle peut constituer un allié solide des littéraires que nous sommes. Et force est de constater que l'examen attentif de la production imprimée de L'Hospital en ces années, capitales et déterminantes pour lui (puisqu'elles marqueront le sommet de sa carrière avec l'attribution des sceaux au $1^{\mathrm{er}}$ avril 1560), apporte un certain nombre de données qui avaient échappé jusqu'alors.

Tout d'abord le nombre important de ces éditions, mais aussi leur caractère très limité dans le temps : plus rien après la dernière salve de 1560, une fois que L'Hospital est devenu chancelier. Il a assurément composé moins de pièces après cette date mais on ne peut se garder de penser que cette soudaine et intense campagne de publication accompagne la promotion rapide de notre chancelier de Berry. Il est sans doute aventureux de voir un lien de cause à effet entre les deux phénomènes mais il n'est pas interdit de deviner des interférences, bien difficiles à caractériser avec sûreté à tant de siècles de distance, entre cette soudaine

61 Voir D. Cuisiat, «La lyre crossée : un épisode de la vie de Ronsard », BHR, 31 (1969), p. 467-480 et D.J. Hartley, «Les poètes français et la prise de Calais (janvier 1558)», art. cit., 1994, p. 725-728.

62 Les poètes français de la Renaissance et leurs "libraires". Actes du colloque international de l'Université d'Orléans (5-7 juin 2013), éd. D. Bjaï et F. Rouget, Genève, Droz, 2015 (L'Hospital et Morel y sont quand même souvent évoqués comme l'atteste l'index...). 
publicité donnée à ses hexamètres grâce aux presses de Morel et la soudaine arrivée de cet humaniste robin au plus haut point du cursus honorum...

Michel MAGNIEN

Université de Paris III - Sorbonne Nouvelle

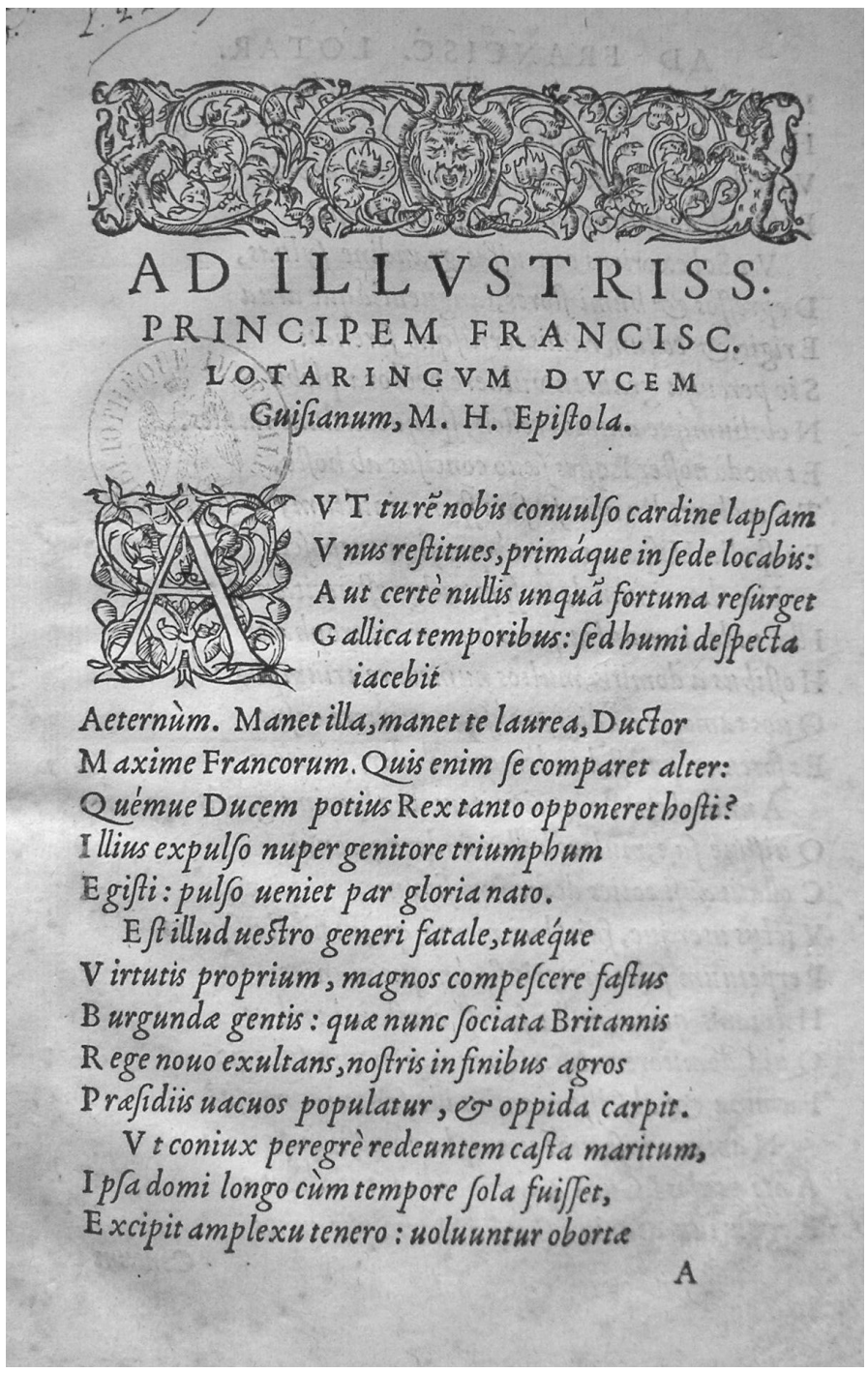

Ill. 3 : Item 11a - Cliché de l'auteur. 


\section{ANNEXE}

Les publications poétiques de L'Hospital de 1558 à 1560 : proposition de classement par ordre de parution

Cumul USTC + KVK + CCFR - NB : sauf l'item 0, tous les recueils ici décrits sont imprimés en beaux caractères italiques, à vingt-huit (ou 29) vers à pleine page, bandeaux et lettrines (A, C, E, I, M, S, V) appartenant au matériel de Morel. Le papier, d'excellente qualité, a deux origines, il s'agit soit de papier troyen de chez Le Bé (filigrane au B couronné, mais non placé à l'intérieur d'un écu comme Briquet $n^{\circ}$ 8067), soit de papier provenant de l'actuelle région de l'Yonne, portant un filigrane à l'écu semé de trois trèfles et traversé par un chevron (proche de Briquet 1121). Tous ces textes sont par ailleurs protégés par un privilège royal, toujours mentionné en bas des pages de titre, mais rares sont les extraits de privilège présents au sein de ces publications de Morel (à ce sujet, voir supra les notes 32 et 33).

\section{DE POSTREMA || GALLORVM IN ITA- | I LIAM EXPEDI-} TIONE I I CARMEN. I I SCRIPTVM ANNO MDLVII. I I s. 1. n. d. - In-8 , 4 fol. [sign. $F^{4} ; F^{1} \mathrm{~V}^{\mathrm{o}}$ blanc]. 32 vers à pleine page ; pas de titre courant ; bandeau initial et cul de lampe terminal n'appartenant pas au matériel de Morel ; papier de piètre qualité, sans filigrane visible. Incipit : Illudi nobis toties patiemur, amici, - Carm., IX, 44. Ex. consultés : BNF, Yc 11259 et Rés. p. Yc 1993 (6: ex. relié avec les poésies de Buchanan, 1609, de Turnèbe, 1580 et de Bèze, s. d., préf. de 1576). Il s'agit très probablement d'une impression de la fin du XVI siècle.

Répertoires: Cioranesco 13652. Exemplaires: Copenhague Kongelige Bib. (relié avec une plaquette de 1602), Paris, BNF (2 ex.), Rostock Universitätsbib., Tubingen Universitätsbibl.

1. AMPLISSIMI CV- | IVSDAM VIRI EPISTOLA AD | | ILLVSTRISS. PRINCIPEM || FRANCISC. LOTARINGVM || DVCEM GVISIANVM. I | [marque au mûrier: Renouard no79063] | | PARI-

63 Sur cette marque au phylactère grec, la première qu'ait utilisée Morel et qu'on retrouve sans exception sur toutes les plaquettes décrites ici, voir J. Dumoulin, Vie et cuvres de Fédéric Morel, op. cit., p. 131-132. 
SIIS, I I Apud Federicum Morellum, in uico Bellouaco, I ad urbanam Morum. | | 155 8. I | CVM PRIVILEGIO REGIS - In-4º 6 fol. [sign. $\mathrm{A}^{6} ; \mathrm{v}^{\mathrm{o}}$ page de titre et dern. fol. blancs]. Pas de titre courant, réclames, 29 vers à pleine page. Incipit: Aut tu rem nobis conuulso cardine lapsam - Carm., IV, 1. Ex. cons. : Cambridge (St John Coll.), Maz. 4 A 15216 (11) et Sorbonne R.XVI B4 (6 $6^{\mathrm{e}}$ pièce), Roanne R 4 $73 / \mathrm{C}$

Répertoires: USTC 152370, Cioranesco 13653. Exemplaires: Cambridge (St John Coll.), La Rochelle BM, Paris Maz. et BIS, Roanne BM.

2. AMPLISSIMI CV-IIIVSDAM VIRI EPISTOLA AD ।| ILLVSTRISS. PRINCIPEM || FRANCISC. LOTARINGVM | | DVCEM GVISIANVM. I C Cui addita est Elegia, IOACH. BELLAII, cum || aliquot eiusdem epigrammatis. I [marque au mûrier] II PARISIIS, II Apud Federicum Morellum, in uico Bellouaco, I I ad urbanam Morum. I| 155 8. I| CVM PRIVILEGIO REGIS - In- $4^{\mathrm{o}}, \mathbf{1 0}$ fol. [sign. $\mathrm{A}^{4} \mathrm{~B}^{6} ; \mathrm{v}^{\mathrm{o}}$ page de titre: priv. de deux ans à Morel du 17 janv. 1557 a. s.] Titres courants, réclames (sauf A $\left.i j \mathrm{v}^{\circ}\right) ; 29$ vers à pleine page. Incipit: Aut tu rem nobis conuulso cardine lapsam - Carm., IV, 1]. Ex. cons. : BNF, Rés. Yc 1466 ; BSG 4 Z 918 INV 682[1];

Répertoires: USTC 152380. Exemplaires: Beaune BM, Caen BM, Dijon BM, Grenoble BM, La Rochelle BM, Le Mans Méd. Louis Aragon, Munich Bayerische, Nancy BM, Paris BNF et BSG, Roanne BM.

3. AMPLISSIMI CV-। IIVSDAM VIRI EPISTOLA AD | | ILLVSTRISS. PRINCIPEM || FRANCISC. LOTARINGVM | DVCEM GVISIANVM. I | Cui addita est Elegia, IOACH. BELLAII, cum || aliquot eiusdem epigrammatis. I | [marque au mûrier] I I PARISIIS, I | Apud Federicum Morellum, in uico Bellouaco, II ad urbanam Morum. I| 155 8. I | CVM PRIVILEGIO REGIS - In-4 , 8 fol. [sign. A ${ }^{4} \mathrm{~B}^{4}$; $\mathrm{v}^{\mathrm{o}}$ page de titre: priv. de deux ans à Morel du 17 janv. 1557 a. s.] Titres courants, 29 vers à pleine page. Incipit: Aut tu rem nobis conulso cardine lapsam - Carm., IV, 1. Ex. cons.: BNF, Rés. Yc 1467; Maz. 10811 C $^{2}$ (6: filigr. à l'écu au chevron); Caen BM Rés. B 739 (3 : filigr. à l'écu au chevron) et Rés B. 703 (10: filigr. à l'écu). 
Répertoires: Dumoulin 8. Exemplaires: BM Caen (2 ex.), Hambourg, Staats- und Universitätsbib., Paris BNF et Maz, catalogue Oberlé, Poètes néo-latins en Europe, 1987, n 31-1.

\section{DE CALETI ET GVI-I INAE, OPPIDORVM PROXIMO I।} HOC BELLO CAPTORVM, EXPV- | | GNATIONE, CARMEN LONGE I I DOCTISSIMVM, I I Cuius auctor is ipse est, qui $\mathcal{E}$ illius eruditiß. Epistolae ad I | Franciscum Guisiorum principem proxime a nobis editae. II marque au mûrier I I PARISIIS, I I Apud Federicum Morellum, in uico Bellouaco I I ad urbanam Morum. I 155 8. I I CVM PRIVILEGIO REGIS. - In-4, 4 fol. [sign. $\mathrm{A}^{4}$; fol. $\mathrm{A} 4 \mathrm{v}^{\mathrm{o}}$ blanc]. Titres courants, réclames, 29 vers à pleine page. Incipit: Sic mutat fortuna vices, $\mathcal{E}$ ludit atrocem Carm., IV, 2; fin fol. A4 $\mathrm{r}^{\mathrm{o}}$, sans les pièces de Du Bellay et E. André. Ex. cons.: Paris BNF, Yc 2695 (filigr. à l'écu au chevron), Caen BM (Rés. B 739[4] filigr. à l'écu au chevron et Rés.B 703 [4] filigr. B couronné64) et Maz. 10811 C $^{2}$ (9) et 15216 (12), Cambridge (St John Coll.), Bayerische Staatsbibliothek (ex. num.)

Répertoires: USTC 152414, Dumoulin 10, Adams L 620. Exemplaires: Cambridge (St John Coll.), Cambridge, MA, Houghton Library Harvard Univ., Caen BM (2 ex.), Grenoble BM, Halle, Univ. und Landesbib, La Rochelle BM, Le Mans Méd. Louis Aragon, Londres BL, Munich Bayer., Paris BNF (2 ex.), BSG et Maz. (2 ex.), Poitiers Méd. Fr. Mitterrand, Roanne BM.

\section{DE CALETI ET GVI-IINAE, OPPIDORVM PROXIMO ।|} HOC BELLO CAPTORVM, EXPV- I I GNATIONE, CARMEN LONGE I I DOCTISSIMVM, I I cuius auctor is ipse est, qui $\mathcal{E}$ illius eruditiß. Epistolae ad I | Franciscum Guisiorum principem proxime a nobis editae II marque au mûrier I I PARISIIS, I I Apud Federicum Morellum, in uico Bellouaco I | ad urbanam Morum. I I 155 8. I I CVM PRIVILEGIO REGIS. - In-4º, 6 fol. [sign. $\mathrm{A}^{4}-\mathrm{B}^{2}$ ]. Incipit: Sic mutat fortuna vices, $\mathcal{E}$ ludit atrocem-Carm.,

64 La différence de rame de papier est l'indice d'un retirage au moins partiel. En effet, sur l'ex. 739/4 une coquille («In medio littus, Nerei...») est corrigée par la suppression d'un trait de plume du verbe. Dans l'ex. B. 703/4, on lit le vers imprimé ainsi: «In medio littus, Nerei quod proluit unda». Il y a eu au moins correction sur forme, voire recomposition puisque la réclame du bas de page n'est pas placée au même endroit sur les deux exemplaires... 
IV, 2 ; fol. Bijro épigr. de Du Bellay («In reditum eiusdem ducis»), suivie d'une épigr. d'E. André à L'Hospital. Ex. cons. : BNF, Rés. p. Yc 1464 et British Lib. 873.h.49

Répertoires: Cioranesco 13654. Exemplaires: Londres Brit. Lib., Paris BNF, Oberlé no 31-2

5bis. L'Hospital-Baif: REMONSTRANCE I I SVR LA PRINSE DE CALAIS | | ET GVINE, FAICTE PREMIERE- | | ment en uers Latins par un excellent I| personnage, \& depuis mise en || François par un des I| Poëtes de ce II temps. I I marque au mûrier || À PARIS, || De l'Imprimerie de Federic Morel, rue S. Ian || de Beauuais, au Franc Meurier. I| M. D. LVIII. - In-4\%, 4 fol. [sign. $\mathrm{A}^{4}$ ]; $\mathrm{v}^{\mathrm{o}}$ page de titre, sonnet «Sur le partement du roy...»- Incipit: Ainsi Fortune change et jouant à sa guise... Bandeau initial au masque, titres courants, texte imprimé en romain, 28 vers à pleine page (sauf sonnet lim. composé dans l'italique des impressions latines) - Ex. cons. : BNF, Résac Yc 4456 (filigr. à l'écu à chevron); BM Caen (Rés. B 739[6: filigr. à l'écu à chevron])

Répertoires: USTC 1154, Girard 2 no 2304, NUC 0332129, Lindsay et Neu no 119, Cioranesco 3007, Vignes BEF n40. Exemplaires: Caen BM, Grenoble BM, Paris BNF, Rés. et ms. NAF 7713 (96), New Haven, CT Yale University, Beinecke Library.

6. IN FRANCISCI | | ILLVSTRISS. FRANCIÆ DEL- | PHINI, ET MARIAE SERENISS. I I SCOTORVM REGINAE NVPTIAS, I | VIRI CVIVSDAM AMPLISS. I I CARMEN. I I marque au mûrier I| PARISIIS, I| Apud Federicum Morellum, in uico Bellouaco, I I ad urbanam Morum. II M. D. LVIII. I I CVM PRIVILEGIO REGIS. - In- $4^{\mathrm{o}} ; 4$ fol. [sign $\mathrm{A}^{4} ; \mathrm{v}^{\mathrm{o}}$ p. de titre blanc] Pas de titre courant, réclames, 28 vers à pleine page. Incipit: Mene etiam cantare iubes $\mathcal{E}$ ludere uersu-Carm., V, 1. Ex. cons. : Maz. $10811 C^{2}$ (8: filigr. à l'écu à chevron) ; BM Caen Rés. B 703 (7: filigr. à l'écu)

Répertoires: USTC 152490, Dumoulin 17, Adams 627, Cioranescu 13655. Exemplaires: Caen BM, Cambridge, MA Houghton Library, Harvard University, Hambourg, Staats- und Universitätsbib., La Rochelle BM, Le Mans Méd. Louis Aragon, Paris BIS, BNF et Maz., Poitiers Méd. Fr. Mitterrand, Roanne BM, Oberlé $\mathrm{n}^{\mathrm{o}} 31-10$. 
7. AD CAROLVM CAR- I | DINALEM LOTARENVM | | MICH. HOSPIT. DE PACE I I CARMEN. I I marque au mûrier I| PARISIIS, I| Apud Federicum Morellum, in uico Bellouaco, I I ad urbanam Morum. II M. D. LVIII. II CVM PRIVILEGIO REGIS. - In- $4^{\circ} ; 4$ fol. [sign $\mathrm{A}^{4}$ ]; $\mathrm{V}^{\mathrm{o}} \mathrm{p}$. de titre et $4^{\mathrm{e}}$ fol. blancs; bandeau initial, pas de titre courant, impression en italiques, 27 vers par pleine page [Incipit: Si pacem tecum referes, tua munia Regi...; Carm., V, 4] Ex. consultés : BNF, Rés. m. Yc 953 (7, filigr. à l'écu couronné), Maz. 4º A 15216 (15) et Maz. $10811 C^{2}$ (8, filigr. à l'écu couronné), Cambridge St John Coll., BM Caen (Res B. 703[8], filigr. p. de titre: B couronné).

Répertoires: USTC 198153, Dumoulin 6, Adams L 618, Cioranesco 13651. Exemplaires: Caen BM, Cambridge (St John Coll.), Dresden, Landesbib., Grenoble BM, Le Mans Méd. Louis Aragon, Leonessa BM, Mannheim, Univ.bib, Paris BIS, BNF, BSG et Maz., Perugia BM, Roanne BM, Venise Marciana, Wien Öster. Nationalbibliothek, Oberlé no 31-4.

8. DE THEAVILLA CAPTA | | MICHAELIS HOSPITALII I | CARMEN. I I marque au mûrier I| PARISIIS, I| Apud Federicum Morellum, in uico Bellouaco, II ad urbanam Morum. II M. D. LVIII. II CVM PRIVILEGIO REGIS. - In- $4^{\mathrm{o}}, 4$ fol. [sign. $\mathrm{A}^{4} ; \mathrm{A} \mathrm{v}^{\mathrm{o}}$ blanc, pas de titre courant, bandeau initial au masque, réclames, 28 vers par pleine page] [Incipit: Ut grauis $\mathcal{E}$ senio confectus miles ad arma...-Carm., IV, 3] Ex. cons. : Cambridge Saint-John; BNF, Rés. m. Yc 953 (6 ; filigr. écu au chevron); BM Caen (Rés. B 703[6: filigr. B couronné] et Rés. B 703[15: écu au chevron])

Répertoires: USTC 152444, Dumoulin 11, Adams L 622, Cioranesco 13656. Exemplaires: Caen BM (2 ex.), Cambridge UK, Cambridge, MA, Houghton Library, Harvard Univ., Grenoble BM, La Rochelle BM, Le Mans Méd. Louis Aragon, Manchester Univ., Paris BIS, BNF, BSG et Maz., Poitiers Méd. Fr. Mitterrand, Roanne BM.

9. DE THEAVILLA CAPTA I I MICHAELIS HOSPITALII I I CARMEN. I I marque au mûrier I| PARISIIS, I I Apud Federicum Morellum, in uico Bellouaco II ad urbanam Morum. I| 1558 || CVM PRIVILEGIO REGIS. - In- $4^{\mathrm{o}}, 4$ fol. [sign. $\mathrm{A}^{4}$ ] [Incipit: Ut grauis $\mathcal{E}$ senio confectus miles - Carm., IV, 3] Ex. cons. : Maz. $10811 \mathrm{C}^{2}$ (9: filigr. B couronné)

Exemplaires: Cambridge, MA, Houghton Library, Harvard Univ., Grenoble BM, La Rochelle BM, Le Mans Méd. Louis 
Aragon, Manchester Univ., Paris Maz., Poitiers Méd. Fr. Mitterrand, Roanne BM.

10. AD MARGARITAM | | REGIS SOROREM, || MICHAELIS HOSPITALII I| EPISTOLA. I I marque au mûrier I| PARISIIS, I| Apud Federicum Morellum, in uico Bellouaco, I I ad urbanam Morum. I I M. D LVIII. I I CVM PRIVILEGIO REGIS. - In- $4^{\text {o }}$, - 6 fol. [sign. A $^{6}$; impression en italiques, 28 vers par pleine page; bandeau initial, pas de titre courant; $\mathrm{A}^{1} \mathrm{v}^{\mathrm{o}}$ et dern. fol. blancs] Incipit: En toties noua cura subit tibi pectus honestum - Carm., II, 8. Ex. consulté : BNF, Rés. M. Yc 953 (8, sur Gallica), Maz. $10811 C^{2}$ (7; filigr. B couronné surmonté d'un trèfle); BM Caen (Res B. 703[9], filigr. p. de titre: B couronné).

Répertoires : USTC 152372, Dumoulin 7, Cioranesco 13652. Exemplaires: Caen BM, Cambridge, MA (USA), Houghton Library, Harvard University, Dresden, Landesbib., Grenoble BM, Le Mans Méd. Louis Aragon, Londres BL, Mannheim, Univ.bib., Paris BNF, Venise Marciana, Brigham Young University, Oberlé no 31-5.

11. DE METI VRBE CAPTA I I ET AB HOSTIVM INGEN- I I TI OBSIDIONE LIBERATA, I I AMPLISS. VIRI M. H. I | CARMEN I| marque au mûrier II PARISIIS, I I Apud Federicum Morellum, in uico Bellouaco, I I ad urbanam Morum. I I 1560. I I CVM PRIVILEGIO REGIS. - In-4o 4 fol. [sign. $a^{4}$ ], signatures et titres courants - Incipit: Ergo militibus tandem Mauortia nostris... - Carm., II, 13; au fol. a[4] $\mathrm{v}^{\mathrm{o}}$ : extrait du privilège du 11 mars 1559 (a. s.). Ex. consultés : BM Caen Rés. B 740 [10]; BM Leonessa R ant. 60 4; Paris Maz. A 15220 (4-7), Maz. 10684 ( $1^{\text {re }}$ p.) et Maz. 10684bis ( $1^{\text {re }}$ p.).

Le plus souvent, sur douze feuillets signés $\mathrm{A}^{4}-\mathrm{C}^{4}$, suivent (parfois précèdent: voir ex. de Caen), les textes suivants, dépourvus de page de titre (les pages débutent par le bandeau qu'on rencontre depuis 1558 dans tous ces tirages, puis vient le titre en capitales):

- 11a cahier A: [Bandeau au masque] I I AD ILLUSTRISS. I I PRINCIPEM FRANCISC. I| LOTARINGUM DUCEM I| Guisianum M. H. Epistola. (Incipit: Aut tu rem nobis conuulso cardine - Carm., IV, 1) Réclames, titres courants, 27 vers par pleine page.

On retrouve ce cahier relié à la suite de la De sacra Francisci II Initiatione de 1560 (ex. Maz. 10684bis, 4e p.); il existe aussi beaucoup d'ex. isolés: v. par ex. BNF, Yc 1431 
- 11b cahier B : [Bandeau au masque] I I DE CALETI ET GVI- I I NAE, OPPIDORVM PROXI-I| MO BELLO CAPTORVM, I I expugnatione, Mich. Hosp. II Carmen (Incipit: Sic mutat Fortuna uices, E ludit... Carm., IV, 2); fol. Biij vo : In reditum Francisci Lotareni Guisiorum ducis (Ite coronati, festiuoque agmine cives... - Carm., VII, 8); fol. B[4] : In reditum eiusdem ducis Ioach. Bellaius.

- 11c cahier C: [Bandeau au masque] II DE THEAVILLA CAPTA I I MICHAELIS HOSPITALII I I CARMEN. (Incipit: Vt gravis et senio confectus miles... - Carm., IV, 3); In Horatii Farnesii necem Mich. Hosp. Carmen (Et Venus, E Mauors Romani scilicet ambo... Carm., VIII, 2); fol. C4 ${ }^{\circ}$ : Privilegii sententia [du 11 mars 1559].

NB : la présence du privilège sur deux pages, en fin du cahier $a$ et fin du cahier $\mathrm{C}$, incite à pressentir une vente (ou une distribution ?) par cahiers séparés, dont témoignent nombre d'exemplaires isolés de tel ou tel cahier.

Répertoires: USTC 152847, Dumoulin 39, Brunet VII 658. Exemplaires : Bordeaux Médiathèque, Cambridge MA Houghton Lib. at Harvard, Chicago Newberry Lib., Leonessa BM, Londres BL, Metz Méd. du Pontiffroy, Paris BNF (2 ex.) et Maz. (3 ex.), Versailles BM, Vienne Österreichische Nationalbibl.

\section{2a. DE | | SACRA FRANCISCI || II. GALLIARVM REGIS | |} INITIATIONE, REGNIQVE | | IPSIVS ADMINISTRANDI PRO- | VIDENTIA, MICH. HOSP. I I SERMO. I I marque au mûrier I| PARISIIS, I| Apud Federicum Morellum, in uico Bellouaco, I I ad urbanam Morum. II M. D. LX. I I - In-4 10 fol. [sign. $\mathrm{A}^{4}-\mathrm{B}^{6}$; bandeau initial au masque, bandeau aux rinceaux de lierre, pas de titre courant, impression en italiques (sauf $A v^{\mathrm{o}}$ ) 28 vers à pleine page] [Au vo p. de t.: épigramme au cardinal de Lorraine, Carm., V, 7 - Incipit: Coelesti est oleo Mariae Puer unctus ad aram - Carm., V, 8; au fol. Bvro ép. Au chancelier Olivier, "Vobiscum remos unà comes ire parabam..." Carm., V, 6. Ex. consultés: Maz. A 15220 (3) et 10684 (2e p. : filigr. p. de titre: B couronné surmonté d'un trèfle)

Répertoires: USTC 152861, Dumoulin 40, Adams L 621, Barbier IV, 3 no 43, Cioranesco 13667. Exemplaires: Besançon BM, Caen BM, Cambridge (Saint John), Cambridge, MA Houghton Library, Harvard University, Chicago, Newberry Library, Cracovie Bibl. Jagiellonska, La Rochelle BM, Le Mans Méd. Louis Aragon, Paris BNF, BIS et Maz., New Haven, Yale University, Beinecke Lib., 
Poitiers Méd. Fr. Mitterrand, Roanne BM, Vienne Österreichische Nationalbibl.

12b. DE || SACRA FRANCISCI || II. GALLIARVM REGIS | | INITIATIONE, REGNIQVE | | IPSIVS ADMINISTRANDI PRO- I VIDENTIA, MICH. HOSP. I I SERMO. I I marque au mûrier I| PARISIIS, I| Apud Federicum Morellum, in uico Bellouaco, II ad urbanam Morum. II M. D. LX.II - In-4 10 fol. [sign. $\mathrm{A}^{4}-\mathrm{B}^{6}$; deux bandeaux initiaux au masque, pas de titre courant, impression en italiques (sauf $\left.A v^{\circ}\right) 28$ vers à pleine page; cahier $B$ recomposé avec des modifications de la ponctuation, ajout de guillemets marginaux au fol. Biijr ${ }^{\circ}$ et d'une réclame au bas du fol. $\left.\mathrm{Bijv}^{\mathrm{o}}\right]$ [Au v $\mathrm{p}$. de t. : épigramme au cardinal de Lorraine, Carm., V, 7 - Incipit: Coelesti est oleo Mariae Puer unctus ad aram - Carm., V, 8; au fol. Bvro ép. Au chancelier Olivier, «Vobiscum remos unà comes ire parabam..."-Carm., V, 6. Ex. consultés : BNF, Rés. m. Yc 953 (5: filigr. p. de titre: B couronné); Ex. détaché : BM Caen Rés. B 703 (12; filigr. au B couronné) et Rés. B 740 (12; filigr. au B couronné); Maz. A 15216 (10)

12bis. L'Hospital-Du Bellay. DISCOVRS SVR LE SA- I I CRE DV TRES CHRESTIEN | | ROY FRANÇOYS II. AVEC I | LA FORME DE BIEN RE-|| GNER ACCOMMODÉE AVX | | MOEVRS DE CE || ROYAUME: I I Faict premièrement en vers latins par Michel de I | L'Hospital Conseiller du Roy en son priué । Conseil, \& premier President de I I ses comptes: \& mis en vers I| Françoys par Ioach. | | du Bellay. | | marque au mûrier | | A PARIS | | De l'Imprimerie de Federic Morel, Rue S. Iean I I de Beauuais, au franc Meurier I I 1560 . I | AVEC PRIVILEGE DU ROY | | In-4º, 12 fol. [sign. A-C ${ }^{4}$; bandeau initial au bucrane; imprimé en romains, à 29 vers par pleine page; fol. C4ro extrait du priv. Du 11 mars 1559] Ex. consulté: Rés.p. Yc 1461

Au fol. Cij : «Traduction d'une épistre latine du mesme autheur escripte peu devant le sacre du Roy à Monseigneur le chancellier Olivier, par Scévole de S. Marthe»

Répertoires: USTC 41769, Dumoulin 41 Exemplaires: Paris BNF et Maz.

13. IN FRANCISCI | | ILLVSTRISS. FRANCIÆ DEL- | | PHINI, ET MARIAE SERENISS. I I SCOTORVM REGINAE NVPTIAS, I | AMPLISS. VIRI M. H. I I CARMEN. I I marque au mûrier I | PARISIIS, I| Apud Federicum Morellum, in uico Bellouaco, I I ad urbanam Morum. I | 1560. I | 
CVM PRIVILEGIO REGIS. - In- $4^{\circ} 4$ fol. [sign. $\mathrm{D}^{4}$ ] ; réclames, pas de titre courant; au fol. D1 $v^{\mathrm{o}}$ : priv. pour 6 ans signé Lalemant du 11 mars 1560 (n. s.) - Incipit: Me ne etiam cantare iubes $\mathcal{E}$ ludere uersu... Carm., V, 1. Ex. cons. : BM Caen Rés. B 740 [11]; BM Leonessa R ant. 601 ; BNF, Rés. 4Z Don 190 (filigr. B couronné) ; Maz. A 15220 (6-8).

Suivent dans ce dernier ex. comme dans d'autres (Maz. 10684bis $2^{e}$ p.), sur six fol. sign. $A^{4}-A^{2}$, les textes suivants, sans page de titre (les pages débutent par le bandeau habituel au masque, suivi du titre en capitales):

- 13a cahier A : [Bandeau au masque] I I AD MARGARITAM I I REGIS SOROREM, I | M. H. EPISTOLA | | s. 1. n. d. [Paris, F. Morel, 1560] In- $4^{\mathrm{o}}, 4$ fol. [sign. $\mathrm{A}^{4}$ ]. Pas de titre courant, réclames, 28 vers à pleine page. Incipit: En toties noua cura subit tibi pectus honestum...; Carm., II, 8. Ex. cons. : Cambridge GB (St John Coll.), BM Caen Rés. B 740 [8: ex. détaché], BM Leonessa

- 13a' cahier A: [Bandeau au masque] II AD MARGARITAM | | REGIS SOROREM, || EPISTOLA. || s. l. n. d. [Paris, F. Morel, 1560] - In-4 ${ }^{\text {o }} 4$ fol. [sign. $\mathrm{A}^{4}$ ]. Pas de titre courant, réclames, 28 vers à pleine page. Incipit: En toties noua cura subit tibi pectus honestumCarm., II, 8. Ex. cons.: Maz. 4 A 15216 (16: filigr. B couronné, surmonté d'un trèfle).

- 13b cahier A[bis]: [Bandeau au masque] II AD CAROLUM CARDINALEM | | LOTARENUM MICH. HOSPIT. I I DE PACE CARMEN. I | Incipit: Si pacem tecum referes, tua munia Regi... - Carm., V, 4. Ex. détaché: BM Caen Rés. B 740 [7]

Répertoires: USTC198412, Dumoulin 46 Exemplaires: Caen BM, Cambridge GB (St John Coll.), Chicago Newberry Library, Leonessa BM, Paris BNF et Maz. 


\section{LES ÉPÎTRES DE MICHEL DE L'HOSPITAL: DES SERMONS LAÏQUES?}

Les Carmina de Michel de L'Hospital sont un véritable laboratoire d'idées et de réflexions sur lui-même, sur la société, sur l'homme et son destin. Ils sont aussi pour le poète un moyen pour se justifier, pour se défendre ou pour chercher la protection d'un grand personnage tout en en faisant l'éloge; le discours épidictique, fréquent chez L'Hospital, contient d'ailleurs en creux un appel à l'imitation d'un comportement présenté comme exemplaire. Le souci d'édification morale, précisément, est l'une des caractéristiques principales des Carmina qui, considérés dans leur ensemble, peuvent être compris comme une exhortation à l'ascension morale. Cet appel à vivre dans la vertu apparaît fréquemment comme une conséquence logique de la satire du système judiciaire, des courtisans, du luxe, de la cupidité. L'Hospital croit en la « vertu pédagogique et psychagogique de la satire ${ }^{1}$ et, plus généralement, du genre de l'épître en vers horatienne. La tendance à la moralisation du discours va même jusqu'à s'accentuer dans la dernière décennie de sa vie, à l'époque des guerres de religion.

L'ascension morale qu'il appelle de ses vœux trouve son accomplissement, ou sa plus haute expression, dans la foi chrétienne. Loin d'être présent dans toutes les épîtres, le discours moral chrétien apparaît toutefois comme une caractéristique essentielle de la pensée de L'Hospital, dont la vision du monde et la vie sont profondément marquées par la foi. C'est ce discours moral chrétien que nous voulons étudier dans cet article. Il s'agira de nous interroger sur son contenu et sur la manière dont il est présenté dans les Carmina.

1 P. Debailly, La Muse indignée, t. I, La satire en France au XVI siècle, Paris, Garnier, 2012, p. 492. 


\section{LE VATES SACERDOS : L'ÉPÎTRE VI, 5}

Voici les derniers vers du Sermo de libertate scribendi, épître programmatique sur la conception de la satire par L'Hospital ${ }^{2}$ :

Omne velim sit castum et lene poema,

Sit mistum gravitate, vacet risuque iocisque,

Qualis sermo fere est media testudine templi

Ad populum magno quem personat ore sacerdos ${ }^{3}$.

Je voudrais que tout poème soit chaste et doux,

Qu'il soit mêlé de gravité, exempt de moquerie et de plaisanteries,

Comme l'est en général le sermon que, sous la voûte du temple,

Fait retentir à l'intention du peuple, d'une voix forte, le prêtre.

Un poème doit être castum, c'est-à-dire chaste, intègre, irréprochable, L'Hospital prenant ainsi le contrepied de Catulle, qui affirme que, si le poète doit être chaste, il n'est pas nécessaire que le poème le soit ${ }^{4}$. Le poème doit aussi être lene, c'est-àdire doux, agréable: c'est ainsi par la persuasion plus que par la contrainte qu'il aidera le lecteur à s'amender. Il doit être grave (mistum gravitate), exempt de rire et de plaisanterie (vacet risuque iocisque $)^{5}$ : L'Hospital suit ici la leçon de Martial, qui indique que les vers doivent épargner les personnes tout en censurant les vices ${ }^{6}$;

2 Nous renvoyons au commentaire, à l'édition et à la traduction de cette épître dans Petris, La Plume et la tribune, p. 159-163 et p. 211-214, et dans L'Hospital, Carmina, t. VI, à paraître. La pièce est probablement postérieure à 1563, mais aucun élément ne permet de la dater avec certitude (Petris, La Plume et la tribune, p. 162).

3 L'Hospital, Carmina, VI, 5, 35-38. L'expression ore sacerdos est une réminiscence de Virgile, Aen., III, 373, en même position métrique, à propos du prêtre Hélénus.

4 Catulle, 16, 5: «Nam castum esse decet pium poetam / Ipsum, versiculos nihil necesse est $\gg$.

5 C'est le rire méchant et malveillant qui est ici visé, non la saine plaisanterie, qui «tranche bien des fois les questions importantes plus fortement et mieux que l'énergie rude» (Horace, Sat., I, 10, 15-16: «Ridiculum acri / Fortius et melius magnas plerumque secat res»). L'Hospital lui-même n'hésite pas à recourir à la plaisanterie (ainsi dans V, 9, 308-316).

6 Martial, Epigr., X, 33, 9-10: «Hunc servare modum nostri novere libelli, / Parcere personis, dicere de vitiis ». Horace quant à lui affirme que la méchanceté sera toujours absente de ses écrits (Epist., IV, 101-103: «quod vitium procul afore 
c'est aussi ce que prône Érasme, pour qui la parole satirique doit éviter les attaques nominatives et respecter la décence et le bon goût $t^{7}$.

Les deux derniers vers de l'extrait sont particulièrement intéressants pour notre propos: le poème tel que le voudrait L'Hospital est comparé au discours du prêtre à l'église, autrement dit à $l^{\prime}$ homélie ou au sermon ${ }^{8}$. «Le discours poétique à visée édifiante rejoint le ton de l'homélie et donc le style et l'intention du sacerdos $»^{9}$. Ainsi, comme le prêtre, le poète a pour mission d'aider les hommes à s'amender et à devenir meilleurs ${ }^{10}$.

chartis / Atque animo prius, ut siquid promittere de me / Possum aliud, vere promitto »); il s'autorise toutefois une certaine franchise, à l'exemple de son père qui n'hésitait pas, pour lui faire fuir les vices, de désigner nommément ceux qui en étaient affligés (Epist., IV, 103-115); Ovide lui aussi rejette les railleries mordantes (Trist., II, 563-566: «Non ego mordaci destrinxi carmine quemquam, / Nec meus ullius crimina versus habet. / Candidus a salibus suffusis felle refugi: / Nulla venenato littera mixta ioco est»).

7 Voir par exemple la lettre préface de l'Éloge de la Folie adressée à Thomas More, ASD IV.3, p. 68: "At enim qui vitas hominum ita taxat, ut neminem omnino perstringat nominatim, quaeso utrum is mordere videtur, an docere potius, ac monere».

8 Nous prenons ici les deux termes comme des synonymes. D'ordinaire, l'homélie désigne un commentaire d'un passage des Écritures; le terme «sermon» a souvent le sens péjoratif de «discours moralisateur» qu'il n'a pas à l'origine.

9 Petris, La Plume et la tribune, p. 161.

10 Comme l'affirme Petris, La Plume et la tribune, p. 162: «Cette épître est aussi programmatique: elle trace un chemin que L'Hospital empruntera durant les guerres civiles, en cherchant, par une parole évangélique, à provoquer une véritable métanoïa susceptible de sauver la concorde civile». C'est par ce même désir d'amender l'homme qu'Érasme justifie la transformation de certains adages en véritables leçons morales. Ainsi, à la fin de l'adage 2201 («Les Silènes d'Alcibiade»), il constate qu'il s'est écarté de son rôle de compilateur de proverbes et s'est transformé en prédicateur (ecclesiastes): "Sed quo me sermonis cursus abripuit ut paroemiographum professus ecclesiastes esse coeperim ? » (ASD II.5, p. 190); mais il a de la sorte contribué à l'emendatio vitae et à la pietas du lecteur (Ibid.). 
II. LE PASSAGE DU SERMO MORAL AU SERMON CHRÉTIEN : L'ÉPÎTRE VI, 3

L'épître VI, $3^{11}$ fournit une belle illustration de la mise en pratique de cet èthos sacerdotal. L'Hospital y console Charles de Guise, cardinal de Lorraine, de la mort de son frère François, duc de Guise, qui vient d'être assassiné (1563). Il définit deux «manières » (mores), ou plutôt deux degrés dans le processus de consolation:

[...] Si quid mea carmina possunt,

Possum si quod, egens solaminis ipse, levamen

Ullum afferre tibi, luctum si demere luctu,

Incipiam solito et populari more querelis

Respondere tuis; si nil vulgaria prosunt,

More sacerdotum proprio, depromptaque sacris

Argumenta feram tibi non incognita libris ${ }^{12}$.

[...] Si mes poèmes y peuvent quelque chose,

$\mathrm{Si}$ je peux, alors que j'ai moi-même besoin de consolation, t'apporter

Quelque réconfort, si je peux dissiper le chagrin par le chagrin,

Je commencerai à répondre à tes plaintes de la manière

Habituelle et populaire; si les arguments communs ne sont d'aucune

[utilité,

Alors, à la manière qui est propre aux prêtres, je présenterai

Des arguments tirés des livres sacrés, bien qu'ils ne te soient pas

[inconnus.

Il s'agit d'un processus qui va de la terre au ciel: afin de consoler le cardinal, L'Hospital commencera par donner des arguments humains, tirés de la sagesse populaire (solito et populari more); mais, si ces arguments sont insuffisants, il emploiera la «manière propre aux prêtres» (more sacerdotum proprio), c'est-à-dire l'homélie, qui consiste à convaincre l'auditoire en s'appuyant sur les textes sacrés (sacris... libris) ${ }^{13}$. Il y a donc passage de la sagesse

11 Pour un commentaire complet de cette épître, voir L'Hospital, Carmina, t. VI, à paraître.

12 L'Hospital, Carmina, VI, 3, 22-28.

13 Dans ses Carmina, L'Hospital s'appuie très fréquemment sur les Écritures Saintes, en particulier sur les évangiles et les épîtres de Paul. Voir infra, 
populaire au sermon chrétien, le second étant le dépassement, ou même l'accomplissement, de la première. On remarquera en passant que L'Hospital prend lui-même part au deuil du cardinal et affirme avoir également besoin de consolation (v. 23); cette participation sincère au deuil, cette compassion dont il fait preuve est essentielle pour l'efficacité du discours «sacerdotal»; nous reviendrons plus bas sur cette idée ${ }^{14}$.

Ce mouvement de l'humain au divin est caractéristique de la pratique de L'Hospital: la lecture de ses Carmina permet en effet de constater que, dans la plupart des cas où il use de ce que nous appelons ici le «sermon» ou «l'homélie», L'Hospital, partant $\mathrm{d}^{\prime}$ une réflexion sur une circonstance particulière, passe du discours moral au sermon chrétien, transformant la parole humaine en sermo evangelicus ${ }^{15}$.

\section{DE LA DÉFAITE AU CIEL : L'ÉPÎTRE IV, 1}

L'épître IV, 1 est un bel exemple de cette pratique. Dans ce poème, L'Hospital espère qu'après la défaite française de SaintQuentin du mois d'août 1557, le duc de Guise, à qui il s'adresse, pourra relever la France ${ }^{16}$. L'évocation de ce désastre lui donne l'occasion d'une réflexion morale sur l'inconstance de la Fortune, sur la luxure et la cupidité qui accompagnent souvent les victoires (la paix pouvant constituer un bonheur trompeur) et détruisent l'âme comme le corps.

Ces réflexions débouchent sur l'affirmation de la nécessité de la conversion à Dieu et de l'acceptation de sa volonté d'un cœur pur, et, dans les derniers vers du poème, sur l'exposition d'un véritable programme de vie chrétienne:

n. 17 et 26 ; voir aussi, pour ne citer que quelques exemples particulièrement significatifs, II, 1, 161-175 ; V, 8, 302-320 ; VI, 1, 116-144 ; VI, 12, 159-180 ; VI, 13, 116-120.

14 Voir infra, p. 91-92.

15 Sur cette expression, voir P. Debailly, La Muse indignée, t. I, La satire en France au XVI siècle, Paris, Garnier, 2012, p. 494.

16 Pour une analyse et un commentaire de cette épître, voir L'Hospital, Carmina, t. IV, p. 24-42. 
Mutemus mores igitur veniamque precemur;

Imprimisque deos et tota mente colamus

Et totis animis; exin nos inter amemus ${ }^{17}$;

Sit bene sarcta velut multorum gratia fratrum,

Nec minor alterius quam nostrae cura salutis.

Quae si fixa animo penitus mandata geremus,

Mortes, exilia, atque fugas, et damna bonorum,

Quaeque solent alia adversis accedere rebus,

Haud magnifaciemus; erunt neque tristia nobis

Aspera, nec vel amara nimis, vel dura ferendo.

Scilicet extinctos merces uberrima coelo

Et promissa manent aeternae praemia vitae ${ }^{18}$.

Changeons donc de comportement et demandons pardon;

Et en premier lieu honorons les dieux de toute notre intelligence

Et de toute notre âme; ensuite aimons-nous les uns les autres;

Que la concorde soit bien rétablie comme dans une grande fratrie,

Et n'ayons pas moins à cœur le salut d'autrui que le nôtre.

Si nous portons ces commandements profondément enracinés dans

La mort, l'exil, la fuite, la perte de nos biens,

[notre cœur,

Et les autres malheurs qui arrivent d'ordinaire dans l'adversité,

Nous n'en ferons pas grand cas ; les difficultés pour nous ne seront pas

Sombres, ni même trop amères ou dures à supporter.

Oui, un bien riche gain attend les défunts au ciel,

Ainsi que la récompense promise de la vie éternelle.

Le mutemus du v. 189 introduit la dernière partie de l'épître et marque un net changement de ton dans le discours : il faut changer de comportement et se convertir! Les réflexions précédentes sont dépassées par ce discours impératif où L'Hospital, qui s'appuie sur l'Évangile, exhorte le lecteur, et donc aussi le duc de Guise, à la

17 Les vers 190-191 rappellent les commandements de l'amour de Dieu et de l'amour du prochain donnés par le Christ en Mt 22, 37-39; Mc 12, 30 et 33 ; Lc 10, 27 (pour le commandement d'aimer Dieu de tout son cœur et de toute son âme, cf. aussi Dt 6, 5;10, $12 ; 11,13 ; 30,6)$. Le v. 190 fait en outre écho au début des célèbres Disticha Catonis, I, 1 : «Si Deus est animus, nobis ut carmina dicunt, / Hic tibi praecipue sit pura mente colendus ». En V, 8, 306-308, L'Hospital rappelle aussi le premier commandement: "Omnibus hunc animi nervis et pectore toto / Diligere atque aliud nihil aeque iussit amare, / Qui coelum et stellas et totum condidit orbem».

18 L'Hospital, Carmina, IV, 1, 189-200. 
manière du prêtre, à demander pardon à Dieu, à l'honorer, à aimer son prochain comme un frère et à se soucier de son salut comme du sien propre. C'est en suivant ces indications, affirme L'Hospital, que l'on supportera les inévitables épreuves de la vie (v. 195-198), et surtout que l'on obtiendra la récompense du ciel (v. 199-200). Le message des deux derniers vers, qui désignent le ciel comme le but à atteindre, constitue le point culminant de l'épître en même temps que du message chrétien.

\section{DE LA VICTOIRE AU CIEL : L'ÉPÎTRE IV, 2}

On retrouve le même mouvement dans l'épître IV, $2^{19}$, légèrement postérieure à IV, 1. L'Hospital commence par y évoquer assez longuement la prise de Calais et Guînes par les Français en janvier 1558 , pour passer à des réflexions morales sur l'horreur que constitue la destruction des villes conquises, ainsi que sur le rôle de Dieu, qui a assisté le roi et le duc de Guise dans leurs entreprises. Ces réflexions morales et religieuses font place, dans les derniers vers, à une exhortation à l'humilité, qui est désignée comme un chemin conduisant au ciel.

Nos hanc gloriolam potius laudemque sinamus

Invicto fortique Deo, turgentia Regum

Colla superborum qui proterit, et pede calcat;

Subiectos humilesque ${ }^{20}$, ipsique accepta ferenteis

Omnia, tollit humo supera ad convexa polorum;

Qui nos successu nimio rebusque secundis

Inflatos ideo castigat more paterno,

Casibus exercens variis, ne nostra putemus

Quae nos ille frui secura mente sinebat,

Ut rerum et columen nostrarum, spemque salutis,

Privati, Regesque, Deo ponamus in uno,

Nec fracti nimium, dura cum sorte gravamur,

Nec rursum elati, veniunt cum prospera nobis ${ }^{21}$.

19 Pour une analyse et un commentaire, voir L'Hospital, Carmina, t. IV, p. 52-64.

20 Cf. la prière du Magnificat dans Lc 1, 51-52: «Fecit potentiam in brachio suo: dispersit superbos mente cordis sui. Deposuit potentes de sede, et exaltavit humiles ».

21 L'Hospital, Carmina, IV, 2, 108-120. 
Cette gloriole et cet honneur, nous, accordons-les plutôt

$\mathrm{Au}$ Dieu invincible et puissant, qui écrase la nuque

Enflée de vanité des rois superbes et la foule au pied;

Les soumis et les humbles, et ceux qui lui offrent tout ce qu'ils ont reçu

De lui, il les élève de terre vers la voûte altière du ciel ;

Lui qui, lorsqu'un succès démesuré et des circonstances favorables

Nous gonflent d'orgueil, nous châtie à la manière d'un père,

Nous mettant à l'épreuve par divers malheurs, pour que nous ne

[croyions pas nôtre

Ce dont il nous permettait de profiter l'esprit tranquille,

Afin que l'appui de notre vie et l'espoir du salut,

Que nous soyons simples citoyens ou rois, nous les placions en Dieu [seul,

Sans être par trop brisés quand un sort cruel nous accable,

Et sans redevenir fiers lorsque la prospérité nous échoit.

Dieu écrase les superbes et conduit les humbles au ciel (v. 109112). Ici aussi, L'Hospital, qui fait écho au Magnificat, où Marie affirme que Dieu "renverse les superbes et élève les humbles", passe d'un sermo moral sur la bonne manière de faire la guerre à un sermon sur la nécessité de mettre tout espoir de salut dans les mains de Dieu, de lui rendre gloire et d'être humble, l'humilité étant donc la porte d'entrée du ciel, des supera [...] convexa polorum ${ }^{22}$.

Dans cette épître, L'Hospital se distingue des autres poètes, tel Dorat ${ }^{23}$, ayant chanté les deux victoires françaises de Calais et de Guînes, en ce qu'il ne se limite pas, comme eux, à décrire les faits et à louer les grands hommes : il se sert des événements pour en tirer des leçons morales et pour inciter le lecteur à confier sa vie à Dieu plutôt qu'aux armes ou aux hommes. Il confère ainsi à son œuvre une grandeur morale peu commune.

22 L'Hospital désigne le ciel en employant un vocabulaire emprunté à l'Antiquité classique; voir aussi infra, n. 28, à propos de IV, 5, 45 et 49, ainsi que, par exemple, I, 6, 100: "aethereas sedes »; IV, 5, 49: "Et clarum feries sublimi vertice caelum »; IX, 33, 11 (cité infra, n. 45). Cette présence des modèles païens est habituelle dans l'évocation des réalités célestes chez L'Hospital tout comme chez les autres poètes de l'époque.

23 Odes, 12, 13 et 14 (Jean Dorat, Les Odes latines, éd. G. Demerson, ClermontFerrand, FLSH, 1979). 


\section{D'UNE VISITE PASTORALE AU CIEL : L'ÉPÎTRE IV, 5}

En IV, 524, qui date probablement de l'année 1556, après avoir évoqué les circonstances qui ont motivé l'épître (il souhaite que le cardinal revienne rapidement de Rome), L'Hospital passe à une réflexion, qui est en même temps un éloge de Charles, sur l'art de vivre des lettrés : le prélat s'entoure de gens cultivés, il lit aussi bien les auteurs antiques que les auteurs modernes. Le poète parle ensuite de la lecture chrétienne: Dieu éclaire l'esprit des hommes qui étudient les textes sacrés, pour peu qu'ils fassent preuve $\mathrm{d}^{\prime}$ humilité ${ }^{25}$. À son tour, cette réflexion sur la lecture chrétienne fait place à des considérations sur le salut de l'homme et sur le ciel qui lui est promis:

Conandum potius dextris et remige multo,

Orandumque etiam tensis ad sidera palmis, Ut Deus errores hominum miseratus ab alto, Signet iter rectum, surdis expurget ut aurem, Ut caecis oculos ${ }^{26}$, positam quo cernere metam Possint et Domini vocem exaudire loquentis, Promissa tandemque potiri sede beatis ${ }^{27}$.

Il faut plutôt travailler à force de mains et de rames,

Et aussi prier, les mains tendues vers les étoiles,

Que Dieu, du ciel, prenne en pitié les errances des hommes,

Indique le droit chemin, purifie l'oreille des sourds,

Les yeux des aveugles, pour qu'ils puissent voir le terme

Fixé et écouter la voix du Seigneur qui parle,

Et enfin posséder le séjour promis aux bienheureux.

Il s'agit, ici aussi, d'un véritable programme de vie chrétienne: l'homme doit faire des efforts pour être bon, il doit prier - L'Hospital soulignant la double exigence évangélique d'action (les

24 Pour une analyse et un commentaire complets de cette épître, voir Michel de L'Hospital, Carmina, t. IV, p. 104-110.

25 En III, 12, L'Hospital affirme que les âmes formées aux Saintes Écritures peuvent déjouer les pièges de l'immoralité: "Has devota Deo librisque exercita sacris / Insidias bona mens rapidis praetervolat alis » (III, 12, 66-67).

26 Cf. notamment Mt 11, 5; Mc 7, 31-37.

27 L'Hospital, Carmina, IV, 5, 39-45. 
œuvres) et d'intériorité (la foi) -, et le Dieu qui ouvre les yeux des aveugles le conduira au ciel. Il conclut:

Quae si pressa teres hominum vestigia paucis,

Ne dubita: maior veniet tibi gloria Cattis,

Maior et Ambrosiis, maior scriptoribus Afris,

Et clarum feries sublimi vertice caelum ${ }^{28}$.

Non exhausta Dei manus est, et qui dedit istis,

Vel tibi vel maiora potest dare, cum volet, illi ${ }^{29}$.

Si tu foules les traces laissées par un petit nombre d'hommes,

Ne doute pas: tu obtiendras une gloire plus grande que les Cattus,

Plus grande que les Ambroise, plus grande que les écrivains africains,

Et tu atteindras le ciel brillant à la voûte sublime.

La main de Dieu n'est pas épuisée, et lui qui a donné à ceux-là

Peut donner davantage, s'il le veut, à toi ou à un autre.

L'Hospital, qui semblait jusque-là destiner son discours moral au lecteur en général, s'adresse directement au cardinal, afin de lui faire comprendre qu'il est lui aussi concerné par ce sermon, ou même que c'est à lui qu'il est d'abord destiné. Il l'exhorte ainsi à s'efforcer de suivre les traces d'Ambroise, des pères africains (on peut penser à Tertullien, Cyprien, Lactance et Augustin) et de Jean Catti, qui fut l'aumônier de Marguerite de France ${ }^{30}$ : c'est en les imitant qu'il pourra gagner le ciel.

On se trouve devant un paradoxe: L'Hospital, un laïc, "sermonne» Charles de Guise, un ecclésiastique, un prêtre, un évêque! Or, cette liberté de ton, qu'autorise le genre du sermo et que l'on retrouve chez Horace, est fréquente chez L'Hospital, qui n'hésite pas à inverser les relations de pouvoir pour s'adresser, en véritable monitor, conseiller ou donneur de leçons, à de grands personnages de l'Église, comme Charles de Guise ${ }^{31}$ ou Jean Du

28 La clausule vertice caelum du v. 49 est virgilienne (Virgile, Aen., I, 225); de même, au v. 45, l'expression sede beatis fait écho à Virgile, Aen, VI, 639: «sedesque beatas». Sur le vocabulaire païen employé par L'Hospital pour désigner le ciel, voir supra n. 22.

29 L'Hospital, Carmina, IV, 5, 46-51.

30 Sur ce personnage, décédé en 1553, voir L'Hospital, Carmina, t. II, p. 282 ainsi qu'infra, p. 90.

31 Voir notamment les épîtres II, 1 ; III, 12 ; V, 4 ; VI, 3. 
Bellay $^{32}$, mais aussi au roi lui-même ${ }^{33}$. Le bon «prédicateur» se doit de réveiller la conscience de chaque individu, quel que soit son rang.

\section{LE CIEL : LE BUT DE LA VIE}

Dans les trois derniers passages étudiés, le ciel est au centre de la réflexion de L'Hospital, et le sommet de cette réflexion est l'espérance du ciel. On pourrait multiplier les exemples. En effet, pas moins de dix épîtres s'achèvent sur l'évocation du ciel présenté comme l'aboutissement de la vie chrétienne ${ }^{34}$. En outre, dans une douzaine de pièces au moins, il est question du ciel ou des autres fins dernières (le jugement, l'apocalypse et l'enfer) non plus dans la conclusion, mais dans le corps du texte ${ }^{35}$. Ces références à la vie éternelle, que l'on trouve dès les années $1540^{36}$, déjà nombreuses dans les années 1550, sont très abondantes dans les dernières années de sa vie.

L'évocation du ciel manifeste ainsi fortement le christianisme de Michel de L'Hospital. En parlant du ciel, il va au cœur du message chrétien. Il ne se contente pas d'élever à un niveau chrétien un sermon moral sur la guerre et sur la cupidité, par exemple, en rappelant que le Christ a prêché la fraternité, le partage des biens et la justice. Tout cela: vivre en frères, partager ses biens, être juste, est une doctrine qui n'est pas exclusivement chrétienne, puisqu'on la trouve notamment dans la philosophie grecque, dans le stoïcisme par exemple. La spécificité du christianisme est d'être une religion d'une personne, le Christ, que l'on doit s'efforcer de

32 Voir notamment les épîtres I, 1 ; I, 8 ; I, 10 ; III, 7.

33 Voir par exemple III, 2, 66-68 ; V, 8 (Discours du sacre de François II), véritable institution du prince chrétien; IX, 30, 53-63 ; IX, 46, 23-29.

34 I, 6, 99-107 (voir aussi le v. 34, ainsi que les v. 85-91 sur le jugement dernier) ; I, 10, 170-178 ; II, 15 (voir infra, p. 91) ; IV, 1 (voir supra, p. 84) ; IV, 2 (voir supra, p. 85); IV, 5; VI, 9; VI, 12; VI, 13 ; VII, 7.

35 Cf. II, 1 (voir infra, p. 92) ; III, 1, 23-28; IV, 8, 465-471; V, 8, 39-49 et 322-323 ; VI, 1, 40-42 et 116-122 ; VI, 3, 153-160 ; VI, 4, 128-133 ; VII, 5, 138-160 ; IX, 31, 78-80 ; IX, 33, 11, 15-16 et 34; IX, 56.

36 Ainsi, l'épître I, 6, mentionnée, supra, n. 34, date de 1546 (cf. Carmina, t. I, p. 168). 
rejoindre, à la mort, au ciel. L'Hospital dépasse ainsi la simple morale christianisée: il ne veut pas seulement transmettre des préceptes moraux, mais surtout rappeler que le ciel est le but de la vie humaine ${ }^{37}$.

Les deux exemples suivants révèlent une caractéristique supplémentaire de ce sermon chrétien prononcé par un sacerdos laïque, si nous osons l'expression: comme tout sacerdos, le poète qui délivre un message chrétien doit s'appliquer à lui-même ce qu'il prêche.

\section{DE LA MORT AU CIEL, L'EXEMPLE DE CATUS... ET DE L'HOSPITAL: L'ÉPÎTRE II, 15}

L'épître II, $15^{38}$ est adressée à Marguerite de France à l'occasion de la mort de son confesseur, Jean Catti ${ }^{39}$, en 1553. Il s'agit d'une epistula consolatoria destinée à atténuer le chagrin de la princesse. C'est en même temps un discours épidictique exaltant la vertu de Catti et louant la sage Marguerite, qui est la seule à se livrer à une lamentatio juste et honorable, puisqu'elle pleure la vertu du mort, non la perte des bienfaits ou des avantages que celui-ci aurait pu lui apporter. C'est enfin une satire des ambitieux et des égoïstes qui, plutôt que d'aspirer à la vertu, cherchent à obtenir des faveurs.

L'Hospital part ainsi d'une circonstance, la mort du confesseur de Marguerite, pour se livrer à une causerie polymorphe sur la vertu de Catti et de la princesse, sur les vices des flatteurs, sur la bonne façon de pleurer les morts, pour s'élever finalement à un sermon dont l'enseignement principal est que la pratique de la vertu conduit au ciel (le ciel étant par ailleurs ce qui constitue la véritable et seule vraie consolation). Voici les derniers vers du poème:

37 Voir par exemple les épîtres VI, 12 et VI, 13, où L'Hospital, déjà vieux, affirme n'avoir plus d'autre attente que celle du ciel.

38 Pour une analyse et un commentaire complets de cette épître, voir L'Hospital, Carmina, t. II, p. 278-287.

39 Sur ce personnage, voir supra, n. 30. 
Pone tuas, virgo, lacrymas, suspiria tolle.

Non mors atra Catum, non impia Parca peremit.

Vivit adhuc vivetque aeternum, et, nubibus ipsis

Altior, in caelo meliores transigit annos.

Quo, Pater, o utinam tua per vestigia cursum

Dirigere, atque iisdem liceat considere tectis! ${ }^{40}$

Cesse de pleurer, vierge, mets fin à tes soupirs!

La noire mort, la Parque impie n'a pas fait périr Catus.

Il vit encore et il vivra éternellement et, plus haut que les nuages

Eux-mêmes, au ciel il connaît des années meilleures.

Père, qu'il nous soit permis, en marchant sur tes pas,

$\mathrm{D}^{\prime} \mathrm{y}$ diriger notre course et de nous établir sous le même toit!

Le ciel est le point culminant de la pièce, mais aussi celui de la vie de l'homme: c'est la consolation évangélique, qui est foi dans la vie éternelle.

Plus encore enfin, dans les deux derniers vers, L'Hospital, utilisant le pronom «nous", se met lui-même en scène et s'adresse à Dieu pour lui demander d'avoir la grâce d'aller lui aussi au Ciel : c'est l'humble èthos du poète qui, en même temps qu'il est appelé à indiquer la bonne voie à ses lecteurs, se présente comme un petit ayant besoin de l'aide de Dieu.

\section{L'HOSPITAL DONNE L'EXEMPLE DE SA MALADIE: L'ÉPÎTRE II, 1}

Dans l'épître II, $1^{41}$, datée de 1552, L'Hospital ne se contente pas de s'inclure parmi les destinataires du sermon, mais se présente comme ayant lui-même besoin d'un examen de conscience.

Partant d'un événement précis, la maladie du cardinal de Lorraine, il aboutit à une réflexion générale, et même, sans doute sur le modèle du livre de Job (d'ailleurs mentionné dans l'épître) ${ }^{42}$, à une véritable méditation philosophico-religieuse sur le sens de la souffrance et sur

\footnotetext{
40 L'Hospital, Carmina, II, 15, 49-54.

41 Pour une analyse et un commentaire complets de cette épître, voir Michel de L'Hospital, Carmina, t. II, p. 15-37.

42 Aux v. 151-160.
} 
l'utilité morale de la maladie ${ }^{43}$. Mais surtout, aux v. 97-106, au cœur de l'épître, L'Hospital se donne en exemple en évoquant sa propre maladie $^{44}$, qui l'a poussé naguère à faire un examen de conscience dans le but d'amender sa conduite et de gagner lui-même le ciel ${ }^{45}$.

Expertus moneo didici quae non ita pridem,

Cum multo fluerent ruptae mihi sanguine venae,

Ac me dira sitis premeretque intercutis undae

Et metus, et praesens, obstent nisi fata, periclum.

Quas ego non aras, quae non delubra deorum

Tum supplex adii, quibus hoc non denique votis

Damnavi funebre caput? Cumque ante pigeret

Actorum, in melius mores mutare parabam,

Expendens mecum factum hoc bene, at hoc male factum.

Sic facies melius, sic te coelestibus addes ${ }^{46}$.

Je parle d'expérience, de ce que j'ai appris il n'y a pas si longtemps: Mes veines se rompirent, ce qui provoqua un grand écoulement de [sang,

Et une soif implacable m'accabla, ainsi que la crainte de souffrir de

Et le risque de mourir, si les destins ne s'y opposaient;

[rétention d'eau

Vers combien d'autels, vers combien de sanctuaires des dieux

Ne me suis-je pas tourné en suppliant, à quels vœux enfin

N'ai-je pas voué ma tête proche du trépas? J'avais honte de mes

Actes, je me disposais alors à améliorer ma conduite,

Réfléchissant en moi-même: j'ai bien fait ceci; cela, je l'ai mal fait.

Ainsi, tu agiras mieux; ainsi, tu rejoindras les habitants du ciel.

Le sermon chrétien aboutit ainsi à un encouragement au lecteur à pratiquer, suivant l'exemple du poète lui-même, l'examen de conscience, nécessaire à quiconque désire entrer dans la vie éter-

43 Ce principe de l'utilité morale d'un soi-disant mal est appliqué aux guerres en II, 12 ; IV, 1, 71-130; V, 5, 155-136.

44 L'Hospital décrit aussi sa maladie en I, 2, 50-80.

45 Voir aussi IX, 33, 7-11, où L'Hospital, s'adressant à Charles IX, malade, lui affirme que la maladie est un bienfait de Dieu qui forge l'homme et peut le conduire au ciel: "Quanto nos melius, qui febrem atque omnia caelo / Morborum genera in terras demissa putamus / Vi non illa sua, sed missu numinis aequi, / Ut tandem coeno mersas et pulvere mentes / Ad superos tollamus, et atria lucida caeli ».

46 L'Hospital, Carmina, II, 1, 97-106, t. II, p. 18-21. 
nelle, dans la droite tradition d'un érasmisme inspiré par la devotio moderna.

\section{VIR PIUS DICENDI PERITUS : L'ÈTHOS «SACERDOTAL » DE MICHEL DE L'HOSPITAL}

Qu'attend-on d'un prédicateur? Qu'il connaisse parfaitement la doctrine qu'il prêche. Ensuite, qu'il maîtrise les outils rhétoriques permettant de convaincre l'auditoire. Mais peut-être surtout qu'il soit convaincu de ce qu'il prêche et, mieux encore, qu'il le vive: «ils disent et ne font pas ${ }^{47}$ est le pire reproche que l'on puisse adresser aux prédicateurs ou, en général, à tous les donneurs de leçon.

L'on reconnaît là une rhétorique: le prédicateur doit incarner ce qu'il enseigne, èthos interne et èthos externe doivent se superposer. Cette idée est très présente chez Érasme, notamment dans son œuvre presqu'ultime qu'est l'Ecclesiastes : «le prédicateur doit être lui-même ce qu'il prêche», comme l'affirme Jacques Chomarat ${ }^{48}$. Dans son Apologia ad Latomum, Érasme donne d'ailleurs la définition suivante du théologien idéal: Theologus est vir pius, de divinis loquendi dicendi peritus ${ }^{49}$, "le théologien est un homme pieux, habile à parler des sujets sacrés ». Le prédicateur lui aussi se doit donc d'être non seulement un vir bonus dicendi peritus, comme le demandaient notamment Caton et Quintilien ${ }^{50}$, mais aussi un vir pius dicendi peritus.

47 Voir Mt 23, 3 ainsi que Rm 2, 21.

48 J. Chomarat, Grammaire et rhétorique chez Érasme, Paris, Les Belles Lettres, 1981, t. II, p. 1103; sur la question du vir pius dicendi peritus (cf. infra), voir id., p. 1103-1107, dans le chapitre consacré à l'Ecclesiastes. Voir aussi M. Fumaroli, L'Âge de l'éloquence. Rhétorique et "res literaria» de la Renaissance au seuil de l'époque classique, Genève, Droz, 2009, p. 107 ; C. Béné, Érasme et saint Augustin ou influence de saint Augustin sur l'humanisme d'Érasme, Genève, Droz, 1969, p. 323-324.

49 Apologia ad Latomum, I, 42, LB IX 90 A : "Quod si probatur a rhetoribus definitio: "Orator vir bonus est dicendi peritus", cur nobis displiceat haec: "Theologus est vir pius de divinis loquendi peritus", et: "Theologia est pietas cum ratione de divinis rebus loquendi coniuncta" ?».

50 Quintilien, Inst., XII, 1, 1: "Sit ergo nobis orator, quem constituimus et qui a M. Catone finitur: "vir bonus dicendi peritus"». 
Ainsi, lorsqu'il exhorte le lecteur à l'ascension morale, Michel de L'Hospital montre qu'il met lui-même en pratique ce qu'il prêche ou qu'il se l'applique à lui-même. Ce faisant, il adopte l'èthos du vates sacerdos qui, bien qu'appelé à indiquer la bonne voie à ses lecteurs, dans une sorte de "pastorale chrétienne » ${ }^{51}$, se présente comme un homme comme les autres ayant lui aussi besoin de conversion et de l'aide de Dieu pour arriver au ciel. Il s'inscrit de la sorte dans une tendance que Perrine Galand a relevée chez les auteurs néo-latins français comme Macrin: celle de se décrire comme un humble parmi les humbles, un pauvre parmi les pauvres $^{52}$.

Cet èthos, cependant, n'est pas une simple posture adoptée par le poète pour se justifier ou pour donner à la postérité une image positive de lui-même ${ }^{53}$, ce dont on peut toujours soupçonner l'écrivain qui, comme L'Hospital, se met en scène. Ses contemporains et les siècles suivants ne s'y sont pas trompés: il y a chez lui une véritable cohérence entre parole et action, entre sermo et action, entre «sermon » et action. Et c'est peut-être cette cohérence qui fait de ses exhortations chrétiennes ce que nous avons appelé, un peu audacieusement, des sermons laïques; c'est peut-être elle qui donne tant de force et d'actualité à ses épîtres.

David AMHERDT Universités de Neuchâtel et Fribourg

51 Voir Crouzet, La Sagesse et le malheur, p. 564; dans sa conclusion, p. 576, Crouzet affirme que L'Hospital se fait «la voix de Dieu», «le messager de Dieu», ou encore «le traducteur de Dieu».

52 P. Galand, «Quelques orientations spécifiques du lyrisme néo-latin en France au XVI ${ }^{\mathrm{e}}$ siècle», dans Acta Conventus Neo-Latini Bonnensis: Proceedings of the Twelfth International Congress of Neo-Latin Studies (Bonn, 3-9 August 2003), Tempe, Arizona Center for Medieval and Renaissance Studies, 2006, p. 27-48, ici p. 30.

53 Cette mise en scène de soi est fréquente, et elle apparaît surtout dans les pièces datant de la guerre civile ou de sa disgrâce, où l'on sent L'Hospital marqué par l'épreuve, déjà âgé, n'aspirant plus qu'à l'otium, et en particulier à l'otium définitif du ciel. Deux exemples suffiront: dans les lettres VI, 12 et VI, 13 (déjà citées supra, n. 34 et 37), L'Hospital se présente lui-même comme un personnage déjà âgé qui doit se préparer au grand voyage, chercher le chemin du ciel, où il devra rendre compte à Dieu de ses actes, mais où, surtout, il vivra pour l'éternité. 


\section{MICHEL DE L'HOSPITAL, LES SOLIDARITÉS TOULOUSAINES ET LE MODÈLE DU SERMO HORATIEN : MODÈLE SATIRIQUE/ MODĖLE PHILOSOPHIQUE}

Si Michel de L'Hospital, jeune étudiant en droit, connut d'emblée à Toulouse les rigueurs de l'injustice et de la prison puisqu'il y fut emprisonné puis relâché ${ }^{\text {à }} 18$ ans en 1523, il y noua aussi de solides amitiés qui constituèrent jusqu'à la fin de sa vie ses liens les plus solides et les plus sûrs, de son alter ego Jacques Du Faur au neveu de ce dernier, Guy Du Faur de Pibrac, sans oublier Arnaud Du Ferrier. Nous commencerons par nous intéresser au témoignage d'un de ses premiers condisciples et professeurs, Boyssoné, avant de revenir à ce cercle toulousain dans son ensemble.

Jean de Boyssoné (1500-1558), quasi contemporain de L'Hospital (1506-1573), est un juriste toulousain, selon le titre qu'il se décerne lui-même dans ses ouvrages, qui a laissé trois manuscrits, en partie autographes, conservés à la Bibliothèque municipale de Toulouse: un recueil de poésie française (le ms. 836), un recueil d'épîtres en prose latine, qui devrait bientôt paraître sous la direction de M. Magnien chez Droz (le ms. 834) et un recueil de poésies latines qui nous intéressera aujourd'hui pour ses liens avec le recueil d'épîtres de Michel de L'Hospital (le ms. 835)². Ce manu-

1 Voir DL, t. I, p. 70 et 304-311, ainsi que Petris, La Plume et la tribune, p. 4.

2 Le lecteur trouvera numérisés en mode image et en cours de transcription et traduction ces trois manuscrits sur le site Bibliotheca-tholosana.fr. L'ensemble des épîtres en vers du ms. 835 y est transcrit par David Fabié et traduit par Bérengère Basset. H. Jacoubet a donné une description complète des ms. 834 et 835 (Les poésies latines de Jehan de Boyssoné résumées et annotées par Henri Jacoubet, 
scrit renferme un livre d'hendécasyllabes, un d'élégies, six odes et des iambes, mais aussi un livre de vingt et une épîtres en vers de facture horatienne, adressées, notamment pendant son procès avec Julien Tabouet (1553-1554), à tout ce que le monde de la justice et de la cour compte d'appuis et en particulier à Michel de L'Hospital, qu'il connaît depuis ses débuts d'étudiant puis de professeur de droit civil à Toulouse ${ }^{3}$. Boyssoné, né en 1500, six ans avant L'Hospital, le devança de peu en effet dans la carrière juridique et est un des membres de ce sodalitium toulousain puis padouan, de ce cercle méridional auquel L'Hospital resta fidèle.

Citons Richard de Boysson, descendant et biographe du juriste toulousain: "Pendant que Jehan de Boysson faisait ses études de droit, de 1520 à 1525 [...] parmi ses condisciples, plusieurs resteront ses amis fidèles et s'attacheront fortement, comme lui, à la culture incessante des Belles Lettres, tels que Michel de l'Hôpital, Arnaud du Ferrier', Jacques du Faur's, Pierre

Toulouse, E. Privat, 1931) et une édition critique du ms. 836: Les trois Centuries de Maistre Jehan de Boyssoné, docteur régent à Tholoze, Toulouse, Privat, 1923.

3 Sur la vie de Boyssoné voir notamment H. Jacoubet, J. de Boyssoné et son temps, Toulouse, 1930 et F. Mugnier, La vie et les poésies de Jean de Boyssoné, professeur de droit à Toulouse et à Grenoble, conseiller au parlement de Chambéry, Paris, 1897 ; Genève, Slatkine Reprints, 1971.

4 Contemporain de Michel de L'Hospital, né vers 1508, il suit des études de droit à Toulouse puis à Padoue (dont il est diplômé en 1533), revient enseigner à Toulouse (il obtient une chaire de droit civil en 1537) où il est le professeur de Cujas et de Forcadel, qui lui rendirent tous deux hommage, ce dernier lui dédicaçant le Penus juris civilis en 1549, et Cujas le célébrant en ces termes dans son discours de réception à l'université de Bourges : «quo fere nemo erat illo tempore in schola Tholosana nec non in orbe quidem peritior» (cité par DL, t. I, p. 334). Du Ferrier devient conseiller au parlement de Paris en 1552 puis en 1557 président de la chambre des enquêtes. Il suit parallèlement une carrière diplomatique à partir de 1562 où il est ambassadeur au concile de Trente, il est ensuite ambassadeur à Venise. Voir E. Frémy, Un Ambassadeur libéral sous Charles IX et Henri III. Ambassades à Venise d'Arnaud du Ferrier d'après sa correspondance inédite, 1563-1567, 1570-1582, Paris, 1880. Voir aussi les notices d'A. Bettoni dans le Dictionnaire des Écrivains juristes et juristes écrivains, Paris, 2015, p. 382-387 et de H. Gilles dans le Dictionnaire historique des Juristes, Paris, PUF, 2007, p. 270. L'ensemble de sa carrière le lie à Michel de L'Hospital, qui le protégea après la Mercuriale et persuada Catherine de Médicis, selon Frémy, Un Ambassadeur libéral, op. cit., p. iii, de l'envoyer au concile de Trente avec Pibrac. La correspondance de Boyssoné comporte de nombreux échanges avec Du Ferrier entre 1533 et 1538 (voir notre appendice 1).

5 Jacques Du Faur (1511-1571) reste le grand ami de L'Hospital tout au long de sa vie. Abbé de la Case-Dieu (1533), il devint vicaire général du cardinal de 
Bunel $^{6}$ et Jean Daffis ${ }^{7} »^{8}$. Robert de Boysson aurait pu ajouter Georges d'Armagnac, né comme Boyssoné en 1500, qui «a travaillé », comme lui, «entre 1518 et 1522 sous l'autorité de Jean Boyssoné dit le Borgne ${ }^{9}{ }^{4}$, l'oncle de notre Boyssoné, qui lui succèda dans sa chaire ${ }^{10}$ comme Jean de Boyssoné le rappelle luimême dans l'épître qu'il adresse à Martin de La Haye pour le remercier de lui avoir fait parvenir l'épître que L'Hospital avait

Gramont puis d'Odet de Châtillon et réforma le collège de l'Esquille. Conseiller au parlement de Toulouse (1536), conseiller-clerc en 1537, député aux États du Languedoc en 1539, puis conseiller au Grand Conseil (1540), il fut nommé président en la première Chambre des enquêtes (1545) puis maître des requêtes (1558). Boyssoné le connaît bien et lui rappelle dans une épître du ms. 834 de 1533, fol. $29 v^{\circ}$, leurs années italiennes. Cf. lettre de 1548, ibid. fol. 43 et les trois dizains des Centuries (Toulouse, Bibl. mun., ms. 836), fol. 19ro $\mathrm{r}^{\circ}$ 20v et $30 \mathrm{r}^{\mathrm{O}}$ adressés « $\mathrm{A} \mathrm{M}^{\mathrm{r}}$ le maistre des requestes Fabri » (voir notre appendice 1). Sur les Du Faur, voir la notice de DL, t. I, p. 341-351. Sur Guy Du Faur, protégé de L'Hospital, neveu du précédent, qui participa à la réunion des Carmina, voir l'introduction à l'édition des Quatrains par L. Petris, Genève, Droz, 2004.

6 Sur Pierre Bunel, voir la thèse d'A. Samouillan, De Petro Bunello Tolosano ejusque amicis, Paris, 1891 et M. Magnien, «Les milieux humanistes toulousains à travers la correspondance de Pierre Bunel (1500-1547) », dans L'Humanisme à Toulouse, éd. N. Dauvois, Paris, Champion, 2006, p. 247-269. Voir en particulier la précieuse annexe-inventaire de la correspondance, p. 266-269, notamment pour les lettres à Jacques Du Faur (datées de 1541 à 1547) et à Arnaud Du Ferrier. Il fut le précepteur de Guy Du Faur de Pibrac.

7 R. de Boysson, Un humaniste toulousain, Jehan de Boysson (1505-1559), Paris, 1913, p. 36: "Jacques du Faur resta fidèle à Rome comme au roi ; moins fidèle à sa province, puisqu'il passa les vingt-cinq dernières années de sa vie soit au parlement de Paris, soit au Grand Conseil. Seul, entre les six amis de Toulouse, Daffis conserva jusqu'à sa mort le culte de son pays natal». Jean Daffis, docteur régent en droit, fut conseiller au Parlement de Toulouse, puis premier président en 1562. Il se montra, à cette occasion, impitoyable envers les protestants. Voir à propos de la lettre qu'il adresse à Boyssoné (ms. 834, fol. $2 \mathrm{v}^{\mathrm{o}}$ ), la brève présentation de sa carrière brossée par J.-C. Margolin, «Le cercle de Jean de Boyssoné », dans L'Humanisme à Toulouse, op. cit., p. 236-237.

8 R. de Boysson, Un humaniste toulousain, op. cit., p. 34. Cf. É. Picot, Les Italiens en France au XVI eiècle, Rome, Vecchiarelli, 1995, p. 284.

9 Nous citons ici N. Lemaître dans son article «Le cardinal d'Armagnac et les humanistes des petites villes du midi», dans L'Humanisme à Toulouse, op. cit., p. 206, qui montre l'importance de ces solidarités méridionales dans la vie et la carrière du cardinal. On peut en dire en partie autant de L'Hospital.

10 En 1524 ou 1525 comme le rappelle H. Gilles, Université de Toulouse et Enseignement du droit, Paris-Toulouse, 1992, p. 120-123. Voir aussi son article «La nomination des régents à la faculté de droit de Toulouse au $16^{\mathrm{e}}$ s.», dans L'Humanisme à Toulouse, op. cit., p. 59-68. 
adressée à Adrien Du Drac pour lui décrire son voyage à Bologne ${ }^{11}$. Jean de Boyssoné précise dans cette épître qu'il connaît Michel de L'Hospital depuis longtemps, depuis l'époque où ce dernier vint étudier le droit à Toulouse: illum / Jampridem nosco, cum discit Jura Tolosae (v. 9-10). Et que L'Hospital fut son auditeur au tout début de sa carrière, quand il commençait à enseigner le droit, à la suite de son oncle:

\section{Urbe Tolosana civilia jura docentem}

Me audieverat, cathedram tum cum moderarer avitam (v. 22-23) ${ }^{12}$

Ce groupe formé à Toulouse s'était retrouvé à Padoue, autour de Lazare de Baïf, alors ambassadeur à Venise. Ainsi se nouèrent des liens durables du cercle toulousain au cercle padouan dont se font l'écho les correspondances et notamment celle de Pierre Bunel ${ }^{13}$. Les épîtres en prose de Boyssoné sont en effet adressées à des destinataires qui sont pour la plupart ceux des Carmina de L'Hospital. Écrites à Jacques Du Faur ou Arnaud Du Ferrier aussi bien qu'au cardinal d'Armagnac ${ }^{14}$, à Bunel ou Coras, elles leur rappellent le plus souvent ces liens d'abord méridionaux. Boyssoné y mentionne à plusieurs reprises L'Hospital, notamment dans une lettre à Guillaume Scève où il fait son portrait en homme d'une intelligence égale à son érudition et à sa constance et en lettré depuis son jeune âge "qui non solum a studiis humanitatis nulla aetate abhorruit, sed etiam illis apprime semper est delectatus ${ }^{15}$ (qui non seulement ne se détourna jamais du culte des Belles Lettres, mais y trouva même toujours un charme particulier) ${ }^{16}$. Boyssoné n'adresse aucune lettre en prose à L'Hospital lui-même mais seulement une épître en vers comme pour mieux souligner le lien de ce

\footnotetext{
11 Il s'agit de l'épître I, 4 des Carmina (t. I, p. 368-376).

12 Texte édité et traduit par P. Galand et L. Petris en annexe de leur édition des Carmina (p. 369-372). Sur l'ensemble de cette lettre, voir infra.

13 Voir notamment dans les Petri Bunelli familiares aliquot epistolae, Paris, Ch. Estienne, 1551, les lettres à Jacques Du Faur p. 89-91, 102-103 et à Arnaud Du Ferrier p. 106-109.

14 Voir notre appendice 1. Nous renvoyons au site Bibliotheca-tholosana.fr pour l'ensemble de ces textes.

15 Toulouse, Bibl. mun., ms. 834, fol. $88 \mathrm{r}^{\mathrm{O}}-89 \mathrm{v}^{\mathrm{o}}$ qui date probablement de 1546. Cf. fol. 233-4 où il se recommande de L'Hospital.

16 Sauf indication contraire, nous traduisons.
} 
genre horatien à son nom, à sa personne, à son œuvre. Si les épîtres en prose de Bunel ${ }^{17}$, de Du Ferrier ou de Boyssoné sont l'occasion pour les Toulousains de faire l'éloge d'une bonne latinité, et particulièrement $d$ 'une belle écriture cicéronienne, insuffisamment cultivée dans la barbare Toulouse ${ }^{18}$, l'épître en vers à la manière d'Horace, telle que très tôt L'Hospital la cultiva, offre en effet à Boyssoné l'occasion d'en penser le modèle. Ce choix entre écriture en vers et écriture en prose est un des enjeux de ces échanges entre amis, déterminant parfois leur modalité même. Si du moins l'on en croit notre juriste toulousain qui, non content de faire l'éloge de l'écriture des sermones de L'Hospital dans ses propres épîtres en vers, ou de féliciter Guillaume de La Perrière dans une de ses élégies d'être revenu de l'écriture de vers français à l'écriture de vers latins (sans doute dans sa Morosophie) ${ }^{19}$, conseille à Arnaud Du Ferrier, dans une élégie de ses poésies latines, de s'essayer à l'écriture en vers, sans opposer utile et dulce, doctrine, savoir et poésie:

Ad Ferrerium ut versus discat componere Scribere quod versus moneo, tibi forte videtur Ridiculum, si quis doctior esse velit.

Nec numeris linguam tu credis posse parari.

17 Donné par Henri Estienne dans son épître au lecteur comme modèle du genre dans les Petri Bunelli, Galli praeceptoris et Pauli Manutii Itali discipuli, Epistolae Ciceroniano stylo scriptae [...], [Paris, Henri II Estienne], 1581, car il sut non seulement incarner en France la belle latinité cicéronienne mais encore en enseigner le modèle («Ad Bunellum autem ut veniam, ego non solum cadere Ciceronianitatem in Gallos quoque homines (contra quam Italus quidam scripserit) sed etiam, quod multo maius et difficilius est, facultatem ad alios ea docendi » épître au lecteur, loc. cit., $4 \mathrm{v}^{\mathrm{o}}$ ) comme l'indique d'emblée le titre du volume.

18 Voir notamment la lettre de Du Ferrier à Boyssoné, qui rapporte une de ses conversations avec Bunel à ce sujet à l'éloge de Boyssoné, ms. 834 , fol. $4 \mathrm{v}^{\circ}$, cité et traduite par M. Magnien, loc. cit., p. 249. Et cf. l'épître en vers à Visagier, ms. 835 , fol. 65 , pour la reprise de ce thème de la barbarie toulousaine qui développe l'accusation faite par Horace aux Romains (par opposition aux Grecs) de ne s'intéresser qu'à l'argent au détriment de la gloire (Ars, 323-332). Cf. ms. 335 , fol. $67 \mathrm{v}^{\mathrm{o}}$.

19 Ms. 835, fol. 43ro : Ad Guglielmum Perrerium: «Audio (quod mihi tam gratum est, ut gratius ullum / Non sit) carminibus te dare nunc operam: Non vulgaribus [...] Sed nunc das operam, ut versus sermone Latino / Scribas, imparibus carmina facta modis...» (j'entends dire (ce qui me cause le plus grand plaisir) que tu t'adonnes à l'écriture en vers: et non en vers vulgaires [...] mais que désormais tu te consacres à l'écriture de vers latins, de poèmes en mètres élégiaques). La Morosophie est publiée à Lyon, par Macé Bonhomme, en 1553. 
Si quid conducat, sermo solutus erit.

Rectius a Cicerone putas te posse doceri,

Quo nemo ingenio nec magis arte valet.

Optimus est, fateor, quis enim vult ista negare?

Ecce damus quod vis: te Cicero doceat.

Quid Cicero versus non scripsit? scripsit: at, inquis,

Est visus multis esse poeta malus.

Quid tum? num nocuit Ciceroni scribere versus?

Verbaque cum pedibus claudere saepe suis?

Profuit, et poterit nobis prodesse, sequamur

Qua Cicero voluit doctus abire via ${ }^{20}$.

À Du Ferrier pour qu'il apprenne à écrire en vers

Il te semble peut-être ridicule que j'invite à écrire en vers qui veut progresser en savoir. Et tu ne penses pas pouvoir soumettre ta langue aux contraintes du mètre. Si elle s'exprime, ce sera en prose. Tu penses avoir davantage à apprendre de Cicéron que personne ne surpassa jamais en inspiration ou en art. Il est le meilleur, je l'avoue, qui voudrait le nier? Nous te l'accordons donc: que Cicéron soit ton maître. Mais quoi! Cicéron n'a-t-il pas écrit de vers? Il en a écrit: mais, dis-tu, il n'a pas été jugé en général très bon poète. Et alors? En quoi cela lui a-t-il nui d'écrire en vers? Ou de refermer ses phrases par des clausules rythmiques? Cela lui a servi et pourra nous servir. Empruntons donc le chemin qu'a voulu emprunter le savant Cicéron.

Fervent partisan d'une belle latinité, Boyssoné semble ainsi souligner à quel point une écriture en vers latins en offre un accomplissement. Et c'est précisément ce dont les épîtres en vers de Michel de L'Hospital lui semblent offrir le meilleur exemple.

\section{L'HOSPITAL ET LE MODÈLE ÉPISTOLAIRE}

Le livre d'épîtres poétiques de Boyssoné ${ }^{21}$ s'ouvre en effet avec le nom de L'Hospital. Boyssoné écrit à Martin de La Haye afin de

\footnotetext{
20 Toulouse, Bibl. mun., ms. 835, fol. $36 \mathrm{v}^{\mathrm{o}}$.

21 Nous citons toujours le texte des épîtres transcrit par David Fabié et traduit par Bérengère Basset sur le site Bibliotheca-tholosana.fr. Cette épître à Martin de La Haye est reproduite dans DL, t. I, p. 309-311 et éditée, traduite et
} 
louer non seulement la personne mais aussi l'écriture épistolaire de Michel de L'Hospital. L'essentiel de cette épître à La Haye est consacré, nous y avons déjà fait allusion, à l'éloge d'une épître en vers adressée par le chancelier à Adrien Du Drac ${ }^{22}$ (Carmina, I, 4). Le recueil d'epistulx en vers de notre juriste toulousain comporte aussi une lettre plus tardive à Michel de L'Hospital, alors maître des requêtes, et une autre à Jacques Du Faur, le grand ami du précédent, qu'il leur adressa au moment de la révision de son procès contre Tabouet, en 1554, pour chercher leur appui ${ }^{23}$.

Cette épître en vers à Martin de La Haye qui ouvre donc la section des epistulae de Boyssoné fait non seulement l'éloge de la portée juridique et morale du portrait de Du Drac brossé par L'Hospital, mais aussi du style du chancelier. Boyssoné y définit un modèle de l'épître en vers, une épître docte ("epistula docta», v. 5) faite à la fois pour instruire (car elle loue et dicte en même temps les principes du droit, d'un droit qui préserve l'équité, comme il le souligne à la suite de L'Hospital) ${ }^{24}$, et pour plaire, en

commentée en annexe de L'Hospital, Carmina, t. I, p. 369-373. Voir pour une présentation d'ensemble et une étude de ce livre d'épîtres en vers de Jean de Boyssoné, notamment dans son rapport au modèle horatien, l'analyse de M. Magnien, «L'épître horatienne comme dérivatif et consolation: l'Epistolarum liber du juriste Jean de Boyssoné, (c. 1542-1555; Toulouse, BM, ms. 835, fol. $64 \mathrm{r}^{\mathrm{O}}-101 \mathrm{r}^{\mathrm{o}}$ )», dans Non omnis Moriar, dir. D. Coppini, M. Laureys et N. Dauvois, Hildesheim, Zürich, New York, Olms Verlag, 2019, p. 1205-1228.

22 Adrien II Du Drac, notaire et secrétaire du Roi qui fut conseiller lai à partir de 1535, voir L'Hospital, Carmina, t. I, p. 136. Cette épître qui narre les épisodes du voyage de L'Hospital pour se rendre au concile qui se tint à Bologne en 1547, a vraisemblablement été composée à l'automne de cette même année. Il est donc probable qu'elle a circulé sous forme manuscrite.

23 Sur tous ces points voir H. Jacoubet, J. de Boyssoné et son temps, op. cit., et l'efficace résumé de la carrière de Jean de Boyssoné (de Toulouse à Padoue, puis Chambéry où il devient conseiller au parlement) par J.-C. Margolin, «Le cercle de Jean de Boyssoné d'après sa correspondance et ses poèmes ", dans L'Humanisme à Toulouse, op. cit., p. 226-227. Il y revient sur les différents épisodes de l'accusation par Tabouet, alors procureur général à Chambéry, de l'emprisonnement en 1550 et de la condamnation de 1551, qui l'obligea à abandonner Chambéry pour devenir professeur à Grenoble jusqu'en 1555 où un jugement annula les décisions précédentes, lui permettant de retrouver son siège à Chambéry en 1556 .

24 Voir les v. 43-44 qui renvoient au proverbe «Summum ius, summa iniuria» (Cicéron, Off., I, 10, 33) en écho au v. 69 de l'épître I, 4 de L'Hospital. Nous renvoyons aux commentaires des éditeurs sur ce point, Carmina, t. I, p. 375. 
introduisant le récit de son voyage en Italie. Ce récit de voyage rivalise en pittoresque avec la satire $\mathrm{V}$ d'Horace mais la dépasse en pathétique par son tableau des flots déchaînés, avant de brosser le tableau encore plus pathétique de l'assassinat à Plaisance du duc de Parme, et d'aboutir aux rives du Mincio, patrie de Virgile, et à Bologne, où se tient le concile de Trente, patrie du droit, dans un retour au calme qui est aussi un retour au thème premier de l'épître. L'admiration de Boyssoné va notamment aux dons de narrateur de L'Hospital, à son aptitude à l'enargeia dans le tableau émouvant de la tempête sur le Pô et la scène frappante de la mort de Pier-Luigi Farnèse ${ }^{25}$ :

Ut navem de lyntre facit! credo Oceanum esse

Cum video Eridanum tantis fervere procellis.

Rursus cum memorat miserabile funus Aloysi,

Farneso extractum referunt quem sanguine Papae ${ }^{26}$.

Comme il transforme une barque en navire! il me semble que c'est l'Océan, quand je vois le Pô agité sous des tempêtes de cette ampleur. Puis quand il rappelle la triste mort de Louis issu, dit-on, du sang farnésien d'un pape.

Il loue aussi au passage chez L'Hospital la prudence de ce benedicere, qu'Horace prône dans son épître à Auguste (Ep., II, 1, 155) :

Multaque prudenter praetermisisse videtur
Alterutram ne in partem is declinare putetur ${ }^{27}$.

Il semble aussi avoir eu la prudence de passer sous silence bien des éléments, pour éviter que l'on ne pense qu'il penche d'un côté ou d'un autre.

L'Hospital illustre ici, selon notre juriste toulousain, mieux et plus que tout autre, à quel point est réussie et souhaitable l'alliance du droit et des Lettres:

25 Voir les commentaires de Petris, La Plume et la tribune, p. 155-156.

26 Ms. 835 , fol. $65 \mathrm{r}^{\mathrm{o}}$, v. $50-54$. Nous citons toujours, sauf mention contraire, la transcription de D. Fabié et la traduction de Bérangère Basset qui figurent sur le site Bibliotheca-tholosana.fr

27 Ibid., fol. $65 \mathrm{v}^{\mathrm{o}}$, v. 59-60. 
Hic plane, si alius quisquam, convincit eorum

Stultitiam, aiunt qui studiis contraria juris Scripta Poëtarum, divinaque carmina vatum ${ }^{28}$

Notre homme, plus que tout autre, confond la sottise de ceux qui disent que sont contraires à l'étude du droit les écrits des poètes, c'est-à-dire les divins chants des poètes inspirés.

L'épître qu'il adresse quelques années plus tard à L'Hospital pour lui demander de l'aide ne met pourtant guère en pratique ces principes de l'écriture épistolaire en vers ici valorisés. Lettre de sollicitation écrite en 1554 au moment de la révision de son procès pour demander l'appui du futur chancelier, elle n'est apparemment pas si différente des nombreuses lettres de sollicitation écrites en prose à la même époque: mêmes allusions ou reprises cicéroniennes, avec au demeurant plus de légéreté dans la rapidité du récit autobiographique et davantage d'humour, ainsi dans sa façon de se référer en ouverture à la législation romaine:

Debeo quae tibi, si repetis, si quaeris ad assem

Omnia persolvui, non possim reddere, non si

Me vendi patiar, quod pridem jure licebat

Aestatis qui bis denos impleverat annos [...]

aut si hoc nondum placare potest te

Non expectatis triginta plus ve diebus

nec tot consumptis libris farris ve farinae ve

Utitor ut lubeat, bissenae jure tabellae:

Scindito, dividito medium, in partesque secanto ${ }^{29}$.

Les dettes que j'ai envers toi, si tu les réclames, si tu demandes que tout te soit entièrement payé jusqu'au dernier sou, je ne pourrais m'en acquitter, non pas même si je consentais à me vendre, ce qui était autrefois juridiquement permis à qui avait accompli deux fois dix années de sa vie. [...] Ou bien si cela ne peut t'adoucir, sans attendre les trente jours ou plus sans consumer tant de livres de blé, fais valoir à ton gré le droit inscrit dans la Loi des XII Tables: déchire-moi, coupe-moi en deux, mets-moi en quartiers.

28 Ibid., v. 64-66.

29 Ibid., fol. $75 \mathrm{v}^{\mathrm{o}}$, v. $4-8$ et $12-16$. 
Une des qualités qu'accorde généreusement Boyssoné à l'épître modèle de Michel de L'Hospital est son caractère docte: c'est la première qualité qu'il lui reconnaît: Quo doctius est quid? Et c'est avec ce caractère qu'il semble principalement rivaliser par les allusions horatiennes ou cicéroniennes, par l'ornementation allégorique et mythologique appuyée de son épître, ici celle de l'adversaire serpent d'Epidaure reprise à Horace (Sat. I, 3, 27), considérablement amplifiée et développée dans le style de l'Enfer de Marot:

Interea serpens Epidauri,

In vitiis aliorum qui tam cernit acute,

In propriis lippus, talpaque et caecior ipsa.

Saevus at hic coluber, dirarum quem soror una

Progenuit, stygiisque ferum nutrivit in undis:

Hos latices primum, primumque haec pocula sumpsit:

Et pro lacte cruor Nessi, pro gramine tetra

Huic data sunt aconita, ipsis in faucibus orci,

Spumantisque ex ore canis collecta trisulci.

Ad regem serpens hic serpsit,

In vitiis aliorum qui tam cernit acute ${ }^{30}$.

Cependant ce serpent d'Épidaure, qui a la vue si perçante pour voir les défauts d'autrui, souffre de problèmes de vue concernant les siens propres et est plus aveugle que la taupe même. Cette cruelle couleuvre dont la mère, l'une des sœurs Furies, a nourri la férocité dans les eaux du Styx s'est d'abord nourrie d'une telle boisson, de telles coupes, et en guise de lait lui fut donné le sang de Nessus, en guise de nourriture, cet horrible poison, recueilli dans les gorges mêmes d'Orcus et de la gueule écumante du chien à trois têtes. Ce serpent a rampé vers le Roi, a lancé de nombreuses fausses accusations, a accablé tout le monde de ses paroles pleines d'aigreur.

Toute l'épître file ainsi cette métaphore du serpent pour s'achever sur une dernière requête:

Ne serpat latius curabis cancer eundo

Fine aliquo facies ut concludatur, ut omnis

Absistat cessetque metus, dolus, et fuga: tantum

Justis certetur rationibus ${ }^{31}$.

30 Ibid., fol. $77 \mathrm{r}^{\mathrm{o}}$, v. 51-61.

31 V. 99-101. 
Veille à ce que ce serpent n'aille pas ramper plus loin, fais en sorte qu'il soit enfermé dans quelque limite pour que s'arrêtent et cessent toute crainte, ruse, fuite et qu'on ne lutte qu'avec des raisons conformes au droit.

Des autres qualités louées chez L'Hospital, la pureté du style et l'harmonie du vers, il s'en dit lui-même, tout au long de ses poésies, dépourvu. Il ne désespère pas néanmoins, une fois l'horrible Tabouet enfin vaincu et oublié, de pouvoir à son tour y prétendre. Telle est du moins la conclusion de l'épître suivante adressée à Jacques Du Faur:

Haec tu, docte Faber, non docta aequique bonique

Consule. verum irato si quid Apolline Musa

Fuderit: ignoscas. longe meliora daturus

Ipse tibi, ut spero, et graviora, peracta

Lite mala. ingenii tum demum viribus uti

A Christo dabetur $[\ldots]^{32}$

Ces vers maladroits, toi, docte Du Faur, juge-les avec équité et bienveillance. Si ma Muse s'est répandue sous le coup de la colère, accorde ton pardon. J'ai l'intention, comme je l'espère, de te donner moi-même de bien meilleures et de plus graves compositions, une fois totalement réglé ce méchant procès. C'est alors seulement que le Christ me donnera d'utiliser les forces de mon esprit.

Dans son épître à L'Hospital comme dans toutes ces épîtres de la période du procès, Boyssoné semble ainsi chercher avant tout à rendre plus variés, sinon plus légers, l'éloge et la demande. Dominent humour et connivence. Les allusions, les clins d'œil à des textes anciens ou aux écrits de L'Hospital lui-même y alternent avec emprunts et amplifications mythologiques à visée satirique. Telles sont les caractéristiques de l'épître en vers de notre juriste toulousain, dans un style plus marotique qu'horatien peut-être, avec une tendance au récit autobiographique à la première personne. Autant de traits que l'on retrouve dans l'épître à Jacques Du Faur qui suit, dans le manuscrit 835, l'épître adressée à Michel de L'Hospital. Cette épître mêle éloge et requête en les

32 Fol. 81ro, v. 114-119. 
enveloppant des mêmes références et allusions savantes qui associent l'humour et la dérision à l'égard de soi-même à l'ironie mordante contre l'adversaire serpentin qu'est pour lui Tabouet:

[...] Penelopes sic

Teximus hic telam, telamque reteximus: aut ut

Filiae aquam Danaï cribris haurimus inanem ${ }^{33}$.

Ainsi, nouvelle Pénélope, nous tissons notre toile et la détissons, semblable aussi aux Danaïdes qui remplissent vainement d'eau leurs cruches.

On retrouve ici la préférence accordée par un Aneau par exemple à l'Horace incisif et léger des satires plutôt qu'au sage philosophe épistolier, au «grave» Horace dont Du Bellay préconise l'imitation dans la Deffence ${ }^{34}$.

C'est en effet un tout autre Horace que s'attache à imiter et réinventer L'Hospital quand il ne choisit pas d'écrire une satire ou une invective contre les procès, comme dans cette pièce à Jacques Du Faur (II, 6), d'abord publiée par Henri Estienne comme poème d'un poète ancien inconnu, à la suite du Moretum de Virgile, sous le titre "Satyra incerti autoris quae inscribitur Lis » ${ }^{35}$. L'écriture de L'Hospital dans ses épîtres et notamment dans celles adressées à ses amis toulousains, ou du moins dont l'amitié remonte à l'époque toulousaine, en particulier les Du Faur, leur donne une autre dimension que l'on pourrait qualifier de philosophique. L'Hospital y préfère à la légèreté satirique, aux traits d'esprit et à l'humour, à l'ornement mythologique du sermo des satires, le sérieux d'un engagement éthique, politique et chrétien ${ }^{36}$

33 Fol. 80ro, v. 55-56.

34 La Deffence et Illustration de la langue Françoyse, II, 4, éd. J.-C. Monferran, Genève, Droz, 2001, p. 135. Voir sur ce point les actes du colloque Chacun son Horace, dir. M. Jourde, J.-C. Monferran et N. Dauvois, Paris, Champion, 2019.

35 Comme le mentionne le titre de l'ouvrage: Epistolia, dialogi, breves oratiunculae, poematia ex variis utriusque linguae scriptoribus. Inter poematia autem est satyra elegantissima quae inscribitur lis, non prius edita, Paris, Henri Estienne, 1577. Cf. le titre du poème dans l'édition $B$ de 1585 (p. 78) comme dans l'édition $A$ de 1732 (p. 84): Ad Jacob. Fabrum, Litium Execratio (II, 6).

36 Cf. le discours, traduit par L. Petris (La Plume et la tribune, p. 213), «Sur la hardiesse dans l'écriture » (VI, 5 De libertate scribendi), où L'Hospital condamne 
plus propre aux épîtres du poète de Venouse, selon ses lecteurs de la seconde moitié du siècle.

\section{UNE POÉSIE PHILOSOPHIQUE : AMITIÉS, CIRCONSTANCES ET ÉLARGISSEMENT GNOMIQUE}

Henri II Estienne, dans l'épître liminaire de son édition d'Horace de 1575, fait l'éloge de la poésie d'Horace, notamment celle des épîtres, en la qualifiant de philosophique ${ }^{37}$, non parce qu'elle donne accès comme celles d'Empédocle ou de Parménide (qu'il a publiées sous ce titre de Poiesis philosophica en 1573) à la connaissance de la nature, mais parce qu'elle forme les mœurs («mores format») et relève de cette «partie de la philosophie que l'on nomme éthique»:

[...] eam in plerisque Epistolarum praesertim locis appellare Philosophicam poesin non dubitarim. Ut enim Empedoclis, Parmenidis, Xenophanis poesis, quae res ad naturae cognitionem pertinentes tractabat, philosophica dicta fuit, tanquam ad eam philosophiae partem quae physice nominantur, spectans: quidni et Horatiana illa, iis in locis ubi mores format, illi philosophiae parti quae dicitur ethice, adscribatur? ${ }^{38}$

[Quant à la poésie d'Horace] je n'hésiterais pas, surtout dans la plupart des passages des épîtres, à la qualifier de philosophique. Puisqu'en effet la poésie d'Empédocle, de Parménide, de Xénophane, qui traite de ce qui a trait à la connaissance de la nature, a été appelée philosophique, de cette partie de la philosophie qu'on appelle la physique, pourquoi ne pas rattacher ces poèmes d'Horace, ceux qui forment les mœurs, à cette partie de la philosophie qu'on appelle l'éthique?

le rire. Voir la conclusion: "Je voudrais que tout poème soit intègre et doux (castum et lene), mêlé de gravité, exempt de rire et de plaisanterie».

37 Cf. Jacques Peletier Du Mans, Art poetique, II, 6, éd. M. Jourde et J.-C. Monferran, dans O. c., dir. I. Pantin, Paris, Champion, 2011, p. 364 pour cette même définition du modèle de l'épître horatienne par son caractère philosophique.

38 Épître liminaire à Jean de Bellièvre de son édition commentée des Poemata d'Horace, Genève, H. Estienne, 1575, A3ro-vo . Cité dans J. Kecskeméti, J. Céard, B. Boudou et H. Cazes, Henri II Estienne, éditeur et écrivain. La France des humanistes, Turnhout, Brepols, 2003, p. 368. 
Tel est bien le rôle qu'assigne L'Hospital à ses épîtres de facture horatienne et peut-être de plus en plus au fur et à mesure qu'elles lui servent à prendre recul et distance avec les troubles du temps. Même l'exécration contre les procès adressée à Jacques $\mathrm{Du}$ Faur quitte rapidement le ton satirique pour passer à des conseils et des recommandations et la plupart des autres grandes épîtres, comme le marquent bien les guillemets des différentes éditions, s'élèvent de la circonstance particulière à la considération générale, du récit autobiographique aux sentences morales universelles.

L'Hospital aurait compris l'épître en vers de facture horatienne, à l'instar d'Henri Estienne, et dans la lignée de Du Bellay et de Peletier, comme la forme idéale d'expression et même de pratique de la sagesse, à la manière même dont Horace dans ses épîtres retrouve le détachement et la dimension philosophique et grecque d'une méditation capable de s'élever au dessus de l'implication toute romaine dans son temps et dans l'action ${ }^{39}$. Cette dimension est marquée par la typographie elle-même, notamment par les guillemets dûment repris et retranscrits dans la belle édition des maîtres d'œuvre de ce colloque, qui mettent en valeur dans la structure du texte ce passage du particulier au général. Dès la première épître à Jean Du Bellay, comme le soulignent Perrine Galand et Loris Petris dans leur commentaire, L'Hospital s'élève de considérations et rappel biographiques à une réflexion sur l'amour de la patrie ${ }^{40}$.

L'épître à Adrien Du Drac, qui comporte un développement guillemetté sur les devoirs du bon juge, en est un autre très bon exemple.

"Scilicet illa bono prima est in iudice virtus

«Ut malit servare suos quam perdere cives

«Et, si quando via modicum discedere recta

39 Voir sur ce point l'étude de M. Citroni, «Images de la vie privée dans les épîtres d'Horace, ambiguïtés d'un modèle», dans L'invention de la vie privée et le modèle d'Horace, éd. B. Delignon, N. Dauvois et L. Cottegnies, Paris, Garnier, 2017, p. 59-76 qui fait un point très utile sur la tradition grecque, philosophique et morale de l'épître qu'Horace, le premier, transfère à Rome dans ses épîtres.

40 Carmina, I, 1, t. I, p. 40, le passage est une admonestation à la deuxième personne. Cf. l'analyse de ces v. 56-76 par les éditeurs comme "passage du particulier au général à la manière d'Horace », ibid., p. 47. 
«Fas erit, in lenem potius propendere partem.

«Nam male corrigitur iudex quod acerbius olim

«Constituit: non est ullo reparabilis error

«Tempore, qui vita famaque et nomine constat.

«Assurément chez un bon juge la première vertu est celle-ci : «Préférer sauvegarder ses concitoyens plutôt que de les perdre, «Et s'il est permis de s'écarter un peu de la voie règlementaire, «Faire pencher la balance plutôt vers le parti le plus doux.

«En effet, on a du mal à corriger une décision trop cruelle:

«Une fois qu'elle a été prise par le juge, elle n'est jamais réparable, «L'erreur qui coûte la vie, la réputation et le nom ${ }^{41}$.

Vers dont on comprend le sens qu'ils pouvaient revêtir pour Michel de L'Hospital, victime de l'injustice et de ses conséquences dès le plus jeune âge, et dont on comprend aussi que Boyssoné ait pu les apprécier. Tel est précisément l'intérêt des épîtres de L'Hospital, certes attachées aux circonstances, mais par excellence les transcendant pour s'adapter à d'autres. Exemple que Boyssoné, attaché lui-même à l'actualité de son procès, ne saurait suivre. Il n'a pas en effet de son côté un usage de l'épître autre que circonstanciel, pas très différent en cela de son usage de l'épître en prose, l'utilisant pour l'éloge et la requête, et l'enrichissant seulement d'ornements mythologiques et de traits d'esprit. Se souvenant des vers d'Horace dans son épître à Auguste, il ne s'excuse pas seulement, auprès de Jacques Du Faur, de sa négligence à lui écrire par une variation sur les vers célèbres de l'incipit de l'épître II, 1 (Cum tot sustineas):

[...] Sola haec me causa morata est:

Otia ne turbare tua officiosus ego ultra

Quam decet videar, sic commoda publica ledens

In quibus assidue versaris: nec vacuo umquam

A curis licet esse tibi: seu Regia tractes,

Seu privata ${ }^{42}$.

Voici la seule raison de mon retard: la crainte de ne donner l'impression, obligé que je te suis, de troubler plus que la

41 Carmina, I, 4, t. I, p. 126-127, pour le texte et la traduction.

42 Ms. 835 , fol. $78 v^{\circ}$, v. $10-16$. 
mesure ton repos, offensant ainsi l'intérêt public, objet d'une application assidue de ta part, sans que jamais il te soit loisible de te départir de tes soucis, soit que tu traites les affaires du roi, soit que tu traites celles de particuliers.

Il propose à son correspondant, toujours par un jeu de variation sur les formules d'Horace s'excusant auprès d'Auguste de lui présenter un ouvrage quand il est fatigué et soucieux («cum tibi librum / sollicito damus aut fesso », II, 1, 220-221), d'oublier ces soucis en le lisant:

Nunc igitur curat, lubeat mode, pone relictis, Tantisper dum nostra legas, animum mihi praebe, Atque oculos: veteris liceat percurrere amici Scripta: licet nullo sint heac ornata lepore: Nec sint digna legi, nec tantos cernere vultus ${ }^{43}$.

Pour l'heure, laisse donc derrière toi, si tu le peux, tous ces soucis, et juste le temps suffisant pour lire ces mots, accordemoi ton attention et ton écoute: qu'il te soit permis de parcourir les lignes écrites par un vieil ami, bien qu'aucune grâce ne vienne les orner, qu'elles ne méritent pas d'être lues ni d'être regardées par un tel visage.

Mais quand Horace introduit par là une autocritique, un autoportrait poétique, et une réflexion plus générale sur le rapport de la poésie au pouvoir, Boyssoné en fait le simple marchepied d'une demande intéressée. Plus généralement Jean de Boyssoné s'appuie, circonstances et position sociale obligent, sur ces solidarités toulousaines pour la requête, alors que Michel de L'Hospital donne de préférence une orientation éthico-philosophique aux textes adressés à ces amis de longue date, à ces membres d'une sodalitas formée à Toulouse et en qui il place toute sa confiance, avec qui il partage une même éthique: de l'épître à Georges d'Armagnac aux dernières épîtres écrites au temps de la disgrâce à Guy Du Faur, cercle d'amis proches et puissants dont Boyssoné n'a jamais fait partie. L'épître à Georges d'Armagnac s'ouvre sur une scène frappante où L'Hospital rappelle à Armagnac les circonstances dans lesquelles il apprit, faussement, sa mort. Mais cette scène rappelle en même

43 Ibid., v. 35-39. 
temps les liens anciens, enracinés dans la jeunesse toulousaine, des trois protagonistes, Armagnac, L'Hospital et Jacques Du Faur:

Coenanti mecum Fabro, manibusque recentem

Ac gelidam famulos poscenti, tristis et asper

Nuntius ecce tuae mortis defertur in aurem

Fabro, qui iam usque a puero te semper amavit,

Ante alios omnes, coluit plus omnibus unum.

Du Faur dînait avec moi et demandait aux serviteurs, pour se laver les mains, de l'eau

Fraîchement tirée et bien froide, quand affligeante et rude,

La nouvelle de ta mort parvient à son oreille,

Du Faur, qui depuis la tendre enfance t'a toujours aimé

Plus que tous les autres, et qui cultiva ton amitié seule de préférence à toutes les autres ${ }^{44}$.

La nouvelle est démentie par les vers suivants qui enchaînent aussitôt avec des considérations générales sur la véritable vertu et les enseignements de la maladie. L'épître est presque entièrement guillemettée, exemple parfait de cette connivence de pensée dans la véritable amitié et de l'enracinement d'une éthique dans des liens et des convictions personnels. La longue épître à Jacques Du Faur contre les procès porte de même guillemettés trois passages qui fondent sur les première et deuxième personnes d'un discours engagé et adressé une défense et illustration des lois et du droit contre ceux qui en abusent à mauvais escient.

Mais c'est peut-être la série d'épîtres plus tardives à Guy Du Faur de Pibrac et Arnaud Du Ferrier qui est la plus exemplaire $^{45}$. Elles incarnent ce rôle de mentor que Pibrac donne à Michau dans ses Plaisirs de la vie rustique. La première épître, qui

44 Carmina, I, 6, 1-5. Nous citons ici l'édition et la traduction de P. Galand et L. Petris, Carmina, t. I, p. 160-161.

45 Alors que P. Galand et L. Petris se fondent pour leur édition sur le ms. Dupuy 901 et sur l'édition d'Amsterdam de $1732(A)$, qui est la plus complète, nous citons ici pour cette série de textes non encore publiés la numérotation et le texte de l'édition de 1585 (B), par commodité mais aussi pour la place qu'occupent ces différents textes dans l'économie générale du recueil et les unes par rapport aux autres. Voir pour un tableau comparatif de cette série notre appendice 2 et, pour un tableau synoptique complet, Petris, La Plume et la tribune, p. 549-556. 
a pour titre «De amore et ignoratione sui ${ }^{46}$, associe critique du milieu courtisan et des corruptions de la justice et considérations et surtout conseils de conduite et de sagesse. La série suivante, qui date de la période des difficultés et de la retraite associe étroitement analyse de la situation actuelle et sagesse face à l'adversité, qu'il s'agisse de s'interroger avec Du Ferrier sur leur commune capacité à résister à l'adversité $(\mathrm{V}, 11)$ ou de lui avouer ses inquiétudes sur l'état de la France $(\mathrm{V}, 13)$; ou dans les épîtres à Guy Du Faur de Pibrac d'associer analyse de la situation actuelle et éloge de la retraite et de l'amitié $(\mathrm{V}, 12)$ ou de la seule retraite (VI, 1 ; VI, 6). On y trouve guillemettées des maximes horatiennes:

Felices vero nimium nimiumque beati

Qui potuere bonis animos compescere rebus

Et servare modum... ${ }^{47}$

Heureux et trop heureux ceux qui ont pu au milieu de la prospérité contenir leurs âmes et garder la mesure.

Même si l'écho ici est virgilien (En., X, 501), on songe aussi à l'épode 2, base de l'éloge de la vie rustique que développent le poème suivant des Carmina et les Plaisirs, hommage de Pibrac à L'Hospital.

Guy Du Faur de Pibrac choisit, lui, le français et notamment la forme resserrée du quatrain gnomique pour diffuser cet enseignement moral que L'Hospital, fidèle à la forme horatienne renferme dans la forme libre et ouverte du sermo. Ce dernier lui permet, comme en témoignent les dernières épîtres à Du Ferrier ou Pibrac, d'associer expérience personnelle et généralités gnomiques, mais aussi fermeté du latin et réflexion morale vouée à dépasser le temps présent. Pibrac préfère, en français, l'héritage des formes denses et gnomiques de l'épigramme, héritage qu'incarnent à Toulouse ces modèles que constituent peut-être pour lui le Boyssoné des Centuries ${ }^{48}$, écrites en dizains, ou le La Perrière des

46 Carmina, IV, 1 dans $B$, p. 199. Cette épitre devient la septième du livre IV dans $A$ et y porte le même titre, p. 208.

$47 \quad B, \mathrm{~V}, 12$, p. 315.

48 Série de dizains dont le premier livre comme le dernier renferment nombre de dizains à portée générale, voir par exemple les titres des premiers dizains qui 
Considérations ${ }^{49}$, écrites elles aussi en quatrains. Cela lui permet de séparer de manière beaucoup plus nette le privé du public, l'épistolarité latine en prose ${ }^{50}$ de la poésie française, à laquelle est confiée désormais la forme durable.

Chacun atteint ainsi à sa manière cette alliance (ou ce partage) des Muses et des Lois, de la poésie et du droit que L'Hospital incarna peut-être mieux et plus que tout autre. Équilibre des formes, des enjeux, des fonctions qu'Étienne Forcadel, qui adressa une épigramme d'éloge à L'Hospital dans ses Epigrammata de 1554 (Lyon, Jean de Tournes) pour en faire le parangon de l'alliance des Muses aux Lois ${ }^{51}$, cherchait lui aussi à atteindre, dans les mêmes années avec d'autres moyens ${ }^{52}$.

Nathalie DAUVOIS

Université de Paris III - Sorbonne Nouvelle

évoquent ceux de certains sermones de L'Hospital, fol. $3 \mathrm{r}^{\circ}:$ « Le riche estre plus indigent que le paovre», fol. $3 \mathrm{v}^{\mathrm{o}}$ : «De ne se mecongnoistre pour les biens de fortune», fol. $4 \mathrm{r}^{\circ}$ : «De bien user de l'administration commise». Seule la seconde centurie est amoureuse et dédiée à Glaucie, sur le modèle de la Delie. Voir l'édition citée d'H. Jacoubet.

49 Les Considérations des quatre mondes divins, angelique, celeste et sensible, comprinses en quatre Centuries de quatrains, Lyon, Macé Bonhomme et Toulouse, Jean Moulnier, 1552.

50 Voir la belle lettre en prose que Guy Du Faur adresse à L'Hospital, en 1556, sur la mort d'Emile Perrot, le grand ami de Bunel, citée et traduite par L. Petris, dans L'Hospital, Discours et correspondance, p. 137-142. Voir aussi ibid. p. 168174 sa lettre d'octobre 1561 au récent chancelier où il le félicite et le remercie de ses faveurs, lettre qui est aussi une réflexion sur les bienfaits des Belles Lettres. Et cf. p. 175-180 la lettre de 1562 écrite du concile de Trente pour lui envoyer le discours qu'il y a prononcé.

51 Citée par Loris Petris dans l'appendice de La Plume et la tribune, p. 537.

52 Nous nous permettons de renvoyer sur ce point à notre contribution "Jura sanctissima fabulis et carminibus miscere" La concorde de la poésie et du droit dans quelques traités d'Étienne Forcadel», dans L'Humanisme à Toulouse, op. cit., p. 91-105 et à la notice que nous lui avons consacrée dans Écrivains juristes et juristes écrivains, dir. B. Méniel, Paris, Garnier, 2015, p. 500-505. Mais voir d'abord sur cet auteur et son importance dans l'histoire du droit et de la littérature, P. Mesnard, «Un rival heureux de Cujas et de Jean Bodin: E. Forcadel », Zeitschrift der Savigny-Stiftung für Rechtsgeschichte - Romanische Abteilung, 67 (1950), p. 440-458. 


\section{APPENDICE 1: TABLE DES TEXTES ADRESSÉS \\ PAR JEAN DE BOYSSONÉ AUX PROCHES DE L'HOSPITAL}

BMT, Ms. 834 : Epistolae mutuae (prose)

$4 v^{o}:$ A. Du Ferrier à J. de B. (1533)

$10 v^{\circ}:$ A. Du Ferrier à J. de B. (1533)

$23 r^{\circ}:$ J. de B. à A. Du Ferrier

$29 \mathrm{v}^{\circ}:$ J. de B. à Jacques Du Faur (1533)

$44 v^{\circ}$ : J. de B. à Jacques Du Faur (1539)

$57 v^{\circ}:$ J. de B. à A. Du Ferrier (1536)

61ro: À Pierre Du Faur

$82 \mathrm{r}^{\circ}$ : À Jacques Du Faur (1543, pour lui recommander G. Scève)

$82 \mathrm{v}^{\circ}$ : À Arnaud Du Ferrier $(1543, i d$.

$87 \mathrm{r}^{\circ}$ : À Jacques Du Faur, 1543

[88 $\mathrm{r}^{\circ}$ : À G. Scève à propos de L'Hospital (1546?)]

$106 \mathrm{r}^{\mathrm{O}}$ : Au cardinal d'Armagnac (lui rappelle leur amité jam inde

a puero et lui demande d'intercéder pour lui)

$128 r^{\circ}$ : À Du Ferrier (1553?).

BMT, Ms. 835 : Poésies latines

Epigramme, 6vo : À Michel Du Faur ${ }^{53}$ (De Tabella Vulcani)

Élégies, 36ro : À Du Ferrier (In Concordata D. Aymae ad Ferrerium)

Élégies, 36vo : À Du Ferrier (Ad Ferrerium ut versus discat componere)

Élégies, $41 r^{\circ}$ : À Pierre Du Faur (sur les vers qu'il lui envoyait $\mathrm{d}^{\prime}$ habitude en mai pour les Jeux floraux)

Élégies, 42ro : À G. de La Perrière (pour le féliciter d'écrire désormais des vers latins et non plus des vers français)

Épîtres, $75 \mathrm{v}^{\circ}$ : À Michel de L'Hospital

Épîtres, $78 v^{\circ}$ : À Jacques Du Faur

Épîtres, 83ro : À Arnaud Du Ferrier

53 Troisième des trois fils d'Arnaud Du Faur, frère de Pierre (le père de Guy Du Faur de Pibrac) et Jacques, Michel, juge ordinaire de 1531 à 1535, puis jugemage de 1535 à 1556, démissionna de cette fonction pour remplacer au parlement de Toulouse son frère Pierre. Il avait épousé Éléonore de Bernuy et eut un fils lui aussi nommé Pierre Du Faur de Saint-Jory, qui étudia le droit sous Cujas, devint maître des requêtes en 1565, puis président du Parlement de Toulouse, auteur de nombreux ouvrages de droit. 
BMT, Ms. 836 : Centuries

- 3 dizains adressés " À Mr le maistre des requestes Fabri », fol. 19ro , I, 36 («Les ans passés, au premier jour de may/ De ma besogne envoyer vous soulois...»), 20v, I, 39 (remerciements, lui annonce 8 dixains); 30ro, I, 58

- I, 56: «Au portail de la maison de Messieurs les Fabris» (sur le portail de l'hôtel de la rue Croix-Baragnon aux trois frères Du Faur Pierre, Michel et Jacques) ${ }^{54}$

- I, 74 : éloge de la concorde des trois frères

\section{APPENDICE 2: TEXTES ADRESSÉS AU SODALITIUM TOULOUSAIN DANS LES CARMINA DE L'HOSPITAL}

Michaelis Hospitalis ... Epistolarum seu sermonum libri sex, Paris, M. Patisson, 1585 ( $B$, en rapport à l'édition $A$ de 1732)

I, 4: Ad Adrianum Dracum ... De suo in Italiam itinere (p. 17-21) [A: I, 4, sans titre]

I, 6: Ad Georgium Armaniacum cardinalem ex morbis quae utilitas percipi possit (p. 22-26) [A: I, 6, même titre]

II, 1 : Ad Iacobum Fabrum, praesid. Inquis. In Sen. Parisiensi, Litium execratio (p. 78-82) [A: II, 6, même titre]

IV, 1 : Ad Vid. Fabrum de amore et ignoratione sui (p. 199-205) [A:

IV, 7 , même titre]

V, 2: Ad Jacobum Fabrum (p. 265-283) [A: V, 9, Iter Nicaeum]

V, 11: Ad Arnol. Ferrerium «Ferreri, quo nec melior... » p. 311-312 [A: VI, 7]

V, 12: Ad Vidum Fabrum «Vates ille...» (p. 312-319) [A: VI, 8]

$\mathrm{V}, 13$ : Ad Arn. Ferrerium «Tam varia atque incerta» p. 319-320 [A : VI, 9]

VI, 1 : Ad Vidum Fabrum «Tu me posse... » p. 321-325 [A : VI, 11]

VI, 6: Ad Vidum Fabrum «Si quis felicem, si quis... » p. 347-354 [A :

VII, 1, sans adresse, titre: De se ipso sermo]

VI, 9 : De obitu Iac. Fabri [à Pibrac] p. 358-361 [A: Tumuli, VIII, 7].

54 Hôtel particulier remanié en 1545, Nicolas Bachelier est sans doute l'auteur du portail. 
过

ํํำ

.

큼

국

(2)

(1)

甲

(8) 


\section{POÉTIQUES ET ESTHÉTIQUES DE L'HUMILITÉ CHEZ MICHEL DE L'HOSPITAL ET JOACHIM DU BELLAY, IMITATEURS D’HORACE ET DE TIBULLE}

Sage De-l'hospital, qui seul de nostre France

Rabaisses aujourdhuy l'orgueil Italien,

Et qui monstres seul, d'un art Horacien,

Comme il faut chastier le vice \& l'ignorance $^{1}$

Lors que je ly \& rely mile fois

Tes vers tracez sur la Romaine grace,

Je pense ouïr, non la voix d'un Horace,

Mais d'un Platon les tant nombreuses loix ${ }^{2}$

Un an après la démission politique en février 1568 de Michel de L'Hospital (1505-1573), poète et chancelier de France (à partir d'avril 1560) ${ }^{3}$, parut pour la première fois, parmi les Divers Poemes (1569) posthumes de Joachim Du Bellay (1522-1560) réunis par l'avocat poitevin Guillaume Aubert et l'ami humaniste Jean de Morel d'Embrun (1511-1581) ${ }^{4}$, un sonnet de l'Angevin «au

1 Joachim Du Bellay, Les Regrets et autres auvres poëtiques, Paris, Fédéric Morel, 1558, s. CLXVII, v. 1-4, fol. 40vo (O. poét., éd. Chamard, t. II, p. 185).

2 Du Bellay, [sonnet de 1559 ?] «Au seigneur de l'Hospital », v. 1-4 ; Joachim Du Bellay, Les CEuvres françoises, éd. Guillaume Aubert et Jean de Morel, 8 parties, Paris, Fédéric Morel, 1568-1569: partie V. Divers Poëmes, 1569, fol. 45v («Sonnets Divers», s. XXVI, v. 1-4, O. poét., éd. Chamard, t. II, p. 275-276).

3 Sur la vie, la carrière politique et les œuvres de ce robin, poète et chancelier, voir M. Simonin, «L'Hospital (Michel de)», dans Centuriæ latinæ II : Cent une figures humanistes de la Renaissance aux Lumières, éd. C. Nativel et al., Genève, Droz, 2006, p. 437-447; Petris, La Plume et la tribune.

4 Jean de Morel, «Pylade» de Joachim, fut le dédicataire de la longue élégie latine, dite "testamentaire», de celui-ci, datée de 1559, et publiée de façon posthume à la fin des Xenia («Étrennes») de Du Bellay, également de 1559: 
seigneur de L'Hospital» (dont nous citons le premier quatrain ici en exergue). Dans ce poème élogieux, datant d'une époque où L'Hospital n'était pas encore chancelier de France (vers la fin des années 1550, au moment de l'avènement de François II au mois de juillet 1559), Du Bellay soulignait le haut statut et la grande sagesse politiques du chancelier de la duchesse de Berry Marguerite de France (1550-1560), assis (v. 5) «au siege de noz Rois» (au pluriel), puisqu'il était devenu Maître des requêtes du roi en octobre 1553, premier président de la Chambre des Comptes du roi en février 1555 (et célébré en tant que tel par Du Bellay dans ses Xenia [«Étrennes»] de 1559) ${ }^{5}$, puis membre du Conseil privé du roi en juillet 1559. Du Bellay n'insistait pas pourtant dans ce poème sur le grand talent poétique néolatin de cet ami «sage » et puissant, dont la carrière politique prenait alors son essor. Mais il n'en reconnaissait pas moins «la Romaine grace» des vers latins du futur chancelier, d'inspiration horatienne, même s'il leur accordait une seconde place, dans le domaine de l'otium, après les acquis et le negotium prestigieux d'une carrière d'homme d'État.

En revanche, dans le sonnet antérieur de Du Bellay, figurant parmi les sonnets-éloges de la fin (s. 151-191 [s. 167]) de ses Regrets et autres cuvres poëtiques, publiés à Paris en 1558 au lendemain du long séjour romain (1553-1557) de leur auteur - chez qui la fiction poétique de son prétendu «exil» italien faisait écho à celui, antérieur et véritable, de L'Hospital, passé en Italie de 1523 à 1534 - dès le premier quatrain (cité également en exergue) jusqu'au dernier tercet, Du Bellay louait presque exclusivement l'art et l'éthique

«Elegia Ad Ianum Morellum Ebred., Pyladem suum», dans Ioachimi Bellaii Andini Poetæ Clarissimi Xenia, seu Illustrium quorundam Nominum Allusiones. His accessit Elegia ad Janum Morellum Ebredun. Pyladem suum, Paris, Fédéric Morel, 1569, fol. 16ro-22v $\mathrm{v}^{\mathrm{o}}$ (O. poét., t. VIII, éd. G. Demerson, p. 104-125). Sur Jean de Morel, ami intime de Joachim Du Bellay, ainsi que de Michel de L'Hospital, et sur le réseau lettré de la famille Morel à Paris, voir P. Ford, The Judgment of Palaemon. The Contest between Neo-Latin and Vernacular Poetry in Renaissance France, Leyde, Brill, 2013, p. 203-226. Cf. G. Gadoffre, «Joachim Du Bellay et Michel de L'Hospital», dans Les Angevins de la littérature. Actes du colloque des 14, 15, 16 décembre 1978, éd. G. Cesbron, Genève, Droz, 1979, p. 79-92.

5 Du Bellay, Xenia, 1569, fol. 9vo : «Mich. Hospitalius in Rationum Regiarum Decuria Praeses » [Xen. 30] (O. poét., éd. Chamard, t. VIII, éd. G. Demerson, p. 82-83). 
« horatiens » de ce confrère néolatin, dont la sagesse morale était comparable, selon ce Du Bellay admirateur de la fin de 1557, à celle quasi divine de Socrate:

Ainsi jusqu'aujourdhuy, ainsi encor' void-on

Estre tant renommé le maistre de Platon,

Pour ce qu'il eut d'un Dieu la voix pour tesmoignage ${ }^{6}$.

Or, dans cette enquête sur Michel de L'Hospital, poète et futur chancelier, tout en tenant compte de son statut politique d'homme d'État, nous mettrons l'accent plutôt sur la question de «l'art» tant «horacien» que tibullien des productions poétiques néolatines de ce «sage De-l'hospital», ami des poètes de la Pléiade - comme l'avait fait le Du Bellay ovidien, tibullien et horatien des Regrets des années 1550, poète bilingue, français-latin, de l'« exil». Et comme devait le faire, en fait, le Du Bellay non moins élogieux de 1559, pour qui le cachet des vers de son devancier L'Hospital, ancien poète d'un «exil» italien, serait, en fin de compte, «la Romaine grace».

En privilégiant ainsi, dans cette double enquête sur Michel de L'Hospital et Du Bellay, des questions d'ordre poétique et surtout métapoétique, nous n'en aurons pas moins pour but de mieux comprendre les enjeux politico-culturels et éthiques tout aussi bien qu'esthétiques et stylistiques d'une poésie "sage» de l'élégance et de la "grâce» chez l'Angevin et chez le poète robin? Nous comptons mieux apprécier ainsi les liens poétiques et sociopoétiques qui rattachaient une poétique et une esthétique de l'humilité pratiquées par Joachim Du Bellay en français et en latin à celles, semblables, des vers latins de Michel de L'Hospital, en opposant un tel choix stylistique et éthique commun à celui, fort différent, du contemporain de la jeune Brigade, Pierre de Ronsard (1524-1585).

Pour ce faire, il nous faut remonter tout d'abord au début des années 1550, à l'époque où le Vendômois dédiait son ode pindarique sur les Muses à Michel de L'Hospital, au lendemain de sa

\footnotetext{
6 Du Bellay, Les Regrets, 1558, fol. 40vo [s. CLXVII, v. 12-14] (O. poét., éd. Chamard, t. II, p. 185).

7 À cet égard, voir surtout P. Galand et L. Petris, «Introduction», dans L'Hospital, Carmina, t. I, p. 7-22.
} 
fameuse querelle (du début de juin 1550) avec le vieux poète de cour Mellin de Saint-Gelais (c. 1491-1558). Dans cette ode flatteuse, composée par Ronsard en guise de remerciement à son défenseur L'Hospital, ami des Muses (rendues «illustres» par ce dernier, selon Ronsard), l'auteur faisait l'éloge des dons poétiques de ce protecteur lettré, ami commun de Jean de Morel d'Embrun et de Joachim Du Bellay ${ }^{8}$ :

Ourdis, ô doulce Lyre mienne,

Encor' un chant à cestui cy [L'Hospital],

Qui met ta chorde Dorienne

Soubz le travail d'un doulx soucy. [...]

C'est luy dont les graces infuses

Ont ramené dans l'univers

Le Chœur des Pierides Muses,

Faictes illustres par ses vers 9 .

Car L'Hospital, chancelier depuis avril 1550 de la princesse Marguerite, sœur du roi, et protectrice, elle aussi, de Ronsard et de Du Bellay, venait de composer et de faire circuler à la cour sa fameuse élégie-plaidoyer «au nom de Ronsard» («Elegia nomine P. Ronsardi adversus eius obtrectatores et invidos ») qui faisait parler Ronsard en distiques élégiaques latins afin de justifier la "nouveauté » de ses Quatre premiers livres des odes de Pierre de Ronsard, Vandomois. Ensemble son Bocage (Paris, Guillaume Cavellat, 1550), dont le langage pindarisant, quelque peu «insolite» et "étranger», avait été ridiculisé par Saint-Gelais devant le roi. Ce stratagème de guerre poétique, issu de la plume habile de Michel de L'Hospital, avait aussi pour but de défendre et de promouvoir, auprès du roi et de la cour, le programme plus large de renouvel-

8 Sur cette querelle entre Saint-Gelais et Ronsard, et sur le rôle de conciliation entre ces deux poètes (et entre deux conceptions opposées de la poésie de langue vernaculaire), joué habilement par Michel de L'Hospital, et raconté par Claude Binet dans son Discours de la vie de Pierre de Ronsard, Paris, G. Buon, 1586, p. 15-16, voir P. de Nolhac, Ronsard et l'humanisme, Paris, H. Champion, 1921, p. 178-187.

9 Pierre de Ronsard, «Ode à Michel de L'Hospital chancelier de Madame Marguerite» [Odes, V, viii], v. 727-730, 749-752, Les Amours de P. de Ronsard Vandomoys. Ensemble le cinquiesme de ses Odes, Paris, la Veuve Maurice de La Porte, 1552, p. 170-201 (p. 198-199) (Ronsard, Lm, t. III, p. 118-163 [p. 159-160]; Ronsard, OC, t. I, p. 695-740 [p. 736-737]). 
lement poétique et linguistique en vernaculaire de Du Bellay et de Ronsard contre la dérision, la jalousie et la peur des poètes de cour, tels que Saint-Gelais et Lancelot de Carles (c. 1508-1568) ${ }^{10}$.

Or, ce qui doit retenir notre attention dans cet épisode célèbre des débuts houleux de la Pléiade et de Ronsard (épisode qui devait être évoqué ultérieurement par Du Bellay dans une élégie intime des Poemata de 1558, «Recommandation de la vie calme» [ «In vitæ quietoris commendationem, ad I. Morellum Ebrod.»]11, adressée au "Pylade» de Joachim, Jean de Morel) - et ce qu'il faut relever dans cette cause célèbre du début de la carrière politique du «sage» et docte futur chancelier de France -, c'est la parfaite équivalence établie par le vrai Ronsard, dans son ode de remerciement « aux Muses » (et à Michel de L'Hospital), entre les vers latins de ce dernier et la poésie de la Brigade, de langue vernaculaire, toutes deux chéries des Muses, qu'elles «illustraient» ensemble ${ }^{12}$. Et même avant cette ode élogieuse de Ronsard, dans la longue pièce latine pseudo-ronsardienne fournie par L'Hospital luimême contre Saint-Gelais (mettant en scène ainsi la voix d'un pseudo-«Ronsard» qui s'y défendait), ce qui nous frappe, c'est le fait que, dans cette fiction poétique, c'est en latin que ce «Ronsard» fictif assurait la défense de sa propre pratique poétique vernaculaire. De plus, tout au début de cette élégie-apologie (dans les treize premiers distiques), ce «Ronsard» pour ainsi dire «lhospitalien» va jusqu'à expliquer, non sans ironie, ce paradoxe ostensible, en le présentant comme le contrecoup d'un choix délibéré, stratégique, de sa part: au dire de ce «Ronsard» de papier, inventé, sa décision

10 Sur cette élégie IX, 43 de Michel de L'Hospital (citée partiellement par de Nolhac, Ronsard, op. cit., p. 180-182), qui devait paraître pour la première fois parmi Les Élégies de P. de Ronsard, dans le t. VI des CEuvres de P. de Ronsard... reveues, corrigées et augmentées par l'autheur, peu avant son trespas, rédigées en dix tomes..., Paris, G. Buon, 1587, p. 158-164 (voir Galand et Petris, "Introduction», dans Michel de L'Hospital, Carmina, t. I, p. 28, n. 90), puis parmi les Miscellanea Carmina de l'édition A, p. 457-462, voir l'édition, la traduction et l'analyse de Petris, La Plume et la tribune, p. 500-515.

11 Ioachimi Bellaii Andini Poematum libri quatuor. Quibus continentur Elegiae, Varia Epigr., Amores, Tumuli, Paris, Fédéric Morel, 1558, fol. 10ro-vo [Eleg. 5] (O. poét., éd. Chamard, t. VII, éd. G. Demerson, p. 56-59).

12 Sur le rapport de «symbiose» entre les domaines poétiques du latin et de la langue vernaculaire en France à la Renaissance, voir P. Ford, The Judgment of Palaemon, passim. 
de se défendre en latin (au moyen des vers latins sobres et simples de Michel de L'Hospital) avait été prise afin d'éviter encore d'autres critiques de son style et langage poétiques «nouveaux» et «insolites » en français.

De façon semblable, dans cette élégie latine lhospitalienne de l'été 1550, comme plus tard dans la lettre du $1^{\mathrm{er}}$ décembre 1552 que devait adresser L'Hospital à l'ami commun Jean de Morel sur les modalités poétiques d'une éventuelle réconciliation entre Ronsard et Saint-Gelais (à effectuer par l'intermédiaire de Morel, porteparole des conseils de L'Hospital visant le comportement poétique peu diplomatique de Ronsard dans cette affaire), Michel de L'Hospital laissait entendre (à deux reprises) que Ronsard devait se montrer moins arrogant et plus modeste et abandonner ce que L'Hospital appelait (ou faisait appeler par ce «Ronsard» latin) le caractère «nouveau», «étranger», et «insolite» de ses vers. Ceci non seulement pour des raisons de tact vis-à-vis de Saint-Gelais et d'autres poètes de la cour, mais aussi pour tourner l'affaire SaintGelais à son propre avantage:

Non etenim nostri tam sum, quam fingis amator,

Ut mea confestim qualiacunqe probem.

Mutem quin etiam, vel te monitore, libenter

Quæ nova sunt scriptis vel peregrina meis.

Car, au contraire de ce que tu imagines, je ne suis pas si amateur [de moi-même

Que j'approuve tout de suite automatiquement tout ce qui [est de moi.

Bien plus, même en fonction de tes critiques, je changerais

Volontiers les nouveautés ou les éléments étrangers de mes [écrits ${ }^{13}$.

Plus etiam rogo: $u$ in iis strenis, quas pridem meditatur, sint ad Carlum Rhegiensem episcopum et Sangelasium aliquot versus, istius amoris in utrumque testes, qui mihi videntur palinodiam canere.

\footnotetext{
13 Michel de L'Hospital, Elegia nomine P. Ronsardi adversus eius obtrectatores et invidos (c. juillet 1550), Carmina, IX, 43, 161-164 (trad. G.H. Tucker), dans A, p. 461 ; Petris, La Plume et la tribune, p. 505-515; cf. P. de Nolhac, Ronsard et l'humanisme, p. 183-185.
} 
Id nisi viderem expedire Ronsardo, cuius merito sum amantissimus, nunquam ad te scriberem. Pene oblitus sum, quod non est prætermittendum ut in iis [strenis] abstineat novis et insolitis, si vult placere, simul ut ostendat posse cum velit et sine iis, quum aliter facit, iudicio facere, non penuria veterum aut inscitia.

Je demande plus encore: je souhaiterais que, dans les Etrennes qu'il [Ronsard] se prépare à publier, il insérât quelques vers dédiés à Carles, évêque de Riez, et à Saint-Gelais, où il leur montrât ses bons sentiments, puisqu'ils semblent chanter la palinodie.

Je ne t'aurais jamais écrit cela, si je n'y voyais l'avantage de Ronsard, que j'ai tant de raisons d'aimer tendrement. J'allais oublier, ce qui est important, de lui recommander de s'abstenir [dans ces étrennes], s'il veut plaire, de ces formes nouvelles et insolites, dont il prouvera ainsi qu'il peut se passer, quand il veut, et que, lorsqu'il fait autrement, il le fait par réflexion, non pas par le manque de modèles anciens, ou par ignorance de ceux-ci ${ }^{14}$.

Bref, tout en défendant Ronsard et sa poésie grécisante, latinisante et italianisante contre les médisances de ses détracteurs à la cour - voire, tout en défendant cette suffisance pindarisante ronsardienne (si dédaigneuse, dans l'ode de 1550 «A Iouachim Du Bellai Angevin », à l'égard de la poésie lyrique plus «basse» $\mathrm{d}^{\prime}$ Horace $)^{15}$-, Michel de L'Hospital semble néanmoins avoir fortement conseillé et prôné un compromis linguistique et esthétique fondamental de la part du Vendômois en faveur de l'adoption d'un langage poétique plus simple, plus humble et moins «insolite», à la manière, en effet, d'un Mellin de Saint-Gelais, dont le «talent

14 Michel de L'Hospital, lettre (du 1 1er décembre 1552) à Jean de Morel d'Embrun (trad. P. de Nolhac [modifiée / augmentée par G.H. Tucker]), citée et commentée dans P. de Nolhac, Ronsard et l'humanisme, p. 183-185; aussi dans Petris, La Plume et la tribune, p. 518-519.

15 Voir surtout Ronsard, Les Quatre premiers livres des odes, 1550, fol. $16 \mathrm{v}^{\mathrm{o}}-21 \mathrm{r}^{\mathrm{o}}$ (fol. 20r ${ }^{\circ}$ ) (Ronsard, Lm, t. I, p. 118) [I.ix] «A Iouachim Du Bellai Angevin», v. 165-172: «Par une cheute subite / Encor je n'ai fait nommer / Du nom de Ronsard la mer / Bien que Pindare j'imite : / Horace harpeur latin / Étant fils de libertin / Basse \& lente avoit l'audace, / Non pas moi de franche race». Voir G.H. Tucker, The Poet's Odyssey: Joachim Du Bellay, and the Antiquitez de Rome, Oxford, Clarendon Press, 1990, p. 32. 
poétique»(ingenium), la «douceur» «de miel»(mellinus), la "grâce»(lepos), l'élégance (venustas) et le caractère "raffiné» (cultus) tibullien (tout aussi bien que néo-catullien) devaient finir par attirer les éloges poétiques funéraires de Joachim Du Bellay à l'automne 1558 et à l'été 1559. À la fin des Tumuli des Poematum libri quatuor (où le «tombeau» poétique pénultième pour Saint-Gelais précédait le tumulus final «Sui-ipsius » [Tum. 40] de Du Bellay «luimême») :

[Mellinus...] cui melle fluebat

Mellita ex lingua dulcius eloquium.

Illius ut cecinit mellitos Regia versus,

Illius interitum sic quoque et ipsa gemat.

[Mellin...] lui qui faisait couler de sa bouche suave comme le miel des propos plus doux que le miel. Ses vers de miel, la cour les a chantés: sur son trépas qu'elle-même aussi gémisse ${ }^{16}$.

Puis, à la suite du Tumulus Henrici Secundi [...] de l'Angevin:

Qui nomen tibi, culte Sangelasi,

Mellini imposuit Gelasiique,

Mores ille tuos, tuos lepores,

Ipso tam bene nomine indicavit. [...]

Mellitos quoque saepe sic vocamus

Dulces versiculos venustulosque,

Et quales tibi Musa dictitabat.

Celui qui t'a donné, ô Saint-Gelais, homme de grande culture, le nom de Mellin et celui de Gelais («souriant»), a si bien révélé ton caractère et ton charme par cette dénomination même [...] nous qualifions ainsi, souvent, les petits vers, doux, gracieux, tels que ceux que te dictait toujours la Muse ${ }^{17}$.

16 Joachim Du Bellay, «[Tumulus] Mellini Sangelasii» [Tum. 39], v. 21-23, dans id., Poematum libri quatuor, 1558, fol. $59 \mathrm{v}^{\mathrm{o}}-60 \mathrm{r}^{\mathrm{o}}$ (O. poét., éd. Chamard, t. VII, éd. G. Demerson, p. 216-219).

17 Joachim Du Bellay, «Mellini Sang. Etymon», v. 1-4, 8-10, dans id., Tumulus Henrici Secundi Gallorum Regis Christianiss. [etc.], Paris, Fédéric Morel, 1559, fol. ciiiro (O. poét., éd. Chamard, t. VIII, éd. G. Demerson, p. 32-33). Voir Du Bellay, Epigr., 12, 1, «Pulchrior ut Nemesis culto dilecta Tibullo» («Némésis était plus belle: le raffiné Tibulle l'a chérie» [trad. Demerson]), dans id., Poematum libri quatuor, 1558, fol. 19v (= id., CEuvres poétiques, t. VII, p. 88-89), et Ovide, 
Or, dans le long commentaire détaillé qu'il fera vers 1597 sur les Odes pindariques de Ronsard, et sur l'ode adressée par Ronsard à Michel de L'Hospital sur les Muses, Nicolas Richelet décrira avec précision les qualités esthétiques, érudites et éthiques des vers latins de L'Hospital lui-même, en citant l'exemple des six livres posthumes d' «Épîtres ou Sermones » horatiens (regroupés, édités et publiés par Jacques-Auguste de Thou et d'autres hommes de Lettres en 1585: B). Ces vers de L'Hospital font preuve, selon Richelet, d'une «douceur \& elegante simplicité» poétique, ainsi que d'une "plenitude d'erudition \& de philosophie morale», d'une trempe esthétique et éthique foncièrement horatienne, à l'imitation de l'Horace du juste milieu stylistique et éthique (mediocris) des Epistolae et des Sermones ${ }^{18}$ :

[Ronsard: Le Chœur des Pierides Muses / Faictes illustres] Illustres à la vérité: car les six livres de ses Epistres que nous avons sont excellens, \& ont outre la douceur \& l'elegante simplicité de vers, une plenitude d'erudition \& de philosophie morale, tesmoins de la docte \& saincte prud'hommie de leur autheur ${ }^{19}$.

Amours, III, 9, 66, «auxisti numeros, culte Tibulle, pios» (à propos du « raffinement » du feu poète «cultivé», Tibulle, qui venait $\mathrm{d}^{\prime}$ «augmenter le nombre des [morts] pieux»). Voir aussi Du Bellay, «Tumulus Mellini Sangelasii», v. 2, "Pater leporis et ioci, Gelasius» ("Gelais, le père de la grâce et du badinage» [trad. Demerson]), «In eiusd. Carmina», et «Bellaii in eand. sententiam», v. 5, «Et poterat sæuum tam dulci carmine Ditem / Flectere» ("Il pouvait par son chant si doux, fléchir le cruel Dis» [trad. Demerson]), dans id., Tumulus Henrici

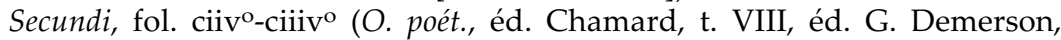
p. 30-35).

18 Voir P. Galand et L. Petris, "Introduction», dans L'Hospital, Carmina, t. I, p. 12-16: «Une poésie évangélique et stoïcienne dans le sillage d'Horace». En effet, «omne tulit punctum qui miscuit utile dulci » («Celui qui a mêlé l'utile au doux, enlève tous les suffrages », Horace, Art poétique, v. 343).

19 Nicolas Richelet ([c. 1576-1597]), sur Les Odes de P. de Ronsard, dans Les CEuvres de P. de Ronsard... reveues et corrigées par l'autheur... augmentées en ceste édition de plusieurs pièces non encore veues, avec plusieurs commentaires sur les Amours, les Odes et les Hynnes, rédigées en $X$ tomes, 10 t. en 5 vol., éd. Jean Galland, Paris, Nicolas Buon, 1604 (t. II : Les Odes de P. de Ronsard commentées par N. Richelet) / Les CEuvres de P. de Ronsard... Reveues et augmentées et Illustrées de Commentaires et remarques, 2 tomes, Paris, Nicolas Buon, 1623, t. I, [Odes I, x, Ronsard, OC, t. I, p. 737], p. 350-373 (p. 372) ; remarque de Richelet citée dans Ronsard, Lm, t. III, p. 160. 
Dans ce jugement si élogieux de la qualité exceptionnellement «douce» et «docte » des vers «horatiens » éthiques de L'Hospital, imprégnés de "philosophie morale», ce qu'il faut souligner, c'est surtout la mise en valeur, en tout premier lieu, de la beauté esthétique des vers horatiens du «sage» chancelier, dont «l'elegante simplicité » pourrait faire penser, d'une part (par analogie), à la beauté simple et élégante de la belle Pyrrha («simplex munditiis») des Odes (I, 5, 5) d'Horace, d'autre part (sur le plan métapoétique), à l'élégance non moins «douce» (comis) ou «cultivée» (cultus) des vers élégiaques de Tibulle («ingenium come, Tibullus» [Ovide, Tristes, V, 1, 18] / «numeri, culte Tibulle, tui» [Ovide, Amours, I, 15, 28 ; cf. III, 9, 66]), dont Quintilien et d'autres opposèrent l'esthétique «simple», «fort fine et élégante» ("tersus atque elegans maxime videtur auctor Tibullus» [Quintilien, Institution de l'art oratoire, $X, 9,93])$ à celle plus ouvertement savante et complexe, plus ostentatoire et plus «alléchante» de Properce («blandique Propertius oris » [Ovide, Tristes, V, 1, 17] $)^{20}$.

De plus, cette distinction traditionnelle entre la prétendue simplicité «facile» mais «ingénieuse» de Tibulle et la complexité «savante » ostensiblement «docte» de Properce fait penser, précisément, à la comparaison semblable faite par les contemporains de Du Bellay et Ronsard entre ces deux protagonistes fort différents de la poésie vernaculaire: «Que l'un est plus facile \& l'autre plus sçavant». En fait, trop simpliste, cette comparaison et cette distinction furent satirisées par Du Bellay lui-même dans l'«Hymne» ironique et parodique «de la Surdité » (de la fin de 1556) de ses Divers Jeux rustiques romains, adressé à Pierre de Ronsard ${ }^{21}$. Mais il s'agissait là aussi d'une comparaison, ou d'une opposition, que

20 Voir F. Cairns, Tibullus: A Hellenistic Poet at Rome, Cambridge, Cambridge UP, 1979 , p. 3-5. Comparer le jugement de Du Bellay lui-même (qui suit celui de Quintilien), dans «A une Dame» [XVIII], v. 137-140, Recueil de Poesie... reveu $\mathcal{E}$ augmenté depuis la premiere edition..., seconde édition, Paris, Guillaume Cavellat, 1553, fol. 68-77 (fol. 73) (O. poét., éd. Chamard, t. IV, p. 205-215 [p. 211]): «Cestui voulant plus simplement aimer / Veult un Properce \& Ovide exprimer, / Et vouldroit bien encor' se transformer / En l'esprit de Tibulle».

21 Joachim Du Bellay, "Hymne de la Surdité » [XXXVIII], v. 18, dans id., Divers Jeux Rustiques, et autres œuvres poëtiques, Paris, Fédéric Morel, 1558, fol. $71 \mathrm{v}^{\mathrm{o}}$ 76ro (fol. 71vº (O. poét., éd. Chamard, t. V, p. 185-196 [p. 186]). Voir G.H. Tucker, The Poet's Odyssey, p. 21-27 (ici p. 27). 
devait articuler plus tard, de façon plus subtile, plus sérieuse et plus positive, un autre ami commun de Du Bellay et de Jean de Morel d'Embrun, le précepteur gantois des filles de Morel, Charles Utenhove, parmi ses «ad...nomina Allusiones», parues en 1560 (avec Les Epitaphes sur le trespas de Ioachim Du Bellay Angevin, Poete Latin $\mathcal{E}$ François) à la suite de l'Epitaphium d'Utenhove et d'autres composés en douze langues pour Henri II :

\begin{tabular}{|c|c|c|}
\hline $\begin{array}{l}\text { amabilis, } \\
\text { BELLAIVS, } \\
\text { promptior ingenio, }\end{array}$ & $\begin{array}{l}\text { admirandus, } \\
\text { RONSARDVS } \\
\text { doctior, }\end{array}$ & ambo pares. \\
\hline \multicolumn{3}{|c|}{$\begin{array}{l}\text { BELLAIVS, RONSARDVS, amabilis, admirandus, } \\
\text { Promptior ingenio, doctior, ambo pares. }\end{array}$} \\
\hline $\begin{array}{l}\text { [aimable, } \\
\text { DU BELLAY, } \\
\text { plus ingénieux, }\end{array}$ & $\begin{array}{l}\text { admirable, } \\
\text { RONSARD } \\
\text { plus docte, }\end{array}$ & tous deux égaux. \\
\hline
\end{tabular}

Dans cette comparaison posthume des deux manières poétiques opposées de Du Bellay et de Ronsard, Utenhove rangeait celle de Du Bellay (qualifiée d' « aimable » et d'une « invention plus facile » / «plus ingénieuse» [«amabilis, promptior ingenio»]) du côté du «doux» Tibulle «ingénieux» («ingenium come») des Tristes d'Ovide, qualifié d' «ingenio facilis» par Du Bellay lui-même dans sa "Comparaison» du parlementaire parisien Jean de Brinon (décédé en mars 1555), feu mécène robin de la jeune Brigade, «avec Tibulle ${ }^{23}$. En revanche, l'humaniste gantois rattachait

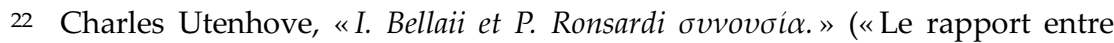
J. Du Bellay \& P. de Ronsard»), dans id. et al., Epitaphium in mortem Herrici Gallorum regis christianissimi, eius nominis secundi per Carolum Vtenhovium Gandavensem, $\mathcal{E}$ alios, duodecim linguis. Accesserunt $\mathcal{E}$ aliquot ad Illustrium quorundam Gallix hominum nomina Allusiones, per eundem, Paris, Robert Estienne, 1560, fol. 180 (= fol. [Diiii]v ${ }^{\circ}$ ) (trad. G.H. Tucker). Voir H. Chamard, Joachim Du Bellay 1522-1560, Lille, au siège de 1'Université, 1900 ; Genève, Slatkine Reprints, 1978, p. 494; V.-L. Saulnier, Du Bellay,

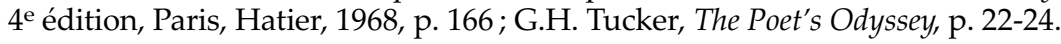

23 Joachim Du Bellay, «Eiusdem [Iani Brynonis senatoris Parisiensis], et Tibulli comparatio», dans id., Poematum libri quatuor, 1558, fol. 49ro [IV Tumuli, 
l'esthétique «plus docte» et «admirable» («doctior, admirandus») de Ronsard implicitement à celle tout aussi "admirable» et «savante» de Properce.

En fait, il s'agit ici d'un discours métapoétique sur deux manières poétiques (l'une élevée et suffisante, l'autre moins «docte» et plus humble) que Du Bellay lui-même n'avait pas rechigné à exploiter en 1552, à la veille de son départ pour Rome, dans la longue épîtrepréface de sa traduction du Quatriesme livre de l'Eneide de Vergile (suivie de ses propres Inventions de l'autheur), qu'il adressa, précisément, à son ami Jean de Morel $^{24}$. Car, afin de se démarquer de Ronsard, Du Bellay y avait épousé on ne peut plus clairement un discours de l'humilité poétique, en évoquant en passant l'ode élogieuse pindarique ronsardienne déjà citée, traitant des Muses et de Michel de L'Hospital. Si, dans cette épître-préface de 1552, Du Bellay avait loué, certes, les «singulieres vertuz » du chancelier de Marguerite de France, conciliateur de Ronsard et de Saint-Gelais ainsi que défenseur des innovations poétiques et linguistiques de Ronsard et de la jeune Brigade, il n'avait pas manqué non plus d'y afficher une déférence hyperbolique à l'égard de «l'inimmitable main de ce Pyndare François Pierre de Ronsart», en refusant d'entrer «laborieusement» en concurrence avec ce nouveau «Pindare» dans la composition d'un éloge poétique de leur ami commun, L'Hospital. Ce « refus» (cette recusatio) bellayen(ne) laissait sans doute entendre que la manière poétique plus «basse» de Du Bellay conviendrait mieux à une célébration appropriée des «singulieres vertuz» du «sage», Michel de L'Hospital, lui-même poète de l'humilité.

Et, encore à la fin de ces réflexions de 1552 sur L'Hospital et sur Ronsard adressées à Jean de Morel, Du Bellay poursuivait cette opposition entre l'humilité de sa propre Muse «laborieuse» et la suffisance pindarique de son confrère poétique pour présenter le

$\mathrm{XIV}, 3]$ : «Ingenio facilis, forma spectandus uterque» («Tous deux avaient un caractère facile; la beauté de tous deux devait attirer les regards.» [trad. G. Demerson]) (O. poét., éd. Chamard, t. VII, p. 182-183).

24 Joachim Du Bellay, [épître-préface] "Au seigneur J. de Morel Ambrunoys", dans id., Le Quatriesme livre de l'Eneide de Vergile, traduict en vers francoys... CEuvres de l'invention de l'autheur, Paris, Vincent Certenas [sic], 1552, p. 3-12 (O. poét., éd. Chamard, t. VI, p. 246-255). 
Vendômois comme un second Virgile, auteur d'une future épopée nationale, en déployant en français la distinction célèbre que Properce avait faite en latin (Élégies, II, 34, 66: "nescio quid maius nascitur Iliade» «je ne sais quoi de plus grand que l'Iliade est en train de naître ») entre sa propre poésie élégiaque plus humble et celle plus élevée de Virgile, émule du Homère de l'Iliade:

Michel De L'Hospital: dont les singulieres vertuz louées de toute la France, \& particulierement admirées de toy (cher amy MOREL) \& de tous ceux qui sont si heureux que de luy estre familiers, seroient par moy plus laborieusement descrites, si je leur pouvoy donner quelque grace apres l'inimmitable main de ce Pyndare François PIERRE DE RONSART, nostre commun amy: des labeurs duquel (si l'Apollon de France est prospere à ses enfentemens) nostre poëzie doit esperer je ne sçay quoy plus grand que l'Iliade $e^{25}$.

Bref, chez le traducteur du Quatriesme livre de l'Eneide de 1552, Du Bellay, comme chez Properce vis-à-vis de Virgile, futur auteur de l'Énéide, il s'agissait pareillement d'une recusatio du genre et du style élevés de l'épopée virgilienne (tout aussi bien que de l'ode pindarique), en conformité avec les choix poétiques et esthétiques et l'èthos plus humble de la Muse horatienne et tibullienne de Du Bellay lui-même, certes, mais en conformité aussi avec les qualités semblables non moins humbles et fines de la Muse horatienne et tibullienne de Michel de L'Hospital (voire peut-être aussi en conformité avec la «douceur» simple, quasi tibullienne, de la poésie vernaculaire de Saint-Gelais).

Or, ces remarques métapoétiques et sociopoétiques adressées par Du Bellay à son «Pylade» Morel tant sur les «vertuz» de leur ami L'Hospital que sur les grandes ambitions poétiques de «l'inimmitable main » de Ronsard, au lendemain de l'affaire Saint-Gelais et de l'intervention du futur chancelier de France, nous mènent à croire fort intéressante et assez probable l'hypothèse signalée récemment par les éditeurs des Carmina de L'Hospital, Perrine Galand et Loris Petris, qui ont suggéré que le dédicataire de la

25 Du Bellay, «Au seigneur J. de Morel Ambrunoys », dans id., Le Quatriesme livre de l'Eneide, 1552, p. 12 (O. poét., éd. Chamard, t. VI, p. 254-255). 
cinquième épître horatienne du premier livre, adressée «au précepteur de Marguerite [de France] fille du roi François», un certain «Pontrone» ("Ad Pontronium, Margar. Franc. Regis filiae Praeceptorem»), aurait pu être, à l'origine, Joachim Du Bellay. C'est du moins ce que laisse penser le témoignage de la version manuscrite de ce poème, conservée dans le fonds Dupuy 901 [fol. 44ro] de la BNF, qui «indique Ad Ioachimum», et «qui laisse penser que la pièce était peut-être d'abord dédiée à Joachim Du Bellay, chantre de Marguerite de France dans L'Olive [1549]», même si «dans toutes les éditions imprimées le dédicataire est Pontrone $»^{26}$.

Car, d'après le commentaire de Perrine Galand et de Loris Petris à cet endroit, l'incipit horatien de ce poème d'environ 1550, «Pontroni, quid agit nunc regia virgo [...]?» («Pontrone, que fait en ce moment la royale jeune fille [...]?» [trad. Galand-Petris]), faisait écho au début de la quatrième épître du premier livre des Épîtres, adressée par Horace à Tibulle, où Horace demande à son confrère poétique ce qu'il est en train de faire, non sans qualifier de «franc» le jugement porté par Tibulle sur ses Sermones à lui, Horace: «Albi, nostrorum sermonum candide iudex, / Quid nunc te dicam facere in regione Pedana?» («Albius, juge franc de nos Sermones, / Que fais-tu actuellement dans la région de Pédum, que dois-je dire? » [Horace, Épîtres, I, 4, 1-4]). Au moyen de cette allusion horatienne(-tibullienne), non seulement L'Hospital faisait ainsi de son propre dédicataire (Du Bellay ou Pontrone) un autre Tibulle (assimilation qui serait particulièrement appropriée, sur le plan métapoétique et esthétique, s'il s'agissait de Joachim Du Bellay), mais aussi, par son emploi de cet intertexte horatien, L'Hospital laissait entendre que ce «Tibulle» qu'était Du Bellay (ou Pontrone) était bien capable de porter des jugements «francs » sur les sermones horatiens de L'Hospital lui-même. Sur le plan sociopoétique, dans le contexte particulier de l'entourage lettré de Marguerite de France, dont Du Bellay, Michel de L'Hospital (et Pontrone) faisaient tous partie, cette dernière interprétation intertextuelle aurait toute sa cohérence.

26 Voir L'Hospital, Carmina, t. I, p. 152. 
Or une telle assimilation implicite de Du Bellay (ou de Pontrone) avec Tibulle chez L'Hospital - lui-même tibullien sur le plan verbal, thématique et métaphorique (dans ses Carmina figuraient pareillement des louanges de la vie simple, la thématique de la maladie et de la mort, et des métaphores semblables de l'équitation $)^{27}$ - devait être amplifiée plus tard chez Du Bellay dans sa propre articulation élégiaque de la thématique tibullienne du voyage malheureux chantée dans la première partie «élégiaque » de ses Regrets. Car le Du Bellay romain de 1553 à 1557 faisait non seulement de l'Ovide (à l'imitation du poète exilé des Tristes et des Lettres Pontiques) ${ }^{28}$, tant dans Les Regrets que dans sa grande élégie latine de l'exil Patriæ desiderium (Poemata, I, 7) ${ }^{29}$, mais il y faisait aussi bel et bien du Tibulle, en adoptant la persona élégiaque du poète expatrié et malade, cantonné à Corfou, de la troisième élégie du premier livre des Élégies de Tibulle ${ }^{30}$. L'explicit du dernier tercet du sonnet 25 des Regrets fait clairement écho à cette troisième élégie tibullienne, dans laquelle le poète élégiaque romain, ami d'Horace, avait exprimé le regret du voyage même («o quotiens [...] mihi tristia dixi / offensum in porta signa dedisse pedem!» [ $\mathrm{O}$ maintes fois! [...] la mauvaise augure du pied qui s'était heurté à la sortie» [Tibulle, Élégies, I, 3, 19-20]), si bien que cette allusion intertextuelle faisait $\mathrm{du}$ «moi » élégiaque bellayen de $l^{\prime}$ «exil» romain des années 1550 un second Tibulle expatrié, maladif et malheureux:

27 Voir L'Hospital, Carmina, t. I, p. 96 (I, 3, 54: «Quantula sunt opibus, non auri pondere mutem» [thématique de l'otium et de la vie simple]), p. 119 (comparaison de ce vers avec Tibulle, El., III, 3, 11: «Nam grave quid prodest pondus mihi divitis auri ? »), p. 162 (I, 6, 42 «contrahit in gyrum et dura compescit habena» [métaphore de l'équitation liée à la thématique de la mort, de la maladie et de la justice divine]), p. 175-176 (comparaison avec Tibulle, El., I, 4, 11: «Hic placet, angustis quod equum compescit habenis » et III, 7, 91-94 [métaphores de l'équitation]).

28 Voir G. Demerson, «Joachim Du Bellay et le modèle ovidien », dans Présence d'Ovide, éd. R. Chevallier, Paris, Les Belles Lettres, 1982, p. 281-294 (p. 281).

29 Voir G.H. Tucker, «Ulysses \& Jason: a problem of allusion in sonnet XXXI of Les Regrets», French Studies 36 (1982), p. 385-396; J. Ijsewijn, «Joachim Du Bellay's Patriæ desiderium », Humanistica Lovaniensia, 41 (1991), p. 244-261.

30 Voir G.H. Tucker, The Poet's Odyssey, op. cit., p. 21. 
N'estoit-ce pas assez pour rompre mon voyage,

Quand sur le seuil de l'huis, d'un sinistre presage, Je me blessay le pied sortant de ma maison? ${ }^{31}$

Quant à l'imitation d'Horace chez Du Bellay, non seulement le poète satirique des Regrets, auteur d' « une prose en ryme, ou une ryme en prose» (Regrets, s. II, v. 10) dans son emploi du vers alexandrin français, s'adonnait aussi, à Rome, à l'imitation du style bas et simple et du sermo pedestris des Sermones et des Epistolx de son devancier antique ${ }^{32}$ - dans la mouvance également de la poétique humble néolatine des Epistolæ et des sermones de Michel de L'Hospital - mais également, déjà lors de ses débuts poétiques parisiens, dans la composition des odes de ses deux recueils de «Vers lyriques» de 1549, dédiés à la «tresillustre Princesse, Madame Marguerite, seur unique du roy ${ }^{33}$, bien avant son départ pour l'Italie (et juste avant la publication des odes pindariques de Ronsard en 1550), Du Bellay s'était rangé fermement du côté de la poésie lyrique d'Horace, d'une «audace» «plus

31 Du Bellay, Les Regrets, 1558, fol. 7ro [s. XXV, v. 12-14] (O. poét., éd. Chamard, t. II, p. 71-72). De plus, vers 1569, cet écho tibullien chez Du Bellay devait être reconnu et relevé par Henri II Estienne, lecteur et annotateur des poésies françaises de l'Angevin, dans les marges de son exemplaire annoté (Les Regrets, édition de Paris, F. Morel, 1559, fol. $7 \mathrm{r}^{\mathrm{O}} /$ recueil factice d'Estienne [Lyon, Bibl. Mun., Rés. 321.834], p. 331), où Estienne devait écrire à cet endroit, "mihi tristia dixi offensum in porta signa dedisse pedem / Tib. puto", en citant donc par cœur («de Tibulle, je crois») ce vers de Tibulle.

32 Voir M.A. Screech, "Introduction», dans Joachim Du Bellay, Les Regrets et autres æuvres poëtiques. Suivis des Antiquitez de Rome. Plus un Songe ou vision sur le mesme subject, éd. J. Jolliffe, introd. et comm. M.A. Screech, $2^{\mathrm{e}}$ éd. Genève, Droz, 1974 [1966], p. 9-36 (p. 17-22) ; F. Gray, La Poétique de Du Bellay, Paris, Nizet, 1978, p. 59-110 (ch. IV «Sermo pedestris »); Les Regrets et autres auvres poëtiques de Joachim Du Bellay, éd. G.H. Tucker, Paris, Gallimard, 2000, p. 63. Sur les « aspects épistolaires » plus larges des Regrets, voir M. Bizer, Les Lettres romaines de Du Bellay, Montréal, PUM, 2001, p. 61-113.

33 Paraissant à la fin de L'Olive et quelques autres œuvres poëticques. Le contenu de ce livre. Cinquante Sonnetz à la louange de l'Olive. L'Anterotique de la vieille, E de la jeune Amye. Vers Lyriques. Par I.D.B.A., Paris, Arnoul L'Angelier, 1549 (fol. Ciiiiro-E[vi] $v^{\circ}$ ) de Du Bellay, et dans son Recueil de Poësie, presenté à tresillustre Princesse Madame Marguerite, seur unique du Roy, et mis en lumiere par le commandement de madicte Dame..., Paris, Guillaume Cavellat, 1549, p. 2467, 96 (O. poét., éd. Chamard, t. III, p. 3-54 et 86-149). 
basse \& lente » au dire de Ronsard ${ }^{34}$, et donc du côté esthétique et éthique horatien de Michel de L'Hospital également, plutôt que du côté du haut vol lyrique et épique, pindarique et virgilien de Ronsard :

Mais toy [Ronsard], si desires pour vivre,

Delaisser quelque Monument,

Pourquoy aussi ne veux-tu suyvre

Quelque haut, \& brave Argument?

Amy, vole plus hautement

Et en lieu si humble n'amuse,

Qu'à me louër ta docte Muse ${ }^{35}$.

De quel soleil, de quel divin flambeau

Vint ton ardeur [celle de Ronsard]? lequel des plus haulx

Pour te combler du parfaict de son mieulx

[Dieux,

$\mathrm{Du}$ Vandomois te fist l'astre nouveau?

Quel cigne encor' des cignes plus beau

Te prêta l'aele? \& quel vent jusq'aux cieulx

Te balança le vol audacieux

Sans que la mer te fust large tombeau $?^{36}$

Bref, à la différence du confrère pindarisant de la jeune Brigade, Ronsard, et tout comme le robin néolatin Michel de L'Hospital ${ }^{37}$, Du Bellay se rangeait vers 1550, sur le plan de ce dialogue métapoétique avec Ronsard, du côté du juste milieu stylistique (mediocritas), en affichant dans ses vers lyriques - comme L'Hospital dans ses épîtres néolatines horatiennes et tibulliennes - une juste crainte poétique et éthique du sort d'Icare ${ }^{38}$, symbole par excellence, selon ce L'Hospital horatien et chrétien (dans l'épître de 1547-1548

34 Voir plus haut, la note 15.

35 Joachim Du Bellay, «Au seigneur Pierre de Ronsard» [Ode X], v. 43-49, dans id., "Vers Lyriques» [à la suite de L'Olive, 1549], fol. E[i]vº-iivo (fol. Eiivo $)$ (O. poét., éd. Chamard, t. III, p. 42).

36 Joachim Du Bellay, L'Olive augmentée depuis la premiere edition. La Musagnoeomachie $\mathcal{E}$ aultres œuvres poëtiques, Paris, Gilles Corrozet et Arnoul l'Angelier, 1550, fol. E[v]vº [L'Olive, s. CXV, v. 43-49] (= Du Bellay, CEuvres poétiques, éd. Chamard et al., t. I, rev. Y. Bellenger, 1982 [1908], p. 124).

37 Voir Galand et Petris, "Introduction », dans L'Hospital, Carmina, t. I, p. 13-14.

Voir G.H. Tucker, The Poet's Odyssey, p. 31-33. 
adressée à l'humaniste bolonais Achille Bocchi [1488-1562] lors du séjour de L'Hospital à Bologne pour le concile de Trente) ${ }^{39}$, du châtiment de l'hubris intellectuel humain ${ }^{40}$ :

Dis adeo magnis impar dabit inde ruinam

Preceps ex alto liquefactis æthere pennies,

Ut male qui servans cauti mandata parentis

Icarus Icario dedit olim nomina pontho.

Sans commune mesure avec les grands dieux, elle tombera ainsi La tête la première de toute sa hauteur, ses ailes ayant fondu: C'est ainsi que celui qui avait mal obéi aux préceptes de son

Icare, à la mer Icarienne donna jadis son nom ${ }^{41}$.

[père avisé,

Concluons. En déjouant l'intrigue des poètes de cour de la vieille garde contre le jeune Ronsard lors de l'affaire Saint-Gelais aux environs de 1550-1552, grâce à l'habileté de sa propre plume de poète néolatin horatien déployée "au nom de Ronsard », non seulement Michel de L'Hospital, au début de sa carrière politique,

39 Voir L'Hospital, Carmina, t. I, p. 260-276 (surtout p. 262-263 [texte], 268 et 275 [commentaire]); M. Simonin, "L'Hospital (Michel de)», p. 438 ; l'édition critique (Les Questions symboliques d'Achille Bocchi (Symbolicæ Quæstiones, 1555), Tours, PUFR et Rennes, PUR, 2015) par Anne Rolet d'Achille Bocchi de Bologne, Symbolicarum Quxstionum de universo genere... libri quinque, Bologne, in ædibus Novæ Academiæ Bocchianæ, 1555, p. 276-281: Symbolon 130, "Summum bonum præstat fides fidem intimus amor in Deum, rite ipse cultus omnia» («La foi donne le bien suprême, l'amour intime pour dieu donne la foi, dieu à son tour, dûment honoré, accorde tout [trad. A. Rolet]»), où $\mathrm{A}$. Rolet souligne les échos verbaux de ce symbolon platonicien et érasmien de Bocchi introduits par L'Hospital. Voir L'Hospital, Carmina, t. I, loc. cit. (p. 268 et 271-272), dont le commentaire sur cette épitre de L'Hospital est en partie inspiré par la lecture de ce symbolon de Bocchi fournie par A. Rolet, "Achille Bocchi's Symbolicx Quæstiones», dans Mundus Emblematicus. Studies in Neo-Latin Emblem Books, éd. K.A.E. Enenkel et A.S.Q. Visser, Turnhout, Brepols, 2003, p. 101-130.

40 Comparer également Horace sur Dédale, inventeur des ailes artificielles de son fils, Icare: «audax omnia perpeti / gens humana ruit per vetitum nefas / [...] / expertus vacuum Dxdalus aëra / pinnis non homini datis» («audacieuse à tout supporter, / la race humaine s'élance sur le chemin du sacrilège et de la transgression. / [...] / Dédale essaya le vide de l'air / sur des ailes refusées à l'homme » [Horace, Odes, I, 3, 25-26 et 34-35])

41 Michel de L'Hospital, «Ad Achillem Bocchium poetam et equitem de fide christiana», I, 11 [d'environ 1548], 55-58 (Carmina, t. I, p. 262-263). 
sut défendre le Vendômois et ses confrères de la jeune Brigade avec art et diplomatie contre la peur et l'hostilité de ces premiers envers la nouvelle poésie de ces derniers - et envers le style et le langage «insolites » des Odes pindariques de 1550 de Ronsard en particulier -, mais le futur chancelier de France sut aussi concilier et réconcilier deux conceptions et deux esthétiques fort différentes, opposées, de la poésie de langue vernaculaire, représentées par les deux grands protagonistes de cette querelle politico-cuturelle: d'une part, le «doux» Saint-Gelais et, d'autre part, le «docte » Ronsard pindarisant.

Ce faisant, L'Hospital sut faire l'apologie de la nouveauté, de $l^{\prime}$ «audace» et de la difficulté poétiques ronsardiennes (dignes de Properce, tout aussi bien que de Pindare), celle, plus largement, des débuts ambitieux et controversés de la Pléiade. Mais L'Hospital manœuvrait en même temps, semble-t-il, pour faire tempérer parfois chez Ronsard un tel langage et style poétiques aussi «étrangers » qu'élevés - pour des raisons de tact envers Saint-Gelais, certes, mais peut-être aussi, pour des raisons de goût esthétique et de conviction éthique - en conseillant au Vendômois, par l'intermédiaire de Jean de Morel, une plus grande flexibilité stylistique et diplomatique dans son dialogue poétique et métapoétique avec les poètes de cour et avec Saint-Gelais en particulier.

Qui plus est, L'Hospital semble s'être rangé ainsi, dans la résolution de cette querelle (et tant soit peu paradoxalement) du côté de ses propres préférences stylistiques et éthiques pour la mediocritas $\mathrm{du}$ «juste milieu» typiquement horatien. Il se plaçait donc aussi du côté du choix poétique horatien et tibullien de Du Bellay, choix plus «modeste» par lequel celui-ci se démarquait de la manière et de l'ambition poétiques ronsardiennes, en pratiquant, lui, une poétique plus simple et plus fine, d'une «audace plus basse» (qu'il devait louer plus tard chez SaintGelais).

De plus, si Joachim Du Bellay se posait ainsi, dans la langue vernaculaire et en latin (tant dans ses odes initiales parisiennes que dans ses Regrets et Poemata ultérieurs de l'«exil» romain), en imitateur horatien et tibullien de la «Romaine grace» (non moins horatienne et tibullienne) du néolatin L'Hospital, ancien poète de l'exil en Italie, Michel de L'Hospital à son tour semble ne pas avoir fait faute de poursuivre un dialogue poétique avec Joachim dans 
ses Epistolæ seu sermones horatiennes, l'une desquelles, adressée "Ad Ioachimum» puis «Ad Pontronium», lassait entendre, sur le plan intertextuel, que son dédicataire était pour lui un second Tibulle.

Enfin, si au début de sa longue carrière politique Michel de L'Hospital faisait preuve ainsi d'une grande habileté de conciliateur dans la résolution d'un conflit esthétique et politico-culturel, en prônant, en fin de compte, l'esthétique et l'éthique du "juste milieu » et de la tolérance, ce rôle de conciliateur érasmien dans cette dispute socio-politico-poétique préfigurait aussi les tentatives ultérieures du futur chancelier de France de neutraliser et de réconcilier, sous Charles IX, l'hostilité réciproque de la Ligue et des huguenots, en affirmant l'importance du «juste milieu» gallican et de l'autorité royale, ainsi que de la tolérance confessionnelle. Si, dans cette dernière tentative, Michel de L'Hospital devait finir par échouer (et démissionner), dans cette première, par contre, il semble avoir réussi. Dans toutes deux, il faisait jouer peutêtre aussi ses propres préférences - d'une part esthétiques et éthiques, d'autre part poétiques et politiques - qu'il semble avoir partagées avec son contemporain gallican - son imitateur horatien et tibullien, poète de l'exil et $\mathrm{du}$ «juste milieu» - Joachim Du Bellay.

George Hugo TUCKER Université de Reading 


\section{MICHEL DE L'HOSPITAL, CARMINA, I, 7: QUELQUES RÉFLEXIONS AUTOUR DE LA POÉSIE CHRÉTIENNE}

Dans la première moitié du siècle, les humanistes chrétiens de toutes sensibilités s'interrogent sur les modalités d'une poésie religieuse en accord avec les valeurs évangéliques qu'ils défendent. Si les poètes médiévaux semblaient privilégier l'inspiration mariale, ceux de la première Renaissance, sans renier l'héritage des grands Rhétoriqueurs, sont à la recherche d'une plus grande simplicité formelle à l'image de la parole du Christ, une simplicité susceptible de traduire immédiatement les élans d'une foi placée au centre de l'existence humaine. L'effervescence religieuse qui caractérise les premières décennies se répercute dans une moindre mesure sur le terrain poétique. Michel de L'Hospital prend ainsi rang parmi ceux qui tentent de repenser la poésie à la lumière d'un évangélisme modéré. Il concentre ses réflexions dans l'épître 7 du livre I des Carmina, composée peu avant Noël 1547 dans le contexte conciliaire ${ }^{1}$. Dédiée à Claude d'Espence, elle serait, selon Loris Petris et Perrine Galand, "une réponse à l'Institution d'un prince chrestien que d'Espence avait dédié à Henri II le premier jour de l'Avent 1547 ». Ce dernier y affirmait notamment avoir pris « congé des Lettres séculières » pour s'adonner désormais à «l'écriture chrétienne $»^{2}$. C'est à une semblable conversion qu'invite L'Hospital dans son épître.

Celle-ci propose un développement en deux temps: d'abord une réflexion théorique sur la poésie chrétienne et sur ses condi-

1 Pour cette épître voir Carmina, t. I, p. 180-208 et Petris, La Plume et la tribune, p. 164-189.

2 Voir L'Hospital, Carmina, t. I, p. 198. Les deux hommes partagent une profonde admiration pour Érasme, dont ils divulguent la pensée éclairée et mesurée. 
tions de réalisation (v. 1-78), puis une illustration des critères énoncés dans la première partie avec la composition d'un hymne de Noël (v. 79-324), qui appartient au genre des Noëls très en vogue au début du siècle ${ }^{3}$. Selon les éditeurs des Carmina, l'épître 7 constituerait l'unique pièce poétique vraiment chrétienne, ou plus exactement biblique, de Michel de L'Hospital ${ }^{4}$. Dans la partie théorique, sur laquelle je m'arrêterai, l'épître définit les grandes lignes d'une poésie chrétienne, dépouillée de l'ornatus païen et gagée sur une sincérité éthique, comme l'avait voulu Macrin lui-même, dans la tradition du Contra Poetas impudice loquentes de Battista Spagnuoli ${ }^{5}$.

La promotion de la simplicité, concept complexe par excellence, ne saurait se comprendre sans une double contextualisation religieuse. Il convient d'abord de rappeler les déceptions nourries par le concile de Trente, qui favorisèrent le repli sur un idéal évangélique de simplicité: "L'Hospital sentait le besoin, nous dit Loris Petris, de définir un anti-modèle basé sur une simplicitas que les dignitaires conciliaires avaient oubliée pour de vaines disputes $»^{6}$. La valorisation de la simplicité est aussi à comprendre comme une reconquête, dans le contexte de la Réforme, qui a fait du terme le maître-mot de ses croyances et de son art. L'épître de Michel de L'Hospital entre en effet en résonance avec les réflexions poétiques contemporaines des réformés. Loris Petris nous invite à voir dans ces convergences une intention presque militante - je veux parler de militantisme poétique - : il s'agirait de lutter contre « une mainmise exclusivement protestante sur la doctrine de la simplicité évangélique dans le style ${ }^{7}$. C'est cette hypothèse stimulante que je voudrais interroger en proposant une relecture de l'art poétique de Michel de L'Hospital à la lumière de la réforme littéraire que mènent à la même époque les protestants.

3 Voir Poétiques de la Renaissance, dir. P. Galand-Hallyn et F. Hallyn, Genève, Droz, 2001, p. 258 (J. Vignes). Voir aussi Petris, La Plume et la tribune, p. 167.

4 Voir L'Hospital, Carmina, t. I, p. 202-203.

5 Ibid., p. 13.

6 Voir Petris, La Plume et la tribune, p. 167-168.

7 Ibid. 


\section{PRÉSENTATION DE L'ÉPITTRE: CONTENU ET CONTEXTE}

Aux vers 74-75 de son épître, Michel de L'Hospital présente sa réalisation poétique en termes de nouveauté :

Ergo rem insolitam te magno authore novamque

Aggredior [...]

Je vais aborder, sous ta puissante égide, un sujet inaccoutumé, Nouveau [...].

Cette nouveauté n'en a que l'apparence puisque, dans les années 1540, la poésie chrétienne a déjà d'illustres représentants ; le genre "populaire» des Noëls connaît du reste un franc succès dans les premières décennies du siècle dans les milieux catholique et réformé: citons, entre autres, les Noelz de Mathieu Malingre (1533) ou ceux de Nicolas Denisot (1545). L'Hospital le précise lui-même dans la suite de la citation:

[...] serasque tibi istius offero tanquam

Primitias generis.

Et je t'offre pour ainsi dire les prémices

Tardives de ce genre.

La nouveauté revendiquée ne porte pas tant sur la matière que sur la manière. En cela, Michel de L'Hospital a aussi quelques célèbres prédécesseurs sous l'autorité tacite desquels il se place: en particulier Jean Salmon Macrin (1490-1557) et Marcantonio

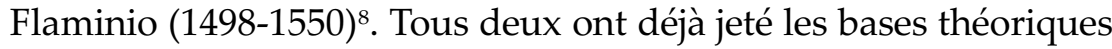
d'un art chrétien dans les préfaces de leurs œuvres. En 1545, Flaminio avait publié une exégèse des psaumes dans laquelle il insistait sur le renouvellement intérieur par la foi et sur l'importance de la grâce ${ }^{9}$. Un an plus tard, en 1546, dans la dédicace de cette Brevis explanatio suivie de paraphrases de trente-deux

\footnotetext{
8 Dans l'épître I, 15, rédigée en mars 1550, Michel de L'Hospital recommande à Marguerite de France les vers sacrés de Marcantonio Flaminio: voir Petris, La Plume et la tribune, p. 169.

9 M.A. Flaminii in librum Psalmorum brevis explanatio [...], Venise, 1545.
} 
psaumes, « il estimait que les enfants ne doivent plus apprendre les fables païennes mais les poèmes sacrés, d'où la nécessité d'employer un style simple et clair ${ }^{10}$. Quant à Macrin, il reniait dès 1537 la Muse classique, considérant que la poésie devait se mettre au service de la religion ${ }^{11}$. Dans les années 1540, la poésie religieuse a déjà de bons représentants mais c'est un courant encore marginal par rapport à la poésie profane, amoureuse en particulier. Elle est pratiquée dans le milieu évangélique, en langue vernaculaire (Marot et Marguerite de Navarre) ou néo-latine (Macrin et Flaminio), et dans le milieu réformé (Mathieu Malingre à Neuchâtel). Dans ces années 1540, la poésie chrétienne commence à devenir un enjeu confessionnel avec la publication des Psaumes de Marot (1541 et 1543) et l'expérimentation d'une langue spirituelle réformée dans le réseau de Neuchâtel.

En revanche, il n'existe pas encore d'art poétique, pas de réflexion théorique sinon par bribes dans les préfaces (Érasme, Flaminio, d'Espence). C'est sans doute en cela que Michel de L'Hospital fait figure de novateur, pour reprendre les mots de Loris Petris : il pose assez clairement par anticipation les principes d'une poésie chrétienne qui seront ensuite repris, nuancés ou transformés dans les préfaces théoriques des poètes de la deuxième moitié du siècle, comme Du Bellay, Du Bartas, La Ceppède ou Desportes, au temps de la conversion officielle des Muses. Les conditions de réalisation de la poésie chrétienne ne vont pourtant pas de soi pour un humaniste pétri de culture antique, car il faut remettre à plat pour ainsi dire ce débat toujours réactualisé depuis Platon entre fable et vérité. C'est ce à quoi s'emploie Michel de L'Hospital en tentant de dépasser le conflit et en argumentant en faveur d'une conciliation de la poésie et de la religion.

\section{ÉLÉMENTS D’UNE POÉTIQUE CHRÉTIENNE}

Aux vers 1-34, Michel de L'Hospital commence par s'interroger sur le désintérêt des poètes pour l'inspiration chrétienne. Après la

10 M.A. Flaminii in librum Psalmorum brevis explanatio [...], Paris, 1546. J'emprunte ces références à Petris, La Plume et la tribune, p. 169-172.

11 Ibid., p. 170-171. 
proposition de trois hypothèses, il retient la troisième, qui concerne l'incompatibilité entre la poésie, conçue comme un exercice artificiel et ornemental, et la matière sacrée, qui exige une expression sincère: «carmina [...] disconvenientia sacris» (v. 14). Jusqu'au vers 34, il semble donner raison aux pourfendeurs de l'union de la poésie et de la religion en feignant d'accréditer l'hypothèse du divorce entre inspiration profane et révélation chrétienne, entre fable païenne et vérité biblique: la poésie susciterait l'agrément par la futilité (v. 15-17) et par la fiction (v. $18 s q)$, alors que la religion relèverait du domaine de la vérité, conformément à la pensée des Grecs. Ce jugement est à replacer dans le débat qui divise la Renaissance sur l'assimilation de la culture antique par le christianisme. Si le transfert d'un mode de pensée à l'autre trouve à se justifier par le recours à l'exégèse allégorique, il peine à s'imposer dans le domaine poétique. Dans La Plume et la tribune, Loris Petris rappelle les querelles qui secouent la Renaissance italienne entre «les défenseurs de la poésie comme seconde théologie compatible avec les Écritures » et les promoteurs d'une séparation bien nette entre les deux domaines au nom d'une impossible analogie ${ }^{12}$. Si Marsile Ficin plaide en faveur d'une sacralisation de la poésie dans son De christiana religione, et si Boccace, dans sa Genealogia deorum (liv. XIV), donne une légitimation poétique aux fables, celles-ci ne cessent d'être mises en question jusqu'au début $\mathrm{du} \times \mathrm{XVI}^{\mathrm{e}}$ siècle, précisément parce qu'elles ne font pas l'objet d'une instrumentalisation spirituelle. Les poètes, comme le souligne Michel de L'Hospital, se complaisent dans la séduction des fictions profanes sans chercher à les mettre au service de la foi. Il s'agit là encore d'une condamnation traditionnelle depuis Érasme et les poètes néo-latins d'origine italienne. Dans son Contra Poetas impudice loquentes carmen (1513), Spagnuoli réclamait déjà une poésie moralement irréprochable débarrassée des fables et des fictions amoureuses. Jean Salmon Macrin lui emboîte le pas en promouvant une poésie antérotique et sacrée contre une veine profane qu'il juge pernicieuse ${ }^{13}$.

12 Voir Petris, La Plume et la tribune, p. 165, qui fait le point sur les tensions entre poésie et religion, entre culture classique et révélation chrétienne, entre fiction profane et vérité biblique à la Renaissance.

13 Pour la lutte contre le paganisme de l'inspiration poétique au début du siècle, voir la mise au point de Jean Vignes, dans Poétiques de la Renaissance, dir. 
Les premiers vers de l'épître font écho à cet arrière-plan théorique et polémique. Dans le sillage de Macrin, Michel de L'Hospital va proposer une autre voie propre à réconcilier le profane et le sacré, la chair et l'Esprit pour ainsi dire, à partir, non pas d'un rapport analogique et allégorique suivant la proposition néo-platonicienne, mais en reconsidérant le discours poétique à la lumière du sermo evangelicus. Contrairement à Du Bellay, qui n'exclura pas les images païennes et mythologiques dans le programme de sa lyre chrétienne (1552), Michel de L'Hospital chasse définitivement la poésie amoureuse et son arsenal de fables. Il invite à une conversion des Muses qui ne s'imposera vraiment dans les Lettres françaises que dans les années 1570 :

Nos vero falsis, mendacibus atque malis Dis

Versus illorum similes similesque poetas,

Et fucum et veneres et titillantia sensus

Linquamus foeda et lasciva et inania scripta,

Et quae lecta docent peccare animosque virorum

Corrumpunt faciles inhonestisque ignibus urunt.

Quant à nous, laissons aux dieux faux, mensongers et mauvais

Les vers et les poètes qui leur ressemblent,

Ainsi que le fard, les grâces et les propos malséants,

Lascifs et futiles qui chatouillent les sens,

Ceux dont la lecture enseigne à pécher, corrompt

Les âmes malléables et les enflamme de feux déshonnêtes. (I, 7, 42-47)

Le changement de sujet, du profane au sacré, exige un changement de discours: contrairement aux poètes chrétiens de la génération 1570, Michel de L'Hospital n'envisage pas la conversion des Muses comme le recyclage d'un même langage poétique mais comme l'invention d'un nouveau langage directement inspiré du cœur, dépouillé et simple («nudoque ac simplice cultu», v. 53). L'invocation du nom de Dieu exige une épuration de la langue, un dépouillement drastique de ses attributs rhétoriques, sans doute efficaces dans l'échange avec les hommes, mais frappés

P. Galand-Hallyn et F. Hallyn, Genève, Droz, 2001, chapitre IV («Poésie et religion au XVI ${ }^{\mathrm{e}}$ siècle»), p. $264 s q$. Jean Salmon Macrin reprend les critiques faites à l'encontre des poètes chrétiens par Érasme et Battista Spagnuoli. 
d'inanité dans la communication avec Dieu. L'Hospital formule ainsi le vœu d'une transparence entre la langue et le cœur, que seul rend possible l'espace resserré de la prière:

Sit sermo incomptus, facilis, non anxius, omnem

Ornatum fugiens, plenus gravitatis, ut intus

Quae concepta animo possit modo reddere sensa

Plane atque auxilio naturae simplicis uno; [...]

Que notre discours soit sans apprêt, aisé non tarabiscoté,

Fuyant tout ornement, plein de gravité, pour être capable

De rendre parfaitement et avec le seul concours de la simple nature

Les pensées que l'âme vient de concevoir ; [...] (I, 7, 55-58)

Les mots, réduits à des signes, n'ont d'autre fonction que d'amener l'âme à Dieu, seul objet de son amour. Le changement de destinataire qu'implique la poésie sacrée exige de repenser les normes de l'éloquence: il ne s'agit plus de plaire à Dieu mais de le toucher, de lui ouvrir son cœur dans un élan spontané de sincérité qui défie les règles de l'art. Jamais Michel de L'Hospital ne fait référence à l'éloquence biblique mais c'est bien pourtant à saint Augustin ou à Érasme qu'il emprunte les mots de son art poétique chrétien. Il semble appliquer à la poésie les analyses esthétiques et spirituelles qui président au chapitre IV du De Doctrina christiana ou de l'Ecclesiastes, en particulier lorsqu'il évoque les cantiques chrétiens de la liturgie:

Quid vero ipsa Dei memorantia carmina laudes

Qualiacunque sacra vulgo cantantur in aede,

Laetitia afficiunt animos auresque bonorum,

Sponte sua, sine delectu, splendore vel arte,

Et lenocinio sermonis?

Mais que dire des cantiques qui proclament les louanges de Dieu,

Tels qu'on les chante souvent à l'église,

Qui remplissent de joie les âmes et les oreilles des hommes de bien,

Spontanément, non par le choix, la splendeur, l'art

Ou la séduction du style? (I, 7, 63-67)

Au livre IV du De Doctrina christiana, Augustin tentait de justifier le dénuement de la langue sacrée, en mettant en avant le critère de 
la majesté du sujet « qui est à elle seule un ornement qui dispense de tout autre ${ }^{14}$. Au-delà des règles, il invoquait une éloquence du cœur pour ratifier un sublime chrétien reposant sur la véhémence et l'ardeur qui exempte le locuteur de la science des rhéteurs. On reconnaît dans la description augustinienne de l'orator Dei celle du poète évangélique qu'appelle de ses vœux Michel de L'Hospital. La simplicitas, comprise comme une coïncidence des res et des verba, engage une sinceritas, toutes deux liées à la dignitas et à la gravitas. La simplicité linguistique et esthétique engage une éthique, inspirée du sujet divin: L'Hospital invite le poète à offrir à Dieu un cœur pur, un culte dépouillé «comme lui-même est simple, nullement sujet au changement» (v. 54-55).

Le langage poétique trouve un modèle approprié dans la prière humble et cordiale, l'inspiration créatrice dans une dévotion cultuelle. Michel de L'Hospital remotive les sources verbales de la poésie en l'articulant à la foi, dont il offre un exemple avec son hymne chrétien. Il résorbe ainsi l'incompatibilité des deux discours, profane et sacré, en défendant et illustrant une «nouvelle» poésie selon ses propres mots, moins innovante toutefois pour son sujet («rem insolitam...novamque», v. 74) que pour sa forme, une poésie à contre-courant de la veine païenne, qui puisse circuler du fidèle à Dieu. Aux règles et aux ornements de la rhétorique, il oppose les critères de simplicité, de sincérité et de dévotion.

La simplicité contre les artifices de la rhétorique, l'élan du cœur contre la fureur néoplatonicienne, la condamnation de l'ornatus paien au profit d'un discours naturel : tels sont aussi les arguments que brandissent les réformés ou «assimilés» dans les mêmes années 1540 ou qu'ils brandiront dans les années 1550 dans le contexte de la polémique autour de Ronsard. La poétique chrétienne que défend Michel de L'Hospital dans l'épître 7 entre en coïncidence avec bien des principes dont se réclament les réformés, issus eux aussi du milieu évangélique français et très marqués euxmêmes par Augustin et Érasme ${ }^{15}$. Ce sont ces convergences qui

\footnotetext{
14 M. Fumaroli, L'Age de l'éloquence. Rhétorique et «res literaria» de la Renaissance au seuil de l'époque classique, Genève, Droz, 1980, p. 73.

15 Petris, La Plume et la tribune, p. 168: «L'Hospital côtoie à Ferrare le milieu hétérodoxe de Renée de France, qui a accueilli en 1536 Marot et Calvin,
} 
n'excluent pas des divergences, que je voudrais à présent considérer en examinant les arguments de la poétique réformée qui commence à s'élaborer dans les années 1540-1550.

\section{D’UNE POÉTIQUE ÉVANGÉLIQUE À UNE POÉTIQUE RÉFORMÉE: CONVERGENCES ET DIVERGENCES}

Cette poétique réformée prend corps dans les années 1525-1530 dans le milieu de Neuchâtel avec les poètes de l'entourage de Guillaume Farel et de Pierre Robert, dit Olivétan, qui participent à la première traduction de la Bible en français. Elle trouve un nouvel élan au moment de la première publication des Psaumes, dont les textes liminaires assoient la réflexion sur la poésie. Dans l'épître qui ouvre les premières éditions du Psautier huguenot à partir de 1543, Calvin se place d'emblée parmi les pourfendeurs du paganisme poétique. Il reprend à neuf les récriminations de ses prédécesseurs contre les productions mondaines qui dénaturent, selon lui, l'origine et la fonction sacrées de la poésie:

Seulement que le monde soit bien advisé, qu'au lieu de chansons en partie vaines et frivoles, en partie sottes et lourdes, en partie sales et vilaines, et par consequent mauvaises et nuisibles, dont il a usé par cy devant, il s'accoustume ci apres à chanter ces divins et celestes Cantiques avec le bon Roy David $^{16}$.

Clément Marot $^{17}$ et, plus tard, Théodore de Bèze transfèrent en 1550 au domaine strictement poétique les accusations du réforma-

inquiétés après l'affaire des Placards ». Ils partagent le même goût pour le style simple et la rudesse biblique.

16 Voir l'épître de Calvin en tête des éditions du Psautier huguenot à partir de 1543 («A tous chrestiens, et amateurs de la Parole de Dieu»), publiée par Gérard Defaux dans son édition des Cinquante Pseaumes de David de Clément Marot (Paris, Champion, 1995), p. 315-320.

17 Clément Marot résume ces deux qualités dans l'épître au Roy qui ouvre sa traduction des Psaumes en 1543 (voir Cinquante Pseaumes de David, op. cit., p. 95-97, v. 39-80: «O donques Roy, prens l'euvre de David, / Euvre plustost de Dieu, qui le ravit, / D'autant que Dieu son Apollo estoit, / Qui luy en train et sa harpe mettoit, / Le saint Esprit estoit sa Caliope: / [...] Finalement son ruisseau cabalin / De Grace fut la fontaine profonde, / Où à grans traitz il 
teur pour mener campagne contre le paganisme ostentatoire des premières œuvres de la Pléiade:

Que pleust à Dieu que tant de bons espriz que je cognoy en France, en lieu de s'amuser en ses malheureuses inventions ou imitations de fantaisies vaines et deshonnestes, (si on en veult juger à la verité) regardassent plustost à magnifier la bonté de ce grand Dieu, duquel ils ont receu tant de graces, qu'à flatter leurs idoles, c'est à dire leurs seigneurs ou leurs dames, qu'ils entretiennent en leurs vices, par leurs fictions et flatteries. À la verité il leur seroit mieux seant de chanter un cantique à Dieu, que de petrarquiser un Sonnet, et faire l'amoureux transy, digne d'avoir un chapperon à sonnettes: ou de contrefaire ces fureurs poëtiques à l'antique, pour distiller la gloire de ce monde, et immortaliser cestuy cy ou ceste là $[\ldots]^{18}$.

Avant Michel de L'Hospital, les auteurs réformés soldent l'héritage païen au nom de sa prétendue malfaisance morale et lui substituent le modèle davidique, le seul qui soit légitime parce $q^{\prime}$ 'il procède de Dieu et qu'il nous met en communication directe avec lui :

Parquoy quand nous aurons bien circui par tout pour cercher çà et là, nous ne trouvons meilleures chansons ne plus propres pour ce faire, que les Pseaumes de David, lesquels le sainct Esprit luy a dictez et faicts. Et pourtant, quand nous les chantons, nous sommes certains que Dieu nous met en la bouche les paroles, comme si luy mesme chantoit en nous, pour exalter sa gloire $^{19}$.

Les auteurs réformés mettent la poésie sous le surplomb de la foi : elle s'exerce dans le cadre d'une dévotion privée sur le modèle d'une piété cultuelle. Apparaît néanmoins une première différence avec Michel de L'Hospital, qui ne propose pas, en dehors des prières liturgiques et de la parole évangélique du Nouveau Testa-

but de la claire unde, / Dont il devint Poëte en un moment, / [...] / Icy sont donq les louanges escrites / Du Roy des Roys, du Dieu des exercites. / [...] / Icy oyt on l'Esprit de Dieu, qui crie / Dedans David, alors que David prie».

18 Théodore de Bèze, Abraham sacrifiant, éd. K. Cameron, K.M. Hall et F. Higman, Genève, Droz et Paris, Minard, 1967, p. 47.

19 Voir l'Epître de Calvin, éd. cit., p. 319. 
ment, un modèle explicitement biblique. Contrairement à Érasme et à Flaminio qui recommandent l'imitation davidique comme ressourcement possible de la poésie, Michel de L'Hospital ne fait pas des Psaumes un élément fondateur de sa poétique chrétienne. Faut-il voir dans ce choix implicite la volonté de se démarquer de la Réforme qui s'est pour ainsi dire annexée le livre davidique sur le plan poétique et liturgique? L'art poétique de Michel de L'Hospital pourrait se lire comme une réponse catholique aux tentatives réformées sur la base d'un nouveau modèle poétique: la langue évangélique plutôt que la langue psalmique.

Ce silence sur les Psaumes est à relever quand on sait l'importance qu'ils revêtent pour les réformés. La quête d'une poésie chrétienne prend assise, chez eux, sur l'imitation de la Bible, traduite à larges mains en ce siècle épris de vérité philologique, plus précisément sur la parole psalmique, riche réservoir de mots et de tours propres à nourrir la prière poétique. Les Psaumes offrent précisément l'exemple absolu d'un langage authentique et émotionnel, seul susceptible de forcer l'écoute de Dieu. «David n'emprunte point une rhétorique fardée (comme celle des orateurs profanes) $»^{20}$, mais il parle la langue du cœur: «c'est l'office du cœur d'esmouvoir la langue et la bien disposer à prier»; «le cœur doit dicter et former les parolles $»^{21}$. Les réformés élaborent ainsi, à partir du modèle psalmique, une poétique de la prière fondée sur un déni de l'ars au profit de la natura et, a contrario, sur une valorisation de la spontanéité et de l'émotion verbales comme gages d'une sincérité éthique et d'un amour inconditionnel, ce fameux zèle qu'exige précisément Dieu de sa créature.

Autrement dit, les réformés fondent les critères de simplicité, de naturel, de dévotion et de sincérité sur le modèle davidique plus que sur le modèle évangélique, dans le domaine poétique à tout le moins. C'est dans la langue biblique qu'ils trouvent le modèle d'une langue du cœur, vraie et immédiate, simple et naturelle, chère à Michel de L'Hospital. Ainsi Calvin dans l'Institution de la religion chrestienne dès 1541 :

20 Calvin, Commentaires sur les Pseaumes, Genève, Conrad Badius, 1558, Ps 38, p. 253.

21 Ibid., Ps 102, p. 632. 
[...] telle simplicité rude, et quasi agreste, nous esmeut en plus grande reverence que tout le beau langage des Rhétoriciens du monde, que pouvons-nous estimer, sinon que l'Escriture contient en soy telle vertu de verité qu'elle n'a aucun besoing d'artifice de parolles? [...] Dont il est aisé d'apercevoir que les Sainctes Escritures ont quelque proprieté divine à inspirer les hommes, vues que de si loing elles surmontent toutes les grâces de $l^{\prime}$ industrie humaine ${ }^{22}$.

La simplicité de la langue est le gage de son infaillible authenticité. L'appréhension directe de la vérité suscite une émotion, bien supérieure à l'art du langage humain :

[...] les Sainctes Escritures nous poindront si vivement, elles perceront tellement nostre cœur, elles se ficheront tellement au dedans de nous, que toute la force qu'ont les Rhetoriciens ou Philosophes, au prix de l'efficace d'icelles, ne sera que fumée ${ }^{23}$.

La simplicité de l'éloquence biblique constitue donc un modèle à double titre: d'abord parce qu'elle met directement au contact de la vérité, ensuite parce qu'elle touche immédiatement le cœur. En un mot, deux qualités propres à soutenir le projet d'édification de la Réforme.

Or là réside une autre différence entre les deux poétiques chrétiennes. Comme le dit Loris Petris, « contrairement aux protestants, à aucun moment L'Hospital ne justifie la recherche d'un style simple par la volonté de vulgariser les Écritures en les rendant abordables aux gens simples». La poétique qu'il défend dans son épître est résolument lyrique - la louange à Dieu - et non pédagogique. Nous sommes là à l'opposé des premières ambitions de la Réforme qui promeut une littérature de vulgarisation pour instruire le fidèle, encadrer son expérience spirituelle, lui fournir des modèles de vie chrétienne, enfin lui apprendre à parler à Dieu en structurant le contenu de sa prière et en lui donnant des mots adéquats. Le poète joue un rôle fondamental dans cette formation.

22 Jean Calvin, Institution de la religion chrétienne, éd. J.-D. Benoît, Paris, J. Vrin, 1957-1963, [éd. 1560], I, 8, p. 101.

23 Ibid. 
Calvin lui confie la charge d'instruire et d'exhorter, «d'inciter à prier et louer Dieu, à mediter ses œuvres, afin de l'aimer, craindre, honnorer et glorifier $»^{24}$. Pour la Réforme, la poésie constitue un instrument idéal d'édification et de dévotion.

Si Michel de L'Hospital ne saurait souscrire à une définition apologétique ou militante de la poésie, sa pratique de poète chrétien le porte plus naturellement vers la prédication, toute laïque soit-elle, que vers le lyrisme de la prière que prône son épître en forme de manifeste et qu'illustre comme un cas unique son Noël. La défense de l'humilis stylus ne s'inscrit pas chez ce dernier dans le cadre du rudis stylus promu par les réformés, mais relève plutôt du sermo evangelicus associé au style moyen ou à la mediocritas d'Horace, qui offre par excellence le modèle d'un èthos modeste et d'un style familier. D'où le choix de l'épitre plutôt que de la prière, dans laquelle il peut concilier sans mal le sermo horatien et le sermo évangélique ${ }^{25}$, l'écriture naturelle et sérieuse du modèle antique et la simplicité grave ou sublime d'inspiration chrétienne ${ }^{26}$. Comme le montre Loris Petris, l'ornatus païen n'est pas définitivement condamné par Michel de L'Hospital mais toléré grâce à la spontanéité et à l'élan dévotionnel qui préside à la poésie chrétienne. Le concept de simplicité passe par un mariage raisonné des

24 Voir l'épître de Calvin en tête des éditions du Psautier huguenot à partir de 1543 («A tous chrestiens, et amateurs de la Parole de Dieu»), publiée par Gérard Defaux dans son édition des Cinquante Pseaumes de David de Clément Marot (Paris, Champion, 1995) p. 319.

25 C'est le langage vrai et dépouillé des apôtres. Voir ses discours politiques, notamment celui prononcé le 31 juillet 1561, devant l'assemblée des prélats convoqués à Poissy (Petris, La Plume et la tribune, p. 423-424) : "Nostre religion ne gist poinct en dispute ny en fondement de doctrine mais en simplicité et humilité, comme il appert par la remonstrance d'un personnage, vieillard non gueres savant, ny versé en dialectique, et ne sachant autre chose que Jesus Christ et iceluy crucifié, comme il est escript en l'Histoire ecclesiastique, lequel par simplicité de parolle et confession de foy convainquit de grandz dialecticiens qui n'auroyent pas plusieurs jours esté convaincus ny confutez par les plus savans. Et certes, Jesus Christ avoit choisi ses apostres gens simples qui ont escript nuement et simplement sans entendre ny savoir l'art du silogisme, comme il appert mesmes par leurs escripts ».

26 Voir Carmina, t. I, p. 14: «Comme Horace dans la célèbre Satire, I, 4, v. 39-44, L'Hospital, en III, 8, v. 65-67, rapproche le style de l'épître du langage courant, le sermo. Dans plusieurs autres lettres, il revendique cette écriture naturelle, en accord avec la poétique chrétienne énoncée dans l'épître I, 7, qui réclame une simplicité, une sincérité et une gravité proche du sermon du prêtre». 
modèles susceptibles de mener à sa pleine réalisation un langage poétique sacré.

Si Michel de L'Hospital se distingue des réformés à la fois par sa conception de la simplicité et par son usage, il s'en éloigne aussi pour le rôle secondaire qu'il accorde à la musique. Dieu n’a pas besoin de musique, semble-t-il dire au vers 62 . Chez les réformés au contraire, musique et poésie marchent l'amble. Le chant constitue de fait un auxiliaire privilégié de la diffusion des Écritures et de l'édification du fidèle. Selon une théorie qui remonte aux Pères, à Augustin en particulier, reprise par Luther et Calvin, la mélodie touche les sentiments du cœur, aidant à sa transformation. Dans l'épître de 1543, Calvin élabore une théorie de la fonction émotionnelle de la musique: la parole ne saurait se suffire à elle-même sans une mélodie sobre et monodique, seule capable d'enflammer les cœurs et de les élever vers Dieu, de soulager les esprits en restaurant leur confiance en lui ${ }^{27}$ : «nous cognoissons par experience, que le chant a grande force et vigueur d'esmouvoir et enflamber le cœur des hommes ${ }^{28}$, pour invoquer et louer Dieu d'un zele plus vehement et ardent $»^{29}$. Le poète ne pourra en effet contribuer à la "réformation» des cœurs que s'il mêle la musique à la parole, et le fidèle n'atteindra l'état dévotionnel adéquat qu'en chantant sa foi.

Issues de l'humanisme chrétien de la première Renaissance, les deux réflexions poétiques, celle de Michel de L'Hospital et celle des réformés, se rejoignent sur bien des points: condamnation de la Muse mondaine et des fables païennes, promotion des critères de simplicité et de naturel, où le mouvement du cœur joue un rôle déterminant, articulation de la poésie à la foi et de l'inspiration à la dévotion. Elles participent à leur manière à une prise de conscience progressive de la nécessité d'adapter le langage poétique aux impératifs de la foi. Mais cette pensée convergente se fissure au gré des sensibilités religieuses ou des inclinations personnelles. La radica-

27 Voir C. Grosse, «L'esthétique du chant dans la piété calviniste au premier temps de la Réforme (1536-1545) », Revue de l'histoire des religions, 227 (2010), p. 13-31.

28 Voir M. Malingre, Noelz nouveaux, [Neuchâtel], [Pierre de Vingle], 1533, préface.

29 Calvin, «Epître» de 1543, éd. cit., p. 318-319. 
lisation des croyances a aussi une incidence sur la théorie et les pratiques poétiques. Attachée à la sola scriptura et à la sola fide, tendue vers un programme de vulgarisation et une ambition théologique, la poésie réformée fonde son idéal poétique sur le modèle biblique à partir duquel elle repense les normes de l'éloquence et l'enrichissement de la langue française. Poète juriste, réfractaire à un usage militant ou pédagogique de la poésie, Michel de L'Hospital prône un évangélisme civique qui se réclame de la parole simple et majestueuse des apôtres, mais qui reste tributaire de la rhétorique antique et de la langue latine classique, dans laquelle il entend illustrer son art poétique. Plus enclin au calor érudit loué par Politien, il défend une poésie dévotionnelle régulée par la louange et centrée sur l'histoire du Christ, alors que les protestants militent en faveur d'une parole pénitentielle marquée par l'examen de soi et la prière davidique. Michel de L'Hospital ne fait pas le choix du vulgaire en un temps où certains traducteurs et poètes expérimentent, avant la Pléiade les possibilités littéraires du français. C'est sans doute là que réside la nouveauté qu'il annonçait au vers 74 : redonner, par une haute conception de la simplicité, une forme de dignité à la poésie chrétienne que des intentions militantes, pédagogiques ou vulgarisatrices tendaient à dénaturer. Il y a sans doute là le désir non avoué de ménager un espace à une poésie chrétienne élitiste, réservée à un cercle d'érudits latinistes, propres à goûter la simplicité élégante des vers sacrés.

L'illustration de sa poétique chrétienne fondée sur la parole cordiale et lyrique de la prière reste néanmoins circonscrite au Noël qu'il produit à la suite de ses vers théoriques. À n'en pas douter, le discours pastoral du prêtre au service de la société et des hommes convenait mieux au chancelier que la parole lyrique du fidèle en prière. Reste que son art poétique témoigne d'une volonté de poser, en marge du modèle psalmique et confessionnel illustré par les protestants, un autre modèle de poésie sacrée, articulant les valeurs civiques et stoïciennes aux élans de la foi. Mais la postérité donnera plutôt raison aux protestants, dont le modèle s'imposera avec de légères inflexions dans le paysage littéraire français de la deuxième moitié du siècle, toutes confessions confondues.

Véronique FERRER Université Paris Nanterre 
过

ํํำ

.

큼

국

(2)

(1)

甲

(8) 


\section{DES PIERRES ET DES MULETS : MISE EN SCÈNE NARRATIVE DANS L'ITER NICAEUM (CARMINA, V, 9)}

\section{SUR LES CHEMINS DE FRANCE}

Je dirai seulement, je dirai dans ce long poème Quel fut notre voyage, quels rivages nous vîmes, Parmi quels peuples, par quelles villes nous passâmes. Puis, si quelque aventure plaisante, agréable ou méritant Récit est survenue, elle vous sera contée de même ${ }^{1}$.

Vaste chorographie modelée sur la satire I, 5 d'Horace, l'épître 9 du livre $\mathrm{V}$ des Carmina de Michel de L'Hospital permet d'étudier comment l'Antiquité est lue, comprise et utilisée dans le cadre d'un discours dont les finalités peuvent être différentes de celles du texte source dont on voit toute la plasticité. Chez L'Hospital, les visées encomiastiques et éthiques constituent deux orientations majeures de sa poésie qui lui permettent de thématiser sa propre position aux côtés des plus grands, à la fois en tant que serviteur du roi et en tant que poète. Sur ce point, les œuvres d'Horace constituent le modèle structurel et thématique essentiel pour une grande partie des Carmina du chancelier-poète, dans leurs dimensions poétiques et éthiques². L'épître

L'Hospital, Carmina, V, 9, 39-43; texte latin cité infra p. 166.

2 Voir notamment A. Bayrou, «La vie privée des serviteurs de l'État. Échos horatiens dans les épîtres de Michel de L'Hospital (c. 1506-1573)», dans L'Invention de la vie privée et le modèle d'Horace, dir. B. Delignon, N. Dauvois et L. Cottegnies, Paris, Garnier, 2017, p. 143-163 ; L. Petris, «Michel de L'Hos- 
$\mathrm{V}, 9^{3}$ permet particulièrement bien d'observer les pratiques intertextuelles de L'Hospital et la construction de sa persona, autant qu'elle nous livre un témoignage intime de ses relations à sa protectrice Marguerite de France.

Dans les principales éditions imprimées, cette longue épître de 544 hexamètres porte le titre Iter Nicaeum ${ }^{4}$, qui évoque aussitôt l'Iter Brundisinum de la $5^{\mathrm{e}}$ satire d'Horace. La pièce de L'Hospital, vraisemblablement composée à la fin du mois de février 1560, veut décrire (le verbe descripsit figure au centre du premier vers) le voyage de trois mois que fit le futur chancelier aux côtés de Marguerite de France à l'hiver $1559-1560^{5}$. Au terme de son périple, la princesse, qui voyage accompagnée de tout un train - son chancelier, ses servantes, mais aussi un poète, des bouffons, officiers, laquais, chevaux et mulets $^{6}$ - doit retrouver EmmanuelPhilibert de Savoie, à qui l'unit son récent mariage scellant le traité du Cateau-Cambrésis ${ }^{7}$. L'enjeu est donc d'importance et touche autant à la sphère personnelle qu'aux intérêts publics. À l'heure du départ, le 18 novembre 1559, les cœurs ne sont toutefois que modérément à la joie. Les noces en effet sont célébrées peu après le décès d'Henri II, frère de Marguerite, mortellement blessé lors d'une joute en l'honneur des époux. Aussi Vieilleville écrit-il

pital lecteur d'Horace: une poétique de la juste distance, entre autoportrait, amitié et nature humaine», Camenae, 17 (2015), p. 1-19.

3 Pour une description de cette pièce, voir C.-O. Reure, "Le "voyage à Nice" du Chancelier Michel de L'Hospital », Revue du Lyonnais, janv. 1899, p. 25-41 ; DL, t. II, p. 163-176.

4 Ce titre est ajouté sur le manuscrit préparatoire de Gand $(G)$ p. 266, établi d'après l'édition $B$ et conservé dans $A$, p. 273.

5 Le départ de Blois a lieu le samedi 18 novembre 1559. Voir C. A. François II, éd. M.-T. de Martel, Paris, CNRS, 1991, p. 500-501 ; DL, t. II, p. 166-167.

6 Le «Memoire de ce qu'il fault pour Madame» (BNF, fr. 3119, fol. 50ro $-51 v^{\circ}$ ) mentionne «Pour l'escurie» quatre pages et quatre laquais, treize chevaux, deux chariots, trois mulets.

7 Le mariage est prévu à l'article 33 du traité: BNF, fr. 6614, fol. 14-16, sign. Sébastien de L'Aubespine; Dupuy 701, fol. 108; Dupuy 847, fol. 124 ; fr. 3253, p. 271 ; fr. 3944 , fol. 184 ; fr. 4331 , fol. 137 ; fr. 4505 , fol. 18 ; fr. 5140 , fol. 47 ; fr. 15872, fol. 86 ; Nafr. 7051, fol. 233-236 ; Morel de Thoisy 45, fol. 294. Le contrat est passé le 27 juin 1559 à l'hôtel de Tournelles. Voir B. Haan, Une paix pour l'éternité. La négociation du traité du Cateau-Cambrésis, Madrid, Casa Velásquez, 2010, p. 209-210. 
dans ses Mémoires que les noces « ressemblaient mieux ung convoy de mortuaire et funérailles qu'à aultre chose ; car au lieu de hautbois, violons et aultres resjouissances, ce n'estoient que pleurs, sanglots, tristesses et regrets [...] $»^{8}$. Le voyage, conduisant Marguerite comparée à une puella au début du texte (v. 29), mais appelée regina dans les derniers vers de l'épître (v. 542), vers une nouvelle destinée et un nouveau rôle, revêt même une dimension initiatique; le déplacement par monts et par eaux a valeur, par ses difficultés réelles et symboliques, d'allégorie de la vie humaine ${ }^{9}$.

L'itinéraire suit les voies habituelles vers le sud de la France, telles que les documente La Guide des chemins de France de 1553 de Charles Estienne ${ }^{10}$, qui énumère, en colonne, un répertoire des étapes. Cette liste, discontinue, sert à la fois de balise au déplacement géographique et de colonne vertébrale à la narration : chaque lieu traversé entraîne dans l'épître de L'Hospital un récit, une description, une explication historique, une anecdote. La topographie, énumérée autant que vécue, organise ainsi le texte et sa progression. Le récit prend par là un aspect linéaire, même si les épisodes s'enchaînent en fait comme des vignettes, suivant «un simple principe de succession chronologique ou de contiguïté spatiale ${ }^{11}$. Si les itinéraires de la Guide ont été établis pour l'essentiel sur la base de récits de voyageurs, de marchands ou de pèlerins - récits que le voyageur peut confronter à sa propre expérience -, la narration lhospitalienne, ancrée dans l'expérience du chemin et l'observation de l'environnement, naturel, humain ou bâti, s'appuie sur d'autres récits ou sources écrites (notamment anti-

8 Cité par C.-O. Reure, «Le "voyage à Nice" ... », art. cit., p. 30. Une lettre de Catherine de Médicis datée de fin novembre 1559 atteste aussi la difficile séparation: "Madame de Savoy s'en vé ausi, de quoy je suys fachaye come povés panser, et se n'etoyt l'espéranse que j'é de byentot la revoyr, je croiy que je scuayterès que feut encore à marier» (Lettres de Catherine de Médicis, éd. H. de La Ferrière, t. I, Paris, Impr. Nationale, 1885, p. 129).

9 Voir R. Gorris Camos, " "Sotto un manto di gigli di Francia" : poésie, allégorie et emblèmes de la dissidence entre Ferrare et Turin », dans Allégorie et symbole. Voies de dissidence, dir. A. Rolet, Rennes, PUR, 2012, p. 439-496 (en particulier p. 456-464).

10 Ch. Estienne, La Guide des chemins de France de 1553, éd. J. Bonnerot, Paris, Champion, 1936 (Genève, Slatkine Reprints, 1978).

11 J. Soler, Écritures du voyage. Héritages et inventions dans la littérature latine tardive, Paris, Institut d'Études augustiniennes, 2005, p. 98. 
ques). Dans cette perspective, l'épître, adressée à Jacques Du Faur $^{12}$, ami intime de L'Hospital, participe à la description du monde, documente et instruit le lecteur curieux et contribue à élargir son horizon.

L'analyse de la mise en scène narrative de ce voyage, inspirée $\mathrm{du}$ modèle d'Horace, permettra de cerner comment, pour définir ses choix poétiques, L'Hospital recourt à l'anecdotique et au pittoresque. Dans un deuxième temps, il s'agira d'expliquer comment ces éléments pittoresques, liés à l'expérience du chemin, souvent bourbeux et chaotique, se mêlent à la commémoration du passé à travers l'évocation de monuments, ruines et vestiges des temps anciens, mais aussi des nouvelles constructions édifiées entre Marseille et Nice par Henri II d'abord, par Emmanuel-Philibert de Savoie ensuite. Ainsi seront éclairées l'intentionnalité et la fonctionnalité du récit et de sa mise en scène.

\section{LE MODÈLE HORATIEN DU VOYAGE À BRINDES}

L'épître $V, 9$ s'inscrit dans la tradition satirique du récit de voyage, opposée à la veine épique du voyage héroïque ${ }^{13}$. Dans l'intertexte principal qui la fonde, l'Iter Brundisinum d'Horace (modelé sur 1'Iter Siculum, autre satire latine composée par son prédécesseur Lucilius), il est question du voyage qu'Horace aurait entrepris en 37 av. J.-C. jusqu'à Brindes, en compagnie, notamment, de Mécène et Virgile, dans un possible but politique: réconcilier Octave et Marc-Antoine ${ }^{14}$. Quoi qu'il en soit, le sérieux de l'entreprise est masqué par le récit léger et anecdotique qu'en propose le poète romain, qui reste très discret sur le potentiel enjeu de cette ambassade diplomatique. Loin de se présenter comme un

12 Sur ce personnage et ses liens avec L'Hospital, voir L'Hospital, Carmina, t. II, p. 117-119.

13 Voir J. Soler, Écritures du voyage, op. cit., p. 93-106.

14 Pour une discussion sur la (non-)réalité historique de ce voyage, voir H.A. Musurillo, «Horace's journey to Brundisium - fact or fiction?», Classical World, 48 (1954-1955), p. 159-162 ; E. Gowers, "Horace, Satires 1.5: an inconsequential journey », Cambridge Classical Journal, 39 (1994), p. 48-66. Voir aussi A. Cucchiarelli, «Iter satiricum. Le voyage à Brindes et la satire d'Horace», Latomus, 61 (2002), p. 842-851. 
citoyen important aux côtés des puissants, Horace adopte la persona du modeste voyageur éprouvé par les divers tracas de la route et des hébergements - un èthos propre aux poètes satiriques et propice à l'observation du monde et de la comédie humaine ${ }^{15}$. Relever quelques points communs et différences entre la narration d'Horace et celle de L'Hospital permet de montrer comment le modèle «satirique» d'Horace détermine, formellement d'abord, l'orientation narrative de L'Hospital. Le récit lhospitalien comme le récit horatien obéit à divers codes du poème de voyage. Tous deux ponctuent l'énumération des étapes par la répétition d'adverbes de transition (hinc ; inde) ${ }^{16}$ marquant un « lien de succession temporelle et géographique ${ }^{17} ; \mathrm{s}^{\prime} \mathrm{y}$ ajoutent des indications de distance ${ }^{18} \mathrm{~d}^{\prime}$ une étape à l'autre qui, chez L'Hospital, coïncident en général avec les données de La Guide des chemins de France. Les deux récits associent aux lieux traversés des épithètes descriptives (notamment des adjectifs en -osus) ${ }^{19}$ qui permettent de les visualiser et, conformément aux prescriptions rhétoriques sur l'ekphrasis, de se les remémorer ${ }^{20}$. Enfin, dans les deux poèmes, la progression des voyageurs est marquée par des verbes à la première personne du pluriel, incluant le narrateur, son protecteur - ou sa protectrice et leurs compagnons de voyage. Toutefois, dépassant son modèle, L'Hospital recourt à plusieurs reprises à des verbes de vision

15 Voir P. Debailly, La Muse indignée. Tome I. La satire en France au XVIe siècle, Paris, Garnier, 2012, p. 136.

16 Horace, Sat., I, 5, 93-98: «Flentibus hinc Varius discedit maestus amicis. / Inde Rubos fessi pervenimus, utpote longum / Carpentes iter et factum corruptius imbri. / Postera tempestas melior, via peior ad usque / Bari moenia piscosi. Dein Gnatia lymphis / iratis exstructa dedit risusque iocosque »; chez L'Hospital, l'adverbe hinc apparaît systématiquement à chaque nouvelle étape: Carmina, V, 9, 74, $79,173,186,195,214,265,291,303,443$ et $456 ;$ l'adverbe inde est plus rare (V, 9 , $435,458$ et 543$)$.

17 J. Soler, Écritures du voyage, op. cit., p. 98, n. 15.

18 Horace, Sat., I, 5, 25-26: «Milia tum pransi tria repimus atque subimus / Inpositum saxis late candentibus Anxur »; 86: «Quattuor hinc rapimur viginti et milia raedis »; dans l'épître de L'Hospital, voir v. 265 («Millibus hinc denis urbs distat Avenio tantum»), 303 («Millibus hinc distat non amplius Orgo duobus») et 456 («Millibus hinc sex Varus abest [...]»).

19 Horace, Sat., I, 5, 97: «Bari moenia piscosi»; L'Hospital, Carmina, V, 9, 57 : «nemorosaeque arva Colubrae».

20 Cf. Quintilien, Inst. or., VIII, 3, 61-62 ; XI, 2, 21. Voir J. Soler, Écritures du voyage, op. cit., p. 84-85. 
(cernimus, v. 458, vidimus, v. 40 et 282), notations absentes de la pièce horatienne et qui ici invitent à visualiser les lieux, selon les ressorts de l'enargeia.

Chez Horace, les étapes mènent les voyageurs vers leur but et la dernière ville citée coïncide avec la fin de la pièce et avec le dernier vers: Brundisium longae finis chartaeque viaequest - «Brindes est le terme de cette longue pièce et de ce long voyage » (Sat., I, 5, 104). Chez L'Hospital en revanche, l'arrivée à Nice, évoquée au v. 458 (Cernimus optatam non iam procul inde Nicaeam) ne coïncide pas avec la fin de l'épître qui se poursuit encore sur quelque quatre-vingts vers consacrés à la description des fortifications édifiées entre Marseille et Nice par Henri II puis par EmmanuelPhilibert ${ }^{21}$.

Réalité du voyage et topos du récit, les mauvais chemins (via peior) sont évoqués par les deux poètes ${ }^{22}$, dans une formulation analogue, mais amplifiée chez L'Hospital qui décrit les mulets pataugeant dans la bouse et la boue, le chancelier à leur suite:

An tibi Borbonias multo cum felle placentas

Et memorem foedo luctanteis aequore mulos,

Sargiacum pontem nemorosaeque arva Colubrae

Inferna peiora via, peiora Pitivi

Fertilibus campis et Lori mollibus arvis?

Et les tartes bourbonnaises ${ }^{23}$, si pleines de fiel,

Dois-je les évoquer pour toi, et nos mulets se débattant dans une mer [de fange,

Le Pont de Sargy ${ }^{24}$ et les terres de la boiseuse Couleuvre,

21 Sur la fonction de cette prolongation de la narration, voir infra p. 168-170.

22 Horace, Sat., I, 5, 94-97: «Inde Rubos fessi pervenimus, utpote longum / carpentes iter et factum corruptius imbri. / Postera tempestas melior, via peior ad usque / Bari moenia piscosi. [...]».

23 Voir G. Ménage, Dictionnaire étymologique de la langue françoise, t. II, Paris, Briasson, 1750, p. 516: "On appelle encore dans le Bourbonnois tartes Bourbonnoises certaines fondrieres qui s'y trouvent, dans lesquelles, croyant marcher en pays bon et uni, on enfonce jusqu'à la ceinture, et les chevaux jusqu'aux sangles». Voir aussi Rabelais, Pantagruel, chap. XV: «[...] il fit une tarte bourbonnaise, composée de force hails, de galbanum, de assa fetida, de castoreum, d'étrons tout chauds [...]».

24 «Mauvais chemin en yver», commente Charles Estienne dans La Guide des chemins de France, op. cit., p. 153. 
Pires que le chemin des Enfers ${ }^{25}$, pires que les campagnes

Fertiles du Poitou et que les champs meubles de l'Auron ?26

Les deux récits mentionnent enfin l'accueil réservé aux voyageurs chez des particuliers, scènes plutôt piquantes chez Horace ${ }^{27}$ alors qu'elles sont chez L'Hospital dénuées de tout burlesque et permettent un éloge de la richesse de ces demeures et de leur propriétaire : le château de Moulins (v. 60-73) ${ }^{28}$; une riche demeure lyonnaise entourée de jardins (v. 148-170) ${ }^{29}$; le château de la famille de Tournon à Roussillon (v. 187-194); chez le capitaine Paulin à Pierrelatte (v. 244-246). Derrière l'aspect ludique du récit se dessine donc aussi une dimension encomiastique.

\section{DU DESCRIPTIF AU NARRATIF : BOUFFONS ET PEUREUX}

Les points communs entre les récits horatien et lhospitalien relèvent, sur un plan assez général, de la narration descriptive d'un itinéraire. Le modèle «satirique» détermine également la mise en scène proprement narrative, qui passe chez L'Hospital par la réécriture de saynètes horatiennes. Dans l'une d'elles, lors d'une étape dans «la très riche villa de Coccéius » (v. 50), Horace fait dialoguer deux «bouffons» (scurrae) qui se querellent sur leur ascendance. Il introduit son récit par une parodie du genre épique, invoquant la Muse pour commémorer (memores) en peu de mots l'épisode $^{30}$. La querelle (pugna), relatée dans la suite sous forme de joute verbale dialoguée et qui consiste en un échange d'injures, a

25 Ou: "pire que la rue d'enfer», mentionnée sur la route de Moulins par La Guide des chemins de France, op. cit. (p. 153), entre Nevers et Magny.

26 L'Hospital, Carmina, V, 9, 55-59.

27 Horace, Sat., I, 5, 38: «Murena praebente domum, Capitone culinam » (scène des bouffons); 50: «Hinc nos Coccei recipit plenissima villa»; 71-76 (modeste dîner de grives qui risqua de brûler); 79-80: «[...] nos vicina Trivici / Villa recepisset lacrimoso non sine fumo » (villa enfumée).

28 Sur ses «merveilleux » jardins, voir infra la conclusion de notre étude p. 170-171.

29 Sans doute chez Léonard Spina, riche marchand lyonnais: L'Hospital, Carmina, V, 9, 167.

30 Horace, Sat., I, 5, 51-53: «[...] Nunc mihi paucis / Sarmenti scurrae pugnam Messique Cicirri, / Musa, velim memores [...]». 
pour effet de déclencher le rire de l'assistance, (v. 56: ridemus), avant que l'un des protagonistes n'entame une "danse du Cyclope» (v. 63: saltaret uti Cyclopa).

L'Hospital s'inspire directement de cette saynète, de l'ordre de la farce, qu'il dédouble et retravaille en deux scènes indépendantes. La première campe deux bouffons de la suite de Marguerite, dans un récit sans dialogue (à l'inverse du modèle horatien):

Bogomarum, quanvis picto confideret ore, 85

Multaque iactantem febris tamen aspera cepit.

Illius amissi morbo lususque iocique!

Sed tamen indutus vulpinae tegmine pellis

Tertullus, nivea perfusus et ora farina

Saltavit satyrum choreasque agitavit agresti

More; $[. .$.

[...] Nisi se libraverit aequo

Pondere, vix certam potis est vitare ruinam.

Hunc alii iuvenes imitati, tum sua duro

Membra pavimento fundebant non sine risu.

Bogomare, malgré la confiance que lui donnait son visage

Avec toutes ses vantardises, fut pourtant saisi d'une fièvre

[peint,

Avec sa maladie, fini les jeux et les plaisanteries!

[cruelle.

Mais du moins, couvert d'un manteau de peau de renard,

Tertulle, le visage poudré de farine blanche comme neige,

Mima un satyre et dansa une ronde à la manière

Paysanne; [...]

[...] S'il ne s'était pas balancé en équilibrant

Son poids, il aurait eu de la peine à éviter une chute certaine.

Les autres jeunes gens l'imitèrent, s'étalant alors

De tout leur long sur le dur pavement, non sans déclencher

[des rires ${ }^{31} . \quad 100$

Le premier bouffon, Bogomare, tombe malade (febris tamen aspera cepit) et ne peut plus, malgré sa face grimée (picto... ore), assumer sa charge d'amuseur. "Fini les jeux et les plaisanteries! », commente L'Hospital (v. 87). Le second bouffon, Tertulle, déguisé

31 L'Hospital, Carmina, V, 9, 85-91 et 97-100. 
d'une peau de renard et fardé de blanc - artifices de la théâtralité -, se met alors à danser «la danse du satyre »: l'expression saltavit satyrum (v. 90), calquée sur celle d'Horace (saltaret uti Cyclopa), signe l'emprunt intertextuel autant qu'elle permet, par la substitution de satyrum à Cyclopa, une référence métapoétique au genre de la satire, que la Renaissance associait le plus souvent au drame satyrique, jusqu'à la mise au point d'Isaac Casaubon ${ }^{32}$. Le bouffon se livre ensuite à des acrobaties sur bâton, imité par des jeunes gens (iuvenes imitati) moins talentueux, dont la chute sur le dur pavé déclenche le rire de l'assistance (non sine risu).

Au-delà de la parenté évidente entre les deux scènes, on peut distinguer une véritable signature intertextuelle: en adaptant dans l'expression «fini les jeux et les plaisanteries» (v. 87: amissi ... lususque iocique) une clausule tirée de la satire I, 5 d'Horace (Sat., I, 5, 99: [...] risusque iocosque), L'Hospital se place explicitement sous le patronage de la muse horatienne et commente sa propre pratique d'imitation (cf. v. 99: imitati). On notera aussi que ce sont ici non les bouffons dans leur fonction d'amuseurs qui déclenchent le rire, mais bien la maladresse et la chute des jeunes gens voulant imiter leurs acrobaties. Or dans la suite de l'épître, L'Hospital se mettra lui-même en scène comme maladroit et ridicule: en exploitant ici la veine satirique, dans le but de faire sourire Marguerite, il prépare donc aussi la mise en scène de sa propre persona.

La querelle des bouffons chez Horace inspire à L'Hospital une deuxième saynète (v. 119-145) où deux compagnons de voyage se disputent sur l'itinéraire, terrestre ou fluvial, à suivre à partir de Lyon $^{33}$. Il reprend cette fois-ci la mise en scène dialogique de la querelle horatienne et sa qualification de pugna (v. 119), ainsi que la dimension de parodie épique, en plaçant le verbe Cantabo en rejet au début du v. 120 :

Lugduni comitum fuerit quae pugna duorum

Cantabo, longis cum diceret alter eundum

120

32 Isaac Casaubon, De Satyrica Graecorum poesi et Romanorum satira, Paris, Drouard, 1605. Voir P. Debailly, La Muse indignée, t. I, op. cit., p. 182-186.

33 L'imitation lhospitalienne se nourrit sans doute également d'un élément du début de la satire horatienne (v. 11-13), où, sur la même thématique fluviale, Horace évoque un bref éclat de voix (convicia), également dialogué, entre esclaves et mariniers à propos du prix de la traversée. 
Navibus et suaderet equi vitare laborem, Alter aquas Rhodanique timeret saxa furentis

Ingentesque pilas et subter euntia pontes

Flumina, nec fragili vellet se credere ligno.

- Nil est quod metuas, ego te (Dorsennius inquit)

Salvum atque incolumem sistam procul urbe Cavarum.

- Qui potes hoc? Etenim nunquam me flumine lavi,

Nunquam nare puer didici. Possum (o bone) possum,

Si me audire voles. [...]

À présent, la dispute, née à Lyon entre deux de nos

[compagnons,

Fera l'objet de mon chant: l'un disait qu'il fallait voyager

[sur des bateaux

Allongés et conseillait d'éviter la fatigue d'une chevauchée,

Mais l'autre redoutait les eaux et les écueils du Rhône

Et les immenses piliers et les courants passant sous

[impétueux,

Les ponts, et ne voulait pas confier sa vie à un frêle morceau [de bois.

- Tu n'as rien à craindre, disait Dorsenne, moi je te 125

Déposerai sain et sauf au-delà de la ville des Cavares.

- En es-tu capable? Car jamais je ne me suis baigné dans un

[fleuve,

Jamais, enfant, je n'ai appris à nager. - Je le peux, mon bon,

Si tu veux bien m'écouter. $[\ldots]^{34}$

[je le peux,

En donnant, au terme de la scène lyonnaise, implicitement raison au plus prudent des deux compagnons (présenté comme le plus craintif, v. 122 : timeret), L'Hospital met à distance le modèle du héros épique voyageant sans peur sur les mers pour atteindre son but. Marquant sa désapprobation à trop d'audace (audax, v. 132), L'Hospital conclut l'anecdote par trois vers de tonalité gnomique où il incite (moneo, v. 145) chacun à suivre sa vraie nature et à préférer la voie de la terre à celle des oiseaux ou des poissons ${ }^{35}$. C'est là une

\footnotetext{
34 L'Hospital, Carmina, V, 9, 119-129.

35 L'Hospital, Carmina, V, 9, 145-147: «Naturam moneo (coget vis nulla) sequitur / Quisque suam nec quo pedibus contendere possit, / Tentet adire mari, transnare vel aera pennis ».
} 
constante de la poésie de L'Hospital, qui vise presque toujours à instruire moralement, ici sur la prudence ${ }^{36}$.

\section{AUTODÉRISION ET PRÉSENTATION DE SOI : LE CHOIX DU MASQUE SATIRIQUE}

Outre les deux saynètes à caractère théâtral, observées «à hauteur d'homme » ${ }^{37}$, L'Hospital emprunte à la satire horatienne la mise en scène pleine d'autodérision du narrateur lui-même ${ }^{38}$. Horace relate ses diverses indispositions physiques (piqûres de moustiques, coassements de grenouilles ${ }^{39}$, fatigue ${ }^{40}$, maux de ventre, yeux irrités, bas-ventre tendu) ${ }^{41}$ dans des anecdotes sans grande noblesse qui n'ont nullement pour but de faire du narrateur un héros ou même un sage. L'Hospital souligne de manière analogue ses faiblesses physiques (fatigue, maux de ventre $)^{42}$ autant que morales, pour mieux instruire en connaissance de cause: sa persona de monitor éthique est la même que celle des Épitres d'Horace où le poète romain ne se pose jamais en donneur de leçon supérieur, mais en expérimentateur de son propre chemin et de ses propres erreurs.

Cette présentation « inférieure» de soi s'observe en particulier à un moment où le train princier est confronté à une tempête

36 De même l'épître III, 5, adressée au cardinal de Lorraine après une tempête qu'il essuya au large de Toulon, se développe comme un plaidoyer pour la prudence.

37 P. Debailly, La Muse indignée, t. I, op. cit., p. 136.

38 Sur la mise en scène de soi comme trait de la «satire topographique», voir J. Soler, Écritures du voyage, op. cit., p. 89-91 et 103-106.

39 Sat., I, 5, 14-15: «[...] Mali culices ranaeque palustres / Avertunt somnos. [...]». Sur la dimension métapoétique de cette anecdote, qui constituerait une possible allusion aux Grenouilles d'Aristophane, voir A. Cucchiarelli, La satira e il poeta: Orazio tra Epodi e Sermones, Pise, Giardini, 2001, p. 25-33 et 57-66. Voir aussi J. L. Ferris-Hill, Roman Satire and the Old Comic Tradition, New York, Cambridge UP, 2015, p. 48-51.

40 Sat., I, 5, 17 et 37.

41 Sat., I, 5, 7-8: «Hic ego propter aquam, quod erat deterrima, ventri / Indico bellum [...]»; 30-31: « Hic oculis ego nigra meis collyria lippus / Inlinere [...]»; 49: «namque pila lippis inimicum et ludere crudis»; 82-85 (frustration sexuelle).

42 L'Hospital, Carmina, V, 9, 185: «Immodicos sensi stomachi ventrisque dolores». 
$\mathrm{d}^{\prime}$ ampleur épique ${ }^{43}$ - que souligne le choix du verbe iactabat (v. 309), récurrent dans l'Enéide ${ }^{44}$ :

Tunc etiam inflatus rapide spirantibus auris

Navigia horrendis iactabat parva procellis.

Hic meus abiecto risum tum pondere mulus

Astanti populo commovit, inire frementes

Dum detrectat aquas parvamque ascendere navem.

Sed tandem iratas constrictum fune retorto

Et frontem atque oculos velamine vestis opertum

Tergaque percussum flagris transire coegit

Mulio, saepe licet ferrata calce petitus.

À ce moment-là aussi, encore gonflée par le souffle

[impétueux des vents,

Elle ballottait nos petites embarcations en proie à de

[terribles bourrasques.

C'est là que, en jetant alors son fardeau à bas, mon mulet

Le rire de l'assistance, en refusant de s'avancer

[provoqua

Dans les eaux grondantes et de monter à bord de la petite

[barque.

Mais finalement, ces eaux déchaînées, fermement retenu

[par sa bride serrée

Le front ainsi que les yeux recouverts par un voile de tissu,

À coups de fouet sur son dos, il fut forcé de les traverser

Par un muletier, bien qu'il cherchât plus d'une fois à

[l'atteindre de ses sabots ferrés ${ }^{45}$.

L'Hospital transpose ici une autre scène de la même satire d'Horace, où un voyageur agacé rosse un batelier et une mule qui rechigne à haler la barque ${ }^{46}$. Dans sa transposition, il se

43 Cette forme d'écriture sur soi s'oppose à la narration pathétique développée dans l'épître I, 4 à Adrien Du Drac à propos de la tempête sur le Pô lors du déplacement de L'Hospital à Bologne. Voir infra n. 50 .

44 Nombreuses occurrences déjà dans le premier chant de l'Énéide: Virgile, Aen., I, $3 ; 29 ; 102 ; 182 ; 332 ; 442 ; 629 ; 668$.

45 L'Hospital, Carmina, V, 9, 308-316.

46 Horace, Sat., I, 5, 20-23: «Iamque dies aderat, nil cum procedere lintrem / Sentimus, donec cerebrosus prosilit unus / Ac mulae nautaeque caput lumbosque saligno / Fuste dolat. $[. .]$.$» .$ 
présente comme chutant de son mulet ${ }^{47}$ entêté face aux eaux et endosse, au travers de cette (mauvaise) posture, le rôle satirique d'amuseur: sa chute, comme celles des imitateurs du bouffon Tertulle, déclenche le rire (v. 310-311 : risum... commovit). Le chancelier de la duchesse apparaît ainsi à son tour comme un bouffon, rôle qu'il assume involontairement face au public assistant à la scène (v. 311 : astanti populo), mais qu'il assume bien consciemment, en tant que poète, quand il commémore cette anecdote (qu'elle soit réelle ou fictive...) pour faire sourire Du Faur et surtout Marguerite, destinataire implicite de l'épître. En s'abaissant de la sorte, au sens propre et au sens figuré, L'Hospital souligne sans doute aussi, sur un plan métapoétique, son humilité et le choix stylistique d'un sermo terre à terre, d'une Musa pedestris à l'image de celle définie par Horace ${ }^{48}$.

Cette construction d'une persona poétiquement et éthiquement humble se confirme plus loin dans l'épître. À l'arrivée à Marseille, plutôt que de prendre la mer pour rallier Nice, L'Hospital (ego) répugne à son tour à se risquer sur les eaux ${ }^{49}$, répétant ainsi, non sans autodérision, l'attitude du peureux de Lyon et celle du mulet refusant de monter dans la barque (v. 311-312 : [...] inire frementes / Dum detrectat aquas parvamque ascendere navem). L'Hospital, que l'on sait échaudé par de précédentes expériences - notamment une tempête sur le Pô lors de son voyage à Bologne en $1547^{50}$ - apparaît comme «un pauvre homme qui ne maîtrise [...] pas l'espace qu'il parcourt ${ }^{51}$. Ainsi, après la mise en scène satirique de diverses figures de comédies présentées comme dans une galerie de

47 Du moins si l'on comprend que abiecto pondere renvoie au cavalier (et donc à L'Hospital) et non aux bagages (dont la chute n'aurait pas le même effet comique) ni aux excréments du mulet.

48 Horace, Sat., II, 6, 17: «Quid prius illustrem satiris Musaque pedestri ? » ; Epist., II, 1, 250: «[...] Nec sermones ego mallem / repentis per humum [...]». Voir P. Debailly, La Muse indignée, t. I, op. cit., p. 135-136.

49 L'Hospital, Carmina, V, 9, 379-381: «Ire mari nuptae placuit dulcique marito / Addere se comitem; pedibus procedere iussi / Queis mare suspectum est, ego non postremus in illis ».

50 L'Hospital, Carmina, I, 4. Sur le motif de la tempête (très métaphorique) dans cette pièce, voir L'Hospital, Carmina, t. I, p. 139-140; Crouzet, La Sagesse et le malheur, p. 27-32.

51 La citation est de J. Soler, Écritures du voyage, op. cit., p. 100-101, à propos de la persona d'Horace dans l'Iter Brundisinum. 
portraits ${ }^{52}$, le poète insère son propre autoportrait et délivre de luimême l'image d'un être à la fois humble, craintif et même risible, pataugeant dans la boue ${ }^{53}$, jeté à bas de son mulet, craignant, comme sa monture, la traversée des eaux.

\section{DU DEUIL À LA JOIE}

Le modèle satirique d'Horace détermine donc de façon majeure l'orientation narrative de L'Hospital et sa présentation de lui-même, mais aussi la finalité de son récit: au début de l'épître, L'Hospital annonce qu'il ne relatera que ce qui est plaisant, agréable ou digne d'être raconté (v. 42: iucundum, gratum aut memorabile dictu):

Quicquid erit, non pauca animi tum signa dolentis

Vidimus in vultu dominae: [...]

Quae mihi non memorare libet, ne versibus atris

Obductum vobis renovem iam pene dolorem.

Dicemus tantum dicemus carmine longo

Ecquod iter nostrum fuerit, quas vidimus oras,

Quorum hominum et per quas vestigia fecimus urbes.

Tum si iucundum, gratum aut memorabile dictu

Acciderit quicquam, narrabitur hoc quoque vobis.

Quoi qu'il advienne, nous avons vu alors bien des signes

Chagrin sur le visage de Madame: [...]

[témoignant d'un coeur

Cela, je n'ai pas le cœur de le raconter, de peur que par

[ces vers sombres

Je ne renouvelle en vous une douleur à peine cicatrisée.

Je dirai seulement, je dirai dans ce long poème

Quel fut notre voyage, quels rivages nous vîmes,

Parmi quels peuples, par quelles villes nous passâmes.

Et puis, si quelque aventure plaisante, agréable ou méritant

Récit est survenue, elle vous sera contée de même ${ }^{54}$.

52 Voir P. Debailly, La Muse indignée, t. I, op. cit., p. 136 n. 6.

53 Voir déjà Lucilius, frgt. 5: "Praeterea omne iter est hoc labosum atque lutosum».

L'Hospital, Carmina, V, 9, 33-34 et 37-43. 
Sous le masque plaisant du bouffon, L'Hospital se refuse à tout pathétique, à toute évocation du chagrin de Marguerite ${ }^{55}$, pourtant visible sur son visage (v. 33-34 : signa dolentis / [...] in vultu), pour ne pas raviver sa douleur (v. 37-38: ne renovem ... dolorem) par des vers sombres (v. 35: versibus atris). L'épître est ainsi placée «sous le signe du silence, de l'omission ${ }^{56}$ en ce qui concerne le chagrin et la séparation; mais plus encore, elle est placée sous le signe du rire, comme le souligne l'importance du modèle horatien dans la mise en scène du iucundum, gratum. La «commémoration» (le verbe memorare du v. 35 sera répété en écho dans la conclusion de l'épître, v. 538: longum sit memorare) des épisodes hauts en couleur du voyage apparaît ainsi comme un remède à la mélancolie de la princesse en deuil, mélancolie qu'elle éprouvera encore une fois à Nice ${ }^{57}$.

Au fil de l'épître, L'Hospital propose ainsi une translatio du deuil à la joie, inversant sur ce point son modèle horatien qui, soulignant les liens d'une douce amitié, évoquait la joie des retrouvailles avec ses compagnons de voyage avant la tristesse de la séparation à la fin du voyage ${ }^{58}$. Pour Marguerite, aux adieux douloureux à sa famille succèdera la joie des retrouvailles avec Emmanuel-Philibert à Marseille et celle de la nuit de noces ${ }^{59}$; puis, dans les derniers vers, L'Hospital dépeint, sans doute sans

55 Sur la douloureuse séparation de Marguerite et des siens, voir supra n. 8. Les sentiments décrits dans les premiers vers de l'épître évoquent la nostalgie de l'élégie Patriae desiderium de Joachim Du Bellay (CEuvres Poétiques. T. VII. CEuvres latines. Poemata, éd. G. Demerson, Paris, Nizet, 1984, p. 62-69). Voir aussi G.H. Tucker, Homo viator. Itineraries of Exile, Displacement and Writing in Renaissance Europe, Genève, Droz, 2003, p. 239-267.

56 L'expression est de R. Gorris Camos, " "Sotto un manto di gigli di Francia"... », art. cit., p. 458

57 «[...] et despuis fus choisy pour conduire madame Marguerite, sœur du roy, ma maitresse, en la maison de son mary nommé Philibert. Là je fis tout debvoir estant près de la personne de ma maitresse tres illustre, qui estoit griefvement malade (gravissime aegrotanti)» (L'Hospital, Discours et correspondance, p. 273 et 279-280).

58 Horace, Sat., I, 5, 43-44: "O qui conplexus et gaudia quanta fuerunt! / Nil ego contulerim iucundo sanus amico»; 93: «Flentibus hinc Varius discedit maestus amicis ».

59 L'Hospital, Carmina, V, 9, 376-377: «Hic dux Emanuel progressus ab urbe Nicaea / Occurrit dominae. Fuerint quae gaudia noctis ». 
y avoir assisté ${ }^{60}$, la liesse populaire (laetitia) à l'entrée du couple princier à Nice ${ }^{61}$. À cet égard, l'épître est une invitation à une élévation du point de vue. Le deuil de Marguerite doit être dépassé ; au travers du voyage «horizontal» vers Nice, s'opère aussi pour la princesse une translatio du passé vers le présent et le futur: Marguerite doit quitter son passé familial (cf. v. 5: [...] dulci patria domibusque relictis) et son deuil pour avancer vers son avenir, conjugal, et vers la joie, et entrer dans la maison de son époux (v. 541-542: cari deducta mariti / Est regina domum) ${ }^{62}$.

\section{DE LA FANGE À LA PIERRE: \\ ENTRE MEMORABILE DICTU ET MIRABILE VISU}

Entre l'arrivée à Nice (v. 458) et la fin de l'épître (v. 544), pleine d'allégresse, L'Hospital insère une longue évocation des fortifications édifiées par Henri II, puis par Emmanuel-Philibert de Savoie, pour protéger la côte entre Marseille et Nice. Cette apparente digression surprend dans l'économie d'un récit de voyage pittoresque et "satirique ", tourné vers la joie et la consolation, et l'on se doit d'expliquer la présence et la fonction de ces imposants édifices de pierre dans un récit dont les protagonistes sont si souvent confrontés au déchaînement des éléments naturels et dont le narrateur, par humilitas, associe la boue à sa propre persona satirique ${ }^{63}$.

Ces édifices s'intègrent dans une opposition entre l'humble et le grand ${ }^{64}$, autant qu'ils s'inscrivent dans la continuité des autres édifices de pierre évoqués au cours de l'épître. Au fil du voyage et du récit,

60 Le couple princier débarque à Nice fin janvier 1560 (voir P. Gioffredo, Histoire des Alpes maritimes. Une histoire de Nice et des Alpes du Sud des origines à $17^{e}$ siècle. Troisième partie (1529-1652), éd. H. Barelli et M. Prève, Nice, Éditions Nice Musées, 2008, p. 215), alors que L'Hospital, voyageant par voie de terre, n'y parvient que mi-février, environ trois mois (cf. v. 1-4) après le départ le 18 novembre (voir supra $\mathrm{n}$. 5).

61 L'Hospital, Carmina, V, 9, 538-542: «Longum sit memorare quibus nos urbe Nicaei / Excepere sua studiis quantaque sit illa / Laetitia celebrata dies, qua classis ad urbem / Appulit. Hanc primam cari deducta mariti / Est regina domum [...]».

62 Cf. Gn 2, 24 ; Mt 19, 5.

63 L'Hospital, Carmina, V, 9, 55-59 et I, 4, 106-109. Voir supra n. 53.

64 Sur cette opposition dans la satire I, 5 d'Horace, voir A. Cucchiarelli, «Iter satiricum. Le voyage à Brindes et la satire d'Horace», Latomus, 61 (2002), p. 842-851. 
L'Hospital décrit en effet les vestiges anciens qu'il observe et qu'il peut confronter aux mentions qu'en font les sources antiques ou contemporaines. Pour les évoquer (notamment à Vienne, Orange, Fréjus ou Cimiez), il joue fréquemment sur une opposition entre passé et présent, qu'il exprime en contrastant la grandeur antique (magnae urbis) - dont il ne reste que des ruines (vestigia, fractas... opes, diruta) - et la petitesse de la ville moderne (parvae... Viennae, parvam... urbem) ${ }^{65}$.

Cette poétique des ruines suggère une conception cyclique de l'histoire, où alternent temps de grandeur et temps de décadence. La ruine, l'effondrement (double tragique des chutes burlesques?), menace tout ${ }^{66}$. L'Hospital formule ainsi une mise en garde contre l'hybris et contre les ravages du temps qui détruit (v. 302: Caetera longinqui delevit temporis aetas), autant qu'il exprime l'espoir d'un retour à un temps de grandeur avec ceux qui, dans le présent, incarnent les nouveaux héros. Car de même que les vestiges du passé et leur grandeur déchue suscitent encore l'admiration, de même l'évocation des «pierres du présent» et des créateurs de nouvelles infrastructures, essentiellement militaires, est au service non plus de la description topographique, mais de l'éloge.

Dans cette translatio du passé glorieux de l'Antiquité au présent, les villes ${ }^{67}$, les palais, les ports, les fortifications, sont décrits pour que soient loués leur propriétaire, leur architecte, leur constructeur. Sur ce point, l'épître de L'Hospital s'accorde avec le dernier terme du programme poétique annoncé en ouverture de la pièce: la commémoration (v. 42: iucundum, gratum aut memorabile dictu) non plus du pittoresque, mais de ce qui fait la grandeur et la force de la France. Ainsi Emmanuel-Philibert est-il loué pour avoir fortifié le port de Villefranche «avec un savoir-faire admi-

65 L'Hospital, Carmina, V, 9, 173: «Nec procul hinc parvae vestigia magna Viennae»; 252-253: «Proximus huic fractas ostendit Arausio magnae / Urbis opes [...]» ; 435438: "Inde Forum Iuli parvam nunc venimus urbem: / Apparent veteris vestigia magna theatri, / Ingentes arcus, et thermae, et ductus aquarum; / Apparet moles antiqui diruta portus »; 490-491: "Cernis adhuc non pauca tamen vestigia magnae / Urbis, aquaeductus, thermas parvumque theatrum».

66 L'idée est chère à L'Hospital qui l'adopte jusque dans sa devise, tirée d'Horace, Carmina, III, 3, 7-8: "Si fractus illabatur orbis / Impavidum ferient ruinae », "Si le monde s'écroulait brisé, ses ruines le frapperaient sans l'effrayer». Voir Petris, La Plume et la tribune, p. 327-329 (p. 327 n. 21).

67 Voir par ex. l'éloge d'Avignon pour son pont et son palais imposant et admirable (v. 269-272, notamment v. 272: «[...] moles etiam miranda palati»). 
rable» (mira arte) ${ }^{68}$. Cet éloge du mari constructeur fait écho à l'hommage rendu, une quinzaine de vers plus haut, à Henri II pour l'édification «multa vi» du Fort Carré d'Antibes ${ }^{69}$. L'Hospital substitue ainsi la figure du mari à la figure du frère défunt, confirmant le passage de Marguerite vers sa nouvelle destinée. Et c'est en commémorant les étapes pittoresques de cette transition autant que les constructions qui jalonnent cette route que L'Hospital entend délivrer ce message aux potentialités consolatoire, parénétique et encomiastique - à l'instar de la démarche d'Ausone dans La Moselle lorsqu'il décrit les villas et leur position dominante ${ }^{70}$.

Conformément à cette visée, ces «nouvelles pierres», fortifications et infrastructures portuaires, servant à la commémoration et à l'éloge, constituent en réalité de nouveaux mirabilia, à la suite d'autres mirabilia naturels évoqués au cours du texte: à Moulins, dans les jardins $\mathrm{du}$ «beau chasteau et ancien palais des ducs de Bourbon ${ }^{71}$, les voyageurs avaient notamment pu observer le prodige (mirabile visu) des fruits restés sur les arbres au cœur de $\mathrm{l}^{\prime}$ hiver $^{72}$. Mirabilia naturels certes, mais qui portent la marque d'une domestication de la nature par l'homme. Car à Moulins, ces citronniers (poma Media) ne constituent pas la seule merveille: la fontaine des jardins semble élever ses eaux plus haut vers le ciel (altius) au passage de Madame Marguerite pour lui témoigner son amour (testari amorem $)^{73}$, à l'image de ce que fait L'Hospital tout au long de son épître. Car si cette épître témoigne des choix, modèles et pratiques d'écriture du chancelier-poète, celui-ci signe aussi ici, sous le masque du voyageur horatien, un témoignage de l'affection profonde qui le lie à Madame Marguerite. Il remplit pleinement le rôle que définit Cicéron dans le De amicitia: face à un ami affligé,

\footnotetext{
68 L'Hospital, Carmina, V, 9, 503: «Emanuel mira Filibertus muniit arte».

69 L'Hospital, Carmina, V, 9, 452-453: «Medium rupes extenditur ardua pontum, I Quam super Henricus multa vi muniit arcem».

70 Voir L'Hospital, Carmina, t. II, p. 82; P. Galand-Hallyn, Le reflet des fleurs. Description et métalangage poétique d'Homère à la Renaissance, Genève, Droz, 1994, p. 312 et 405.

71 Ch. Estienne, La Guide des chemins de France, op. cit., p. 153.

72 L'Hospital, Carmina, V, 9, 67-68: «[...] pendentiaque arbore poma, / Media quae misit quondam (mirabile visu)».

73 L'Hospital, Carmina, V, 9, 69-71: «Fons etiam dominae testari visus amorem / Maiores fundebat aquas caeloque ferebat / Altius. [...]».
} 
«il faut bien plutôt faire tous ses efforts pour relever son courage abattu et lui rendre espoir et confiance ${ }^{74}$. La mise en scène de soi comme humble et risible permet donc, par effet de miroir, de relever et d'élever l'autre.

La mise en scène narrative du récit de voyage de L'Hospital propose ainsi un équilibre entre évocation satirique du pittoresque, consolation, présentation de soi d'une part, et élévation d'autrui jusqu'à l'éloge, commémoration et appel à la joie d'autre part: un mélange tout horatien entre humilité et grandeur, entre plaisant et sérieux ${ }^{75}$, en conformité avec le genus medium idéal, dont L'Hospital est un représentant et un défenseur, que ce soit sur le plan poétique, éthique ou politique.

Laure CHAPPUIS SANDOZ Université de Neuchâtel

74 Cicéron, De amicitia, 16, 59: «[...] eniti et efficere ut amici iacentem animum excitet inducatque in spem cogitationemque meliorem».

75 Cf. Horace, Ars Poet., v. 226: «[...] vertere seria ludo» (à propos du drame satyrique). 
过

ํํำ

.

큼

국

(2)

(1)

甲

(8) 


\section{LE «DISCOURS DE MONSIEUR LE CHANCELIER DE L'HOSPITAL \\ À SES AMIS » : NICOLAS RAPIN, TRADUCTEUR DE L'ÉPÎTRE $A D$ AMICOS (VI, 2)}

En 1601 paraît chez Jean Blanchet à Poitiers le Discours de Monsieur le chancelier de L'Hospital, à ses amis. Tourné du latin ${ }^{1}$. Il s'agit d'une traduction en décasyllabes et en orthographe "réformée» de l'épître intitulée $A d$ amicos, parue en 1585 dans l'édition princeps des Carmina ${ }^{2}$. Le nom du traducteur n'apparaît nulle part dans cette plaquette et il faut attendre la parution de l'édition posthume des OEuvres latines et françoises de Nicolas Rapin en 1610, partiellement procurée par Scévole de Sainte-Marthe, l'un des intimes du magistrat poitevin, pour en découvrir l'iden-

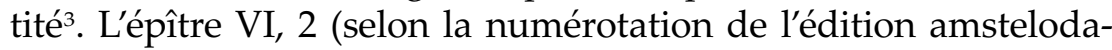
moise des Carmina) est un dialogue fictif entre le magnus quaestor (v. 1) et des interlocuteurs anonymes, qualifiés $d^{\prime}$ «amis» dès le titre. Au moyen d'un vigoureux plaidoyer pro domo, L'Hospital y

1 Discours de Monsieur le chancelier de L'Hospital, à ses amis. Tourné du latin, Poitiers, Jean Blanchet, 1601; CEuvres I. Vers publiés du vivant de l'auteur, éd. J. Brunel à partir des travaux de E. Brethé, Genève, Droz, 1982, p. 625-654.

2 Dans l'édition de 1585 (B), Ad amicos est la cinquième pièce du livre VI (p. 338347). Toutes les citations se référeront à l'édition princeps, ainsi que la numérotation des vers (le vers 168 est raturé dans l'exemplaire de Gand et disparaît de l'édition d'Amsterdam). Les traductions sont issues du travail collectif réalisé dans le cadre du projet FNS «Édition critique des Carmina de Michel de L'Hospital», sous la direction de L. Petris et de P. Galland ; www.unine.ch/ micheldelhospital.

3 «Discours de Monsieur le chancelier de L'Hospital, à ses amis. Tourné mot à mot du Latin », dans Les CEuvres latines et françoises de Nicolas Rapin Poictevin, grand prevost de la Connestablie de France. Tombeau de l'Autheur avec plusieurs Eloges, Paris, Pierre Chevalier, 1610, p. 137-151. 
défend son èthos et son bilan politiques face à des familiers et des membres de sa famille qui lui reprochent son inflexibilité morale et son refus obstiné de sacrifier aux règles du jeu courtisan. Rédigé en 1563 à l'issue de la première guerre de religion, ce texte se veut par ailleurs un réquisitoire incisif contre la noblesse catholique, ainsi qu'une critique, à peine moins vive, de l'irresponsabilité du roi mineur. Dans l'édition de 1585, le poème se termine sur un hexamètre tronqué: l'hypothèse selon laquelle les éditeurs auraient jugé préférable de retrancher une fin considérée comme trop virulente à l'égard de la couronne paraît plausible, mais ce geste de censure n'est en réalité que le coup d'éclat final d'un texte qui surprend de bout en bout par sa franchise et son tranchant.

Il s'agit dès lors de comprendre ce qui a pu, environ un quart de siècle plus tard, motiver Nicolas Rapin, dont l'essentiel de la carrière s'est déroulé sous les règnes d'Henri III et d'Henri IV, à choisir précisément cette épître-là. Si Rapin, né en 1539, n'a sans doute jamais rencontré L'Hospital, il a été très proche de ceux qui publient, en 1585, la première édition des Carmina, en particulier de Scévole de Sainte-Marthe, qu'il fréquente dès les années $1550^{4}$, de Jacques-Auguste de Thou et de Pierre Pithou; il connaît également Pibrac, à qui il dédie ses Plaisirs de la vie rustique en $1575^{5}$. Placer la traduction dans ce contexte éditorial ne suffit pourtant ni à la dater ni à expliquer les motivations du traducteur. Jean Brunel, dans son édition des œuvres de Rapin et dans la monumentale thèse qu'il a consacrée au «poète, humaniste et soldat» fontenaisien, s'en tient aux environs de 1585, sans pousser les investigations plus loin 6 . Mais essayer de mieux circonscrire la fourchette chronologique ne relève pas de l'exercice gratuit : une lecture même superficielle des 461 décasyllabes permet de prendre la mesure de la relative liberté avec laquelle sont traduits les 318 hexamètres du chancelier. La précision "tourné mot à mot du latin », que l'on trouve dès l'édi-

4 Étudiant, il fréquente Sainte-Marthe dès 1550-1555 à Paris (J. Brunel, Un Poitevin poète, humaniste et soldat à l'époque des guerres de religion: Nicolas Rapin (1539-1608). La carrière, les milieux, l'œuvre, Paris, Champion, 2002, vol. I, p. 79 et 242 et ss.).

5 J. Brunel, Un Poitevin poète, op. cit., vol. I, p. 244-249.

$6 \quad$ Ibid., p. 1256-1257; CEuvres, t. I, p. 625-632. 
tion de $1601^{7}$, flaire à première vue l'argument commercial, mais constitue peut-être avant tout une précaution oratoire, au même titre que le mot "chancelier», qui traduit magni Quaestoris: le texte de Rapin se révèle un trompe-l'œil. Les adaptations, qui se rapportent tant à la situation personnelle du traducteur qu'à un contexte historique précis, sont discrètes mais une lecture attentive permet de les repérer avec une relative facilité. Cet effort d'actualisation n'est du reste pas propre à cette pièce puisqu'il s'agit d'une constante de ses traductions ${ }^{8}$.

Afin de mieux cerner les enjeux idéologiques et poétiques de ces deux textes aux accents très personnels, nous proposerons, dans une première partie, un survol, rapide, de l'épître VI, 2 en précisant le contexte historique qui en a motivé la rédaction et en esquissant une brève analyse comparative avec un autre texte politique majeur de L'Hospital, le Discours du sacre $(\mathrm{V}, 8)$, rédigé deux ans et demi auparavant ${ }^{9}$. Sur la base de ces remarques liminaires, l'analyse des modifications significatives opérées par Rapin permettra, dans un second temps, non seulement d'éclairer d'un jour nouveau les circonstances rédactionnelles de la traduction et de fixer sa datation, mais aussi d'amorcer une réflexion sur la réception de l'œuvre du chancelier dans les milieux «politiques » vers la fin du règne d'Henri III.

La datation de VI, 2 est rendue possible grâce à trois indices chronologiques présents dans le texte, qui nous orientent vers le printemps de l'année $1563^{10}$ : le v. 274 mentionne un traité qui est menacé par les ennemis du roi ${ }^{11}$, le v. 294 évoque une "année complète de guerres civiles ${ }^{12}$ et, enfin, le v. 103 parle d'un rex puer: l'épître a donc été rédigée entre l'édit d'Amboise, signé le 19 mars, qui met un terme à la première guerre de religion, et la

7 Discours de Monsieur le chancelier de L'Hospital, p. 3.

8 Ce fait concerne en particulier ses traductions d'odes politiques d'Horace : voir à ce sujet l'introduction aux OEuvres, t. I, p. LVIII-LIX.

9 Pour une analyse plus exhaustive de l'épître $A d$ amicos, voir l'édition, à paraître, du livre VI des Carmina.

10 Cette datation a été proposée par Petris, La Plume et la tribune, p. 327, n. 24.

11 VI, 2, 274: «percussumque velint confundere foedus » («ils voudraient rompre le pacte conclu»).

12 VI, 2, 294: «exactus bellis civilibus annus». 
proclamation de la majorité de Charles IX le 17 août suivant. Comme l'a montré Loris Petris, l'épître présente par ailleurs de fortes similitudes avec un mémoire inachevé adressé au roi, que l'on peut dater de la dernière dizaine de juin ${ }^{13}$. Le contexte politique, en cette période d'après-guerre, est marqué par les dissensions profondes qui opposent les modérés - dominants alors au Conseil du roi - et les tenants d'une ligne plus dure, l'enjeu étant la mise en œuvre de l'édit d'Amboise. Ce dernier est rapidement enregistré par le parlement de Paris, mais sa mise en application s'avère problématique ${ }^{14}$ et sa pérennité paraît en outre menacée par le concile de Trente. L'Hospital, qui partage le gouvernement avec la reine-mère, défend avec vigueur tant le traité d'Amboise qu'un autre édit controversé, portant sur l'aliénation des biens ecclésiastiques. Alors que le conflit qui l'oppose au Parlement et à ses prétentions législatrices culminera en août dans le lit de justice convoqué pour la première fois de l'histoire extra muros, à Rouen, L'Hospital doit faire face à une vive résistance dans la magistrature et, plus généralement, auprès de tous ceux qui sont en désaccord avec la politique de tolérance qu'il incarne ${ }^{15}$.

$\mathrm{Au}$ regard du contexte que nous venons d'esquisser, l'épître VI, 2 concentre trois finalités : elle se veut, à l'intention de ses proches, une défense des principes moraux qui guident son action politique et qu'il juge incompris - ce plaidoyer, aux forts accents stoïciens, occupe grosso modo les deux tiers de la pièce (v. 1-203); le dernier tiers se présente comme un règlement de comptes, particulièrement virulent, avec la noblesse d'épée catholique, à laquelle il impute la responsabilité de la guerre tout en la taxant d'hypocrisie (v. 203-318) ; enfin, elle propose, à différents moments du texte, une réflexion sur la monarchie et sur le rôle que L'Hospital entend assumer, en tant que chancelier, auprès d'un roi mineur. Nous focaliserons ici notre attention sur le dernier aspect, qui permet non seulement d'appréhender, grâce à une comparaison avec

13 Petris, La Plume et la tribune, p. 460-461.

14 Voir S. Daubresse, Le Parlement de Paris ou la voix de la raison (1559-1589), Genève, Droz, 2005, p. 128-140. L'enregistrement ne comporte en revanche pas la réserve «jusqu'à la majorité du roi »: voir ibid., p. 131, n. 55.

15 Pour ce contexte historique, voir Petris, La Plume et la tribune, p. 54-57 et Histoire et dictionnaire des guerres de religion, éd. A. Jouanna, J. Boucher et al., Paris, Robert Laffont, 1998, p. 130-136. 
certains éléments du Discours du sacre, l'évolution de la pensée lhospitalienne depuis 1559, mais également de mettre en évidence plusieurs points susceptibles d'éclairer la démarche de Nicolas Rapin.

L'épître VI, 2 est, pour le chancelier, le lieu d'une affirmation extraordinairement incisive de sa volonté, celle du «sage » (sapiens, v. 76, 136, 151, 302), de l'« homme de bien» (vir bonus, v. 127, 143) qui, investi des plus hautes responsabilités politiques, agit dans l'intérêt exclusif du roi et ce, en dépit de toutes les forces d'opposition qu'il rencontre sur son chemin. En premier lieu, il agit ainsi malgré ses proches, qui le blâment de négliger les intérêts de sa famille (v. 226-243); il le fait ensuite malgré tous ceux qui gravitent dans l'orbite de la cour et qui recherchent eux aussi en priorité leur intérêt personnel (v. 271-293); et, ce qui est plus inattendu, il protège également les intérêts du roi contre la volonté du roi luimême, idée suffisamment importante pour être exprimée à deux reprises (v. 53 et 214-215: illius inviti; invitique... Principis). Or, ce principe a priori paradoxal, qui allie la possibilité de la désobéissance à la fidélité la plus absolue, s'explique dès lors que l'on postule une dissociation de la personne du roi d'avec sa fonction royale. L'Hospital se pose en serviteur de cette dernière, qui se confond du reste avec la patrie ou la res publica ${ }^{16}$, et non de la personne du roi, faillible et influençable. Ce principe de subordination de l'individu à la fonction royale est esquissé dès le Discours $d u$ sacre qui, à l'orée du règne de François II, dit l'inquiétude de voir accéder au trône un roi «inactif ou mou » $(\mathrm{V}, 8,198$ : vel iners vel mollis) déléguant ses responsabilités à des conseillers corrompus. "C'est un roi », sous-entendu une personne qui sache se rendre pleinement digne du pouvoir royal dont elle est investie, "que je veux conduire au règne, et non un faux bourdon", affirme L'Hospital dans l'épître $V, 8{ }^{17}$, à travers une formule audacieuse qui dit, déjà, l'ampleur de sa détermination.

Or, ce qui s'exprime comme une crainte sourde mais insistante dans le Discours du sacre devient une certitude dans l'épître VI, 2 et,

\footnotetext{
16 VI, 2, 121: «At pietas patriae, pietas et debita regi / Omnibus antistat». Voir aussi v. 292-293: "nullumque recusem ferre laborem, / Dum patriae prodesse sciam. Respublica testis [...]».

$17 \mathrm{~V}, 8,204$ : «Regem nanque volo, non fucum inducere regnis ».
} 
plus particulièrement, dans le dernier vers (v. 318), censuré dans l'édition princeps mais complété, à la main, dans l'exemplaire de Gand, puis dans l'édition d'Amsterdam : « les lois restent sans effet, à défaut d'avoir un vengeur [ou juge, ou défenseur] ${ }^{18}$. Ce vindex n'est autre que le roi lui-même, comme l'avait rappelé le Discours du sacre: à l'image du Christ, devant qui il répondra ultimement de ses actes, le roi est juge (vindex) et, dans sa qualité de juge, «serviteur inflexible des lois » $(\mathrm{V}, 8,23)^{19}$. Nullo vindice: la fin censurée de l'épître $A d$ amicos fait ouvertement état d'un inquiétant vide du pouvoir monarchique, conclusion qui pouvait paraître d'autant plus audacieuse en 1585 qu'elle ne manquait pas de faire écho à la faiblesse dont Henri III faisait preuve face aux Ligueurs ${ }^{20}$. Ce qui fait défaut, aux yeux des Politiques, en 1563 - comme en 1585 et ultérieurement, comme nous allons le voir -, c'est un roi doté de discernement (prudentia) et d'une volonté forte, rigoureusement orientée vers le service de la loi, qui inclut la mise en application et le respect des édits de pacification. On notera, dans ce contexte, que le mot clementia ne figure pas dans l'épître VI, 2, comme si cette vertu, intensément prônée en 1559 (V, 8, 328), n'était plus de saison face à ceux qui sont devenus, en 1563, les principaux ennemis de l'État, les catholiques intransigeants. Or, en l'absence d'un tel souverain, tout se passe comme si ses serviteurs avaient le devoir de se substituer à la personne du roi dans l'intérêt supérieur de la patrie. Le magistrat qui met en application les principes de la sagesse stoïcienne est animé d'une détermination qui ne craint ni la disgrâce ni la mort: sa longum mansura voluntas, sa "volonté appelée à durer longtemps», peut donc et doit corriger, ou à tout le moins neutraliser, la volonté sans cesse changeante du

\footnotetext{
18 Comparer les derniers vers de l'édition princeps avec ceux de l'exemplaire de Gand et de l'édition d'Amsterdam: «et quae poterant succurrere tantis / Sola malis, ea muta jacent oppressa timore / Iudicia* (v. 316-318); "et quae poterant succurrere tantis / Sola meis, ea muta jacent oppressa timore / Iudicia et nullo languentes vindice leges » (v. 315-317).

19 V, 8, 22-23: "Tardus et ad poenam, dubiis idem acer apertis / Criminibus vindex, rigidus legumque minister» ("Qu'il [le roi] soit un juge lent à la punition quand les crimes sont douteux, / Sévère quand ils sont patents; et qu'il soit le ministre inflexible des lois »).

20 La dédicace de l'édition date du $1^{\mathrm{er}}$ juin. Le traité de Nemours, qui entérine les revendications des Ligueurs, est signé le 7 juillet.
} 
roi $^{21}$. L'idéal du roi immobile, tenant le juste milieu, tel qu'il est énoncé dans le Discours du sacre $(\mathrm{V}, 8,16)$, se reporte ici sur son plus proche serviteur : «Et je reste pourtant identique à moi-même, quelles qu'en soient les conséquences, je continue de veiller, fût-ce à son corps défendant, aux intérêts du prince» (v. 213-215) ${ }^{22}$. Le parallèle entre le roi et le serviteur semble aller bien plus loin encore: si le roi idéal est appelé à croître tel un arbre et à "étendr[e] ses branches au-dessus des astres élevés », comme le dit l'image conclusive du Discours du sacre (V, 8, 360), le sage est lui aussi promis, par delà les épreuves qu'il a à subir, à une croissance verticale: «vainqueur, il finira par placer sa tête honorée parmi les astres $»^{23}$. Pour autant, il ne faut pas confondre grandeur morale et grandeur politique : le pouvoir du conseiller reste suspendu au bon vouloir du prince, et c'est la raison pour laquelle son action demeure souvent limitée à la parole, voire aux aboiements du chien de garde ${ }^{24}$, image qui résume non sans autodérision l'état auquel il se voit réduit. Ce droit à l'indignatio qu'il revendique non seulement contre l'avis de ses «amis» mais encore contre l'idéal d'une certaine apatheia stoïcienne (v. 112-135) complète ainsi et nuance son pouvoir d'action.

Plusieurs des principaux motifs de l'épître Ad amicos nous orientent d'emblée, pour la datation de la traduction, vers la période 1585-1589: 1'inébranlable fidélité au roi et à l'État, la revendication d'une certaine liberté de parole ainsi que le conflit ouvert qui oppose le je de l'épître à ses adversaires, qui sont aussi les adversaires d'un roi perçu comme faible: si ce dernier n'est plus

21 VI, 2, 204-208: "Quid si / Nunc vult, mox paucis ubi se collegerit horis / Idem nolet. Age haec longum mansura voluntas / Non potior, quam praecipitans animi impetus expers / Consilii, subitis impulsus motibus? ( «Que faire si / aujourd'hui il veut une chose, mais que bientôt, lorsque quelques heures plus tard, il se sera ressaisi, / il ne voudra plus la même chose. Eh bien, cette volonté appelée à durer longtemps / n'est-elle pas préférable à une impulsion précipitée de l'esprit, dépourvue / de réflexion, induite par des élans incontrôlés?»).

22 VI, 2, 213-215: «Et muto nihil ipse tamen, quicunque sequetur / Exitus, invitique suam rem pergo tueri / Principis ».

23 VI, 2, 147: "Victor honoratum tandem caput inferet astris ».

24 VI, 2, 109-110: «Non saltem acclames et vociferere, malisque / Furibus adlatres » ( «Du moins ne pousserais-tu pas des cris et des clameurs, n’aboierais-tu / pas contre les méchants voleurs »). 
mineur, il est encore significativement qualifié de «jeune» (v. 141). Sans entrer ici dans les détails de sa carrière ${ }^{25}$, rappelons que Nicolas Rapin, homme de guerre dont le loyalisme s'illustre à de nombreuses occasions du côté catholique, reste dans son Poitou natal jusqu'à l'été 1585 lorsqu'il est nommé lieutenant-criminel de robe courte à Paris, grâce notamment à son protecteur Achille de Harlay, premier président du Parlement. Rattaché au Châtelet, investi de compétences judiciaires, il a sous son commandement une troupe de vingt archers, qui font partie des forces de l'ordre parisiennes. La nomination de Rapin, également reconnu pour ses qualités d'humaniste et de poète - il participe au tombeau de Ronsard en 1585 -, intervient dans le contexte de la résurgence de la Ligue après la mort de François d'Alençon, alors qu'Henri III souhaite une reprise en main des institutions de la capitale. Cet épisode parisien dure jusqu'en juillet 1588, date à laquelle Rapin est chassé par les Ligueurs.

J. Brunel affirme que «le sens de l'attitude de Nicolas Rapin au cours [de ces] quelque trente mois [...] tient tout entier dans une formule: la fidélité au roi ${ }^{26}$. Son activité, tant sur le plan professionnel que littéraire, est entièrement consacrée à la lutte contre la Ligue $^{27}$; il évolue dans l'entourage des Politiques, qui perpétuent, dans les années 1580, l'héritage de Michel de L'Hospital. Son éviction, en 1588, témoigne dès lors de la fermeté et de l'efficacité avec lesquelles il répond aux attentes placées en lui. De fait, les Ligueurs finissent par lui vouer une haine implacable, qui manque de lui coûter la vie lors de la Journée des Barricades ${ }^{28}$. Force est de constater que le loyalisme à toute épreuve et la lutte acharnée contre les ennemis de l'État, qui ne sont plus les huguenots mais bien les catholiques intransigeants, rencontrent un écho parfait dans les vers de L'Hospital. Que le texte soit resté à l'état manuscrit durant plus d'une décennie n'a rien d'exceptionnel, et il faut se

25 Pour la carrière de Nicolas Rapin, voir, outre le premier volume de la thèse de J. Brunel, son introduction aux CEuvres et sa notice dans Centuriae latinae II: cent une figures humanistes de la Renaissance aux Lumières : à la mémoire de M.-M. de la Garanderie, éd. C. Nativel, Genève, Droz, 2006, p. 721-726.

26 J. Brunel, Un Poitevin poète, op. cit., vol. I, p. 369.

27 Ibid., vol. I, p. 410.

28 Pour cet épisode, voir ibid., vol. I, p. 435 et ss. 
souvenir que Rapin ne publie rien pendant ses années d'exil ${ }^{29}$. La publication en 1601, à une époque où il estime avoir atteint le sommet de sa carrière et où il commence à envisager sa retraite ${ }^{30}$, pourrait s'expliquer, comme le suggère J. Brunel, par des circonstances particulières, notamment ses contacts avec un imprimeur intéressé par la réforme de l'orthographe et, peut-être aussi, par la volonté d'établir un parallèle entre L'Hospital et Sully. Pour autant, peut-on exclure une rédaction plus tardive, soit au début du règne d'Henri IV? Les passages qui portent l'empreinte d'une actualisation du message forment, nous allons le voir, un faisceau d'indices qui, sans apporter une preuve formelle, il est vrai, rendent néanmoins peu probable une datation postérieure à la mort d'Henri III.

La plupart de ces passages renvoient à une période troublée et deux ajouts méritent à cet égard une attention particulière. Les vers 157-158 évoquent l'irruption violente de «larrons » dans l'enceinte urbaine ainsi que des pillages, là où L'Hospital ne parle que de «fourberies» et de «larcins » ${ }^{31}$. Le vers 41 (E puis se voir d'un haut degré démis) fait, quant à lui, allusion à une destitution ou à une disgrâce. Ce risque est certes abordé par L'Hospital quelques vers plus haut à travers l'exemple des chanceliers Poyet et Olivier (VI, 2, 9-19) mais le caractère redondant du vers, qui ne correspond à rien de précis dans le texte source ${ }^{32}$, ainsi que l'emploi réfléchi du verbe voir suggèrent fortement que le traducteur parle ici de son vécu propre. Or, si on les replace dans le contexte mouvementé de l'année 1588, ces deux passages renvoient, sans équivoque, à deux événements précis, soit la Journée des Barricades (12 mai),

29 Ibid., vol. I, p. 461.

30 Ibid., vol. I, p. 571.

31 VI, 2, 116: «cum videam fraudes et furta». Cf. les v. 157-159 de la traduction: «E moi qui voi larrons de toutes pars / Estre aux aguetz, é fausser les rampars / Pour piller tout sans iustice [...]».

32 VI, 2, 27-29: "Neve nimis studii, nimiumve ad publica curae / Adiiciat, tantum laturus iniqua laboris / Praemia: cum nihil ipse sibi, nil prosit amicis » (« et aussi de consacrer trop de zèle ou trop d'attention aux affaires / publiques pour ne retirer de sa peine que des avantages / dérisoires, alors qu'il n'est utile ni à luimême ni à ses amis»). Cf. les v. 38-42 de la traduction: "À quel propos, employer ses moyens / E se tuer aux afaires publiques / Pour n'y gagner qu'inimitiez é piques, / E puis se voir d'un haut degré démis / N'aiant rien fait pour soi ne ses amis?». 
et à ses conséquences - entre autres la confiscation des biens des sujets fidèles au roi -, d'une part, et à l'éviction de Rapin de son office de lieutenant criminel de robe courte dans le courant de juillet, d'autre part.

D'autres ajouts ou modifications significatifs permettent d'étayer cette datation et de préciser la fourchette chronologique: les vers 143 à 146 expriment la crainte d'une dislocation du royaume $^{33}$ - au lendemain de la Journée des Barricades, le roi et la cour quittent la capitale et, dans les mois qui suivent, la plupart des provinces et des grandes villes font allégeance aux Ligueurs $^{34}$ - ; le vers 250 fait précisément allusion à une cour itinérante (quand la cour fait seiour) ${ }^{35}$, celle d'Henri III, que Rapin suit à partir de juillet jusqu'à ce qu'elle se fixe à Blois en automne; le vers 456 évoque des assassinats là où L'Hospital parle des «choses d'autrui », ou de «ce qui arrive à autrui » $(\text { aliena })^{36}$ : si la Journée des Barricades n'a pas fait de mort - hormis une soixantaine de Suisses $^{37}$-, la révolte des Toulousains en février 1589 fait au moins deux victimes, le président du Parlement et le procureur général ${ }^{38}$. Les XVIII Sonnets, rédigés dans les premiers mois de 1589 et sur

33 VI, 2, 104-106: «falli miserum, pellique superbe / Omnibus aspicias fortunis, ut nihil illi / Iam reliquum praeter nomen titulumque supersit» («[...] tu souffrirais que ce malheureux soit trompé et écarté / avec arrogance de toutes les richesses, au point que bientôt rien, / hormis son nom et son titre, ne lui resterait! »); cf. les v. 143-144 de la traduction: «Pourroi ie voir, moi vivant, qu'on le pipe, / Que son roiaume en cent pars on dissipe».

34 J. Brunel, Un Poitevin poète, op. cit., vol. I, p. 461.

35 VI, 2, 180-182: «Nec gravor auriculas hominum praebere querelis. / Omne adeo nobis tempus consumitur in re / Communi: siquid reliquum» (« et je ne me refuse pas à prêter une oreille aux plaintes des gens. / D'ailleurs, mon temps est tout entier consacré au bien / commun ; s'il m'en reste un peu, [...]») ; cf. les v. 249250 de la traduction: «J'oi les pleintifs, é presque tout le iour / Je passe einsi quand la cour fait seiour.»

36 VI, 2, 314-316: «Nil opis, auxilii nil suppetit, a quibus esse / Debeat, aut metuunt, aut non aliena dolentes / Aspiciunt» («[la force des lois, vis legum] ne dispose d'aucun pouvoir ni d'aucun soutien, car ceux qui devraient / le lui fournir soit ont peur, soit regardent, sans éprouver aucune douleur, / ce qui arrive à autrui [...]»). Cf. les v. 453-456 de la traduction: «Ceus qui devroient i aporter secours / Tremblent de peur, é n'ont autre recours / Qu'a deplorer sans passion aucune / La mort d'autrui comm'a eus non commune».

37 Histoire et dictionnaire, op. cit., p. 337.

38 J. Brunel, Un Poitevin poète, op. cit., vol. I, p. 459; P. de L'Estoile, Nouvelle Collection des mémoires pour servir à l'histoire de France. 2, Registre-journal de 
lesquels nous reviendrons, dénoncent clairement ce que Rapin y qualifie de massacre ${ }^{39}$. Enfin, les vers conclusifs de la traduction déplorent le silence des «Parlements» (v. 457) - mot qui traduit iudicia -, ces «parlements qui seuls avoient resté / Pour maintenir du Roi la magesté ${ }^{40}$. Ce dernier vers (v. 458) forme, là encore, une adjonction, qui s'élucide lorsque l'on place le passage dans le contexte de l'«épuration» du parlement de Paris, qui eut lieu le 16 janvier 1589 et qui vit l'arrestation au Parlement et l'embastillement d'une cinquantaine de conseillers, à commencer par le premier président Achille de Harlay et d'autres amis de Rapin ${ }^{41}$. Alors que «la meilleure et plus saine partie de la cour», pour reprendre les mots de Pierre de L'Estoile ${ }^{42}$, est emprisonnée, restent les complices volontaires ou involontaires de la Ligue, rendus muets par la peur, comme le dit le dernier vers de la traduction, et prêts à toutes les compromissions.

Il faut répondre ici à une objection qu'il est possible de formuler à propos de l'identification des allusions de Rapin aux événements de 1588-1589: sa destitution, à laquelle le vers 41 fait vraisemblablement allusion, a été a priori le fait des Ligueurs et non celui du roi. L'accord appelé «Édit de l'Union» que Henri III et les Ligueurs signent à la mi-juillet, est précédé d'une liste de Remonstrances demandant au roi la réorganisation de la police parisienne et, notamment, la révocation de Rapin et son remplacement ${ }^{43}$. Or, dans sa réponse, le roi promet d'affecter Rapin à une autre fonction et de lui «commande[r] de resigner la dite charge» à quelqu'un d'autre $^{44}$. Dans les faits, les Ligueurs ne semblent pas avoir attendu que le roi signifie son congé à Rapin; il est placé devant le fait

Henri III, Paris, Ed. du commentaire analytique du Code civil, 1837, p. 289; J.-A. de Thou, Histoire universelle, t. X, Londres, s. n., 1734, p. 567-571.

39 Sonnet XI, v. 9. Voir J. Brunel, Un Poitevin poète, op. cit., vol. I, p. 459 et CEuvres, t. I, p. 411 et 433 .

40 Cf. VI, 2, 316-318: "et quae poterant succurrere tantis / Sola malis, ea muta iacent oppressa timore / Iudicia*» (« et les jugements qui, seuls, auraient pu remédier à de si grands / maux, restent muets, opprimés / par la peur*»).

41 CEuvres, t. I, p. 412.

42 P. de L'Estoile, Registre-journal de Henri III, éd. cit., p. 281.

43 Article IX des Remonstrances, cité par J. Brunel, Un Poitevin poète, op. cit., vol. I, p. 433.

44 Ibid. 
accompli et chassé de Paris aux alentours du 11 juillet ${ }^{45}$. Alors que sa maison du Poitou est occupée par les protestants et qu'il a neuf enfants à charge, Rapin subit une chute brutale. Cette destitution n'est certes pas une disgrâce, et Henri III le réhabilitera largement vers la fin de l'année ${ }^{46}$, mais l'événement se révèle très éprouvant, et fin octobre, il se plaint encore, dans une lettre, de $l^{\prime}$ «extresme necessité, où je suys reduict [...], depuys que je suys hors de l'exercice de mon estat $»^{47}$. Dans une élégie de protestation aussitôt adressée au Conseil d'État, il affirme que sa charge lui a été enlevée «Principis et plebis pacto» (v. 1), «par un traité conclu entre le prince et le peuple», allusion à l'Édit de l'Union. J. Brunel estime que Rapin, «ne comprend pas (ou, avec habileté, feint de ne pas comprendre) qu'il est victime d'une capitulation du roi $»^{48}$; or, il est permis de penser, et ce vers le prouve justement, qu'aux yeux de Rapin le roi porte bien une responsabilité égale à celle des Ligueurs. Son loyalisme, dont il se vante dans les vers suivants, ne l'aura pas mis à l'abri d'une ruine imméritée, et cette injustice, assumée, est encore en parfaite adéquation avec l'épître VI, 2. La traduction de ce texte lui fournit donc l'occasion de dire, plus ouvertement qu'ailleurs, qu'il a vécu son éviction comme une forme de trahison de la part du roi. Les vers 73-78, notamment, le disent avec force, et là encore nous avons affaire à un remaniement et à une amplification du texte d'origine:

Il vaut bien mieus céder aucunefois

De la rigueur des éditz é des lois

E obliger les grans pour peu de chose

Que se bander à defendre la cause

Du Roi, qui point ne vous en sora gré

E dont plu tôt vous serez denigré ${ }^{49}$.

\section{Ibid.}

46 Il est nommé successivement prévôt de l'armée du Poitou (28 octobre), puis prévôt général de la Connétablie et Maréchaussée de France (24 novembre 1588). Rapin l'en remercie par un sonnet (voir Un Poitevin poète, op. cit., vol. I, p. 450 ; CEuvres, éd. cit., t. II, p. 134). Voir aussi ci-dessous, p. 188.

47 Dans la lettre au duc de Nevers, datée de Blois, le 29 octobre 1588 (CEuvres, t. II, p. 307).

48 CEuvres, éd. cit., t. I, p. 420.

49 Cf. VI, 2, 51-54: «Utilius de iure aliquid concedere regis, / Multorumque animos, et gratiam inire merendo, / Illius inviti quam rem servare, tibique / Invidiam atque 
La traduction accentue considérablement la charge contre le roi en le taxant non seulement d'ingratitude mais aussi de diffamation. Les vers suivants (v. 81-82), «souvent ceus qui pénent le plus / Sont les premiers de la faveur exclus », dont le dernier ne correspond à rien dans le texte lhospitalien ${ }^{50}$, parachèvent l'image du serviteur dont le sacrifice personnel au service de l'État est mal récompensé. Enfin, lorsqu'il assène, dans une autre adjonction: «Ie ne fui point par faute de courage» (v. 439) $)^{51}$, il réaffirme certes son indéfectible sens du devoir mais on peut également comprendre qu'il rend autrui responsable de son exil, en l'occurrence le roi, qui l'a sacrifié comme un vulgaire pion en faisant des calculs politiques à courte vue.

Au-delà de la critique du roi motivée par sa situation personnelle, l'épître VI, 2 permet à Rapin de réfléchir au rôle de censeur de la politique royale qu'il s'est donné ailleurs, notamment dans la traduction des Sept Pseaumes penitentiels publiés en avril $1588^{52}$. Cette position de censeur est revendiquée haut et fort dans notre traduction, notamment aux v. 141-166, qui contiennent deux importantes adjonctions déjà vues plus haut ${ }^{53}$. Or, il assumera ce rôle, avec une force allant crescendo, dans deux œuvres rédigées vers la même époque et d'abord dans l'élégie latine adressée à Henri de Navarre vers la fin de l'année 1588, dans laquelle Rapin

odium multos adquirere in annos " ("Il est plus avantageux de faire des concessions aux dépens du droit du roi / et de gagner le cœur et la faveur de nombreuses personnes par ses mérites, / que de protéger les intérêts du roi à son corps défendant, et de / t'attirer l'envie et la haine pour de nombreuses années »).

50 VI, 2, 55-57: «Ecquid enim tantum respublica praeter inane / Nomen habet, vel cui navas studiosus opellam, / Ipsi quae regi atque aliis male grata futura est? " ("Que possède en effet l'État pour tout bien, hormis / un vain nom, ou pour qui accomplis-tu avec application ta modeste tâche / qui sera mal reçu du roi luimême et des autres?»).

51 VI, 2, 304-305: «Nec statione tamen nostra decedimus unquam, / Tantum animi nobis caelo datur» («Et pourtant, de notre position, jamais nous ne reculons, / si grand est le courage que le Ciel nous a donné!»). Cf. les v. 437-440 de la traduction: "E toutefois ie ne laisse' au danger / De conseruer ma place sans bouger: / Ie ne fui point par faute de courage: / E me tien ferme au plu' fort de l'orage».

52 Voir J. Brunel, Un Poitevin poète, op. cit., vol. I, p. 397-408.

53 Voir ci-dessus les notes 31 et 33. 
fait acte d'allégeance au futur roi. Ce poème s'adresserait en réalité, si l'on suit l'analyse proposée par J. Brunel, autant, sinon plus, au roi de France qu'au roi de Navarre, en ce qu'il appelle à frapper l'ennemi commun, les Guises, avec rapidité et détermination ${ }^{54}$.

Les XVIII Sonnets presentés au Roy, quant à eux, vont dans le même sens tout en présentant des parallèles plus éclairants encore avec notre texte. Rapin les rédige fin février-début mars 1589, et leur diffusion débute peu de temps après ${ }^{55}$. En dehors de plusieurs coïncidences formelles - notamment l'emploi du décasyllabe ${ }^{56}$ et l'existence de quelques rimes identiques ${ }^{57}$-, force est de souligner l'évidente cohérence thématique et rhétorique qui rapproche ces sonnets de notre traduction. C'est un èthos en tout point similaire qui s'y exprime: prenant violemment à parti ses adversaires, qui sont aussi les adversaires du roi, il défend avec ardeur la cause de ce dernier et celle de la France, qui est au bord de l'abîme (sonnet XVII, v. 3). Les pièces centrales (sonnets VII à XI), qui sonnent la charge contre les Ligueurs, reprennent les principaux chefs d'accusation formulés dans le Discours de M. le chancelier: en premier lieu l'hypocrisie $^{58}$, le mépris $\mathrm{du}$ roi, des lois et $\mathrm{du}$ «bien public », la passion de la guerre et le refus de toute perspective de paix. Mais, tout en adoptant cette posture de pourfendeur de la Ligue, il se veut d'une séverité sans concession à l'égard de la politique du roi et de son entourage ${ }^{59}$. Ce qu'il condamne dans les termes les plus vifs et il se fait ici le porte-parole de tous ceux qu'il appelle les « Roiaux

54 J. Brunel, Un Poitevin poète, op. cit., vol. I, p. 451.

55 Voir CEuvres, éd. cit., t. I, p. 407-417 et J. Brunel, Un Poitevin poète, op. cit., vol. I, p. 462.

56 Il utilise le décasyllabe, dans les mêmes années, pour sa traduction de l'Ode IV, 5 d'Horace (publiée fin 1587; CEuvres, t. I, p. 336).

57 Notamment les rimes signifiantes rigueur-vigueur (Discours de M. le chancelier, v. 449-450 et sonnet IV, v. 12-13) et citoyens-moyens (Discours de M. le chancelier, v. 37-38 et sonnet III, v. 9-10).

58 On notera à cet égard plus particulièrement le sonnet IX qui, en rapport avec les processions organisées à Paris en janvier 1589, insiste sur la couleur blanche, en totale contradiction avec la lutte armée que prônent les "prescheurs » acquis à la cause ligueuse. Une réflexion similaire sur la dichotomie blanc-noir se trouve aux vers 268-270 de VI, 2 (dans la traduction aux v. 382-385).

59 J. Brunel, Un Poitevin poète, op. cit., t. I, p. 465. Voir notamment le sonnet III, CEuvres, éd. cit., t. I, p. 424. 
et Politiques » (sonnet X, v. 8) -, c'est la temporisation coupable et la clémence mal placée à l'égard de ce «membre vitieux» qu'est la Ligue. L'ensemble des sonnets II à VI appelle le roi à se départir de sa «douceur» et à mobiliser tout ce que la France compte de forces vives et loyalistes ${ }^{60}$. On se contentera de citer ici le dernier tercet du sonnet IV, qui présente la même rime signifiante - rigueur / vigueur - que les vers 449-450 du Discours:

Si vous eussiez prattiqué la rigueur Lorsque le mal n'estoit en sa vigueur, Vous seriés Roy bien craint, et bien paisible.

Les vers 448-451 se lisent comme l'écho désabusé de la vigoureuse admonestation adressée au roi dans le sonnet $I V$, qui était elle-même déjà formulée sur le mode du regret:

Ie crie assez, é s'il avient qu'il faille

Punir le crime, é user de rigueur

Ie montre assez de zele', é de vigueur.

Mais quoy? la méin de la iustice' est morte ${ }^{61}$ :

Au même titre que L'Hospital, Rapin tâche de compenser l'inaction du roi en faisant mine de pallier - par ses moyens personnels l'absence d'une politique répressive clairement dirigée contre ceux qui entendent "arracher les fleurs des Lis de France» (sonnet $X$, v. 13). Surtout, et les Sonnets le disent formellement, la clémence est une vertu pour les temps de paix et accorder le pardon aux assassins relève de la « cruauté $»^{62}$ : Rapin va donc ici au bout du raisonnement resté implicite chez L'Hospital. Cette impatience à voir sortir Henri III de son attentisme explique finalement la virulence de ses accusations dans les extraits cités plus haut: même à

60 Au sujet de la question de savoir si Henri de Navarre est compris dans l'appel à la noblesse, voir J. Brunel, Un Poitevin poète, op. cit., vol. I, p. 467-468.

61 Cf. les vers correspondants dans VI, 2, 311-313: "Mihi deesse monenti / Verba putas, animumque, ita si feret usus, agendi / Legibus. At per se ipsarum vis irrita legum» («Dans mes remontrances, les mots / Me manquent, penses-tu, ainsi que le courage, quand cela s'avère nécessaire, d'agir / Par les lois. Mais la force des lois mêmes est inefficace à elle seule»).

62 Voir le sonnet II, v. 12-14, le sonnet III, v. 9-14 et le sonnet IV. 
supposer qu'il comprenne bien que la capitulation du roi lui a été dictée par les circonstances extérieures et qu'elle n'est aucunement assimilable à une disgrâce, son éviction représente une conséquence, parmi bien d'autres, de ce manque d'initiative et de fermeté qui, à ses yeux et aux yeux de tous les Politiques, entache la totalité de la politique royale vis-à-vis des Ligueurs. Si Rapin, qui s'est basé sur l'édition princeps ${ }^{63}$, ignorait la teneur complète de l'hexamètre conclusif, la véhémence de ses attaques s'avère en parfaite résonance avec le constat lhospitalien du vindex absent.

Un ultime argument, d'ordre plus général, en faveur de cette datation peut être retenu: la décision de reprendre à son compte, certes derrière le masque du traducteur, le je d'un personnage politique de premier plan, dont la voix s'exprime, à l'endroit du roi, avec une audace inédite, présuppose une légitimité suffisamment importante pour autoriser une telle prise de parole, dût-elle rester confidentielle. Or, cette condition semble acquise précisément entre la fin de l'année 1588 et la mort du roi. Comme l'observe J. Brunel avec prudence, il n'est pas impossible, même si l'on ne dispose pas d'une preuve formelle, que, durant les derniers mois du règne, Rapin ait accédé au statut de conseiller du roi, voire de confident mis au courant de l'exécution imminente du projet d'assassinat des Guises ${ }^{64}$. Quoi qu'il en soit, l'office de Prévôt général dont il est pourvu le 24 novembre est «quelque chose de plus qu'une compensation à l'éviction [...] de l'office parisien $»^{65}$. Colletet, dans sa biographie, affirme qu'après l'avoir élevé à cette charge $^{66}$, «Sa Majesté [...] le prit en singuliere affection, et [...] le considera comme une des plus fortes testes de son royaume ${ }^{67}$. Bien que serviteur fidèle et apprécié, Rapin ne semble jamais avoir atteint un tel degré de familiarité auprès d'Henri IV. Et, faut-il ajouter, inversement, il n'a plus jamais subi de revers socio-professionnel comparable à celui de 1588 .

63 L'inachèvement du poème est signalé non seulement par les mots « La fin est à dire» mais aussi par le caractère tronqué du dernier décasyllabe: «La peur qui les possede / Les rend muéts ».

64 J. Brunel, Un Poitevin poète, op. cit., vol. I, p. 455-456.

65 Ibid., vol. I, p. 450.

66 Pour la date exacte, voir ibid., vol. I, p. 446-447.

67 Cité par J. Brunel, Un Poitevin poète, op. cit., vol. I, p. 473, n. 166. 
La traduction de l'épître $A d$ amicos s'inscrit donc avec une grande probabilité dans le contexte des événements consécutifs à la Journée des Barricades ; elle pourrait être plus ou moins contemporaine des XVIII Sonnets, avec lesquels elle partage d'importants parallèles, mais il n'est pas impossible que la rédaction, sans doute commencée dès l'été 1588 , se soit échelonnée sur plusieurs mois, entraînant ainsi la superposition de plusieurs couches d'événements. Sur le plan méthodologique, Rapin traduit L'Hospital de la même façon qu'il traduit les odes politiques d'Horace: il s'identifie au je et adapte, dans une large mesure, mais non de façon systématique, le contenu aux circonstances actuelles. La plupart de ces actualisations restent toutefois discrètes, comparées à celles que l'on trouve dans les versions d'Horace. Si elles le sont, c'est que Rapin juge que la situation politique aussi bien que la situation personnelle décrites par L'Hospital sont parfaitement transposables respectivement à celle que connaît le royaume dans les années 1588-1589 et à la sienne propre, acteur de premier plan durant ces années-là.

Entre vie publique et vie privée, soit sur un mode plus intime que dans les Sonnets, Rapin peut y exprimer l'inquiétude - qui est celle de tous les Politiques - que lui inspire un roi indécis; il peut y dénoncer le pouvoir de nuisance de la noblesse ligueuse imbue de ses privilèges et agissant, sous le couvert de la religion, à l'encontre $\mathrm{du}$ bien commun; il peut y dire sa détermination à "avertir», «crier» et «aboier» (v. 149) lorsqu'il estime que le salut de la «France ${ }^{68}$ est en péril. À la suite du chancelier, loin de toute complaisance courtisane, il y trace le sentier étroit qui est celui du serviteur à la fois totalement loyal au prince et lucide quant à ses défauts. Cette tâche paradoxale, ce «sacerdoce civil » ${ }^{69} \mathrm{qu}^{\prime} \mathrm{il}$ assume au péril de sa carrière et de sa vie, il estime enfin nécessaire de les défendre face à des proches matériellement touchés par les conséquences de ses choix éthiques ${ }^{70}$. L'épître $A d$ amicos lui fournit

68 La France est nommée plus souvent dans la traduction que dans l'épître VI, 2 : v. 187 (VI, 2, 134, Gallia), 368, 417 (VI, 2, 293, patriae), 424 (VI, 2, 299, patriae... parentem).

69 Petris, La Plume et la tribune, p. 451.

70 Il les nomme, dans un ajout, avec bien plus de précision que L'Hospital : « mon gendre », un « parent proche » et un « alié, sur qui j’ai du pouvoir » (v. 352-353).

Cf. VI, 2, 244: «Hos ego iure meo tanquam mihi sanguine iunctos». 
le miroir dont il a besoin pour penser ses actes mais aussi pour leur donner un surcroît de légitimité, à l'ombre du grand chancelier (magnus quaestor).

Ruth STAWARZ-LUGINBÜHL Université de Neuchâtel 


\section{AFFECTUS PLENA: MICHEL DE L'HOSPITAL, «CELUY QUE J'AYME, HONORE ET ESTIME COMME MON PERE ET MILIEUR AMI»}

À mon ami Loris

\section{«LEI ERA VESTITA DI TELA D’ARGENTO » : L'ARRIVÉE À NICE}

Le 25 janvier 1560, Marguerite fit son entrée solennelle à Nice. Le duc de Savoie avait prévu sept mules blanches avec un manteau en or et des fleurs de lys, sur l'une desquelles la duchesse parcourut les rues de la ville sous

un baldacchino d'argento e cremisi portato dai quattro sindaci della città affiancati da venti nobili nizzardi in raso bianco e catena d'oro, e venti mercanti in raso rosso. Lei era vestita di tela d'argento con sopravveste di velluto nero stellata d'oro, con cappello di velluto, fregiata di gioie di valore inestimabile, con grosso carbonchio per medaglia con quattro o cinque penne di corvo di Polonia, ed in cima di detto cappello un grossissimo diamante in punta con quattro grosse perle e rotonde, il tutto di prezzo straordinario. Il suo candidissimo collo era adornato da un collare d'oro tempestato di finissimi rubini e diamanti con tre perle lunghette e grosse come pere moscatelle per fermaglio. Era poi cinta la sua persona di vari giri di grosse finissime perle con una croce pesante in mezzo al petto, tutta fatta a punta di grandissimi e preziosissimi diamanti e braccialetti ${ }^{1}$.

1 Pierre Gioffredo, Storia delle Alpi marittime, Turin, Reale, 1839, t. V, p. 397, qui cite une relation manuscrite évoquant le jour de la conversion de saint Paul; trad. fr. Histoire des Alpes-Maritimes : une histoire de Nice et des Alpes du Sud des origines au XVII siècle, trad. H. Barelli et M. Prève, Nice, Nice Musées, 2007- 
C'est probablement le même chapeau en velours que Marguerite porte dans les deux portraits en huile sur bois peints par Corneille de Lyon ${ }^{2}$.

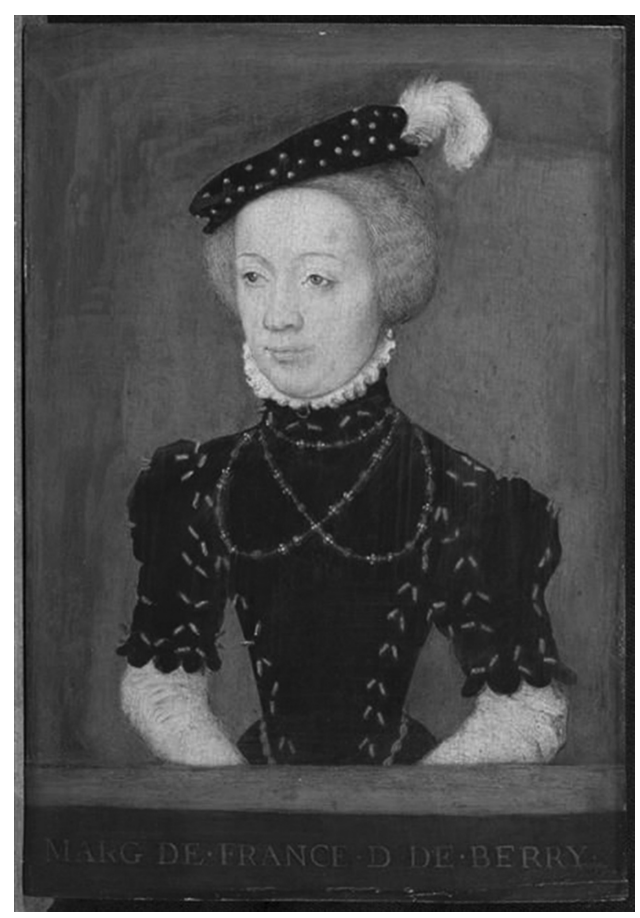

Ill. 4: Portrait de Marguerite par Corneille de Lyon, huile sur bois $(22 \times 15)$, actuellement conservé à Chantilly, Musée Condé (n. inv. PE 245). (C) RMN-Grand Palais (domaine de Chantilly) / René-Gabriel Ojéda

2008. Voir aussi P. Condulmer, Emanuele Filiberto e Margherita di Valois, Turin, Codella Editore, s.d., p. 129-130.

2 Ce portrait a appartenu au fil des siècles à : Jean-Baptiste Colbert de Torcy (il porte au dos son cachet); Roger de Gaignières; Alexandre Lenoir (1838); George III e duc de Sutherland (1876). Voir D. Bentley-Cranch, «L'iconographie de Marguerite de Savoie (1523-1574)", dans Culture et pouvoir au temps de l'Humanisme et de la Renaissance, Genève, Slatkine et Paris, Champion, 1978, p. 245 ; R. Gorris Camos, «I volti della duchessa : icone e rappresentazioni del potere alla Corte di Margherita di Francia, duchessa di Savoia », dans Iconologia del potere. Rappresentazioni della sovranità nel Rinascimento, Vérone, les 16-18 mars 2009, éd. D. Carpi et S. Fiorato, Vérone, Ombre Corte, 2011, p. 75. Il en existe un croquis à la BNF avec la mention: "Copié sur l'original peint par Corneille dans le cabinet de M. de Gaignières » et avec cet ajout: « agée de 25 ans, 1548 ». La mode du chapeau pour les femmes date toutefois des années 1550. 
Dans celui conservé à Chantilly, Marguerite est peinte à mi-corps sur un fond bleu clair tirant au vert. Elle porte une robe de velours noir, semée de perles bleues et roses, sur ses cheveux un petit bonnet de cour en velours noir, orné de perles bleues et roses. Dans l'autre portrait de Corneille de Lyon, conservé à Versailles, Marguerite porte le même bonnet de cour en velours noir, mais son corsage est garni de fourrure ${ }^{3}$.

C'est probablement aussi le même chapeau que Marguerite porte dans l'enluminure du ms. B. L. Sloane 2421, fol. 2, où nous voyons Marguerite en compagnie de deux de ses dames recevoir en hommage un livre de la part d'une "mansueta asinella », une petite ânesse. Le ms. Sloane, qui contient une Canzone. In lode dell'Asina dal cui latte fu risanata a Niza la Serenissima Margherita di Francia. Duchessa di Savoia, l'anno 1560, nous apprend que Marguerite tomba gravement malade à Nice et que le médecin Castellan, envoyé par la reine Catherine, la soigna avec du lait d'ânesse ${ }^{4}$. Dans une lettre, le duc donne à Catherine quelques détails sur la maladie de Marguerite («une fievre» dit-il, mais plus probablement une grave dépression nerveuse) et la remercie de lui avoir envoyé son médecin Castellan ${ }^{5}$. La reine est très inquiète de la maladie de sa «sœur» et écrit au duc une lettre où elle révèle toutes ses craintes:

3 Voir D. Bentley-Cranch, «L'iconographie de Marguerite de Savoie (15231574) », art. cit., p. 248. Il a servi de modèle pour le Promptuarium iconum de Guillaume Roville dans lequel un petit médaillon reproduit exactement ce portrait de Corneille. L'édition française du Promptuaire des medalles, Lyon, Roville, 1553 (Arsenal, 4\% H 7879) est dédiée par le libraire «A Tres Haulte et Tresillustre Princesse Madame Marguerite de France, sœur unique du Roy, Duchesse de Berry etc. » (fol. a2).

4 Voir la lettre de Marguerite au duc de Lorraine, du 12 juin 1560 : «le sieur de Castellan m'a ordonné de prendre du lait d'ânesse et les bains à certains jours» (Lettres inédites de Marguerite de France, éd. Ph. Tamizey de Larroque et J. Loutchitsky, Revue historique, XVI (1881), $2^{\mathrm{e}}$ fascicule, p. 315). Dans une autre lettre, le duc donne à Catherine quelques détails sur la maladie de Marguerite et la remercie de lui avoir envoyé son médecin Castellan (BNF, fr. 3898, fol. $65 \mathrm{v}^{\mathrm{o}}$ ). Voir Lettres de Catherine de Médicis, éd. H. de La FerrièrePercy, Paris, Imprimerie nationale, 1880, t. I, p. 141, 142, 144, 147-148 et 154155.

5 BNF, fr. 3898, fol. 65. 
J'é peur que ses nouvelles [la conjuration d'Amboise] ayent fyt empyrer Madame, porquoy je vous suplye l'asseurer, come la verité ayst ausi, que touttes chauses s'en vont sy apèsée qu'il ne s'en fault plulx donner de la pouyne, mès remercier nostre Signeur de la grase qui ha fayte, laquele je aystimeré encore plulz grande, se rant tyeule senté à madame de Savoye que luy desyre ${ }^{6}$.

Quant à elle, Marguerite parle souvent, dans ses lettres d'avril à juin 1560 au roi et au cardinal de Lorraine, de sa maladie et de sa lente guérison ainsi que de ses difficultés à «supporter la longuer de cete dicte malladye, qui toutefois va tousjours en diminuant, par ce soing et diligence, que le sieur de Castellan faict aupres de moy, donc j'espere bientost garison avec l'ayde de Dieu $»^{7}$.

Or, le ms. Sloane, emblème de ce don d'un livre précieux offert comme un magnifique et somptueux bouquet aux duchesses et aux princesses ${ }^{8}$, n'est pas le seul hommage offert à la duchesse à Nice. Un autre manuscrit enluminé, datant de la même période, est conservé à la Bibliothèque de l'Université de Spalding aux États-Unis. Il s'agit d'un Livre d'heures, Horae Beatae Virginis Mariae, secundum usum Romanum cum calendario, enluminé pour Marguerite à l'occasion de son mariage avec Emmanuel-Philibert (au fol. 21 on peut voir au recto les armes de France et au verso les armes de Savoie ainsi que la devise de Marguerite, Rerum Sapientia

$6 \quad$ Lettres de Catherine de Médicis, éd. cit., p. 134.

7 Voir Lettres originales de Marguerite de France, duchesse de Savoie, adressées à la famille royale de France, 1560-1574, éd. G. Bertrand, Revue des Sociétés savantes, $5^{\mathrm{e}}$ série, tome IV (1872), p. 475-476 et Lettres inédites de Marguerite de France, éd. cit., p. 311. En mai, elle va mieux et écrit au cardinal de Lorraine, le 17, qu'elle a «laissé pour quelques heures du jour le lict depuis quatre ou cinq jours, et me faiz porter dans une chaise le plus longtemps que je peux par mon logis, affin que peu à peu je puisse prendre l'air et me fortiffier, pour m'en aller par apres losger au chasteau où j'ay esperance de recouvrer le demeurant de ma santé avecques l'ayde de Dieu ». Pour résoudre les problèmes du royaume, elle suggère au cardinal de demander l'aide de L'Hospital, «qui vous y servira aussi fidellement et suffisamment qu'il vous est obligé et que vous le congnoissiez homme de bien » Lettres originales, op. cit., p. 475.

8 Voir M. Orth, «French Renaissance Manuscripts and histoire du livre », Viator, 32 (2001), p. 259-262 ; ead., «Dedicating Women: Manuscript Culture in the French Renaissance and the case of Catherine d'Amboise and Anne de Granville», Journal of the Early Book Society, I/1 (1997), p. 17-47 et «Family Values: manuscripts as Gifts and Legacies among French Renaissance Women », Journal of the Early Book Society, IV (2001), p. 88-111. 
(ustos) $)^{9}$. Une des enluminures du manuscrit montre à l'arrièreplan une ville qui ressemble beaucoup à Nice. C'est donc dans cette ville que commença la nouvelle vie de Marguerite, qui était accompagnée dans son Iter Nicaeum par les membres de sa maison, que nous voyons défiler dans le cortège lors de son entrée, et escortée par les deux éminences grises de sa cour, le chancelier Michel de L'Hospital ${ }^{10}$ et le maître d'Hôtel Bartolomeo Del Bene ${ }^{11}$.

\section{«À MES YEUX TA VIE PEUT SERVIR DE MODÈLE SUBLIME AUX FEMMES COMME AUX JEUNES FILLES » : UNE CARRIÈRE À L'OMBRE DE MARGUERITE}

Si Marguerite assumait désormais ses nouvelles fonctions politiques, le voyage de trois mois vers Nice avait été long et difficile comme tous les adieux. Michel de L'Hospital, défini comme «celuy

9 Voir www.byu.edu/ hurlbut/dscriptorium/ où l'on peut voir les enluminures et la description de l'ouvrage. Sur la devise de Marguerite, voir C. Paradin, Devises Heroïques, Lyon, J. de Tournes et G. Gazeau, 1551, p. 234 : «Madame Marguerite de France, tresillustre Duchesse de Berri, fait sa Devise de l'Olive, ensemble du Serpent, sinifiant ainsi, toutes choses estre regies, et gouvernées par sapience, ou sagesse». Sur les manuscrits offerts à Marguerite, voir Les manuscrits enluminés des comtes et ducs de Savoie, éd. A. Paravicini Bagliani et al., Turin, U. Allemandi, 1990 ; R. Gorris Camos, « La Bibliothèque de la duchesse: de la bibliothèque en feu de Renée de France à la bibliothèque éclatée de Marguerite de France, duchesse de Savoie», dans Poètes, princes et collectionneurs, Mélanges offerts à Jean Paul Barbier-Mueller, Genève, Droz, 2011, p. 473525.

10 Michel repartira en avril 1560. Le cardinal de Lorraine lui écrit que, « combien Madame de Savoye est ayse de vous avoir pres d'elle et que je ne voudroye en rien du monde troubler son ayse et plaisir, si est ce que je ne vous puis nyer que je desire infiniment vous veoir, tant pour sçavoir des nouvelles bien amplement de madite Dame que pour communiquer avecques vous de beaucoup de chose importante pour le service du Roy » (2 février 1560, L'Hospital, Discours et correspondance, p. 161, n. 15). Le départ de son chancelier sera un autre coup très dur pour elle.

11 Pierre Gioffredo, Storia delle Alpi marittime, op. cit., t. V, p. 309. Sur la maison de Marguerite dans les années 1550, voir BNF, fr. 10394, Comte septiesme de $M^{e}$ François Barquin, tresorier et receveur general de la maison de madame Marguerite de France [...] durant le quartier de janvier, fevrier et mars 1549 [1550]. Parmi les Dames et Damoyselles, on trouve de nombreuses dames qui accompagneront Marguerite dans son voyage vers la Savoie. 
que j'ayme, honore et estime comme mon pere et milieur ami » et pour lequel elle mettra en exergue, dans ses lettres turinoises deux mots de sa main, Affectus plena ${ }^{12}$, l'accompagnait. L'Hospital, son chancelier à partir de $1550^{13}$, ne l'avait jamais quittée depuis son retour d'Italie en $1548^{14}$, où il avait rencontré Renée ${ }^{15}$ et avait noué des relations durables avec des humanistes italiens comme Pietro Vettori, Lilio Gregorio Giraldi, Marcantonio Flaminio ${ }^{16}$ et Alessandro Farnese qui fréquentaient l'académie d'Achille Bocchi, dédicataire de l'épître I, $11^{17}$.

Quand Anne d'Este épousa François de Guise, L'Hospital devint son curateur pour la renonciation à l'héritage des

12 Marguerite de Savoie à L'Hospital, [1567, fin novembre], dans L'Hospital, Discours et correspondance, p. 225-226, n. 56.

13 Le 29 avril 1550, Marguerite reçoit l'usufruit du duché du Berry en apanage $\mathrm{du}$ roi et appelle L'Hospital à sa chancellerie. Voir « Lettres d'Henri II portant donation du duché de Berry à Marguerite de France », BNF, Dupuy 832, p. 142 et Dupuy, fol. $297 \mathrm{v}^{\text {o }}$ (29 avril 1550). Voir en outre DL, t. I, p. 149-178 et Petris, La Plume et la tribune.

14 Voir Petris, La Plume et la tribune, p. 8-10.

15 Envoyé au Concile, à Bologne (voir A. Tallon, La France et le concile de Trente, 1518-1563, Rome, EFR, 1995, p. 191-217), L'Hospital s'était lié à Renée de France, qui le nomme curateur de sa fille Anne, lors de son mariage avec François de Guise. Dans l'épître I, 4 Ad Adrianum Dracum, il évoque son étape ferraraise, ville «coniuncta» (I, 4, 183 ; Carmina, t. I, p. 134) à sa patrie par le sang du roi Louis XII. Voir Crouzet, La Sagesse et le malheur, p. 29-30 et p. 77. L'Hospital dédie d'ailleurs plusieurs poèmes à Anne d'Este. Dans l'épître VII, 4, il écrit se rappeler «l'époque où je te vis à Ferrare» et où elle l'emportait «en beauté sur toutes les jeunes filles, en vertu sur toutes les mères de famille, en courage sur tous les hommes » L'Hospital, Poésies complètes, p. 361-362.

16 Voir R. Gorris Camos, " “L'Olive de l'Europe, et l'effroy d'Ignorance" : l'Olive de Du Bellay et les poètes de Pallas » et l'épître I, 15 (éditée dans Carmina, t. I, p. 338-350) où il recommande à Marguerite le poète des De rebus divinis carmina qui, pour elle, a abandonné les Muses profanes pour les Muses du ciel et souligne l'importance de cette gerbe de poèmes sacrés offerts à Marguerite par le poète malade, encouragé par Pietro Carnesecchi (De rebus divinis carmina, Paris, chez Robert Estienne, 1550).

17 Carmina, t. I, p. 260-276. Sur Bocchi et les liens avec Renée, voir A. Rolet, Les Questions symboliques d'Achille Bocchi. (Symbolicae Quaestiones, 1555), Tours, PUFR et Rennes, PUR, 2015; A.M. Rambaldi, «Il simbolo di Renata di Francia nelle Symbolicae Quaestiones di Achille Bocchi », dans L'aquila bianca. Studi di storia estense per Luciano Chiappini, Ferrara, Corbo Editore, 2000, p. 315-332. 
Este $^{18}$. Après avoir été présent à la cérémonie du 28 septembre, quand au Palazzo San Francesco ${ }^{19}$ fut décidé le mariage entre Anne et le duc de Guise, il escorta la fille de Renée à Paris pour son mariage qui eut lieu le 4 décembre 1548 à Saint-Germain-enLaye $^{20}$. Anne lui avait confié vouloir continuer à se consacrer à l'étude, comme sa mère lui avait appris ${ }^{21}$, et L'Hospital lui proposa comme modèle Marguerite, «qui préfère l'immortelle poésie à tout l'éclat d'un trône ${ }^{22}$. Il n'est pas étonnant d'ailleurs, pour ceux qui connaissent l'éducation que Renée avait fait donner à ses filles, qu'Anne, lors de son arrivée en France, ait dû «dissimuler et feindre», cacher sa «vraie religion». Michel, dans son épître Ad Annam Aestensem (VII, 4), lui écrit:

Il t'a fallu dissimuler et feindre en face de cette foule accourue de tous les points de l'Europe. Jamais tu ne te serais pliée à leurs exigences, si tu avais vécu à ta propre cour, si tu n'avais pas été liée à ton époux et forcée d'obéir à un maître puissant. Mais quel est le vaisseau qui peut rester immobile au milieu des mers quand les tempêtes enflent ses voiles? ${ }^{23}$

18 BNF, Dupuy 701 et DL, t. I, p. 130.

19 Sur ce Palais, voir R. Gorris Camos, " "D'un château l'autre" : la Corte di Renata di Francia a Ferrara», dans Palazzo Renata di Francia, Ferrare, Il Corbo, 1997, p. 139-173.

20 Le contrat fut signé le 28 septembre 1548, voir Petris, La Plume et la tribune, p. 10 ; DL, t. I, p. 136-144. Sur Anne d'Este, voir DBI, t. 43, p. 315-320 (M. Sanfilippo); C. Coester, Schön wie Venus, mutig wie Mars. Anna d'Este, Herzogin von Guise und von Nemours (1531-1607), Munich, Oldenbourg, 2007; H. Leloup, «Anne d’Este (1531-1607). Fille aînée de Renée de France, Duchesse de Guise puis duchesse de Nemours, Dame de Montargis », Bulletin de la Société d'Émulation de l'Arrondissement de Montargis, sér. 3, 119 (2002); J. Munns et P. Richards, «Exploiting and destabilizing Gender Roles: Anne d'Este », French History, 6 (1992), p. 206-215; C. Coester, Livre de comptes d'Anne d'Este de l'année 1593, Paris, Cour de France.fr, 2009 (http://cour-de-france.fr/ article998.html).

21 Sur l'éducation d'Anne et des princesses ferraraises, voir R. Gorris Camos, " "Donne ornate di scienza e di virtù" : donne e francesi alla corte di Renata di Francia», dans Olimpia Morata: cultura umanistica e Riforma protestante tra Ferrara e l'Europa, Atti del Convegno di Ferrara, 18-20 novembre 2004, éd. G. Fragnito, M. Firpo et S. Peyronel, Ferrare, Istituto di Studi Rinascimentali, 2007, p. 175-205.

22 Voir DL, t. I, p. 130-135.

23 VII, 4 Ad Annam Aestensem, dans L'Hospital, Poésies complètes, p. 360-362. Voir sur l'attitude religieuse d'Anne, E. Belligni, Evangelismo, Riforma ginevrina e 
Sans doute ces liens italiens, voire franco-ferrarais, ne pouvaient que représenter un atout important pour la carrière que Michel allait entreprendre à l'ombre de Marguerite. En effet, si Jean de Morel d'Embrun, maréchal des logis de Marguerite ${ }^{24}$, avait déjà présenté Michel de L'Hospital à Marguerite avant 1547 (III, 15), celui-ci devint son protégé à partir de son retour en 1548: «J'ai de plus, au retour de la mission qui m'avait conduit en Italie, jugé, par moi-même, de la bonté de ton cœur pour tout ce qui t'approche; depuis ce moment tu m'as permis de compter au nombre de tes familiers », écrit Michel dans l'épître II, 2, sorte de petit traité contre les courtisans ${ }^{25}$.

Les attaques contre les mauvais conseillers se multiplient sous la plume de L'Hospital qui condamne, à plusieurs reprises, dans ses onze épîtres à Marguerite ${ }^{26}$, leur attitude mensongère et protéiforme. La cour est un lieu qui cache, sous la magnificence, le serpent de l'inquiétude, de la douleur de vivre et du malaise. Le portrait du frère de Marguerite dans l'épître II, $2^{27}$, entouré, voire presque suffoqué, par la foule des quémandeurs se ruant sur lui, semble sorti d'un cauchemar:

nicodemismo. L'esperienza religiosa di Renata di Francia, Cosenza, Brenner, 2008, p. 245-246. L'éducation religieuse d'Anne, après son mariage, fut confiée par sa mère à Boturnio de' Boturnei, qui recouvrait la charge d'aumônier mais s'occupait de la gestion de la vie religieuse de la maison de la jeune épouse. Sur cet hérétique, chassé de la cour du duc d'Este et dont on disait que «non camini bene nella religione», voir B. Fontana, Renata di Francia duchessa di Ferrara: sui documenti dell'archivio estense, del mediceo, del Gonzaga e dell'archivio secreto vaticano, Rome, Forzani e C., Tipografi del Senato, 1889, t. III, p. XLII et XXXIII et Belligni, op. cit., p. 245-246. C'est Boturnio qui renseigne Renée sur les inquiétudes spirituelles de sa fille (au moins jusqu'à son arrestation en 1554). Renée fut toujours très attentive au cheminement spirituel d'Anne. Boturnio écrit en mars 1550: "Dice [Anne] che sono predicatori che parlano liberamente et che Madama sua ne ode uno et spiera che col tempo non sarà perseguitati li buoni christiani come sono stati per il passato». Voir Fontana, id., t. III, p. XXXIII.

24 Voir DL, t. I, p. 97-105 et t. II, p. 27-33; Petris, La Plume et la tribune, p. 11 et n. 70.

25 II, 2 Ad Margaretam Valesiam, Regiam Virginem, Francisci Regis Filiam, dans Carmina, t. II, p. 38-55.

26 I, 15 ; II, 2 ; II, 8 ; II, 15 ; III, 11 ; III, 15 ; IV, 4 ; V, 3 ; VII, 5 ; IX, 24 ; IX, 36. Il faut y ajouter des épîtres dédiées à son entourage et dans lesquelles L'Hospital mentionne Marguerite (I, 5; III, 16; V, 9, etc.). Pour un tableau synoptique des Carmina, voir Petris, La Plume et la tribune, p. 548-556. 
Henri était pressé par une multitude de gentilhommes;

L'air du lieu était lourd et vicié ; le roi était assis

Au centre d'un espace étroit et sur son visage perlait

Et coulait une abondante sueur - de fait, c'était l'été

Et le soleil dans sa course dépassait déjà les pinces du Cancer brûlant - ;

Je vis comme ses serviteurs réclamaient à la nombreuse

Assistance de s'écarter un peu de la fenêtre

Qui se trouvait en face de lui, afin de laisser passer un souffle d'air.

Ils réclamaient cela avec force prières. Qui l'aurait cru?

Ils ne purent jamais l'obtenir! Ton frère

Se taisait et jamais il ne donna le moindre signe d'une souffrance

[pourtant bien réelle.

Ainsi le grand roi mendiait un tout petit peu

De cet air dont le malheureux mendiant jouit en abondance dans les

[carrefours ${ }^{28}$.

Ce roi impassible, hiératique, est le paradigme de la feinte habile, presque stoïque, de la corruption et du mensonge qui entourent le roi et qui empoisonnent «les splendeurs» de ce "vaste théâtre». Toutefois l'ambition et le besoin de puissance, «deux tyrans contre nature», entraînent les hommes de bien à «forcer la porte, pourtant close des demeures / Des nobles, et entrer malgré l'opposition des gardiens, / Harceler sans répit et assommer les pauvres rois ${ }^{29}$. D'ailleurs, Michel même n'est pas insensible à cette «peste» car dans une autre épître (II, 8), où il réfléchit aux revers de fortune des courtisans, il se montre bien conscient de son «exigeante ambition » qui lui a fait pousser à lui aussi, homme juste et presque timide, la porte du palais ${ }^{30}$.

Les Epistres, à partir de 1550, l'année où il est nommé par Marguerite chancelier du Berry ${ }^{31}$, marquent le début d'un double

28 II, 2, 57-69, dans Carmina, t. II, p. 41-43.

29 II, 2, 53-55, dans Carmina, t. II, p. 41.

30 II, 8, dans Carmina, t. II, p. 148-171. Michel est conscient de ses limites et invite à plusieurs reprises Marguerite à l'indulgence, mais aussi à une autoconscience critique de ses actions et de ses forces. Voir par ex. en II, 8, 106108, dans Carmina, t. II, p. 155.

31 C. A. Henri II, t. IV, p. 89, $\mathrm{n}^{\circ} 6471$ pour la donation du Berry en apanage, le 29 avril 1550 . 
rapport épistolaire, vrai (lettres) ${ }^{32}$ et fictif (Carmina), qui va durer, même après la séparation, jusqu'à la mort du chancelier ${ }^{33}$. Les poèmes de Michel de L'Hospital sont le miroir fidèle de cette amitié «sincère et indéfectible à Marguerite ${ }^{34}$, qui va bien au-delà d'un rapport officiel entre la duchesse et son chancelier, et où la déférence ne cache pas, comme pour Baccio Del Bene, l'affection voire la connivence. Marguerite et les siens partagent une «relligion» ou «inspiration evangelique» pour laquelle la vertu de l'amicitia joue un rôle fondamental ${ }^{35}$. Les épîtres du chancelier à Marguerite sont des exempla de fraternité et de connivence, des éléments d'une communication, cominus eminus ${ }^{36}$, qui ne veut et ne peut pas être interrompue, un exercice d'écriture qui défie l'éloignement physique et le temps qui passe ${ }^{37}$. Dans ce rapport d'amitié, la communion spirituelle semble presque annuler la profonde différence de statut social entre la princesse et son chancelier. Michel est pour elle non seulement «celuy que j'ayme, honore et estime comme mon pere et milieur ami ${ }^{38}$, mais aussi un Te quasi me alterum, dans une dialectique amicale et rhétorique évoquant Cicéron-Atticus, Érasme-saint Jérôme, Maistre ClémentLyon Jamet, Montaigne-La Boétie ${ }^{39}$. De son côté, Michel l'appellera,

32 Voir les lettres de Marguerite publiées dans L'Hospital, Discours et correspondance, p. 159, 215 et 225.

33 Voir aussi l'épître I, 5 dans Carmina, t. I, p. 148-158, adressée à l'humaniste Pontronius (dans BNF, Dupuy 901, fol. 44ro , le dédicataire est Ad Ioachimum, peut-être Joachim Du Bellay; Carmina, t. I, p. 152), qui suit Marguerite dans ses études, mais qui parle en réalité des choix culturels de la princesse. Cette épître est postérieure à 1550 .

34 Petris, La Plume et la tribune, p. 11. Sur la «familiarité respectueuse» des rapports de Michel avec ses protecteurs, voir DL, t. I, p. 106.

35 Voir I, 8 pour la manière de se conduire envers les puissants en évitant la servilité et l'impertinence.

36 Il s'agit de la devise de Vittorio Baldini, voir R. Gorris Camos, " "Cominus Eminus": les pages de titre des imprimeurs-libraires ferrarais", dans La Page de titre à la Renaissance, éd. J.-F. Gilmont et A. Vanautgaerden, Turnhout, Brepols, 2008, p. 95-153.

37 Voir VII, 5 à Marguerite, rédigée après la Saint-Barthélemy, à la demande de Marguerite via Del Bene, et où il se compare à Laërte (p. 367).

38 Voir supra n. 12.

39 Sur cette amitié que « Mort n'y mord », voir R. Gorris Camos, «"Va lettre, va ... droict à Clément" : Lyon Jamet, sieur de Chambrun, du Poitou à la ville des Este, un itinéraire religieux et existentiel », dans Les Grands Jours de Rabelais en 
plus tard, dans III, 11, «mater», très souvent «Regina», «Diva» (faisant écho au portrait de sa tante et marraine, cf. II, 8 ; VII, 5), mais aussi «Virgo» (I, 5; IV, 4) et «puella», bien que Marguerite, dans ces années 1549-1550, fût proche de la trentaine.

Ses Carmina, qui recueillent, selon nous, les plus beaux portraits de Marguerite, sont l'écho de lectures communes (Horace, Cicéron, Flaminio, Du Bellay et la constellation des poètes du comte d'Alcinois) ${ }^{40}$, de sentiments partagés (la joie, la mélancolie pour leur départ et le deuil pour la mort des protégés, comme ce Catus de l'épître II, 15) ${ }^{41}$, de conseils de vie, de gestion du pouvoir, de suggestions de lecture, par exemple, celui de lire Cicéron «qui enseigne les devoirs de la vie (officium vitae) ${ }^{42}$, le droit chemin à suivre », plutôt qu'Horace, auteur que Marguerite affectionne tout particulièrement et qui reste le modèle esleu de Michel, dans ce mélange raffiné $\mathrm{d}^{\prime}$ " autofiction », d'entretien amical et de discours éthico-politique ${ }^{43}$.

Les deux auteurs sont l'objet d'une longue variante (de 1585) de l'épître I, 1544, où Michel décrit ses valeurs éthiques et politiques:

Poitou, éd. M.-L. Demonet, Genève, Droz, 2006, p. 145-172. Sur ces «affinités électives » et ces doubles littéraires, voir L'auteur à la Renaissance, L'altro che è in noi, dir. R. Gorris Camos et A. Vanautgaerden, Turnhout, Brepols, 2009, passim.

40 Sur le cercle de Denisot, voir maintenant le beau livre de D. Speziari, La Plume et le pinceau, Nicolas Denisot, poète et artiste de la Renaissance (1515-1559), Genève, Droz, 2016.

41 Pour l'identification de ce personnage, cité aussi en IV, 5, 23-24 comme Catus, voir Carmina, t. II, p. 282. Il s'agit de l'aumônier de Marguerite, Jean Catti qui figure en tête de la liste des Aumosniers, chapelains et clercs de chapelle de L'Estat de la maison de Marguerite, BNF, Clairambault 1216, fol. 43vº et fr. 10394.

42 Sur l'importance de Cicéron, voir Crouzet, La Sagesse et le malheur, passim.

43 «Introduction », Carmina, t. I, p. 16.

44 I, 15 Ad Margaretam Valesiam, Regiam Virginem, Francisci Regis filiam. De sacris Carminibus M. A. Flaminii, dans Carmina, t. I, p. 347. En mars 1550, L'Hospital fait l'éloge de Cicéron à Marguerite: c'est lui qui enseigne de vitae officio, le droit chemin à suivre quand l'honneur et l'intérêt ne s'accordent pas, les exigences des affaires publiques et privées, la modération dans la gloire et l'amour pour la patrie, l'amitié et enfin la piété filiale. Voir aussi I, $5 \mathrm{Ad}$ Pontronium, dans Carmina, t. I, p. 148-158, où l'on trouve la liste des auteurs appréciés par la jeune princesse: Virgile, Horace, Cicéron, princes de la langue latine. Michel se demande toutefois: «les a-t-elle quittés dans ces temps sacrés pour se pénétrer des livres saints?», ce qui semble indiquer un revirement 


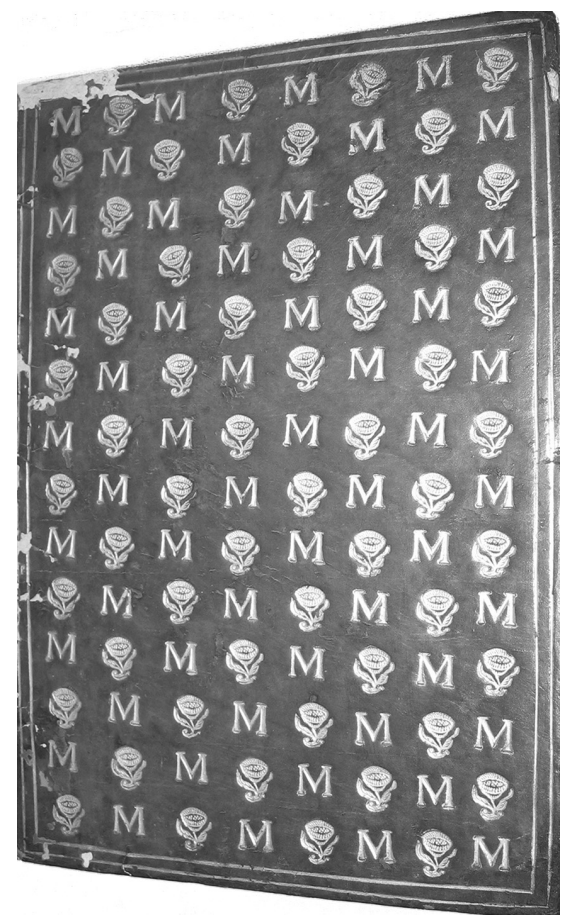

Ill. 5 : Reliure de l'exemplaire d'Horace de Marguerite (Turin, BNU, Ris.16.19) ${ }^{45}$.

vers 1550. Sur le cicéronianisme érasmien de L'Hospital, voir Crouzet, La Sagesse et le malheur, p. 144, p. 292 sq. et passim. Érasme publie Cicéron, De officiis (1501, 1519), De amicitia et le De senectute (1519) ainsi que les Tusculanes (1523). Voir Ch. Béné, «Érasme et Cicéron», dans Colloquia Erasmiana Turonensia, t. II, Paris, Vrin, 1972, p. 571-579. Sur Horace à la Renaissance, voir R. Lebègue, «Horace en France pendant la Renaissance », BHR, 3 (1936), p. 141-164, 289-308 et 384-419.

45 L'exemplaire des Poemata d'Horace (Vascosan, 1545) ayant appartenu à Marguerite est conservé à la BNU de Turin, Ris.16.19. Voir sur ce livre et sa magnifique reliure en veau ornée, sur les plats et sur le dos, de son monogramme $\mathrm{M}$ et des marguerites en semé, F. Malaguzzi, «Legature sabaude del XVI secolo", dans Bollettino della Società piemontese di archeologia e belle arti, Nuova Serie, XLII (1988), p. 154; R. Gorris Camos, «La Bibliothèque de la duchesse ...», art. cit., p. 502-503. C'est probablement le même qu'elle fit acheter avec des Commentaires en 1550. Michel la félicite de «remplir ses oreilles des causeries socratiques " du poète latin mais l'invite à délaisser certains passages scabreux. Voir Estat, BNF, fr. 10394, fol. 59; Petris, La Plume et la tribune, p. 227. 
Ainsi souviens-toi de pratiquer le poète de Vénouse,

Mais pas au point cependant de négliger les écrits d'or de Cicéron

Que tu as en main en ce moment; il y enseigne en effet un à un

Tous les devoirs de la vie, il indique, quand on hésite entre deux

[décisions,

La meilleure, celle qu'il faut choisir de préférence,

Et toutes les occasions où l'utilité semble en conflit avec le bien,

Et ce que les affaires publiques, et de même les affaires privées,

[exigent d'activités

Ou d'études, ce que sont la modération et la limite dans la recherche [des honneurs,

Quelle piété est due à la patrie, ou aux parents ${ }^{46}$.

Une variante importante qui nous révèle que le chancelier connaissait et orientait les lectures de Marguerite («quae nunc in manibus tibi sunt»), mais qui nous montre aussi ses tourments et ses hésitations quand l'utile entre en conflit avec le bien, la raison d'État avec les préceptes moraux, l'ambition avec la modération. Une hésitation, une obsession pour la vertu ${ }^{47}$, pour une parole et une action éthique qui fonde l'action de cet homme juste, vir bonus $^{48}$ qui va orienter non seulement la politique de Marguerite, mais aussi les choix culturels de sa cour et influencer les ouvrages qu'elle commande, de la traduction de l'Ethique à Nicomaque, en 1565, aux travaux de Giraldi Cinthio, publiés chez Torrentino ${ }^{49}$, aux poèmes éthiques de Chandieu et de ses poètes de cour, $\mathrm{y}$ compris les emblèmes moraux du mystérieux Jean Grangier. Une

46 Carmina, t. I, p. 347. Sur ses rapports avec son père, voir notre travail « "Le lys et la croix": constellations familiales dans la bibliothèque de Marguerite de France, duchesse de Savoie", dans La verve, la plume et l'échoppe. Études renaissantes à la mémoire de Michel Simonin, éd. C. Lastraioli, T. Uetani, M.-L. Demonet, Turnhout, Brepols, à paraître.

47 Sur la vocation apologétique et sa volonté de brosser un portrait vertueux de lui dans une série d'autoportraits en fragments d'une épître à l'autre, voir «Introduction », Carmina, t. I, p. 13 et p. 16.

48 Id., p. 7. Voir Ronsard, Ode à Michel de L'Hospital, au livre V des Odes (1550), dans Ronsard, OC, t. I, p. 626. Voir Petris, La Plume et la tribune, p. 150 qui évoque ce modèle posé par Caton et repris par Cicéron et Quintilien.

49 Voir R. Gorris Camos, «Giovan Battista Giraldi Cinthio, entre Ferrare et Turin, vero rifugio e sicurissimo porto ", dans Giovan Battista Giraldi Cinthio: hombre de Corte, preceptista y creador, dir. I. Romera, Colloque de València, 810 novembre 2012, Critica letteraria, anno XLI, fasc. I-II, no 158-159, 2013, p. 239-289. 
orientation qui l'amène à changer sa devise Rerum sapientia custos en Rerum prudentia custos $^{50}$. La variante B est parcourue par une tension politique, absente de la version $\mathrm{A}$, où il est surtout question des mérites intellectuels et moraux («moribus et studiis», v. 33) de cette docte Pallas qui sert d'exemple aux jeunes filles studieuses (et où le droit des femmes, nobles, surtout des mères à l'étude, est mis en évidence, v. 25-26), mais aussi aux hommes (v. 35).

Cette partie (I, 15, 37 sq.) est suivie d'une belle image, aux accents qui évoquent Pic de La Mirandole et où souffle cette force («afflata»), cet élan du savoir qui fait que l’homme, comme les plantes («omnia quae varie crescunt dispersa per orbem », v. 39) attirées par les rayons du soleil, lève sa tête vers le ciel («Externaque afflata, caput vi tollere coelo", v. 40). Un élan, un regard vers les astres et la lumière du soleil qui nous fait penser aux poètes de la dignitas - une notion si bien étudiée par Lionello Sozzi ${ }^{51}$ - mais aussi à un très beau poème qui sera publié à l'occasion du baptême de Charles-Emmanuel, ce petit prince du miracle, l'emblème et le sonnet de la «chicorée ${ }^{52}$ :

La plante que tu vois se nomme cicorée

Elle ayme du soleil les veritables rays,

Elle s'ouvre aussy tost que les rayons dorez

Du clair soleil l'ont veu au millieu de la prée. (fol. 88)

50 Voir pour les raisons de ce changement R. Gorris Camos, " "Sotto un manto di gigli di Francia" : poésie, allégorie et emblèmes de la dissidence entre Ferrare et Turin ", dans Allégorie et symbole. Voies de dissidence, dir. A. Rolet, Rennes, PUR, 2012, p. 439-496.

51 Voir les beaux travaux de Lionello Sozzi sur la dignitas, L. Sozzi, Rome n'est plus Rome, La polémique anti-italienne et autres essais sur la Renaissance suivis de "La dignité de l'homme», Paris, Champion, 2014.

52 PASTORALES SUR LE BAPTESME DE MONSEIGNEUR CHARLES EMANUEL, PRINCE DE PIEDMONT. Par I. Grangier, Lorrain. Avecques un Recueil de quelques Odes et Sonnetz, Faictz par le mesme aucteur, Imprimé à Chamberi, par Françoys Pomar l'eyné, 1568. Nous en connaissons deux exemplaires, conservés à la Bibliothèque Royale de Turin (BRT) et aux ASTO, Biblioteca Antica, sous la cote: I.VII. 38. Sur cet ouvrage, voir R. Gorris Camos, «La Muse desrobée: Jean Grangier et les Pastorales sur le baptesme de Charles-Emmanuel (1568)», dans R. Gorris Camos, Princesse des frontières. Poésie, éthique et religion à la Cour de Marguerite de France, Genève, Droz, à paraître; D. Speziari, «Les Pastorales de Jean Grangier et la tradition européenne du recueil d'emblèmes", dans Actes du XI colloque de la Society for Emblem Studies (3-7 juillet 2017), Tours et Rennes, PUFR et PUR, à paraître. 
Ce n'est d'ailleurs pas un hasard si Jacques Grévin (I. G.), l'une des Muses les plus fidèles à Marguerite, insère, dans une longue chaîne de prisci poètes et hommes de science, médecins et philosophes, théologiens et juristes anciens et modernes qui ont su allier la science à la poésie, la philosophie et la littérature, «ce tant sage Chancellier de France Monsieur de l'Hospital $»^{53}$. Dans ce paratexte qui insiste sur la «légitimité de la composition poétique » ${ }^{54}$ pour les savants, juristes compris, il est aussi question de Jean Lezeau (Laezius), né vers 1540 et décédé vers 1570, avocat à La Rochelle et auteur d'un Carmen ad amplissimum virum Michaelem Hospitalium Franciae cancellarium (La Rochelle, Barthélemy Berton, 1566), dont nous avons retrouvé un exemplaire à la Biblioteca estense de Modène. Dans ce poème, cet auteur, que Grévin a dû rencontrer chez Plantin (il y publie un commentaire du Pro Archia de Cicéron, défense du droit de cité du poète Archias par l'éloge de la poésie et des lettres, sujet du paratexte de Grévin) ${ }^{55}$, compare la situation de la France à une mer en tempête et Michel, dont il tisse l'éloge, est celui qui a su calmer les vents et rapporter la paix («tot praelia, bella tumultus / Foederibus, Pacique...»). Il évoque une maladie qui aurait frappé depuis peu le chancelier, mais dont il a pu guérir pour la joie de la France, et souhaite que la discorde s'exile «ad Gangis et ultra». Et c'est cette force, cet afflato, cette inspiration et cet élan vers le ciel qui «tire» (verbe cher à Marguerite) les poètes comme Flaminio, le vates inspiré qui va offrir à la princesse sa dernière gerbe de poèmes, ces Rebus divinis carmina, ces «sydera carmen » (I, 15, 49), ces poèmes du ciel (comme les définit Michel), qui vont orienter aussi le «cangiato stile» des autres poètes de Pallas ${ }^{56}$.

53 «Préface» dans Le second discours de Jaques Grévin, docteur en medecine à Paris, sur les vertus et facultez de l'Antimoine [...], À Paris, chez Jacques du Puys, 1567, fol. 1-12 (Mazarine 29071 et Mazarine 29905). Sur ce paratexte, voir maintenant R. Gorris Camos, " "Une Muse perfette” : Jacques Grévin entre poésie, science et religion », dans La Renaissance au grand large. Mélanges en l'honneur de Frank Lestringant, Genève, Droz, 2019, p. 759-777.

54 «Introduction», Carmina, t. I, p. 10.

55 Io. Laezii Rupellani de poeticorum studiorum utilitate. In Orationem M. Tullij Ciceronis pro A. Licinio Archia Poeta. Ad clarissimun virum Ioachimum Hopperum, Iurisconsultum, Antverpiae, ex officina Christophori Plantini, Anno MDLX.

56 Voir notre " "Sous le signe de Pallas" : paroles ailées et ascension de l'esprit dans l'Olive", dans L'Olive de J. Du Bellay, éd. R. Campagnoli, E. Lysoe et A. Soncini Fratta, Bologne, CLUEB, 2007, p. 167-232. 
Pour L'Hospital, elle est comme le soleil qui «fait éclore tant de poètes » parmi lesquels Marcantonio Flaminio, qui, dans l'épître I, 15, lui offre ce «dernier souvenir» (il meurt le 17 février 1550), ce "royal présent à une royale princesse», et tant d'autres qui en font de même comme Du Bellay, Denisot ${ }^{57}$, Macrin ${ }^{58}$, Ronsard, Peletier ${ }^{59}$, Bandello et une constellation de poètes français et italiens que nous avons étudiés dans notre Princesse des frontières ${ }^{60}$.

\section{«CET ENFANT QUI VINT CHASSER LA NUIT PLEINE D’OBSCURITÉ »}

Marcantonio Flaminio, membre du cercle de Bembo à Padoue et de celui de l'évêque Giberti à Vérone et, plus tard, de celui de Valdès à Naples, dont il était le disciple esleu («Allevo» qui «più di ogni altro l'amava ed ammirava $»)^{61}$, poète du Christ, non seulement traduit et publie les ouvrages de son maître Valdès, mais il écrit des ouvrages comme les Meditationi et orationi formate sopra l'epistola di san Paolo a Romani, restées longtemps inédites, qui sont aussi dédiées à une autre femme «spirituale», Giulia Gonzaga, et où l'on voit triompher son « unico alato maestro ... Sancto Paolo»62.

57 L'Hospital envoie à Marguerite le Tombeau de Marguerite de Navarre avec l'épître IV, 4 (L'Hospital, Poésies complètes, p. 186-187; Carmina, t. IV, p. 88-99), dans laquelle il souligne la valeur poétique du recueil réuni par Denisot. Sur ce tombeau, voir D. Speziari, La Plume et le pinceau, op. cit., p. 167-205.

58 Voir L'Hospital, Poésies complètes, p. 123-126 et Galand-Hallyn, «Michel de L'Hospital à l'école de Jean Salmon Macrin », p. 15.

59 Sur les rapports entre Marguerite et Peletier du Mans, voir R. Gorris Camos, " "Je và et vien par volontaire fuite" : La Savoye en bleu, en vert, en noir", dans Textes au corps. Promenades et musardises sur les terres de Marie Madeleine Fontaine, Genève, Droz, 2015, p. 227-252.

60 Voir R. Gorris Camos, Princesse des frontières, op. cit.

61 M. Firpo et D. Marcatto, Il processo inquisitoriale del cardinal Giovanni Morone, Rome, Istituto italiano per l'età moderna e contemporanea, 1981-1995, t. II, p. 363, 462 ; I, 228. Voir M. Firpo, "Il “Beneficio di Christo" e il concilio di Trento (1542-1546)", Rivista di storia e letteratura religiosa, XXXI (1995), p. 50 et M. Flaminio, Apologia del «Beneficio di Christo» e altri scritti inediti, éd. D. Marcatto, Florence, Olschki, 1996, p. 200 sq.

62 «Introduzione» de D. Marcatto à M. Flaminio, Apologia, op. cit., p. 7 sq. Sur Giulia Gonzaga, voir S. Peyronel, Una gentildonna irrequieta. Giulia Gonzaga fra 
Flaminio ne fait que souligner partout la centralité de la foi qui, écrit-il, " piantata» par son esprit "nel core degli eletti, cresce ognhora e produce frutti dolcissimi di carità ${ }^{63}$.

Or, ce poète (mis à l'Index en 1559) ${ }^{64}$, entre eros et agapé, qui présente plusieurs affinités avec Marot et L'Hospital (par ex. l'utilisation de l'épître dans son Liber quintus), est l'emblème de la complexité et des différences des milieux hétérodoxes italiens qu'il a traversés l'un après l'autre, d'une ville l'autre, de Venise à Padoue, de Vérone à Naples et Viterbe ... dans sa vie inquiète et vagabonde $^{65}$. Il publie en 1546 chez Alde sa Paraphrasis in XXX Psalmos versibus scripta ${ }^{66}$, composée lors des travaux d'ouverture du concile de Trente. Il y condense ses aspirations spirituelles et son

reti familiari e relazioni eterodosse, Rome, Viella, 2012 et «I carteggi di Giulia Gonzaga », dans Donne di potere nel Rinascimento, Actes du Colloque de Milan, les 29 novembre-2 décembre 2006, Rome, Viella, 2008, p. 709-742 ; B. Amante, Giulia Gonzaga contessa di Fondi e il movimento religioso femminile nel secolo XVI, Bologne, Zanichelli, 1896; C. Russell, Giulia Gonzaga and the Religious Controversies of Sixteenth Century Italy, Turnhout, Brepols, 2006.

63 M. Flaminio, Apologia, op. cit., p. 72.

64 Sur la condamnation des œuvres de Flaminio, voir Index des livres interdits, éd. J. Martinez De Bujanda, Sherbrooke, Centre d'Études de la Renaissance de l'Université de Sherbrooke et Genève, Droz, 1984, t. VII, p. 292-96. Voir aussi le «Terzo costituto di Pietro Carnesecchi», Rome, 15 mai 1560, dans M. Firpo et D. Marcatto, I processi inquisitoriali di P. Carnesecchi, op. cit., t. I, p. 59, où l'ami de Flaminio déclare avoir lu des livres «prohibiti da Papa Paulo IIII, como saria le Adnotatione di Erasmo sopra il Testamento novo et Psalmi di Marcantonio Flaminio », et id., p. 174, 251, 288, 310, 423 et 476.

65 Voir sa biographie «nel tempestoso mare dell'eretica confusione» par Alessandro Pastore, Marcantonio Flaminio. Fortune e sfortune di un chierico nell'Italia del Cinquecento, Milan, Franco Angeli, 1981 et l'édition des inédits du poète par D. Marcatto, op. cit.

66 Les ouvrages de Flaminio sur les Psaumes furent publiés à plusieurs reprises en Europe. En 1540, il publie à Venise In librum Psalmorum brevis explanatio ad Alexandrum Farnesium Cardinalem amplissimum, Venetiis, Aldus, MDXL (BNF, A 6751 et Rés. A 6751bis), réédité à plusieurs reprises (Venise, Alde, 1545; Paris, Ruelle, 1546 ; Lyon, Rovillium, 1548 ; Paris, Parvum, 1549; Lyon, Rovillium, 1552 et 1553 ; à Venise avec la Paraphrasis, en 1564, chez Paolo Manuzio). En 1546, toujours à Venise, mais chez Vincenzo Valgrisi, il publie sa Paraphrasis in triginta Psalmos versibus [...] (ex. BNF, A 6848 (1), composée pendant les travaux d'ouverture du concile de Trente et reprise, avec un immense succès, à Paris, chez R. Estienne en 1546, à Florence, 1548 et 1552 chez Torrentino; à Paris, chez Petit, 1549 (ex. Turin, Fondation Firpo). En 1548, Gryphe publie, à Lyon, ses Carminum libri duo, suivi par la Paraphrasis (ex. Arsenal, $8^{\circ}$ B 5602). Ces œuvres marquent son retour à la réflexion sur les psaumes déjà 
désir d'abandonner la poésie profane pour la poésie sacrée : «di non saper altro che Iesu crocifisso ${ }^{67}$. Dès son paratexte (dédicace au cardinal Farnese, Trente, le 9 février), il met sa poésie sous le signe de David.

Il s'agit d'un ouvrage qui fut particulièrement apprécié par Marguerite de France, qui pouvait le lire, dès 1546, dans l'édition fournie par Robert Estienne (dont la marque éditoriale était, rappelons-le, l'olivier) ${ }^{68}$ des Psalmi triginta, Latine cum poetica paraphrasis latina M. Antonii Flaminii ${ }^{69}$, étroitement lié, on le sait, à son maître Pierre Du Chastel ${ }^{70}$, dédicataire de la magnifique épître I, 13 qui est surtout une épître de la paternité, dédiée à leurs deux pères, Jean et François.

Le thème de la filiation tourmentée est si important pour Michel (cf. II, 7) et pour Marguerite, tout comme pour Marot et Flaminio, non seulement pour l'héritage poétique et culturel, mais aussi pour la dimension dialectique d'un rapport de tendresse, d'affection profonde que rien ne brisera, et de tensions, d'émulation, de nœuds et de larmes ${ }^{71}$. Figures complexes de pères, adjuvants et opposants, combinant les deux traditions (Ovide, Pétrarque /

entamée lors des années véronaises dans sa Paraphrasis in duo et triginta psalmos, Venetiis, in officina Joanni Patavini, 1538 (ex. Vérone, Bibl. Civica).

67 Lettre à Alvise Priuli, 12 mars 1546, dans Lettere, n. 52, p. 154.

68 Voir Jacques Grévin, «Puisse l'immortelle Olive / T'ombrager à tout jamais, / Afin que ton nom revive», dans «A Robert Estienne, Ode», v. 82-84, Gélodacrye, éd. M. Clément, Saint-Étienne, PUSE, p. 113 et p. 114: «En faveur de l'Olive».

69 M. Antonii Flaminii Paraphrasis in triginta Psalmos versibus scripta. Ad Alexandrum Farnesium Cardinalem amplissimum, Lutetiae, ex officina Roberti Stephani, 1546. La même année, Estienne publie La Coltivatione d'un autre protégé de Marguerite, Luigi Alamanni. Voir sur l'édition de Flaminio, E. Armstrong, Robert Estienne, Royal Printer: an Historical Study of the Elder Stephanus, Abingdon, Sutton Courtenay Press, 1986, p. 29. Une autre édition fut publiée en 1556 par Henri II Estienne : Davidis Psalmi aliquot, Latino Carmine expressi a quatuor illustribus poetis [...], [Genève], ex officina H. Stephani, 1556, in-4 ${ }^{\circ}$ (BNF, A 3140), voir La France des humanistes, Henri II Estienne éditeur et écrivain, dir. J. Céard, Turnhout, Brepols, 2003, p. 14.

70 Voir sur les liens entre les Estienne et Du Chastel qui les défendit avec vigueur, E. Armstrong, Robert Estienne, op. cit., p. 111, 124, 127-31, 136, 145, 153, 206, 260, 284, 174-183, 191, 327-336 et passim.

71 Voir sur les larmes de Marguerite pour son père, R. Gorris Camos, " "Le lys et la croix" : constellations familiales ... », art. cit. 
Stace, si bien mises en lumière par Perrine Galand ${ }^{72}$, responsables $\mathrm{d}^{\prime}$ une " vocation contrariée ${ }^{73}$ mais enfin triomphante et, en même temps, présence tutélaire dont le deuil ne sera jamais fait ni pour l'un ni pour l'autre. Les consolations de Simeoni, d'Espence et de tant d'autres mettent en scène une Marguerite «dolente », le visage inondé de larmes, comme la décrit Gabriele Simeoni :

E tu bella e dolente Margherita

Figlia d'un tanto Re, dotta et accorta,

Piangendo a' pianger tutto il mondo invita $?^{74}$

Marguerite fit mettre en musique plusieurs psaumes ${ }^{75}$ du poète italien qui avait aussi dédié ses Carmina, publiés à Lyon en 1546 (les deux premiers livres sont dédiés à Francesco della Torre, noble véronais) $^{76}$ à une constellation de personnages du réseau évangélique franco-italien (Vittoria Colonna ${ }^{77}$, Reginald Pole ${ }^{78}$, Gasparo Cantarini, Achille Bocchi ${ }^{79}$, Antonio Giberti, Pietro Carnesecchi $\left.{ }^{80} \ldots\right)$, où l'on retrouve plusieurs membres du réseau de

72 Voir Galand-Hallyn, «Michel de L'Hospital à l'école de Jean Salmon Macrin », p. 15.

73 Id., p. 17. Michel défendra toujours son père; voir I, 13, dans Carmina, t. I, p. 292. Sur sa demande à Pierre Du Châtel d'intercéder pour lui auprès de François I rer, voir I, 13 Ad Petrum Castellanum, dans Carmina, t. I, p. 292-329; Crouzet, La Sagesse et le malheur, p. 299-300.

74 Voir R. Gorris Camos, " "Le lys et la croix" : constellations familiales ... », art. cit.

75 M.H. Seiler, Anne de Marquets poétesse religieuse $d u$ XVIe siècle, thèse de l'Université Catholique d'Amérique, Washington 1931, p. 56; E. Balmas, «Note sulla fortuna del Flaminio in Francia: Anne de Marquets e Claude D’Espence», Bollettino Società Studi Valdesi, 87 (1966), p. 25-49; A. Gendre, «Naissance des échanges polémiques à la veille des guerres civiles: Anne de Marquets et son adversaire protestant », BHR, 62 (2000), p. 317-357.

76 Voir Flaminio, Carmina, p. 141 sq.

77 Ad Villam Marianam De Victoria Columna, dans Flaminio, Carmina, p. 44-45. Il dit des poèmes de Vittoria: «illa carmina, quae movere mentes ». Il évoque sa mort dans une épître latine à Gerolamo della Torre: "Ad Hieronimum Turrianum de morte Victoriae Columnae», p. 144 sq.

78 Ibid., p. 46-48.

79 Voir I, 11 Ad Achillem Bocchium, dans L'Hospital, Carmina, t. I, p. 260 sq. et Ad Achillem Philerotem Boccium, dans Flaminio, Carmina, p. 93.

80 Voir Ad Petrum Carnesecum, dans Carmina, p. 157 et Ad Petrum Carnesecum. De Emanuele Chio Medico, Carmina, p. 170. Sur Pietro Carnesecchi, voir O. Orto- 
Michel. Or, le poète malade, encouragé par son ami Carnesecchi (brûlé en 1567) ${ }^{81}$ et qui était alors en France protégé par la duchesse:

essendo io in contumacia allhora col papa, havevo disegnato di retirarmi in una terra di madama Margarita, sorella del re Henrigo, dove è ordinariamente uno Studio assai frequente et per consequente vi si viveva ancora più libera et più sicuramente per quelli che non potevano bevere d'ogni acqua, come non potevo io per la persequutione che havevo alle spalle. Et questa terra si chiama Burges ${ }^{82}$.

offre donc son dernier recueil, «personalissimo libro d'ore» mais aussi testament spirituel ${ }^{83}$, à Margaritae Henrici Gallorum Sorori M. Antonius Flaminus, "puella candida» "caelestis ardens ignibus», ravie au ciel par son feu céleste:

\author{
PUDICA virgo Regiae \\ Stirpi propago nobilis, \\ Ornata sanctis moribus \\ Et literis et ingeni \\ Decore fulgens, scripsimus \\ Haec, insideret aridis \\ Cum longa febris artubus: \\ Iis addituri plurima,
}

lani, Pietro Carnesecchi, Florence, Le Monnier, 1963; Estratto del processo di Pietro Carnesecchi, éd. G. Manzoni, Miscellanea di storia italiana, X (1870), p. 189-573 ; M. Firpo et D. Marcatto, Il processo inquisitoriale di Pietro Carnesecchi (1557-1576), t. I, Città del Vaticano, ASV, 1998 (sur son séjour français, p. X, n. 22) et t. II, Città del Vaticano, ASV, 2000 ; M. Firpo, Riforma protestante, op. cit., p. 41, 90, 119, 135, 139 et 193.

81 Voir M. Firpo, Il Beneficio di Christo e il Concilio di Trento (1542-1546), op. cit., p. 45-72 et M. Flaminio, Apologia del Beneficio di Cristo e altri scritti inediti, éd. cit., p. 7 sq. Lors de son séjour parisien (1547-1553), il fréquenta l'hétérodoxe espagnol Juan Morillo, collaborateur de Pole à Trento (voir Processo Morone, op. cit., VI, 266). Voir la sentence de son procès dans Estratto, op. cit., p. 553-555. Sur son séjour parisien, voir M. Firpo, «Pietro Carnesecchi, Caterina de' Medici e Juan Valdès. Di una sconosciuta traduzione francese dell'Alphabeto Christiano ", dans Dissenz und Toleranz im Wandel der Geschichte, Festschrift zum 65. Geburstag von H.R. Guggisberg, Mannheim, Palatium Verlag, 1996, p. 75-88. Sa maison à Venise était «come un asilo di lutherani in Venetia». Voir Processo Morone, op. cit., VI, 234-235.

82 Voir Processo Carnesecchi, op. cit., vol. II, t. I, p. 301.

83 Carmina, p. 287. 
Ni mens gravata corporis

Laboribus languesceret.

Sed tu puella candida,

Caelestis ardens ignibus,

Amoris, ut mens augurat,

Libentius hunc perleges

Parvum libellum, sed pium,

Quam prisca vatum carmina

Nugis referta inanibus ${ }^{84}$.

L'édition Estienne de 1550 présente un important paratexte, une dédicace qui représente une sorte de conversion du poète à la poésie du Christ et deux poèmes, l'un à Pietro Carnesecchi, qui fréquente le cercle de Marguerite, et l'autre à la Princesse, qui est très sensible à l'exemple du Christ ${ }^{85}$.

Le magnifique portrait que l'exilé italien donne de la princesse est frappant et évoque les camées de Marguerite et de Renée de

84 Fol. 30. Dans l'édition Plantin, ce poème AD MARGARITAM HENRICI Gallorum Regis Sororem est remplacé par un autre poème $A D$ CHRISTUM. Sur la pratique $\mathrm{du}$ double paratexte, voir G. Ferroni, « Rilievi sulla struttura dei De rebus divinis carmina di M. Flaminio », Studi (e testi) italiani, 38 (2016), p. 147-148.

85 M. Antonii Flaminii De Rebus Divinis Carmina, ad Margaritam Henrici Gallorum Regis Sororem, Lutetiae, ex officina Rob. Stephani, 1550 (ex. BNF, Rés. Yc 786 (1), avec reliure aux armes de Richard Vincent, devise «IUVAT PIOS» (voir E. Olivier, G. Hermal et R. de Moton, Manuel de l'Amateur de Reliures armoriées, Paris, Bosse, 1925, planche 170); Résac. Yc 1369; Arsenal 4 BL 1987). Le recueil fut imprimé par Robert Estienne, grâce à la médiation de Pietro Carnesecchi et, ensuite, par Bononius et Mathurin Dupuys, en appendice aux travaux sur les Psaumes de Flaminio. Nous y trouvons des poèmes dédiés à : Vittoria Colonna (fol. 157), Pietro Carnesecchi (fol. 171), Lodovico Beccadelli (fol. 177), Savonarole (fol. 181), Reginald Pole. Il existe une édition moderne de M. Flaminio, Liber octavus Carminum sacrorum libellus ad Margaritam Henrici Gallorum Regis Sororem Carmina, San Mauro Torinese, RES, 1993, p. 287 sq. Une édition critique est actuellement en préparation par G. Ferroni, "Notizie di un cantiere flaminiano (e qualche proposta per Valdès) ", dans $\mathrm{La}$ letteratura tra la Riforma e il Concilio di Trento. Discussioni di studi recenti e proposte di ricerca, Turin, les 2-3 mars 2018. Voir aussi G. Ferroni, " "Liber ultimus". Note sui "De rebus divinis carmina" di Marco Antonio Flaminio », dans Roma pagana e Roma cristiana nel Rinascimento, Florence, Cesati, 2014, p. 301-310; id., Rilievi sulla struttura dei De rebus divinis carmina di M. Flaminio, op. cit., p. 147-167. Ces poèmes furent traduits par Anne de Marquets (Les Divines Poesies de Marc Antoine Flaminius [...], Paris, N. Chesneau, 1568). Voir E. Balmas, Sulla fortuna del Flaminio in Francia, op. cit. 
France écrits par Betussi, par Brucioli, mais aussi les belles épîtres de Michel, notamment l'épître II, 8, où la magnificence, due à leur naissance, s'allie à la caritas chrétienne inspirée par la foi en Christ («per regeneratione divina», pour Renée on parle aussi de «Re-nata», de «re-naissance» en Christ) ${ }^{86}$. Ces humanistes en font une incarnation de Marthe et de Marie:

Quanto poi a quello che io dico di madama Margarita, cioè che la fusse una donna per natura reale et per regeneratione divina, volevo intendere ch'[e]lla haveva quella generosità et grandezza d'animo che conveniva a una che fusse nata di sangue reale come lei et d'altra parte era dotata di quella charità, humiltà et mansuetudine [cf. II, 8] che si rechiedeva a una excellente christiana et che fusse regenerata per lo spirito di Dio, cioè che havesse racquistato mediante la gratia de medesimo Dio quella divina imagine secondo la quale siamo simili a Dio ${ }^{87}$.

Et dans l'une de ses lettres ${ }^{88}$, il compare les idées de la princesse à celles de Giulia Gonzaga, fidèle disciple de Valdès, comme Flaminio et en correspondance avec lui lors de son exil:

$\grave{E}$ ben vero che io presupponevo che la signora donna Giulia [Gonzaga] ${ }^{89}$ et lei dovessino convenire insieme ancor quanto alle cose della religione, havendo io per opinione che la prefata madama

86 «DI / REAL / SANGUE / NATA = IN / CHRISTO / SOL RENATA » est en effet la devise de Renée, qui orne les plats d'un ouvrage de sa bibliothèque: Innocenzo Ringhieri, Cento Giuochi liberali et d'ingegno, Novellamente da M. Innocentio Ringhieri Gentilhuomo Bolognese ritrovati, $\mathcal{E}$ in dieci Libri descritti, in Bologna, per Anselmo Giaccarelli, 1552, in $-4^{\circ}$ (voir T. de Marinis, «Legatura artistica fatta per Renata di Francia, duchessa di Ferrara », Gutenberg Jahrbuch, 39 (1964), p. 373-374). Voir R. Gorris Camos, «La Bibliothèque de la duchesse ... », art. cit., p. 481. Le livre, après nos vérifications sur place (avril 2010), n'est plus présent dans le fonds de la Bibliothèque Cini sur l'île de San Giorgio à Venise.

87 Voir Processo Carnesecchi, op. cit., vol. II, t. II, p. 415.

88 Marcantonio Flaminio, Apologia del Beneficio di Cristo e altri scritti inediti, op. cit., recueil qui contient d'importantes lettres sur la prédestination: Lettere sulla giustificazione: Della giustificazione e Della medesima giustificazione.

89 Voir sur Giulia Gonzaga, fidèle disciple de Juan de Valdès, supra n. 62 et DBI, t. 57, p. 783-787 (Guido Dall'Olio) ; M. Firpo, Tra alumbrados e "spirituali". Studi su Juan de Valdès e il valdesianesimo nella crisi religiosa del 500 italiano, Florence, Olschki, 1990, passim. Les Archives de la «Congregatione della dottrina della fede» conservent 250 lettres échangées entre Giulia et Pietro Carnesecchi. Il s'agit de 18 lettres de Giulia et de 230 lettres du réformé à la comtesse de Fondi, la plupart publiées dans I processi inquisitoriali di P. Carnesecchi, op. cit. 
Margherita non dissentisse ne l'articolo della giustificatione per la fede da quel modo che lo teneva la signora donna Giulia [Gonzaga] ${ }^{90}$.

D'Espence, Olivier, L'Hospital, soit les esprits les plus proches de Marguerite, partagent le christocentrisme de Flaminio, la même philosophia christiana qui sous-tend la Consolation de 1547 et qui peut expliquer ce choix qui a pu paraître surprenant de traduire le texte de Luther et de l'offrir à la princesse en deuil ${ }^{91}$. L'entourage de Marguerite est donc ouvert à cette poésie du Christ qui oriente aussi les choix poétiques de ses poètes esleus, comme Du Bellay ${ }^{92}$ ou comme le deus ex machina du Tombeau de 1551, Nicolas Denisot, qui publie dans ces années des Noelz et en 1553 des Cantiques du premier advenement de Jesu-Christ ${ }^{93}$. Ils partagent (L'Hospital utilise le «nous») les mêmes idées sur la poésie.

Quant à nous, laissons aux dieux faux, mensongers et mauvais les vers et les poètes qui leur ressemblent, ainsi que le fard, les

90 Fol. 237-239; voir aussi fol. 730-731. Voir M. Firpo, Pietro Carnesecchi, Caterina de' Medici e Juan Valdès, op. cit., p. 154-155.

91 Voir L. Petris, «Le théologien et le magistrat: Claude d'Espence et Michel de L'Hospital », dans Un autre catholicisme au temps des Réformes? Claude d'Espence et la théologie humaniste à Paris au XVI siècle, éd. A. Tallon, Turnhout, Brepols, 2010, p. 191-211, ici p. 194 qui cite la lettre de François Olivier à L'Hospital, où il écrit «hic Christo, ac mihi vivo» (L'Hospital, Discours et correspondance, p. 148).

92 Voir sur la poétique de Du Bellay et sur son évolution vers la poésie sacrée, R. Gorris Camos, Le saule et l'olivier: échos, résonances et intertexte dans L'Olive de Du Bellay, op. cit., passim.

93 Sur Nicolas Denisot, voir D. Speziari, La Plume et le pinceau, op. cit. ; Grente, Dictionnaire de la littérature du XVI siècle, Paris, LGF, 2001, dir. M. Simonin, ad vocem; C. Jugé, Nicolas Denisot du Mans (1515-1559), Le Mans, 1907 (Genève, Slatkine, 1969); E. Balmas, «Un poeta francese in Inghilterra nel Cinquecento (con documenti inediti)", dans Critical dimensions (Mélanges A. Zanco), éd. Curreli et A. Martino, Cuneo, Saste, 1978, p. 21-38; J. Nash, The devotional Aesthetics of an humanist: Nicolas Denisot's Cantiques, Essays in Early French Literature Presented to Barbara Craig, éd. N. Lacy et J. Nash, York, S.C., 1982, p. 129-146; R. Jousselin, Nicolas Denisot, poète de la Pléiade, Paris, Christian, 2006. Denisot est l'auteur de Noelz par le Conte d'Alsinoys presentez à Madamoyselle Sa Valentine, s.l., in- $8^{\circ}$ (Le Mans, Médiathèque Louis Aragon, BL $8^{\circ} 1974$; les Noelz de Denisot, composés en 1545, occupent les seize premiers feuillets) et de Cantiques du premier Advenement de Jesus-Christ (Paris, Veuve M. de La Porte, 1553 ; l'extrait du privilège et l'épître dédicatoire à Antoinette de Loynes sont datés du 17 décembre 1552 ; Le Mans, Médiathèque Louis Aragon, cote MAINE $8^{\circ} 7052$; Arsenal, $8^{\circ}$ BL 10.495 Rés). 
grâces et les propos malséants, lascifs et futiles qui chatouillent les sens, ceux dont la lecture enseigne à pécher, corrompt les âmes malléables et les enflamme de feux déshonnêtes. Nous, adorons le Dieu unique et éternel, auquel les tréfonds de notre cœur sont ouverts, à qui rien n'échappe ni ne reste caché nulle part; ne lui adressons ni prière mélodieuse, au vocabulaire varié, ni poème destiné à plaire à la foule présente, mais adorons, dis-je, ce Dieu suprême, saint, unique, avec un cœur pur, par un culte dépouillé et simple, comme lui-même est simple, nullement sujet au changement ${ }^{94}$.

Les réflexions métapoétiques de Flaminio qui émaillent ses commentaires des Psaumes, ses lettres et ses paratextes présentent des affinités frappantes avec cette théorie poétique chrétienne que Michel de L'Hospital expose dans sa magnifique épitre I, 7, Ad Claudium Espensium nobilissimum \& doctissimum Theologum, de poesi Christiana iudicium, $\mathcal{E}$ exemplum ${ }^{95}$ (composée peu avant Noël 1547), qui est une sorte de manifeste de la poésie sacrée: le même culte du sermo humilis, de la parole simple, «nue» (le mot revient deux fois, en I, 7, 13 et 53) ${ }^{96}$, sans fard, sans fables et mensonges. Michel associe ces deux hommes épris de la vérité de la parole de Dieu, au cœur «pur» (le terme apparaît trois fois, en I, 7, 12, 54 et 81). Pour ces deux poètes profondément centrés sur le fils de Dieu, le Christ, "le roi commun et unique du monde entier», "Regem illum populis communem unumque futurum omnibus» (v. 130-131), devrait être le seul et l'unique sujet d'une poésie qui célèbre son " extraordinaire naissance», «mystica partus » (v. 80 sq., v. 202 sq.), et son sacrifice pour nous tous, ses «actions divines" («divina facta», v. 145, où il n'utilise pas le mot «miracles»). "Cet enfant qui vint chasser la nuit pleine d'obscurité » est aussi, pour eux, celui qui «chassa » (v. 246) les idoles (v. 245).

Dans la dédicace de sa Paraphrasis, Flaminio souligne la nécessité de définir le sens de sa lecture des Psaumes, marque de l'exi-

94 I, 7, 42-54 dans Petris, La Plume et la tribune, p. 187 ; L'Hospital, Carmina, t. I, p. 182-183.

95 Carmina, t. I, p. 180-207; Petris, La Plume et la tribune, p. 183-188.

96 Cf. le discours du 31 juillet 1561, où L'Hospital précise que le Christ «avoit choisi ses apostres gens simples qui ont escript nuement et simplement» (Petris, La Plume et la tribune, p. 424). 
gence d'un renouvellement intérieur de l'homme qui doit modeler son existence à l'exemple du Christ, le seul et l'unique qui puisse nous aider: "ab illo certissimam opem expectandam, qui nullius spem fallere potest; reliqua omnia praesidia et adiumenta inania existere et pro nihilo ducenda ${ }^{97}$. Il souligne son effort pour la divulgation des Saintes Écritures et insiste sur sa fidélité au texte, son effort de clarté, son désir de simplicité et son désintérêt pour les interprétations anagogiques et allégoriques ${ }^{98}$. Il préfère aux interprétations de ceux qui lisent la Bible comme "res commentitias et inanes fabulas" après avoir "ab huius vitae tenebris et tractatione rerum humanarum» une lecture "communi ... et populari» ${ }^{99}$. Ses travaux sur les Psaumes doivent beaucoup à Bucer et se caractérisent par leur clarté et leur simplicité, par le recours à la patristique et, notamment, par leur christocentrisme. Lors de sa déposition, Simone Paoli déclare que «leggendo l'opra di Marcantonio sopra $i$ salmi, nel primo vedde che pigliava $i$ detti et dottrina del Felino ${ }^{100}$, ma con la bella eloquentia et dolce lingua trasmutando pareva che fusse sua». «Ma dopoi che l' diede fuori alcuni Paraphrasi sopra alcuni Psalmi, si disse che in quella opera non appareva che fusse toppo neta farina ${ }^{101}$. Il conclut: "In queste cose spirituali io giudico che si debbia usare uno stile semplice et lontano da ogni fuoco, advertendo però che egli sia latinno et candido $\gg^{102}$.

Un jeu de miroirs de dédicaces et un engagement nouveau vers la poésie sacrée, un «cangiato stile» comme on le dit pour Vittoria Colonna ${ }^{103}$, qui resserrent les liens entre Michel et Marguerite, entre 1549-1550, se reflètent dans cette nuée de textes en réseau qui vont tous dans la même direction et que nous avons étudiés

97 Lettere, éd. cit., p. 232.

98 A. Pastore, Marcantonio Flaminio, op. cit., p. 84-89 et p. 142-143 sq.

99 Flaminio, Paraphrasis, fol. $\mathrm{cVv}^{\mathrm{o}}$.

100 Aretius Felinus est le pseudonyme de Martin Bucer, qui avait publié ses Sacrorum Psalmorum libri quinque ad ebraicam veritatem versi et familiari explanatione elucidati, Strasbourg, 1529, réimprimé en 1532 et à Bâle en 1547.

101 Voir M. Firpo et D. Marcatto, I processi inquisitoriali di P. Carnesecchi, op. cit., I, p. 116 et p. 114.

102 Lettere, éd. cit., p. 169.

103 Voir R. Gorris Camos, " "Le ali del pensiero" : échos, résonances et intertextes dans L'Olive de Du Bellay ", Italique, XV (2012), p. 73-136. 
ailleurs ${ }^{104}$ : 1'Epitome vitae Iesu Christi (Paris, David, 1549)105 de Salmon Macrin dédié à Marguerite, qui contient deux épitres, absentes de l'édition princeps de 1585 (IX, 10 à Macrin et IX,12 à Anne d'Este) ${ }^{106}$; le De rebus divinis carmina (Paris, Estienne, 1550) du poète de la Réforme italienne (dont Michel conseille la lecture dans I, 15) et le magnifique Tombeau de Marguerite de Valois (Paris, Fezandat et Granjon, 1551) ${ }^{107}$. Trois textes offerts à Marguerite, trois textes qui émaillent les Carmina et qui reflètent, en miroir, les conceptions poétiques de Michel et d'une constellation de poètes autour de Pallas, y compris son poète esleu, Joachim Du Bellay ${ }^{108}$.

La recherche d'un «bonheur utile à ton peuple» réunit le chancelier à Marguerite, qui sait mettre en pratique «les vertus que t'enseignent de longs travaux ${ }^{109}$. La vertu, tant célébrée dans cette princesse dont le cœur pour Michel est celui d'une reine (II, 8) ${ }^{110}$, consiste dans l'exercice des devoirs de la vie, dans la

104 R. Gorris Camos, "Sous le signe de Pallas" : paroles ailées et ascension de l'esprit dans l'Olive», dans L'Olive de J. Du Bellay, op. cit., p. 167-232.

105 Sur les rapports entre Macrin et L'Hospital, voir l'important article de GalandHallyn, «Michel de L'Hospital à l'école de Jean Salmon Macrin ».

106 Ibid. Les Naeniae de Macrin portent au verso de la page de titre douze vers adressés à Marguerite. Voir I.D. Mc Farlane, «Jean Salmon Macrin (14901557) », BHR, 22 (1960), p. 73-89.

107 Voir D. Speziari, La Plume et le pinceau, op. cit., p. 167-203.

108 Voir R. Gorris Camos, " "Le ali del pensiero" ...», art. cit.

109 Ibid. Voir I, 5 (Carmina, t. I, p. 148-158), où L'Hospital exalte la politique de Marguerite dans son duché de Berry.

110 «Apollon t'a douée du sens et de l'entendement poétiques, ton cœur de reine n'est pas insensible aux beaux-arts », dans L'Hospital, Poésies complètes, p. 186. Voir sur le «haut cœur» (Pasquier) de Catherine de Médicis, D. Crouzet, Le Haut Cour de Catherine de Médicis, Paris, Albin Michel, 2005 et sur ce thème, souvent associé à celui de la paix et aux mythes monarchiques, voir J. Nagle, La Civilisation $d u$ cour. Histoire $d u$ sentiment politique en France $d u$ XII $e^{a}$ XIX ${ }^{e}$ siècle, Paris, Fayard, 1998. Marguerite, comme Catherine, incarne une vertu féminine qui voudrait apaiser le monde marqué par la violence et la guerre. Son frère est associé par Michel et d'autres Muses à Mars, Marguerite à Pallas, la paix. Voir par exemple le paratexte de la traduction du tome $X$ $\mathrm{d}^{\prime}$ Amadis que Gohory adresse à Marguerite. Celle-ci incarne la douceur, la paix et le refus du monde et ses poètes reconnaissent en elle une tension et un élan néo-platonicien vers le Ciel refusant ce bas-monde secoué par le «vent des accidens ». 
justice, mais aussi dans la «bonté », la charité envers son prochain, ce philos dont parle Aristote. La virtus est la tension qui nous « tire » (verbe tant cher à Marguerite, sa tante et marraine) vers Dieu, adhésion à la grâce qui devient, sur la terre, mouvement vers l'autre, une offrande de soi à l'autre, négation de l'égoïsme et de l'amour-propre ${ }^{111}$. La vertu concentre ce bouquet de vertus que Del Bene, l'un des membres les plus brillants de la cour de Marguerite, qui l'accompagne dans son voyage vers Nice et qui restera avec elle jusqu'à sa mort, concentre dans sa Civitas Veri ${ }^{112}$. Marguerite, «regina» pour son «haut cœur» et sa vertu, incarne pour son

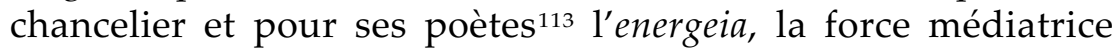
entre la terre et le ciel, qui veut rapprocher de Dieu l'homme tourmenté par le mal, entraîné vers la terre par le poids de «ce monde tout immonde».

L'admiration du chancelier pour la duchesse est sincère. Marguerite est un modèle: " $\mathrm{A}$ mes yeux ta vie peut servir de modèle sublime aux femmes comme aux jeunes filles. Le jour de ta naissance, la nature t'a dotée de tous ses dons: en grandissant tu as développé ces heureux germes, et les bons livres viennent les rendre efficaces » ${ }^{114}$. Marguerite lit donc beaucoup, elle «pâlit » sur «les ouvrages les plus sérieux», ce que confirme sa bibliothèque dispersée que nous avons reconstituée ainsi que les nombreux ouvrages dédiés à la princesse ${ }^{115}$. Son désir de lire est immense comme celui de son chancelier, qui écrit en I, 3 à Tournon en 1543, que la lecture est le désir de sa vie, les livres ses compagnons

111 Voir l'épître II, 15 (Carmina, t. II, p. 278-287) où L'Hospital, à la mort de l'aumônier Catti, tant pleuré par Marguerite, décrit la vertu de princesse, plus complexe et vaste que la simple «droiture morale».

112 Voir nos travaux sur la Civitas veri dans R. Gorris Camos, "La città del vero" : éthique, politique, poésie à la Cour de Marguerite de France, duchesse de Savoie», dans Dire le vrai dans la première modernité. Langue, esthétique, doctrine, dir. D. de Courcelles, Paris, Garnier, 2013, p. 135-173 et ead., «La Città del vero, une ville en papier entre utopie et hétérotopie», Seizième siècle, 9 (2013), p. 171-196.

113 Voir R. Gorris Camos, Princesse des frontières, op. cit.

114 L'Hospital, Poésies complètes, p. 75. Voir R. Gorris Camos, " "Sotto un manto di gigli di Francia"...», art. cit.

115 Voir R. Gorris Camos, «La Bibliothèque de la duchesse ... », art. cit. et Princesse des frontières, op. cit. «Appendice». 
fidèles ${ }^{116}$, mais que la Parole de Dieu est le port, la lampe qui éclaire notre chemin ${ }^{117}$. Et comme pour Marguerite de Navarre: «Paulus et his valde melior, quique eius alumni / Libris ostendere suis incognitus ante / Quis Deus, et qua sit nobis pietate colendus »118. Par la vertu, cette vertu tant célébrée par le poète de Marguerite et qui, grâce à la lecture des Carmina, retrouve toutes ses connotations spirituelles, l'homme démontre son adhésion intime à la Parole de Dieu $^{119}$.

\section{«NOTRE ESPRIT ERRE DANS LES TÉNÈBRES ET NE PEUT, AVEUGLE QU'IL EST, DISCERNER LE VRAI» : MICHEL OU LE JUSTE PERSÉCUTÉ}

Dans l'épître II, 8 Ad Margaritam, Regis Sororem ${ }^{120}$, qui a été publiée en plaquette chez Morel en 1558 ${ }^{121}$, L'Hospital ouvre son cœur à la princesse, Regia virgo (v. 2). Il évoque, à travers la force de l'amicitia, des liens («nехu», v. 17) qui les unissent, ce sens obscur $\mathrm{du}$ malheur, son obsession de la nuit et de l'aveuglement («nocte » v. 7 et «obscura», v. 9, et la célèbre devise que Michel de Montaigne fera graver sur ses poutres, v. 48 sq.: "Nostra vagatur / In tenebris, nec caeca potest mens cernere verum / « Notre esprit erre dans les ténèbres et ne peut, aveugle qu'il est, discerner le vrai »), ses peurs, sa hantise de la «ruina», de la disgrâce, de la «chute terrible qui glace d'effroi le cœur» / "sequitur gravis ecce ruina / Horrendumque malis intentat visa pavorem»(II, 8, 35-36) ${ }^{122}$ de la solitude, qui

116 Sur la bibliothèque du chancelier, voir Petris, La Plume et la tribune, p. 520 sq.

117 L'Hospital, Carmina, t. I, p. 94-122.

118 L'Hospital, Carmina, VI, 8, 18-20. Voir R. Gorris Camos, «Voler avec le Christ », Travaux de littérature publiés par l'ADIREL, 2008, p. 47-63.

119 VI, 8 Ad Vidum Fabrum. Sur Paul, voir VI, 12 à Corbinelli et Crouzet, La Sagesse et le malheur, p. 292.

120 L'Hospital, Carmina, t. II, p. 148-171; Poésies complètes, p. 89 sq.

121 Voir maintenant M. Magnien, supra «Le plomb et les sceaux», p. 75 n. 10, ainsi que Cioranescu, Bibliographie de la littérature française du XVI siècle, Paris, 1959, p. 441.

122 L'Hospital, Carmina, t. II, p. 150. Sur la disgrâce du chancelier, voir T. Wanegffelen, «La disgrâce du chancelier. Michel de L'Hospital ou l'irénisme malgré tout », dans Ni Rome ni Genève. Des fidèles entre deux chaires au XVIe siècle, Paris, Champion, 1997. Wanegffelen rappelle les tensions entre Michel et le cardinal 
l'obsèdent. Nouvelle incarnation de $\mathrm{Job}^{123}$ ou du Juste persécuté ("Tristis $\mathcal{E}$ aspectu miserabilis usque bonorum / Casus erat», II, 8, 43$44)$, Michel commente sa situation à la princesse qui n'a cessé, pour lui faire honneur, "d'accumuler bienfaits sur bienfaits et resserrer les liens de [ses] obligations » ${ }^{124}$ : «la catastrophe du juste est navrante, surtout s'il tombe sans que son crime soit avéré, sans que sa cause soit instruite ${ }^{125}$. Ailleurs, il dira ne pas supporter «que les bons soient frustrés au profit des méchants » ${ }^{126}$.

C'est un thème cher au chancelier, marqué par la disgrâce de son père ${ }^{127}$, qui rappelle, dans l'épître Ad Antonium Vaccam Italicum VI, $13^{128}$, combien peuvent être cruelles les dents des «loups et des tigres » qui entourent le roi, combien ces gens qui hantent les cours ignorent que la Fortuna domine nos destinées, car «sur terre rien ne peut demeurer perpétuel et fixe et [...] aux choses humaines il n'y a pas de constance ${ }^{129}$. Il sonde le mystère de la conduite divine car "notre intelligence erre dans les ténèbres, et son éloignement l'éloigne de la verité ». Toutes nos aspirations sont vaines et il est inutile de tant nous agiter, demander, convoiter, car tout dépend

de Lorraine, en 1564, à propos de l'adoption des décrets du concile de Trente, à laquelle Michel est hostile, et en 1566 à Moulins, où ils s'affrontèrent de nouveau. En 1568, il quitte la cour. Voir J. Bonnet, «Deux altercations entre le cardinal de Lorraine et le chancelier de l'Hospital», BSHPF, 10 (1875), p. 409-415. Emmanuel-Philibert aussi ne fera jamais appliquer les décrets tridentins dans ses États, voir L. Felici, «La repressione dell'eresia in Piemonte durante l'occupazione francese (1539-1559)», dans I tribunali della fede : continuità e discontinuità dal Medioevo all'età moderna, Atti del XLV Convegno di studi della Riforma sui movimenti religiosi in Italia, Torre Pellice, 3-4 sett. 2005, Turin, Claudiana, 2008, p. 163 sq. Sur la Réforme au Piémont, voir maintenant R. Gorris Camos, "Je voys, je viens ça et là tout pensif": poesia ed eresia nel Piemonte francese», dans Verso la Riforma. Criticare la Chiesa, riformare la Chiesa (fine XV-inizio XVI secolo), Atti del Convegno di Torre Pellice, 31 agosto-3 settembre 2017, éd. S. Peyronel, Turin, Claudiana, 2019, p. 315-352.

123 Voir II, 1 De morbo tertianae quo laboravit ann. MDLII au cardinal de Lorraine, dans Carmina, t. II, p. 14-37.

124 L'Hospital, Poésies complètes, p. 90.

125 Ibid.

126 VI, 2 Ad amicos, dans Poésies complètes, p. 345.

127 Voir l'épître I, 13 à Pierre Du Châtel, dans Carmina, t. I, p. 292-311.

128 L'Hospital, Poésies complètes, p. 332-337.

129 IV, 1 Ad Franciscum Lotharingium, ducem Guisianum. De duce Guisio e Latio sub cladem Quintinianum in Galliam redeunte, dans L'Hospital, Poésies complètes, p. 232-239. 
de la volonté de Dieu. Dans l'épître VII, 5 à Marguerite le message sera clair : il est vain de croire que nos œuvres peuvent concourir à notre salut, seule la grâce de Dieu peut nous conduire au Ciel, mais il faut coopérer ${ }^{130}$.

Toutefois, dans ce très beau texte qu'est l'épître II, 8, émaillée des thèmes et des motifs obsédants dans les Carmina (l'ambition excessive, v. 18 ; l'injustice v. 4 ; l'ingratitude v. 30 ; la malveillance v. 50 et le mensonge; l'envie v. 55 ; la difficulté de garder le pouvoir sans se perdre v. 119), Michel enseigne la prudence, la bienveillance, la lucidité d'esprit (v. 64), la conscience de nos limites et, surtout, l'attitude qu'il faut observer quand la tempête arrive (v. 72 sq.). C'est ainsi qu'il évoque deux exempla tirés de Plutarque, auteur cher à Marguerite (l'historien et conseiller au Parlement de Bordeaux, Arnoul Le Ferron venait de lui offrir son édition de Plutarque publiée chez Gryphe en 1556) ${ }^{131}$ et à Michel qui le «lit et exploite constamment ${ }^{132}$. Le premier est Thémistocle, homme de loi qui n’avait pas hésité à prendre le commandement de l'armée contre les Perses pour sauver Athènes. Le second est Épaminondas qui à son tour «fit de Thèbes la dominatrice de la Grèce » ${ }^{133}$. Ce sage vertueux sait combattre, mais aussi s'amuser et apprécier la musique, la poésie qui peut être utile pour tempérer la violence de la guerre, le furor par la douceur des vers. Mais l'homme capable de diriger les affaires publiques doit avoir, à côté du courage, piété

130 VII, 5 Ad Margaritam Sabaudiae ducem. Voir A. Buisson, Michel de L'Hospital (1503-1573), Paris, Hachette, 1950, p. 74, qui parle de «formulation nette de la doctrine de la prédestination ». Pour Thierry Wanegffelen, Ni Rome ni Genève. Des fidèles entre deux chaires en France au XVIe siècle, op. cit., p. 219, n. 219, la formulation est excessive: "contentons-nous d'y lire une affirmation de la gratuité du salut».

131 Plutarchi Chaeronei Pro nobilitate libri fragmentum. Arnoldo Ferrono Burdegalensi regio consiliario interprete. Ad Margaritam Valesiam, Henrici regis Franciæ sororem, Biturigum ducem, Lugduni, apud Seb. Gryphium, 1556 (ex. Bib. Civica de Mondovi).

132 Un ex. des Moralia, Froben et Episcopium, 1542, qui avait probablement appartenu à Michel, est conservé à la BNF. Voir Petris, La Plume et la tribune, p. 148 et p. 521 .

133 Montaigne réserve une place de choix à Épaminondas, maître de sagesse et prince de justice, dans ses Essais. Voir J.-L. Vieillard-Baron, «Epaminondas », dans Dictionnaire de Michel de Montaigne, dir. Ph. Desan, Paris, Champion, 2004, ad vocem, p. 330-331. 
et vertu, «religione et fide» (v. 102) qui le rendront «firmo » à tous les vents (v. 103-104) ${ }^{134}$.

L'Hospital évoque en II, 8 une constellation de thèmes qui reviennent d'une épître l'autre et que nous retrouvons, par exemple, dans son $A d$ amicos (VI, 2), sorte de dialogue où il se met en scène en Cassius et Libon (incarnant la gravité et la sévérité, il refuse le modèle de Timon, le misanthrope: «je ne me renferme point dans un sanctuaire impénétrable $»)^{135}$. Or, ce dialogue dramatise une sorte de dédoublement de lui-même, pour révéler son déchirement, ses peurs de la chute, la dialectique qui l'angoisse entre le bien et l'utile, la raison d'État et le bien ainsi que la gloire de ce monde et le bonheur éternel. Il brosse le portrait du vir bonus, ce sage invincible qui ne plie pas sous le fardeau des coups de la Fortune (II, 8, 104). En effet, s'il est parfois facile de monter aux honneurs (II, 8, 110), la voie est glissante, la lumière excessive peut aveugler et on peut se perdre comme dans un labyrinthe (Dédale, v. 125) ou s'agiter en vain comme Callipède (v. 130). Le sage par contre ne doit jamais baisser la tête (VI, 1) ni la garde, afin d'avoir «le droit de tourner vers le ciel son front». Et encore une fois revient l'image de la fleur qui tourne avec les rayons du soleil ${ }^{136}$.

La morale est claire. S'il invite la princesse et lui-même à " apprendre à modérer [leurs] désirs », leurs passions et leur ambition, à être prudents (v. 57, «reddere cautos»), L'Hospital n'hésite pas à glisser de l'éthique à la politique: «offre plutôt tes services, si tu espères réussir mieux que d'autres ». Il faut «saisir le gouvernail ${ }^{137}$. Il faut chasser les loups et «pacem redditi ovili» (v. 150). Une image, celle des loups et de la brebis noire, qui revient comme un refrain dans les Carmina, comme en VI, 2, où il réaffirme avec force, en écho aux propos de Marguerite dans plusieurs de ses lettres, «j'aime la paix»:

Telle est la conduite, tel est aussi le signe de ralliement des enfants de la vraie foi, des pieux adorateurs du vrai Dieu.

134 Voir VI, 2 Ad amicos, où nous trouvons la même image.

135 L'Hospital, Poésies complètes, p. 345. Sur ses différences avec Montaigne, voir Crouzet, La Sagesse et le malheur, p. 304-305 et surtout ici-même l'article de Jean Balsamo.

136 L'Hospital, Poésies complètes, p. 344.

137 II, 8, 77 dans L’Hospital, Carmina, t. II, p. 152-153; Poésies complètes, p. 91. 
Ô brebis infâmes et souillées! non non, ce n'est point là ton troupeau, mon bon pasteur, je ne vois que la progéniture des loups malfaisants. Tes brebis à toi sont blanches comme la neige, mais celles que je rencontre sur mon passage sont noires par le cœur, noires par la langue, noires par la bouche, noires par la pensée, noires par tout le corps ${ }^{138}$.

L'épître II, 8 s'achève sur un long passage consacré à Marguerite, qu'il appelle Regina (v. 171 et 186), dont L'Hospital apprécie la foi, la prudence, la constance (v. 160-161), son être imperméable aux mensonges et aux délateurs (v. 162 sq.), son maintien doux et agréable (sa «mansuetudine», disait Carnesecchi), son amour pour la paix ("ut in te pacis amorem», v. 178), mais surtout, "tu sola bonorum es Perfugium» (v. 167-168), son être charitable envers les pauvres et les démunis, les persécutés, ce qui sera le chiffre de son existence vouée à la caritas et à la protection des lettrés et des bannis du monde:

\section{Scilicet adiutrix inopum, tu sola bonorum es \\ Perfugium: tua sancta domus : tibi regia circum \\ Mensa frequens hominum laudatis coetibus omnem, \\ Quam longa est, coenam vario sermone trahentum ${ }^{139}$.}

Marguerite est lumière, elle est la Lune parmi les étoiles (v. 189190), comme elle était le soleil dans I, 15 (v. 45, «Virgo tuis, tanquam solis fulgore videntur $\gg$ ). Elle incarne une vertu féminine qui voudrait apaiser le monde marqué par la violence et la guerre. Son frère est ici associé à Mars et Marguerite à Pallas, qui incarne la douceur, la paix et le refus du monde. Ses poètes reconnaissent en elle une tension et un élan néo-platonicien vers le Ciel refusant ce basmonde secoué par le «vent des accidens». Elle est pour eux «le port et la brise ${ }^{140}$.

\footnotetext{
138 L'Hospital, Poésies complètes, p. 347. Sur le thème de la blancheur de la neige, voir Petris, La Plume et la tribune, p. 148. L'entourage doit être niveo.

139 II, 8, 167-170, dans Carmina, t. II, p. 156-157.

140 Voir notre " "Du sens mystique des romans antiques" : il paratesto degli "Amadigi" di J. Gohory", dans Il romanzo nella Francia del Rinascimento: dall'eredità medievale all'Astrea, Atti del Convegno Internazionale di Studi (7-9 ottobre 1993), Fasano, Schena, 1996, p. 61-83.
} 


\section{«TU ES POUR MON GÉNIE ET LE PORT ET LA BRISE» (DU BELLAY)}

L'image de la tempête, qui revient d'ailleurs dans les Carmina ${ }^{141}$, apparaît dans cette épître II, 8, 72 sq. :

Lorsque, dans une tempête menaçante, un navire est dirigé par un pilote sans expérience qui va le faire briser contre un écueil, pourquoi attendre, si tu peux te sauver? Tes compagnons de voyage t'appellent à leur aide, et tu hésites à saisir le gouvernail ? ou bien, si l'ennemi escalade les murailles et si le commandant abandonne lâchement son poste, ne le traîneras-tu pas de force aux murailles, puis, lui arrachant les insignes de son grade ne feras-tu pas, quoique simple citoyen tous tes efforts pour sauver la patrie ?142

C'est la même image que Du Bellay, nouvel Ulysse ${ }^{143}$, utilise dans la première élégie du livre I de ses Poemata (1558), dédiés à Marguerite ${ }^{144}$, où il évoque «la funeste tempête » de l'exil étranger, ainsi que les inquiétudes de cet «orage sombre», existentiel, poétique et historique, qui va porter les hommes et le poète «jusqu'à des fonds aveugles»:

La France! Bien que nos rames abandonnent maintenant ses calmes eaux et affrontent les courants profonds de la mer latine, ce n'est pas de mon gré que mon bateau a glissé jusqu'ici sous le vent ô ma divinité: tu es pour mon génie et le port et la brise, mais tant que tes yeux semblables aux flammes des astres, tes yeux plus brillants que le flambeau d'amycles, guidaient ma course sur l'azur des mers de ma patrie, tant que la funeste tempête ne secouait pas notre esquif, alors, c'était permis, j'allais à pleine voile en toute sûreté; lors je ne connaissais ni Scylla ni Charybde, mais l'Océan paternel, Téthys et les Nymphes - des sœurs - les

141 Voir Crouzet, La Sagesse et le malheur, passim et notamment le chapitre I, «Une tempête évangélique», p. 27-100.

142 Poésies complètes, p. 91 ; II, 8, 72-82 dans L'Hospital, Carmina, t. II, p. 152-153.

143 Voir G.H. Tucker, The Poet's Odyssey: Joachim du Bellay and the Antiquitez de Rome, Oxford, Clarendon Press, 1990.

144 Voir la dédicace Ad Marg. Henr. II Regis christianiss. sororem unicam, dans CEuvres latines, éd. G. Demerson, CEuvres poétiques, t. VII, Paris, Nizet, 1984, p. 32-33. 
autres puissants dieux de la mer sans limites, sur les flots aplanis par leur char azuré offraient tout au long des détroits des routes faciles.

Mais sous un astre hostile et des vents dévorants, ma poupe m'entraîna à l'étranger, au large: alors je fus saisi, précipité dans la Mer tyrrhénienne, alors l'orage sombre m'a porté jusqu'à des fonds aveugles. Depuis, des écueils énormes, des rochers que l'eau cache, depuis les tourbillons de l'onde insatiable jettent l'épouvante sur notre esquif. Maintenant plus de Nymphes: des monstres marins courent se jeter sur moi ; maintenant les eaux se gonflent. L'Auster fait rage.

Que s'il m'était permis de contempler encore en un ciel serein les astres qui, un temps, ont protégé mes voiles, alors, seulement, j'abandonnerais les flots et les vents d'Ausonie, je regagnerais les rivages des mers de la patrie, je les connais ${ }^{145}$.

Michel partage avec Joachim Du Bellay et les poètes de Marguerite évoquant les Ruynes de Rome (Grévin, Chandieu, Du Chesne.... ${ }^{146}$ la vision de Rome comme un infelix regnum, une sorte de "vautour» $(\mathrm{I}, 10,11)$ avalant les richesses du monde, un amas de ruines poudreuses, comme il la décrit dans l'épître I, 10 au cardinal Du Bellayy ${ }^{147}$. Dans l'épître au cardinal de Lorraine ${ }^{148}$, L'Hospital cite la II ${ }^{\mathrm{e}}$ nouvelle de la Ire journée du Décaméron pour évoquer la corruption des mœurs de Rome. Comme Du Bellay, il oppose Rome-Babylone à Paris, lieu de vertu et de droit: "Paris s'approche du ciel et lève la tête plus que Rome ${ }^{149}$. À Paris, d'ailleurs, la divina sapientia et les studia de la chaste Minerve,

145 Joachim Du Bellay, "Cur intermissis Gallicis Latine scribat», dans CEuvres latines: Poemata, éd. cit., p. 34-35. G. Demerson, «Introduction», p. 24 définit ce poème comme «l'étrange élégie qui ouvre le recueil Cur intermissis Gallicis Latine scribat, dans laquelle, bien loin de justifier rationnellement son choix du latin, Du Bellay ne fait que révéler ses angoisses profondes ». Voir aussi G. Demerson, «Les obsessions linguistiques de Joachim Du Bellay», dans A.C.N.T., éd. J.-C. Margolin, Paris, Vrin, 1980, p. 513-527.

146 Voir G.H. Tucker, The Poet's Odyssey, op. cit. ; E. McPhail, The Voyage to Rome in French Renaissance Literature, Saratoga, Anma Libri, 1990 ; R. Gorris Camos, Princesse des frontières, op. cit.

147 L'Hospital, Carmina, t. I, p. 238-259.

148 L'Hospital, Carmina, t. III, p. 242-259; Poésies complètes, p. 197-199 et 268-270.

149 I, 1 Ad Musas romanas, ut Bellaium cardinalem, Romae commorantem, in patriam, dans L'Hospital, Carmina, t. I, p. 38-62. 
nouvelle incarnation de sa protectrice, sont florissants comme jamais.

Si L'Hospital orchestre donc le « code évangélique anti-romain » et que les Carmina sont sous-tendus d'une forte connotation gallicane ${ }^{150}$, ou plutôt « d'une sémiologie explicite et implicite de l'indignation à l'égard de Rome » ${ }^{151}$, le poète néo-latin s'approprie l'emblème margaritique par excellence: le serpent, ce double serpent qui semble s'élancer vers le ciel et qui accompagne la branche d'olivier (L'Olive) et la devise de Marguerite ${ }^{152}$. Symbole du Christ (Jn 3, 14), ce serpent est l'emblème de la vie de Marguerite et du chancelier placée, comme les sonnets finaux de l'Olive, sous le signe de la Croix.

Si nous avons étudié ailleurs les thèmes ascensionnels qui révèlent le désir obsédant de l'envol, l'envie déchirante de s'élancer vers le ciel pour oublier la terre qui hante le poète de $L^{\prime} O l i v e^{153}$, on retrouve dans les Carmina le même puissant désir de se délivrer «de ce monde trop immonde» et du poids des affaires terrestres mais sans jamais perdre sa confiance en la praxis. D'un côté, l'on ressent le désenchantement vis-à-vis de la misère des hommes, de l'envie (II, 8, 140-141, «Invidiae flamma est nulla vitabilis arte, / Nullis consiliis »), des peines et des soucis inévitables. Mais de l'autre, on relève l'aspiration à l'envol (afflata), le désir d'un monde meilleur, mais avec l'assurance que l'on peut «saisir le gouvernail», pour amoindrir les effets négatifs par la sagesse. En effet, s'il existe une " épistémologie critique de soi » ${ }^{154}$, la conscience très nette de nos vices et de nos péchés, l'espoir reste de réussir, par le Christ, à aimer Dieu et notre prochain. De la Chute à la Rédemption, le christocentrisme de Michel s'appuie sur cette certitude. Mais l'homme «irrequietus» (II, 8, 133) ne cesse de courir en vain et, en courant, il s'éloigne de Dieu. Sur les traces de saint Augustin, via

150 Sur ces «perspectives d'une écriture gallicane», voir J. Rieu, L'Esthétique de Du Bellay, Paris, SEDES, 1995, p. 90-97.

151 Voir Crouzet, La Sagesse et le malheur, p. 67.

152 Voir sur ce thème Crouzet, "Le paradoxe du serpent aux "ailes légères" ", dans La Sagesse et le malheur, p. 101-188. Sur la devise de Marguerite, voir supra n. 50.

153 Voir notre «Sous le signe de Pallas : paroles ailées et ascension de l'esprit dans l'Olive», dans L'Olive de J. Du Bellay, op. cit., p. 167-232.

154 Voir Crouzet, La Sagesse et le malheur, p. 101. 
le Pétrarque des Familiares mais aussi d'Horace ${ }^{155}$, il condamne cette course infinie, loin de nous-mêmes, dans un vide que l'ignorance de Dieu creuse en nous:

Nous étudions les sciences les plus diverses; nous envoyons au-delà des mers nos enfants en bas âge, nous leur apprenons à courir les places publiques et les marchés, à braver le froid au péril de leur existence, à se garder des pièges et des discours mensongers, à ne se fier à aucun inconnu: triste expérience, qu'ils acquièrent après avoir été victimes de leur crédulité ${ }^{156}$.

Les mots de Pétrarque résonnent aussi dans l'épître II, 8, 136 sq. que Michel dédie à sa protectrice et, par ricochet, lui-même, alter ego de la princesse:

C'est ainsi que l'homme passe presque toute sa vie à se priver de ses légitimes ressources: il cherche bien loin au-delà des mers ce dont il abonde ${ }^{157}$.

Mais la pire ignorance est celle qui se cache dans notre cœur, notre vaine ambition qui nous fait glisser et précipiter ou qui nous entraîne vers de nouvelles chimères ${ }^{158}$.

La lutte acharnée de Marguerite contre vilaine ignorance, contre ce Faux Cuyder, déjà commencée par Marguerite de Navarre dans sa poésie de $\mathrm{Dieu}^{159}$, trouve ici son apogée. Le Christ a parlé par paraboles, par énigmes. Le poète l'imite et veut «dire le Vray»,

155 Voir Horace, Epistola I, 1, 45 sq. ; Pétrarque, Familiarium rerum libri IV, 1, éd. Jakob-Formica, p. 17, traduction en français, par nous-même: «Et vont les hommes, à admirer les monts très haults et les grandes vagues de la mer et les longs cours des fleuves et l'immensité de l'Océan et les révolutions des astres mais ils délaissent eux-mêmes ». Voir aussi Marguerite de Navarre chez qui le regard passe du paysage extérieur, les monts, la terre et ses rochers escarpés, l'eau bruyante, assourdissante du Gave à son propre moi («connais toimême») par le biais de saint Augustin, clé de lecture de l'épître de Pétrarque (mais aussi de la poésie de la Reine), une expérience, justement définie par la critique la plus récente comme une conversio augustinienne.

156 IV, 7, 11-17, dans Poésies complètes, p. 205.

157 L'Hospital, Poésies complètes, p. 92.

158 Ibid. ; L'Hospital, Carmina, t. II, p. 154-155 (II, 8, 106-116).

159 Voir R.D. Cottrell, La Grammaire du silence. Une lecture de la poésie de Marguerite de Navarre, Paris, Champion, 1995. 
divulguer la Parole de Dieu dans sa poésie. Michel adopte le discours allégorique, tant cher à Bocchi et à son Académie ainsi qu'aux poètes de Renée et de Marguerite, pour révéler sa «vraye religion » ${ }^{160}$ («verum fidei cultum » $\mathrm{I}, 11,4$ ), pour répondre à l'amour de Dieu. Pour dire la Vérité, il se place dans la voie du Christ, comme Flaminio, Grévin et les autres poètes de Pallas, celui qui sait

calmer d'un geste la mer, la tempête et les vents, se promener sans sombrer, sur la surface des flots, obscurcir, en mourant dans les ténèbres d'une profonde nuit, les rayons du soleil [...] Mais la route était dure et orageuse, il fallait éprouver des souffrances, passer à travers des épreuves difficiles et des peines nombreuses, des ignominies infâmes et chaînes insupportables $^{161}$.

Pour dire Dieu, le poète ne doit pas recourir à l'artifice : son style doit être «facile, sans apprêt, sans recherche, sans ornements, mais rempli d'une dignité sérieuse » $(I, 7,55-56)$. Car si les conseils des philosophes peuvent enseigner la sagesse humaine, la parole de Dieu est le seul port, la lampe qui éclaire notre existence, le roc contre la tempête.

\section{SOURIRES ET BAISERS}

Si nous ne pouvons pas ici analyser toutes les épîtres à Marguerite, il ressort de cette constellation de poèmes que l'éloge de sa Regina au haut cœur qui revient d'une épître l'autre a une fonction parénétique, comme Loris Petris l'a bien souligné pour d'autres textes ${ }^{162}$.

160 Sur l'emploi de cette épithète, voir I. Garnier, L'épithète de la connivence : écriture concertée chez les Évangéliques français, Genève, Droz, 2005, passim.

161 I, 7 De poesi christiana iudicium et exemplum à Claude d'Espence, dans Poésies complètes, p. 37 et 39 ; Carmina, t. I, p. 180-207. Claude d'Espence a composé un texte sur Noël, BNF, fr. 454, fol. 80. Sur les Noëls, voir D. Speziari, La Plume et le pinceau, op. cit. et $i d$. , "Mise en musique et mise en scène de la musique dans les noëls manceaux du XVI ${ }^{\mathrm{e}}$ siècle (Samson Bedouin, Nicolas Denisot) », Studi francesi, 189 (2019), p. 417-429.

162 Petris, La Plume et la tribune, p. 157 à propos de l'éloge de Ronsard au cardinal de Lorraine et Galand-Hallyn, «Michel de L'Hospital à l'école de Jean Salmon Macrin », p. 34. 
L'éloge des vertus de Marguerite a une finalité spéculaire, miroir des vertus de cette Reine des poètes et des malheureux. Elle les accueille sous son aile comme des poussins, ce qui évoque Marot comparant Renée à une « geline » ${ }^{163}$ : «De même, quand l'oiseau de proie du haut des nues, le milan, guette les poussins picorant dans l'herbe, ceux-ci, dès qu'ils l'ont vu, prennent aussitôt la fuite pour lui échapper: leur mère accueille les fugitifs sous son aile ${ }^{164}$. Elle devient, par le biais de ces textes, un modèle actif, mais qui reflète aussi un dialogue incessant entre la Muse et le poète, un dialogue engagé, émaillé de livres, comme «leur» Horace, dont les Epistolae ${ }^{165}$ avaient tout pour séduire le magistrat-poète, d'idées, de projets pour l'avenir, d'affaires pratiques (Michel est celui «che tien cura di tutti i negotii di lei») ${ }^{166}$, de tendresse réciproque, de regrets poignants (VII, 5).

Si Du Bellay et Macrin incarnent pour L'Hospital « une figure paternelle dédoublée ${ }^{167}$, Marguerite est sœur et mère, une figure maternelle (III, 11 «comme une mère») qui assume, au fil des épîtres, un rôle toujours plus important dans lequel l'éloge aux visées didactiques se transforme bientôt en échange entre pairs, un dialogue entre personnes confrontées à des problèmes de gestion du pouvoir et d'une familia toujours plus exigeante et complexe.

Les textes adressés à sa protectrice sont sous-tendus de conceptions éthiques, politiques et religieuses, mais ils sont aussi le

163 Renée, écrit ce grand poète-romancier de Venise, «c'est la geline à qui on veult oster / Tous ses poussins, et scorpions bouter / dessoubz son esle». Voir C. Marot, Complaincte à la Royne de Navarre du maltraitement de Madame de Ferrare, par le duc son mary, dans CEuvres complètes, éd. G. Defaux, Paris, Bordas, t. II, 1993, p. 183187, v. 49-52, ainsi que Pantagruel, chap. XXXII. La source est Mt 23, 37.

164 III, 11, 108-111 dans L'Hospital, Carmina, t. III, p. 220-221 ; Poésies complètes, p. 194.

165 Voir Galand-Hallyn, «Michel de l'Hospital à l'école de Jean Salmon Macrin », p. 33 qui souligne précisément le caractère pratique des Epîtres d'Horace. Voir aussi L. Petris, "Michel de L'Hospital lecteur d'Horace: une poétique de la juste distance, entre autoportrait, amitié et nature humaine», Camenae 17 (janvier 2015), p. 1-19.

166 Voir la lettre du 19 mars 1559, Trivulzio à Caraffa, Vatican, ASV, Segr. Stato, Principi 11, fol. 400ro.

167 Voir Galand-Hallyn, «Michel de L'Hospital à l'école de Jean Salmon Macrin », p. 24. 
modèle et l'exemple d'un lyrisme familial ${ }^{168}$, où le furor cède sa place au calor, où le portrait du vir bonus, du bon magistrat et chancelier qui enseigne la sagesse et la prudence à la jeune duchesse de Berry (et par ricochet à lui-même), se mélange aux paroles de consolation (par ex. II, 15 sur la mort de Catti), aux conseils concernant la gestion des membres de sa maison (III, 11) ${ }^{169}$ et au sourire des enfants qui jouent devant sa porte (II, 2 et IX, 36). Marguerite ne cache pas sa tendresse pour ses petits neveux qu'elle aime comme siens. Leurs rapports étaient très affectueux et, dans l'épître IX, 36, on voit François II jouer dans ses chambres. Michel évoque les baisers qu'elle voudrait donner aux enfants de son frère: «je donnerais mille et mille baisers, à celui qui doit porter une si belle couronne et aux autres ». Il évoque les inquiétudes d'un père $(\mathrm{V}, 3)^{170}$, mais aussi le rire pour les mauvais tours des nains et des bouffons dans l'Iter Nicaeum $(\mathrm{V}, 9)$. Les Carmina sont ainsi parcourus d'une indéniable tendresse pour cette Mater aux yeux tristes. Tout comme dans le manuscrit italien inédit de la Civitas veri où, dans cette géographie des vices et des vertus aristotéliciens commandée par Marguerite un jour d'automne, dans son château de Rivoli en 1565, l'on voit apparaître le sourire du petit prince, Charles-Emmanuel, qui arrive en courant vers sa mère et qui avait, à la date de la commande de ce poème de l'automne, l'Anno, 3 ans ${ }^{171}$.

Même dans l'amour exagéré de Marguerite pour son enfant (selon ses contemporains et tant critiqué par les ambassadeurs) l'on perçoit les conseils de son chancelier, comme père, qui non

168 Voir P. Galand, «Un aspect de la poésie latine dans la France de la Renaissance: le lyrisme familial», dans Actes des IVe rencontres classiques de l'Université de Paris XII-Créteil, Chloé, n. 4 et Galand-Hallyn, «Michel de L'Hospital à l'école de Jean Salmon Macrin », p. 34 sq.

169 Voir la lettre du 15 août 1568, elle lui écrit «le plaisir que vous avez du bon ordre que j'ay donné à ma maison afin que ma despense ne surpasse poinct la recepte de mes finances » L'Hospital, Discours et correspondance, p. 227.

170 Dans cette épître, il est question de la charge de maître des requêtes dont il dota sa fille qui épousa, au début de 1557, Robert Hurault de Belesbat, conseiller au Grand Conseil depuis 1554, chancelier de Marguerite de France et maître des requêtes. Les héritiers de Potier s'opposèrent à ce que cet office revienne à L'Hospital. Les époux eurent neuf enfants. Voir Petris, La Plume et la tribune, p. 69 et DL, t. II, p. 73-99.

171 Cf. le sourire de son petit-fils en III, 2, 6-14, dans Carmina, t. III, p. 42-43. 
seulement prônait l'allaitement maternel dans III, 2 à Jean de Morel (ce que Marguerite ne pourra pas faire pour son enfant né le 12 janvier $1562^{172}$, à cause de sa santé très fragile), mais il rêvait de restaurer une société fondée sur l'amour maternel et sur l'espérance dont cet amour est porteur.

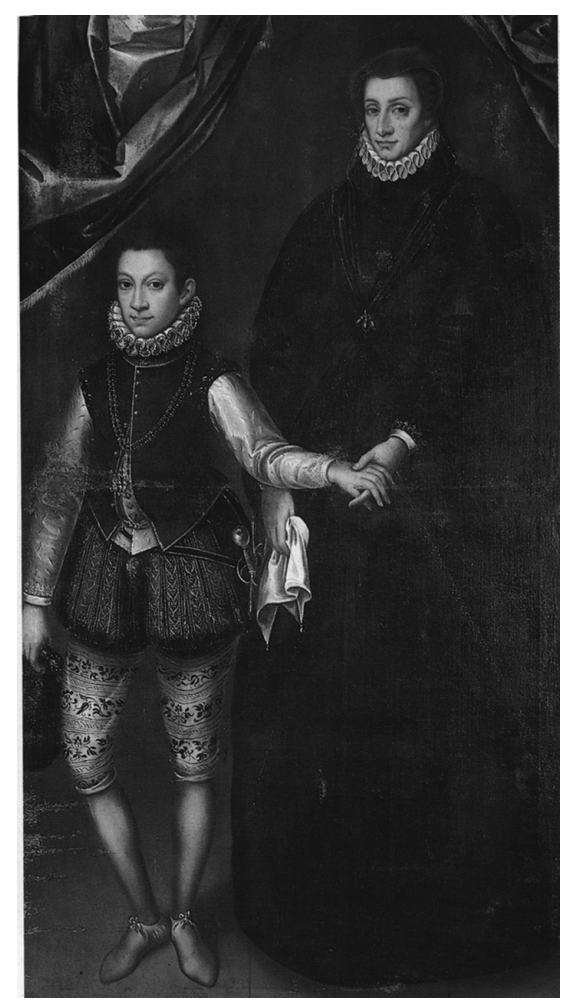

Ill. 6: Portrait de Marguerite et de son fils Charles-Emmanuel conservé au château de Racconigi, n. inv. 5528. Il s'agit de son dernier portrait avant sa mort ${ }^{173}$.

172 Sur la naissance miraculeuse de Charles-Emmanuel, voir notre " "Una bellissima festa in bianco e verde" : les fêtes pour le baptême de Charles-Emmanuel I I (Turin, 1567) », dans Faire la fête à la Renaissance. Actes du Colloque RSA, New York (26-28 mars 2015), à paraître.

173 Sur ce portrait voir R. Gorris Camos, «I volti della duchessa: icone e rappresentazioni del potere alla Corte di Margherita di Francia, duchessa di Savoia », op. cit., p. 45-86; P. Astrua, A. Bava, C. Spantigati, Il nostro pittore fiamengo. Giovanni Caracca, Turin, Umberto Allemandi, 2005, p. 29. 
Charles-Emmanuel devint le centre de l'existence de Marguerite. L'Hospital, vieilli (v. $20 s q$.) ${ }^{174}$, en VII, 5 remarque que «ton enfant concentre toutes tes attentions de mère ", "mox filius omnis / Maternas sese curas convertit ad unum» (v. 3-4) et il regrette de ne pouvoir peindre le sourire de l'enfant qui a alors sept ans (ce qui ferait dater la lettre de 1569) et qui allie la grâce maternelle à la force paternelle: "O mihi si liceat festivi scribere formam / Et vultum pueri»(VII, 5, 5-6). Il décrit aussi les baisers qu'il donne à ses parents attendris ("quot basia utrique parentum complexusque dedit», v. 6-7). L'éducation du petit sera d'ailleurs, désormais, le fil rouge des travaux des poètes de la cour de la duchesse, de Giraldi à Grangier ${ }^{175}$. Autour de Marguerite, nous voyons donc œuvrer de nombreux médecins (souvent il s'agit de professeurs du Studio qui, en prêtant leur service à la cour, complétaient leur salaire en recevant des dons $)^{176}$ et hommes de science qui s'occupent de sa santé et de celle de Charles-Emmanuel, assez "gracile», et dédient leurs traités à la duchesse et aux membres de sa cour ${ }^{177}$ : des Italiens comme Berga et Baravalle, mais aussi des Français comme Rochefort, Grévin, Peletier et Simon de Vallembert. Ce dernier écrit pour la duchesse, «sa maitresse ${ }^{178}$, ses Cinq livres

174 Ce thème de la vieillesse est récurrent en II, 8.

175 Voir R. Gorris Camos, Princesse des frontières, op. cit.

176 Voir Storia di Torino, t. III, éd. G. Ricuperati, Torino, Einaudi, 1998, p. 537 sq. Voir aussi B. Trompeo, Dei medici e degli archiatri dei Principi della Real Casa di Savoia, 1857 et Bonino, Biografia medica piemontese, Turin, Bianco, 1824-25. Voir aussi notre «L'insaisissable Protée: Ludovic Demoulins de Rochefort, médecin, poète et bibliophile entre Turin et Bâle», dans Pouvoir médical et fait du prince, Actes du Colloque de Tours, CESR, les 17-18 juin 2010, éd. J. Vons et S. Velut, Paris, De Boccard, 2011, p. 147-209 et ead., « La bibliothèque bleue de Louis des Moulins de Rochefort", dans Littérature et voyages de santé, dir. C. de Buzon et O. Richard Pauchet, Paris, Garnier, 2017, p. 119-162.

177 Voir Bersano Begey, t. II, p. 1045 et Bonino, Biografia medica piemontese, op. cit., I, 287-300. Sur Berga, voir DBI, t. 9, p. 61-63.

178 Il devient son médecin en 1558 (voir éd. C. Winn, Genève, Droz, 2005, p. 16). Il suit la duchesse au Piémont et écrit dans la page de titre de son traité: «M. Simon de Vallambert, Medecin de madame la Duchesse de Savoye et de Berry, et depuys peu de temps, de monseigneur le duc d'Orleans » (1565) et dans la dédicace: «je l'ay composé premierement et principalement pour le service du petit enfant, Prince de Piemont, fils de madame la duchesse de Savoye, vostre tres chere seur, ma maistresse, considerant qu'en faisant ce devoir de mon estat à son Altesse, envers son fils, en enseignant par escript en faveur de son nom, la maniere de nourrir et gouverner les enfants, je ne puis 
de la maniere de nourrir et de gouverner les enfants des leur naissance ${ }^{179}$, premier traité de pédiatrie en langue française, l'un des premiers manuels d'enseignement pour les mères, les sages-femmes et les nourrices, et enfin l'un des plus anciens régimes de santé consacrés à l'enfance. L'attention avec laquelle Marguerite élevait son petit prince, qui avait une cour à sa disposition, était extrême et les ambassadeurs vénitiens en étaient surpris. Nous avons retrouvé une relation aux Archives de Turin (ASTO) où l'on décrit le cadeau que Catherine de Médicis, qui avait suivi avec tendresse toutes les étapes de la grossesse ${ }^{180}$, envoya pour l'occasion: des vases d'argent et un lit à baldaquin en damas blanc et tous les meubles de la chambre de l'enfant ${ }^{181}$. Il s'agissait d'un "gran padiglione quadrato fatto a mano di una tenda di damasco bianco con grande frangia di argento che tocca terra, e restava serrato come una piccola camera sotto il qual padiglione il letto di damasco bianco anco guarnito di argento fatto a courtina ». À cette petite chambre la reine avait ajouté une sorte de lit-gigogne pour la gouvernante, des oreillers, le linge, des draps et des tapis. Ce document, qui est, d'après une note manuscrite biffée, une Relation de ce qui se fit à la naissance du Duc Charles Emmanuel I ${ }^{e r}$, est extrêmement intéressant car il décrit aussi la petite cour qui entoure le prince dès sa naissance: une gouvernante, deux nourrices, deux valets, Mgr Ginod, évêque d'Aoste, des femmes de chambre, la plupart françaises, qui s'occupaient de la lingerie et berçaient le

faire sinon chose que je pense vous pouvoir estre aggreable, comme ainsi soit que ce n'est qu'un cœur et une ame de vous et d'elle, et que ce qui se fait pour le service de l'une, ne peut estre separé du service de l'autre ». Il collabore au Tombeau de Gélonis auquel participent plusieurs poètes liés à Marguerite. En 1566, Jacques Dalechamps dédie sa traduction de Galien à Jacqueline d'Entremont, De l'usage des parties du corps humain, Livre XVII, escripts par Claude Galien et traduicts fidelement du Grec en françoys, Lyon, Rouillé, 1566.

179 Simon de Vallembert, Cing livres de la maniere de nourrir et de gouverner les enfants des leur naissance, Poictiers, Marnefz et Bouchetz frères, 1565 (éd. C. Winn, Genève, Droz, 2005).

180 Voir Lettres de Catherine de Médicis, éd. cit., t. I, p. 201, 226 et 244.

181 Turin, ASTO, Corte, Ceremoniale, Nascite e Battesimi, mazzo I, n. 5, qui décrit longuement le cadeau envoyé par Catherine. Sur la cour du petit prince, voir aussi P. Merlin, Tra guerre e tornei. La corte sabauda nell'età di Carlo Emanuele I, Torino, Società Editrice Internazionale, p. 2 qui écrit : «Carlo Emanuele aveva una propria corte come fosse un uomo di vent'anni e sapeva leggere e scrivere in italiano e in francese». 
prince («una parisiena, vidua chiamata Giachelina» qui passait son temps «cullando il Serenissimo Principe per farlo dormire») et une autre qui veillait toute la nuit à côté du «braciere». Il reste que Marguerite était extrêmement attentive aux conseils de ses médecins et ouverte aux idées et aux thérapies nouvelles en médecine.

Dans la constellation d'épîtres dédiées à Marguerite ainsi que dans celle, parallèle et de quelque façon complémentaire qu'il adresse à Anne d'Este ${ }^{182}$, l'on retrouve une attention mêlée de respect à l'égard de ces donne ornate di scienza e di virtù qui avaient le droit de poursuivre leurs études.

Si dès I, 15 Michel indiquait à Marguerite la gloire qui lui viendrait de ses études et de ses vertus («Moribus et studiis, quam celsae stirpis honore», v. 33) ${ }^{183}$ et se demandait " pourquoi les arts de Pallas ne conviendraient pas aux chastes mères de famille» («Nam cur Palladiae castis non matribus artes / Conveniant? », I, 15, 25-26), il reprend ce thème dans l'épître IX, 12 à Anne d'Este en l'invitant à se consacrer à l'étude quand les devoirs de la maternité seront pressants. Comme Marot l'avait fait pour la naissance d'Éléonore, il met en scène, dans l'épître des rires et des sourires, IX, 13 («ridentes, gaudens, laetum, risus, gauda pectus...») ${ }^{184}$, l'accouchement d'Anne d'Este, la naissance de ce «puerum nitentem / Syderis instar» qui a inspiré les poètes de Marguerite célébrant la naissance de l'enfant du miracle. Dans IX, 36, Anne est évoquée, juste après ses neveux, et c'est à cette dame, «l'honneur de Ferrare, sortie... de la race des Rois», que Marguerite avoue ses espoirs de maternité («si j'ai la douceur de me voir mère ou d'un fils ou d'une fille ... il sera le lien de l'amitié des deux peuples » IX, 36).

182 Voir les épîtres VII, 4; IX, 12; IX, 13 pour son accouchement et IX, 22. Sur l'éducation d'Anne d'Este, voir notre " "Donne ornate di scienza e di virtù" : donne e francesi alla corte di Renata di Francia », dans Olimpia Morata: cultura umanistica e Riforma protestante tra Ferrara e l'Europa, op. cit., p. 175-205.

183 I, 15, 33 dans Carmina, t. I, p. 340. L'Hospital développera cette idée dans son discours sur le sacre de François II (V, 8).

184 Voir la belle analyse de Galand-Hallyn, « Michel de L'Hospital à l'école de Jean Salmon Macrin », p. 48-49, qui édite IX, 13. 


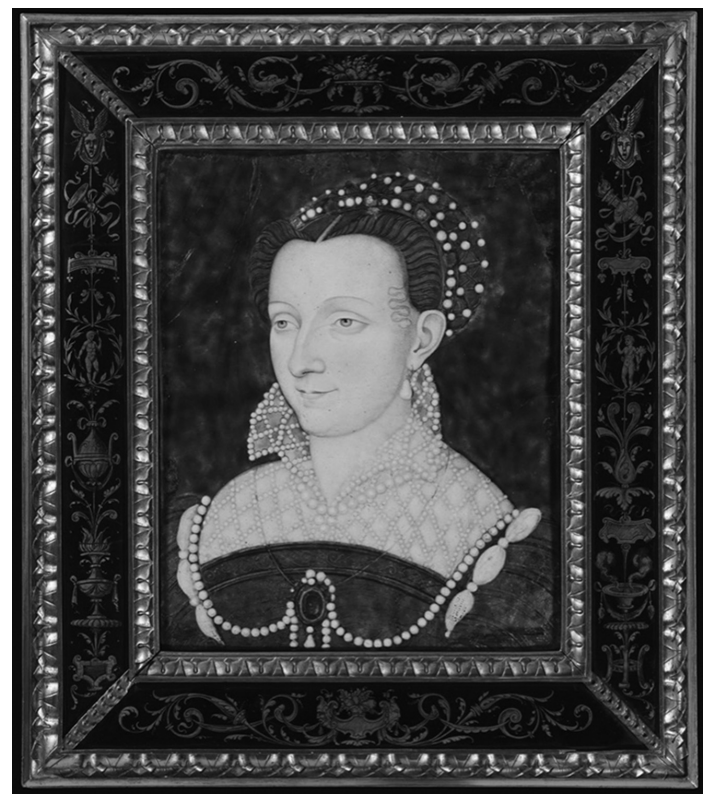

Ill. 7 : Léonard Limousin, Portrait d'Anne d'Este, émail peint conservé au British Museum, The Waddesdon Bequest, WB 24, 1563-66 ${ }^{185}$.

L'ombre du chancelier se projette aussi sur la politique religieuse de Marguerite à l'égard des Vaudois puisque l'épître II, 8 est précédée de II, 7 Ad Franciscum Olivarium, Franciae cancellarium, de causa Merindolii Lutetiae acta in Senatu. Marguerite fera tout son possible pour éviter guerres et persécutions contre les Vaudois et c'est sans doute à elle et à sa politique de paix et de tolérance que l'on doit le traité de Cavour ${ }^{186}$, et son indulgence se poursuit bien

185 Sur cet émail, voir T. Crépin-Leblond, «Une suite de portraits mythologiques émaillés par Léonard Limosin », Revue de l'Art, 116 (1997), p. 20 ainsi que «Les Emaux Peints du Musée Condé à Chantilly», Le Musée Condé, 56 (octobre 1999), p. 3, fig. 4 ; A. Zvereva, Portraits dessinés de la cour des Valois : Les Clouet de Catherine de Médicis, Paris, Arthena, 2001, no 388; D. Thornton, A Rothschild Renaissance: Treasures from the Waddesdon Bequest, Londres, British Museum, 2015, p. 116-119.

186 Voir notre " "Pia ricevitrice di ogni cristiano" : poésie, exil et religion autour de Marguerite de France, duchesse de Savoie », dans Chemins de l'exil, havres de paix. Migrations d'homme et d'idées au XVI siècle, Tours, CESR, 8-9 novembre 2007, éd. C. Lastraioli et J. Balsamo, Paris, Champion, 2010, p. 177-223. 
au-delà comme le démontre la lettre qu'elle écrit de «Envers » (Inverso) dans les vallées en 1565 à l'occasion de la reprise des persécutions de la part du duc:

Monsieur le chancellier,

Ces pauvres gens de Pigne ${ }^{187}$ me font pityé d'estre si longtemps à la poursuicte de la grace qu'ils poursuyvent envers Monsieur pour estre relevez de leur bannissement, qui me faict vous prier de les avoir pour recommandez pour l'amour de moy, et ne les renvoyer pardevant leur evesque sans leur expedition, car ils craingnent d'estre retenus comme leurs peres ont cy devant esté. Et pource que c'est une oeuvre charitable et pour le regard de leur pauvretté considerable, je m'asseure que vous aurez souvenance d'eulx. Et pour ce il me suffira de prier Dieu, Monsieur le chancellier, vous avoir en sa saincte garde.

De Envers ce 6 e jour de decembre

Vostre bonne amye Marguerite de Savoye ${ }^{188}$

«JE VIS COMME LAERTE» (VII, 5, 47): AD SUMMUM, SUIVONS LA SAPIENCE

Si les épîtres sont, selon Horace (Satires I, 4), « des œuvres plus proches du langage de la conversation, de la narration », un genre hybride, marginal, autobiographique ou autofictif, utile, dit Peletier, pour les narrations familières ${ }^{189}$ et dont le caractère pratique et pragmatique est souvent exploité dans les Carmina (la parole et le portrait agissent sur le destinataire mais aussi sur l'auteur), elles sont utilisées par Michel pour entretenir un «dialogue d'âme à âme» qui défie les distances de tout genre, ce sine te dit et redit dans les épîtres à Marguerite, qui ajoute de sa main au-dessus de

187 Sur la tolérance de Marguerite, notamment à l'égard des Vaudois, voir G. Jalla, Storia della Riforma in Piemonte fino alla morte di Emanuele Filiberto, 1517-1580, Firenze, Claudiana, 1914, passim ; L. Addante, Giampaolo Alciati della Motta e gli eretici piemontesi nell'Europa del 500, Torino, Nino Aragno editore, 2013 et notre " "Pia ricevitrice di ogni cristiano" ...", art. cit.

188 L'Hospital, Discours et correspondance, p. 215.

189 Voir Peletier du Mans, Art poetique français, dans Traités de poétique et de rhétorique de la Renaissance, éd. F. Goyet, Paris, LGF, 1990, p. 299-300. 
ses missives «affectus plena». "Je te respecte comme une mère, et puis tout te dire ${ }^{190}$.

Exemple paradigmatique, mais aussi complexe, de ce dialogue ininterrompu, l'épître VII, 5 sollicitée par l'éminence grise de la cour de la duchesse, Baccio Del Bene, parallèle à la lettre qu'il écrit en pleine tempête à Madame de Savoie (lettre qu'il recommande tout particulièrement à sa fille) ${ }^{191}$, contient le récit adressé à Marguerite de sa nouvelle vie en famille, «sine te» (v. 39), sa «rustica vita» (v. 30), parmi ses livres ${ }^{192}$; il écrit, il lit, il médite, mais il voit aussi ses forces diminuer, il révèle toute sa tristesse après le départ de sa protectrice et sa douleur à la vue des guerres civiles. Il compose ses Regrets et évoque leurs échanges, les conseils réciproques, la générosité de la princesse envers sa famille. «Ces consolations me manquent aujourd'hui, et je n'ai plus aucune raison de regretter le monde et la cour» (v. 40 sq.). Si la vie solitaire à la campagne semble lui être agréable, en réalité le lexique qu'il utilise (solo, exul, exilium) est aussi révélateur que la longue liste de proscrits: Aristide, Thémistocle, Marcellus et Métellus Numidicus, bannis pour leur vertu, éloignés de leur patrie.

Son bonheur familial qu'il sait évoquer, comme dans un tableau d'intérieur, semble ne pas suffire à cet homme vieilli qui orchestre le thème de l'abandon de la poésie comme le faisait Horace ${ }^{193}$. Michel écrit ici son De senectute et aspire désormais à un autre monde. Le tableau rustique et familial tourne en effet, dans la deuxième partie, en envolée mystique et en poésie du Christ.

J'avise à escalader le ciel, non pas comme le géant de la fable, mais comme le Christ l'enseigna à ses disciples sur la terre. J'essaie quoique vieux et retardé par l'âge, de suivre le sentier que mon Dieu m'a tracé: heureusement que les croyants qui touchent à leur dernière heure sont recompensés sans distinction de temps et de travaux.... Nul n'arrive au ciel par sa propre

190 L'Hospital, Carmina, t. III, p. 217 ; Poésies complètes, p. 192 (III, 11, 20-22).

191 L'Hospital, Discours et correspondance, p. 265.

192 Son petit-fils Michel héritera de sa bibliothèque. Voir Petris, La Plume et la tribune, p. 520. On a retrouvé sa Bible aldine in-folio en grec, truffée de notes mss.: Sacrae Scripturae veteris, novaeque omnia, Venetiis, in aedibus Aldi et Andreae soceri, 1518 (Londres, BL, C.18.b.4) et son Pugio fidei de Raymundus Martinus (Sainte-Geneviève).

193 Horace, Epist., I, 1, 10-13. 
vertu, malgré sa piété, malgré son innocence; nul ne peut être son propre guide. C'est la grâce de Dieu qui nous parle et nous conduit ${ }^{194}$.

Il désire lui aussi «fouler aux pieds les Muses et la lyre des profanes pour changer en joie la sombre affliction dans laquelle je suis plongé ${ }^{195}$. À nouveau Job, le Juste persécuté fait irruption dans cette épître qui avait commencé par le sourire et les baisers enfantins, mais dans laquelle, comme dans une épître horatienne, on passe de la sagesse aux «narrations familieres », des regrets aux consolations, de l'enfance à la vieillesse, de Sophocle à la fable de la tortue, coupable d'avoir trop levé sa tête vers le ciel, de la parole au silence.

Comme dans l'épître III, 11, où les conseils sur la vie privée, l'attitude du maître à l'égard des serviteurs, les questions de la vie quotidienne dont on parle autour de la table, au lever de la nappe, avec des proches, dans ce cas sa comme-mère Madame de Brissac (Boesia mater $)^{196}$, on passe à la théorie des passions, aux tensions entre le corps et l'âme, à la question fondamentale, dans son système de l'équilibre, de la maîtrise de soi qui est au centre de l'éthique aristotélicienne ${ }^{197}$, si importante pour la duchesse ${ }^{198}$, où famille et politique sont comparées ${ }^{199}$, ainsi qu'aux réflexions sur les pouvoirs thérapeutiques de la poésie et de la musique orphiques. Marguerite, mère des poètes et Regina, est le paradigme de

194 L'Hospital, Poésies complètes, p. 366-367.

195 Ibid.

196 Il s'agit de Charlotte de Gouffier-Boisy, femme de René de Cossé, sieur de Brissac, gouvernante des enfants de François I $^{\text {er }}$ et mère du maréchal de Brissac. Voir VIII, 8 De morte D. Brissacae; Poésies complètes, p. 238. Son mari, René de Cossé, seigneur de Beaulieu et de Brissac puis de Cossé, fut familier des rois Charles VIII, Louis XII et François I ${ }^{e r}$, Grand Panetier du Roi, Gouverneur des Princes de France, Grand-Fauconnier de France, Capitaine d'Angers et de Falaise, Gouverneur d'Anjou. Le mariage avec Charlotte Gouffier de Boisy eut lieu avant 1503.

197 Marguerite possédait dans sa bibliothèque un manuscrit de la traduction de Du Bellay du Discours du sacre $(\mathrm{V}, 8)$. Voir notre " "Una notte d'inferno" : autour de l'incendie de la Bibliothèque Nationale de Turin: livres détruits, livres rescapés ", dans Les labyrinthes de l'esprit, éd. R. Gorris Camos et A. Vanautgaerden, Genève, Droz, 2015, p. 489-547.

198 Voir nos travaux sur la Civitas veri cités supra n. 112.

199 Voir Crouzet, La Sagesse et le malheur, p. 303. 
qui a su vaincre ses passions, véritable incarnation de la mansuétude, de la clémence : "Tu marches victorieuse vers le ciel au milieu des troncs et des flammes des débordements humains, sans en être atteinte ». Marguerite est dans III, 11 l'incarnation du sage prudent et imperturbable qu'Horace évoque en Ep., I, 6, 1-2 («Nil admirari prope res est una Numici, / Solaque, quae possit facere et servare beatum $»)^{200}$. Cette épître contient des questions fondamentales qui seront à la base de ses théories politiques fondées sur la clémence décrites dans le Discours du sacre $(\mathrm{V}, 8)$, qui est la «transposition au niveau politique de ce modèle domestique» (Loris Petris). Marguerite possédait d'ailleurs dans un manuscrit jadis conservé à Turin, le Ms. L.V. 40, et brûlé en 1904, sa traduction par Joachim Du Bellay:

Chartaceus, habens folia 14, saeculi XVI, in quo Poema Latinum Michaelis de l'Ospital de Sacra Francisci Gallorum Regis Unctione et de optimo instituendo Imperio, Gallicis versibus redditum a Joachino de Bellay. Meminit hujus Poematis Antonius de Verdier ${ }^{201}$.

Or, il n'est pas surprenant, en connaissant les rapports entre Marguerite et Du Bellay, de trouver ce manuscrit du Discours sur le sacre du treschrestien Roy Françoy II ${ }^{202}$. Marguerite possédait toute une constellation d'ouvrages concernant les membres de sa famille et des manuscrits de dédicace à son père et à ses frères ${ }^{203}$ et, surtout, elle était très intéressée par ce sujet, l'institutio principis. L'esprit qui anime ce texte magnifique cristallise en outre ses sentiments les plus profonds notamment quand son chancelier écrivait: "Aut quid discipulos Christi nos esse fatemur, / Si nulla in nobis expressa illius imago est?», «Autrement, pourquoi nous décla-

200 Voir Petris, La Plume et la tribune, p. 97-98 et 232-233.

201 G. Pasini, Codices manuscripti Bibliothecae Taurinensis Athenaei, pars altera, Taurini, ex Typographia Regia, 1749, p. 497, ancienne cote Codex CLII.K.71. Voir notre «"Una notte d'inferno"... », art. cit., p. 487-547. Du Bellay avait sans doute travaillé sur un manuscrit procuré par l'auteur, la plaquette du De initiatione sermo ne paraissant qu'en 1560, chez Morel, alors qu'en automne 1559 il avait déjà presque achevé son travail.

202 Nous avons reparcouru les rapports entre le poète et la princesse ailleurs, par ex. dans notre " "Le ali del pensiero"...», art. cit.

203 Voir R. Gorris Camos, "Le lys et la croix" : constellations familiales ...", art. cit. 
rons-nous disciples du Christ, si aucune image de Lui n'est exprimée en nous ? »204. Cette invocation à la justice, à la clémence, qui « est le propre des rois » devait beaucoup plaire à la duchesse qui en fera son emblème en défendant tous ses sujets (y compris Vaudois, réformés et juifs) ${ }^{205}$, en accueillant les persécutés et bannis de tous bords. Cette théorie du «juste milieu» dont elle fera son mot d'ordre, la prudence et ce regard tourné en arrière vers son père et son grand-père ne pouvaient que toucher profondément la duchesse, qui est d'ailleurs évoquée par Du Bellay au v. 309, «à ta tante», et par L'Hospital, v. $259^{206}$.

Michel peint ici son visage, serein, tranquille et confiant: «la grâce et la bienveillance de ton visage [...] dès que je te vois, je suis plus heureux que les oiseaux qui s'élancent hors du fleuve où ils se baignaient et étendent au soleil leurs ailes humides pour les sécher sur la rive ${ }^{207}$. Il reconstruit à travers une série de blasons cet être

204 V, 8, 18-19, édité dans Petris, La Plume et la tribune, p. 337 et trad. p. 352. Voir Du Bellay, Discours, éd. cit., p. 172, v. 19-20. Voir aussi R. Repetti, L'educazione di un "Re fanciullo". Michel de l'Hospital e la consacrazione di Francesco II, Gênes, ECIG, 1990 (2e éd. 1995).

205 Voir R. Gorris Camos, Princesse des frontières, op. cit., passim et pour ses rapports avec les auteurs juifs qui lui dédient de très beaux poèmes en hébreu et en araméen, voir aussi ead., "Vanitas vanitatum": tradurre e commentare il Qohèlet all'ombra di Margherita di Francia, duchessa di Savoia", dans Sconfinamenti. Omaggio a Davide Bigalli, Milan, Bietti, 2013, p. 185-196.

206 Les rapports entre Marguerite et ses neveux étaient très étroits. Voir l'épître IX, 36 où elle évoque souvent François II qui joue, les baisers qu'elle voudrait donner aux enfants de son frère: "je donnerois mille et mille baisers, à cellui qui doit porter une si belle couronne et aux autres». Voir aussi les lettres conservées à la BNF, Nafr. 1234, fol. 192ro-193ro, François II à Marguerite, 3 juillet 1560, Saint-Léger, «Ma tante je suis merveilleusement ayse ... »; BNF, Nafr. 1234, fol. 243vo $-244 \mathrm{r}^{\mathrm{o}}$, François II à Marguerite, 31 août 1560, Fontainebleau, "Ma tante je ne vous feray point de redict ... »; BNF, fr. 4673, fol. 19, Henri d'Angoulême à Marguerite, 25 juin 1567, Paris, « Madame j'ay receu la lettre ...»; fol. 24ro , minute d'une lettre de mai 1567 de Jean de Morel à Marguerite; fol. 27ro, Marguerite à Henri d'Angoulême, 9 juillet 1567, Turin, «Mon neveu j'ay receu les honestes lettres... »; fol. 29, de la même au même, 1567, «Mon frere en desirant l'advancement...». Nous remercions Loris Petris pour son aide précieuse.

207 L'Hospital, Poésies complètes, p. 242 ; Carmina, t. III, p. 299 (III, 15, 21-23). 
aimé, son visage, la main, ses yeux, son regard, le sourire ${ }^{208}$; il tisse et peint, au fil des épîtres, le portrait de la princesse aux yeux tristes pour remplir le vide de ce Sine te. L'épître lui permet de parler avec l'autre qui est absente, de raconter à l'autre, cominus eminus, qui est loin mais qui est proche, des fragments de vie publique et privée.

Marguerite est partout non seulement dans les Épîtres qu'il lui adresse, dans leurs lettres, mais en filigrane dans une constellation de textes qui parlent d'elle et de ses proches, du long voyage $(\mathrm{V}, 9$ Iter Nicaeum), de ses études et de ses livres (I, 5), de ses larmes (Catti, le départ), de sa maison, de son enfant et de ses cadeaux innombrables (la dot de sa fille, des charges, des vases, des médailles...), mais surtout de son affection. Affectus plena.

Michel continue à être celui «che tien cura di tutti i negotii di lei », celui qui s'occupe de ses affaires ainsi qu'en témoigne la lettre du 15 août 1568, dont le porteur est Batisse, son maître d'hôtel à Turin : à propos de la question des offices, Marguerite lui demande de «tenir la main comme vous avez accoustumé de le faire en tout ce qui me touche ${ }^{209}$ mais elle nous révèle que le chancelier continue à lui prodiguer ses conseils sur la gestion financière de sa maison et à se réjouir « du bon ordre que j'ay donné à ma maison afin que ma despense ne surpasse poinct la recepte de mes finances ${ }^{210}$. Elle lui promet d'être «bonne mesnagere» (sa générosité envers les membres de sa maison était bien connue) et de suivre ses conseils, "comme s'il m'estoit donné de mon propre pere », phrase qu'elle ajoute de sa main.

\section{LE FLEUVE ET LE LIERRE}

Fragments d'un discours autobiographique, mais aussi autofictif, les épîtres de Michel à Marguerite tracent l'itinéraire d'une amitié et d'une connivence spirituelle profondes entre deux êtres dont le mouvement intérieur est constamment dirigé l'un vers l'autre. Ils partagent non seulement les mêmes idéaux religieux

\footnotetext{
208 Id., p. 197 et 248.

209 L'Hospital, Discours et correspondance, p. 227.

210 Ibid.
} 
et politiques, cet évangélisme civil ${ }^{211}$ qui oriente leur action et leur existence, mais aussi des traits de caractère. Marguerite est timide et Michel l'est également, ainsi qu'il lui écrit en II, 8 pour lui expliquer ce qui l'arrête devant sa porte, ce seuil qu'il n'ose franchir:

Qu'est-ce donc qui m'arrêtait quand je voulais entrer? Une timidité que je tiens de la nature et que la réflexion est encore venue augmenter (comme nous aimons à justifier nos défauts). C'est elle qui me paralyse en présence du roi, et qui ferme mes oreilles aux divers avis qu'on me donne; pourtant les rois apprécient davantage les ambitions remuantes et ne songent qu'à ce qu'ils voient, sans s'inquiéter du passé ou de l'avenir ${ }^{212}$.

Ils ont en commun leur solitude, leur marginalité, Michel en tant que poète-magistrat au statut ambigu, Marguerite en tant que princesse étrangère régnant sur une cour française où l'on cultive la dissidence ${ }^{213}$ comme une fleur rare, une cour-île, entourée de soupçons et qui sera démantelée après sa mort. L'épître IX, 36 dans laquelle elle parle à la première personne («C'est elle qui parle») pour dire son être-otage de l'histoire (le mot revient deux fois): «Je suis le sceau et l'otage», «sa vie en otage», ses regrets de quitter sa famille, son frère, sa comme-soeur Catherine, leurs promenades et leurs conversations en litière, ses petits neveux tant aimés, François II «qu'on voit jouer à votre cour», son Pays et ses fleuves, Paris, ses poètes dont la «séparation [lui] semble affreuse ${ }^{214}$, ces pauvres exilés et bannis qu'elle protégeait, ses

211 Petris, La Plume et la tribune, p. 94.

212 L'Hospital, Poésies complètes, p. 65 ; Carmina, t. II, p. 39 (II, 2, 13-24).

213 Voir R. Gorris Camos, " "Sotto un manto di gigli di Francia"... », art. cit.

214 Voir P. de Ronsard, Discours à tresillustre et vertueux prince. Philebert de Savoye, et de Piemont, dans Ronsard, OC, t. II, p. $64 \mathrm{sq}$. : «Tu as aussi comme par destinée / La Sœur du Roy pour espouse emmenée» et surtout le Chant Pastoral, t. II, p. 198, v. 158-159: «ceste Nymphe à la fin il osa / Ravir au dos, l'emportant en Savoye». Du Bellay considère ce départ comme un «desastre» (Lettre du mesme autheur à un sien amy sur la mort du feu Roy et le departement de madame de Savoye) qui l'a «tellement estonné et fait perdre le cœur, que je suis deliberé de jamais plus ne retenter la fortune de la court, m'ayant, nescio quo fato, esté jusques icy tousjours si marastre et cruelle... ». Elle était pour lui «l'unique support et refuge de la vertu, et de ceux qui en font 
larmes, et ses craintes (les montagnes, la neige, les frimas, l'hiver), le regret de sa liberté perdue («m'ôte la liberté, et me fait partir pour les États étrangers »). Cette épître, très proche du noir Epithalame marotique pour Renée, ouvre les coulisses et semble révéler les enjeux de ce «mariage de la paix » qui se condensent dans cette phrase: «J'obéis». L'image du lierre est paradigmatique de leur lien indestructible: «Le lierre, aimable Reine, ne s'attacheroit pas plus fortement à l'arbre, son appui, que moi à votre col d'albâtre $»^{215}$.

Dans son Testamentum daté du 13 mars 1573, magnifique message de vertu et de charité, Michel évoque un don de Marguerite qui devait lui être particulièrement cher:

Je veulx que toutes mes medalles de cuivre, marbre, et aussy les monnoyes d'antiquaille d'or et d'argent et autre matiere, soient gardées en ma maison par indivis, à la discretion de ma femme, et quatre beaux vazes, ouvrage d'Allemaigne, et cette medalle de taureau que madame ma maitresse m'a donné ${ }^{216}$.

Marguerite et son comme-père partagent cette «relligion» ou «inspiration evangelique», une religion où la vertu de l'amicitiacaritas joue un rôle fondamental ${ }^{217}$. Les épîtres du chancelier à Marguerite et ce qu'il reste de leurs lettres ${ }^{218}$ sont des exemples de fraternité et de tendresse, des éléments d'une communication qui ne doit pas être interrompue, un exercice d'écriture qui défie

profession» (O. poét., éd. Chamard, t. VI, p. 99-100). Sur Ronsard et Marguerite, voir F. Rouget, «Ronsard et le mécénat de Marguerite de Savoie », dans Mecenati, artisti e pubblico nel Rinascimento, Actes du XXIe Colloque International de Pienza-Chianciano Terme, 20-23 juillet 2010, Florence, Cesati, 2011, p. 245-254.

215 J.-M.-L. Coupé, Essai de traduction de quelques épîtres et autres poésies latines de Michel de L'Hospital, Paris, Moutard, 1778, t. II, p. 260 («Non hederae foliis arbor magis ulla teneret / Quam manibus, Regina, meis tua candida colla»).

216 Discours et correspondance, p. 284 (trad. Brantôme).

217 «Vous qu'une amitié sincere, étayée sur la vertu, m’unit d'un indissoluble nœud» IX, 29 Ad Morellas, p. 432-433. L'amitié-charité est une expérience de fusion des âmes, métaphysique. L'amitié implique une gratuité, une réciprocité basée sur l'estime et les services. Voir Crouzet, «Les devoirs de l'amitié», dans La Sagesse et le malheur, p. 292 sq.

218 Voir Discours et Correspondance, n. 47, p. 215, n. 56, p. 225-226, n. 57, p. 227-228, n. 81, p. $270-271$. 
l'éloignement physique et le temps qui passe ${ }^{219}$. Elles sont aussi les pièces d'une mosaïque qui, au fil des épîtres, compose l'autoportrait de leur auteur ainsi que le portrait, en miroir, de son alter ego. Cette constellation d'épîtres est le fruit d'une écriture humaniste en action visant non seulement des objectifs éthiques, mimétiques, affectifs, allégoriques, narratifs, mais aussi une durée qui une fois encore défie le temps et l'espace et se prolonge dans l'éternité. Il s'agit d'un processus qui va bien au-delà de la rhétorique de l'éloge, d'une «opération clientélaire de dédicace » : elle est un défi au temps, à l'espace, à la mort ${ }^{220}$. La mort n'y mord.

Michel est et restera pour elle « celuy que j'ayme, honore et estime comme mon pere et milieur ami». Elle fera bâtir pour lui un mausolée et elle le suivra l'année suivante, le 15 septembre 1574, en écrivant, juste avant sa mort, une lettre touchante, où elle $s^{\prime}$ inquiète des siens ${ }^{221}$ et pour devenir, ainsi que la constellation de tombeaux le dit et le redit: « ange» (B. Tasse) « revetu de si heroique charité » qui a «favorisé les exilans et bannis pour le service de Dieu et de sa parole», Reine de Saba (pour les poètes juifs) et vierge au livre pour Ronsard («son cœur elle addonnoit au livre, / À la science, à ce qui fait revivre / L'homme au tombeau») $)^{222}$. Michel aurait aimé son épitaphe: «Ici gyt la vertu» (Del Bene).

Si tout avait commencé sur le Pô en tempête, sur ce fleuve où Michel prend conscience de son être, tout avait continué par ce long voyage allégorique, entre vents et tempêtes et tout finissait sur les bords de ce fleuve et dans la ville dont l'emblème est ce Taureau que Marguerite lui avait donné.

Rosanna GORRIS CAMOS Université de Vérone

219 Voir l'épître que Michel écrit, après la Saint-Barthélemy, à la demande de Marguerite via Del Bene, où pour ses cheveux blancs, il se compare à Laërte (L'Hospital, Poésies complètes, p. 363-369).

220 Crouzet, La Sagesse et le malheur, p. 294.

221 Turin, ASTO, Corte Real casa, Matrimoni, mazzo 19, n. 10.

222 Ronsard, Discours à tresillustre et vertueux Prince, Philebert duc de Savoye, et de Piemont, dans OC, t. II, p. 70, v. 267-269. 
过

ํํำ

.

큼

국

(2)

(1)

甲

(8) 


\section{MICHEL DE L'HOSPITAL ET JEAN-ANTOINE DE BAÏF}

Pourquoi Jean-Antoine de Baif ne nomme-t-il pas Michel de L'Hospital dans son œuvre, alors qu'il a immortalisé le mariage de sa fille unique Madeleine et qu'il a été son premier traducteur en français? Tel pourrait être la petite énigme à laquelle ce travail tentera de répondre. Mais c'est loin d'être la seule interrogation que soulèvent les relations éphémères entre les deux hommes. En fait, elles ne sont documentées que pour une seule année (du début 1557 au début 1558) et n'inspirent que deux poèmes de Baï. Je ne sache pas que L'Hospital ait pour sa part jamais mentionné Baiff dans un texte.

Après avoir rappelé d'abord les premières occasions de rencontre entre nos deux héros, mon objectif sera de présenter les pièces de Baïf que l'on peut lire dans le volume des Neuf livres des Poemes ${ }^{1}$ et de poser quelques questions à leur sujet, tout en me demandant dans quelle mesure elles peuvent apporter à la connaissance ou à la compréhension de la vie et l'œuvre de L'Hospital.

\section{DE POSSIBLES RENCONTRES DURANT L'ENFANCE ET LA JEUNESSE DE BAÏF}

Malgré leur notable différence d'âge (L'Hospital est probablement né en $1505^{2}$, Baïf en 1532), les deux hommes sont issus d'un

1 Voir J.-A. de Baïf, Neuf Livres des Poemes, éd. G. Demerson, P. Galand-Hallyn, A.-P. Pouey-Mounou, D. Ménager et J. Vignes, dans CEuvres complètes, dir. J. Vignes, t. I, Paris, Champion, 2002, III, 3, «Remonstrance...», p. 240-244 et VII, 9, «Epithalame», p. 424-429. Désormais abrégé en OC I.

2 Petris, La Plume et la tribune, p. 3. 
milieu comparable et fréquentent peu ou prou la même société : celle des serviteurs de François I ${ }^{\text {er }}$ issus de la noblesse lettrée, nourris de culture humaniste et ouverts aux idées érasmiennes et évangéliques. En somme, Michel et Jean-Antoine étaient voués à se croiser et on peut imaginer la possibilité de premières rencontres qui n'ont pas laissé de trace.

Au moment de la naissance de Baï, Michel de L'Hospital étudie à Padoue et nous savons qu'il fréquente à Venise l'ambassadeur de François I ${ }^{\mathrm{er}}$, l'humaniste Lazare de Baïf ${ }^{3}$. C'est justement pendant ce séjour vénitien que Lazare engendre, d'une mère inconnue, le futur poète qui nous occupe. On ne peut exclure, mais c'est une pure supposition, que le jeune L'Hospital, alors âgé de 27 ans environ, a appris la naissance de cet enfant et l'étrange projet de Lazare de remmener en France ce bébé pour l'élever ! ${ }^{4}$ Ira-t-on jusqu'à imaginer Lazare présentant fièrement son rejeton à Michel, et jusqu'à supposer que le bambin lui aurait fait risette?

Second épisode: entré au parlement de Paris (1534), L'Hospital épouse en 1537 Marie Morin, fille de Jean Morin, lieutenant criminel au Châtelet. Selon Loris Petris, elle apporte en dot « une charge de conseiller clerc au parlement de Paris, ce qui accélère l'ascension de L'Hospital $»^{5}$, mais non sans difficultés, car la charge en question est en fait occupée... par Lazare de Baï! Lazare vient d'être nommé maître des requêtes en remplacement de René Ragueneau, suspendu par le Parlement suite à une accusation pour faux en écriture... Mais l'office qu'occupe Ragueneau n'est pas immédiatement vacant pour autant et Lazare reste conseiller en attendant que le poste se libère effectivement quelques mois plus tard. Ici les intérêts de carrière et les attentes de Michel et de Lazare se rejoignent et on peut imaginer leur impatience partagée: plus tôt Ragueneau sera démis de ses fonctions, plus tôt Lazare accèdera enfin à la charge de maître des requêtes et pourra par conséquent céder sa charge de conseiller à L'Hospital! Ce bref épisode de l'été 1537 aura pu rapprocher les deux hommes, successeur l'un de l'autre.

3 Petris, La Plume et la tribune, p. 5.

4 On connaît les vers de Baîf à ce sujet: «Moy chetif enfantelet tendre, / Ce croyje, encore emmailloté, / En des paniers je fus osté, / Pour dur à tout ennuy me rendre / Hors la maternelle Cité [...]. »(Poemes, IV, 8, v. 33-37; OC I p. 289).

5 Petris, La Plume et la tribune, p. 7. 
En visite chez Lazare, visite d'affaire ou de courtoisie, a-t-on présenté à Michel la fierté de la maison de la rue des Bernardins, le studieux Jean-Antoine, abreuvé «dès le berceau [...] au greclatin ruisseau $»^{6}$ ? A-t-il pu admirer les progrès du petit prodige sachant déjà "prononcer le langage Romain [...] de mode non barbare» sous la gouverne de son précepteur Charles Estienne et même calligraphier «l'écriture Grécque » à l'imitation d'Ange Vergèce ?7

Quoi qu'il en soit, cette éducation porte ses fruits et JeanAntoine, confié aux bons soins de Jean Dorat, devient bientôt le condisciple de Ronsard et de Du Bellay, et s'initie avec eux à la poésie française. Il est notable que le premier texte publié par Baïf, selon ses propres dires ${ }^{8}$, célèbre la Paix d'Outreau signée en 1549, mais aussi les poètes voués à chanter le triomphe d'Henri II:

Le hautain luc à Ronsard, de sa gloire

Ne téra pas la bruiante mémoire.

Ne du Bellay, ne Mellin'.

Dans ces vers, Baîf n'oppose pas les générations comme Du Bellay dans La Deffence et illustration de la langue françoyse; il associe au contraire dans un même hommage les poètes de la nouvelle école et leur aîné Mellin de Saint-Gelais; par la suite il restera fidèle à l'un comme aux autres. On est bien loin du ton arrogant et agressif qui déclenchera la querelle que l'on sait entre Saint-Gelais et Ronsard, querelle dans laquelle Baïf se gardera de prendre parti. Cette attitude paisible de Baif annonce ainsi celle de L'Hospital, qui se fera comme on sait, en décembre 1552, l'apôtre de la réconciliation entre Ronsard et Saint-Gelais ${ }^{10}$.

Mentionnons encore au début des années 1550 la présence du jeune Baïf dans l'entourage de Jean de Morel $^{11}$, où il pourra

OC I, p. 472 , v. 99-100.

OC I, p. 105, v. 77-84.

8 «De mes écris le premier que jamais / Je mis au jour» (OC I, p. 469, v. 3-4).

9 OC I, p. 472, v. 95-97.

10 Petris, La Plume et la tribune, p. 515-519.

11 Jean de Morel, seigneur de Grigny (1511-1581), ancien élève d'Érasme, très lié à la Pléiade comme à Michel de L'Hospital. Baïf lui rendra encore un discret hommage dans les Etrenes ( « À Mgr le Grand Prieur »), avant d'offrir une pièce latine pour son tombeau en 1583 (BEF, no 125). Sur Morel, voir P. de Nolhac, 
presque à coup sûr croiser L'Hospital. Loris Petris a bien retracé les liens étroits entre L'Hospital et la famille Morel, qui le présente avant 1547 à la princesse Marguerite de France ${ }^{12}$. Tout ce milieu partage les idées évangéliques de Marguerite de Navarre et lui voue un grand respect. Quand elle décède en 1549, Baïf est associé au premier tombeau latin de la reine (son épigramme grecque en hommage aux sœurs Seymour apparaît dès l'édition latine de $\mathrm{l}^{\prime}$ Hecatodistichon) ${ }^{13}$. Dans l'édition française du Tombeau de Marguerite de Valois Royne de Navarre, parue en mars ou avril $1551^{14}$ (Paris, Michel Fezandat et Robert Granjon, 1551), de nouvelles pièces de Baï, traduites des distiques des sœurs Seymour, voisinent avec les traductions des mêmes vers par Antoinette de Loynes, l'épouse de Morel. Manifestement les distiques en question ont inspiré une sorte de concours de traduction, auquel Baïf et l'épouse de Morel (entre autres) ont été associés. Tout se passe comme si le tombeau était l'œuvre du salon Morel où fréquente L'Hospital, qui aura pu, à cette occasion, remarquer les talents de traducteur du jeune Baiif. L'Hospital est d'ailleurs le dédicataire de l'une des pièces de Morel incluses dans le Tombeau ${ }^{15}$.

Ronsard et l'humanisme, Paris, Champion, 1921, p. 170-177; R. Cooper, Litterae in tempore belli, Genève, Droz, 1997, p. 116-145; L'Hospital, Carmina, t. III, p. 52-56.

12 Petris, La Plume et la tribune, p. 11.

13 Annae, Margaritae, Janae, Sororum virginum, heroidum Anglarum, In mortem Divae Margaritae Valesiae, Navarrorum Reginae, Hecatodistichon [...], Paris, R. et C. Chaudière, 1550, fol. civ ${ }^{\circ}$ et ss. Voir ce poème de Dorat dans ses Poematia, Odarum Liber I, p. 187, ou dans Odes latines, éd. G. Demerson, ClermontFerrand, FLSH, 1979, ode VI, p. 283-284.

14 Sur ces deux tombeaux de Marguerite de Navarre, voir G. Demerson, Dorat en son temps, p. 33, 79, 126-128; D. Ménager, «Voix d'homme/voix de femme: les deux Tombeaux de Marguerite de Navarre», dans Poétique et narration. Mélanges offerts à Guy Demerson, éd. F. Marotin et J.-Ph. Saint-Gérand, Paris, Champion, 1993, p. 129-141; J. Lecointe, «L'idole de la Reine: les rapports entre Marguerite de Navarre et la Pléiade, d'après le Tombeau de Marguerite de Valois (1551) », dans Les Fruits de la saison. Mélanges André Gendre, éd. P. Terrier, L. Petris, et M.-J. Liengme Bessire, Genève, Droz, 2000, p. 95-103 ; F. Rouget, «Entre l'offrande chrétienne et le don poétique: les Tombeaux latins et français de Marguerite de Navarre, (1550-1551)», BHR, 62 (2000), p. 625-636.

15 Petris, La Plume et la tribune, p. 468, n. 235. 


\section{LES NOCES DE MADELEINE DE L'HOSPITAL ET DE ROBERT HURAULT}

C'est précisément à la demande de Jean de Morel que Baï va être invité à la fin de 1556 ou au début de $1557^{16}$ à composer un épithalame assorti de musique pour les noces de Robert Hurault, conseiller au grand conseil, et de Madeleine de L'Hospital, la fille aînée de Michel. C'est la première preuve indiscutable d'une rencontre entre nos deux héros, mais aussi, notons-le, la première réalisation concrète avérée de Baïf en matière d'union de la poésie et de la musique. Tout cela mérite que l'on s'y arrête.

Rappelons d'abord que Madeleine, née le 5 mars 1539, était la fille aînée et en quelque sorte la fille unique de Michel de L'Hospital (puisque ses deux sœurs cadettes, Jeanne et Charlotte, nées respectivement en 1541 et 1542, n'avaient pas vécu). Le texte de Baïf désigne d'ailleurs Madeleine comme fille unique (v. 57). Michel, âgé de plus de cinquante ans à la date du mariage, avait très probablement renoncé à avoir d'autre héritier. Il s'agissait donc pour lui d'un mariage important, qu'il avait préparé de longue date et avec le plus grand soin. De 1554 à 1556, il sollicite le cardinal de Lorraine ${ }^{17}$ puis Marguerite de France, dont il réussit non sans peine à obtenir une dot pour sa fille ${ }^{18}$.

Autre difficulté, le choix du mari: Michel avait d'abord espéré donner la main de sa fille à Guy Du Faur de Pibrac, neveu de son ami et condisciple Jacques Du Faur, futur auteur des fameux Quatrains. Mais Madeleine et sa mère, de confession réformée,

16 Selon Dupré-Lasale, «Ce mariage fut nécessairement postérieur au 17 juillet 1556, date de la réception de Dauvet. Il fut antérieur au mois d'août 1557, puisque le premier enfant des nouveaux époux naquit en mai 1558. » (DL, t. II, p. 84).

17 Voir Carmina, II, 9 Ad Illustriss. principem Carolum Card. Lothar., t. II, p. 172-182.

18 Il la remercie dans Carmina, V, 3. Voir aussi BNF, fr. 5128, fol. 351 (3 nov. 1554), cité dans DL, t. II, p. 71-99 (p. 73), et Petris, La Plume et la tribune, p. 14-15, note 102. Dupré-Lasale résume ainsi l'affaire: «Les mentions des registres complétées par l'épître à Marguerite révèlent ce qui s'était passé. L'Hospital avait promesse d'un office dont le prix devait servir à doter sa fille. La duchesse de Berry lui fit donner celui de Potier. À la vérité, Potier l'avait déjà résigné en faveur de Dauvet». Après un imbroglio juridique, ce dernier «obtint de conserver la charge, à condition de payer à L'Hospital l'indemnité stipulée au profit du cédant. La dot de Madeleine fut ainsi constituée». 
s'opposèrent à ce projet, Pibrac étant catholique. Michel se laissa convaincre et accepta de marier sa fille avec un jeune protestant, Robert Hurault de Belesbat, conseiller au Grand Conseil depuis 1554, à la condition toutefois que les enfants nés de cette union joindraient à leur nom celui de L'Hospital ${ }^{19}$.

Le mariage que Baif accepte d'illustrer est donc une noce protestante, ce qui ne l'empêche pas de produire un texte à peu près dénué de toute référence chrétienne, et marqué au contraire de l'empreinte du paganisme affirmé de la jeune Pléiade, dans le droit fil de la fameuse "Ode à Michel de L'Hospital, chancelier de Madame Marguerite» de Ronsard ${ }^{20}$, qui mettait en scène les divinités de l'Olympe et les Muses, et qui avait fait l'objet dès 1553 d'une mise en musique par Claude Goudimel, publiée dans le «supplément musical des Amours ».

Il est probable que le poème de Baïf aura été interprété dans le cadre du banquet suivant le mariage (peut-être dans le salon de Morel commanditaire de la pièce). Quoi qu'il en soit, Baïf imagine là une sorte de "pompe» à l'antique qui n'est pas sans rappeler, plus modestement, la fameuse «pompe du bouc » qu'il avait organisée pour le succès de la Cléopâtre captive de Jodelle en 1553. Dans un cas comme dans l'autre, il s'agit de tenter de faire revivre l'esprit et les formes des célébrations antiques, dans une performance collective associant poésie, musique et danse en costume.

Un autre aspect remarquable du texte est son caractère polyphonique: idéalement, le poème semble conçu pour être déclamé et/ou chanté à douze voix (trois voix d'homme et neuf voix de femmes). J'en décrirai rapidement la structure relativement complexe. Le texte se compose de 27 septains d'octosyllabes rimés $a B a B c c B$. La première strophe (v. 1-7), adressée à Morel, est une addition tardive qui sert de dédicace et sur laquelle nous reviendrons en détail. L'épithalame proprement dit commence par une sorte de prologue qui décrit en six strophes l'entrée en scène de la bande des Muses, conduites par Hyménée et Apollon, puis annonce le chant qu'elles réservent à Madeleine qui est pour elles comme une sœur (v. 8-49). De façon amusante, comme dans

\footnotetext{
19 Voir H. Amphoux, Michel de L'Hospital et la liberté de conscience au XVI siècle, Paris, Fischbacher, 1900, p. 45 ; et surtout DL, t. II, p. 73-99.

20 Ronsard, Cinquième Livre des Odes, Paris, 1553, ode VIII (Lm, t. III, p. 118-163).
} 
un prologue de comédie, le maître de cérémonie décrit en vers, en direct, les préparatifs du petit spectacle:

Chacun à chanter se dispose :

Elles chanteront quelque chose

Qui doit estre de grand valeur.

Apollon qui mene la dance,

Leur frere, leur guide et leur chef,

Leur fait signe que l'on commance,

Branlant le Lorier de son chef:

Premier sa chanson il va dire... (v. 40-47)

On peut se demander si cette rêverie mythologique est purement fictive et imaginaire, ou si ces vers sont au contraire la trace d'une mise en scène effectivement réalisée le jour du mariage.

La suite est constituée des chants proprement dits: chaque dieu prononce une strophe adressée aux époux. Apollon fait l'éloge de leur fidélité. Les neuf Muses chantent tour à tour (dans l'ordre défini par la Théogonie d'Hésiode, v. 75-79)21 : Clio célèbre les parents de Madeleine (l'éloge de Michel est rapide et banal mais chaleureux / chaleureux mais rapide et banal: «Fille sage d'un sage père, / Qui est de vertu le soutien », v. 59-60) ${ }^{22}$ et elle encourage la jeune fille à se laisser «doucement estreindre»; Euterpe rappelle la rumeur d'une brouille survenue entre les fiancés mais qui n'est plus qu'un mauvais souvenir; Thalie souligne l'envie que peuvent inspirer les époux; Melpomène évoque la fin des «ennuis» de Hurault; Terpsichore vante les qualités de musicienne de Madeleine et la «douce armonie» de

21 Le procédé consistant à donner la parole successivement à chacune des Muses rappelle Guillaume Crétin, «Plainte sur le trespas du saige et vertueux Chevallier, feu de bonne mémoire messire Guillaume de Byssipat, en son vivant seigneur de Hanaches, Viconte de Falayse et l'ung des gentilz hommes de l'ostel du tres victorieux Roy Loys XII e de ce nom ", dans CEuvres poétiques, éd. K. Chesney, Paris, Droz, 1932 ; Genève, Slatkine Reprints, 1977, p. 73-93. Les Muses y prononcent chacune un rondeau, dans le même ordre que chez Baï; leurs interventions sont séparées par un neuvain de «L'Acteur». Je remercie Nathalie Dauvois pour ce rapprochement.

22 Par comparaison, l'éloge du père de la mariée est beaucoup plus développé dans l'autre épithalame de Baïf que nous conservent les Poemes: « Epithalame. À Monsieur d'Asserac Seigneur de la Feuillée » (OC I, p. 393-396). 
son luth ${ }^{23}$; Eraton encourage les époux à se livrer à d'innombrables jeux érotiques pour procréer avant la fin de l'année; Polymnie loue Henri II, Charles de Lorraine, la Reine et Marguerite de France (respectivement assimilés à Jupiter, Phébus, Junon et Pallas), qui ont «saintement autorisé» le mariage; Ouranie loue l'horoscope favorable de cette union; Calliope salue l'arrivée de l'Aube. Enfin Hyménée met fin au concert en encourageant Hurault et Madeleine au plaisir (v. 50-126).

Puis la divine bande disparaît avec la nuit (v. 127-140) et le maître de cérémonie reprend la parole pour neuf strophes, en multipliant les présages favorables, puisque «Dieu fait que là tout bien prospère » (v. 148). Il annonce à Hurault une carrière de courtisan («La faveur des grans tu suivras », v. 156) et le peint en ambitieux («cherchant, pour mieux apparoistre, / En biens et grans honeurs de croistre», v. 159-160). Il promet surtout à Hurault un fils qui lui ressemblera (v. 167-175). Baïf s'attarde plaisamment sur ce point: un tableau touchant illustre ce lyrisme familial dont Perrine Galand a identifié l'importance dans la poésie humaniste de l'époque ${ }^{24}$ : on y retrouve cet «ingenium de la tendresse », d'inspiration à la fois catullienne (au plan esthétique) et érasmienne (au plan éthique et spirituel), qu'avaient exploité en France Germain de Brie et surtout Jean Salmon Macrin. Comme l'a souligné notre amie, loin de se tarir à l'époque de la Pléiade, cette veine intimiste reste très appréciée après 1550 dans le milieu des parlementaires gallicans, notamment dans l'entourage du couple Morel. Du Bellay, dans une élégie latine peu antérieure à l'épithalame de Baïf, adressait à Morel une pièce où il chantait le bonheur familial dont le privait son exil romain ${ }^{25}$. Plus tard, c'est L'Hospital lui-même qui célèbrera en vers latins les filles de Morel (IX, 29 Ad Morellas) ou vantera, dans une longue épître au

\footnotetext{
23 L'Hospital raconte lui-même que, lorsqu'il revenait triste et fatigué d'une audience, il aimait à se délasser en écoutant chanter Madeleine, s'accompagnant d'un luth (Carmina, III, 11, 98-99; t. III, p. 218-219).

24 Voir P. Galand-Hallyn, "L'ode latine comme genre "tempéré" : le lyrisme familial de Macrin dans les Hymnes de 1537 », Humanistica Lovaniensia, 50 (2001), p. 221-265; «Un aspect de la poésie latine dans la France de la Renaissance: le "lyrisme" familial ", Actes des quatrièmes rencontres classiques de l'Université de Paris XII-Créteil, Chloé, 4 (2002), p. 25-40.

25 Elegiae, V, dans Joachim Du Bellay, CEuvres poétiques, t. VII, CEuvres latines: Poemata, éd. G. Demerson, Paris, Nizet, 1984, p. 56-59.
} 
même Morel, les vertus de l'allaitement maternel (III, 2). À ce corpus néo-latin révélé par les travaux de Perrine Galand, il faut donc ajouter quelques pièces françaises de Baïf, dont cet épithalame est l'une des plus représentatives, ne serait-ce que par le milieu spécifique pour lequel il est composé.

Comme devraient l'indiquer les notes de notre édition (que l'on corrigera sur ce point), toute la fin de la pièce procède en fait de l'amplification d'un extrait du Carmen LXI de Catulle connu sous le titre d'Epithalame de Julie et de Manlius (v. 216-225). Un esprit chagrin pourrait reprocher à Baïf une imitation un peu « servile » $d^{\prime}$ un modèle qu'il n'a pas su ou pas voulu «contaminer»; mais on peut aussi s'émerveiller de la façon dont les mots de Catulle lui permettent, en ce jour de fête, de peindre en français, devant la famille rassemblée pour la noce, un idéal de bonheur intime qui est très exactement celui qu'ambitionnent les amis auxquels il adresse ce texte:

Je veu voir peupler vostre race

D'un petit Huraut, dont la face

Les traits du pere monstrera.

Un chacun sans qu'il le conoisse,

Auquel il sera presenté,

Du premier coup le reconoisse,

Voyant Huraut representé :

Clairement son petit visage

Témoigne d'un vray témoignage

De sa mere la chasteté.

Luy d'entre les bras de sa mere

Alongera ses petis bras,

Voulant estre pris de son pere,

Qui ne l'en refusera pas:

L'enfant d'une levre mignarde

Déja leur rit: et les regarde,

Et leur donne cent mille ébas ${ }^{26}$.

Soigneusement mis en valeur (au prix d'une inversion par rapport au modèle catullien) ${ }^{27}$ avant la strophe ultime qui célèbre

26 Poemes, VII, 9, p. 429, v. 166-182.

27 En effet Baïf transpose successivement les v. 221-225 puis 216-220 du texte de Catulle. 
la «douce union amoureuse » de «consors bien-heureux» (v. 184185), le joli tableau de famille s'enrichit de notations personnelles discrètes qui en renforcent tant la qualité picturale que la charge affective: au geste (imaginé par Catulle) de l'enfant tendant les bras vers son père répond chez Baïf la réaction émue de celui-ci, le poète anticipant habilement le mouvement de tendresse réciproque du père. Quant au sourire mignard que le petit Torquatus de Catulle réservait à son seul père, il vise ici les deux parents : trois pronoms successifs (leur, les, leur) soulignent le lien qui s'établit entre l'enfant et la «couple heureuse » (v. 183) de ses parents, façon simple mais efficace de chanter l'unité du couple parental comblé se mirant tendrement dans sa progéniture ${ }^{28}$. Enfin Baïf semble jouer sur le nom de Robert Hurault de Belesbat en lui promettant «cens mille ébas » (v. 182)!

Il est remarquable en revanche que le nom «L'Hospital» n'apparaît pas dans le texte. Alors que le nouveau marié n'est désigné que par son nom de famille Hurault (v. 51, 121, 141, 155, $167,172)$, l'épouse n'est désignée que par son prénom Madeleine $(36,124,141,157)$. Je reviendrai pour finir sur une cause possible de ce silence.

Je conclurai provisoirement sur cet épithalame en commentant la strophe de dédicace qui l'introduit dans l'édition de 1573:

C'EST à toy, MOREL, que je vouë

Ce chant que tiras une fois

De ma Muse qui ces vers jouë

Au son des trombons et hauboys.

Si j'ay senty leur âme ingrate,

O bon MOREL (je ne t'en flate)

Premier trompé tu me trompoys.

Cette strophe difficile est riche d'information. Les premiers vers nous indiquent clairement que Morel est le commanditaire de la

28 Même souci chez Michel de L'Hospital lui-même dans son ode latine pour Anne d'Este composée peu après (Carmina, IX, 13 Ad Annam Estensem; l'ode célèbre en 1558 la naissance de l'un des fils d'Anne et de François de Guise): "Disce tu patrem puer atque matrem / Prosequi risu faciemque nosse / Et loquentum mollia verba », «Et toi, enfant, apprends à honorer ton père et ta mère / De ton sourire, à connaître leur visage / Et leurs mots tendres quand ils te parlent ». 
pièce; c'est probablement la preuve du rôle qu'il a joué pour rapprocher L'Hospital et Baï.

Baïf semble indiquer par ailleurs qu'il a lui-même «joué» ces vers «Au son des trombons et hauboys». C'est l'affirmation claire de la dimension musicale de la performance, mais qui pose beaucoup de questions sans réponses:

- une musique originale a-t-elle été composée, que nous avons perdue? Par qui ? De façon très hypothétique, peut-on hasarder le nom Claude Goudimel qui avait mis en musique l'ode de Ronsard pour L'Hospital et qui avait embrassé la Réforme protestante?

- faut-il imaginer que les vers de Baïf sont plutôt une sorte de contrafactum composé sur un timbre qu'il faudrait identifier ?29

- les vers étaient-ils chantés, et par qui? Les «trombons et hauboys » accompagnaient-ils les chanteurs, ou produisaient-ils plutôt une musique instrumentale entre les strophes? Le «trombon» notamment n'est pas en principe un instrument d'accompagnement. Le terme est d'ailleurs intéressant. Notre texte offre, si l'on en croit le TLF, la première attestation de ce mot en français, dès 1573: il s'agit d'un mot d'origine italienne (dérivé de trompone ou trombone) qui désigne un instrument de cuivre à coulisse, ce qu'on appelait jusqu'alors en français la « trompette saicqueboute» (c. 1488) ou sacqueboute, l'ancêtre du trombone moderne ${ }^{30}$.

29 Selon Martinon, Répertoire général de la strophe française depuis la Renaissance, Paris, Champion, 1911, p. 69, la strophe de Baif a plusieurs précédents chez Forcadel (Chant des Seraines) ou Magny (Gayetés, Amours et Odes), mais le schéma des rimes adopté par Baïf est original.

30 Selon F. Gétreau et C. Homo-Lechner (Guide la musique de la Renaissance, éd. F. Ferrand, Paris, Fayard, 2011, p. 255), le mot trombone «ne sera introduit en France qu'à la fin du XVIII siècle». D'autres situent son apparition au XVII ${ }^{\mathrm{e}}$ siècle et l'attribuent à Lully. On voit qu'il faut nuancer ces affirmations. Mais il est vrai que le terme courant au $\mathrm{XVI}^{\mathrm{e}}$ siècle est sacqueboute, attesté depuis 1466 (Pierre Michault, Doctrinal, X, 198, éd. Th. Walton, p. 16, cité par TLF). Olivier de La Marche mentionne la «trompette-saicqueboute» entonnée par un «haut menestrel» pour accompagner un motet aux noces de Charles le Téméraire en 1468 (Mémoires, III, iv, "S'ensuy le recit des nopces de Monseigneur de Bourgoingne et de Madame Marguerite d'York, seur du Roy d'Angleterre»). Johannes Tinctoris dans son De inventione et usu musicæ (entre 1483 à 1487) décrit un instrument de cuivre appelé tuba ductilis en latin, trompone en Italie, sacque-boute en France. Pierre de Brach associera à son tour «le son des hauts-bois et sacqueboutes, jouans le branle de Cupidon» (Les 
Enfin, le sens des vers 5-7 pose question ${ }^{31}$. En éditant le texte, Daniel Ménager et moi avions chacun notre interprétation entre lesquelles nous avons laissé le lecteur libre de choisir. Mon cher maître, attentif à la syntaxe, pensait que «leur âme ingrate» ne pouvait renvoyer qu'aux vers de Baïf mentionnés plus haut; il en déduisait cette lecture: «au moment de les publier, Baiff trouve ses vers ingrats, mais il a pour excuse la trop grande indulgence de Morel, qui l'a trompé à leur sujet». Pour ma part, j'observe que l'adjectif ingrat, fréquent chez Baïf, renvoie toujours chez lui à l'idée qu'il est mal récompensé de ses efforts; est ingrat celui qui «le prix de tels dons n'entend » (Poemes, II, 1, 33). Il me semble donc que ces vers comportent une anacoluthe et que «leur âme ingrate» vise les familles Hurault et L'Hospital : Baiff les accuse d'ingratitude parce que, malgré ce que lui avait annoncé Morel en toute bonne foi, il n'a jamais été rétribué pour sa participation aux noces. À travers ce détail, deux conceptions de la poésie se révèlent et s'opposent: si L'Hospital envisage la poésie comme un loisir et comme un moyen d'expression à la fois élégant et militant (ou parénétique), Baïf la conçoit aussi comme un métier et n'a pas honte de réclamer le salaire de ses vers.

\section{BAÏF TRADUCTEUR DES VERS DE L'HOSPITAL SUR LA PRISE DE CALAIS ET DE GUÎNES (1558)}

Au-delà du cercle de Morel, L'Hospital et Baïf sont amenés à se croiser dans un autre cercle, ou plutôt une clientèle, celle des Guises. Retraçant la carrière de L'Hospital, Loris Petris décrit les

Poemes de Pierre de Brach Bourdelois, divisés en trois livres, Bordeaux, Simon Millanges, 1576, «Masquarade du Triomphe de Diane, représentée en faveur de Mademoiselle Diane de Foix», fol. $\left.181 v^{\circ}\right)$. Quant à l'évolution technique de l'instrument, voir l'article Trombone du New Grove Dictionary of Music, éd. S. Sadie, Londres, Macmillan Publishers, 1980, t. 19, p. 166, et H. Vereecke, The Sixteenth-Century Trombone: Dimensions, Materials ans Techniques, Turnhout, Brepols, 2016.

31 Dupré-Lasale s'était lui aussi interrogé sur le sens de ces vers: "Quel était le motif d'une si longue rancune? Nous l'ignorons, et nous n'y attachons pas d'importance. Trop souvent une bagatelle excite la colère des poètes. » (DL, t. II, p. 89). Je retiens pour ma part l'idée de rancune, qui me semble juste; le mot «âme ingrate» ne suffit-il pas à suggérer le motif? 
années 1555-1560 comme celles de «l'ascension du client des Guises » ${ }^{32}$ : «les multiples poèmes latins que L'Hospital adresse [alors] aux Guises prouvent sa forte intégration à leur réseau de clientèle $»^{33}$. Mais la formule, on le sait, vaut aussi pour nombre de poètes français dans ces mêmes années: Lancelot de Carles, Mellin de Saint-Gelais, Dorat, Ronsard, Jodelle, et Baïf, qui, encouragé par Saint-Gelais, semble avoir dédié au cardinal de Lorraine un recueil d'églogues manuscrites. C'est Ronsard qui nous l'apprendra en 1558 dans son Hymne de Charles cardinal de Lorraine, où il évoque

[...] le docte Baïf, qui seul de noz Poëtes

A fait en ton honneur bourdonner ses Musettes,

Te sacrant ses pasteurs, que d'un gentil esprit

En France il a conduit des champs de Théocrit ${ }^{34}$.

Si ce recueil n’a hélas pas été conservé en l'état, les pièces qui le composaient n'ont pas pour autant disparu et nous en retrouvons les principaux éléments au sein du recueil XIX Eclogues dédié à Charles IX en 1572, dans le volume des Jeux ${ }^{35}$. L'analyse approfondie de cette collection imprimée permet de dater certaines pièces et d'identifier celles où se lit l'hommage de Baïf au puissant cardinal: "Charles» est nommé dans l'églogue IX; l'églogue XVI fait allusion à son château de Meudon; l'églogue XVII met en scène les encouragements du berger «Melin» (Saint-Gelais) à «Toinet» (double de Baïf) qu'il invite à solliciter «Charles». Surtout, l'églogue I («Au Roy») telle que nous la lisons aujourd'hui est très certainement une version (revue et corrigée en 1572 pour l'adapter à Charles IX) de la première dédicace à Charles de Lorraine $^{36}$.

Malgré la différence de génération, L'Hospital et Baïf sont donc engagés dans la même course à la reconnaissance: ils ont placé leurs espoirs dans la même puissante famille et leur « effort pour

32 Petris, La Plume et la tribune, p. 13.

33 Id., p. 15.

34 Plaquette publiée en 1559, Lm, IX, p. 69, v. 725-728.

35 J.-A. de Baïf, Les Jeux, vol. 1. XIX Eclogues, éd. J. Vignes, dans O. c. de J.-A. de Baif, dir. J. Vignes, t. III, Paris, Champion, 2016.

36 Voir Les Jeux, éd. cit., p. 49-52, et notes p. 150-156. 
s'élever passe par une entreprise poétique, encomiastique et éditoriale ${ }^{37}$. La seule différence est que le premier écrit en latin, tandis que le second privilégie le français. En 1557, toutes les conditions sont réunies pour que leurs trajectoires se rejoignent et puissent aboutir à une forme de collaboration poétique.

L'occasion qui va permettre aux talents de L'Hospital et de Baïf de se manifester conjointement est un double événement militaire un peu oublié aujourd'hui, mais qui fit grand bruit en son temps, et pour cause: quelques mois après la défaite cuisante de SaintQuentin (10 août 1557), dans une situation militaire qu'on pouvait croire désespérée, il marquait le redressement subit de la France dans sa lutte contre l'Angleterre. Dans les premières semaines du mois de janvier 1558, François de Lorraine, duc de Guise, reprend aux Anglais les villes de Calais (1-8 janvier) puis de Guînes (20 janvier), ce qui prive l'Angleterre de ses dernières bases sur le sol français. Cette reconquête suscita comme on sait un prodigieux enthousiasme ${ }^{38}$. Cette double victoire est célébrée dans de nombreuses plaquettes contemporaines, en prose ou en vers, tant en latin (Buchanan, Adrien Turnèbe, Léger du Chesne, Pierre Galland, Jean Dorat) qu'en français (par Belleau, Du Bellay, Magny et bien d'autres).

Compte tenu de ses liens avec la famille des Guises, Michel de L'Hospital ne pouvait que s'associer à ce concert d'éloges. Il avait déjà publié à l'automne sous les presses de Fédéric Morel une première plaquette célébrant comme un soulagement le retour de François de Lorraine au lendemain du désastre de Saint-Quentin $(\mathrm{IV}, 1)$. Il compose et publie rapidement une nouvelle pièce, De Caleti et Guinæ, oppidorum proximo hoc bello captorum, expugnatione, carmen longe doctissimum, cuius auctor is ipse est, qui et illius eruditiss. Epistolx ad Francisc. Guisiorum Principem, proxime a nobis editx,

37 Petris, La Plume et la tribune, p. 15.

38 Voir Antoine de Montaiglon, Recueil de Poésies françoises des XVe et XVI siècles morales, facétieuses, historiques, t. IV, Paris, P. Jannet, 1856, p. 284-325; V.L. Saulnier, «Deux œuvres inconnues de Jean Sève et une édition inconnue de Baïf», Bulletin du Bibliophile, 1949, p. 274-275; D.J. Hartley, «Les poètes français et la prise de Calais (janvier 1558)», BHR, 56 (1994), p. 19-28; J. Vignes, "Le Poète et la guerre: autour de la prise de Calais, 1558 », dans Cité des hommes, cité de Dieu, Mélanges Daniel Ménager, Genève, Droz, 2003, p. 207-218. 
Paris, F. Morel, $1558^{39}$. La pièce sera rééditée dans les Carmina, sous le titre De Caleti et Guinæ oppidorum expugnatione (IV, 2), juste après celle à laquelle le titre fait allusion, l'épître à François de Guise dont elle constitue en quelque sorte la suite.

La date du privilège (17 janvier 1557, ancien style) pourrait donner à penser que L'Hospital a composé la pièce en toute hâte, dès la réception de l'heureuse nouvelle. Mais comme l'a souligné ici même Michel Magnien ${ }^{40}$, il s'agit en réalité d'un privilège général de l'imprimeur Morel, qui ne vaut pas spécifiquement pour cette plaquette et ne nous renseigne donc pas sur la date de composition. Un meilleur indice de datation confirme toutefois la rapidité de la publication: une lettre de Giovanni Dalmatio, agent des Farnèse à la cour de France, datée du 18 février, nous indique que le texte de L'Hospital constitue l'un des premiers textes publiés sur le sujet, du moins parmi les mieux informés: "Je vous envoye le vray portraict de Callais et certayne poésie faicte par mons ${ }^{\mathrm{r}}$ de L'Hospital, n'ayant pour le présent rien de meilleur ${ }^{41}$.

Baîf publie peu après chez le même Fédéric Morel une traduction anonyme en alexandrins français du carmen de L'Hospital, assortie du même privilège du 17 janvier:

REMONSTRANCE / SVR LA PRINSE DE CALAIS / ET GVINE, FAICTE PREMIERE- / ment en uers Latins par un excellent / personnage, \& depuis mise en / François par un des Poëtes / de ce temps. / [vignette] / À PARIS, / De l'Imprimerie de Federic Morel, rue S. Jan / de Beauuais, / au Franc Meurier. / M.D.LVIII. (plaquette in $\left.-4^{\circ}\right)^{42}$

39 Pour une description bibliographique complète et la localisation des deux états de cette plaquette, voir la contribution de Michel Magnien dans ce volume.

40 Voir sa contribution dans le présent volume, p. 43-78.

41 L. Romier, «Lettres de Giovanni Dalmatio au Cardinal Farnèse », BEC, LXXI (1910), lettre du 18 février 1558.

42 Pour une description bibliographique complète et la localisation de cette plaquette, voir la contribution de M. Magnien dans ce volume. L'USTC répertorie cinq exemplaires connus : Caen (Fr), Bibliothèque municipale : Rés. B 739 (6) ; Grenoble (Fr), Bibliothèques municipales: Rés. F 5836 ; Paris (Fr), Bibliothèque nationale de France: NAF 7713 (96); Paris (Fr), Bibliothèque nationale de France: YC 4456; Yale University, Beinecke Library, New Haven, CT (USA) : BNF Résac Yc 4456 (filigr. A l'écu). Au verso du titre figure la pièce intitulée «Sur le partement du Roy pour aller à Calais, après la procession 
Cette publication, qui est à ma connaissance (et selon Loris Petris) la première traduction française d'un poème de L'Hospital, constitue une excellente traduction en vers, aussi fidèle qu'élégante. Elle pose aussi une série de questions à propos de certaines desquelles je risquerai quelques hypothèses. D'abord, qui a confié à Baïf ce travail de traduction? Est-ce une initiative personnelle de sa part, qui nous révélerait son admiration pour L'Hospital et son adhésion à ses idées? Est-ce plutôt une commande de L'Hospital, ou bien de Fédéric Morel, déjà conscient des talents de traducteur de Baïf, et soucieux d'élargir le retentissement du message humaniste audacieux lancé par L'Hospital? L'Hospital et Baïf ont-ils plus ou moins collaboré dans l'élaboration de cette traduction? L'Hospital, comme on peut le penser, a-t-il plus ou moins supervisé, contrôlé ou approuvé la traduction? Enfin et surtout pourquoi l'auteur et le traducteur restent-ils anonymes?

Pour tenter de répondre sur ce dernier point, il faut souligner ici le titre de Remonstrance adopté par Baïf, titre inusité en poésie dans les années précédentes ${ }^{43}$, qui met l'accent, qui attire même nettement l'attention sur la dimension critique du carmen, assez inattendue en pareille circonstance; cette valeur d'admonestation, voire de répréhension, constitue peut-être la clé du double anonymat. Il ne s'agit pas d'un éloge de la prise de Calais, ou d'un chant de victoire comme on en compose tant à l'époque, mais bien d'une remonstrance, qui profite d'une circonstance $a$ priori propice à l'éloge, mais ne craint pas de le tempérer presque aussitôt par une mise en garde et un blâme d'inspiration érasmienne. En d'autres termes, le choix du titre français par Baïf ou par Morel met en évidence la portée critique du texte de L'Hospital, que le titre latin ne laissait nullement deviner. Baïf nous invite donc à mesurer les enjeux éthiques de la célébration d'un événement guerrier, fût-il une belle victoire nationale.

generale, Sonnet». Elle sera reproduite en 1573 dans les Passetems de Baï (Livre III, pièce 90, «Au Roy Henri »).

43 Voir A. Tarrête, « Ronsard et le genre de la remontrance », dans Poésie et guerre civile. Pierre de Ronsard, Discours des misères de ce temps, éd. P. Debailly et J. Vignes, Cahiers, 33 (2009), p. 107-119. 
J'ai montré ailleurs comment les différents poèmes consacrés à la prise de Calais témoignaient de nombreuses divergences dans l'interprétation de l'événement. Michel de L'Hospital tire d'emblée une leçon morale du retournement de la situation militaire, où il voit une illustration exemplaire du «jeu cruel / atrocem ludum» de la Fortune (v. 2), ce qui relativise implicitement la victoire: si les gagnants d'aujourd'hui sont les perdants d'hier, tout peut s'inverser! Ce constat vaut avertissement. L'information factuelle sur la bataille, le chant de triomphe, l'éloge du vainqueur sont ainsi différés, et largement relativisés, au profit d'un didactisme moralisant, de forme gnomique, dans la tradition de l'institution du prince, qui semble la vraie priorité du vates. De même, l'exaltation de la vaillance aristocratique (illustrée dans la même circonstance par le poème de Belleau) ne trouve guère d'écho dans les vers de L'Hospital, qui privilégient une leçon plus chrétienne de mansuétude, et en viennent à s'indigner des crimes et des destructions perpétrés.

Car non content de tirer de la victoire une leçon de vertu ou de constance, et plutôt que d'en faire un exemple héroïque, L'Hospital ose s'ériger en censeur des dévastations commises, et tenir un discours qu'on dirait aujourd'hui humanitaire. C'est l'écho de la prise de Guînes, du massacre de sa garnison, puis de sa destruction systématique qui suscite ce sursaut de conscience, et qui motive le plus nettement le titre de Remonstrance. La traduction de Baif rend bien l'élan d'indignation par la multiplication des rejets et des enjambements :

Quelle fureur cruelle est-ce icy? quelle rage,

De n'estre pas content de faire le carnage

Des hommes, si ensemble on ne rue à l'envers

Villes et Citoyens, si aux dieux des enfers

Tout n'en est devoué? [...] et ne pardonner rien

À son propre païs, auquel l'ennemy mesme

Vainqueur pardonneroit, quelle fureur extreme

Pensez vous que ce soit? Des hommes sont-ce icy

Les œuvres, ou plustost des bestes sans mercy ? ${ }^{44}$

44 OC I, p. 242-243, v. 79-94. 
La description poétique de l'événement militaire n'a plus seulement vocation à informer les civils, moins encore à donner à voir un spectacle triomphal pour flatter Dieu sait quel orgueil national. Elle vise, Baïf l'a bien compris, à susciter une prise de conscience morale, en montrant la guerre telle qu'elle est, dépouillée de ses oripeaux épiques, en évitant surtout l'exaltation du «carnage»; elle vise à détourner les hommes de l'ivresse de la destruction, au nom de l'humanité et du sentiment chrétien.

Les divergences les plus nettes entre les nombreux poèmes inspirés par la prise de Calais portent enfin sur l'attribution du mérite de la victoire. L'Hymne de Du Bellay formule explicitement la question: «Mais à qui fault-il, SIRE, attribuer l'honneur / D'une si grand' victoire \& d'un si grand bon-heur?» (v. 71-72). L'apparente unanimité de la réjouissance officielle masque à cet égard une réelle diversité d'interprétations. Si Belleau prête tout le mérite au duc de Guise, Dorat s'efforce au contraire de répartir les mérites entre le roi et le prince lorrain ; d'autres, comme Magny et Costeley, tendent au contraire à privilégier Henri II et à souligner le caractère national et collectif de la victoire (nulle mention de Guise dans la chanson de Costeley). La vision de Michel de L'Hospital, relayée par Baiff, est tout autre, puisqu'il fait de sa Remonstrance un instrument d'édification d'inspiration évangélique, et une leçon d'humilité à l'usage des princes. On a vu le poème s'ouvrir sur le rappel des jeux capricieux de la Fortune: la traduction très ingénieuse de Baïf trouvait le moyen d'y faire retentir, à la rime du premier vers, le nom du vainqueur, mais plaisamment détourné au profit d'un jeu de mot:

AINSI Fortune change, et joüant à sa guise Son jeu cruel, ceux-ci maintenant favorise Et maintenant ceux-là ${ }^{45}$.

À ce premier avertissement, d'inspiration païenne, répond, à la fin du texte, une méditation toute chrétienne sur les ressorts de l'Histoire. Au souci délibéré de ne pas attribuer au seul Guise la victoire, s'ajoute celui d'interdire à Henri II un orgueil pernicieux et

45 p. 240 , v. $1-3$. 
impie. D'où ce distique qui confisque aux deux princes tout mérite personnel, par le bas et par le haut, si l'on peut dire, c'est-à-dire au profit de leurs hommes et de Dieu:

Sed nostris Ducibus praeclaro munere Divum

Intentata prius Caelo victoria venit. (v. 75-76)

Tant y a, qu'aujourd'huy, aux Chefs [on notera le pluriel] de nostre

La victoire devant impossible estimee,

[armee

Est venue d'enhaut de la grace de DIEU. (v. 95-97)

L'Hospital a parfaitement conscience de l'audace de sa formule, qu'il affecte aussitôt de tempérer en concédant le rôle décisif $\mathrm{d}^{\prime}$ Henri II, sa «constance» dans son «premier dessein » (v. 106). Mais cette apparente concession est un leurre et le poète, si j'ose dire, recule pour mieux sauter; la «sage constance» du roi n'est louée que pour en tirer une leçon universelle quant à notre ignorance des desseins de Dieu:

Apprenant aux humains que Dieu, comme il lui plaist

Tire et pousse des Rois, par un celeste arrest,

Le courage et le sens, sans qu'on doyve pretendre

Le motif de leurs faicts par la raison entendre,

Ny s'esmaïer pourquoy ils auront faict cela

Car l'esprit des mortels n'atteint pas jusques là. (v. 109-116)

En d'autres termes, l'action des rois échappe en fait à toute rationalité psychologique ou même politique: ils ne sont que les instruments de la toute-puissance divine, dont les desseins nous sont impénétrables. Pour dissiper toute ambiguïté, la suite du poème applique la règle générale au cas précis de la récente victoire: c'est Dieu qui a donné au roi l'idée de reprendre Calais («Dieu qui premier de ce conseil t'advise»), et «luy-mesme a conduict l'entreprise, / Voire a guidé tes Chefs» (encore au pluriel). C'est Dieu encore qui a permis à Charles de Guise de réunir «la finance» pour payer les mercenaires, prêts à déserter... La conclusion semble imparable: «Donc», le « remerciment » de la victoire est dû à Dieu seul, «car la gloire en est sienne». Mieux, la leçon est assortie d'une menace: nous devons 
Laisser l'honneur à DIEU invincible puissant,

Qui foule aux pieds le chef du Roy s'orgueillissant.

Et qui jusques au Ciel d'en bas leve, \& supporte

Le Roy qui humblement tous ses faicts luy rapporte. (v. 145-148)

La fin du poème élargit la leçon religieuse à tous les «faicts » humains, dont nous aurions tort de penser «que l'heur vienne de nous »; alors que Du Bellay achevait son poème en suggérant l'incomparable supériorité du prince et son rapport privilégié à Dieu dont il est l'image, L'Hospital et Baïf tendent au contraire à ramener au même plan «Princes et populaire» pareillement soumis à la divine Providence et invités à fonder toute action sur «l'espoir salutaire» de la seule «grace» de Dieu.

On peut évidemment se demander comment la famille de Guise, notamment François de Lorraine, a pu accueillir la publication d'un texte aussi critique composé par l'un de leurs "clients", et assez manifestement inspiré par des idées évangéliques, bien proches de la Réforme. Certes l'œuvre était anonyme, mais on a vu que Giovanni Dalmatio, l'agent des Farnèse à la cour de France, attribuait le texte à L'Hospital dès le 18 février 1558. Cela suggère que la paternité du texte n'était pas un grand secret ${ }^{46}$.

\section{ÉPILOGUE ET CONCLUSION}

À ma connaissance, on ne possède aucun document illustrant dans les années suivantes une amitié ou une collaboration entre Baïf et L'Hospital. Pourquoi Baïf ne traduit-il pas d'autres plaquettes de L'Hospital? Pourquoi L'Hospital ne le mentionnet-il pas? Tout porte à croire que les deux hommes se perdent de vue ou que leurs relations se dégradent.

Si l'on en croit le titre d'une chanson reproduite dans plusieurs recueils manuscrits ${ }^{47}$, Lancelot de Carles, Ronsard et Baïf s'associent, au moment du colloque de Poissy (août-octobre 1561), pour

\footnotetext{
46 Comme on sait, seule l'édition tardive des Carmina (B) révélera en 1585 enfin au grand jour la paternité de la pièce.

47 BNF, fr. 1662 , fol. $27 v^{o}$; fr. 12616 , p. $115-119$; fr. 22560 , p. $173-174$; fr. 22561 ,

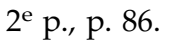


en railler les participants en ajoutant un prolongement satirique à une célèbre chanson plaisante attribuée à Mellin de Saint-Gelais («Saint Augustin, instruisant une Dame...»), parfois connue sous le titre Louange de l'Amour ${ }^{48}$. Mais cela ne signifie sans doute pas nécessairement une hostilité à L'Hospital lui-même.

La «Remonstrance sur la prinse de Calais et de Guine» sera réimprimée parmi les Euvres en rime de Jean-Antoine de Baïf en 1573 (l'année de la mort de L'Hospital), mais plus rien n'indique alors qu'il s'agit d'une traduction. Tout se passe comme si Baïf s'appropriait seul la paternité de ce poème, et d'aussi grands savants que Charles Marty-Laveaux ou Mathieu Augé Chiquet ${ }^{49} \mathrm{~s}^{\prime} \mathrm{y}$ laisseront prendre ; il faudra attendre l'érudition d'un V.-L. Saulnier pour que la première édition et sa source soient identifiées ${ }^{50}$. Signalons que par une sorte de retour de bâton, l'Universal Short Title Catalogue (USTC) attribue aujourd'hui la traduction à L'Hospital sans mentionner le nom de Baï !

En définitive, la façon dont sont publiés l'épithalame de 1557 et la remonstrance de 1558 dans les IX Livres des Poèmes en 1573 ne laisse rien deviner au lecteur des relations de Baïf et de L'Hospital. Le nom de L'Hospital n'apparaît pas dans le recueil des Poemes. Comment comprendre ce silence? Il me semble que Baï, qui adresse à Catherine de Médicis, dans le même recueil, un éloge de la Saint-Barthélemy, est soucieux de ne pas afficher les liens qu'il a pu entretenir avec les protestants. Il ne renie pas pour autant ces amitiés, dont le recueil témoigne mutatis mutandis, mais il évite soigneusement que des noms de personnes ou des titres de pièces puissent attirer l'attention sur elles.

À cet égard, le cas de L'Hospital n'est pas isolé, et relève donc probablement d'une politique qui s'applique bien au-delà de son

48 Voir la «Chanson faite par Lancelot Carles Evesque de Gier [sic, pour Riez] contre les docteurs \& ministres assemblez à Poissy, 1561. Ronsard et Baif y ont aussy besogné», Euvres en rime, éd. Marty-Laveaux, t. V, p. 289; et l'étude approfondie de ce texte par V.L. Saulnier, «Autour du Colloque de Poissy: les avatars d'une chanson de Saint-Gelais à Ronsard et Théophile », BHR, 20 (1958), p. 56-70.

49 M. Augé-Chiquet se montre sévère pour ces vers : « La description de l'assaut a la précision un peu sèche d'un récit d'histoire ; c'est de la prose rimée» (p. 147).

50 Voir V.L. Saulnier, «Autour du Colloque de Poissy: les avatars ...», art. cit. 
cas personnel. Pour ne citer que trois exemples, Baïf publie une épître à Isabeau de Limeuil qu'il a écrite en 1564 au nom du prince de Condé, sans le nommer explicitement et en dédiant la pièce à un ami extérieur à l'affaire («Au Seigneur Bertelemi », Poemes, IV, 7); il a composé une épitaphe de Jeanne d'Albret qu'il publie sans la nommer sous le titre «Épitaphe» (Passetems, III, 27); et l'un de ses principaux collaborateurs dans l'Académie de Poésie et de Musique, Claude Le Jeune, n'est évoqué qu'à demi-mot dans une églogue sous le pseudonyme pastoral de Claudin, qui ne saurait suffire à l'identifier avec certitude (XIX Eclogues, X) ${ }^{51}$.

Comme Condé, comme Jeanne d'Albret, comme Le Jeune, L'Hospital fait partie de ces hommes dont Baiff a su apprécier les qualités, mais que leur adhésion ou leur proximité avec la Réforme rendent en quelque sorte innommables dans l'espace des Euvres en rime, publiées au lendemain de la Saint-Barthélemy. Baï compte donc probablement parmi ceux qui considèrent L'Hospital comme un «crypto-protestant» (selon les mots de Loris Petris) ${ }^{52}$ avec lequel il serait imprudent de manifester ostensiblement les liens qu'il a pu entretenir jadis avec lui.

Jean VIGNES

Université de Paris

51 Voir aussi Passetems, III, 55, «Au Seigneur J. du Faur», v. 13.

52 Petris, La Plume et la tribune, p. XVII. 


\section{L'HOSPITAL ET MONTAIGNE OU MONTAIGNE CONTRE MICHEL DE L'HOSPITAL?}

Indépendamment de toute approche encomiastique, dans le cadre d'un panthéon littéraire et civique célébrant la parenté de deux belles figures, la question des relations entre Michel de L'Hospital et Michel de Montaigne est en premier lieu une question d'histoire et de biographie, celle des liens éventuels entre deux magistrats français, appartenant à deux générations différentes, mais dont les carrières ont pu se croiser. Cette question s'élargit à certains aspects de l'action politique du chancelier et ses conséquences en Guyenne, au parlement de Bordeaux, au moment d'une reprise en main des cours souveraines par le pouvoir royal ${ }^{1}$.

Pour les spécialistes de L'Hospital, il s'agira d'une simple question de réception, portant sur la réputation et peut-être l'influence posthume de celui-ci, à travers la représentation qu'en a donnée Montaigne dans les Essais, publiés en 1580 et dans leur version définitive de 1595. La question est sans doute d'un intérêt plus grand en ce qui concerne Montaigne. Il s'agit là aussi d'une question d'ordre biographique, portant sur la carrière d'un magistrat de province, au début des guerres de religion et des choix contradictoires qui s'imposaient à lui². L'échec du parti protestant, qui avait vainement tenté de s'emparer de Bordeaux en 1562, trans-

1 Voir A.-M. Cocula, «Michel de L'Hospital, Étienne de La Boétie et Michel de Montaigne: histoire d'une filiation », dans De Michel de L'Hospital à l'Édit de Nantes. Politique et religion face aux églises, dir. T. Wanegffelen, ClermontFerrand, PU, 2002, p. 565-574. Dans une perspective plus générale, Crouzet, La Sagesse et le malheur.

2 Sur ce point, voir P. Desan, Montaigne. Une biographie politique, Paris, O. Jacob, 2014. 
forma durablement la cité en une citadelle catholique. Le Parlement manifesta sa résistance à la politique de concorde de L'Hospital, qui lui-même jouait de l'opposition entre les jurats et les conseillers $^{3}$. La position de Montaigne, un conseiller subalterne, est connue. Dès 1563, il apparaissait engagé dans le parti catholique en tant que client de la famille de Foix, en compagnie de son futur beau-père, le président de La Chassaigne. Il assista à l'entrée de Charles IX dans la cité et à la séance présidée par L'Hospital. Cette expérience semble avoir été décisive pour lui, mais peut-être de façon moins univoque et moins favorable que la critique l'a prétendu.

Cette question est surtout d'ordre littéraire. En tant que telle, elle se justifie en premier lieu dans la mesure où le seul document connu attestant cette relation, dans un sens unique, est de cet ordre: la dédicace à L'Hospital, par Montaigne, de l'édition des Poemata de La Boétie. Les choix politiques et religieux se complétaient d'une pratique lettrée et d'une dimension symbolique. La question se justifie aussi en raison de la présence du chancelier dans les Essais, sur un mode direct ou allusif. Elle contribue ainsi à l'interprétation du livre de Montaigne.

\section{LA DÉDICACE DES POEMATA DE LA BOÉTIE}

En date du 30 avril 1570, Montaigne adressa à «Monseigneur, Monsieur de L'Hospital, Chancellier de France », l'épître de dédicace qui accompagnait les Poemata d'Étienne de La Boétie ${ }^{4}$. Ces pièces ne constituaient toutefois qu'une partie d'un ensemble, le recueil collectif des CEuvres latines et françaises, procuré par Montaigne sous le titre de La Mesnagerie de Xenophon [...] le tout traduict de Grec en François par feu M. Estienne de La Boetie [...] ensemble quelques vers Latins et François. Le volume fut publié à

3 Voir A.-M. Cocula, «La Guyenne de Montaigne», dans Montaigne Politique, éd. P. Desan, Paris, Champion, 2006, p. 177-203.

4 M. de Montaigne, épître, dans La Boétie, La Mesnagerie de Xenophon, Paris, F. Morel, 1570, fol. 100-101v . Cette épître a été reproduite à de nombreuses reprises. Elle a été éditée avec une riche annotation dans L'Hospital, Discours et correspondance, p. 239-242. 
Paris, chez Fédéric Morel, à la date de 1571, avec un achevé d'imprimer du 24 novembre $1570^{5}$. La dédicace à L'Hospital s'inscrivait dans une ordonnance complexe, qui lui donnait sa portée réelle et relative. Le recueil en effet est dédié dans son ensemble à Louis de Saint-Gelais, seigneur de Lansac, surintendant des finances, membre du Conseil privé, capitaine de cent gentilshommes de la maison du roi. Suivent une épître à Henri de Mesmes, à l'épouse duquel sont dédiées les Règles de mariage traduites de Plutarque, une épître à Mme de Montaigne pour la Lettre de Consolation, également tirée de Plutarque, enfin l'épitre à L'Hospital (fol. 100ro) ouvrant la section des Poemata, qui ellemême précède le Discours sur la mort de La Boétie, adressé au père de Montaigne. Un second tome, qui a été publié séparément, contient les Vers français, introduits par une épître de dédicace à Paul de Foix, ambassadeur à Venise.

Immédiatement après l'épître à Lansac, Montaigne avait inséré un avertissement au lecteur, qui éclaire les conditions de la rédaction des pièces, de leur transmission et de leur publication. Il révèle en particulier qu'il avait renoncé à publier d'autres textes de La Boétie, Le Discours de la servitude volontaire et des mémoires sur l'Édit de janvier:

Mais quant à ces deux dernieres pieces, je leur trouve la façon trop delicate et mignarde pour les abandonner au grossier et pesant air d'une si mal plaisante saison' ${ }^{6}$.

La Servitude volontaire connaissait alors une diffusion manuscrite séparée dans les milieux politique et diplomatiques, qui en comprenaient parfaitement la portée scandaleuse: une dénonciation de la tyrannie monarchique et un appel à la résistance des parlements. Les annotations portées par Henri de Mesmes sur le manuscrit en sa possession insistent sur cet aspect. Tout en prétendant renoncer à publier le discours, Montaigne attirait ainsi l'attention sur lui et de surcroît, il révélait pour la première fois, le nom de son auteur. Cet aveu pouvait nuire à la mémoire de La Boétie, mais il valait aussi comme une forme de rétractation, qui permet-

\footnotetext{
5 Sur les circonstances de l'édition, voir P. Desan, Montaigne, op. cit., p. 210-225.

6 M. de Montaigne, "avertissement au lecteur», dans La Mesnagerie de Xenophon, éd. cit., fol. $A v^{\mathrm{o}}$.
} 
tait de transformer l'ancien héros de la résistance parlementaire en un homme du roi, tardivement rallié à la défense de l'ordre monarchique $^{7}$.

On ne connaît pas le manuscrit ni l'exemplaire de présentation du recueil des œuvres latines et française de La Boétie ni des sections particulières qui le composent, et encore moins l'exemplaire des Poemata qui aurait été adressé à L'Hospital. Le petit volume, d'une publication privée, connut toutefois une circulation discrète, principalement dans les milieux parlementaires bordelais, selon le témoignage de Pierre de Brach ${ }^{8}$.

La dédicace à L'Hospital ne porte que sur une mince section de l'ouvrage, représentant vingt feuillets sur 120. Elle peut s'expliquer en termes politiques et de carrière, mais aussi en termes culturels. À côté du père et de l'épouse de Montaigne, les dédicataires étaient quatre hauts personnages de l'administration royale, des hommes $d u$ roi, membres du Conseil privé (Lansac, De Mesmes, L'Hospital et Foix), parfois présentés comme des proches de la reine-mère. Si leurs liens avec Montaigne sont connus en partie (en mai 1565, Montaigne avait assisté Henri de Mesmes au cours d'une mission en Saintonge), ceux qui les unissaient entre eux demanderaient à être mieux précisés pour vérifier la cohérence apparente de ce choix, en particulier les liens entre De Mesmes et L'Hospital. On a avancé l'hypothèse que Montaigne leur aurait adressé les œuvres de son ami dans l'espoir d'être appelé à de plus hautes fonctions, et de se voir confier un rôle public, mettant en œuvre sa «science de l'entregent ${ }^{9}$. À un moment charnière de sa carrière, il aurait souhaité lui-même devenir un homme du roi. Si la dédicace à L'Hospital devait servir à une telle fin, elle n'était guère pertinente. L'Hospital en effet n'exerçait plus sa charge depuis octobre 1568, les sceaux lui ayant été retirés à cette date et avaient été confiés provisoirement à Jean de Morvillier, avant d'être donnés, au mois de mars 1571, à René de Birague. Il avait perdu son pouvoir

$7 \quad$ Sur cette question, voir D. Knop et J. Balsamo, Rhétorique et politique sous les derniers Valois, Rouen, PUHR, 2014.

8 P. de Brach, «Hymne de Bordeaux », dans Les Poèmes, Bordeaux, S. Millanges, 1576, fol. 84 .

9 A. Legros, «Montaigne politique malgré lui?», dans Montaigne Politique, op. cit., p. 113-126. 
politique et son influence, même s'il conservait son titre à titre honorifique. À cet égard, l'appellation que Montaigne lui donnait dans la dédicace n'était ni une marque de flatterie ressortissant au genre de la dédicace ni une négligence, elle correspondait bien à l'étiquette $^{10}$. Il est peu probable toutefois que Montaigne ait fait un pari sur l'avenir et ait envisagé un hypothétique retour du chancelier aux affaires. Dans le contexte politique, la dédicace à L'Hospital apparaît ainsi, sinon en contradiction, du moins comme décalée tant par rapport aux autres dédicaces particulières, adressées à des personnages actifs auprès du souverain, en particulier Henri de Mesmes, que par rapport à l'actualité politique.

Dans son épître, Montaigne s'adresse à L'Hospital comme à un homme d'État, représentant ceux qui ont «en main le gouvernement des affaires du monde». Pour pouvoir exercer cette charge, ceux-ci doivent s'appliquer à bien choisir leurs collaborateurs. Suivant un raisonnement par gradation et par comparaison, Montaigne peut à la fois insister sur la difficulté de ce choix, qui repose sur une connaissance de l'homme et de ses ressorts cachés, et déplorer le mauvais choix des candidats aux plus hautes fonctions; celles-ci sont pourvues le plus souvent par la brigue ou la malice et non pas au mérite, sauf lorsque la fortune joue son rôle et rééquilibre les choses, en les accordant avec la raison. De ce point de vue, selon Montaigne, la carrière de L'Hospital illustre la rencontre exceptionnelle de ces deux ordres, le mérite et la chance. À l'inverse, cet argument, qui met en évidence la difficulté du choix et le rôle de la fortune, sert à consoler Montaigne lorsqu'il examine l'échec de la carrière de son ami La Boétie: par ses talents, celui-ci était propre "aux premières charges de la France», et pourtant, il était resté «mesprisé ès cendres de son fouyer domestique », oublié dans les fonctions subalternes de conseiller dans une juridiction provinciale, au grand dommage de l'État. Montaigne rend La Boétie, «nonchalant de se pousser soy mesme en lumiere », responsable en premier de ce gaspillage de talent, mais il n'accuse pas moins ceux qui n'avaient pas su ou qui n'avaient pas voulu le distinguer. La lettre à L'Hospital est marquée par une tonalité de réprobation. Malgré l'admiration

10 Voir M. Magnien, notice «L'Hospital», dans Dictionnaire Michel de Montaigne, dir. P. Desan, Paris, Champion, 2004, 22007, p. 677-678. 
que Montaigne portait au chancelier, il semble lui reprocher de n'avoir pas su exploiter les qualités de La Boétie et de n'avoir pas fait de lui un collaborateur dans les plus hautes fonctions de l'État. Dans cette étrange relation qui place La Boétie entre Montaigne et l'ex-chancelier, la critique a voulu voir une forme de duplicité : sous le masque de La Boétie, et de son échec, Montaigne parlerait en fait de lui-même, il serait le véritable objet de cette admonestation adressée au destinataire, afin que celui-ci lui confie des fonctions d'importance.

Le propos de Montaigne se présente en réalité comme un hommage à la mémoire de son ami, en le faisant connaître post mortem à des "personnes d'honneur et de vertu", par ce qui restait de lui, ses œuvres, en l'occurrence ces vers latins. Ceux-ci ne représentaient certes que l'écorce de sa véritable valeur, dont Montaigne dresse le répertoire en une longue accumulation combinant les vertus morales aux vertus intellectuelles et aux vertus politiques ou plus exactement civiques:

La tendre amour qu'il portoit à la misérable patrie, et sa haine capitale et jurée contre tout vice, mais principalement contre ceste vilaine traficque qui se couve sous l'honorable tiltre de justice ${ }^{11}$.

L'objet de la dédicace est bien un hommage à La Boétie. Montaigne mettrait en évidence les éminentes qualités de son ami, pour le représenter dans les hautes fonctions qu'il aurait mérité de remplir. Fruit modeste de son étude, les vers latins qu'il avait laissés sont le seul moyen de remonter à la connaissance de ce qu'il était véritablement et de le faire aimer. Ce sentiment que Montaigne témoigne publiquement par le biais de cette publication et qu'il veut faire naître chez le dédicataire, est présenté comme le juste retour du sentiment que La Boétie aurait éprouvé à l'égard du personnage de L'Hospital, en raison d'une vertu analogue à la sienne. Montaigne justifie ainsi sa dédicace par l'amitié qui le liait à La Boétie, et il en fait un témoignage de «l'honneur et révérence » qu'il porte lui-même à L'Hospital pour les mêmes raisons.

11 L'Hospital, Discours et correspondance, p. 241. 
La dédicace des Poemata a pu être considérée comme l'expression d'une «sorte de fascination pour un faiseur de livre qui aurait su se muer en acteur de l'Histoire». C'est sans doute inverser les termes définissant la carrière et la personnalité de L'Hospital: celui-ci fut sans rupture un magistrat, un homme d'État et un poète. C'est en même temps caractériser sur un mode péjoratif l'autorité littéraire et culturelle dont L'Hospital bénéficiait dans les cercles les plus savants. Le chancelier était un grand magistrat et nullement un "faiseur de livres », un humaniste de collège, un collaborateur de libraire-éditeur, un de ces savants compilateurs dont Montaigne se moqua à plusieurs reprises dans les Essais. Au sommet des hiérarchies littéraires et savantes, dont la poésie latine était précisément le couronnement, son œuvre, rare et diffusée sur un mode confidentiel, était celle d'un homme d'État et un poète néo-latin, considéré comme le premier de son temps en France, qui donnait l'illustration la plus haute des Lettres dans leur conjonction avec le pouvoir politique.

Or ce qui est singulier dans la dédicace de Montaigne, c'est qu'elle ne fait pas mention de l'œuvre poétique du chancelier. Les Poemata qu'elle introduit ne font pas l'objet, même implicitement, d'une comparaison d'ordre poétique entre deux auteurs, alors qu'ils sont d'une même inspiration, et qu'ils traitent de sujets analogues ${ }^{12}$, en particulier l'amitié. La dédicace met en évidence deux points précis. Elle souligne d'abord la proximité civique entre La Boétie et L'Hospital, précisée en une même conception de la justice et de la magistrature. La critique que La Boétie aurait formulée contre la «vilaine trafique» de la justice de son temps correspond exactement aux reproches que L'Hospital avait adressés aux parlementaires bordelais en $1563^{13}$. La dédicace d'autre part tourne autour de la notion d'amitié. En dédiant les Poemata de La Boétie à L'Hospital, Montaigne s'adressait tout natu-

12 Voir ainsi l'analyse de J. Hirstein, «La Boétie et la justification difficile d'une amitié précoce: le début de la "satyre latine" (Poemata, XX) et le Laelius de Cicéron", Montaigne Studies, XI (1999), p. 121-136. Il manque toutefois une référence au modèle poétique donné par L'Hospital; voir P. Galand-Hallyn, "Les essais latins de La Boétie (Poemata, 1571)», dans Estienne de La Boétie. Sage révolutionnaire et poète périgourdin, Actes du colloque, Duke University, 1999, éd. M. Tetel, Paris, Champion, 2004, p. 212-156.

13 Voir sur ce point, voir L'Hospital, Discours et correspondance, p. 70-79. 
rellement à celui-ci et les plaçait sous son patronage, comme à une figure tutélaire de la Grande robe, pour laquelle la maîtrise de la poésie latine était un critère de distinction et la culta amicitia la définition même des liens qui unissaient ses membres. Ce n'est sans doute pas un hasard de surcroît si Montaigne fit imprimer le recueil de La Boétie chez Fédéric Morel, l'imprimeur du roi et de la Grande robe, et de L'Hospital en particulier ${ }^{14}$. Enfin, jouant de la notion d'amitié, en rappelant l'amitié qui le liait à La Boétie et qu'il illustrait par un travail savant d'édition de texte, Montaigne montrait sa connaissance des codes lettrés de la haute magistrature, alors même qu'il ne se pliait pas lui-même au plus difficile, la maîtrise de la poésie latine. Vingt ans plus tard, un autre grand poète néo-latin, Scévole de Sainte-Marthe, allait réunir La Boétie et L'Hospital dans ses Elogia et accorder une place à Montaigne, en vertu de ses liens avec le premier. Cette dédicace, qui célébrait La Boétie comme poète latin et non pas Montaigne lui-même, simple éditeur dévoué, qui de surcroît écrivait en français, n'était guère pertinente pour solliciter un appui dans une carrière à venir. Elle constituait un hommage, elle avait bien pour but de garantir à La Boétie sa réputation posthume au sein du milieu lettré et selon les valeurs de celui-ci, en même temps qu'elle désignait Montaigne comme un parfait ami ; c'est à ce titre seul qu'il pouvait accéder à la Respublica literaria.

\section{L'HOSPITAL À L'ÉPREUVE DES ESSAIS}

La dédicace des Poemata, ou plus exactement l'édition des CEuvres de La Boétie couronne la carrière de magistrat de Montaigne sans la servir. Celui-ci quitta le Parlement pour d'autres honneurs, ceux d'un gentilhomme d'épée pris dans le mouvement des guerres pour la religion. Mais il ne chercha pas moins à adapter à cette nouvelle carrière l'idéal robin, ou mieux, sénatorial de l'otium lettré, voué au culte des Muses, dont les Essais furent le fruit singulier. Le décor de la «librairie» où ils furent

14 Voir Ph. Desan, «La Boétie poète et ses deux éditeurs: Federic Morel et Montaigne", dans Les Poètes français de la Renaissance et leurs "libraires », éd. D. Bjaï et F. Rouget, Genève, Droz, 2015, p. 485-506. 
élaborés est bien connu, et en particulier les poutres peintes, portant des sentences en latin et en grec, qui en faisaient comme un livre ouvert. Parmi celles-ci, sur une solive de la troisième travée, figure le vers, "Nostra vagatur in tenebris nec cæca potest mens cernere verum». Il est pris d'une épître de L'Hospital, qui l'avait adapté de Lucrèce (De Natura rerum, II, 14; VI, 34). Montaigne avait pu le lire dans la plaquette originale, ou plus probablement dans un recueil collectif réunissant au poème satirique Franciscanus de Buchanan une anthologie de poètes néolatins ${ }^{15}$. Sur les poutres de la librairie, la sentence s'inscrit dans une suite de formules de même portée, prises de l'Écriture et des Hypotyposes pyrrhoniennes de Sextus Empiricus. Elle illustre de la façon la plus précise le scepticisme de Montaigne, ses enjeux et sa portée, tels qu'ils ont été développés dans l'Apologie de Raimond Sebond: un scepticisme chrétien de nature polémique, portant non pas sur Dieu ou la religion mais sur la faiblesse de l'esprit humain et son incapacité à comprendre par lui-même les vérités divines.

Michel de L'Hospital avait disparu en 1573 sans être revenu aux affaires. C'est à travers la médiation des Essais, sur un mode rétrospectif, que s'exprime la relation que Montaigne eut avec lui. L'écrivain mentionne deux fois le nom du chancelier. Il le cite une première fois dans une liste des "plus notables hommes» de son temps dans le domaine militaire et dans le domaine administratif. Cette liste est constituée de deux couples, d'un côté le duc de Guise et le maréchal Strozzi "pour le faict de la guerre et suffisance militaire», de l'autre les deux chanceliers Olivier et L'Hospital, "gens suffisants et de vertu non commune ${ }^{16}$. Montaigne prend soin de préciser que son jugement n'est fondé que sur les «apparences externes », sans qu'il ait pu véritablement éclairer le fond de ces personnalités. Sa réserve reprend un argument clairement

15 Voir «Sentences peintes et autres inscriptions de la bibliothèque de Montaigne", éd. A. Legros, dans M. de Montaigne, Les Essais, éd. J. Balsamo, M. Magnien et C. Magnien-Simonin, Paris, Gallimard, 2007, 42014, p. 1314 et note p. 1900. Le vers avait été publié pour la première fois dans Ad Margaritam regis sororem Epistola, Paris, Morel, 1558, v. 48 ; L'Hospital, Carmina, t. II, p. 150 (II, 8, 48-49); voir la bibliographie par M. Magnien, ci-dessus, no 7-8.

16 Les Essais, II, 17, éd. cit., p. 700. 
formulé dans le chapitre «De l'inconstance de nos actions» (II, 1), qui fonde le projet anthropologique des Essais : comment connaître un homme. Elle correspond précisément à ce qu'il avait écrit quelques années plus tôt à L'Hospital dans la dédicace des Poemata pour excuser celui-ci de n'avoir pas su reconnaître les qualités de La Boétie:

Veu que ny vos yeulx [...] ne peuvent entrer jusques au fond des cœurs pour y veoir les intentions et la conscience, pieces principales à considérer.

En comparaison aux autres personnages figurant sur cette première liste, dans l'ensemble des Essais, L'Hospital fait l'objet d'un traitement moins gratifiant: François de Lorraine apparaît comme un exemple de magnanimité à l'instar d'Auguste (I, 22) et comme un capitaine victorieux, dont Montaigne justifie le choix lors de la bataille de Dreux (I, 45); Strozzi est célébré comme un capitaine lettré (II, 34); le chancelier Olivier est évoqué avec humour comme l'auteur du bon mot caractérisant les Français comme des guenons qui «montrent le cul» (II, 17). On évoquera aussi Paul de Foix, un des dédicataires des poésies de La Boétie, objet d'un bel éloge (III, 9).

Dans les Essais, L'Hospital n'est nommé que dans cette page, même s'il y apparaît deux fois, et il n'est jamais célébré en tant que grand législateur ou qu'orateur. La seconde mention, s'inscrit dans une autre liste, celle des bons poètes contemporains, constituée de six noms : Dorat, Bèze, Buchanan, L'Hospital, Mondoré, Turnebus. Cette seconde mention est dissociée de la première, et Montaigne n'associe pas le poète au chancelier, alors que cette excellence poétique, reconnue par tous ses contemporains, jointe à une excellence politique aurait pu contribuer à distinguer le personnage, à la fois des grands hommes et des grands poètes. Cette liste des poètes néo-latins est analogue au canon des poètes latins du chapitre « Du jeune Caton»; Montaigne toutefois ne cite pas de vers des modernes pour illustrer leur talent. Peut-être cette liste correspond-elle moins aux goûts personnels de Montaigne qu'à un canon reconnu, transmis partiellement sous forme d'anthologie par l'édition du Franciscanus (1568) de Buchanan, que complétait une riche section de Poemata de certains de ces auteurs: Buchanan 
lui-même, Turnèbe, des œuvres de Dorat, et surtout la «variorum poematum silva» de L'Hospital ${ }^{17}$, première édition collective des poèmes du futur chancelier. De cette anthologie, Montaigne en revanche ne retient pas les noms de Charles Utenhove, éditeur du volume et dont le recueil des Xenia était augmenté de nombreux autres poèmes des membres du cercle de Jean de Morel $\mathrm{d}^{\prime}$ Embrun $^{18}$. Mondoré lui-même, plus connu comme mathématicien et comme garde de la bibliothèque du roi, avait été associé à Turnèbe et à d'autres érudits français dans un hommage à L'Hospital accompagnant un présent fait par Henri de Mesmes ${ }^{19}$.

Le traitement réservé à ces poètes dans les Essais fait apparaître de subtiles nuances. Dans l'Apologie, Montaigne cite trois vers attribués à Dorat, pris d'un recueil de polémique anti-protestante ${ }^{20}$. D'autre part, comme la mention de Bèze avait fait l'objet de la censure romaine des Essais en 1581, Montaigne dissocia le poète dont il citait un vers obscène (III, 5), et le protestant, et il opposa nettement l'excellence du poète et le fanatisme du réformateur (III, 10 : 1058). Enfin, Buchanan, dont un vers était inscrit sur une autre poutre de la librairie ${ }^{21}$, et qui avait été plus étroitement lié à la familia de Montaigne que les autres, est mentionné et cité à plusieurs reprises ${ }^{22}$, de même que Turnebus, «le plus grand homme qui fut». Dans ce contexte, L'Hospital n'est pas l'objet d'une mention particulière. Il semble avoir été nommé comme Mondoré, dans une liste que Montaigne reprenait du Franciscanus, sans que cela correspondît à une dilection particulière et encore moins à une relation personnelle, dans l'hypothèse où, selon

17 M. de L'Hospital, Variorum poematum silva, dans Georgii Buchanani Scoti Franciscanus et fratres. Quibus accessere varia eiusdem et aliorum Poemata, Bâle, Guarinus, [1568], p. 63-118.

18 Sur les liens entre ces poètes, voir Galand-Hallyn, «Michel de L'Hospital à l'école de Jean Salmon Macrin ».

19 Voir P. de Nolhac, Ronsard et l'humanisme, Paris, Dorbon, 1914, t. 1, p. 178. Sur le personnage, voir L. Dorez, «Pierre de Montdoré maître de la librairie de Fontainebleau (1552-1567)», Mélanges d'archéologie et d'histoire, XII (1892), p. 179-194.

20 Les Essais, II, 12, éd. cit., p. 462.

21 Voir A. Legros, «Buchanan et Cicéron chez Montaigne: deux sentences inédites de sa "librairie" », Montaigne Studies, XXVI (2016), p. 171-175.

22 Voir P. Ford, «George Buchanan et Montaigne», dans La Familia de Montaigne, éd. J. O’Brien, Montaigne Studies, XIII (2001), p. 45-65. 
certains biographes, Montaigne aurait fréquenté le cénacle de Jean de Morel lors de son séjour à Paris ${ }^{23}$.

À en croire Pierre Villey, « les Essais semblent ne rien emprunter à Michel de L'Hospital $»^{24}$. Une approche fondée sur la recherche des «emprunts » ne peut en effet qu'être décevante. Elle montre à la fois les limites d'une enquête de sources, toujours provisoire, et surtout celles d'une méthode qui identifie les Essais aux emprunts textuels, citations, exemples et allégations qui nourrissent le discours de Montaigne, et qui néglige leur dynamique en tant que discours. Or un développement du chapitre «De l'art de conférer» (III, 8) reprend l'argument de l'épître de dédicace des Poemata de La Boétie. Montaigne évoque la difficulté que les princes ont à bien choisir leurs officiers, faute de pouvoir entrer dans le cœur de leurs sujets "pour en discerner la precellence», alors qu'il s'agit de leur devoir, ainsi qu'il le résume par un précepte adapté d'un vers de Martial, "principis est virtus maxima, nosse suos ${ }^{25}$. Certes L'Hospital n'est pas directement évoqué, mais il est à l'arrière-plan de cette critique.

On trouvera au moins une autre évocation de L'Hospital par le biais d'une subtile intertextualité. Dans le chapitre «De mesnager sa volonté»(III, 10), publié pour la première fois en 1588, Montaigne consacre un long développement à la prudence, conçue comme prévision des risques et des passions: il faut «se préparer avant les occasions ». Il illustre le précepte par l'exemple de son propre renoncement aux risques du jeu, par celui de Socrate, par autorité de l'Écriture. La conséquence positive qu'il tire de cette prudence est illustrée à nouveau par son propre exemple: il a su, il sait conserver son calme et sa sérénité devant le spectacle douloureux de la ruine de la France, assumant luimême une attitude qu'il attribuait au début de son argumentation à «aucuns sages» seuls, capables de s'engager en assumant les plus hautes responsabilités publiques, tout en conservant une entière équanimité :

23 Voir P. Desan, Montaigne, op. cit., p. 70.

24 P. Villey, Les Sources et l'évolution des Essais de Montaigne, Paris, Hachette, 21933, t. I, p. 177.

25 Les Essais, III, 8, éd. cit., p. 978. 
Qui desirera du bien à son païs comme moy, sans s'en ulcerer ou maigrir, il sera déplaisant, mais non pas transi, de le voir menassant, ou sa ruine, ou une durée non moins ruineuse. Pauvre vaisseau, que les flots, les vents et le pilote, tirassent à si contraires desseins!

In tam diversa, magister,

Ventus et unda trahunt ${ }^{26}$.

L'argumentation repose sur une comparaison: ce que les Caton et leurs semblables font par patience et grandeur d'âme, lui, Montaigne, se représente capable de le faire par un exercice bien conduit de prudence.

Les vers latins qui lui servent à illustrer le cours de la vie humaine et qu'il avait paraphrasés sont à nouveau adaptés du Franciscanus ${ }^{27}$. Dans le développement qui paraphrase la citation, où il évoque les sages, maîtres d'eux-mêmes au point de «voir résolument et sans se troubler la ruyne de leur pays », Montaigne traduit ici la devise latine de L'Hospital, «Impavidum ruinæ ferient», et l'adapte à son propre cas, étant lui-même, écrit-il, «non pas transi de le voir menassant ou sa ruine». Montaigne avait trouvé la devise du chancelier en tête de la Silva éditée dans le même recueil du Franciscanus, où elle faisait l'objet d'un éloge dans le poème liminaire encomiastique célébrant L'Hospital, adressé à Jean de Morel d'Embrun ${ }^{28}$. Cette devise est prise d'Horace (Odes, III, 3, 8). Elle définit selon les termes stoïciens de la mens immota la constance de l'homme juste, ferme en sa résolution, que n'émeuvent ni la furie des citoyens révoltés ni les grimaces du tyran, ni les éléments déchaînés, ni même la main de Jupiter foudroyant: si le monde se brisait et s'écroulait, «ses débris le frapperaient sans qu'il en fût épouvanté». Gabriel Naudé, dans ses Considérations politiques, en donna plus tard le commentaire, en éclairant le lien avec la devise du chancelier:

26 Les Essais, III, 10, éd. cit., p. 1062.

27 "Quam venti, violensque aestus, canusque magister / In diversa trahunt, tuto subducere portu decrevi», Franciscanus, fol. A1, v. 13-14.

28 «Aliud in illud. Mich. Hosp. Elogium. Impavidum ferient ruinæ», dans Franciscanus, éd. cit., fol. ee $8 \mathrm{v}^{\mathrm{o}}$ [p. 64]. 
Monsieur le chancelier de l'Hôpital, qui était pourvu de cette force d'esprit autant qu'aucun autre qui l'ont précédé ou suivi, la décrivait encore plus brièvement, quoiqu'en termes beaucoup plus hardis, desquels même il avait composé sa devise $^{29}$.

La critique des sources n'a été attentive qu'aux vers latins qu'elle a bien identifiés. Elle a négligé ce qu'elle considérait comme le discours propre de Montaigne développant des lieux communs stoïciens, alors qu'il s'agissait de la traduction et la paraphrase en français d'autres vers latins, et par là-même, elle a négligé non seulement la relation d'imitation liant L'Hospital à Horace, mais la relation d'intertextualité liant Montaigne et L'Hospital via Horace et Buchanan. Cette subtile construction que savaient lire les lettrés de l'époque, permettait un parallèle entre Montaigne et le chancelier, l'un, célébré en héros à l'antique, l'autre, en anti-héros moderne, non moins résolu et non moins prudent; elle prolongeait ainsi le parallèle tout autre que dépréciatif que Montaigne avait tracé entre les grands hommes de son temps et lui-même dans le chapitre «De la présomption ${ }^{30}$.

L'Hospital peut ainsi apparaître comme une figure présente dans les Essais et dans les discours politiques de Montaigne, à titre personnel ou comme un avatar du sage stoïcien, mais il s'agit d'une figure implicite, objet d'un discours contrasté. Montaigne rend hommage à la grande âme; il est réservé à l'égard de l'homme d'État ou du moins du législateur. Deux allusions dans le même livre III font même de L'Hospital une figure contestée, sur un mode presque satirique. Le chapitre «De la vanité » s'ouvre sur le développement topique d'une figure de modestie, par laquelle Montaigne justifie comme un moindre mal le fait d'écrire au sein de la «corruption du siècle» et des troubles civils, en opposant les choses vaines et futiles aux actions méchantes. Il amplifie son propos privé par un exemple politique :

29 Cité par F. Goyet, Les Audaces de la prudence, Paris, Garnier, 2009, p. 294.

30 Sur ce point, voir J. Balsamo, " "Ma fortune ne m'en a fait voir nul”. Montagne et les grands hommes de son temps", dans L'Écrivain et le grand homme, Travaux de Littérature, ADIREL, XVIII (2005), p. 139-155. 
Je vis pourtant sur ce propos, il y a quelques années, qu'un personnage, de qui j'ay la mémoire en recommandation singulière, au milieu de nos grands maux, qu'il n'y avoit ny loy, ny justice, ny magistrat, qui fist son office: non plus qu'à cette heure: alla publier je ne sçay quelles chetives reformations, sur les habillemens, la cuisine et la chicane. Ce sont amusoires de quoy on paist un peuple mal-mené, pour dire qu'on ne l'a pas du tout mis en oubly ${ }^{31}$.

Il s'agit d'une claire allusion à L'Hospital, et à ses lois somptuaires promulguées par les édits de 1563 et l'ordonnance de Moulins, de $1566^{32}$. Montaigne rappelle le contexte de l'action législatrice du chancelier, pour souligner la vanité des mesures prises: celles-ci ressortissent à une forme de diversion servant à détourner l'attention du peuple. L'hommage personnel qu'il rend au personnage, à l'homme autant qu'à l'homme d'Etat, met en exergue par contraste non seulement la critique plus vive de sa politique de diversion et de son échec politique, mais souligne le cynisme qui l'accompagne. Les grandes ordonnances prises à l'initiative de L'Hospital, des monuments de la législation royale, conçue comme l'œuvre positive du souverain, sont aussi des moyens de gouverner, des «instrumenta regni », selon une expression de Tacite que Montaigne paraphrase ailleurs.

Le début du chapitre «De l'Expérience» doit probablement aussi se lire comme une allusion voilée à l'action du chancelier et à son échec. Montaigne, sans entrer dans le détail des lois, dénonce l'excès législatif:

Nous avons en France plus de loix que tout le reste du monde ensemble; et plus qu'il n'en faudroit à régler tous les mondes d'Epicurus. Vt olim flagitiis, sic nunc legibus laboramus ${ }^{33}$.

31 Les Essais, III, 9, éd. cit., p. 990-991.

32 L'identification avec le président de Lagebaston, bien qu'elle soit appuyée par l'autorité de Fl. de Ræmond, néglige précisément le fait que les ordonnances étaient de l'initiative du garde des sceaux et non pas d'un président de cour souveraine. Voir A. Boase, "Montaigne annoté par Fl. De Ræmond », Revue du XVI siècle, XV (1928), p. 275-276.

33 Les Essais, III, 13, éd. cit., p. 1112. 
Il en dénonce la conséquence, la variété et la contradiction de leur interprétation, pour indiquer ce qui, selon lui, aurait été une saine politique: «il falloit effacer la trace de cette diversité » ${ }^{34}$.

\section{DES CHOIX POLITIQUES ET LITTÉRAIRES}

Le 12 avril 1565, accompagnant le roi, L'Hospital se trouvait à Bordeaux, où il tint devant le Parlement, en présence du souverain, un discours d'une grande sévérité. Montaigne assista à cette séance ${ }^{35}$. La similitude des arguments du chancelier dans sa critique de la justice et ceux que Montaigne avait développés dans une intervention au cours d'une séance précédente destinée à préparer la séance officielle a souvent été soulignée. Montaigne déplorait en particulier le trop grand nombre d'officiers et la vénalité des charges.

Le discours de L'Hospital exerça sur Montaigne une forte et durable impression, dont l'effet se retrouve dans les Essais ${ }^{36}$. Le chapitre «Des Cannibales » s'ouvre en effet sur les exempla utilisés par L'Hospital, ainsi que l'a révélé Loris Petris, et reprend en particulier la conclusion de ceux-ci, opposant barbares et non barbares $^{37}$ : d'un côté l'exemple de Pyrrhus et les paroles de celui-ci «Je ne sçay [...] n'est aucunement barbare», celui des Grecs et celui de Philippe ${ }^{38}$; de l'autre celui de Philippe et les mots de ses éclaireurs "point armée barbare», et celui de Paul Emile et les mots des Macédoniens, «festin à la grecque et non à la barbare». L'intertexte est le recueil des Vies de Plutarque, auquel a recours Montaigne pour proposer une variation sur la formule de L'Hospital, et non pas pour masquer un emprunt. Dans son discours, le chancelier avait tiré de ces exemples le moyen d'une

34 Ibid., p. 1113 ; sur les conceptions juridiques de Montaigne, voir G. Hubrecht, "Montaigne juriste», dans IVe Centenaire de la naissance de Montaigne. Conférences organisées par la ville de Bordeaux, Bordeaux, Delmas, 1933, p. 239-297.

35 Voir C.-B. Boscheron Des Portes, Histoire du Parlement de Bordeaux depuis sa création jusqu'à sa suppression (1451-1790), Bordeaux, Lefèvre, 1877, t. I, p. 191193.

36 Selon Hubrecht, Montaigne aurait pu se sentir personnellement visé par les reproches du chancelier, «Montaigne juriste», op. cit., p. 271.

37 L'Hospital, Discours et correspondance, p. 15 et 72.

38 Les Essais, I, 30 (31), éd. cit., p. 208. 
double célébration en une subtile gradation, d'une part la célébration du parlement réuni devant lui, une assemblée qu'il cherchait à séduire en la qualifiant de "toute romaine ou bien grecque", d'autre part celle du roi et de la monarchie, qu'il proclamait très supérieurs aux Romains eux-mêmes, et donc au Parlement. Chez Montaigne en revanche, les exemples illustrent un paradoxe, au sens rhétorique et argumentatif du terme, et servent à fonder un discours critique:

Voilà comment il se faut garder de s'attacher aux opinions vulgaires, et les faut juger par la voye de la raison, non par la voix commune.

Ces exemples seraient-ils simplement un souvenir que Montaigne aurait mis en œuvre, de façon approximative, comme une ressource topique, pour fonder son exorde? La relation à L'Hospital serait-elle seulement de l'ordre de l'imitation et de la copia dicendi ? À côté de sa portée anthropologique bien connue, le chapitre «Des Cannibales » avait une portée symbolique. Il a servi à Montaigne, ainsi que l'a démontré Philippe Desan, à récrire en termes nobiliaires un épisode lié à sa carrière de magistrat subalterne. À cette fin, Montaigne situait à Rouen l'épisode de la rencontre avec les Indiens, dans l'entourage royal, et non pas à Bordeaux, où elle avait effectivement eu lieu, devant le chancelier ${ }^{39}$. On ajoutera même une troisième clé de lecture. À la fin du chapitre, Montaigne rapporte son entretien avec les Indiens, qui lui permettait de faire une sévère critique des institutions et de la société française, sous la fiction d'un discours naïf rapporté. Le premier trait dont ses interlocuteurs soulignaient l'absurdité de leur point de vue «barbare», était que le pouvoir fût confié à un roi enfant, que

De grand hommes portant barbe, forts et armez [...] se soubmissent à obeir à un enfant.

Or la question de la majorité de Charles IX, un roi-enfant avait été fort débattue depuis 1560. L'Hospital lui-même avait joué un rôle décisif dans la déclaration de la majorité royale, au cours du lit de justice, qui se tint précisément devant le parlement de Rouen,

39 Voir P. Desan, Montaigne, op. cit., p. 179-189. 
le 17 août $1563^{40}$. Ce n'est sans doute pas un hasard alors si Montaigne déplaçait à Rouen l'épisode des Cannibales, pour donner, par la bouche de ceux-ci, une réponse ironique à ce qu'il pouvait considérer comme un nouveau coup de force anti-parlementaire de L'Hospital.

Publiée en 1580 dans les Essais, longtemps après l'événement, après la mort du roi et après celle du chancelier, la satire de Montaigne n'avait plus qu'une portée générale et l'allusion polémique était devenue indéchiffrable à la plupart des lecteurs. Le chapitre «Des Cannibales» révèle pourtant la dynamique de longue durée qui anime le livre de Montaigne. Le discours, allusif voire crypté, qui met en œuvre la référence à L'Hospital est décalée de l'actualité. Ce décalage doit conduire à dissocier les enjeux de l'œuvre littéraire de Montaigne de ceux de sa première carrière. Or c'est dans le cadre de cette première carrière que la relation avec L'Hospital pouvait avoir un sens, sous forme d'approbation ou d'hostilité. Cette relation semble avoir été nuancée. D'un côté, la leçon du chancelier a sans doute confirmé la position critique de Montaigne face à la pratique judiciaire des juridictions bordelaises à laquelle il était lui-même intéressé. Mais les positions étaient tranchées en termes politiques, religieux et idéologiques. L'Hospital rappelait aux parlementaires leur devoir de soumission à l'autorité royale; sa pratique politique de tolérance se heurtait à la pratique d'un Parlement et d'un Montaigne engagés dans la lutte contre les «remuements et nouvelletés ${ }^{41}$; c'est enfin contre un chancelier penchant vers la Réforme que Montaigne ne cessait de confirmer publiquement son catholicisme. Quinze ans plus tard, voire vingt ans pour le livre III, dans les Essais, tout ce qui avait trait au chancelier appartenait à l'histoire et servait, dans un contexte politique renouvelé, pour nourrir un projet littéraire et moral inédit.

C'est ce point qui devrait être développé, sur un mode comparatif, indépendamment des relations effectives entre les deux hommes. Montaigne et L'Hospital appartenaient à deux générations différentes, et en tant qu'écrivains, ils avaient été formés en d'autres lieux. Ils partageaient d'innombrables références

40 Voir L'Hospital, Discours et correspondance, p. 40-57.

41 R. Ritter, «L'Hospital et Montaigne devant les guerres civiles », BSAM, 30 (1964), p. 57-59. 
communes et une même expression de l'èthos, ils avaient en commun un même idéal héroïque, centré autour de la notion de constance, de maîtrise, ainsi qu'une forme d'universalisme ${ }^{42}$. Toutefois, ils ne s'inscrivaient pas exactement dans la même culture; autant que les similitudes et les continuités comptent les différences et les singularités: d'un côté, chez L'Hospital, la quintessence des pratiques lettrées de la Grande robe et une spiritualité évangélique, de l'autre, une culture nobiliaire moderne et un catholicisme polémique. L'écriture personnelle des Essais, en prose et en français, destinée à des gentilshommes et des dames, rompt entièrement avec la langue, l'art et les lecteurs des Poemata de L'Hospital. On pourra même se demander si le projet des Essais ne peut pas s'éclairer par cette relation, de façon positive, sous la forme d'une émulation avec un ancien modèle littéraire prestigieux et le magistère moral exercé par L'Hospital sur la génération de 1560, mais aussi sous une forme négative, comme une réaction contre lui. À la fin du chapitre "Sur des vers de Virgile», Montaigne évoque sa première expérience littéraire:

Quand je me meslois de faire des vers (et n'en fis jamais que des Latins) ils accusoient evidemment le poëte que je venois dernierement de lire ${ }^{43}$.

Il n'est pas impossible que les Essais soient nés d'un refus initial peut-être lié à un échec dont ils porteraient la marque: le rejet par Montaigne du code de la poésie néo-latine comme mode d'expression et comme statut, faute de parvenir à l'excellence et à l'originalité. Ce choix l'aura conduit au pari d'une œuvre sans précédent, des sermones en langue vulgaire, dans laquelle il pouvait parler de soi et tenir un discours moral, sans singer ni les anciens ni L'Hospital, le plus illustre poète néo-latin français.

Jean BALSAMO Université de Reims

42 Sur ce point, voir en particulier L. Petris, «Trois magistrats écrivains face au stoïcisme à la Renaissance: L'Hospital, Pibrac, Montaigne», dans Stoïcisme et christianisme à la Renaissance, "Cahiers V.-L. Saulnier», n 23, Paris, ENS, 2006, p. 71-91.

43 Les Essais, III, 5, éd. cit., p. 918. 
过

ํํำ

는

국

(2)

(1)

甲 


\title{
LETTRES INÉDITES DE MICHEL DE L'HOSPITAL
}

\author{
éditées par Loris Petris
}

Ces lettres, toutes inconnues, complètent les œuvres françaises éditées dans Petris, La Plume et la tribune et L'Hospital, Discours et correspondance ${ }^{1}$.

\section{BIS. [1559], 5 SEPTEMBRE, [CHARLES DE GUISE] À MICHEL DE L'HOSPITAL, [VILLERS-COTTERÊTS] ${ }^{2}$}

\section{Mons $^{\mathrm{r}}$ de L'Hospital,}

Le Roy vous escript et envoye les lectres pour Mons ${ }^{r}$ de Savoye qu'il luy escrit de sa main pour accompagner Madame sa tante, laquelle il luy recommande infiniment. Vous verrez comme c'est qu'elle se trouvera là à ce commancement, et puys, incontinant que je penseray que pouvez estre arrivé là ${ }^{3}$, je vous feray escrire ung

1 On ne retient pas la lettre du 20 septembre 1566 de Henri de Mesmes à un destinataire inconnu, identifié à tort par Ph. Tamizey de Larroque comme L'Hospital, et cela pour différentes raisons: rien ne prouve que le destinataire soit L'Hospital, à qui Mesmes écrit habituellement en latin et avec qui aucune relation d'Angelo Vergerio n'est attestée, contrairement à ce que Mesmes écrit dans la lettre: «[...] un tel home, qui vous a servy en vos premiers ans, qui est unique en son art et qui est en extrême pauvreté » BNF, fr. 15882 (non paginé), édité par Ph. Tamizey de Larroque, «Un document inédit relatif au calligraphe Ange Vergèce», Revue critique d'histoire et de littérature, VI/1 (1872), p. 159-160.

2 Voir Lettres du cardinal Charles de Lorraine, p. 361. Je remercie Vladimir Chichkine de m'avoir signalé l'original de cette lettre ainsi que celui de la suivante.

3 À Nice, où Marguerite de France allait rejoindre son nouvel époux, Emmanuel-Philibert de Savoie, et où elle arriva à la mi-février 1560. Le récit de 
mot de lectre par le Roy pour vous mander et faire revenir ${ }^{4}$. Car nous serons bien ayses d'entendre de vous comme c'est qu'ilz seront accommodez, le traictement qu'elle aura receu et le contentement qu'elle en aura. Je faictz escrire au conte de Tende ${ }^{5}$ qu' $^{\prime}$ il ayt à venir jusques à Avignon au davant d'elle, avec la partie de noblesse qu'il pourra, pour l'accompagner jusques à Marseille, où j'ay entendu que Mons ${ }^{r}$ de Savoye se doibt trouver. Et là leur ferez tout l'honneur et bonne chere dont il se pourra adviser. Et semblablement est mandé à mon frere le Grand Prieur ${ }^{6}$ ou à son lieutenant sur les gallaires, qu'il ayt à l'accommoder, si elle veult aller par mer, de telle quantité de gallaires qu'elle vouldra et en aura besoing. Je ne sçauroys que vous dire, si n'est que je vous prie m'entretenir en la bonne grace de madite dame et l'asseurer bien honnestement pour moy qu'elle ne trouvera jamais de plus affectionné serviteur que je luy seray toute ma vie. Et prieray Dieu, Mons $^{r}$ de L'Hospital, vous donner bonne et longue vie. Le 5 septembre.

Orig. : Saint-Pétersbourg, Bibliothèque nationale de Russie, Département des manuscrits, Collection Dubrovsky, Dossier 17, $\mathrm{n}^{\circ} 18$.

Copie: BNF, Nafr. 1234 , fol. $17 \mathrm{r}^{\mathrm{O}}-\mathrm{v}^{\mathrm{o}}$.

son voyage avec Michel de L'Hospital est rapporté dans l'épître V, 9 Iter Nicaeum.

4 Charles de Guise à Michel de L'Hospital, Blois, 2 février 1560, dans L'Hospital, Discours et correspondance, p. 161-162, lettre no 15.

5 Claude de Savoie, comte de Tende et frère de Madeleine de Savoie, l'épouse du connétable Anne de Montmorency.

6 François de Guise, grand prieur des galères depuis mars 1549. Quand L'Hospital apprit sa nomination comme chancelier, il partit et «arriva à Chinon, où $\mathrm{M}^{\mathrm{r}}$ le duc de Guyse le fit chevalier» (Jules Gassot, Sommaire mémorial, éd. P. Champion, Paris, H. Champion, 1934, p. 26). 


\section{TER. [1559], DÉCEMBRE, FRANÇOIS II À MICHEL DE L'HOSPITAL, CHAMBORD}

\section{Mons $^{\mathrm{r}}$ de L'Hospital,}

Je vous envoye une petite lectre que j'escriptz de ma main pour mon oncle Mons ${ }^{r}$ de Savoye ${ }^{7}$ en creance sur vous, par laquelle je luy recommande ma tante ${ }^{8}$ comme l'une des choses de ce monde que j'ay le plus chere, vous priant le luy faire bien entendre et tesmoigner tant l'amytié que je luy porte qu'il congnoisse qu'il ne scauroyt jamays riens tant faire pour me monstrer l'amytié qu'il me porte et m'en donner parfaicte asseurance qu'en l'aymant comme ses vertuz meritent et la traictant comme ma tante que j'ayme et honore infiniment. Et ancores que je m'asseure qu'il l'ayme et estime tant qu'il ne vouldra y faire faulte, si est ce que, recevant bien la recommandation que je luy en faictz comme il doibt, elle ne servira qu'à luy en croistre et augmenter la volunté. A quoy vous adjousterez ancores tout ce que vous pensez pouvoir servir à luy en donner telle asseurance qu'il croie fermement que il n'y a moyen qu'il y manque pour plus nourrir l'amytié qui est entre nous que l'amour et bon traictement dont il usera à l'endroict de madite tante, le contentement de laquelle j'estimeray comme le mien propre. Et pour n'avoir de quoy vous faire la presente plus longue, je prieray Dieu, Mons ${ }^{r}$ de L'Hospital, vous avoir en Sa saincte garde. De Chambord, ce ... jour de decembre.

Orig. : Saint-Pétersbourg, Bibliothèque nationale de Russie, Département des manuscrits, Collection Dubrovsky, Dossier 17, $\mathrm{n}^{\circ} 21$.

Copie: BNF, Nafr. 1234, fol. $7 \mathrm{r}^{\mathrm{O}}-\mathrm{v}^{\mathrm{o}}$.

7 Emmanuel-Philibert, duc de Savoie.

8 Marguerite de France, devenue duchesse de Savoie par son mariage avec Emmanuel-Philibert. 


\section{BIS. 1564, 31 JUILLET, PIERRE SÉGUIER ET GUY DU FAUR}

\section{À MICHEL DE L'HOSPITAL ${ }^{9}$, PARIS}

\section{Monseigneur,}

Nous sommes de retour de Calais apres avoir bien au long conferé de tous les differens avec les deputez de la Majesté catholique. Et pour ce, Monseigneur, que le discours feroit noz lettres trop longues, nous avons dressé et signé ung memoire que vous envoions pour (s'il vous plaist) le fere entendre au Roy et à la Royne, ainsi que sera advisé pour le mieulx. Et semble, Monseigneur, estre besoing y pourveoir, sinon qu'on vueille dissimuler les entreprises de ceulx de Gravelines, car ilz nous ont declarez qu'ilz garderont leurs possessions.

Monseigneur, ilz ont faict une ouverture pour les enclaves $\mathrm{d}^{\prime}$ Arthois et ung offre pour ceste presente controverse. Tout cela, neant. De nostre part, Monseigneur, apres y avoir pensé, nous avons offert (et à nostre advis) plus que ne debvons mais ce a esté pour achapter paix. Les officiers du Roy à Calais se tiennent contrains en toutes les contrarietez, qu'ils fourniront tesmoings. Mais nous avons apris que de l'autre costé ilz n'en auront pas moings.

Monseigneur, vous adviserez par vostre prudence accoustumée à y donner quelque ordre et attandant, Monseigneur, nous prions Dieu vous donner en parfaicte santé treslongue et tresheureuse vye. Escris à Paris ce dernier jour de juillet 1564 .

\section{Voz treshumbles et tresobeissans serviteurs}

P. Seguier G. Dufaur

Orig. : BNF, fr. 6619 , fol. $90 \mathrm{r}^{\circ}$.

9 Adresse: «Messieurs les Conseillers Seguier et Du Faur, du dernier juillet 1564. Monseigneur, Monseigneur le Chancelier». 


\section{BIS. 1571, 2 JUILLET, MICHEL DE L'HOSPITAL À MADELEINE DE L'HOSPITAL, BUTTE DE CHAUMONT ${ }^{10}$}

Ma fille,

Oultre nos memoires et letres que ay escriptes et escris à Monsieur de Belesbat, je vous prie, trouvant la Reine à propos, apres vos discours, luy dire que de la bonté du Roy et sienne je retiens les marques et ensegnes de chancelier encores que l'exercice n'i soit, qu'il a desja douze ans que suis en l'estat, que la tapisserie de fleur de lis est usée, que son plaisir soit fere ordonner et commander une tapisserie de fleur de lis de sale et chambre, et en charger le grand audiencier et son commis de la fere fere et la me delivrer et paier sur les deniers de Sens, comme l'on a aprins cy devant. Et, combien que les chanceliers aient cy devant acostumé l'ordoner sans en parler au Roy, toutefois je ne le veulx entreprandre et me semblera mieulx que le commandemant de leur Majesté y soit. Et luy dirés que, si l'on voit ma maison sans fleur de lis, les bonnes gens panseront que ne suis plus chancelier. Si elle vous l'acorde, ferez fere ung ordonnance signée d'ung secretaire d'Estat pour la bailler sur l'audiancier, et ferez que la Roine luy commande et ferez solliciter que la besogne soit advancée. Et qu'il $\mathrm{y}$ ait pieres pour remplir une bien grand sale et chambre. Toutesfois ceci suivra nos plus grans affaires. Tout se porte bien icy, Dieu mercy. Et nous recommanderons à votre bonne grace, prians Dieu vous tenir en la sienne. De Bute ${ }^{11}$ deuz ${ }^{\mathrm{e}}$ julies 1571.

Votre bon pere M. Delospital

Orig. autogr. : Londres, British Library, Add Ms 18741, fol. 41.

\footnotetext{
10 Adresse: «À ma fille Madamoisele de Belesbat».

11 Butte de Chaumont, à une dizaine de kilomètres au sud-est de Champmotteux et de Gandevilliers, proche du Vignay où L'Hospital se trouve encore le 31 mai (lettre no 77; L'Hospital, Discours et correspondance, p. 264-265).
} 
过

ํํำ

.

큼

국

(2)

(1)

甲

(8) 


\section{TABLEAU SYNOPTIQUE DES CARMINA}

Afin de faciliter la localisation des poèmes de L'Hospital, nous reproduisons ici le tableau synoptique des principales éditions des Carmina publié dans Petris, La Plume et la tribune, p. 549-556. La numérotation se fonde sur l'édition la plus complète, $A$ (Amsterdam, B. Lakeman, 1732).

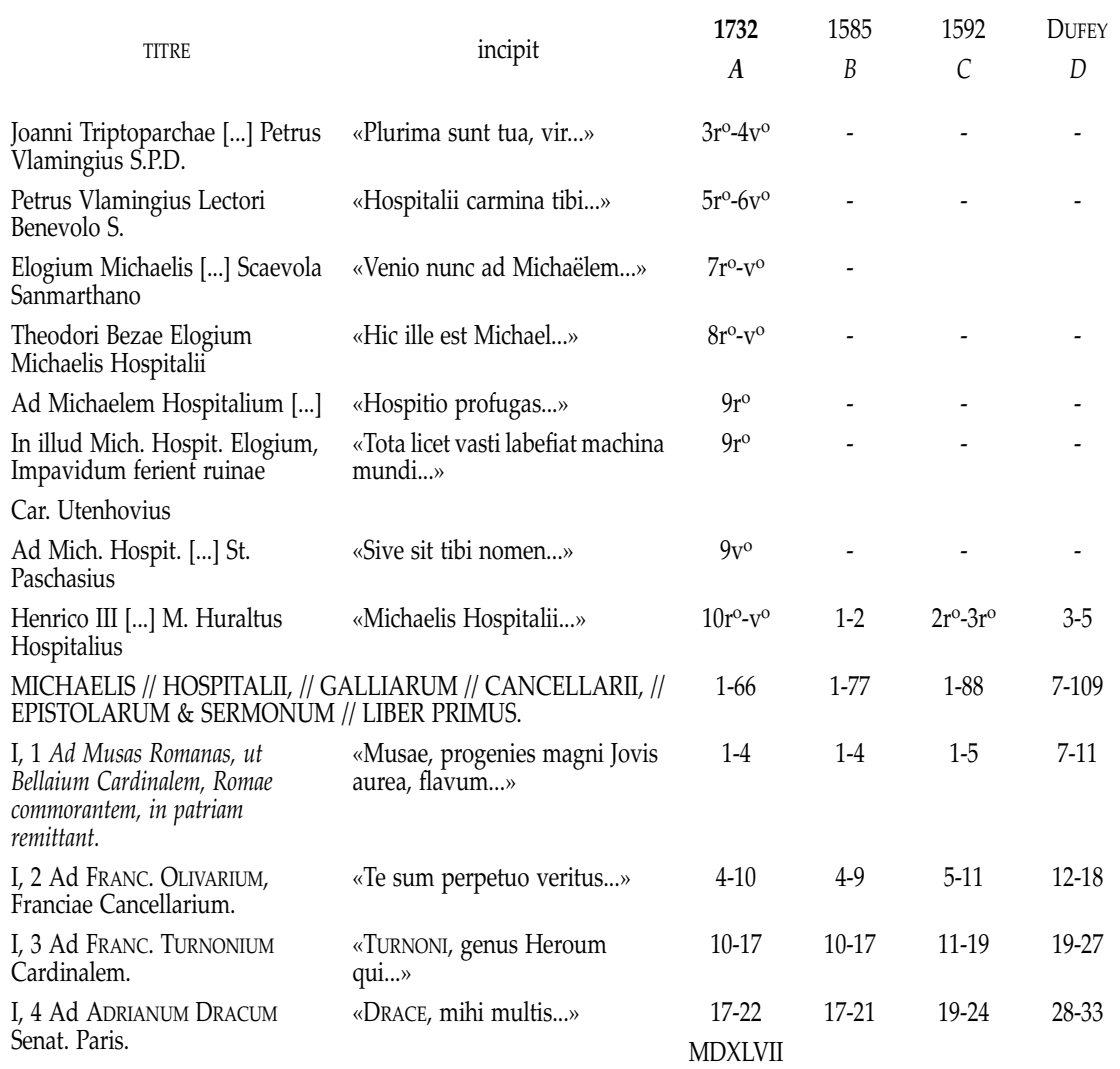


TITRE

incipit

I, 5 Ad Pontronium, Margar.

Franc. Regis filiae

Praeceptorem.

I, 6 Ad Geor. ArmenIACum

Cardinalem. Ex morbis quae

utilitas percipi possit.

I, 7 Ad Claud. ESPENS. nobiliss. $\&$ doctiss. Theologum, de poësi

Christiana judicium, \&

exemplum.

I, 8 Ad Jo. Bellaium Card. \& Episcop. Hostiensem.

I, 9 Ad Odetum Castillionaeum

Cardinalem. Consolatio in matris luctu.

I, 10 Ad Jo. Bellaium Card. \& Episcop. Hostiensem.

I, 11 Ad Achillem Bocchium

Poëtam \& Equitem

Bononiensem, de fide

Christiana.

I, 12 Ad Lancelotum Carlum, Episcopum Regiensem.

I, 13 Ad Petrum Castellanum, Regium Doctorem.

I, 14 Ad Jo. Card. Bellaium.

I, 15 Ad Margaretam Valesiam, Regiam Virginem, Francisci

Regis Filiam, De sacris

Carminibus M.A. Flaminii.

\section{LIBER SECUNDUS}

II, 1 De morbo tertianae quo laboravit ann. MDLII. ad Illustriss. Principem Carolum Card. Lothar.

II, 2 Ad Margaretam Valesiam Regiam Virginem.

II, 3 Ad Jo. Bellaium

Cardinalem.

II, 4 Ad CARDINALEM

LOTHARING.

II, 5 Ad Petr. Montaureum, magni concilii R. Senatorem, elegantissimum poëtam, \&

Mathematicum

praestantissimum.

II, 6 Ad JaCOB. FabRUm Litium execratio.

II, 7 Ad Franciscum Olivarium, Franciae Cancellarium, de causa Merindolii Lutetiae acta in

Senatu. revixi!...»

videre...»

longissima venit...»
«PONTRONI, quid agit nunc regia virgo...»

«COENANTI mecum FABRO,

manibusque recentem...»

«Qui, pater ESPENSI, qui fit res carmine sacras...»

«DONEC vos bello miles vexavit...»

«Tu quem tot natura bonis

ornavit abunde...»

«Jampridem numero menses...»

«BocchI, percelebri jamdudum cognite fama...»

«Dissimulare etiam potuisti,

CARLE...»

«CASTELLANE decus

Musarum...»

«QUAE mihi Campanis...»

«EST modo quod miserum

possis defendere Flaccum...»

$51-5$

$53-63$

$$
\text { 63-6 }
$$

64-66

24-27
DUFEY

D

23-24 21-22

24-25

34-35

$22-26$

25-29

$36-40$

27-37 26-36

29-41

41-52

$\left.\left({ }^{*} 40\right)-41\right)$

37-38 $\quad 36-37 \quad 41-43 \quad 53-55$

$39-42 \quad 38-40 \quad 43-46 \quad 56-59$

$42-47 \quad 40-46 \quad 46-52 \quad 60-66$

$\begin{array}{llll}48-51 & 46-49 & 53-56 & 67-70\end{array}$

$51-53 \quad 49-50 \quad 56-57 \quad 71-72$

$\begin{array}{lll}3-63 & 68-77 \quad 78-88 \quad 99-109\end{array}$

$\begin{array}{llll}63-64 & 66 & 76 & 95\end{array}$

67-131 $\quad 78-144 \quad 89-164 \quad 113-201$

«UT biduo plane perii, biduoque

$67-73 \quad 51-57 \quad 58-64 \quad 73-80$

«ANTE fores me, Diva, tuas

$\begin{array}{llll}73-77 & 57-60 & 65-68 & 81-85\end{array}$

«Tandem, BeLLAI, superas...»

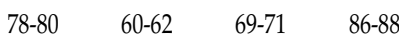

«LOTHARI magnum...»

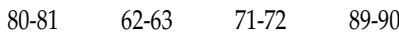

«UlTima quae nobis a te

$81-84 \quad 63-66 \quad 73-76 \quad 91-94$

«O Rabidae lites, \& jurgia...»

\begin{tabular}{|c|c|c|}
\hline $\begin{array}{c}\text { 84-89 } \\
\text { MDXLIIX }\end{array}$ & 78-82 & $89-94$ \\
\hline $89-92$ & 104-107 & $119-122$ \\
\hline
\end{tabular}

«Quid Romana bonus, quid Graeca per oppida Rhetor...» 
TITRE

incipit

II, 8 Ad Margaretam Regis sororem.

II, 9 Ad Illustriss. principem CAROLUM Card. Lothar.

II, 10 Ad Franc. Olivarium, Franciae Cancellarium, post secessum.

II, 11 Ad JOANNEM CARDINALEM Bellaium.

II, 12 Ad P. CRASSINUM, doctissimum Senatorem.

II, 13 De Meti Urbe a FR. LOTHARINGO GUSIANO defensa.

II, 14 Ad Henricum II.

II, 15 Ad Margaritam Regis sororem.

II, 16 Ad Lancelotum CARLum Episc. Rhegiensem.

II, 17 Ad SALMONIUM

MACRINUM.

II, 18 Ad CAROLUM

MARILLIACUM Archiepiscopum Viennensem, \& Regis in sacro Consistorio consiliarium.

II, 19 Ad illustrissimum principem CAROLUM Cardinalem Lotharingum, In P. Ronsardi commendationem.

II, 20 Ad Hospites.

\section{LIBER TERTIUS}

III, 1 Ad Franciscum

OLIVARIUM, Franciae

Cancellarium.

III, $1 \mathrm{~b}$ Francisci OLIVARII, ad superiorem Epistolam RESPONSIO

III, 2 Ad Janum Morellum, de matribus, quae filios suos ipsae non alunt, nec apud se domi educari patiuntur.

III, 3 In HenRICUM II. ad Carolum Lotharingum Card.

III, 4 Ad Odetum Cardinalem CASTILIONEM.

III, 5 Ad CARDINALEM

LOTHARINGUM.

III, 6 Ad CAROLUM

LOTHARINGUM Cardinalem.

III, 7 Ad Janum Bellaium Cardinalem. probaret,...»

minacis...»

Mavortia...»

«I Felix, quo te...» inermis...»

assuescere rebus,...» norat Homeri...» scripsisse...» rure futurum,...» auctore subortus...» nititur ipse...»

Carole, nugis...»
«EN toties nova cura subit...»

«SI virtus \& sola viris se forma

«Vicit, OLIVARI, tua virtus saeva

«ERGO tibi reditum...»

«QUICQUID ubique latet...»

«ERGO militibus tandem

«EsT illud quod saepe queri,...»

«IBIS, amice, tuo Regi comes, ibis

«PAUPERIES semper...»

«CERTE ut difficile est duris

«QuAM facile in multis antiqui

128-130

$122-12$

139-141

173-175

«Hospitibus caris ad nos...»

130-131

124-126

$141-143$

176-177

132-188

145-198

165-227

205-277

«TOT Francisce dies me nil

132-138

$145-152$

165-172

205-213

«JANUS MORELLUS tuam nobis epistolam reddidit,...»

139-141

$152-15$

$173-176$

214-217

«QUINQUE dies tantum dixi me

141-146

154-158

176-181

218-223

«CAROLE, si vano non est

«NEMPE suis, mi Castilio, qui

«SCIS tamen ista maris...»

«Qui te distineat levibus nunc,

«NUNC canas hiemes...»
$146-148 \quad 142-144 \quad 162-164 \quad 199-201$

$148-151 \quad 159-161 \quad 182-184 \quad 224-226$

$151-154 \quad 161-164 \quad 185-189 \quad 227-231$

$154-160 \quad 136-142 \quad 155-162 \quad 191-198$

$160-162 \quad 194-196 \quad 223-225 \quad 272-274$ 


\begin{tabular}{|c|c|c|c|c|c|}
\hline TITRE & incipit & $\begin{array}{c}1732 \\
A\end{array}$ & $\begin{array}{c}1585 \\
B\end{array}$ & $\begin{array}{c}1592 \\
C\end{array}$ & $\begin{array}{l}\text { DuFEY } \\
\text { D }\end{array}$ \\
\hline III, 8 Ad SALMONIUM MACRINUM. & «SI videas, Macrine.... & $\begin{array}{l}\text { 162-164 } \\
\text { MDXLVI }\end{array}$ & $196-198$ & $225-227$ & $275-277$ \\
\hline III, 9 Ad SAL. MACRINUM. & «NON ego tot...» & $165-166$ & $235-236$ & $269-270$ & $324-325$ \\
\hline $\begin{array}{l}\text { III, } 10 \text { Ad Jo. BelLaiUm } \\
\text { Cardinalem. }\end{array}$ & «O mihi te qualem plectro...» & $166-168$ & $184-185$ & $211-213$ & $257-259$ \\
\hline $\begin{array}{l}\text { III, } 11 \text { Ad Illustr. MARGARITAM } \\
\text { Regis sororem. }\end{array}$ & $\begin{array}{l}\text { «FORTE fuit tecum mihi sermo } \\
\text { Diva...» }\end{array}$ & 168-174 & $185-191$ & 213-219 & $260-267$ \\
\hline $\begin{array}{l}\text { III, } 12 \text { Ad CAROLUM } \\
\text { LOTHARINGUM Cardinalem. }\end{array}$ & $\begin{array}{l}\text { «QUAM te nostra diu } \\
\text { praesentem Gallia vidit,...» }\end{array}$ & 174-176 & 191-194 & $219-222$ & $268-270$ \\
\hline $\begin{array}{l}\text { III, } 13 \text { Ad BART. FAIUM } \\
\text { Senatorem Parisiensem. }\end{array}$ & «PRIME Senatorum, nostri...» & 176 & 194 & 222 & 271 \\
\hline $\begin{array}{l}\text { III, } 14 \text { Ad JANUM MoReLLUM, } \\
\text { Ebredunaeum. }\end{array}$ & $\begin{array}{l}\text { «Hae mea quorundam } \\
\text { sermonibus...» }\end{array}$ & 177-181 & $131-136$ & 149-155 & $185-190$ \\
\hline $\begin{array}{l}\text { III, } 15 \text { Ad MARGARITAM Regis } \\
\text { Sororem. }\end{array}$ & «MENTITO toties Remorum...» & 181-183 & $238-240$ & $272-275$ & $328-330$ \\
\hline $\begin{array}{l}\text { III, } 16 \text { Ad Paullum Camborea } \\
\text { VIlla Regia. }\end{array}$ & «CAMBOREAE qui visus ager...» & 183-184 & $126-127$ & $143-145$ & $178-179$ \\
\hline $\begin{array}{l}\text { III, } 17 \text { In Librum ANDRAEAE } \\
\text { TIRAQUELLI de Legibus } \\
\text { connubialibus. }\end{array}$ & $\begin{array}{l}\text { «QUI nondum plane tersus, } \\
\text { nondumque politus...» }\end{array}$ & $\begin{array}{l}\text { 185-186 } \\
\text { MDLIV }\end{array}$ & $127-128$ & $145-147$ & $180-181$ \\
\hline $\begin{array}{l}\text { III, } 18 \text { Ad LANCELOTUM CARLUM, } \\
\text { Episc. Reginensem. }\end{array}$ & $\begin{array}{l}\text { «Quid tu, quid Frexus, quid } \\
\text { melle...» }\end{array}$ & 186-188 & $129-131$ & $147-149$ & $182-184$ \\
\hline LIBER QUARTUS & & $189-230$ & $199-254$ & $228-291$ & $281-350$ \\
\hline $\begin{array}{l}\text { IV, } 1 \text { Ad FRANCISC. } \\
\text { LoTHARINGUM Ducem } \\
\text { Guisianum. De Duce Guisio e } \\
\text { Latio sub cladem Quintinianam in } \\
\text { Galliam redeunte. }\end{array}$ & $\begin{array}{l}\text { «AuT tu rem nobis convulso } \\
\text { cardine lapsam...» }\end{array}$ & $\begin{array}{l}\text { 189-195 } \\
\text { MDLVII }\end{array}$ & $165-171$ & $189-196$ & $232-239$ \\
\hline $\begin{array}{l}\text { IV, } 2 \text { De CALETI ET GUINAE } \\
\text { oppidorum expugnatione. }\end{array}$ & $\begin{array}{l}\text { «SIC mutat Fortuna vices, \& } \\
\text { ludit atrocem...» }\end{array}$ & 195-199 & $171-174$ & $196-200$ & $240-244$ \\
\hline IV, 3 DE TheaVILla CAPTA. & «UT gravis \& senio...» & 199-203 & $175-179$ & $200-205$ & $245-250$ \\
\hline $\begin{array}{l}\text { IV, } 4 \text { Ad MARGARITAM Regis } \\
\text { sororem. }\end{array}$ & «EN, VIRGO, tibi nobilium...» & 203-205 & $179-180$ & $205-207$ & $251-252$ \\
\hline $\begin{array}{l}\text { IV, } 5 \text { Ad CAROLUM } \\
\text { LOTHARINGUM Cardinalem. }\end{array}$ & $\begin{array}{l}\text { «USQUE adeo magnum est } \\
\text { componere...» }\end{array}$ & 205-206 & 181-182 & $207-209$ & $253-254$ \\
\hline $\begin{array}{l}\text { IV, } 6 \text { Ad CARDINALEM } \\
\text { LOTHARINGUM. }\end{array}$ & «Hos ego versiculos...» & 206-208 & $182-184$ & 209-211 & $255-256$ \\
\hline $\begin{array}{l}\text { IV, } 7 \text { Ad VIDUM FABRUM. De } \\
\text { amore \& ignoratione sui. }\end{array}$ & $\begin{array}{l}\text { «MORTALES animos agit } \\
\text { ignorantia...» }\end{array}$ & 208-214 & $199-205$ & $228-235$ & $281-288$ \\
\hline $\begin{array}{l}\text { IV, } 8 \text { SERMO In LuXUM. Ad Chr. } \\
\text { THUANUM P. PAR. }\end{array}$ & «AEQUIUS ad postem...» & $214-228$ & $205-219$ & $235-251$ & 289-305 \\
\hline IV, 9 Ad MusAS. & «MUSAE, quas...» & $228-229$ & $292-293$ & $334-335$ & $400-401$ \\
\hline IV, 10 Ad P. VictorIUM. & «VICTORI, tanto...» & $229-230$ & $336-338$ & $384-386$ & $458-460$ \\
\hline
\end{tabular}




\begin{tabular}{|c|c|c|c|c|c|}
\hline TITRE & incipit & $\begin{array}{c}1732 \\
A\end{array}$ & $\begin{array}{c}1585 \\
B\end{array}$ & $\begin{array}{c}1592 \\
C\end{array}$ & $\begin{array}{l}\text { Dufey } \\
\text { D }\end{array}$ \\
\hline LIBER QUINTUS & & $231-289$ & $255-320$ & $292-367$ & $353-436$ \\
\hline $\begin{array}{l}\text { V, } 1 \text { In FRANCISCI illustriss. } \\
\text { Franciae Delphini, \& MARIAE } \\
\text { sereniss. Scotorum Reginae } \\
\text { nuptias. }\end{array}$ & $\begin{array}{l}\text { «MENE etiam cantare jubes \& } \\
\text { ludere versu...» }\end{array}$ & $231-236$ & 240-244 & $275-280$ & $31-336$ \\
\hline $\begin{array}{l}\text { V, } 2 \text { Ad CAROLUM } \\
\text { LOTHARINGUM Cardinalem. }\end{array}$ & «HunC etiam cari morbo qui...» & $236-237$ & $245-246$ & $280-282$ & $337-33$ \\
\hline $\begin{array}{l}\text { V, } 3 \text { Ad MARGARITAM Regis } \\
\text { sororem. }\end{array}$ & «AfFLICtum Regina malis...» & $237-242$ & $246-251$ & $282-288$ & $339-34$ \\
\hline $\begin{array}{l}\text { V, } 4 \text { Ad CAROLUM Cardinalem } \\
\text { Lotharingum. }\end{array}$ & $\begin{array}{l}\text { «Si Pacem tecum referes, tua } \\
\text { munia Regi...» }\end{array}$ & $242-244$ & $251-253$ & $288-290$ & $346-3$ \\
\hline V, 5 Ad JANUM MorvilLIERIUM. & «SIQUIS agro longe veniens...» & $245-259$ & $220-234$ & $251-268$ & $306-323$ \\
\hline $\begin{array}{l}\text { V, } 6 \text { Ad FRANC. OLIVARIUM, } \\
\text { Franciae Cancellarium. }\end{array}$ & «VoBiscum Remos una comes...» & $259-261$ & $283-284$ & $324-326$ & $387-389$ \\
\hline $\begin{array}{l}\text { V, } 7 \text { Ad ampliss. illustriss.que } \\
\text { Principem CAROLUM } \\
\text { CARDINALEM LOTH. EPIGRAMMA. }\end{array}$ & $\begin{array}{l}\text { «Hoc etiam loculis munus tibi, } \\
\text { CAROLE, nostris...» }\end{array}$ & 261 & 254 & 291 & 350 \\
\hline $\begin{array}{l}\text { V, } 8 \text { De sacra FRANCISCI II. } \\
\text { Galliarum Regis initiatione, } \\
\text { regnique ipsius administrandi } \\
\text { providentia. }\end{array}$ & $\begin{array}{l}\text { «CAELESTI est oleo Mariae Puer } \\
\text { unctus ad aram...» }\end{array}$ & $262-272$ & $255-266$ & $292-305$ & $353-3$ \\
\hline $\begin{array}{l}\text { V, } 9 \text { Ad JAC. FABRUM Iter } \\
\text { Nicaeum. }\end{array}$ & «TREIS adeo totos descripsit...» & $273-289$ & $266-283$ & $305-323$ & $367-3$ \\
\hline LIBER SEXTUS & & $290-349$ & $321-377$ & $367-432$ & $439-513$ \\
\hline $\begin{array}{l}\text { VI, } 1 \text { Ad CAROLUM CARDINALEM } \\
\text { Lotharingum. TRIDENTUM } \\
\text { MDLXIII }\end{array}$ & $\begin{array}{l}\text { «Dum tuus hic bellum germanus } \\
\text { cofincit agrestis...» }\end{array}$ & $290-296$ & 285-292 & $327-334$ & $391-399$ \\
\hline VI, 2 AD Amicos. & «DURUS \& ...» & 297-306 & $338-347$ & $386-397$ & $461-472$ \\
\hline $\begin{array}{l}\text { VI, } 3 \text { Ad CAROLUM CARDINALEM } \\
\text { Lotharenum. }\end{array}$ & $\begin{array}{l}\text { «CAROLE, sinceri videar } \\
\text { malefunctus...» }\end{array}$ & $\begin{array}{l}\text { 306-313 } \\
\text { MDLXIII }\end{array}$ & 293-300 & $336-344$ & $402-410$ \\
\hline VI, 4 SERMO. & «UT qui se...» & $314-317$ & $300-304$ & $344-348$ & $411-415$ \\
\hline $\begin{array}{l}\text { VI, } 5 \text { SERMO de libertate } \\
\text { scribendi. }\end{array}$ & «SCRIPTORUM quosdam...» & $318-319$ & 304-306 & $349-350$ & $416-417$ \\
\hline $\begin{array}{l}\text { VI, } 6 \text { De Bello Civili. Ad Chr. } \\
\text { Thuanum P.P. }\end{array}$ & «SIVE malum hoc Pandora...» & $319-324$ & 306-311 & $350-356$ & $418-423$ \\
\hline VI, 7 AD ARNOLDUM FERRERIUM. & «FERRERI, quo nec melior...» & $324-325$ & $311-312$ & $356-357$ & $424-425$ \\
\hline VI, 8 AD VIDUM Fabrum. & «VATES ille...» & $325-331$ & $312-319$ & $358-365$ & $426-433$ \\
\hline VI, 9 AD ARNOLDUM FERRERIUM. & «TAM varia atque incerta...» & $332-333$ & 319-320 & $365-367$ & $434-436$ \\
\hline VI, 10 AD ADRIANUM TURNEBUM. & $«$ ME tam praeclari noli,...» & $333-334$ & 285 & 326 & 390 \\
\hline VI, 11 AD VIDUm Fabrum. & «Tu me posse...» & $334-338$ & $321-325$ & $367-371$ & $439-443$ \\
\hline $\begin{array}{l}\text { VI, } 12 \text { AD JACOBUM } \\
\text { CORBINELLUM. }\end{array}$ & «CORBINELLE, libens te...» & $338-343$ & $325-330$ & $372-378$ & 444-450 \\
\hline $\begin{array}{l}\text { VI, } 13 \text { AD ANTONIUM VACCAM } \\
\text { ITALUM. }\end{array}$ & «VACCA, tibi multis frons...» & $344-349$ & $331-336$ & $378-384$ & $451-457$ \\
\hline
\end{tabular}




\begin{tabular}{|c|c|c|c|c|c|}
\hline TITRE & incipit & $\begin{array}{c}1732 \\
A\end{array}$ & $\begin{array}{c}1585 \\
B\end{array}$ & $\begin{array}{c}1592 \\
C\end{array}$ & $\begin{array}{l}\text { DuFEY } \\
\text { D }\end{array}$ \\
\hline LIBER SEPTIMUS & & $350-377$ & - & - & - \\
\hline VII, 1 DE SE IPSO SERMO & «SI quis felicem, si quis...» & $350-356$ & $347-354$ & $\begin{array}{c}398 \\
\left({ }^{*} 401-5\right)\end{array}$ & $473-481$ \\
\hline $\begin{array}{l}\text { VII, } 2 \text { Ad Barth. FaIUM } \\
\text { SenATOREM. }\end{array}$ & «SPERABAM, dilecte mihi...» & $357-358$ & $354-355$ & $\begin{array}{l}405-407 \\
\left({ }^{*} 401-7\right)\end{array}$ & $482-483$ \\
\hline $\begin{array}{l}\text { VII, } 3 \text { AD EUNDEM, CLASSIS } \\
\text { INQUISITIONUM PRAESIDEM } \\
\text { FACTUM. }\end{array}$ & $\begin{array}{l}\text { «NoN quo more solent alii } \\
\text { gaudere...» }\end{array}$ & $\begin{array}{l}\text { 358-361 } \\
\text { MDLXVII }\end{array}$ & $356-358$ & $407-410$ & $484-487$ \\
\hline VII, 4 Ad ANNAm Aestensem. & «ANNA, mihi natis haec de...» & $\begin{array}{l}\text { 361-363 } \\
\text { MDLXXII }\end{array}$ & $361-363$ & $\begin{array}{c}413-416 \\
\left({ }^{*} 409-12\right)\end{array}$ & $491-494$ \\
\hline $\begin{array}{l}\text { VII, } 5 \text { Ad MARGARITAM } \\
\text { Sabaudiae Ducem. }\end{array}$ & «OBLECTARE meis te versibus...» & $363-370$ & $363-370$ & $\begin{array}{c}416-424 \\
\left({ }^{*} 412-24\right)\end{array}$ & $495-503$ \\
\hline VII, 6 Ad Barth. Faium. & «NoLIM me pigrum...» & $\begin{array}{l}\text { 370-373 } \\
\text { MDLXIX }\end{array}$ & $370-373$ & $424-427$ & $504-507$ \\
\hline VII, 7 Ad Chr. Thuanum P. P. & «NEC victus jaceo, quanvis...» & $373-375$ & $374-375$ & $428-430$ & $508-510$ \\
\hline $\begin{array}{l}\text { VII, } 8 \text { In reditum FRANCISCI } \\
\text { LOTHARENI Guisiorum Ducis, } \\
\text { Carmen. }\end{array}$ & «ITE coronati, festivoque...» & $375-376$ & $376-377$ & $430-431$ & $511-512$ \\
\hline VII, 9 De ponte Gardonis. & «Admirandi...» & 377 & 377 & 432 & $513^{1}$ \\
\hline TUMULI & & $378-386$ & $378-386$ & $\begin{array}{c}433-437 \\
\left({ }^{*} 429-33\right)\end{array}$ & $517-522$ \\
\hline $\begin{array}{l}\text { VIII, } 1 \text { In PETR. CastelLanI } \\
\text { Aureliae Episcopi. }\end{array}$ & $\begin{array}{l}\text { «SI pulchrum est ducibus } \\
\text { pugnando...» }\end{array}$ & 378 & 378 & $\begin{array}{c}433 \\
(* 429)\end{array}$ & 517 \\
\hline VIII, 2 HoRATII FARNESII. & «ET Venus, \& Mavors,...» & $378-379$ & $378-379$ & $\begin{array}{c}433-434 \\
\left({ }^{*} 429-30\right)\end{array}$ & 518 \\
\hline $\begin{array}{l}\text { VIII, } 3 \text { Fr. LOTHARINGII Ducis } \\
\text { Guisii. }\end{array}$ & «Hunc belli rabies, civilis...» & $\begin{array}{c}379 \\
\text { MDLXIII }\end{array}$ & 379 & $\begin{array}{c}434 \\
\left({ }^{*} 430\right)\end{array}$ & $518-519$ \\
\hline $\begin{array}{l}\text { VIII, } 4 \text { JAC. BURDINI Regis } \\
\text { Secretarii. MDLXVII }\end{array}$ & «HIC turbas inter medias...» & 379 & 379 & $\begin{array}{c}434-435 \\
\left({ }^{*} 430-31\right)\end{array}$ & 519 \\
\hline VIII, 5 Ejusdem & «Hunc Deus aetatis medio...» & $379-380$ & $379-380$ & $\begin{array}{c}435 \\
(* 431)\end{array}$ & $519-520$ \\
\hline $\begin{array}{l}\text { VIII, } 6 \text { Jo. CAPELLANI \& Hon. } \\
\text { CASTELLANI Medic. Regior. } \\
\text { Tumulus. }\end{array}$ & $\begin{array}{l}\text { «DivisI patria longa regione } \\
\text { locorum,...» }\end{array}$ & $\begin{array}{l}\text { 380-381 } \\
\text { MDLXIX }\end{array}$ & 380 & $\begin{array}{c}435-436 \\
\left({ }^{*} 431-32\right)\end{array}$ & $520-521$ \\
\hline VIII, 7 De OBITU JaC. FABRI & «ERGO tam prope me \& sine...» & $381-383$ & $358-361$ & $\begin{array}{c}410-413 \\
\left({ }^{*} 409\right)\end{array}$ & $488-490$ \\
\hline VIII, 8 De Morte D. Brissacae. & «MATURUM ut celsa...» & $383-385$ & $236-238$ & $271-272$ & $326-327$ \\
\hline $\begin{array}{l}\text { VIII, } 9 \text { P. MONTAUREI Aurelii } \\
\text { Tumulus. }\end{array}$ & «MUSAE, vester honos,...» & $385-386$ & 381 & $\begin{array}{c}436-437 \\
\left({ }^{*} 432-33\right)\end{array}$ & $521-522$ \\
\hline
\end{tabular}

Les pièces suivantes ne sont présentes que dans $A$

MANTISSA CARMINUM MISCELLANEORUM MICHAELIS HOSPITALII.

$387-491$

1 Suivi de 3 vers «De se ipso ». 
IX, 1 IN MORTEM GUIDONIS, LAVALLI COMITIS. «HIC satis in primis vivens ostenderat

IX, 2 In Gulielmum Langeium.

annis,...»

IX, 3 EPITAPHIUM Francisci Regis.

«HIC sunt LANGEII cineres notissima...»

«HIC sunt relliquiae FRANCISCI Regis...»

IX, 4 EPITAPHIUM ClaUdII LOTHARINGI, SUESSIONUM DUCIS.

«CONDITUS hoc tumulo est Siculorum e

391

IX, 5 EPITAPHIUM ANNAE MOMORANTII, EQUITUM MAGISTRI.

sanguine Regum...»

«Dum fera bella geris, pietatis imagine

391

IX, 6 Epitaphium Baptistae MenilliI, Regil falsa,...»

IN SENATU ADVOCATI.

«MENILLI, tecum longe felicius actum...»

393-394

ET FARNESIO.

IX, 8 De EODEM Farnesio.

«FELIX ille prior natus, qui pubere Roma...»

«Ut longo requievit ager qui tempore...»

394

«NON hunc cum peteret fugiens per devia

394-395

IX, 9 IN REGIS ADVENTUM FORTUITUM AD

MAURI FANUM.

cervus...»

IX, 10 Ad Salmonium Macrinum.

«PostQuam SALMONI me jussa haud mollia Regis...»

IX, 11 Ad Venerem.

IX, 12 AD ANNAm ESTENSEM.

IX, 13 AD ANNAM ESTENSEM.

IX, 14 AD CAROLUM.

IX, 15 In Germanos Fratres.

IX, 16 In CAsum AnNae Estensis.

IX, 17 In Simulachrum ab ERrico Rege,

BONONIA RECUPERATA, VIRGINI MARIAE

POSITUM.

IX, 18 In Napos In Grinaeo Pago

NASCENTES.

«Alma Venus, fidos cui jungere semper...»

«ACCEPI dubiis primum rumoribus, aegram...»

«ANNA Francorum generata magnis...»

"CARLE, quot insomnes credis me ducere...»

«VIVIs perpetuo quoniam mens una...»

«UnUS equi lapsus pariter duo corpora...»

«Hoc, Regina, tibi consecrat nobile signum, ,...»

395-399

399-400

400-404

404-407

$407-411$

412

412

413

«GRINAEIS cur prima napis sit gloria

$413-414$

IX, 19 De Miseris Civilis Belli incepti ANNo MDLXII.

quaeris,...»

«TERTIUS hic tandem nostrae jam praeterit annus...»

IX, 20 In MoRTem ReGis SCotiae.

«Discite Diis geniti Reges confidere solis...»

IX, 21 Ad ANDREAm TIRAQUELLUM

SENATOREM PARISIENSEM.

«AUSIM quin etiam in genere hoc componere nostros...»

IX, 22 AD ANNAm ESTENSEM, GUISIORUM DUCEM.

«MULTos imperia \& paucorum falsa dierum...»

IX, 23 Ad Carolum Card. Lotharingum.

«CASUNE an studio factum est, ut ne ipse venire...»

IX, 24 Ad Margaritam Regiam Virginem.

«VIDI, quae bona te nunquam vidisse dolebam...»

IX, 25 Hesiodi [...]

IX, 26 De Imaguncula Aristotelis Hospitali Vultum ReFerente.

«Ergo ut difficile est duris assuescere...»

«Dicor Aristoteli similis, tantique referre...»

414-416

IX, 27 IN Rumores De SE Lutetiae SpARsos.

«QUAE fuerit subiti ex aula mihi causa recessus,...»

IX, 28 Ad Surianum, Patritium Venetum.

«IGNOTAE quamvis animae, longisque locorum...»

IX, 29 AD MORELLAS.

«MuLTaM virginibus castis doctisque...»

416-417 MDLXIX

$417-418$

418-419

$419-421$

421-425

425

$425-428$

$428-432$

«Vixi tamque diu vitae me poenitet actae...»

«FERRERI jam poene decem pugnavimus...»

$432-433$

433-435 MDLXXII

436-438 
IX, 32

IX, 33 Ad CARolum Regem Febre LABORANTEM.

IX, 34

IX, 35

IX, 36 Pro Margarita Regis Henrici II SORORE.

IX, 37 Vitae Rusticae Laus.

IX, 38

IX, 39 AD SODALES.

IX, 40 AD Francos.

IX, 41

IX, 42 Ad Henricum N. Engolismens [...].

IX, 43 ELEGIA NOMINE P. RONSARDI, ADVERSUS EJUS OBTRECTATORES ET INVIDOS.

IX, 44 De Gallorum In Italiam EXPEDITIONE POSTREMA.

IX, 45

IX, 46

IX, 47

IX, 48 De pace.

IX, 49

IX, 50 De Sponsalibus DUCIS LOTHARINGIAE

\& Claudiae Henrici II Regis filiae.

IX, 51

IX, 52

IX, 53

IX, 54 Ad BARTH. FAIUM.

IX, 55

IX, 56 AD Amicos.

IX, 57

IX, 58

J.B. Menilius Adv. Reg. MDLXIIX
«FINIS cuique rei suus est; nec singula...»

438-440

«FEBREM olim fecere Deam, fecere

Metumque...»

«SUAVIUS \& melius nobis fuit ante...»

«Nescieram agresti tantum dulcedinis

esse..."

«PRIMA mihi tenerae pars est transacta

juventae,...»

«URBANAM si cui est animus componere...»

«OMNE mihi studium naturae, ut in haec...»

«MAJUS non potuere mihi dare munus...»

«RURSUS ad arma vocat, rursus vesana...»

«MuLTA bonis falso culpaeque insontibus...»

«Noli fidere equo, pedibus confidere

noli, ,..»

"MAGNIFICIS aulae cultoribus atque

Poëtis,...»

«LLUDI nobis toties patiemur, amici...»

«MENILLI vereor mala ne praesentia nobis...»

«BELLA senis nutu soliti regere omnia solo...»

«AMBO pares aetate, pares virtutibus ambo...»

«PACEM omnes lingua \& placido...»

440-442

$442-444$

$444-445$

$446-450$

450-451

451-452

452-453

454-455

455-456

456

457-462

462-464

464-466

$466-467$

$467-468$

468-469

469-470

«INTER \& assiduas lites \& plena negoti...»

470-471

Carli...»

«ET mihi scribendi studium gravis abstulit aetas...»

472-475

«SEU vinces, seu tu vincere, pericula quae

476

te...»

"QUAM misera \& risu aut lacrymis...»

476-480

«BARTHOLOMAE tibi cessator inersque...»

480-482

482-485

485-487

487-488

488-490

491 


\section{ILLUSTRATIONS}

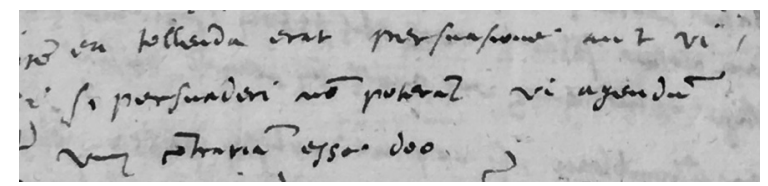

Ill. 8 : «[...] en tollenda erat persuasione aut vi [...] si persuaderi non poterant, vi agendum [...] vim contrariam esse Deo » (Staatsbibliothek zu Berlin - PK /

Handschriftenabteilung, Sig. Darmstaedter, 2h 1561 ; notes autogr., jamais repérées à ce jour)

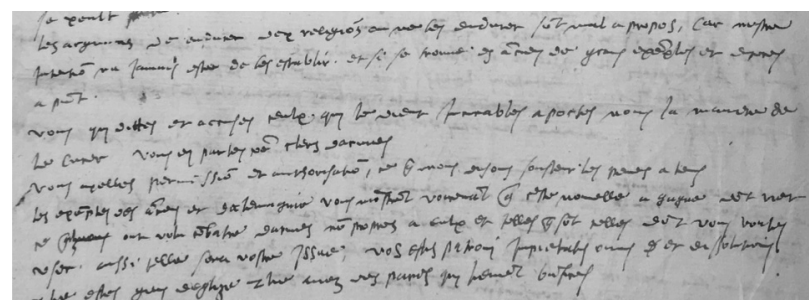

Ill. 9 : Notes autographes préparatoires des discours (Staatsbibliothek zu Berlin PK / Handschriftenabteilung, Sig. Darmstaedter, 2h 1561; autogr., jamais repérées à ce jour)

Les argumans de endurer deux religions ou ne les endurer sont mal à propos, car nostre intention n'a jamais esté de les establir, et si se trouve es Anciens de grans exemples et depuis à present.

Vous qui dittes et accusés ceulx qui le dient incurables, aportés nous la maniere de le curer. Vous en parlés comme clers d'armes.

Vous apellés permission et authorisation, ce que nous disons soustenir les peines à tems. 
Les exemples des Anciens et d'Alemagnie vous monstrent voiremant que ceste nouvelle a gagné, dont vient ce qu'ilz ont volu combatre d'armes non propres à eulx, et telles que sont celles dont vous voulés user, aussi telle sera vostre issue. Vos estis patroni impietatis omnes per et dissolutionis.

Plus estes gens d'Eglize, plus avez des parens qui tienent benefices.

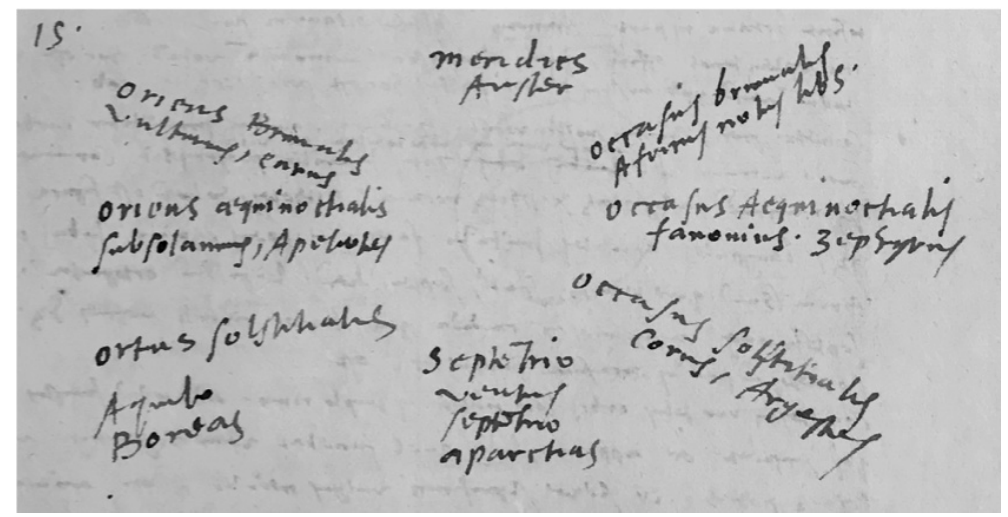

Ill. 10: Carte des vents dans les notes de L'Hospital sur l'Histoire naturelle de Pline l'Ancien (BNF, Dupuy 491, fol. 107vo) 


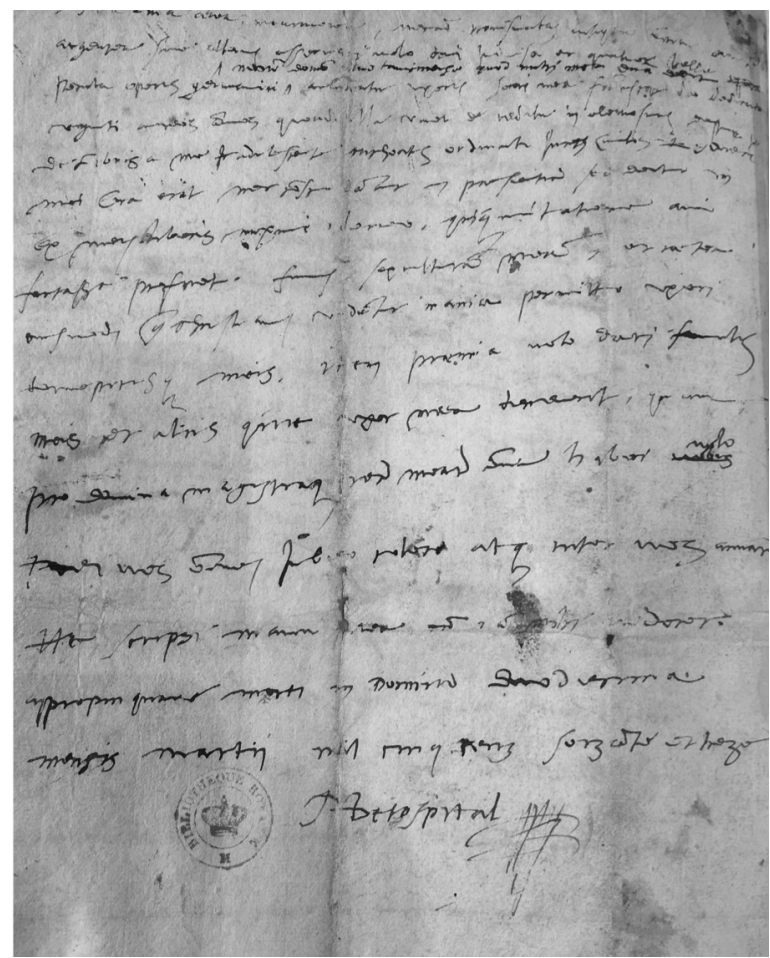

Ill. 11 : Minute autographe du testament de L'Hospital, jamais repérée jusqu'à ce

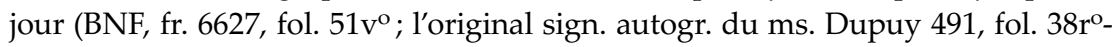
$40 r^{\circ}$ est édité dans L'Hospital, Discours et correspondance, p. 271-285, avec sa traduction par Brantôme). Au bas de ce folio, une note précise que René de Voyer d'Argenson, assesseur ordinaire (et père du futur garde des sceaux Marc-René de Voyer de Paulmy), donna ce testament original en janvier 1647 à son patronus le chancelier de France Pierre II Séguier, petit-fils d'un correspondant de Michel de L'Hospital (voir supra, p. 290, Petris, La Plume et la tribune, p. 477-482 et L'Hospital, Discours et correspondance, p. 267-270). Émile III Perrot, seigneur d'Argenson, fut le filleul de L'Hospital (DL, t. II, p. 219). 


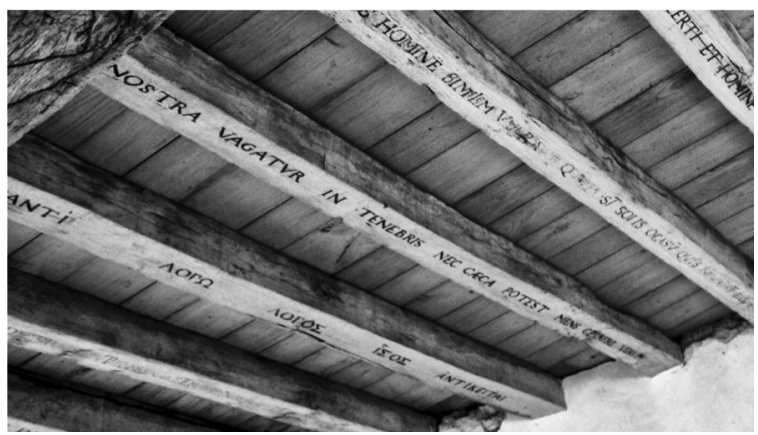

Ill. 12: Vers de Michel de L'Hospital sur les poutres de la bibliothèque de Montaigne, tirés d'une épître de L'Hospital à Marguerite de France: «Nostra vagatur / In tenebris, nec caeca potest mens cernere verum », « Notre esprit / Erre dans les ténèbres et dans son aveuglement ne peut reconnaître la vérité » (Carmina, II, 8, 48-49, t. II, p. 150-151).

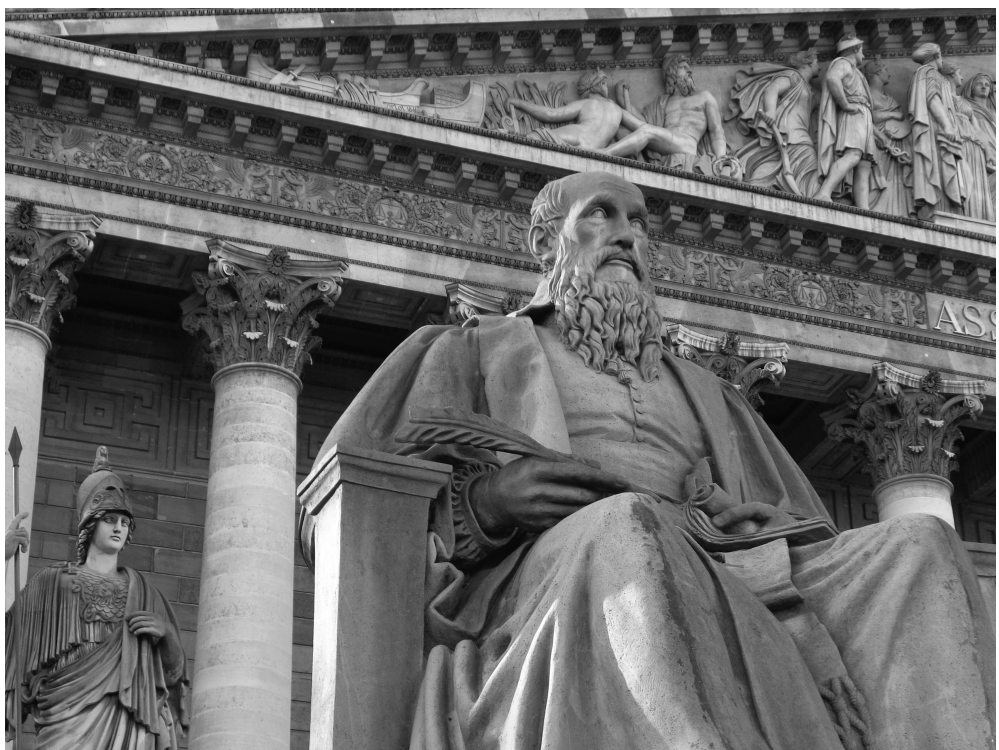

Ill. 13: Statue de Michel de L'Hospital par Louis-Pierre Deseine (1810) devant le Palais Bourbon (versions réduites au Musée du Louvre, au Musée Carnavalet ainsi qu'à la Bibliothèque Marmottan). En 1990, la tête originale fut installée dans le hall du Tribunal de Commerce de Paris, L'Hospital ayant créé les Tribunaux de Commerce en 1563. 


\section{INDEX DES NOMS DE LIEUX ET DE PERSONNES}

Achille : 8

Africains : 88

Ajax : 8

Alamanni, Luigi : 208n

Albius: voir Tibulle

Albon, Jacques d', $\mathrm{s}^{\mathrm{r}}$ de Saint-André : 29

Alde, famille : 207

Allemagne: 242, 301

Amboise : édit, 175-176 ; conjuration, 194

Ambroise, saint: 88

Amelin, Jean de: 67

Amyot, Jacques : 24, 54

André, Elie : 57n, 59, 63n, 66-67, 72-73

Aneau, Barthélemy: 66, 106

Anglais : 258

Angleterre: 21, 258

Angoulême, Henri d' : 239n, 300

Antibes : 170

Antoine de Bourbon, roi de Navarre: 21-22, 24n, 30-32, 37

Apollon: 129, 145n, 216n, 250-252

Apôtres: 149n, 151, 214n

Archias : 205

Aristide: 236

Aristophane: $163 \mathrm{n}$

Aristote: 203, 217, 229, 237, 299

Armagnac, Georges d' : 38, 48-49, 97-

98, 110-111, 114-115, 294

Artois : 290

Asti : 23
Athènes: 220

Atticus : 200

Aubert, Guillaume: 19n, 24, 67, 117

Auguste: 102, 109-110, 156, 276

Augustin, saint: 13, 88, 143-144, 150, 225-226n, 265

Auron: 159

Ausone: 170

Ausonie : 224

Avignon: 162, 169n, 288

Babylone: 224

Bachelier, Nicolas: $115 \mathrm{n}$

Bade, Josse : 51, 55, 73

Baiff, Jean-Antoine de : 8, 14-15, 67, 245-266 passim

Baï, Lazare de : 98, 246-247

Baldini, Vittorio : 200n

Bandello, Matteo : 206

Baravalle, Cristoforo : 231

«Batisse», s $\mathrm{s}^{\mathrm{r}}$ de : 240

Beaumont, François de, baron Des Adrets : 39

Beccadelli, Lodovico : $211 n$

Belleau, Rémy : 258, 261-262

Bellièvre, Jean de : 107n

Bembo, Pietro : 206

Bénévent, Claude de: $62 \mathrm{n}$

Berga, Antonio: 231

Bernuy, Éléonore de : 114n

Berry: 196n, 199n, 216n 
Béthune, Maximilien de, duc de

Sully : 181

Betussi, Giuseppe : 212

Bèze, Théodore de: 26, 35, 70, 145146, 276-277, 293

Bible: 82n, 87n, 138, 141, 144-148, 150-151, 215, 236n, 275, 278; Gn, 168n; Dt, 84n ; Ps, 145-147, 149n, 151, 207-209, 211n, 214-215; Jb, 91 ; Mt, 84n, 87n, 93n, 168n, 228n ; Mc, $84 n, 87 n$; Lc, $84 n-86$; Jn, 225 ; Rm, 93n

Binet, Claude: $120 \mathrm{n}$

Birague, René de : 270

Blanchet, Jean : 173

Blois : 154n, 182

Boccace: 9, 141, 224

Bocchi, Achille : 14, 134, 196, 209, 227, 294

Bogomare : 160

Bologne: 48, 98, 101n, 134, 164n-165, 299

Bonhomme, Macé : 99n

Bologni, Girolamo : 211n

Bordeaux : 220, 267-268, 270, 273, 282284

Borromeo, Carlo : 33n

Boturnei, Boturnio de' : 198n

Bourbon, famille: 170

Bourbon, Charles de, cardinal : 30

Bourbon, Henri de, marquis de Beaupréau : 30

Bourbon, Louis Ier de, prince de Condé: 26, 37, 266

Bourbon, Nicolas: 19, 53n, 62n

Bourbon-Montpensier, Charles de, prince de La Roche-sur-Yon : 30

Bourbonnais : 158

Bourdin, Jacques : 298

Bourges : 96n, 210

Bourgogne: 28

Bovelles, Charles de: 52
Boyssoné, Jean de: 12, 48, 65, 95-105, 109-110, 112-114

Boyssoné, Jean de, dit le Borgne: 97

Brach, Pierre de: 255n-256n, 270

Brantôme, Pierre de Bourdeille, $\mathrm{s}^{\mathrm{r}}$ de : 242n, 303

Bresse: 23

Bretagne: 29

Brie, Germain de : 252

Brigade: voir Pléiade

Brindes : 156, 1578

Brinon, Jean de: 127

Brucioli, Antonio : 212

Bucer, Martin : 215

Buchanan, George : 8, 43, 47n, 53n, $70,258,275-277,279-280$

Budé, Guillaume : 7

Bunel, Pierre: 96-99, 113n

Buon, Gabriel : 24, 47n, 68

Butte de Chaumont: 291

Cabrières : 48

Calais : 15, 46, 58, 63, 85-86, 256, 258263, 265, 290, 296

Calliope: 145n, 252

Callipède : 221

Calvin, Jean : 35, 144n-150

Cantarini, Gasparo: 209

Carafa, Carlo: 20n

Carles, Lancelot de: 19n, 121, 123, 257, 264-265n, 294-296

Carnesecchi, Pietro : 14, 196n, 207n, 209-211, 222

Casaubon, Isaac: 161

Case-Dieu (La), abbaye: 96n

Cassius : 221

Castellan (ou Châtelain), Honoré: 193-194, 298

Cateau-Cambrésis (Le): 19-20, 47, 63n, 154

Catherine de Médicis : 19-22, 24-25, 30-32, 36, 38-40, 67n, 96n, 155n, 
176, 193, 216n, 232, 241, 252, 265, 270, 290-291

Caton l'Ancien: 93, 203n, 279

Caton le Jeune: 279

Catti, Jean : 88, 90-91, 201, 217, 229, 240

Cat(t)us : voir Catti, Jean

Catulle: 80, 124, 252-254

Cavares, ville des: voir Avignon

Cavellat, Guillaume: 120

Cavour: traité, 234

Cerbère: 104

Chalons : 50

Chambéry: $48,101 n$

Chambord: 289, 296

Champagne: 50

Champmotteux : 291n

Chandieu, Antoine de: 203, 224

Chantilly: 192-193

Chapelain, Jean : 298

Charles VIII, roi de France: $32,237 \mathrm{n}$

Charles IX, roi de France: 24, 28-33, 35-38, 40, 92n, 136, 174, 176-177, 257, 268, 282-284, 290-291, 300

Charles d'Orléans : 239

Charles-Emmanuel, duc de Savoie: 204, 229-233, 240

Charles le Téméraire : $255 \mathrm{n}$

Charles Quint : 20, 46

Charybde: 223

Chesneau, Nicolas: 52

Chevallon, Claude : 50

Chieri: 20

Chinon: 9, 288n

Chivas: 20

Christ : voir Jésus-Christ

Cicéron : 8, 12, 99-101n, 103-104, 170171, 200-203, 205

Cimiez: 169

Claude de France, duchesse de Lorraine : 22, 300

Claudin: voir Le Jeune, Claude
Clermont, Louise de, dame de Crussol : 37

Clio : 251

Cocceius : 159

Colbert de Torcy, Jean-Baptiste : 192n

Coligny, Gaspard II de : 29

Coligny, Odet de, cardinal de

Châtillon : 30, 37, 97n, 294-295

Colletet, Guillaume: 188

Colonna, Vittoria : 209, 211n, 215

Côme Ier de Médicis : 26n

Coras, Jean de: 98

Corbinelli, Jacopo : 297

Corfou: 131

Corneille, Pierre: 7

Cossé, Charles Ier de, comte de

Brissac: 29, 237n

Cossé, René de, $\mathrm{s}^{\mathrm{r}}$ de Brissac : $237 \mathrm{n}$

Costeley, Guillaume: 262

Couleuvre: 158

Crétin, Guillaume : 251n

Cujas, Jacques : 96n, 114n

Cupidon : 255n

Cyclope : $160-161$

Cyprien, saint: 52, 88

Daffis, Jean : 97

Dalechamps, Jacques : 232n

Dallier, Joachim : 9n

Dalmatio, Giovanni : 58-59, 259, 264

Danaïdes : 105

Dauphiné: 22

Dauvet, Jean II : 249n

David : 145-147, 151, 208

Dédale: 134n, 221

Del Bene, Baccio : 200, 236, 243n

Del Bene, Bartolomeo: 195, 200, 217

Della Rovere, Girolamo : 11, 19-41 passim

Della Torre, Francesco : 209

Della Torre, Gerolamo : 209n

Deloynes, Antoinette: 9n, 248, 252

Denisot, Nicolas : 139, 201, 206, 213 
Des Aimars, Antoine Escalin, $\mathrm{s}^{\mathrm{r}}$ de Pierrelatte, dit le capitaine Paulin: 159

Deseine, Louis-Pierre : 304

Desportes, Philippe: 140

Disticha Catonis : $84 \mathrm{n}$

Doge: 20n-21n

Dorat, Jean : 63n, 66, 86, 247-248n, 257-258, 262, 276-277

Dorsenne: 162

Dreux : 276

Du Bartas, Guillaume de Saluste : 140

Du Bellay, famille: 11

Du Bellay, Guillaume, $\mathrm{s}^{\mathrm{r}}$ de Langey: 19, 67, 299

Du Bellay, Jean : 8, 19, 48, 88-89, 108, 224, 293-296

Du Bellay, Joachim : 8, 11-13, 19-20, 49n, 52-53, 55-60, 62n-63n, 65n-67, 71-72, 76-77, 106, 108, 117-136 passim, 140, 142, 167n, 200n-201, 206, 213, 216, 223-224, 228, 237n239, 241n, 247, 252, 258, 262, 264

Du Chastel, Pierre : 208-209n, 219n, 294, 298

Du Chesne, Léger : 8, 47n, 224, 258

Du Drac, Adrien : 12, 48, 98, 101, 108, 115, 164n, 293

Du Faur, famille: 97n, 106

Du Faur, Arnaud : 114n

Du Faur, Guy, s ${ }^{r}$ de Pibrac: 8, 95-97n, 110-115, 174, 249-250, 290, 296297

Du Faur, Jacques : 12, 95-98, 101, 105106, 108-111, 114-115, 156, 165, 249, 266n, 294, 297-298

Du Faur, Michel : 114-115

Du Faur, Pierre : 114-115

Du Faur, Pierre, $\mathrm{s}^{\mathrm{r}}$ de Saint-Jory : $114 n$

Du Ferrier, Arnaud: 12, 95-100, 111112, 114-115, 297, 300

Du Mayne, Guillaume: 53n
Dumesnil, Baptiste: 299-300

Du Moulin de Rochefort, Louis : 231

Dupuys, Mathurin : 211n

Duthier, Jean : 55n-56n

Du Verdier, Antoine: 52, 238

Élisabeth de France, reine d'Espagne: 22

Elizabeth Ire, reine d'Angleterre: $37 \mathrm{n}$ Emmanuel-Philibert, duc de Savoie: 13, 20, 22-25, 27, 37, 39-41, 56n, 58n, 154, 156, 158, 167-170, 191, 193-194, 197, 219n, 235, 241n, 287289

Empédocle: 107

Entremont, Jacqueline : 232n

Envers : 235

Épaminondas : 220

Épicure: 281

Épidaure: 104

Érasme: 12-14, 65, 81, 93, 134n, 136, 137n, 140-144, 147, 200, 202n, 207n, 246-247n, 252, 260

Ératon : 252

Espagnols : 46

Espence, Claude d' : 13, 137, 140, 209, 213-214, 227n, 294

Este, famille: 197

Este, Anne d' : 46, 54, 196-198n, 216, 233-234, 254n, 298-299

Este, Éléonore d' : 233

Este, Hercule d' : 198n

Estienne, famille: 208n

Estienne, Charles : 155, 157-159n, 170n, 247

Estienne, Henri II : 99n, 106-108, 132n, 208n

Estienne, Robert: 51, 67, 207n-208, 211

Europe: 15, 63, 197, 207n

Euterpe : 251

Eyquem, Pierre, $\mathrm{s}^{\mathrm{r}}$ de Montaigne: 270

Farel, Guillaume : 145 
Farnèse, famille: 259, 264

Farnèse, Alexandre: 58-59, 196, 208

Farnèse, Horace : 76, 298-299

Farnèse, Pier-Luigi, duc de Parme: 65n, 102

Faye, Barthélemy : 65n, 296, 298, 300

Felinus, Aretius : voir Bucer, Martin

Ferrare: 144n, 196n-198, 233

Ficin, Marsile: 141

Flaminio, Marcantonio: 14, 139-140, 147, 196, 201, 205-216, 227, 294

Florence: $207 \mathrm{n}$

Foix, famille: 268

Foix, Paul de: 269-270, 276, 296

Fontainebleau : 25-26, 33-34

Fontenay-le-Comte : 174

Forcadel, Étienne: 96n, 113, 255n

Forcadel, Pierre : 25

Fortune : 261-262

Fossano: 23

Français : 85, 99n, 206, 209, 231-232, 276, 300

France: 19-20, 23, 28, 36, 40, 66, 99n, $117,121 \mathrm{n}, 129,146,155,169,182$, 184n, 187, 189, 194, 197-198, 205, 210, 252, 255n, 257-259, 264, 271, $273,278,281,296$

François Ier : 67, 130, 203n, 208-209, 237n-238, 239, 246, 294

François II, roi de France: 9, 20, 2226, 28, 31-32, 34, 47, 56n, 58, 66n, 89n, 118, 177, 194-195n, 229, 233n, 239n, 241, 287-289, 297, 299

François de France, duc d'Alençon : 180

Fréjus: 169

Furies : 104

Gaignières, Roger de: 192n

Galien : 232n

Galland, Pierre: 67, 258

Gandevilliers : 291n

Gange: 205
Garamond, Claude : 55

Gard, pont: 298

Garnier, Robert: 7

Gattinara, Mercurino Arborio di : 10

Giberti, Antonio : 209

Giberti, Gian Matteo : 206

Ginod, Jean Godefroid, évêque d'Aoste : 232

Gioffredo, Pierre: 191, 195n

Giraldi, Giovanbattista Cinthio: 203, 231

Giraldi, Lilio Gregorio : 196

Glaucie: $113 \mathrm{n}$

Gohory, Jacques : 216n

Gonzaga, Giulia: 14, 206, 212-213

Gonzaga, Guillaume, duc de Mantoue : 20n

Gonzague-Nevers, Louis IV de: $184 \mathrm{n}$

Goudimel, Claude : 250, 255

Gouffier, Claude: 29

Gouffier de Boisy, Charlotte, dame de Cossé-Brissac : 237, 298

Gourmont, Jean II de : 27

Gramont, Gabriel de : 97n

Grangier, Jean : 203-204, 231

Grassin, Pierre : 295

Gravelines : 290

Grèce : 220

Grecs : 99n, 141, 282

Grenoble: $101 \mathrm{n}$

Grévin, Jacques : 205, 208n, 224, 227, 231

Gryphe, Sébastien : 207, 220

Gualterio, Sebastiano: 33n, 40n

Guarinus, Thomas : 47n

Guidobaldo II, duc d'Urbin : 19

Guillard, Charlotte : 50, 59, 63n

Guînes : 15, 46, 85-86, 256, 258-259, 261, 265, 296

Guise, famille: 11, 15, 21-22, 44, 4648, 54, 62, 65n, 67-68, 186, 188, 256-258, 264; voir aussi Lorraine 
Guise, Charles de, cardinal de

Lorraine: 11, 21, 24n, 30, 35, 3840, 46-47, 50n, 60, 65, 67-68, 76, 82-83, 87-88, 91, 163n, 194-195n, 218n-219n, 224, 227n, 249, 252, 257, 287-288, 294-297, 299

Guyenne: 28, 267

Harlay, Achille de: 180, 183

Hélénus, personnage virgilien : 80

Hennequin, Jeanne, femme d'Henri de Mesmes : 269

Henri II, roi de France: 13, 19-21, 45$46,58,63,127,137,154,156,158$, $168,170,196 \mathrm{n}, 198-199,210,216 \mathrm{n}$, 222, 229, 239n, 247, 252, 262-263, 295, 299

Henri III, duc d'Orléans, puis roi de France : 14, 30, 174-175, 178, 180189, 231n, 293

Henri IV, roi de France : 174, 181, 185186, 188

Hésiode : 251, 299

Homère: 129, 295

Horace: 7, 12-13, 48, 65, 79-81n, 88, 95-96, 99, 101n-102, 104-110, 112, 117-119, 123, 125-126, 129-136, 149, 153-171 passim, 175n, 189, 201-203, 226, 228, 235-238, 279280

Horatius Cocles, Publius : 299

Hurault, famille: 253, 256

Hurault, Robert, $\mathrm{s}^{\mathrm{r}}$ de Belesbat: 7-8, 14, 47, 229n, 249-254, 291

Hurault de L'Hospital, Charles : 47

Hurault de L'Hospital, Michel, $\mathrm{s}^{\mathrm{r}} \mathrm{du}$ Fay et de Belesbat: 8, 236n, 293

Hyménée: 250, 252

Icare : 133-134

Icarienne, mer: 134

Impériaux : 46

Indiens : 283

Inverso : 235
Italie : 7, 45-46, 65n, 97n, 102, 117-119, $132,135,196,198,255 n, 300$

Italiens : 99n, 141, 206-207, 209, 211, 231

Jacques V, roi d'Écosse: 299

Jamet, Lyon : 200

Jamot, Frédéric : 53-53

Jean Chrysostome, saint: 51-52

Jeanne d'Albret, reine de Navarre:

37,266

Jérôme, saint : 200

Jésus-Christ: 84n, 89, 105, 137, 149n, $151,178,206,208,211-215,225-$

$227,236,238-239$

Job : 219, 237

Jodelle, Étienne: 250, 257

Jules II, pape: 19

Junon : 252

Jupiter : 252, 279

La Boétie, Étienne de: 15, 53, 200, 268-274, 276, 278

La Ceppède, Jean de : 140

La Chassaigne, Françoise de : 269-270

La Chassaigne, Joseph de: 268

Lactance : 88

Laërte: 10, 200n, 235, 243n

Lagebaston, Jacques Benoist de : $281 \mathrm{n}$

La Haye, Martin de: 12, 48, 97, 100101

Lalamantius, Johannes : 51-52

Lalemant: 56, 78

La Marche, Olivier de : 255n

L'Angelier, famille: 53

Languedoc: $97 \mathrm{n}$

La Perrière, Guillaume de : 99, 112114

La Plâtière, Imbert de, $\mathrm{s}^{\mathrm{r}}$ de

Bourdillon : 23-24

La Rochelle : 205

Latium : 296

Le Bé, Guillaume : 70

Le Ferron, Arnoul : 220 
Le Jeune, Claude: 266

Le Maistre, Gilles : 35

Le Mangnier, Robert: 68

Lenoir, Alexandre: 192n

Le Roy, Louis : 54, 67

L'Estoile, famille : 50

L'Estoile, Louis de: 50

L'Estoile, Pierre de : 50, 62n, 182n-183

Lezeau, Jean : 205

L'Hospital, famille : 256

L'Hospital, Charlotte de: 249

L'Hospital, Jean de: 208-209n, 219

L'Hospital, Jeanne de : 249

L'Hospital, Madeleine de: 7, 14, 47, 229n, 236, 240, 245, 249, 251-254, 291

L'Hospital, Michel de:

Carmina: 67n, 79, 82n-83, 97n-98, 131, 200, 216, 218, 220-221, 223, 225, 229, 235 ; diffusion manuscrite, 8, 43, 48-50n, 57n, 65; BNF Dupuy 901, 46n, 111n, 130 ; édition princeps de 1585 (B), 8, 14, 57n, 106n, $111 n-112,115,125,154 n, 173-$ 174, 178, 188, 201, 204, 216, 264n, 295-298; manuscrit de Gand (G), 154n, 173n, 178 ; édition d'Amsterdam de 1732 (A), 46n, 106n, 111n, 115, 121n, 173, 178, 204, 293-300 ; I, 1, 48, 89n, 108, 224n, 293 ; I, 2, 45, 92n, 293 ; I, 3, 131n, 217, 293 ; I, 4, 12, 48, 65n, 98n, 101104, 108-109, 115, 164n-165n, 168n, 196n, 293 ; I, 5, 13, 130, 136, 198n, 200n-201, 216n, 240, 294 ; I, 6, 48-49, 86n, 89n, 110111, 115, 131n, 294 ; I, 7, 13, 137-151 passim, 213-214, 227, 294 ; I, 8, 89n, 200n, 294 ; I, 9, 294 ; I, 10, 89n, 224, 294 ; I, 11, 134, 196, 209n, 227, 294 ; I, 12,
294 ; I, 13, 7n, 46, 208-209n, 219n, 294 ; I, 14, 294 ; I, 15, 139n, 196n, 198n, 201, 203-206, 216, 222, 233, 294 ; II, 1, 46, 50n, 83n, 88n-89n, 91-92, 219n, 294 ; II, 2, 198-199, 229, 241n, 294 ; II, 3, 294 ; II, 4, 46, 50n, 294 ; II, 5, 294 ; II, 6, 106, 108, 111, 115, 294 ; II, 7, 48, 208, 234, 294 ; II, 8, 59-60, 67, 75, 78, 199, 201, 212, 216, 218-223, 225-226, 231n, 234, 241, 275, 295, 304 ; II, 9, 50n, 249n, 295 ; II, 10, 295 ; II, 11, 295 ; II, 12, 92n, 295 ; II, 13, 49, 56n, 59, 6162n, 65, 75, 295 ; II, 14, 295 ; II, 15, 89n-91, 198n, 201, 217, 229, 295 ; II, 16, 8, 295 ; II, 17, 295 ; II, 18, 295 ; II, 19, 47n, 50n, 65, 295 ; II, 20, 7n, 295 ; III, 1, 89n, 295 ; III, 2, 89n, 229n-230, 253, 295 ; III, 3, 169n, 295 ; III, 4, 295 ; III, 5, 46, 50n, 163n, 295 ; III, 6, 50n, 295 ; III, 7, 89n, 295 ; III, 8, 8, 149n, 296 ; III, 9, 296 ; III, 10, 8, 296 ; III, 11, 198n, 201, 228-229, 237-238, 296 ; III, 12, 46, 50n, 87n-88n, 296 ; III, 13, 296 ; III, 14, 296 ; III, 15, 7n, 239n, 296; III, 16, 198n, 296 ; III, 17, 8, 296 ; III, 18, 296 ; IV, 1, 58, 60, 65n, 67, 70-71, 75, 83-85, 89n, 92n, 219n, 258-259, 296 ; IV, 2, 8, 15, 46, 58, 63, 66, 72-73, 76, 85, 89n, 258-265, 296; IV, 3, 59, 62n, 74-76, 296; IV, 4, 198n, 201, 206n, 296 ; IV, 5, 50n, 86n89n, 201n, 296; IV, 6, 46, 50n, 296 ; IV, 7, 112, 115, 226n, 296; IV, 8, 89n, 296; IV, 9, 296 ; IV, 10, 296; V, 1, 46, 58, 61, 73, 7879, 297 ; V, 2, 8, 50n, 297; V, 3, 
198n, 229, 249n, 297; V, 4, 50n, 58-59, 67, 74, 78, 88n, 297 ; V, 5, 92n, 297; V, 6, 66n, 76-77, $297 ; \mathrm{V}, 7,50 \mathrm{n}, 76-77,297 ; \mathbf{V}, \mathbf{8}$, 8, 14, 56n, 67, 75-77, 83n-84n, $89 n, 175,177-179,233 n, 237 n-$ 239, 297 ; V, 9, 13, 115, 153-171 passim, 198n, 229, 240, 288n, 297 ; VI, 1, 83n, 89n, 221, 297 ; VI, 2, 7n, 14, 173-190 passim, 219n, 221-222, 297 ; VI, 3, 8283, 88n-89n, 297; VI, 4, 89n, 297 ; VI, 5, 80-81, 106n-107n, 297 ; VI, 6, 297 ; VI, 7, 112, 115, 297 ; VI, 8, 112, 115, 297 ; VI, 9, 89n, 112, 115, 297 ; VI, 10, 297 ; VI, 11, 7n, 112, 115, 297 ; VI, 12, 83n, 89n-90n, 94n, 297 ; VI, 13, 83n, 89n-90n, 94n, 219, 298 ; VII, 1, 8, 112, 115, 298 ;

VII, 2, 298 ; VII, 3, 298 ; VII, 4, 196n-197, 233n, 298; VII, 5, 7n, 10n, 89n, 198n, 200n-201, 220, 228, 231, 235-237, 243n, 298 ; VII, 6, 298 ; VII, 7, 89n, 298 ; VII, 8, 46, 76, 298 ; VII, 9, 298 ; VIII, 1, 298 ; VIII, 2, 76, 298 ; VIII, 3, 298 ; VIII, 4, 298 ; VIII, 5, 298 ; VIII, 6, 298 ; VIII, 7, 115, 298 ; VIII, 8, 237n, 298 ; VIII, 9, 298 ; IX, 1, 299 ; IX, 2, 299 ; IX, 3, 299 ; IX, 4, 46, 299 ; IX, 5, 299 ; IX, 6, 299 ; IX, 7, 299; IX, 8, 299; IX, 9, 299 ; IX, 10, 216, 299; IX, 11, 299 ; IX, 12, 46, 216, 233, 299 ; IX, 13, 46, 233, 254n, 299; IX, 14, 299 ; IX, 15, 299; IX, 16, 299 ; IX, 17, 299; IX, 18, 299 ; IX, 19, 66n, 299 ; IX, 20, 299; IX, 21, 8, 299 ; IX, 22, 233n, 299; IX, 23, 299 ; IX, 24, 198n, 299; IX, 25, 299; IX, 26, 299 ; IX, 27, 299; IX, 28,
299 ; IX, 29, 242n, 252, 300 ; IX, 30, 89n, 300 ; IX, 31, 89n, 300; IX, 32, 300 ; IX, 33, 86n, 89n, 92n, 300 ; IX, 34, 300 ; IX, 35, 300 ; IX, 36, 198n, 229, 239n, 241-242, 300 ; IX, 37, 300 ; IX, 38, 300 ; IX, 39, 7n, 300 ; IX, 40, 300 ; IX, 41, 300 ; IX, 42, 300 ; IX, 43, 120-122, 300 ; IX, 44, 57, 65, 70, 300 ; IX, 45, 300 ; IX, 46, 89n, 300 ; IX, 47, 300 ; IX, 48, 300 ; IX, 49, 300 ; IX, 50, 300 ; IX, 51, 300 ; IX, 52, 300 ; IX, 53, 300 ; IX, 54, 300 ; IX, 55, 300 ; IX, 56, 89n ; IX, 57, 300 ; IX, 58, 300

Discours : 5 juillet 1560,$8 ; 21$ août 1560,$26 ; 13$ décembre 1560 , 27, 30-31 ; 31 juillet 1561, 149n, $214 \mathrm{n}$; 9 septembre 1561, 34 ; 17 août 1563,10

Correspondance : 65n, 122-123, $196,199-200,213 n, 229 n, 235-$ 236, 240, 242, 303

Autres écrits : devise, 169n, 279280 ; mémoire au roi, 176 (juin 1563); notes autographes, 10 , 301-303 ; testament, 10n, 242, 303

Carrière: études à Toulouse, 9596, 98 ; études à Padoue, 96, 98, 246; conseiller au Parlement, 9, 45, 246 ; client des Guises, 11, 21-22, 44, 4647, 257 ; curateur d'Anne d’Este, 196 ; délégué au concile de Trente (déplacé à Bologne), 101n-102, 134, 137, 164n-165, 196n; chancelier du Berry, 9, 43, 45, 68, 118, 120, 128, 154, 196, 199; maître extraordinaire des requêtes, 9 , 45, 54, 118 ; premier président 
surnuméraire de la Chambre des comptes, 9, 45-46, 56n, 118 ; conseiller au Conseil privé, 9,47 , 56n, 118 ; chancelier de France, 9, 11, 21, 43, 47, 68, 113n, 117, 119, 121, 129, 135-136, 154, 205 ;

disgrâce, 94n, 110, 218n

Libon: 221

Limeuil, Isabeau de : 266

Londres : 15

Lorraine : 46

Lorraine, famille: 15, 24n, 54; voir aussi Guise

Lorraine, Charles III, duc de: 300

Lorraine, Claude de: 46

Lorraine, Claude II de, duc d'Aumale: 30

Lorraine, François de, duc de Guise : 30, 46-47, 58, 60, 67, 82-85, 193n, 196-197, 254n, 258-259, 262-264, 275-276, 288, 295-296, 298

Lorraine, Henri de, duc de Guise : 46, 233

Lorraine, Louis de, cardinal de Guise : 30, 35

Lotichius, Petrus : $53 \mathrm{n}$

Louis XII, roi de France: 196n, 237n

Lucilius : 156, 166n

Lucrèce, poète : 275

Lully, Jean-Baptiste : 255n

Luther, Martin : 150, 213

Lyon: 99n, 113, 159, 161-162, 165, 207n, 209

Lyon, Corneille de: 192-193

Macédoniens : 282

Macrin, Jean Salmon, dit : 13, 49, 53n, 94, 138-142, 206, 216, 228, 232n, 252, 295-296, 299

Magny: 159n

Magny, Olivier de: 255n, 258, 262

Malingre, Mathieu : 139-140, 150n
Manuzio, Paolo : 207n

Marc-Antoine : 156

Marcoing : 46, 59

Marguerite de France, duchesse de Savoie: 9, 13-14, 20-22, 24, 41, 43, 45, 47, 50n, 59-60, 67, 88, 90-91, $118,120,128,130,132,139$ n, 154$155,160-161,165-167,170,191-$ 243 passim, 248-249, 252, 287-289, 294-300, 304

Marguerite de France, reine de Navarre, puis reine de France : 30

Marguerite de Navarre: 16, 140, 206n, 216-218, 226, 248

Marie, Vierge : 86, 137, 297, 299

Marie, sœur de Marthe : 212

Marie Stuart: 47, 58, 297

Marillac, Charles de : 295

Marot, Clément: 41, 104-105, 140, 144n-145, 200, 207-208, 228, 233, 242

Marquets, Anne de: 211n

Mars : 216n, 222

Marseille : 156, 158, 165, 167-168, 288

Marthe, sœur de Marie : 212

Martial : 80, 278

Martin, Reymond : 236n

Meaux : 39

Mécène : 156

Melpomène : 251

Mérindol: 48, 234, 294

Mesmes, Henri de: 269-271, 277, $287 \mathrm{n}$

Metellus Numidicus, Quintus Caecilius : 236

Metz: 46, 49, 295

Meudon : 257

Michiel, Giovanni : 20n, 22, 25n

Mincio : 102

Minerve: 224

Mizaud, Antoine: 67

Mondoré, Pierre de: 276, 294, 298

Monluc, Jean de: 37 
Montaigne, Michel de: 7, 15, 53, 200, 218, 220n-221n, 267-285 passim, 304

Montesquieu : 7

Montferrat : 23

Montmorency, Anne de: 11, 30, 3536, 288n, 299

More, Thomas: 10, 81n

Morel, famille: 118n, 127, 248, 252, 300

Morel, Fédéric: 11, 43-78 passim, 218, 238n, 258-260, 269, 274

Morel, Fédéric II : $62 \mathrm{n}$

Morel, Jean de, $\mathrm{s}^{\mathrm{r}} \mathrm{d}^{\prime}$ Embrun: 9n, 1112, 16n, 19, 24, 45, 48-49n, 57n, 65, 117-118n, 120-123n, 127-129, 135, 198, 230, 239n, 247-250, 252-254, 256, 277-279, 295-296

Morillo, Juan : 210n

Morin, Jean : 246

Morin, Marie: 7, 242, 246, 249, 251

Morvillier, Jean de: 47, 270, 297

Moulins : 159, 170, 219n, 281

Muses : 48, 105, 113, 119-121, 124-125, 128-129, 133, 140, 142, 150, 159, 161, 196n, 228, 237, 250-251, 254, 274, 293, 296

Naples : 206-207

Naudé, Gabriel : 279-280

Navarre: 26

Nemours : $178 \mathrm{n}$

Nessus : 104

Neuchâtel, groupe de: 140, 145, 150n Nevers : $159 \mathrm{n}$

Nice: 9n, 13, 20, 23, 47, 156, 158, 165, 167-168, 191, 193-195, 217, 287n

Normandie: 28

Nymphes : 223-224

Océan: 102, 223, 226n

Octave: voir Auguste

Olivétan, Pierre Robert dit : 145
Olivier, François : 47-49n, 57n, 59n, 65-66n, 76-77, 181, 213, 234, 275276, 293-295, 297

Olympe : 250

Orange: 169

Orcus : 104

Orléans : 39 ; États généraux, 21, 26$27,33-35$

Ouranie : 252

Outreau: paix, 247

Ovide : 8, 81n, 119, 124n-127, 131, 208

Pacciotto, Francesco : 24

Padoue: 96, 98, 101n, 206-207, 246

Pallas: 204-205, 216, 222, 227, 233, 252

Paoli, Simone : 215

Paradin, Claude: $195 \mathrm{n}$

Paris : 15, 19, 27-28, 37, 46, 50-52, 55n56n, 58, 118, 120, 132, 174n, 180, 182, 184, 186n, 197, 207n, 210n, 224, 241, 259, 269, 278, 280, 299, 304 ; bois de Vincennes, 38 ;

Châtelet, 180, 246 ; Collège royal, 19, 50 ; Notre-Dame de Paris, 39 ; palais des Tournelles, $58 \mathrm{n}$;

Parlement, 25, 33-36, 38, 45, 96n97n, 176, 180, 183, 234, 246, 294 ; rue des Bernardins, 247

Parisiens : 37-38

Parménide : 107

Parque: 91

Pasquier, Étienne: 216n, 293

Paul, saint: 82n, 191n, 206, 218

Paul IV, pape: $46,207 \mathrm{n}$

Paul Émile : 282

Peccais : 22

Pédum : 130

Peletier Du Mans, Jacques : 107n-108, 206, 231, 235

Pénélope : 105

Perrault, Charles: 7

Perrissin, Jean : 27 
Perrenot de Chantonnay, Thomas : 23n, 33n-38, 40

Perrot, Émile : $113 \mathrm{n}$

Perrot, Émile III, $\mathrm{s}^{\mathrm{r}}$ d'Argenson : 303

Perses : 220

Petit, Oudin : 207n

Pétrarque: 9, 208, 226

Phébus: voir Apollon

Philippe II, roi d'Espagne : 23n, 37

Philippe V, roi de Macédoine: 282

Pibrac: voir Du Faur, Guy, s ${ }^{r}$ de

Pic de La Mirandole, Jean : 204

Pie IV, pape: $38,57 \mathrm{n}$

Piémont: 23, 25, 40, 54, 219n, 231n

Piérides: 120, 125

Pierrelatte: 159

Pignerol : 20, 235

Pindare: 123, 125, 128-129, 132-133, 135

Pithou, Pierre : 174

Plaisance: 102

Plantin, Christophe: 205, 211n

Platon: 117, 119, 134n, 140

Pléiade: 7, 11, 19, 53, 119, 121, 127 $128,133,135,146,151,247 n, 250$, 252

Pline l'Ancien : 302

Pline le Jeune: 8,10

Plutarque: 24, 220, 269, 282

Pô: 102, 164n-165, 243

Poissy: 24, 149n ; colloque, 21, 24, 33$35,264-265 \mathrm{n}$

Poitiers : 39, 173

Poitou: 159, 180, 184

Pole, Reginald : 209-211n

Politien, Ange: 151

Polymnie : 252

Pontoise : 34

Pontrone: 13, 130-131, 136, 200n, 294

Portugal : 21

Potier, Jean : 249n

Poyet, Guillaume : 181

Priuli, Alvise : 208n
Properce: 12, 126, 128-129, 135

Provence: 22

Pylade: 117n, 121, 129

Pyrrha, personnage horatien : 126

Pyrrhus: 282

Quintilien : 12, 93, 126, 157n, 203n

Rabelais, François : 158n, 228n

Raemond, Florimond de : $281 \mathrm{n}$

Ragueneau, René : 246

Ramus, Pierre : 54

Rapin, Nicolas : 14, 173-190 passim

Reims : 66n

Renée de France, duchesse de Ferrare: 30, 144n, 196-198n, 211212, 227-228, 242

Rhétoriqueurs : 137

Rhône: 162

Richelet, Nicolas : 125-126

Ringhieri, Innocenzo : 212n

Rivoli: 229

Rochefort: voir Du Moulin de Rochefort, Louis

Romains : 99n

Rome: 13, 19, 46, 66, 87, 97n, 103, $108 \mathrm{n}, 118,128,131-132,135,224-$ 225, 252, 293

Ronsard, Pierre de: 7-8, 12, 19, 24, 47n, 53n-54, 63n, 65, 68, 119-123, 125-129, 132-135, 144, 180, 203n, 206, 227n, 241n-243, 247, 250, 255, 257, 264, 295, 300

Rouen: 10, 176, 283-284

Roussillon : 159

Roville, Guillaume: 193n

Roye, Éléonore de, princesse de Condé : 37

Saba: 243

Sainte-Marthe, Charles de: 16

Sainte-Marthe, Scévole de: 8, 67, 77, 173, 274, 293

Saint-Gelais, Louis de, $\mathrm{s}^{\mathrm{r}}$ de Lansac: 269-270 
Saint-Gelais, Mellin de: 43, 57, 120 125n, 128-129, 134-135, 247, 257, 265

Saint-Germain-en-Laye : 35, 197

Saint-Maur : 299

Saintonge : 270

Saint-Pétersbourg: 15

Saint-Quentin : 20, 46, 83, 258, 296

Saluces, marquisat: 20, 23

Santa Croce, Prospero di : 23-24n, 37$38,40 \mathrm{n}$

Sargy, pont: 158

Savillan : 20

Savoie: 19-20, 22, 35, 194-195n

Savoie, Claude de, comte de Tende: 288

Savoie, Madeleine de: $288 \mathrm{n}$

Savonarole, Jérôme : $211 n$

Scaliger, Jules César : 51-53n

Scève, Guillaume: 98, 114

Scylla: 223

Séguier, Pierre : 290, 303

Séguier, Pierre II : 303

Sextus Empiricus : 275

Seymour, Anne: 248

Seymour, Jane : 248

Seymour, Marguerite: 248

Seyssel, Claude : 54

Silly, Jacques de : 27

Simeoni, Gabriele : 209

Sixte IV, pape : 19

Socrate: 119,278

Sophocle: 51-52n, 237

Spagnuoli, Battista : 13, 138, 141-142n

Spina, Léonard : 159n

Stace : 209

stoïcisme: 7, 89, 151, 176, 178-179, 279-280

Strozzi, Ercole : 20n-21, 26n, 32-33n, 37

Strozzi, Pierre : 275-276

Styx : 104

Suisses : 37, 182
Suriano, Michele: 21, 26n, 34, 38n, 40n, 299

Sutherland, George III, duc de: 192n

Tabouet, Julien : 12, 96, 101, 105-106

Tacite : 281

Tasso, Bernardo : 243

Terpsichore : 251

Tertulle : 160, 165

Tertullien : 88

Téthys : 223

Thalie: 251

Thèbes : 220

Thémistocle : 220, 236

Théocrite : 257

Thionville: 46, 55, 59, 296

Thou, Christophe de : 296-298

Thou, Jacques-Auguste de : 8, 125, 174

Thouzat, Jacques : 50-51

Throckmorton, Nicolas : 37

Tibulle: 12-13, 117, 119, 124-127, 129 133, 135-136

Timon : 221

Tinctoris, Johannes : 255n

Tiraqueau, André: 8, 49, 296, 299

Tornabuoni, Niccolò : 26, 32n-37

Torquatus, personnage catullien : 254

Torrentino, Lionardo : 203, 207n

Tortorel, Jacques : 27

Toulon: 19, 27, 163n

Toulousains : 99, 106, 182

Toulouse : 12, 39, 95-99, 101n, 110-112, $114 n-115$

Tournes, Jean de : 113

Tournon, famille: 159

Tournon, François de: 30, 34-35, 217, 293

Toussaint, Guillaume: 19

Trente: 208 ; concile, 34, 40, 96n, 102, 113n, 134, 137-138, 176, 196n, 207, 210, 219n, 297

Triptoparcha, Joannes : 293

Trivulzio, Agostino: 19 
Trivulzio, Antonio : 20n

Tryphiodore: 54

Turin: 19-20, 23, 40-41, 196

Turnèbe, Adrien: 47n-48n, 67, 70, 258, 276-277, 297

Tyrrhénienne, mer : 223

Ulysse: 8, 223

Utenhove, Charles: 12, 127-128, 277, 293

Vacca, Antonio : 219, 298

Valdès, Juan de: 206, 212

Valgrisi, Vincenzo : 207n

Vallembert, Simon de : 231-232

Vascosan, Jeanne de: 51-52

Vascosan, Michel de: 11, 51-55, 68

Vaudois: 234-235n, 239

Vendôme: 39

Venise: 21-22, 34, 96n, 98, 207, 210n, 212n, 228n, 246, 269

Vénitiens : 232

Vénus : 299

Vergèce, Ange : 247, 287n

Vérone: 206-209
Versaille: 193

Vettori, Piero: 196, 296

Vieilleville, François de Scépeaux, $\mathrm{s}^{\mathrm{r}}$ de: 154-155

Vienne: 169

Vignay: 37, 291n

Villefranche: 169

Villers-Cotterêts : 287

Vincent, Richard : 211n

Vineus ou Vineuf: voir Della Rovere, Girolamo

Virgile: $80,88 \mathrm{n}, 102,106,112,128-$ 129, 133, 156, 164, 201

Visagier, Jean : 99n

Viterbe: 207

Vlamingius, Petrus : 293

Voyer d'Argenson, René: 303

Voyer de Paulmy, Marc-René: 303

Wassy: 21, 37

Wechel, André: 44n, 54, 63, 67-68

Xénophane : 107

Xénophon: 268

Yonne: 70 
过

ํํำ

.

큼

국

(2)

(1)

甲

(8) 


\section{TABLE DES ILLUSTRATIONS}

Ill. 1 : Pourtraict du plant de la salle des Estatz et de l'ordre et seance tenu en iceulx

Ill. 2: Pourtraict de l'assemblée des estatz, tenuz en la ville d'Orleans, au mois de Janvier

Ill. 3 : Item 11a - Cliché de l'auteur

Ill. 4 : Portrait de Marguerite par Corneille de Lyon .....

Ill. 5 : Reliure de l'exemplaire d'Horace de Marguerite de France

202

Ill. 6: Portrait de Marguerite et de son fils CharlesEmmanuel

Ill. 7 : Léonard Limousin, Portrait d'Anne d'Este

Ill. 8: «en tollenda erat persuasione aut vi [...] si persuaderi non poterant, vi agendum [...]»

Ill. 9: Notes autographes préparatoires des discours ....

Ill. 10 : Carte des vents dans les notes de L'Hospital sur l'Histoire naturelle de Pline l'Ancien....

Ill. 11 : Minute autographe du testament de L'Hospital

303

Ill. 12: Vers de Michel de L'Hospital sur les poutres de la bibliothèque de Montaigne

304

Ill. 13: Statue de Michel de L'Hospital par Louis-Pierre Deseine (1810) 
$\dot{4}$

กิ

는

ํㅡㄹ

(2)

(11)

(日) 


\section{TABLE DES MATIÈRES}

Perrine GALAND-WILLEMEN et Loris PETRIS

Introduction ......................................................

Abréviations ........................................................ 17

Richard COOPER

Le nouveau chancelier jugé par les ambassadeurs à la cour de France: les dépêches de Girolamo Della Rovere (1560-1562)

Michel MAGNIEN

Le plomb et les sceaux : les publications poétiques de Michel de L'Hospital chez Fédéric Morel (1558-1560)

David AMHERDT

Les épîtres de Michel de L'Hospital: des sermons laïques?

\section{Nathalie DAUVOIS}

Michel de L'Hospital, les solidarités toulousaines et le modèle du sermo horatien : modèle satirique / modèle philosophique

George Hugo TUCKER

Poétiques et esthétiques de l'humilité chez Michel de L'Hospital et Joachim Du Bellay, imitateurs d'Horace et de Tibulle

Véronique FERRER

Michel de L'Hospital, Carmina, I, 7: quelques réflexions autour de la poésie chrétienne 
Laure CHAPPUIS SANDOZ

Des pierres et des mulets: mise en scène narrative dans l'Iter Nicaeum (Carmina, V, 9)

Ruth STAWARZ-LUGINBÜHL

Le «Discours de Monsieur le chancelier de L'Hospital à ses amis »: Nicolas Rapin, traducteur de l'épître $A d$ $\operatorname{amicos}(\mathrm{VI}, 2)$

173

\section{Rosanna GORRIS CAMOS}

Affectus plena: Michel de L'Hospital, «celuy que j'ayme, honore et estime comme mon pere et milieur ami »

Jean VIGNES

Michel de L'Hospital et Jean-Antoine de Baiff

Jean BALSAMO

L'Hospital et Montaigne ou Montaigne contre Michel de L'Hospital?

Lettres inédites de Michel de L'Hospital 287 éditées par Loris Petris

14bis. [1559], 5 septembre, [Charles de Guise] à Michel de L'Hospital, [Villers-Cotterêts]

14ter. [1559], décembre, François II à Michel de L'Hospital, Chambord

43bis. 1564, 31 juillet, Pierre Séguier et Guy Du Faur à Michel de L'Hospital, Paris

77bis. 1571, 2 juillet, Michel de L'Hospital à Madeleine de L'Hospital, Butte de Chaumont

Tableau synoptique des Carmina

Illustrations

Index

Table des illustrations 